\title{
Energy Development Opportunities for Wyoming
}

November 2012

The INL is a

U.S. Department of Energy National Laboratory

operated by

Battelle Energy Alliance

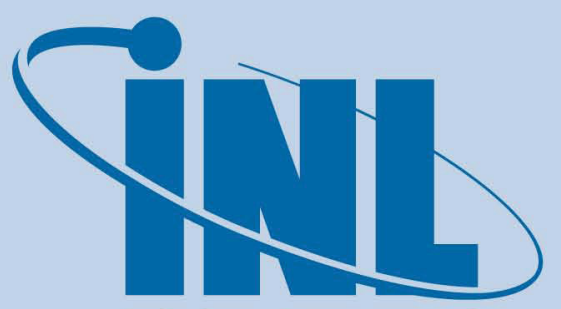

Idaho National Laboratory
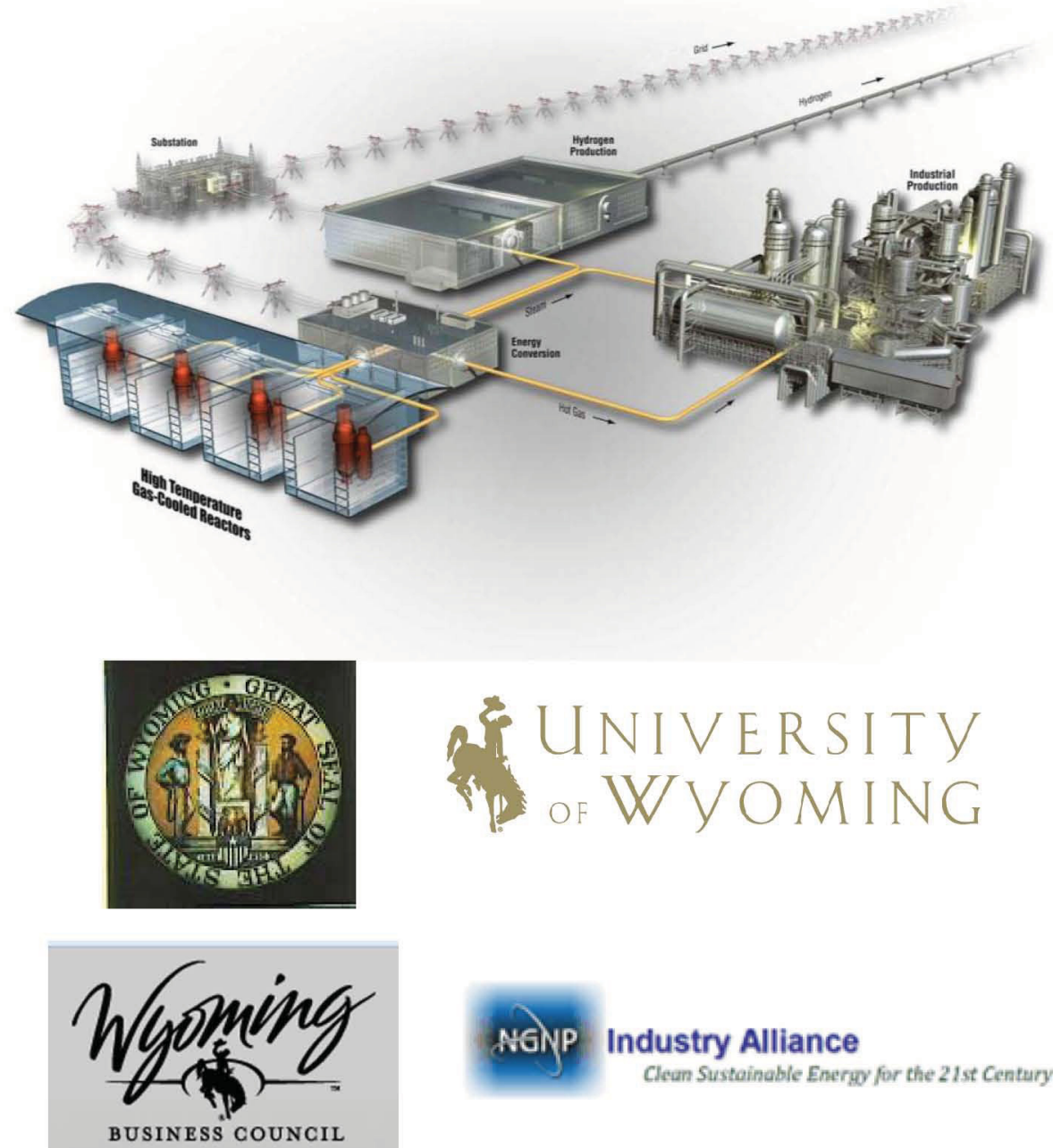


\section{DISCLAIMER}

This information was prepared, in part, as an account of work sponsored by an agency of the U.S. Government. Neither the U.S.

Government nor any agency thereof, nor any of their employees, makes any warranty, expressed or implied, or assumes any legal liability or responsibility for the accuracy, completeness, or usefulness, of any information, apparatus, product, or process disclosed, or represents that its use would not infringe privately owned rights. References herein to any specific commercial product, process, or service by trade name, trade mark, manufacturer, or otherwise, does not necessarily constitute or imply its endorsement, recommendation, or favoring by the U.S. Government or any agency thereof. The views and opinions of authors expressed herein do not necessarily state or reflect those of the U.S. Government or any agency thereof. 


\section{Energy Development Opportunities for Wyoming}

November 2012

Idaho National Laboratory

Idaho Falls, Idaho 83415

http://www.inl.gov

In collaboration with:

State of Wyoming

Wyoming Business Council

University of Wyoming

NGNP Industry Alliance Limited

Prepared for the

Wyoming Business Council

Under DOE Idaho Operations Office

Contract DE-AC07-05ID14517 



\begin{abstract}
The State of Wyoming (represented by the Governor's office, the Wyoming Business Council and the University of Wyoming), the NGNP Industry Alliance Limited, and the Idaho National Laboratory, have conducted an evaluation of energy development opportunities for Wyoming that concludes deployment of a carbon conversion industry producing synthetic transportation fuels and chemicals can provide a long term and stable market and add considerable value to Wyoming's indigenous coal and natural gas resources with the potential of providing substantive economic benefit to the State. The evaluation has also developed a conceptual strategy for transformation of Wyoming electricity generation from an industry dominated by coal-fired plants to a more diverse mix of generating technologies that provides flexibility in adapting to changes in policy and regulation and shifts in the energy market.
\end{abstract}




\section{EXECUTIVE SUMMARY}

An important opportunity exists for the energy future of Wyoming that will...

- Sustain and possibly grow its coal industry

- Add substantive value to its indigenous coal and natural gas resources

- Reduce dramatically the environmental effect of its energy production capability

- Add substantive opportunities to develop an advanced manufacturing industry in the State, and

- Increase the State's Gross Domestic Product

These can be achieved through development of a carbon conversion industry for transformation of coal and natural gas to synthetic transportation fuels, chemical feedstock and chemicals that are the building blocks for the chemical industry. Over the longer term, environmentally clean nuclear energy (e.g., high temperature gas-cooled reactors) can provide the substantial energy needs of a carbon conversion industry and be part of the diverse mix of replacement technologies for the current fleet of aging coal-fired electric power generating stations.

Wyoming has a wealth of primary energy resources in the forms of coal, natural gas, wind, uranium, and oil shale. Most of Wyoming's coal and gas resources are exported from the state in their unprocessed form rather than as more refined, higher value products. Further, important challenges have arisen from expanding and more demanding government environmental regulations whether these resources are used in-state or exported for use elsewhere and low natural gas prices have resulted in substantive reductions in State tax income. Wyoming's leadership recognizes the opportunity to address these challenges and broaden the State's economic base by using its energy resources to make value-added products such as synthetic transportation fuels and commodity chemicals. Producing these higher value products in an environmentally responsible manner will require use of clean energy technologies including nuclear energy (e.g., high temperature gas-cooled reactors). These higher value products can be used by Wyoming's populace and industry, and considerably larger quantities can be exported to regional, national, and international markets.

The Wyoming Business Council, under direction from the State's Legislature commissioned collaborative evaluations of selected energy futures for Wyoming comprising two complementary approaches. One, collaboratively led by the NGNP Industry Alliance Limited and the Idaho National Laboratory (INL), identified and evaluated alternative processes that have technical and economic viability for conversion of Wyoming's indigenous coal and natural gas to synthetic fuels and chemicals. The results, conclusions and recommendations of those evaluations are reported herein. The second included a collaborative effort of the Wyoming Business Council, the University of Wyoming and the Idaho National Laboratory that characterized the nature and potential size of the markets for Wyoming synthetic fuels and chemicals, including a limited assessment of distribution networks for those products, and evaluated the application of hybrid energy systems to deployment of the carbon conversion processes in a manner compatible with stabilizing wind power generation. The results, conclusions and recommendations of this work are presented in the report, Preliminary Feasibility of Value-added Products from Cogeneration and Hybrid Energy Systems in Wyoming (INL/EXT-12-27249). The conclusions of the evaluations reported herein and in the companion report, provide a conceptual foundation upon which Wyoming, in partnership with industry, can develop policy and projects for implementation.

Regardless of the approach taken to address Wyoming's energy future, the investment decisions made by industry and enabled by Wyoming must be technologically diverse and flexible to allow Wyoming and its industries to adjust to changing global energy realities. 


\section{Developing a Carbon Conversion Industry}

As a far reaching example, notionally redirecting the current Wyoming coal production to making synthetic fuels (e.g., gasoline or diesel) would supply over $50 \%$ of the current total U.S. consumption of liquid hydrocarbon fuels - at prices competitive with current refining processes. However, the capital investment to achieve this capability would be substantial. Practically carving out the achievable part of this possible energy future requires developing a far-sighted partnership with industry, starting with an incremental strategy that can set Wyoming on the path to becoming a major player in an environmentally responsible carbon conversion industry and in deployment of next generation nuclear energy technology.

Entry into a carbon conversion industry can be through phased construction of a process facility using conventional technologies that can be operational within the next decade focused initially on producing transportation fuels (e.g., a coal-to-liquids or natural gas-to-liquids facility to produce gasoline). The notional initial carbon conversion facility described herein is based on a coal-to-gasoline process plant using natural gas in steam methane reforming to produce hydrogen. The design of the initial and followon carbon conversion facilities should be intentionally compatible with integration of nuclear energy technology such as high temperature gas-cooled nuclear reactor (HTGR) technology. ${ }^{\text {a }}$ In this regard, because the commercialization of the HTGR is expected to extend over the next 10 to 15 years, a phased strategy has been developed to initiate deployment of carbon conversion facilities using conventional processes in the short term, anticipating incorporation of the HTGR technology over the longer term. This strategy promotes earlier realization of the benefits of deploying these carbon conversion processes to the Wyoming economy. Use of HTGRs will be an important part of addressing anticipated, ever more demanding environmental requirements and mitigating potential volatile international energy pricing.

\section{Transforming Electric Power Generation}

As a separable and practical reality, the retirement over the next five decades of Wyoming's aging coal-fired electric power generating fleet requires long range planning to ensure that the replacement power generating technologies fulfill the desired or policy-imposed environmental requirements. As described in this report, selecting a diverse set of replacement power generating technologies is warranted, considering the uncertainties inherent in predicting the future energy resources and needs, nationally and internationally. Best available information suggests that the transformation to this diverse set of technologies should initially include natural gas combined cycle generation and renewables, subsequently complemented by clean coal technologies and nuclear energy - the mix primarily determined by anticipated energy price trends, Wyoming's expected long term industrial base, and desired energy self-sufficiency and export posture (currently over $60 \%$ of power generated is exported to neighboring states). This diverse mix allows Wyoming and its industries to adjust to changing global energy realities.

\section{Growing Industrial Infrastructure}

A growing carbon conversion industry and transforming the electric power generating industry to achieve a diverse technology mix can be complemented by development of a manufacturing and service infrastructure. The size of the potential market for HTGR applications suggests that there is substantial opportunity for development of a nuclear industry infrastructure in Wyoming (see Appendix C). These industries provide the opportunity for significant job growth and important contributions to the State's economy.

a Nuclear energy provides an environmentally responsible source of energy that addresses anticipated carbon constraining regulatory requirements. Further, nuclear energy mitigates the effects of volatile fossil fuel energy pricing. HTGR nuclear energy technology provides highly efficient generation of electricity and the high temperature process heat that fulfills the requirements of process plants. 
The approach to Wyoming's energy future described in this report is bold. However, the transformation can be achieved in steps that can be accommodated by industry and Wyoming with the opportunity to adjust direction as Wyoming's energy future matures and becomes clearer. 


\section{CONTENTS}

ABSTRACT iii

EXECUTIVE SUMMARY $\mathrm{v}$

ACRONYMS XV

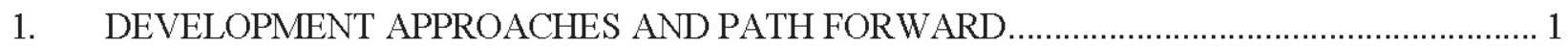

1.1 Energy Development Approaches for Wyoming ........................................................... 1

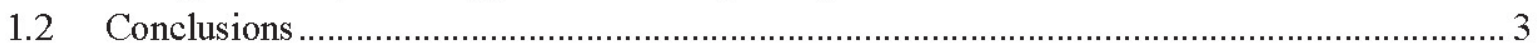

1.3 Suggested Overall Path Forward .................................................................................. 5

2. BACKGROUND AND REPORT STRUCTURE................................................................ 6

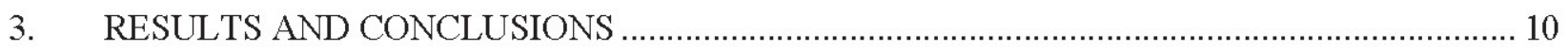

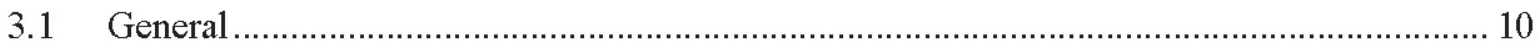

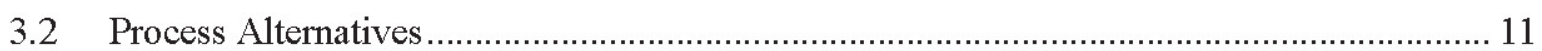

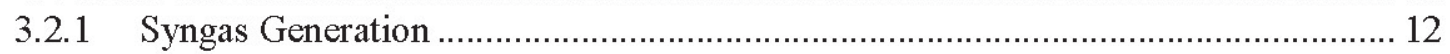

3.2.2 Indirect Processes for Carbon Conversion .......................................................... 14

3.2.3 Direct Process for Carbon Conversion............................................................. 15

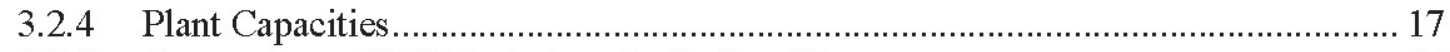

3.2.5 Comparison of $\mathrm{CO}_{2}$ Emissions for Indirect Processes ....................................... 17

3.2.6 Alternative Process Economics ...................................................................... 18

3.3 Notional Selection of the Processes for Evaluating Deployment of a Carbon

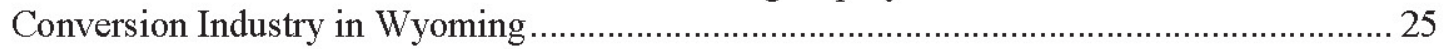

3.3.1 Selection of the Initial Carbon Conversion Process .............................................. 25

3.3.2 Notional Plant Performance, Costs and Revenues ................................................. 27

3.4 Deployment of the Carbon Conversion Industry ............................................................. 31

3.4.1 Objectives of Deploying the Carbon Conversion Industry ….............................. 31

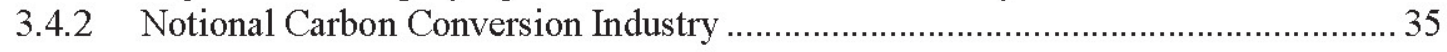

3.5 Transformation of Wyoming Electricity Generation Industry …....................................... 39

3.5.1 Electricity Generation Transformation Objectives ............................................. 39

3.5.2 Electricity Generation Transformation Strategy …............................................. 40

3.5.3 Electricity Generation Transformation Costs.................................................... 42

3.5.4 $\mathrm{CO}_{2}$ Emissions Reductions Resulting from Electric Power Industry

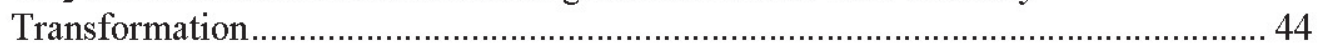

3.6 Composite Effect of Developing a Carbon Conversion Industry and the Electric

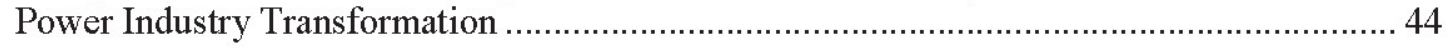

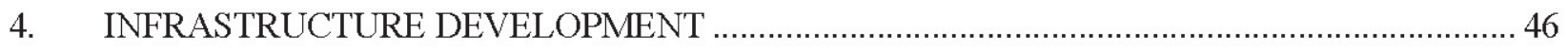

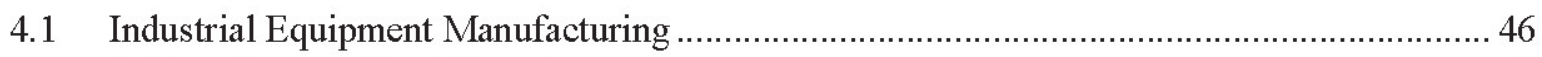

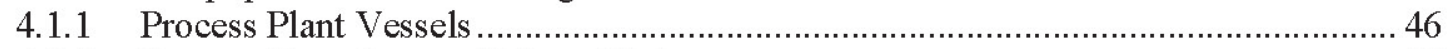

4.1.2 Process Plant Pumps, Valves, Piping ................................................................ 48

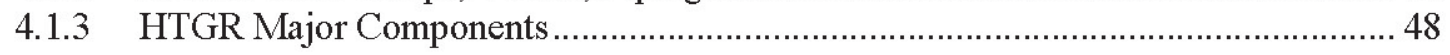

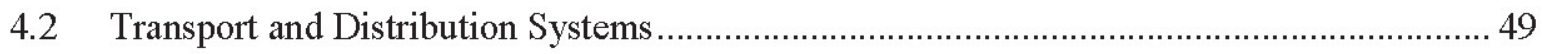

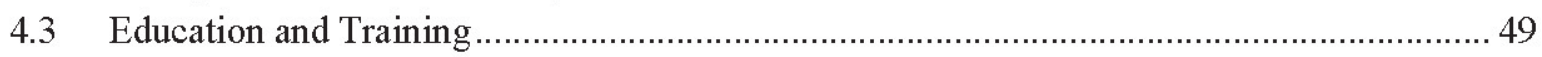


Appendix A Site Evaluation Data Requirements .................................................................... 54

Appendix B High Temperature Gas-cooled Reactor Technology and Safety Basis............................. 58

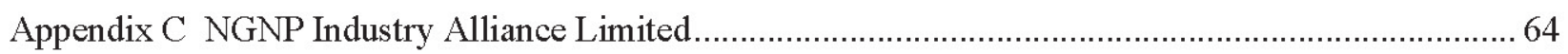

Appendix D Process Alternatives Functional and Performance Characteristics .................................. 66

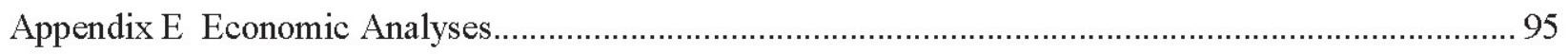

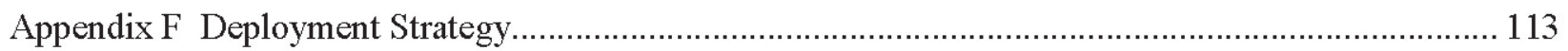

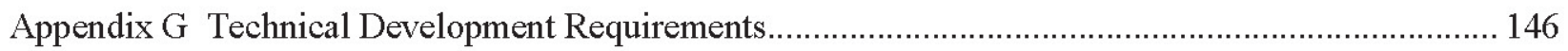

Attachment NGNP Industry Alliance Limited Business Plan ............................................................ 149

\section{FIGURES}

Figure 3-1. Syngas generation. 13

Figure 3-2. Alternative syngas supply feedstocks and configurations.............................................. 13

Figure 3-3. Conventional FT production of diesel, naphtha and LPG .............................................. 14

Figure 3-4. Alternative further processing of F-T naphtha to produce chemicals. .................................. 15

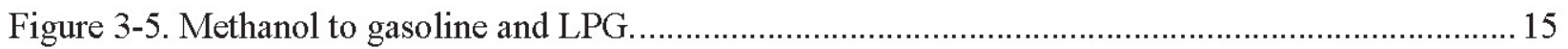

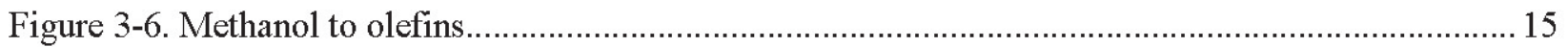

Figure 3-7. Direct coal liquefaction conversion of coal to liquids........................................................... 16

Figure 3-8. Comparison of $\mathrm{CO}_{2}$ emissions of alternative processes..................................................... 17

Figure 3-9. Comparison of the production costs of conventional carbon conversion processes with the production cost of diesel refined from crude oil versus the price of crude oil.

Figure 3-10. Comparison of the production costs of conventional carbon conversion processes with the production cost of gasoline refined from crude oil versus the price of crude oil. 19

Figure 3-11. EIA projections on future crude oil prices. 20

Figure 3-12. Production costs of CTG processes vs. natural gas price; no $\mathrm{CO}_{2}$ costs. 21

Figure 3-13. Production costs of CTG processes vs. costs of natural gas; $\$ 50 /$ ton $\mathrm{CO}_{2}$ costs. .22

Figure 3-14. Comparison of gasoline production costs for natural gas to gasoline process with refining from crude oil as a function of the costs of natural gas, $\mathrm{CO}_{2}$ and crude oil. .23

Figure 3-15. Comparison of production costs for all alternatives............................................................2 24

Figure 3-16. Coal to methanol to gasoline and LPG process with SMR hydrogen supply......................26

Figure 3-17. Performance characteristics of coal to gasoline plant. .......................................................2 27

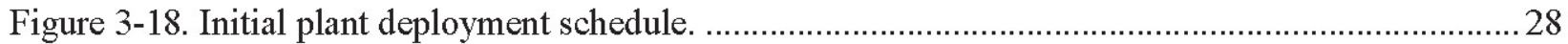

Figure 3-19. Schedule for Integrating the HTGR with the initial natural gas to gasoline plant. ...............30 
Figure 3-20. Coal production in Wyoming 1994-2014.

Figure 3-21. EIA projections on retirements of coal-fired plants through 2020 (Source: U.S.

Energy Information Administration, National Energy Modeling System) .............................32

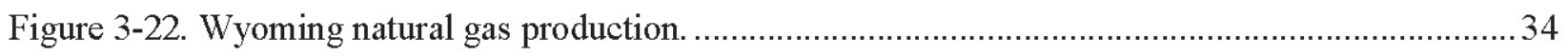

Figure 3-23. History of Wyoming natural gas wellhead prices. ...................................................... 34

Figure 3-24. History of mining component contributions to the Wyoming GDP though 2011................35

Figure $3-25$. Carbon conversion industry deployment by calendar year. ............................................ 37

Figure 3-26. Carbon conversion industry deployment expenditures and annual contributions to the

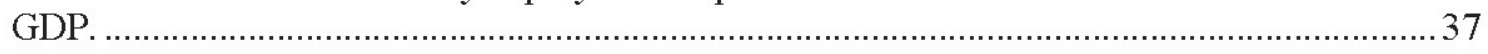

Figure $3-27$. A distributed carbon conversion industry concept. ........................................................ 38

Figure 3-28. Transformation of the Wyoming electricity generation industry. ....................................... 41

Figure 3-29. Comparison of electricity generation costs for HTGR with other power conversion

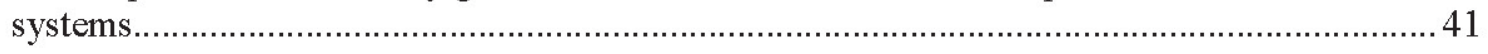

Figure 3-30. Transformation of electricity generation sources..................................................... 42

Figure 3-31. Capital expenditure to replace coal-based generation in Wyoming................................... 43

Figure 3-32. Net production and cost of production during replacement of coal-based generation.......... 44

Figure 3-33. Contributions of carbon conversion industry and electricity generation

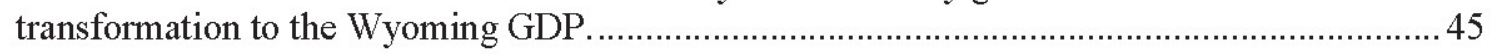

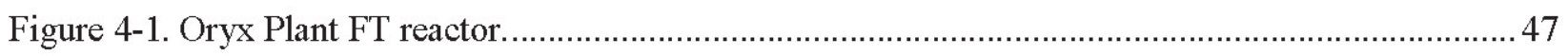

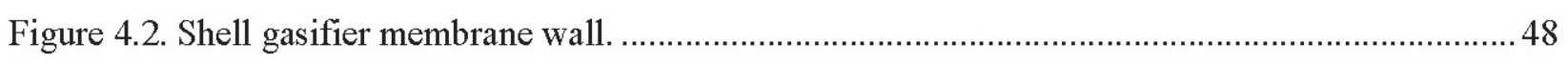

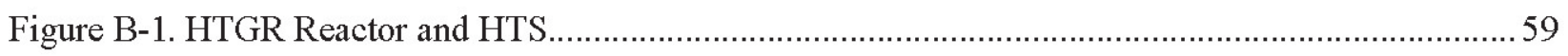

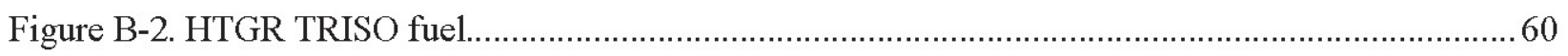

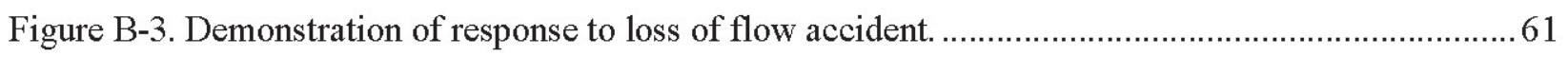

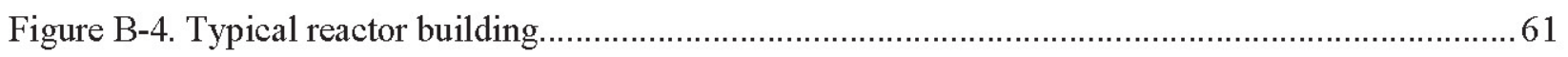

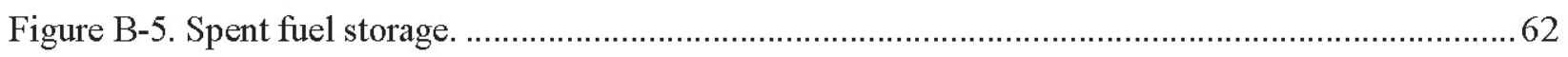

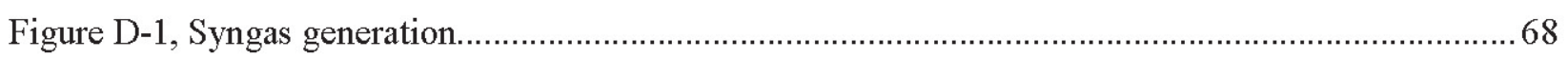

Figure D-2. Alternative syngas supply feedstocks and configurations............................................... 69

Figure D-3. Conventional FT production of diesel, naphtha and LPG. ............................................ 70

Figure D-4. Alternative further processing of F-T naphtha to produce chemicals. ............................... 70

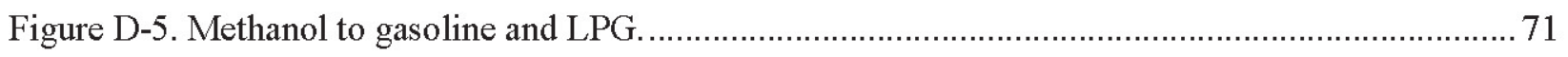

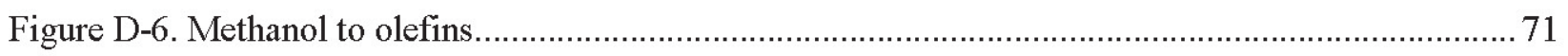

Figure D-7. Comparison of $\mathrm{CO}_{2}$ generation and the potential for capture in coal to liquids process

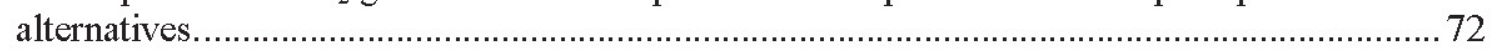

Figure D-8. Conventional coal to liquids using the traditional Fischer-Tropsch process....................... 73

Figure D-9. Coal to liquids process incorporating HTGR and HTSE technologies. ..............................73

Figure D-10. CTL FT process using conventional steam methane reforming for hydrogen supply. .........74 
Figure D-11. CTL FT process using HTGR incorporated steam methane reforming for hydrogen supply.

Figure D-12. Conventional coal to gasoline using the methanol to gasoline process............................. 76

Figure D-13. Coal to gasoline process applying HTGR and HTSE technologies. ................................. 77

Figure D-14. Coal to gasoline using an SMR hydrogen supply. .................................................... 77

Figure D-15. Coal to gasoline using an SMR with HTGR hydrogen supply....................................... 78

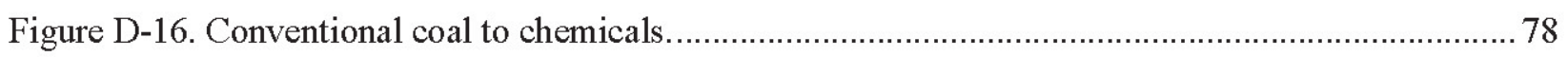

Figure D-17. Coal to chemicals process incorporating HTGR and HTSE technologies. ......................... 79

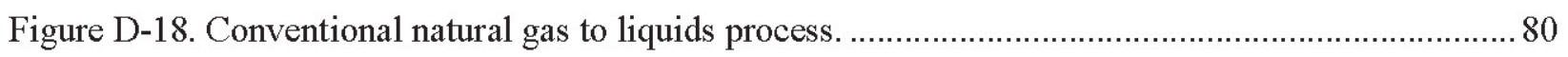

Figure D-19. Natural gas to liquids process incorporating HTGR heat................................................ 81

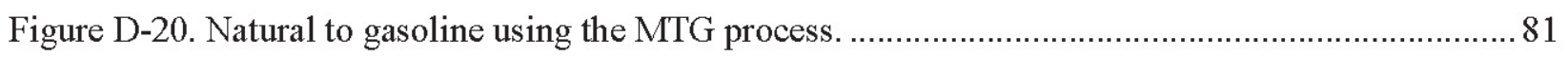

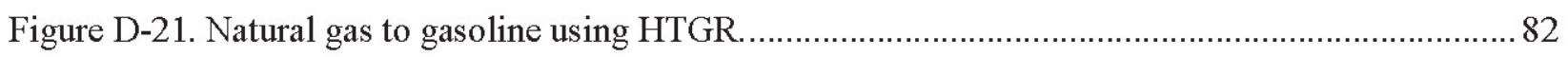

Figure D-22. Coal to liquids process with and without HTGR and HTSE......................................... 83

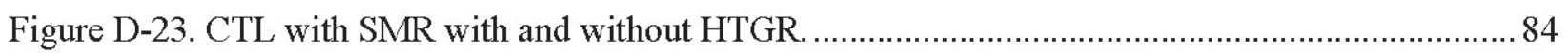

Figure D-24. Coal to gasoline process with and without HTGR and HTSE. ...................................... 85

Figure D-25. Coal to gasoline with SMR hydrogen supply and with HTGR heat. ................................. 86

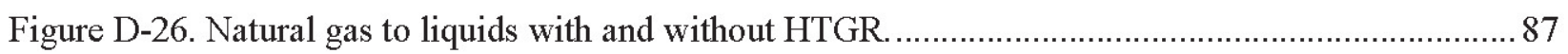

Figure D-27. Natural gas to gasoline without and with incorporation of HTGR heat and

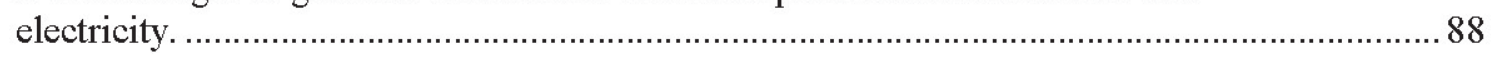

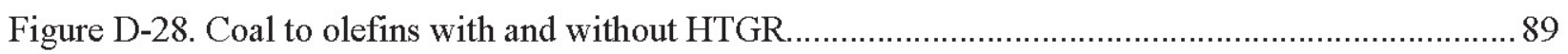

Figure D-29. Expansion of the CTL process to producing chemicals from naphtha..............................90

Figure D-30. Net cost of employing CCS within the U.S ........................................................... 92

Figure D-31. History of natural gas prices to industrial consumers, January 2001 through

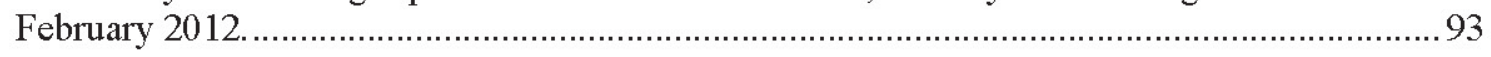

Figure E-1. Comparison of the production costs of conventional carbon conversion processes with the production cost of diesel refined from crude oil vs. the price of crude oil.

Figure E-2. EIA projections of the potential range of crude oil prices from the present through 2035.

Figure E-3. Production costs of conventional and nuclear incorporated coal and natural gas to gasoline processes compared with the production cost of gasoline refined from crude oil vs. the price of crude oil.

Figure E-4. Comparison of production costs for alternative carbon conversion processes. .................... 101

Figure E-5. HTSE hydrogen production cost versus cost of electricity............................................. 102

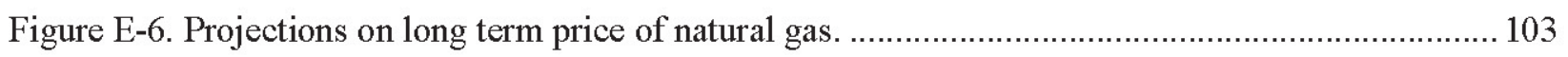

Figure E-7. Comparison of U.S. with international natural gas prices in 2010 . ................................ 103

Figure E-8. Total capital investment for candidate process plants. .................................................. 105

Figure E-9. Comparison of costs of electricity generation for several technologies. ............................ 106 
Figure E-10. Effect of variations in key parameters on diesel pricing for conventional CTL without and with HTGR and HTSE (top chart).

Figure E-11. Effect of variations in key parameters on diesel pricing for CTL with SMR without and with HTGR (bottom chart).

Figure E-12. Results of Monte Carlo analysis of parameter variations on the probability of diesel productions costs using the CTL with SMR process.

Figure E-13. SMR hydrogen production costs vs cost of natural gas and $\mathrm{CO}_{2}$ with sequestration.

Figure E-14. SMR hydrogen production cost versus cost of natural gas and $\mathrm{CO}_{2}$ without sequestration.

Figure F-1. Wyoming coal production (2000-2011).

Figure F-2. Coal to gasoline process using a steam methane reforming hydrogen supply.

Figure F-3. Integration of HTGR technology with the coal to gasoline process.

Figure F-4. Coal to gasoline plant performance characteristics.

Figure F-5. Notional plan view of fully deployed coal to gasoline plant.

Figure F-6. Statewide site suitability analysis.

Figure F-7. Initial coal to gasoline plant deployment.

Figure F-8. Initial plant annual and accumulative funding requirements.

Figure F-9. Jobs during construction of the initial process plant.

Figure F-10. Project accumulative cash flow. 126

Figure F-11. HTGR \& HTSE technology development projected schedule. 127

Figure F-12. Annual and accumulative funding required for deployment of the HTGR plant........ 128

Figure F-13. Jobs during deployment of the HTGR plant. 128

Figure F-14. History of Wyoming coal production, 2000-2012. 130

Figure F-15. Wyoming monthly natural gas withdrawal. 130

Figure F-16. Wyoming natural gas wellhead annual price, 1968-2010. 131

Figure F-17. Natural gas futures, August 14, 2012. 131

Figure F-18. Wyoming State and mining contribution to GDP 2005-2011. 132

Figure F-19. Influence of reductions in coal production on Wyoming economy. 133

Figure F-20. EIA projections on retirements of coal-fired plants through 2020 (Source: U.S.

Energy Information Administration, National Energy Modeling System). 134

Figure F-21. Carbon conversion industry development. 136

Figure F-22. Expenditures and contributions to the state's GDP from deployment of the carbon conversion industry..... 137

Figure F-23. Effect of carbon conversion deployment on the Wyoming GDP. 138

Figure F-24. Potential reductions in Wyoming coal production through 2035 due to coal-based electricity generation retirements.

Figure F-25. Actual and potential natural gas prices thru 2035. 139 
Figure F-26. Adding generation to replace retirement of coal-based generation.................................. 141

Figure F-27. Generation type added to replace retired coal-based generation...................................... 141

Figure F-28. Capital expenditure to replace coal-based generation in Wyoming.................................. 143

Figure F-29. Net production and cost of production during replacement of coal-based generation......... 144

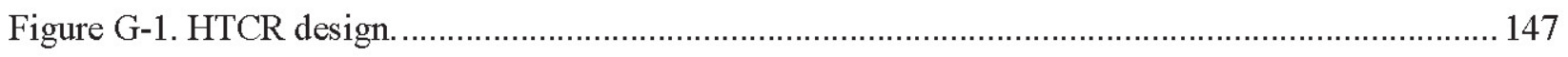

Figure G-2. HTER internals being installed at Sasol facility....................................................... 148

\section{TABLES}

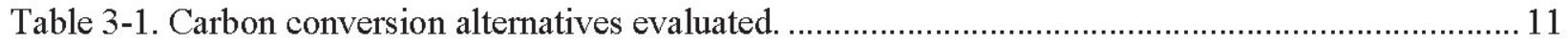

Table 3-2. Characteristics of the notional Wyoming carbon conversion industry process plants. .............35

Table 3-3. Characteristics of the HTGR plants integrated with the process plants..................................36

Table 3-4. Final mix of electricity generation technologies. ............................................................... 42

Table D.1. Carbon conversion alternatives evaluated........................................................................ 71

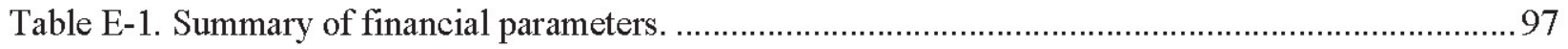

Table E-2. Variations for conventional CTL processes without HTGR and HTSE technologies............ 108

Table E-3. Variations for CTL processes with HTGR and HTSE technologies.................................... 108

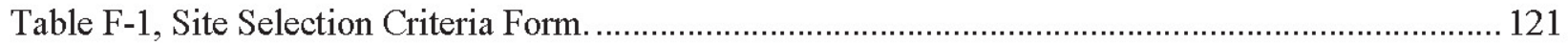

Table F-2, Characteristics of the Notional Wyoming Carbon Conversion Industry Process Plants......... 136

Table F-3. Characteristics of the HTGR plants integrated with the process plants. ............................ 140

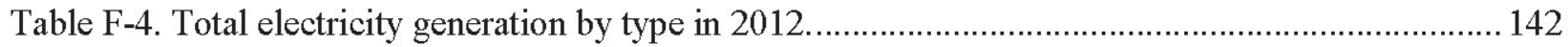

Table F-5. Total electricity generation by type after retirement of coal based generation. ..................... 142 


\section{ACRONYMS}

CCS carbon capture and sequestration

CTG coal to gasoline

CTL coal to liquids

CTO coal to olefins

DCL direct coal liquefaction

DOE Department of Energy

EIA Energy Information Administration

EOR enhanced oil recovery

EPA Environmental Protection Agency

GAV gross added value

GDP gross domestic product

GTG gas to gasoline

GTL gas to liquid

HTGR high temperature gas-cooled reactor

HTSE high temperature steam electrolysis

INL Idaho National Laboratory

LPG liquid petroleum gas

MTG methanol to gasoline

NETL National Energy Technology Laboratory

NGCC natural gas combined cycle

NGNP Next Generation Nuclear Plant

SMR steam methane reforming

WyGISC Wyoming's Geographic Information Science Center 


\section{Energy Development Opportunities for Wyoming}

\section{DEVELOPMENT APPROACHES AND PATH FORWARD}

An important opportunity exists for the energy future of Wyoming that will...

- Sustain and possibly grow its coal industry

- Add substantive value to its indigenous coal and natural gas resources

- Reduce dramatically the environmental effect of its energy production capability

- Add substantive opportunities to develop an advanced manufacturing industry in the State, and

- Increase the State's Gross Domestic Product

These can be achieved through development of a carbon conversion industry for transformation of coal and natural gas to synthetic transportation fuels, chemical feedstock and chemicals that are the building blocks for the chemical industry. Over the longer term, environmentally clean nuclear energy (e.g., high temperature gas-cooled reactors) can provide the substantial energy needs of a carbon conversion industry and be part of the diverse mix of replacement technologies for the current fleet of aging coal-fired electric power generating stations.

\subsection{Energy Development Approaches for Wyoming}

The opportunities for Wyoming's energy future can be achieved through the following:

\section{Strengthening the coal and natural gas economy in Wyoming by building a carbon conversion industry}

The extraction and utilization of coal is an important part of Wyoming's economy - contributing $\sim 12 \%$ of the Gross Domestic Product. Over $95 \%$ of the extracted coal is exported from Wyoming, currently providing about $40 \%$ of the nation's energy needs - but is not used to directly expand the state's economy. The future of coal is being challenged by changing and ever more demanding environmental requirements for its extraction and use.

Over $90 \%$ of the natural gas extracted in Wyoming is exported, providing about $9 \%$ of the nation's natural gas needs - in recent years contributing $\sim 18 \%$ of Wyoming's gross domestic product. However, the decreased natural gas prices over the last few years necessary to compete with shale gas extracted elsewhere has reduced that contribution. Natural gas commodity futures suggest that the reduced prices may last for a decade.

New industries are needed that are focused on value-added processes which will retain more of the end-use value of indigenous carbon resources within Wyoming. Strengthening the carbon industry economy by targeting new markets can be achieved through development of a carbon conversion industry for transformation of coal and natural gas to synthetic transportation fuels and chemicals that are the building blocks for the chemical industry. Over the longer term, environmentally clean nuclear energy (e.g., high temperature gas-cooled reactors) can provide the substantial energy needs of a carbon conversion industry.

As a far reaching example, notionally redirecting the current Wyoming coal production to making synthetic fuels (e.g., gasoline or diesel) could supply over $50 \%$ of the current total U.S. consumption of 
liquid hydrocarbon fuels at prices competitive with traditional refining processes. However, the capital investment to achieve this capability would be substantial. Practically carving out the achievable part of this possible energy future requires developing a far-sighted partnership with industry, starting with an incremental strategy that can set Wyoming on the path to becoming a major player in an environmentally responsible carbon conversion industry and in deployment of next generation nuclear energy technology.

Entry into the carbon conversion industry can be through phased construction of process facilities using conventional technologies that can be operational within the next decade focused initially on producing transportation fuels (e.g., coal-to-liquids or natural gas-to-liquids facilities to produce gasoline). The potential expansion of the carbon conversion industry using a distributed process model is shown in the figure. The design of carbon conversion facilities should be intentionally compatible with integration of nuclear energy technology such as high temperature gascooled nuclear reactor (HTGR) technology. Because the commercialization of the HTGR is expected to extend over the next 10 to 15 years, a notional strategy would be to deploy carbon conversion facilities using conventional processes in the short term (e.g., beginning in 2013) anticipating incorporation of the HTGR technology over the longer term (e.g., in the mid-to-late 2020s).This strategy

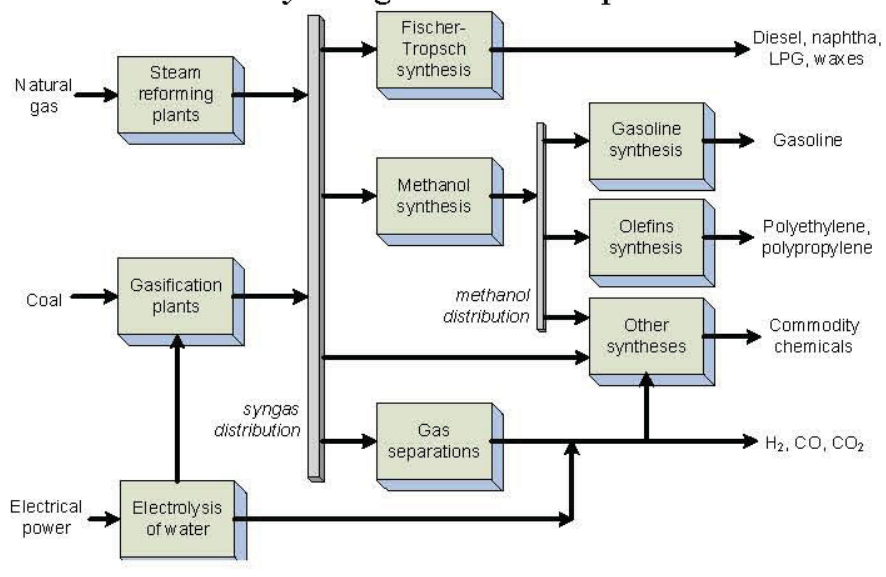
promotes earlier realization of the benefits of deploying these carbon conversion processes to the Wyoming economy. Use of nuclear energy will be an important part of addressing anticipated ever more demanding environmental requirements and mitigating expected volatile international energy pricing.

\section{Ensuring continued reliable and affordable sources of energy for Wyoming's industries and people by diversifying the technologies for generating electric power}

Today, over $95 \%$ of Wyoming's electricity is generated by burning coal with a delivered electric power price that is among the lowest in the United States. Anticipated increased environmental requirements necessitate looking at alternative forms of energy production, and in particular electric power generation. Further, managing the anticipated future mix of energy production methods, some of which are highly variable such as wind turbine-produced electricity, may involve adapting hybrid energy system approaches building on the experience with other mixed energy production systems.

The anticipated retirement over the next several decades of Wyoming's aging coal-fired electric power generating fleet - both a challenge and an opportunity - requires long range planning to ensure that the replacement power generating technologies fulfill the desired or policy-imposed business and environmental requirements. Selecting a diverse set of replacement power generating technologies is warranted, considering the uncertainties inherent in predicting future energy resources and demand, both nationally and internationally. Best available information suggests that the transformation to this diverse set of technologies should initially include natural gas combined cycle generation and renewables, subsequently complemented by clean coal technologies and nuclear energy - the mix primarily determined by: 
- Anticipated energy price trends, nationally and internationally

- Wyoming's long term industrial base

- Extent of desired energy selfsufficiency

- Wyoming's energy export posture.

The transformation to a diverse technology mix such as that shown in the figure will allow Wyoming and its industry to adjust to evolving global energy realities.

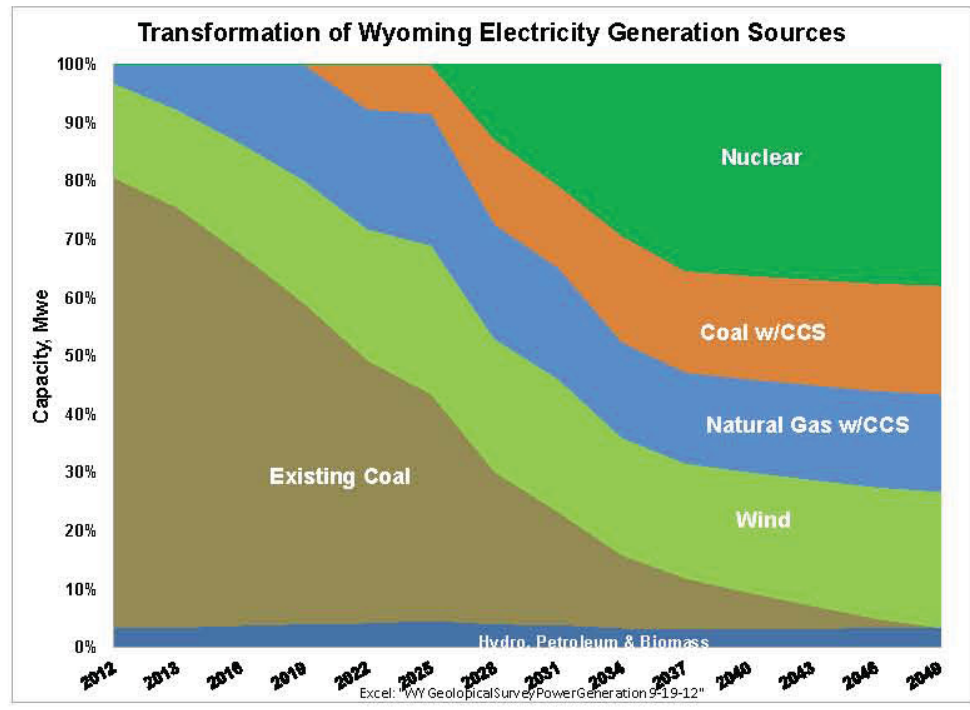

\section{Capitalizing on anticipated growth of the nuclear energy industry by producing higher-value products from uranium}

Wyoming produces a large fraction of the country's uranium and currently exports it as yellowcake which is processed elsewhere for use as nuclear reactor fuel. The immediate next stage of processing, conversion to uranium hexafluoride, could be accomplished in Wyoming, providing considerable valueadded.

As part of ongoing activities to investigate these approaches, the Wyoming Business Council, representing the state's interests, has participated in collaborative evaluations of energy development opportunities with the NGNP Industry Alliance (an industry consortium), the University of Wyoming, and the U.S. Department of Energy's (DOE) Idaho National Laboratory (INL). This report summarizes the results of these evaluations to identify:

- Technically and economically viable methods to increase the value added to the economy associated with the extraction and processing of indigenous resources including coal and natural gas

- Opportunities for application of nuclear energy technologies as part of the overall energy mix.

Nuclear energy provides an option that is environmentally clean and provides stable, competitive energy prices.

- Industrial infrastructure capabilities and needs that support the long term energy future.

A companion report, Preliminary Feasibility of Value Added Products from Cogeneration and Hybrid Energy Systems in Wyoming (INL/EXT-12-27249) summarizes the possible options for hybrid energy systems management to potentially optimize the projected mix of energy production methods.

The conclusions of these two reports provide a foundation upon which Wyoming, in partnership with industry, can develop energy policy and projects for implementation.

\subsection{Conclusions}

This report concludes that a viable option for the state of Wyoming is the development of a carbon conversion industry that uses a variety of processes for conversion of coal and natural gas to synthetic transportation fuels, chemical feedstock and chemicals that are the building blocks for the chemical industry. This option provides substantive increases in the value of these indigenous resources, with a corresponding improvement in the gross domestic product. 
It appears most attractive to adopt a phased approach with industry building one or more initial carbon conversion process plants that present a viable business case, and over the longer term adding process plants as needed to maintain and grow the State's economy. Additionally, as environmental requirements demand, nuclear energy (e.g., high temperature gas-cooled reactor technology) can be integrated as the primary source of energy for process operations.

Several carbon conversion processes for coal and natural gas were evaluated, with many showing promise for application in Wyoming. Either coal or natural gas can be chosen as the feedstock for initiating a carbon conversion industry - and the choice will be that of the industrial entities that invest, own, and operate these process facilities. However, these choices may be strongly influenced by the policies and incentives established by the federal and State governments.

A notional reference concept for initiating and expanding the carbon conversion industry is described herein. The reference concept was chosen to provide a basis for the economic analyses. The notional concept includes a coal-to-gasoline process plant using steam methane reforming of natural gas for hydrogen production and conventional methanol-to-gasoline technologies (producing gasoline and liquid petroleum gas [LPG]). This is judged a prudent early choice to demonstrate the added value in consideration of the reduction in coal production over the last few years and the low natural gas futures prices over the next decade with the corresponding reduction in the gross domestic product. This process plant would be similar to the DKRW Advanced Fuels coal to gasoline plant being pursued for Medicine Bow and is complementary to the natural gas to gasoline plant developed in the companion Hybrid Energy Report. ${ }^{1}$ Presuming the necessary industry investment, this initial coal conversion plant could be operational by 2018 . This plant can be expanded and the number of plants increased as described herein as the market supports. Over the longer term, the process plant can be integrated with nuclear energy technology such as the HTGR to improve overall carbon utilization efficiency and reduce emissions (2031 and beyond).

The figure provides a perspective from Wyoming's view on the potential differences in revenue derived from coal and natural gas by comparing the contribution to the gross domestic product (GDP) for 1) continuing with coal and natural gas exports and instate use similar to that done today, with 2 ) investing in a carbon conversion industry and the resulting value-added products. There are important assumptions and uncertainties in developing this figure which are discussed in more detail in Section 3 of the report. However, such overall predictions, even if uncertain,

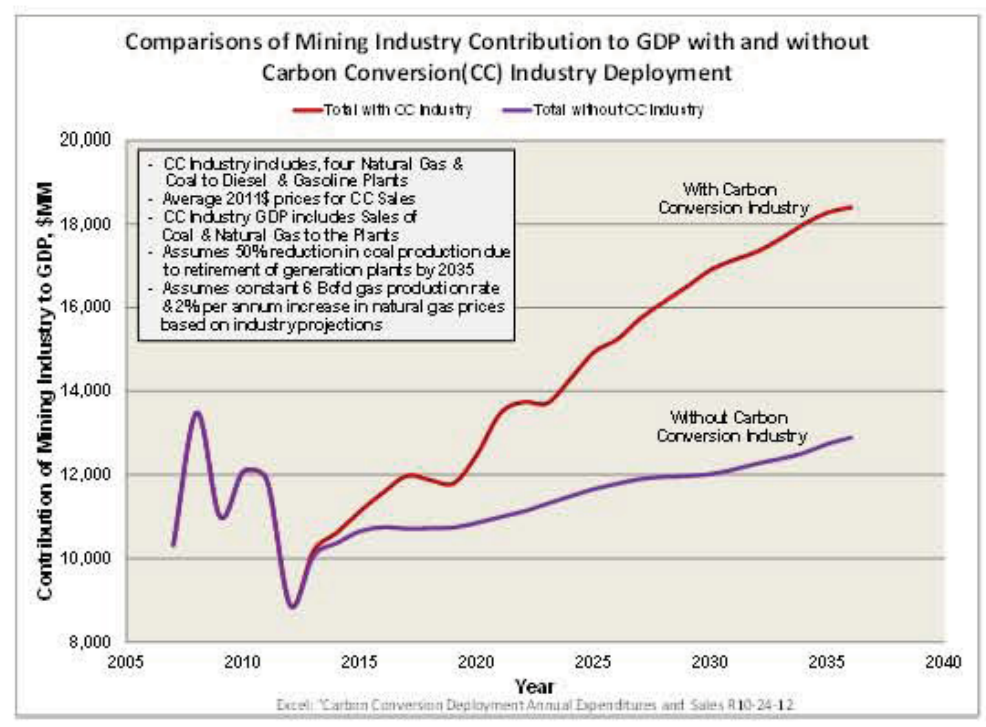
are important in gaining an approximate understanding regarding the course to pursue.

With an initial focus on providing energy for this to-be-developed carbon conversion process industry, nuclear energy provides an environmentally clean and stable price competitive alternative as the current coal-fired electric power generation fleet is retired. Scenarios are presented regarding the anticipated retirement rate profile and the investments necessary by industry to ensure reliable and cost effective electric power is available for Wyoming and its industries, as well as available for sale outside of the state to surrounding jurisdictions and the region. The companion report (Preliminary Feasibility of Value Added Products from Cogeneration and Hybrid Energy Systems in Wyoming [INL/EXT-12- 
27249]) summarizes the possible approaches to hybrid energy systems management to potentially optimize the projected mix of energy production methods that may evolve with the combination of remaining coal and gas-fired power plants, renewable energy (e.g., wind), increased growth of the carbon conversion industry and use of nuclear energy technologies.

Additionally, broad opportunities exist for the development of the industrial infrastructure that supports the carbon conversion industry and nuclear energy industry. Such infrastructure could include providing equipment and systems including modular assemblies for the carbon conversion and nuclear energy portions of such complexes as well as supplying materials and maintenance and outage services.

\subsection{Suggested Overall Path Forward}

This report provides a suggested path forward for Wyoming to pursue a carbon conversion industry as a central feature improving the value of indigenous resources to the overall state economy with nuclear energy providing the primary source of energy and part of achieving a diverse mix of power generating technologies to replace retiring conventional coal-fired generation. Summarizing:

- Pursue developing a collaborative partnership with industry to build the initial portions of a carbon conversion industry. This collaborative partnership will include planning for the initial carbon conversion process(es) to be deployed, the site(s) selection and the overall approach to building-out the carbon conversion industry based on best available projections of the market for the products to be produced and planning for development of transport for these products to both regional and distant markets

- In the planning basis for the carbon conversion industry, ensure that economically competitive and environmentally compatible process plant design configurations are chosen that support a phased approach to integrating nuclear energy technology as the long term source of energy.

- Prepare a plan that anticipates retirement of portions of the current coal fired power generation fleet (e.g., considering age and evolving regulations), modification of other portions of the current fleet for carbon capture and storage and/or use in enhanced oil recovery applications, continued increases in renewable generation capabilities and the deployment of nuclear energy technologies for base load capabilities. This report provides a notional basis for such planning and requires looking ahead for management of the future energy mix using techniques such as those utilized in hybrid energy systems. An essential decision is the extent to which Wyoming and its power generation industry plan to continue to be a net exporter of energy in the form of electricity considering tradeoffs such as investments in new generating capacity and expanded transmission system capacity.

- Prepare a plan for industrial infrastructure development based on the needs of a growing carbon conversion industry and in the future, a nuclear energy industry. This includes state regulatory and educational institution changes that will be required.

- Prepare an evaluation of the overall effect on the economy and demographics in Wyoming as these industrial capabilities are realized. 


\section{BACKGROUND AND REPORT STRUCTURE}

A complementary two part evaluation has been conducted as a collaboration of the Wyoming Business Council, the University of Wyoming, the NGNP Industry Alliance Limited (Alliance) and INL. The following correspondence and legislation developed the approach to these evaluations:

- Letter from Frederick L. Moore (Alliance) to Greg Gibbs (Project Director, NGNP Project, INL Forthcoming Meeting on Energy Development Opportunities in Wyoming, December 13, 2011 ${ }^{2}$

- Letter from Governor Matthew H. Mead to Frederick L. Moore (Alliance), [Expression of interest in HTGR technology and welcome to meeting in Cheyenne], January 13, $2012^{3}$

- Letter from Frederick L. Moore (Alliance) to Governor Matthew H. Mead, Nuclear Concepts - WY and High Temperature Gas Reactor, January 17, $2012^{4}$

- Letter from Frederick L. Moore (Alliance) to Governor Matthew H. Mead, [Regarding] Meeting with NGNP Industry Alliance, January $30,2012^{5}$

- Codification by the Wyoming Legislature in the following Act (Note: Only the relevant portions of the Act relating to the scope of work are shown):

ORIGINAL SENATE

FILE NO. 0014

\section{ENROLLED ACT NO. 23, SENATE \\ SIXTY-FIRST LEGISLATURE OF THE STATE OF WYOMING 2012 BUDGET SESSION}

AN ACT relating to business development; requiring the Wyoming business council to contact the department of energy and other entities regarding next generation nuclear plants and hybrid energy system facilities as specified; providing an appropriation; requiring a report; and providing for an effective date.

Be It Enacted by the Legislature of the State of Wyoming:

Section 1.

(a) The Wyoming business council, in consultation with the governor, shall contact the United States department of energy and other entities regarding the possibility of locating within the state of Wyoming any next generation nuclear plant project under consideration by the department of energy under its nuclear energy research initiative. In addition, the Wyoming business council shall investigate the feasibility of locating hybrid energy system facilities that include the use of other forms of energy resources in Wyoming including, without limitation, coal and coal gasification, natural gas, oil, wind and other renewable resources. The Wyoming business council shall also evaluate supply chain industries related to nuclear and hybrid energy systems facilities including, without limitation, those industries that provide equipment and feed stocks. This evaluation shall include, without limitation, consideration of whether the supply chain industries would limit the development of projects and opportunities for adding value to Wyoming resources.

(b) Not later than November 1,2012, the Wyoming business council shall report the results of any discussions with the United States department of energy or other entities under this section to the joint minerals, business and economic development interim committee. The report shall include any suggested legislation which may encourage the location of a next generation muclear plant, hybrid energy system facility or supply chain manufacturing facility project within the state of Wyoming.

(c) There is appropriated two hundred fifty thousand dollars $(\$ 250,000.00)$ from the general fund to the Wyoming business council. This appropriation shall only be expended for the purpose 
of conducting the investigations and providing the report as specified under this act. No portion of this appropriation shall be expended prior to an agreement between the Wyoming business council and the Idaho national laboratory or other entity that the Idaho national laboratory or other entity will expend an amount not less than two hundred fifty thousand dollars $(\$ 250,000.00)$ in conducting the investigations and providing information for the report as specified under this act. Of this general fund appropriation, fifty thousand dollars $(\$ 50,000.00)$ shall be provided to the University of Wyoming for support from the college of engineering and applied sciences, the college of business, the school of energy resources and for coordination with the state geological survey. Of this general fund appropriation, fifty thousand dollars $(\$ 50,000.00)$ may be used to contract with outside entities including nuclear reactor and next generation nuclear power facilities.

This report documents the work performed by the INL in accordance with provision (c) of the Act, "...the Idaho national laboratory or other entity will expend an amount not less than two hundred fifty thousand dollars $(\$ 250,000.00)$ in conducting the investigations and providing information for the report as specified under this act."

Two complementary scopes of work have been completed.

- The first scope of work is covered by this report that includes an evaluation of the technically and economically viable approaches for increasing the value to the economy associated with the extraction and processing of indigenous resources including coal and natural gas. This evaluation focused on the viability of developing a carbon conversion industry that could produce synthetic transportation fuels, chemical feedstock and chemicals that form the building blocks for the chemical industry in a phased manner. High temperature gas-cooled nuclear energy technology (HTGRs) is examined as a long term source of energy for the process industry and electric power generation in consideration of the high temperature process heat that can be produced and the highly efficient electric power generation capability. The robust nuclear safety characteristics of HTGR technology allow use adjacent to major industrial facilities.

- The second scope of work is covered in reference 1 and includes an evaluation of the technical and economic viability of alternative nuclear energy sources, an assessment of markets for the products from a carbon conversion industry and the viability of applying hybrid energy system techniques to address the anticipated future energy mix of energy production methods.

- An Overview Report has been prepared to meld the results of the two scopes of work into a coherent set of recommendations on the path forward for Wyoming. ${ }^{6}$

This report summarizes the analyses, results, conclusions and recommendations of the evaluation focused on the following:

- Technically and economically viable methods to increase the value added to the economy associated with the extraction and processing of the indigenous resources of coal and natural gas. The primary approach adopted for evaluation is the conversion of coal and natural gas to other hydrocarbon forms for use in transportation and manufacturing

- Opportunities for application of nuclear energy technologies, with emphasis on HTGR technology, as a major part of the energy mix in meeting the energy needs of the State, including for the extraction and processing of indigenous resources and generation of electricity

- Specific alternative and preferred processes for coal and natural gas conversion and possible sites for demonstrating and deploying such process facilities. Such evaluations will include assessment of technical feasibility, economic viability, national policy uncertainty and regulatory risk 
- Deployment strategies that examine:

- A phased approach to achieve deployment of the viable process(es) at the earliest practical time by applying primarily conventional processes. The phased approach spreads out capital investment and minimizes project risk

- Integration of nuclear energy technologies (e.g., high temperature gas-cooled reactor technology) for environmental and economic considerations over the longer term

- Flexibility to adapt to new processing developments and evolving government policies and regulations, prices of energy, prices of feedstock, and State objectives.

- Technical and economic analyses of alternative processes and strategies necessary and sufficient to enable selection and structuring of the path forward to implement the most favorable approach

- Infrastructure needs for implementing the path forward for both a carbon conversion industry and a transformed electric power industry utilizing HTGR technology as part of the technology mix. Opportunities exist within the State to utilize or update current workforce resources or add resources to meet these needs. Identify where infrastructure needs provide an opportunity for development of industries to support local, regional, national and international markets in these areas.

As cited previously, an objective of this evaluation is to establish the possible roles of HTGRs in Wyoming's energy future with emphasis on the application to carbon conversion processes and the generation of electricity. The development of the HTGR is expected to extend over the next 10 to 15 years with construction of a first-of-a-kind four module plant ${ }^{\mathrm{b}}$ beginning in about 2020 with completion in about 2029. Broader commercial application will begin about 2030. Because there is a need to address the issues with reduced coal production and low natural gas prices sooner than this, a strategy has been developed to initiate deployment of carbon conversion facilities using conventional processes in the short term ( beginning in 2013), anticipating incorporation of the HTGR technology over the longer term (beginning in mid-to-late 2020s). This strategy promotes earlier realization of the benefits of deploying these carbon conversion processes to the Wyoming economy. To these ends, alternative carbon conversion processes were evaluated on their readiness for short term deployment (components are commercially available and processes proven) and ready adaptability to the HTGR technology when commercialized.

The structure of the remainder of this report is summarized in the following:

- Section 3 - Results and Conclusions: Detailed discussions of the results and conclusions regarding the technologies and phased approaches to developing and deploying a carbon conversion industry, the sources of energy for that industry and the long term transition to a diverse energy production capability.

- Section 4-Infrastructure Development Opportunities: Characterization of the equipment, material, construction and operating labor, maintenance services and other resources that are required for successful deployment of the carbon conversion process that can provide opportunities and potential economic benefit from expansion of existing or development of new infrastructure and industries within the State to support the expansion and operation of a carbon conversion and nuclear energy industry.

The following appendices provide important background information in support of this evaluation:

Appendix A - Summary of the Site Suitability Requirements

b The site for the first-of-a-kind four module plant has not been chosen. There is an opportunity for this plant to be located in Wyoming. 
Appendix B - High Temperature Gas-cooled Technology and Safety Ba

Appendix C -NGNP Industry Alliance Limited

Appendix D - Process Alternatives Functional and Performance Characteristics

Appendix E - Process Alternatives Economic Analyses

Appendix F - Deployment Strategy

Appendix G - Technical Development Requirements 


\section{RESULTS AND CONCLUSIONS}

\subsection{General}

As part of a broad collaborative effort among Wyoming interests led by the Wyoming Business Council, the NGNP Industry Alliance and the INL, several investigations were performed to identify and formulate opportunities for expanding the market and increasing the value of the indigenous coal and natural gas resources in Wyoming. The investigations focused on the deployment of a carbon conversion industry and the potential use of nuclear energy to satisfy the long term energy needs in the State. These investigations (1) identified carbon conversion processes that match up with the characteristics of the coal and natural gas in Wyoming and the market for the products from these processes (2) established the role of nuclear energy with emphasis on the HTGR technology to be integrated with the carbon conversion processes and as a part of the replacement mix for existing coal-fired electricity generation, and (3) identified the alternatives that meet the objectives of this collaborative effort and are technically and economically viable

An important opportunity exists for the state of Wyoming to develop and deploy a carbon conversion industry using coal and natural gas as feedstock for the production of synthetic transportation fuels, chemical feedstock and chemicals. A notional strategy for developing and deploying a carbon conversion industry is described herein to provide perspective on the elements that need to be addressed and the scope, costs and schedule required. The deployment strategy applies to the use of either or both coal and natural gas as feedstock and the conclusions regarding technical and economic viability apply to either.

This deployment strategy includes a phased effort. A notional reference initial carbon conversion process and full industry deployment approach and sequence are developed to provide a basis for the analyses. The actual choice of the initial process plant concept and the sequence for deploying and expanding the carbon conversion industry will be made by industrial entities that will invest in, own and operate the facilities. However, these choices may be strongly influenced by the policies and incentives established by the federal and State governments.

The notional first phase initiates the development of a coal-to-gasoline plant with hydrogen supplied via steam methane reforming of natural gas via deployment of a single module (train) of modest size to initiate development of the carbon conversion industry. The design, construction and operation of this module would initiate development of the processes and infrastructure needed for wider deployment of the carbon conversion industry. This initial module would be operated for some period (a year has been used herein) to identify and resolve construction and operational problems. Once that period is complete the second phase of the strategy includes expanding this initial plant to full capacity by adding an additional three modules and then adding an additional three plants using coal or natural gas as the primary feedstock to produce synthetic transportation fuels.

Evaluation of this notional carbon conversion industry leads to conclusions that its deployment is technically feasible, would produce fuels at a production cost competitive with similar products from traditional industries, and generates returns on investment at these production costs that are expected to be consistent with industry objectives. Further, such a carbon conversion industry adds substantive value to the Wyoming economy beyond the market price of the coal and natural gas as feedstock through conversion to higher value products for use within Wyoming and for national and international export. Deployment of this industry would better retain the value of these indigenous resources within Wyoming and increase the contribution of mining and processing these resources to the Wyoming GDP.

Over the longer term, nuclear energy provides an important option to address the energy needs of a growing carbon conversion industry and to be part of a diverse mix of energy production technologies to replace coal-fired electric power generation facilities being retired due to age and potentially required 
non-economic upgrades to satisfy ever more demanding environmental requirements. Nuclear energy provides an environmentally clean source of energy that is competitive with other alternatives. The HTGR technology is best suited for the high temperature process heat needs of a carbon conversion industry and achieves high net electricity generation efficiencies with no greenhouse gas emissions making it ideally suited as part of replacing the existing coal-fired generation in Wyoming within a diverse mix of electric power generation technologies.

The following sections present the results of the evaluations supporting these conclusions including:

- The functional and performance characteristics and economics of the alternative processes that could be applied in developing the carbon conversion industry.

- The specific processes used as examples to evaluate a carbon conversion industry development and the strategy for siting plants in Wyoming

- The application of HTGR nuclear energy technology to reduce emissions and stabilize energy costs in the carbon conversion industry and as part of the installation of new generation to replace retired coal based generation

- The transformation of the electricity generation sources in Wyoming over the longer term

- Assessment of the impact of these activities on the Wyoming economy and GDP.

\subsection{Process Alternatives}

Table 3-1 summarizes the attributes and nomenclature for the several carbon conversion processes evaluated in this effort.

Table 3-1. Carbon conversion alternatives evaluated.

Acronym

Process

Coal to Liquids (CTL) $)^{7, \mathrm{e}}$-- producing diesel, naphtha and liquefied petroleum gas

CTL Conventional CTL using the Fischer-Tropsch (FT) process

CTL w/SMR Conventional CTL with steam methane reforming (SMR) supplying hydrogen to the coal gasifier

CTL w/SMR \& CTL with SMR (CTL w/SMR) with HTGR supplying heat and electricity to the steam methane HTGR reformers

CTL w/HTGR \& CTL with HTGR and high temperature steam electrolysis (HTSE) supplying hydrogen to the HTSE coal gasifier

Natural Gas to Liquids (GTL) ${ }^{4}$ - producing diesel, naphtha and liquefied petroleum gas

GTL Conventional natural GTL using the FT process

GTL w/HTGR 1 GTL with HTGR supplying heat to the primary reformer

Natural Gas to Gasoline $(\mathrm{GTG})^{8}$ - producing gasoline and liquefied petroleum gas

GTG Conventional natural GTG using the methanol to gasoline process (MTG)

GTG w/HTGR GTG with HTGR supplying heat to the primary reformer

Coal to Gasoline $(\mathrm{CTG})^{5 \text {-- }}$ producing gasoline and liquefied petroleum gas

CTG Conventional CTG using MTG process

CTG w/SMR Conventional CTG with SMR supplying hydrogen to the coal gasifier

c All of the INL references in this report as well as other documentation of interest to the subjects of carbon conversion and the HTGR can be retrieved from the INL Website - https://inlportal.inl.gov/vhtrinformation. 


\begin{tabular}{|c|c|}
\hline Acronym & Process \\
\hline $\begin{array}{l}\text { CTG w/SMR \& } \\
\text { HTGR }\end{array}$ & $\begin{array}{l}\text { CTG with SMR (CTG w/SMR) with HTGR supplying heat and electricity to the steam } \\
\text { methane reformers }\end{array}$ \\
\hline $\begin{array}{l}\text { CTG w/HTGR \& } \\
\text { HTSE }\end{array}$ & CTG with HTGR and HTSE supplying hydrogen to the coal gasifier \\
\hline \multicolumn{2}{|c|}{ Coal to Chemicals ${ }^{9}--$ including olefins such as ethylene and propylene } \\
\hline $\mathrm{CTO}$ & Conventional coal to olefins (CTO) \\
\hline $\begin{array}{l}\text { CTO w/HTGR \& } \\
\text { HTSE }\end{array}$ & CTO with HTGR and HTSE supplying hydrogen to the coal gasifier \\
\hline \multicolumn{2}{|c|}{ Direct Coal Liquefaction -- producing diesel, naphtha and liquefied petroleum gas } \\
\hline DCL & Direct coal liquefaction (DCL) based on Bergius-Pier process \\
\hline
\end{tabular}

\subsubsection{Syngas Generation}

All of the processes listed in Table 3-1 involve conversion of coal and/or natural gas into some combination of diesel, naphtha, LPG, gasoline and commodity chemicals (e.g., ethylene and propylene). In all cases, except for the DCL process, the first step in the process is the conversion of the feedstock to synthetic gas composed of a specific ratio of $\mathrm{H}_{2}$ and $\mathrm{CO}$, see Figure 3-1. With coal as the feedstock the synthetic gas is produced in a gasifier at high temperature.

In the coal gasification process the coal is burned in the gasifier generating $\mathrm{CO}$ and hydrogen among other tramp constituents in the coal and slag. There are several types of gasifiers commercially available; for the purposes of this evaluation a dry-fed gasifier similar to those supplied by Uhde and Shell was used. ${ }^{10}$ There is insufficient hydrogen in the coal to achieve the required ratio of $\mathrm{CO}$ to $\mathrm{H}_{2}$ in the syngas; hence, another supply of hydrogen is required. In most commercial gasifiers this is done by injecting steam and using the water shift reaction to produce the hydrogen; $\mathrm{CO}+\mathrm{H}_{2} \mathrm{O} \gg \mathrm{CO}_{2}+\mathrm{H}_{2}$. This is a major source of $\mathrm{CO}_{2}$ generation in this process.

For natural gas feedstock the syngas is produced through a reforming process splitting the carbon and hydrogen in the gas and adding oxygen to produce the $\mathrm{H}_{2}$ and $\mathrm{CO}$ components of the syngas. In this case there is sufficient hydrogen in the natural gas to obtain the required ratio of $\mathrm{H}_{2}$ to $\mathrm{CO}$. This is an endothermic process and the heat is supplied by burning some of the natural gas. This is a major source of $\mathrm{CO}_{2}$ generation in this process.

The quantities of $\mathrm{CO}_{2}$ produced in the coal gasification process are significantly higher than that for the natural gas reformer. In both cases, however, the majority of the $\mathrm{CO}_{2}$ generated in these processes can be captured, compressed and transported for sequestration or enhanced oil recovery (EOR). ${ }^{d}$ However, this is costly, there are important uncertainties regarding the viability of sequestration as a method for disposing of this, and there is insufficient capacity in EOR to make that a viable long term disposal pathway; see Section 3.2.6.3 and Appendix D.3 for more discussion on sequestration and EOR. Pending government regulation of $\mathrm{CO}_{2}$ emissions also make release economically unattractive. Accordingly, there is advantage to reducing the amount of $\mathrm{CO}_{2}$ generated in the syngas processes. Figure 3-2 shows four approaches that are evaluated herein.

d Disposition of captured $\mathrm{CO}_{2}$ through sequestration or EOR is discussed in more detail in later sections. 


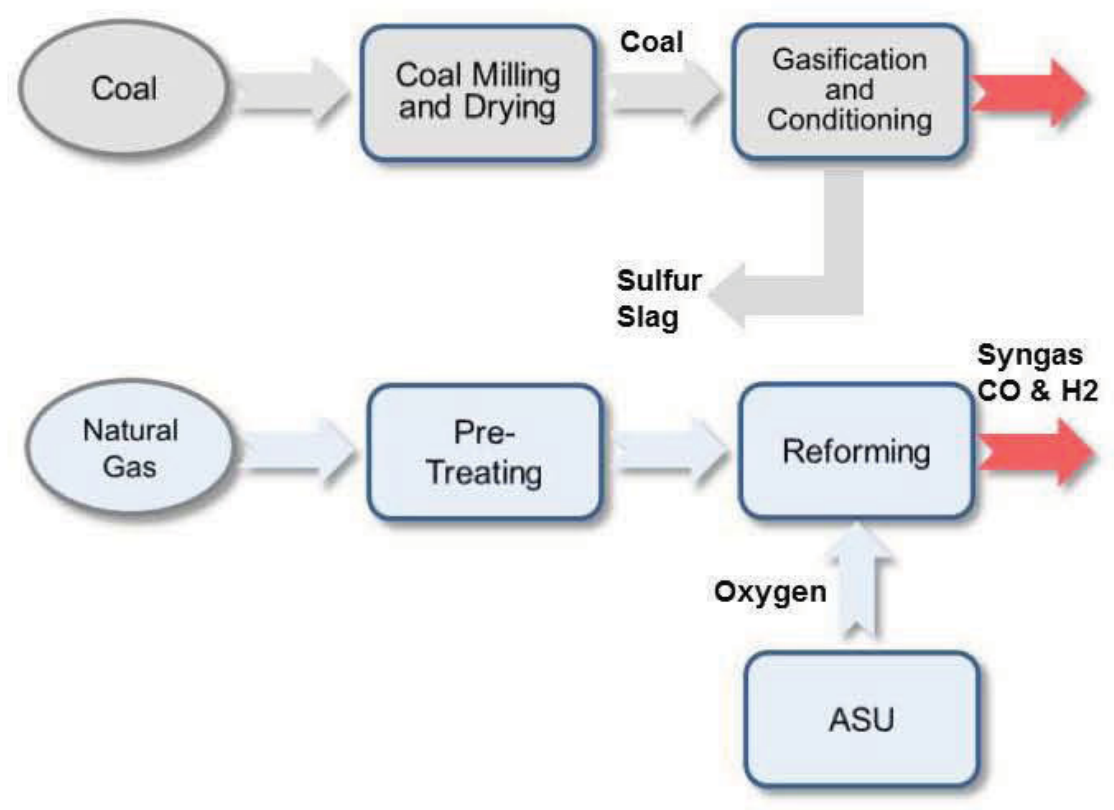

Figure 3-1. Syngas generation.

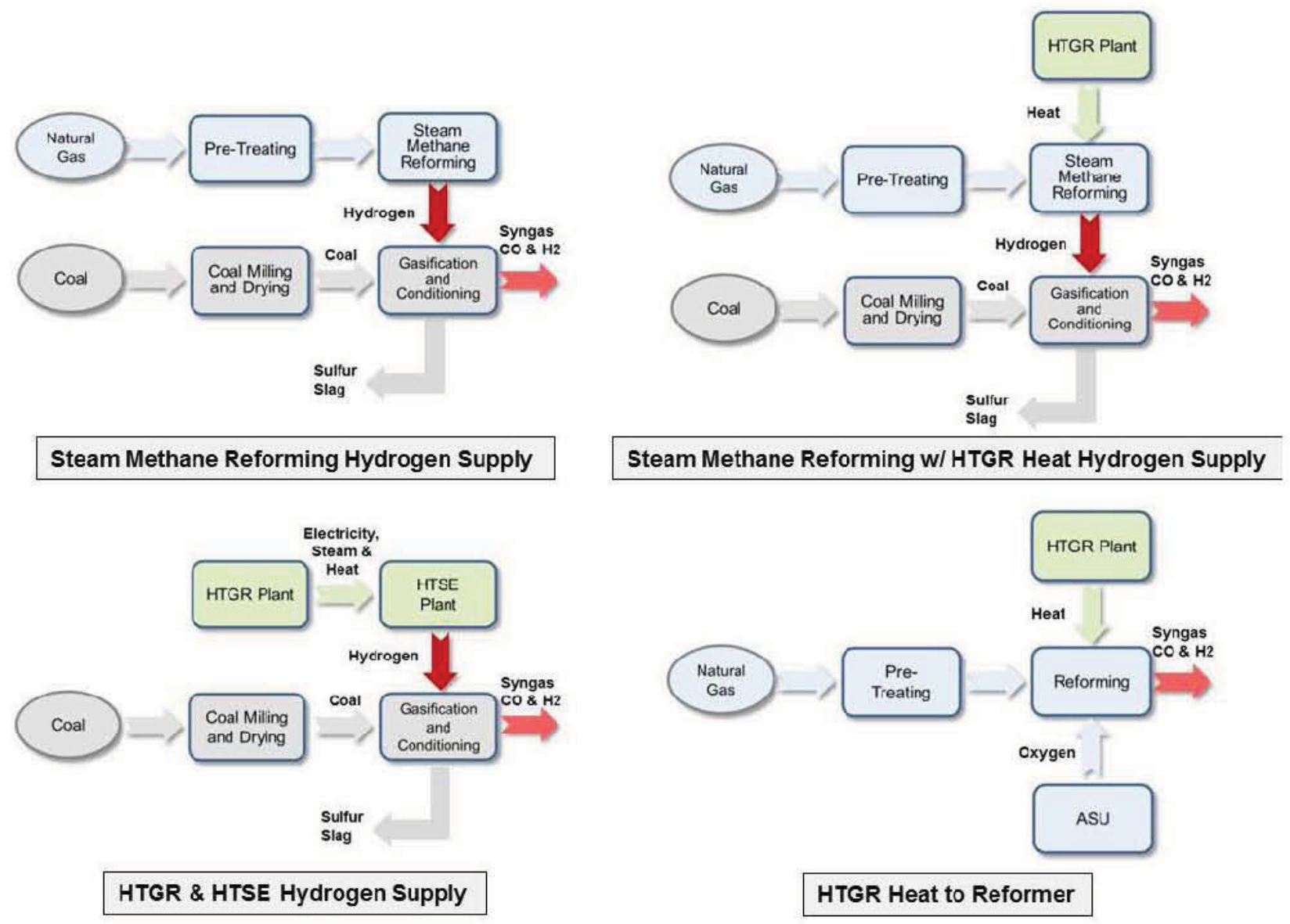

Figure 3-2. Afternative syngas supply feedstocks and configurations. 
Referring to Figure 3-2, three different configurations are shown for providing an external supply of hydrogen to the coal gasifier as a substitute for the water shift reaction to produce the required $\mathrm{H}_{2}$ to $\mathrm{CO}$ ratio, as follows:

- Steam Methane Reforming (SMR); steam methane reforming is a common process used in the United States to produce hydrogen from natural gas and water. This process is used throughout the petrochemical industry with good success. Use of SMR reduces the $\mathrm{CO}_{2}$ generated in the process by $\sim 60 \%$ compared to a process using water gas shift to produce hydrogen.

- $\quad$ SMR with HTGR heat; conventional steam methane reforming burns some of the natural gas to supply the heat required for the endothermic reaction. This and the reaction itself produce about 9 tons of $\mathrm{CO}_{2}$ for every ton of hydrogen produced. Adding high temperature heat from the HTGR reduces $\mathrm{CO}_{2}$ generation by $83 \%$ and also generates about $15 \%$ more hydrogen for the same feed rate of natural gas.

- HTGR and HTSE; the HTGR supplies heat and electricity to the HTSE process to produce hydrogen with no $\mathrm{CO}_{2}$ emissions. This is the most effective process for reducing $\mathrm{CO}_{2}$ emissions in the gasification process.

The fourth configuration describes Natural Gas Reforming, wherein the addition of HTGR heat to the reformer in the natural gas to syngas process reduces the generation of $\mathrm{CO}_{2}$ by $23 \%$ and reduces the amount of natural gas required for the process by $\sim 10 \%$.

All of these methods for providing an external supply of hydrogen and heat have been evaluated for the process alternatives considered herein.

\subsubsection{Indirect Processes for Carbon Conversion}

The syngas can be used to synthesize many different products as listed in Table 3-1. Figures 3-3 through 3-6 schematically represent indirect cycles for carbon conversion that were evaluated.

- Coal and Natural Gas to Liquids producing diesel fuel, naphtha and LPG using the conventional Fischer-Tropsch (FT) process.

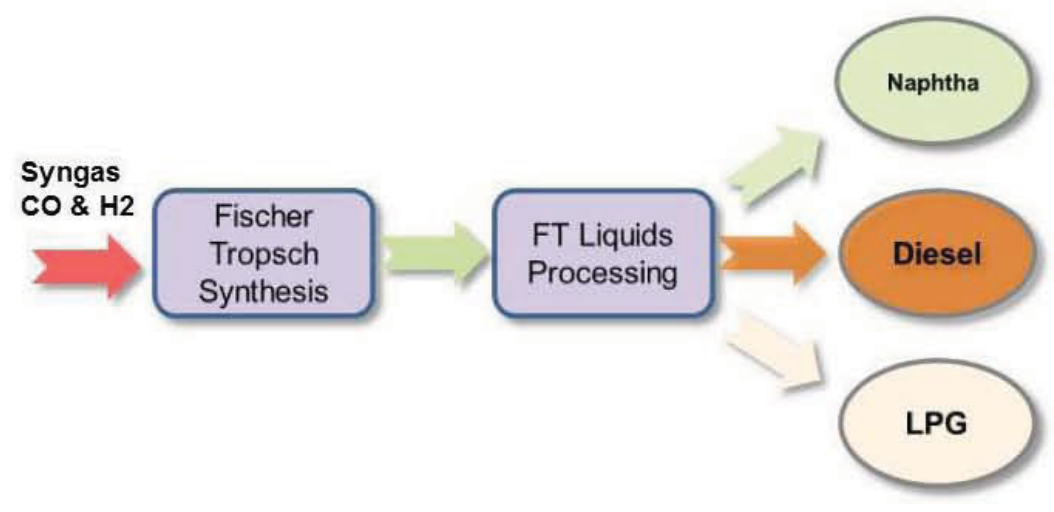

Figure 3-3. Conventional FT production of diesel, naphtha and LPG. 
- A CTL alternative of converting the naphtha to higher value products including gasoline and olefins.

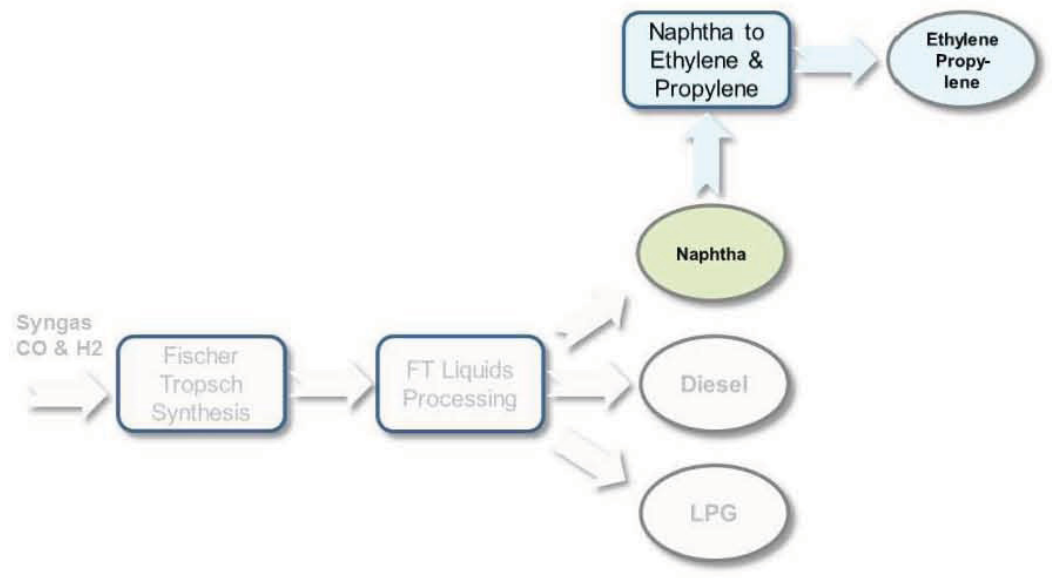

Figure 3-4. Alternative further processing of F-T naphtha to produce chemicals.

- Coal and Natural Gas to Gasoline using the methanol to gasoline (MTG) process.

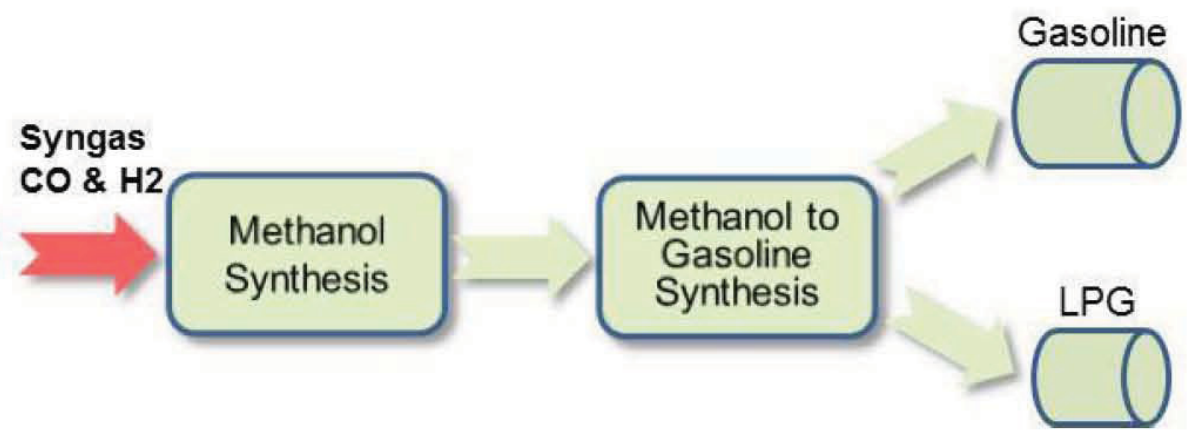

Figure 3-5. Methanol to gasoline and LPG.

- Coal to chemicals (e.g., olefins such as ethylene, propylene) using the coal to methanol to olefins (CTO) process.

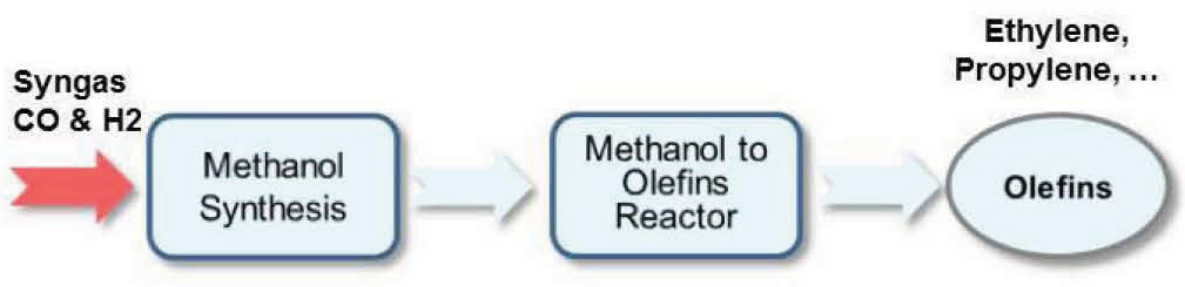

Figure 3-6. Methanol to olefins.

\subsubsection{Direct Process for Carbon Conversion}

The direct coal liquefaction (DCL) process was developed early in the twentieth century based on research by F. Haber (University of Karlsruhe, 1910), commercialized by BASF (starting in 1924 by M. Pier) based on further research work by F. Bergius (University of Hanover, 1913) and applied by the Germans until the end of WWII for production of transportation fuels ${ }^{11}$. This carbon conversion 
techmology has been the subject of potential application for coal cormersion to tansportation fuels by

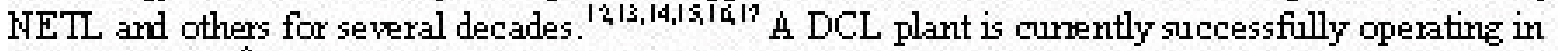
Shentrua China". Fizure $3-7$ is a schematic of the process used in that plant. INL has not conducted as complete an evabuation of this process as that perfomed for the other altematives. However, Reference 8 surmanized ab nief his torical revien of the development of this technology and it status in 2011 and conchuded:

\begin{abstract}
"Coal can play a key role in oug energy fixure in ways that go beyond electric power generation. Clecon liquid fivis from coal can become a promising option to fill in a sigrificant and widening gay between supply and demand Coal is an important bridge to a sustainable futwe. Divect coal liquefaction to produce transport fiels is techically feasible; major advances have been achieved in improving liquid yields ( -4 bbl per ton coal) and quality through laboratory ReD and pilot plants in 1980 's and 1990 's. Liquids from direct coal liquefaction are valuable feedstocks for fuels as well as chemicals and materials.
\end{abstract}

DCL commercialization in Shening China is a major step forward in the world DCI is still more expensive than petroleum-based proces ses, owing to its high copital and operating costs in the US. Studies suggest that DCL would emit sigrificant ly more $C O$, so DCI plants need to incorporate carbon managenent strategy.

DCI achieves therml conversion efficiency of $-6 \mathcal{F} / \mathrm{a}$ but given thes e benefits DCL techology for deployment in the US is likely not to be cost conpetitive with r fined cnude oil products based on curent cnude oil prices. Fundanenally more energy efficien DCL proces ses with high coal to oil yields that will work effectively and continuously must be commercialiy demonstrated"

This altemative is judged to be potentially viable, depending on successfiul resolution of these limitations. However, this process is particularly well suited to operation with high sulfiur coal and, thus, may be not be suitable foruse with low sulfur Wyoming coal (e.z., Fowder River Bas in coal).

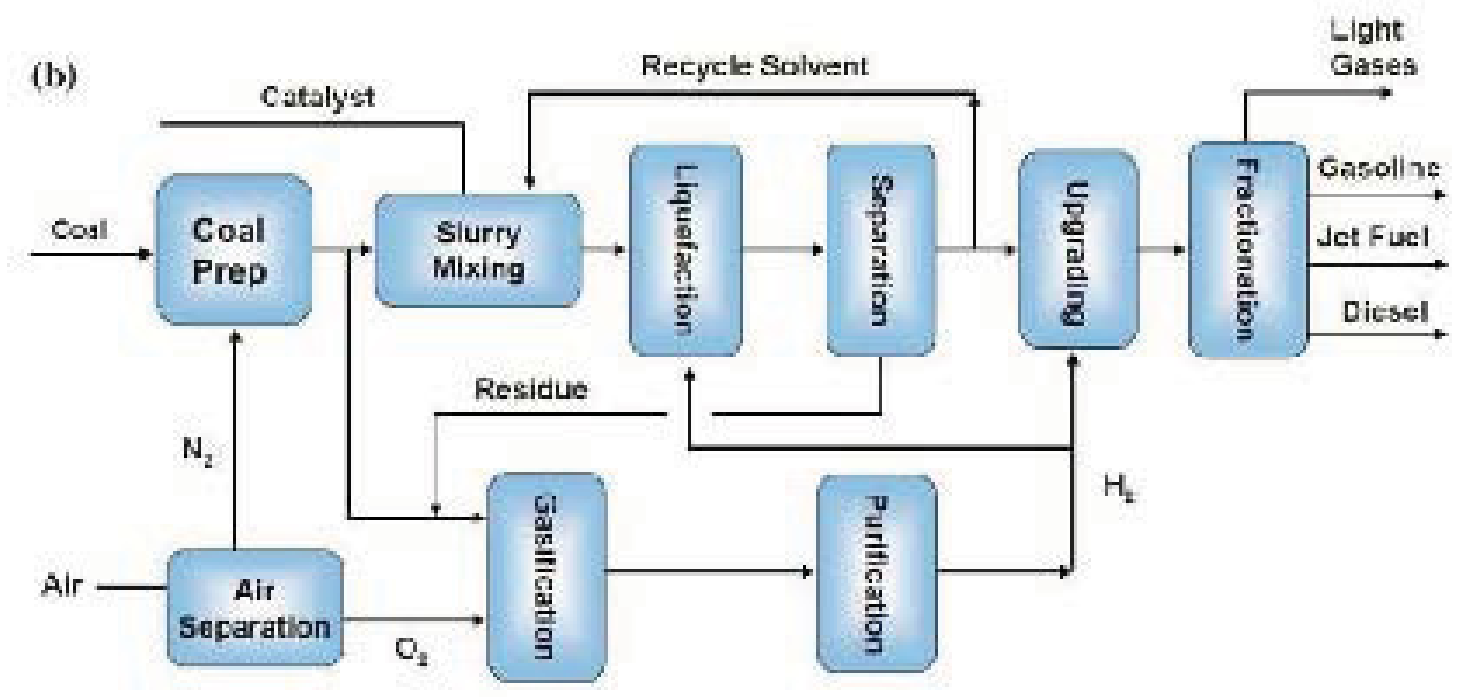

Figure 3-7. Direct coal liquefaction con version of coal to liquid's. 


\subsubsection{Plant Capacities}

All of these processes can be deployed in facilities comprised of multiple trains or modules of 10,000 to 20,000 bpd capacities, each. For the purposes of the analyses herein total plant capacities of $\sim 50,000$ bpd to $\sim 60,000$ bpd have been considered; comprised of four modul ar trains each with $25 \%$ of the full plant capacity.

\subsubsection{Comparison of $\mathrm{CO}_{2}$ Emissions for Indirect Processes}

The extent of $\mathrm{CO}_{2}$ generation and emissions is a distinguishing characteristic of these processes as shown in Figure 3-8. The benefits of generation and emissions reductions through the incorporation of SMR, HTGR and HTSE technologies are apparent in this figure. This figure shows that a substantial percentage of the emissions generated by all of the processes can be captured for sequestration or EOR. However, there are substantive operational costs associated with capture and transport of these emissions that add to the production costs of these processes. The potential to reduce the generation of emissions through incorporation of these technologies is a key element in selection of the processes to be deployed to address the effects on production costs of current and potential regul ations of $\mathrm{CO}_{2}$ emissions by Environmental Frotection Agency (EPA).

There is insufficient information available on the $\mathrm{CO}_{2}$ generation in modern DCL processes. As cited in the quote above successful deployment of DCL processes will require incorporation of effective carbon management processes.

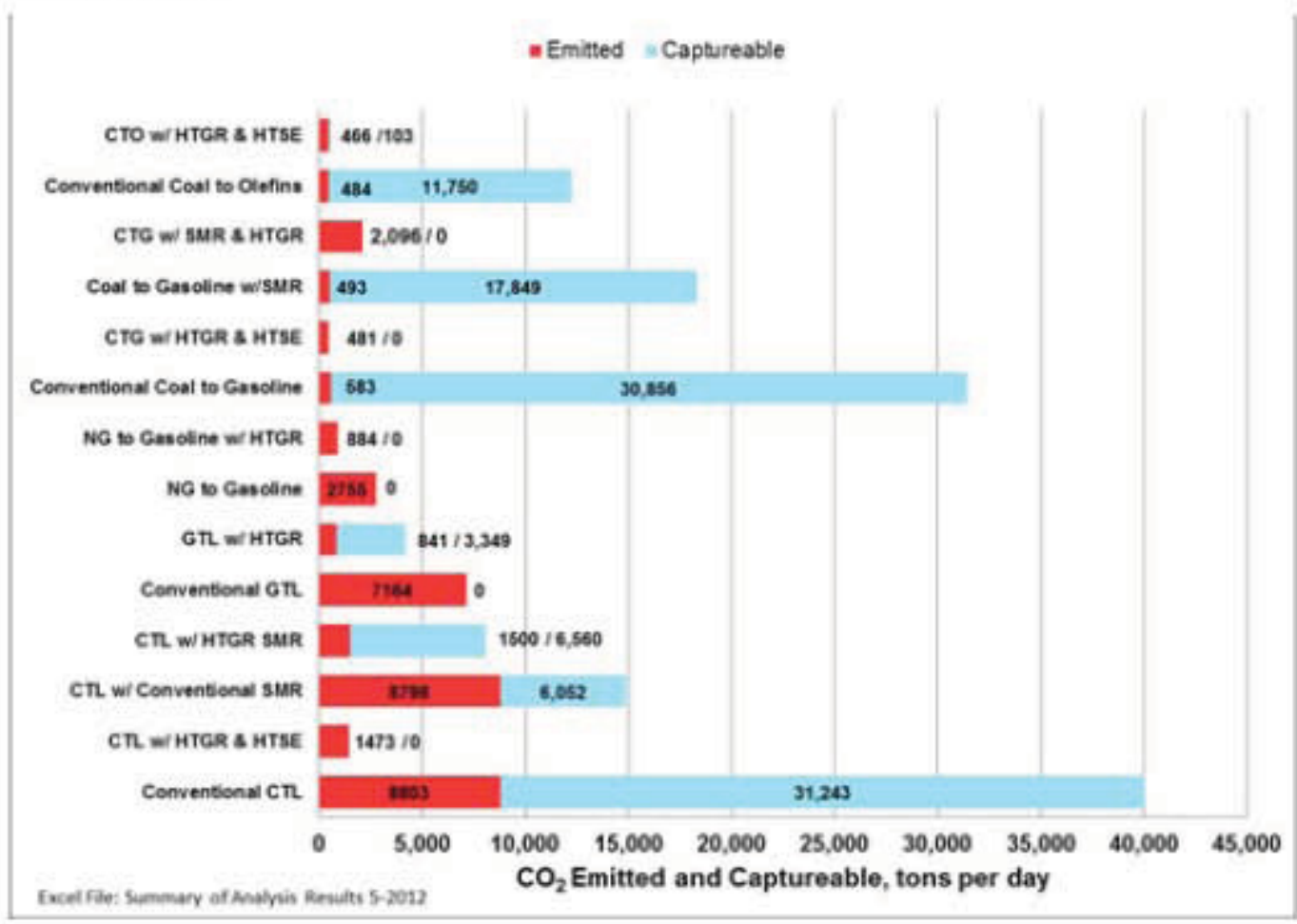

Figure 3-8. Comparison of $\mathrm{CO}_{2}$ emissions of alternative processes. 


\subsubsection{Alternative Process Economics}

\subsubsection{Production Costs of Synthetic Transportation Fuels}

The economic viability of the candidate processes was evaluated by comparing the calculated production costs for each process with the production costs for the products using other more traditional processes (e.g., the production cost for refining crude oil or generating chemicals from natural gas liquids). These calculations were made for consistent economic factors (e.g., return on investment, debt to equity ratio, interest rates and terms) and were made for the conventional carbon conversion processes and those in which the HTGR and, where applicable, the HTSE technologies were incorporated. These analyses are documented for each process in the references in Table 3-1. Figures 3-9 and 3-10 summarize the results of those analyses associated with the production of synthetic fuels.

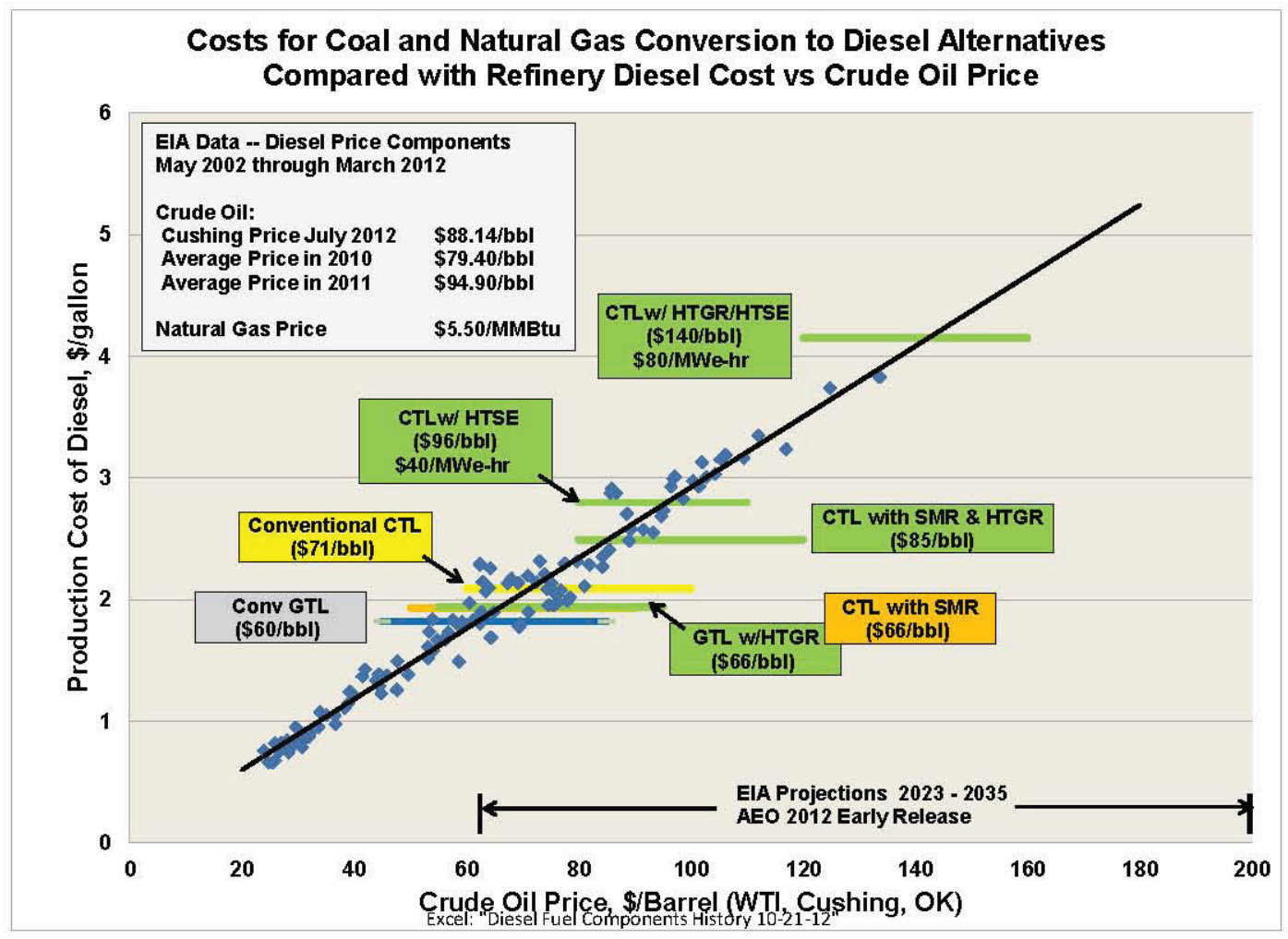

Figure 3-9. Comparison of the production costs of conventional carbon conversion processes with the production cost of diesel refined from crude oil versus the price of crude oil. 


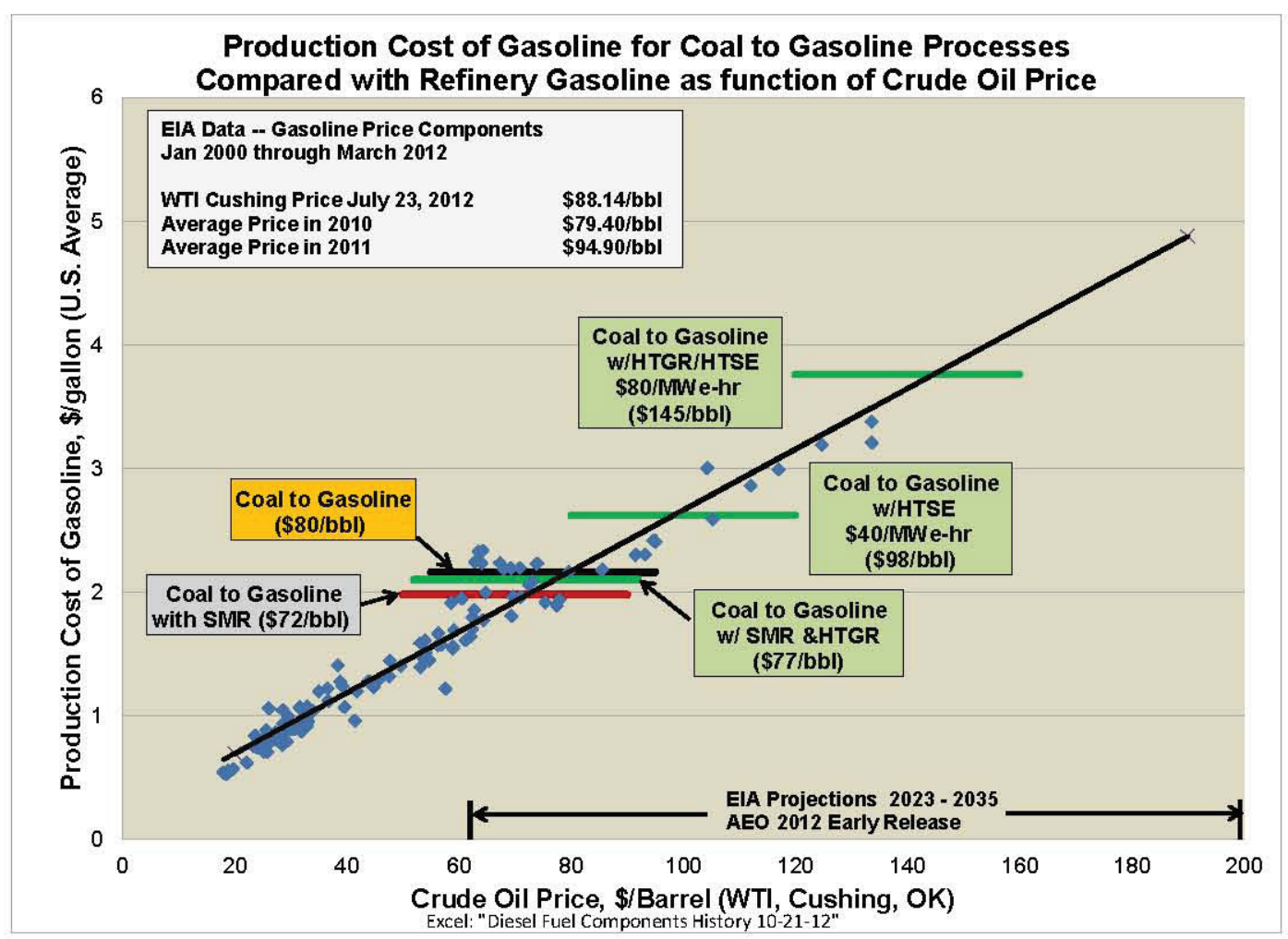

Figure 3-10. Comparison of the production costs of conventional carbon conversion processes with the production cost of gasoline refined from crude oil versus the price of crude oil.

Figure 3-9 summarizes the production cost of diesel fuel for the six coal and natural gas to diesel alternative processes evaluated compared with the historical costs of refining diesel from crude oil as a function of the price of crude oil. This historical data was extracted from DOE Energy Information Agency data bases for the period May 2002 through March $2012 .^{18}$ The line through the data was produced using a linear regression analysis.

Figure 3-10 shows a similar comparison of the production costs for the six coal and natural gas to gasoline processes evaluated with the production costs of refining gasoline from crude oil.

On both figures Energy Information Administration (EIA) projections of the price of crude oil in the 2023 to 2035 time frame (from Figure 3-11) is shown. In all cases the projections on the costs of production for the alternatives fall within the EIA projections of crude oil prices over time (i.e., the production cost of diesel and gasoline produced using carbon conversion processes can compete with those products produced by conventional crude oil refining processes). This range is very wide, however, and all but those alternatives that use the combined HTGR and HTSE technologies for the hydrogen supply are grouped in a lower range, $\$ 58$ to $\$ 85 / \mathrm{bbl}$, that is more closely aligned with the range of variations experienced over the last five years and projected as the reference case by EIA (see Figure 3$11)$. 


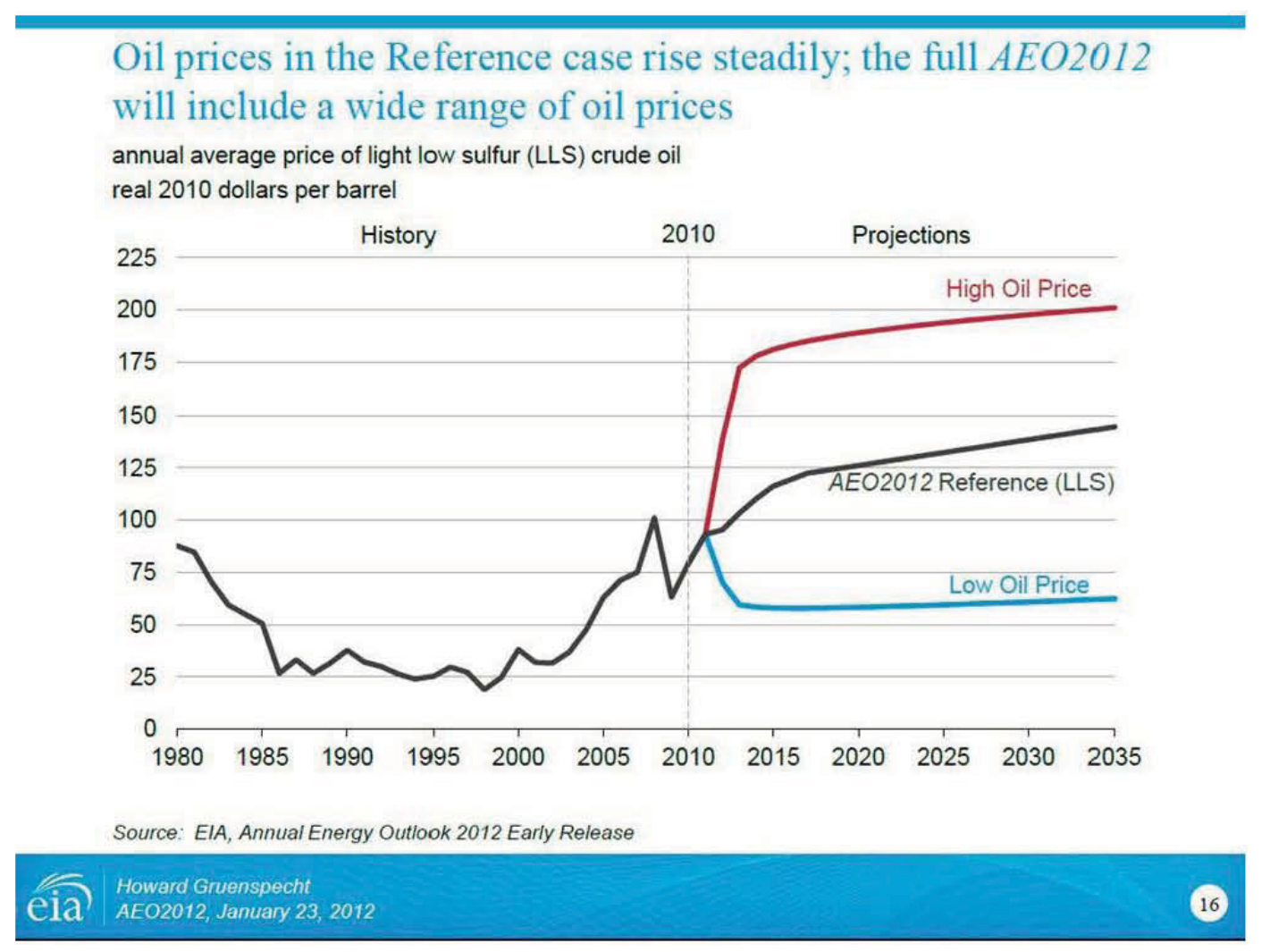

Figure 3-11. ElA projections on future crude oil prices.

The production costs for the processes using HT SE in Figures 3-9 and 3-10 are shown for a range of electricity prices. The higher production costs (equivalent crude oil prices in the $\$ 140 / \mathrm{bbl}$ range) are associated with supply of electricity using the HTGR which has an equivalent price of $\sim \$ 80 / \mathrm{MW}(\mathrm{e})$-hr. The production costs using HTSE are a strong function of the price of electricity and if electricity can be obtained in the range of $\$ 40 / \mathrm{MW}(\mathrm{e})$-hr, the production costs become more competitive with the other alternatives (equivalent crude oil prices in the $\$ 100 / \mathrm{MW}(\mathrm{e})$-hr). Although the lower prices for electricity are in the range currently available to industrial users in Wyoming they are highly dependent on coal-fired generation that may not be available over the long term for the reasons cited earlier in this report. Over the long term such low prices for electricity may be available off-peak or from generation that has been fully amortized and dedicated to the plant.

It is important to note, however, that independent of costs, the HTSE option for hydrogen production could become a necessary alternative to steam methane reforming if government regulation leads to, for example, any or all of the following: prohibition on $\mathrm{CO}_{2}$ emissions, EOR is not available and costs for capture, compression and transport for sequestration are prohibitive (e.g., equivalent to $\$ 100 /$ ton $\mathrm{CO}_{2}$ ). In this event the HTSE supported process would have to be competitive with crude oil refining that as shown is a strong function of crude oil price. The price of crude oil would need to be in the range of $\$ 100 / \mathrm{bbl}$ or higher for the HTSE supported process to be competitive. Since the price of crude oil is set internationally it is judged conceivable that both high crude oil prices and high costs for $\mathrm{CO}_{2}$ generation could be concurrent. With overall net efficiencies at least a factor of two better than conventional low temperature electrolysis and with projected hydrogen production prices significantly lower than for alternative high temperature developmental chemical processes, HTSE is a viable option for non-GHG emitting hydrogen production. ${ }^{19}$ Accordingly, it is recommended that Wyoming interests continue to support commercialization of the HTSE process and monitor its development so it is available if needed in the future. 


\subsubsection{Effect of Natural Gas Cost Variations and $\mathrm{CO}_{2}$ Costs on Production Costs}

Other factors that affect the viability of alternative processes are the costs of carbon (either a tax on emissions and/or the costs for capture and transport for sequestration or EOR) and the cost of natural gas. Figure 3-12 and Figure 3-13 show the impact of varying natural gas price and $\mathrm{CO}_{2}$ costs on the production cost of coal to gasoline processes with "No Cost of $\mathrm{CO}_{2}$ " and with " $\$ 50$ /ton Cost of $\mathrm{CO}_{2}$ ". The second case represents the equivalent cost effect of either a direct tax or of the plant modifications necessary to capture, compress, transport and inject the $\mathrm{CO}_{2}$ emissions for sequestration. The costs associated with the regulatory process and liability exposure for release of the sequestered $\mathrm{CO}_{2}$ are not included due the immaturity of these estimated costs (see additional discussion in paragraph 3.2.6.3)

The processes include conventional CTG, CTG with SMR and CTG with SMR with integrated HTGR providing energy requirements. The production costs are shown as a function of the price of natural gas with Figure 3-12 showing costs for no cost of $\mathrm{CO}_{2}$ and Figure 3-13 showing the production costs for a cost of $\$ 50$ /ton of $\mathrm{CO}_{2}$. In the former case the production costs for the non-conventional plants using SMR and natural gas for hydrogen production exceed those of a conventional CTG plant for a natural gas price of $\$ 4.30$ to $\$ 5.65 / \mathrm{MSCF}$ and above. In the second case with a cost of $\$ 50 /$ ton of $\mathrm{CO}_{2}$ the crossover point is much higher at $\sim \$ 8.00$ to $\$ 12.00$ /MSCF. These charts show that there is a clear choice on which process to choose depending on the perceived risks for rising natural gas prices and the potential for costs to be imposed on $\mathrm{CO}_{2}$. If the risk for the former is judged to be higher than the latter the conventional CTG process is favored. If the risk of the latter is judged to be higher or if both risks are judged significant then use of the SMR source of hydrogen and ultimately integrating the HTGR into the SMR process is favored. The potential that both risks are significant has been used for the analyses performed herein; hence, the SMR with HTGR configuration is used.

Note that comparable analyses for the CTL process obtain similar results as that for the CTG plant.

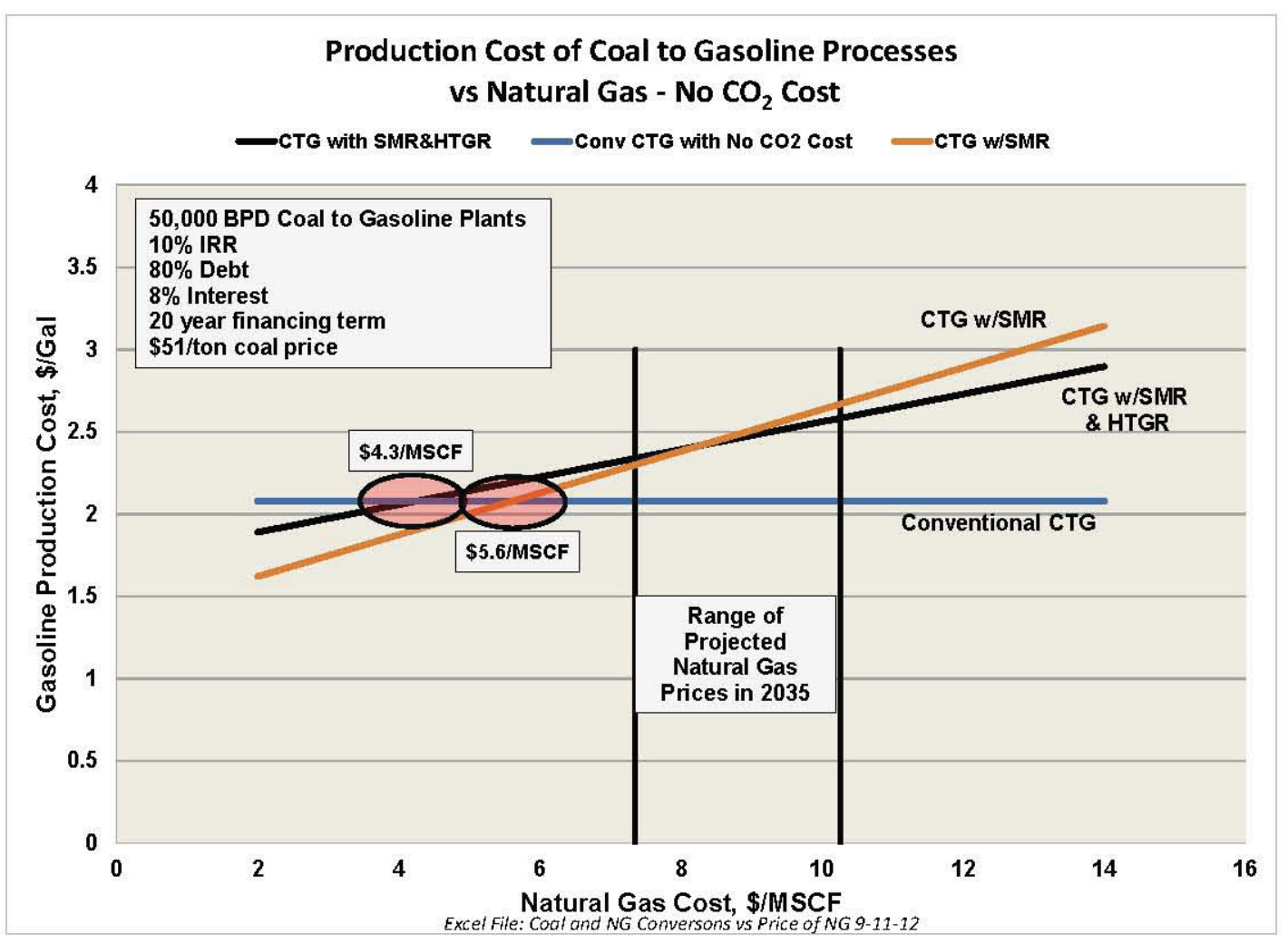

Figure 3-12. Production costs of CTG processes vs. natural gas price; no $\mathrm{CO}_{2}$ costs. 


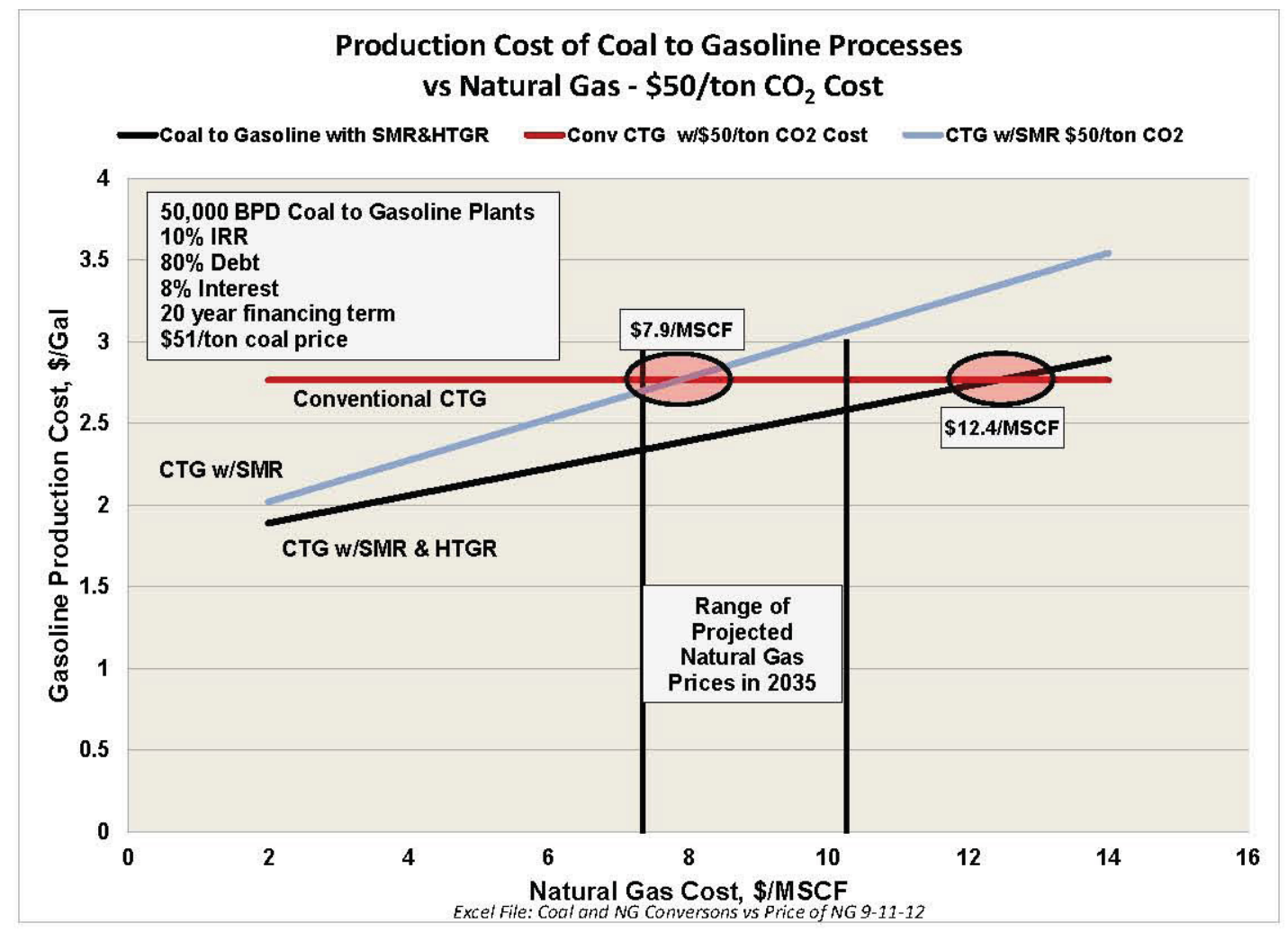

Figure 3-13. Production costs of CTG processes vs. costs of natural gas; $\$ 50 /$ ton $\mathrm{CO}_{2}$ costs.

Imposition by the government of regulations that develop a cost for carbon such as those currently pending by the EPA ${ }^{20}$ would also affect the production costs for refining gasoline and diesel from crude oil. Figure 3-14 shows the effect of a $\$ 50 /$ ton cost for $\mathrm{CO}_{2}$ on the production costs of gasoline refined from crude oil as a function of the price of crude oil. Because the emissions generated in the refining processes are not high $\left(\sim 96 \mathrm{Kg} \mathrm{CO}_{2} / \mathrm{bbl}\right.$ for gasoline and $\sim 110 \mathrm{Kg} \mathrm{CO}_{2} / \mathrm{bbl}$ for $\left.\mathrm{Diesel}^{21}\right)$ the effect adds only a few cents to the production costs. Also shown on this figure are the results for varying natural gas prices from $\$ 4 / \mathrm{MSCF}$ to $\$ 10 / \mathrm{MSCF}$ and $\mathrm{CO}_{2}$ costs from $\$ 0 /$ ton to $\$ 50 /$ ton on the production costs of a natural gas to gasoline process. As shown in the preceding figures the effect of natural gas variations is larger than for $\mathrm{CO}_{2}$ costs because these processes have low $\mathrm{CO}_{2}$ generation rates. The large swing in production costs ( $\$ 47 / \mathrm{bbl}$ to $\$ 100 / \mathrm{bbl}$ crude oil price equivalent) is still within the projected range of crude oil prices over the next several decades.) 


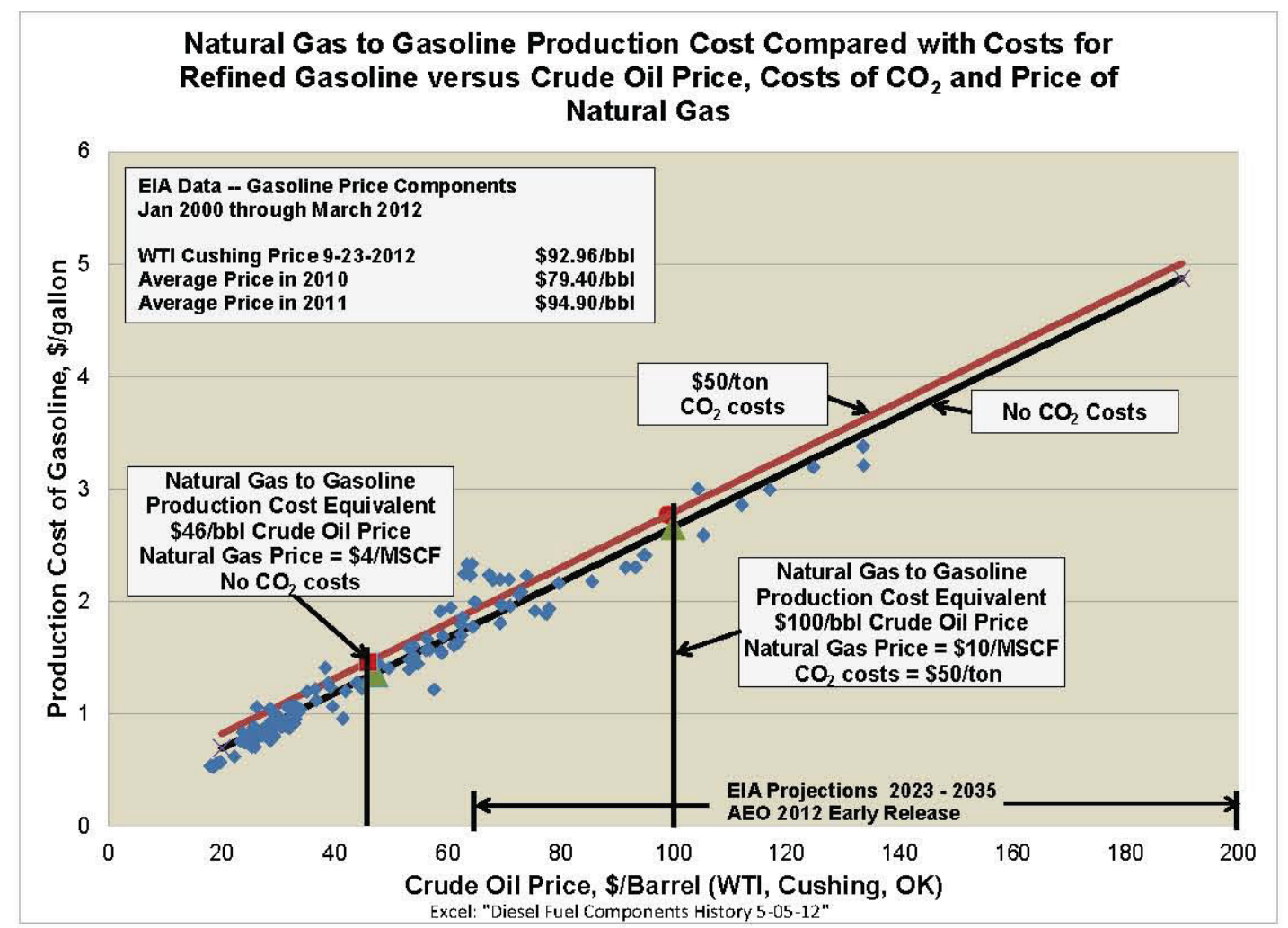

Figure 3-14. Comparison of gasoline production costs for natural gas to gasoline process with refining from crude oil as a function of the costs of natural gas, $\mathrm{CO}_{2}$ and crude oil.

\subsubsection{Comparison of the Production Costs of All Alternatives}

Finally, Figure 3-15 compares the production costs for all of the alternatives evaluated and shows the costs of $\mathrm{CO}_{2}$ that would make the production costs for conventional processes equal to a process where $\mathrm{CO}_{2}$ reducing technologies are incorporated (HTGR and HTSE technologies). In those cases where natural gas is either the primary feedstock or used for SMR to produce hydrogen, a cost of $\$ 5.50 / \mathrm{MSCF}$ has been used. This was the average cost of natural gas to industrial users in 2009. As shown the $\mathrm{CO}_{2}$ costs for incorporating HTGR and HTSE are high; $\$ 95$ to $\$ 125 /$ ton in the CTL and CTG processes. However, the coal to gasoline process with SMR and the HTGR supplying heat and electricity requires only a $\$ 17 /$ ton cost of $\mathrm{CO}_{2}$ to be equal to the production cost without it.

Projections on the cost of $\mathrm{CO}_{2}$ capture, compression and transport for sequestration and $\mathrm{EOR}$ range from a low of $\sim \$ 20 /$ ton to $>\$ 100 /$ ton depending on the location and nature of the process ${ }^{\mathrm{e}}$. There are also several projects currently under way to prove these concepts and determine costs. ${ }^{22,23,24,25}$ Where the analyses discussed herein include costs for capture, transport and sequestration, the costs for the equipment and operations required for capture and compression are included in the model and a cost of $\sim \$ 16 /$ ton is assessed for the cost of transport. ${ }^{16}$ As shown in Figure 3-15 other parametric analyses are performed varying the total costs of dealing with $\mathrm{CO}_{2}$ over wider ranges.

e A more detailed discussion of sequestration and EOR is covered in Section D.3. 


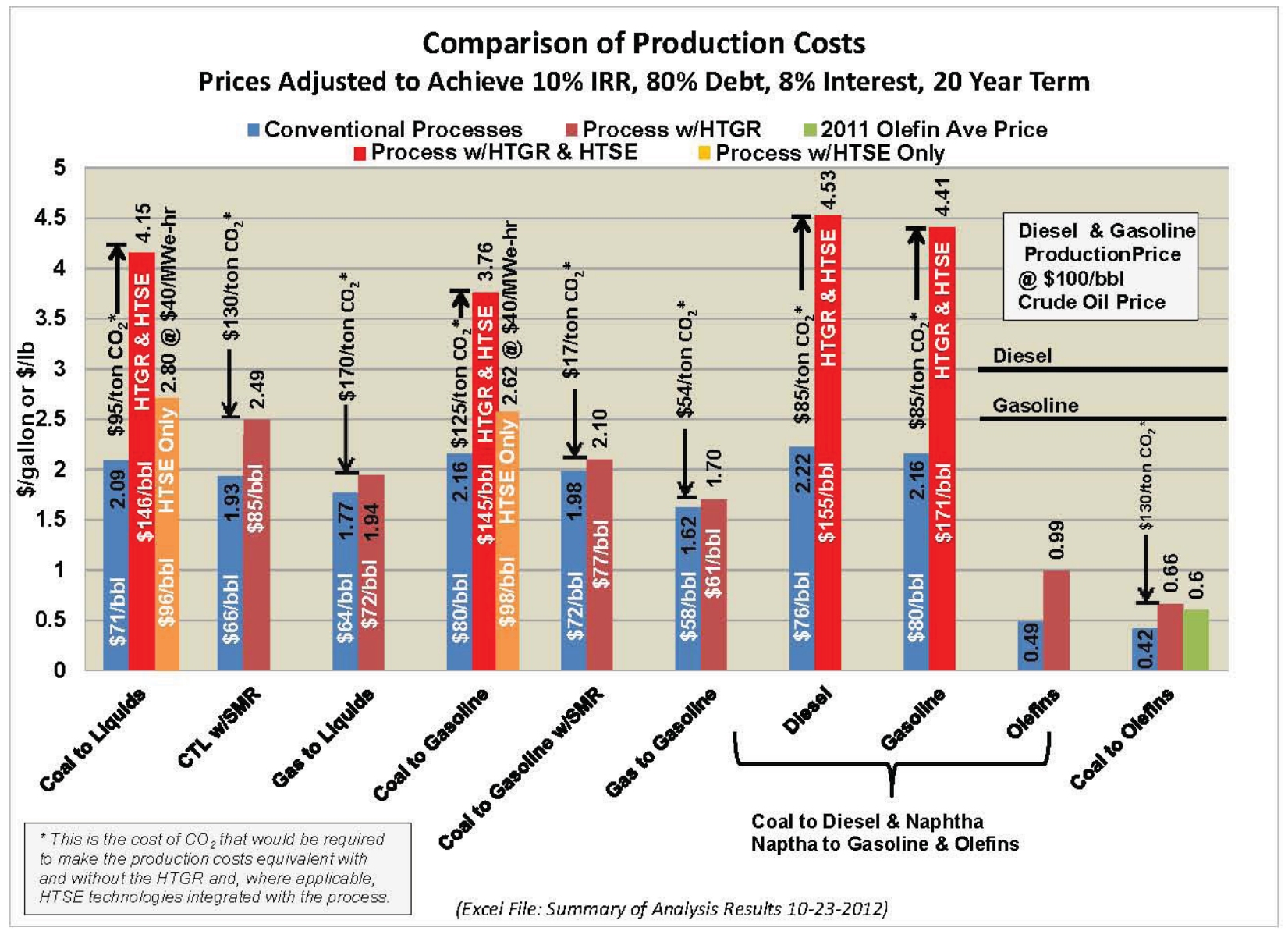

Figure 3-15. Comparison of production costs for all alternatives.

This figure also clearly illustrates the effect of electricity costs on the production costs for processes using HTSE for hydrogen production. These processes are distinguished in this figure by red bars which show production costs where HTGR technology is providing the electricity required for the HTSE process (designated with the phrase "Includes HTSE") and orange bars where the electricity is supplied from another lower cost source (designated as HTSE @ \$40/MW(e)-hr). This lower value is about half the equivalent price of electricity supplied by the HTGR; $\sim \$ 80 / \mathrm{MW}(\mathrm{e})-\mathrm{hr}$. As noted previously the lower cost of electricity is typical of the average cost to industrial users in Wyoming. It may be achievable over the longer term off-peak or from fully amortized dedicated sources. In any event the factor of two reduction in electricity cost for these processes results in $\sim 30 \%$ reductions in production costs, making the application of HTSE for hydrogen production more competitive with the other processes.

There are costs associated with carbon capture and sequestration (CCS) that have not yet been matured in the industry. These are the costs of regulation and of liability for ensuring the security of the sequestration. Many studies have defined the need for and recommended structures for assigning liability and several states have initiated legislation covering liability. ${ }^{26,27,28,29,30,31,32,33,34,35}$ Wyoming, Kansas and Montana legislatures, for example, have adopted liability frameworks and Texas and Illinois have initiated actions for the purposes of addressing these liability issues. Reference 20 summarizes the required structure as follows:

"Developing a framework to manage CCS project liability requires several conditions to be met: (1) responsibility should be assigned for damages from a CCS project over a defined time period; (2) funds must be available for monitoring, 
remediation, and damage payment throughout the CCS project life-cycle; and (3) the regulatory framework should be adaptive and incorporate site-specific data into CCS risk management. Additionally, regulatory and liability frameworks should be structured to provide incentives for good site selection and operation and an effective monitoring regime. These conditions must be met not only to manage environmental, health, and safety risks, but also to integrate CCS within a larger climate policy."

The consensus of these references is that several phases of CCS will require coverage of liability:

- Bonding and/or insurance held by the owner will be required during the period of injection

- The owner will retain liability after the last injection either for a pre-determined period or until specific performance criteria have been met (e.g., reduction or stabilization in site pressure, validation of $\mathrm{CO}_{2}$ migration models by measurement and monitoring of critical variables). Bonding and insurance will cover this period.

- There is general agreement that some form of general insurance will be required to cover the owners during these periods for major leaks or damage to property in addition to the bonds and owners direct insurance. This would be funded by periodic payments into a fund run by a consortium of operators/owners similar to the self-insurance funds covering nuclear plants.

- There is also general agreement that some form of State (or more likely) Federal government program will be required to assume liability over the very long term. These costs would be covered by funds financed by the owners through payments based on quantities sequestered, annual fees and fees per wells. This is similar to the Price-Anderson Act covering major events in nuclear plants and the Trans-Alaskan Pipeline Authorization Act that covers major leaks on land and in the water.

Review of the literature, however, has not identified any experience with the actual costs to the owner of the facility to deal with these issues. National Energy Technology Laboratory (NETL) estimated the costs for capture, transport and storage on a hypothetical basis with emphasis on the equipment and piping costs associated with getting the $\mathrm{CO}_{2}$ to the injection site. They included a $\$ 5 \mathrm{MM}$ premium for a bond to cover the operational period. This seems low when some State legislations place limits of liability of $\$ 500 \mathrm{MM}$. This cost also does not cover contributions to governmental or consortium funds to cover long term storage liability. It is judged that these costs may be substantial additions to the injection cost; potentially comparable to those cited for capture, compression and transport. Confidence on these costs will become apparent once regulations are in place and actual sequestration is initiated.

\subsection{Notional Selection of the Processes for Evaluating Deployment of a Carbon Conversion Industry in Wyoming}

\subsubsection{Selection of the Initial Carbon Conversion Process}

Any of the processes discussed in the preceding can be used to deploy the carbon conversion industry in Wyoming. Clearly, the selection of the specific process(es) used in the initial plant and in the deployment of an expanded carbon conversion industry within Wyoming would be the responsibility of the investors, owners and operators of the plants. These selections would be made after consideration of several factors, including market conditions, energy costs (e.g., crude oil, coal, natural gas), plant costs, financing, site characteristics, including feedstock supply, infrastructure, distribution network, etc. The evaluations summarized herein provide some insight into the influence these factors have on the selection of a process.

As will be discussed in more detail later, four different processes are evaluated for a notional development of this industry. For the purposes of illustrating the general business economics, effects on 
the economy of Wyoming, nominal schedule and potential integration with HTGR technology of each of these plants, a coal to gasoline and LPG (GTG) plant using the MTG process will be used for the initial plant in the notional carbon conversion industry. This plant is also configured to use a natural gas steam reforming hydrogen supply to achieve the appropriate $\mathrm{H}_{2}$ to $\mathrm{CO}$ ratio in the synthesis gas. Figure 3-16 is a high level schematic of this process, which shows, when commercially available, the HTGR plant (shown in phantom) could be integrated with the reforming process to supply heat and electricity to the process. This would reduce emissions and provide long term stable energy pricing.

The specific functional, performance and economic characteristics of all of the carbon conversion processes evaluated are summarized in Appendices D and E.

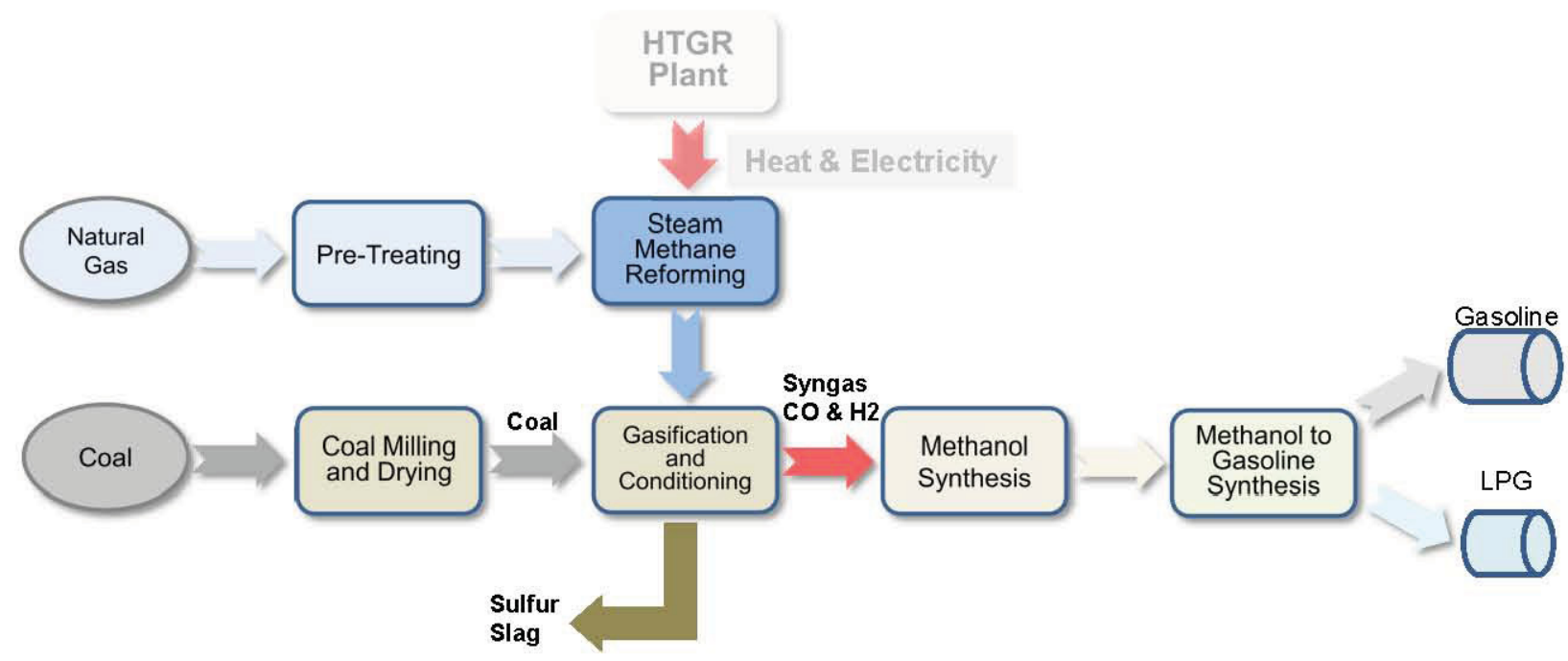

Figure 3-16. Coal to methanol to gasoline and LPG process with SMR hydrogen supply.

The bases for notionally selecting the indirect coal to methanol to gasoline and LPG process using natural gas steam reforming as the hydrogen supply for the initial plant include the following:

- Coal as the feedstock provides an alternative market for Wyoming coal to begin to offset the reduction in severance tax revenue attendant to the reducing production and export of coal from Wyoming due to the retirement of coal fired power plants nationally in response to increasing regulations of emissions by the EPA.

- The steam reforming process to supply hydrogen also requires significant quantities of natural gas. This provides an alternative market for Wyoming natural gas to begin to offset the recent reduction in natural gas revenue to the State due to the current low prices for natural gas nationally. The low prices of natural gas (e.g., Henry Hub) have resulted from the large low cost production from gas shale over the last several years and are expected to continue for at least the next decade.

- Gasoline and LPG are high value products with mature national and international markets

- As shown in Figure 3-10 the calculated costs for production of gasoline and LPG using this process are competitive with their production costs from crude oil using conventional refining techniques at crude oil prices in the range of $\$ 75 / \mathrm{bbl}$ and above. This price of crude oil is at the lower end of projections of the future price of crude oil in the 2023 to 2035 time frame as shown Figure 3-11.

- The coal to methanol to gasoline process and the steam methane reformer use conventional technologies, commercially available equipment, and deployment of these processes could be initiated as soon as Project funding is available. There are several plants using the methanol to gasoline process concept under construction or planned in the U.S. ${ }^{36,37,38}$ Some of these plants that 
originally were going to use coal as the feedstock have switched to natural gas due to its current low cost. ${ }^{39} \mathrm{DKRW}$ is currently constructing a coal to gasoline plant in Wyoming. ${ }^{40}$ The deployment of the coal to gasoline plant developed herein would be similar to the DKRW plant but may use a different grade of coal. It will also be different in the use of steam methane reforming as a hydrogen supply. As noted previously this would be the first plant in a series of plants that will make up the carbon conversion industry in Wyoming; it is expected that the full complement of plants eventually deployed will include several different processes

- The methanol process can also be used to produce chemicals used as building blocks in the chemical industry (Figure 3-6) providing flexibility to maintain plant economic viability in changing market conditions.

\subsubsection{Notional Plant Performance, Costs and Revenues}

\subsubsection{Initial Plant Capacity and Deployment Schedule}

The coal to gasoline plant selected for initiating the notional carbon conversion industry has an ultimate plant capacity of $\sim 57,700 \mathrm{bpd}$ of gasoline and 9,100 bpd of LPG, see Figure 3-17.
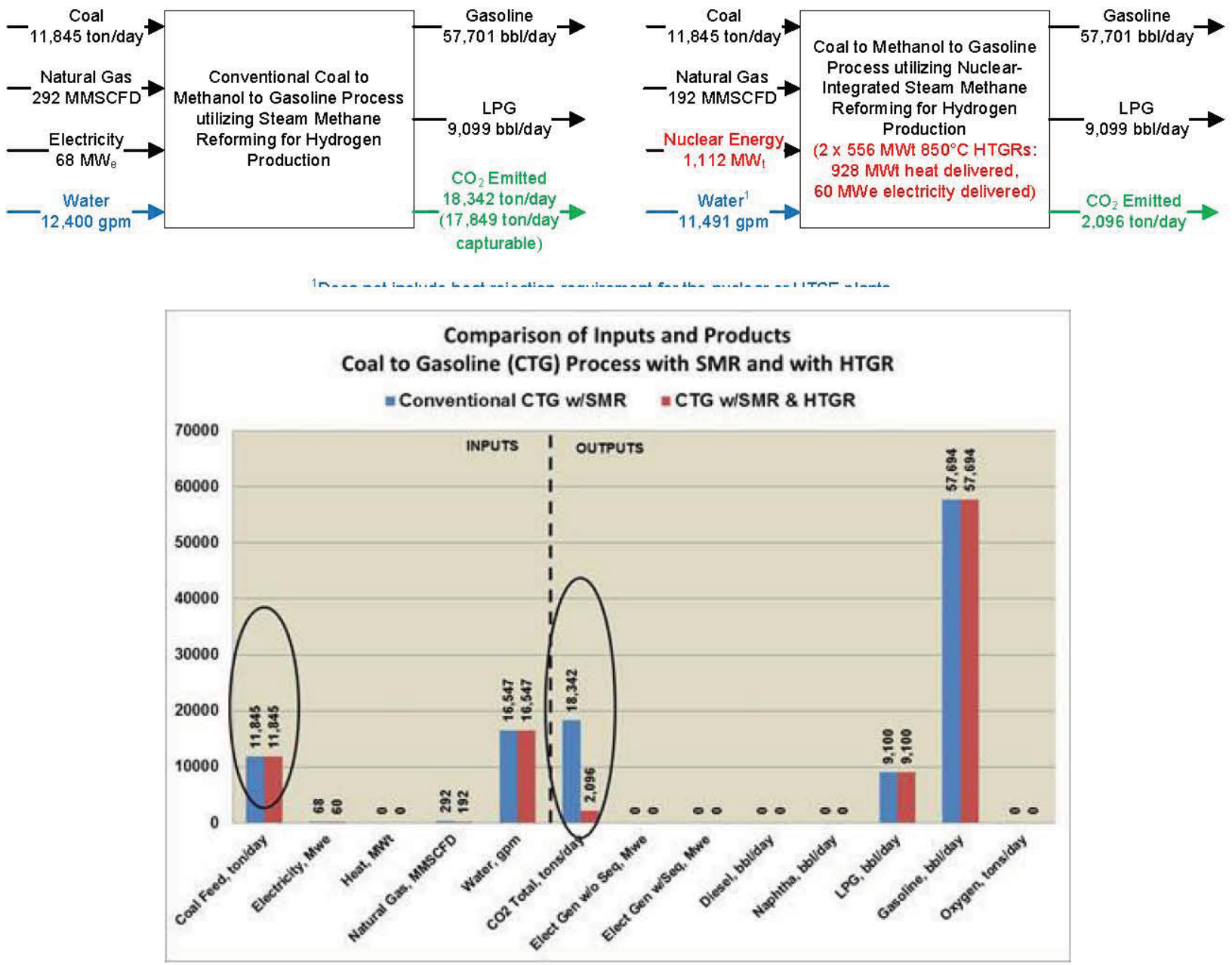

Figure 3-17. Performance characteristics of coal to gasoline plant. 
Conventional processes (without integration of HTGR technology) will be applied in the initial deployment of this plant. The deployment strategy involves two phases of construction of modules of $25 \%$ of full capacity each ( $\sim 10,000$ bpd each). The deployment of the first module would include final design w ork for the full plant site, initiation of long term procurement, site preparation, construction, commissioning and 1year of operation. At that time the remaining three modules would begin to be deployed. This 1-year period would be used to iron out design and operating problems and to support development of the project processes and infrastructure required by the State for full deployment of the initial plant and the full carbon conversion industry. The schedule for this phased deployment in Figure 3-18 shows that the first module would begin operation in 2018 and the full plant could be operating at full capacity in 2022 if the deployment project were initiated in early 2013.

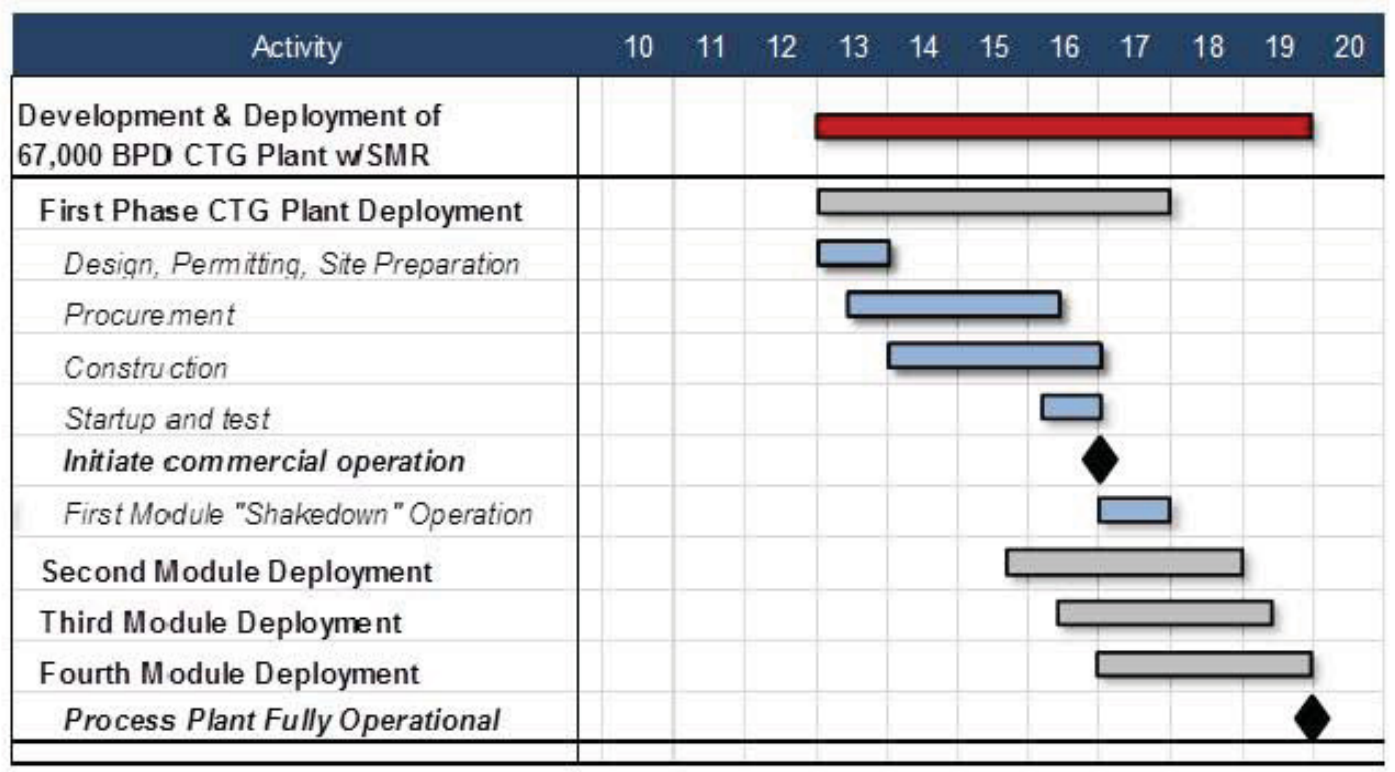

Figure 3-18. Initial plant deployment schedule.

Appendix F provides detail of the deployment strategy and economics for this plant. As noted previously the selection of the processes for every plant discussed herein will be the purview of the owners. The use of the coal to gasoline process for this plant is notional to support completing the analyses performed herein.

\subsubsection{Initial CTG Plant Revenues and Benefit to Wyoming Economy}

This initial plant would consume $\sim 4.3$ million tons of coal and $\sim 105$ BSCF of natural gas each year (at a $90 \%$ capacity factor). This is $\sim 1 \%$ of the total production of coal and $\sim 5 \%$ of the total production of natural gas in Wyoming in 2011. This is a single plant; the addition of additional plants to develop the carbon conversion industry will add to this and provide long term internal markets for coal and natural gas in Wyoming

In general, conversion of the indigenous natural gas and coal resources to synthetic fuels or chemicals in the carbon conversion industry would provide a substantial increase in the value of these resources to the economy of the State. The products of the plants increase the value of the coal and natural gas due to the increased rev enues for the higher prices of the products. The value multipliers can range from 5 to 40 times the retail value of the coal and natural gas depending on the price assigned to the coal, natural gas and the products (e.g., diesel fuel, gasoline, chemicals). It is estimated that the initial full scale coal to gasoline plant will generate revenue of $\sim \$ 2.1 \mathrm{~B}(2011 \$$ ) per annum assuming a sales price equal to the 
average wholesale price of gasoline and LPG from crude oil refineries (price at the gate) in 2010 and 2011. This plant alone would add $\sim \$ 1.6 \mathrm{~B}(2011 \$)$ annually to the Wyoming GDP.

Construction of the initial coal to gasoline plant and its operation will create jobs and have economic benefit to Wyoming. As cited in the preceding the construction of the conventional plant is projected to extend over seven years. The total cost is estimated to be in the range of $\sim \$ 5.9$ billion. Construction of each plant will require a total of $\sim 26,000$ man-years over this seven year period with an average workforce of $\sim 3,700$ per year and a peak of $\sim 9,200$ in year five. The addition of HTGR plants would extend over another seven years at a cost of $\sim \$ 6$ billion, and require an additional 15,000 man-years of effort with an average workforce of $\sim 2000$ per year for each plant. The process plant is expected to employ 400 and the HTGR plant an additional 400 personnel.

At this level of activity and expenditure this initial plant would provide a substantial contribution to the Wyoming economy both during construction and operation. Appendix F provides more details of the economics of these plants.

\subsubsection{Integrating the HTGR Technology}

The HTGR is particularly well suited to integration with the carbon conversion processes because it operates in a temperature range $\left(700\right.$ to $\left.850^{\circ} \mathrm{C}\right)$ similar to the temperatures at which many of the processes operate. It also has a very high margin of safety that permits its collocation with the processes (see Appendix B). The high operating temperature of the HTGR also results in much higher net efficiencies in the generation of electricity when compared with light water reactor technologies. Accordingly, it is particularly well suited for providing heat and electricity to the process as shown in Figure 3-16

Figure 3-2 shows the application of the HTGR and HTSE technologies for supporting the supply of hydrogen in the production of syngas in the several configurations evaluated using coal and natural gas as feedstocks. The DCL process would also require a supply of external hydrogen and the HTGR and HTSE technologies could be adapted to this process in a manner similar to those shown in Figure 3-2. The ready adaptability of these plant configurations to application of non-emitting HTGR and HTSE technologies provides the ability to apply these technologies to any of these carbon conversion processes as needed to respond to governmental actions on emissions regulation or taxation, in addition to market changes (e.g., rapid increases in the costs of the natural gas feedstock to the steam methane reforming process).

Based on current planning the HTGR and HTSE technologies are expected to be commercially available in the late-2020 time frame. This would be following design, licensing, construction and initial operation of the first HTGR demonstration module. This module is projected to begin operation in 2025 and complete a three year operational period to complete licensing by late 2027. It is recommended that the progress in development of these technologies be supported and monitored by Wyoming interests to support making a decision in the early to mid-2020s on adapting these technologies to the process plants.

For the purposes of analyzing the strategies developed herein, initiation of integrating the HTGR technology into the carbon conversion processes begins in 2024 with initial design, site selection early licensing and permitting activities. These preliminary activities will comprise a couple of years and provide a basis in combination with completion of the first year of operation of the HTGR demonstration plant to make a final decision to go forward with the integration. By that time all open licensing issues on the HTGR technology will have been resolved to permit full power operation of the demonstration plant and the performance of the plant will have been proved.

The conceptual HTGR plant to be integrated with the initial coal to gasoline process plant will include 4-600 MW(t) modules supplying $387 \mathrm{MW}(\mathrm{t})$ of heat and $115 \mathrm{MW}(\mathrm{e})$ to the process plant and 963 MW(e) to the regional grid. The addition of excess capacity in these plants and in all of the HTGR plants included in the carbon conversion industry has two purposes. The first is to provide $100 \%$ availability of 
the HTGR energy supply to the process even if two of the HTGR plants are not in service (e.g., during refueling or unscheduled outages). The second is to provide the nuclear component of new generation on the Wyoming grid as original coal - fired generation is retired due to age and/or government regulations that make them uneconomic to operate. Full deployment of this plant and its integration with the process plant would comprise staggered commissioning of the four modules over $\sim 8$ years. As shown in Figure $3-$ 19 , it is projected that three years of design, planning and permitting effort and 5-1/2 years of construction will be required to complete the full integration. The first HTGR module would be on-line in mid-2030 with the plant at full capacity in the 4th quarter of 2031. This is more than 10 years after initiating operation of the process plant. This would be an appropriate time for initiating major maintenance on the plant such as modifying the reformers to interface with the HTGR heat supply. The HTGR plant will also be interfaced with the grid transmission lines at that time. The projected cost of the HTGR plant is $\sim \$ 5$ billion (2011\$). The inflated cost is estimated at $\$ 6.5$ billion including interest on debt. During construction

\begin{tabular}{|c|c|c|c|c|c|c|c|c|c|c|c|c|c|c|c|c|c|c|c|c|c|c|c|}
\hline Activity & 10 & 11 & 12 & 13 & 14 & 15 & 16 & 17 & 18 & 19 & 20 & 21 & 22 & 23 & 24 & 25 & 26 & 27 & 28 & 29 & 30 & 31 & 32 \\
\hline $\begin{array}{l}\text { Development \& De ployment of } \\
67,000 \mathrm{BPD} \text { CTG Plant w/SMR }\end{array}$ & & & & & & & & & & & & & & & & & & & & & & & \\
\hline First Phase CTG Plant Deployment & & & & ㄷ & & & & & & & & & & & & & & & & & & & \\
\hline Design, Permitting, Site Preparation & & & & $\square$ & & & & & & & & & & & & & & & & & & & \\
\hline Procurement & & & & ᄃ & & & & & & & & & & & & & & & & & & & \\
\hline Construction & & & & & & & ] & & & & & & & & & & & & & & & & \\
\hline Startup and test & & & & & & & $\square$ & & & & & & & & & & & & & & & & \\
\hline Initiate commercial operation & & & & & & & & & & & & & & & & & & & & & & & \\
\hline First Module "Shakedown" Operation & & & & & & & & $\square$ & & & & & & & & & & & & & & & \\
\hline Second Module Deployment & & & & & & ᄃ & & & & & & & & & & & & & & & & & \\
\hline Third Module Deployment & & & & & & & & & & & & & & & & & & & & & & & \\
\hline Fourth Module Deployment & & & & & & & & & & & & & & & & & & & & & & & \\
\hline Process Plant Fully Operational & & & & & & & & & & & & & & & & & & & & & & & \\
\hline HTGR Plant Deployment & & & & & & & & & & & & & & & ᄃ & & & & & & & & \\
\hline Licensing & & & & & & & & & & & & & & & ᄃ & & & & & & & & ] \\
\hline Design & & & & & & & & & & & & & & & ᄃ & & & & & & & & \\
\hline Procurement & & & & & & & & & & & & & & & & & & & & & & 1 & \\
\hline 1st Module Const \& Commissioning & & & & & & & & & & & & & & & & & & & & - & & & \\
\hline 2nd Module Const \& Commissioning & & & & & & & & & & & & & & & & & & & & & & & \\
\hline 3rd Module Const \& Commissioning & & & & & & & & & & & & & & & & & & & & & & ב & \\
\hline 4th Module Const \& Commissioning & & & & & & & & & & & & & & & & & & & & ᄃ & & & \\
\hline HTGR Plant Fully Operational & & & & & & & & & & & & & & & & & & & & & & & \\
\hline
\end{tabular}

Figure 3-19. Schedule for Integrating the HTGR with the initial natural gas to gasoline plant.

the site will employ 3,400 personnel on average each year and 9,300 peak in the fifth year of the project. The finished plant will employ 400 personnel. When fully deployed the process and HTGR plant will employ at least 800 personnel.

The construction, permanent employment and added value of coal and natural gas attendant to the deployment of the initial plant with integration of the HTGR would provide significant benefit to the Wyoming economy. The following section discusses expansion of the number of these plants to develop the carbon conversion industry and deployment of HTGR technology to reduce emissions and provide long term stable energy costs for the process industry and for statewide electricity generation and projections of the long term benefits of these developments. 


\subsection{Deployment of the Carbon Conversion Industry}

\subsubsection{Objectives of Deploying the Carbon Conversion Industry}

The initial coal to gasoline plant would be the first in deployment of a carbon conversion industry comprised of several additional carbon conversion plants within Wyoming. Objectives of deploying this industry are to provide long term internal markets for Wyoming coal and natural gas and increase their value to the Wyoming economy.

\subsubsection{Coal Production in Wyoming}

Figure 3-20 shows that total production of coal in Wyoming peaked in 2008 and has had a declining trend since. This reduction in coal production is due to retirement of coal-fired electricity generation and addition of emissions control equipment to other coal-fired plants so they no longer need to use the low sulfur Wyoming coal. There are several other factors such as the low natural gas prices causing utilities to switch from coal to natural gas fired plants and pending EPA regulations on $\mathrm{CO}_{2}$ emissions ${ }^{41}$ that are expected to result in no new construction of coal based electricity generation. ${ }^{42}$ The EPA has also indicated in this reference that it is developing New Source Performance Standards with the States that will include greenhouse gas emissions. This latter action could cause early retirement of coal based generation. These factors provide other incentives for developing an industry for use of Wyoming coal and for increasing its value to the Wyoming economy.

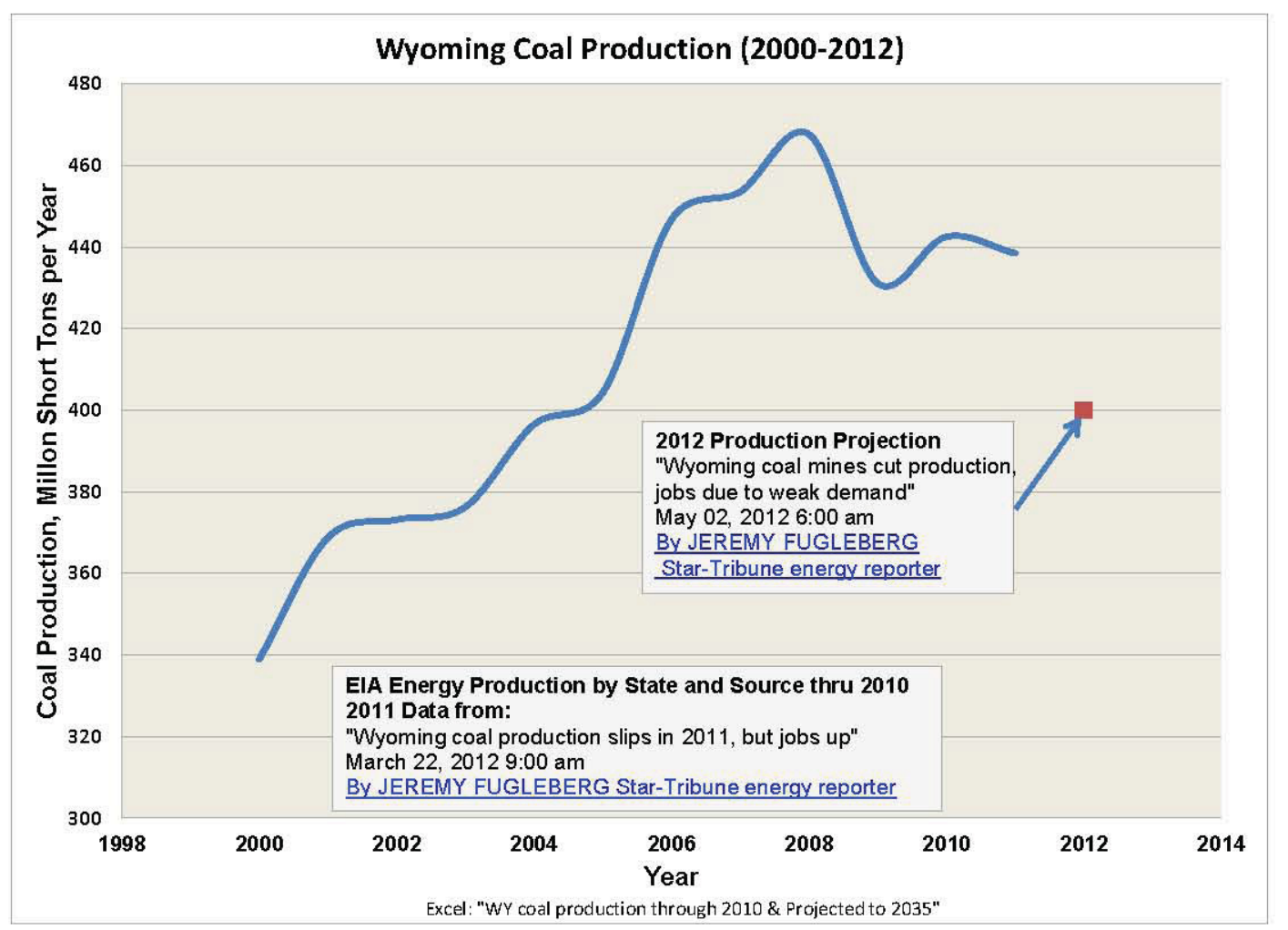

Figure 3-20. Coal production in Wyoming 1994-2014

Figure 3-21 shows the projections by EIA for retirement of coal-fired electricity generation through 2020. This chart shows a range of retirements depending on assumptions on economic growth and the trends in natural gas prices. Assuming that natural gas stays in the $\$ 4 / \mathrm{MMBtu}$ to $\$ 6 / \mathrm{MMBtu}$ range over the long term and the economy continues to slowly improve the total retirements are projected to be in the 
50 to $55 \mathrm{GW}$ (e) range (e.g., Gas Price Case - low and Economic Growth Case - Reference). This is $\sim 16 \%$ of the total coal-fired electricity capacity in the U.S.in $2011 .^{12}$

It is understood that this does not reflect any increased regulation of $\mathrm{CO}_{2}$ emissions on existing plants. Legislation proposed by Senator Jeff Bingaman ${ }^{43}$ provides some insight into the potential effect of such regulation. The EIA analysis of this legislation projects the following ${ }^{44}$ :

"The policy also results in a significant shift in the long-term electricity generation mix, with coal-fired generation in 2035 falling $54 \%$ below the Reference case level. The significant increase in coal retirements under the $B C E S 12$ policy is primarily offset by increased natural gas-fired generation through 2020, while increased nuclear and non-hydropower renewable generation plays a larger role between 2020 and 2035. In addition, total electric power generation falls slightly under the BCES12 policy.

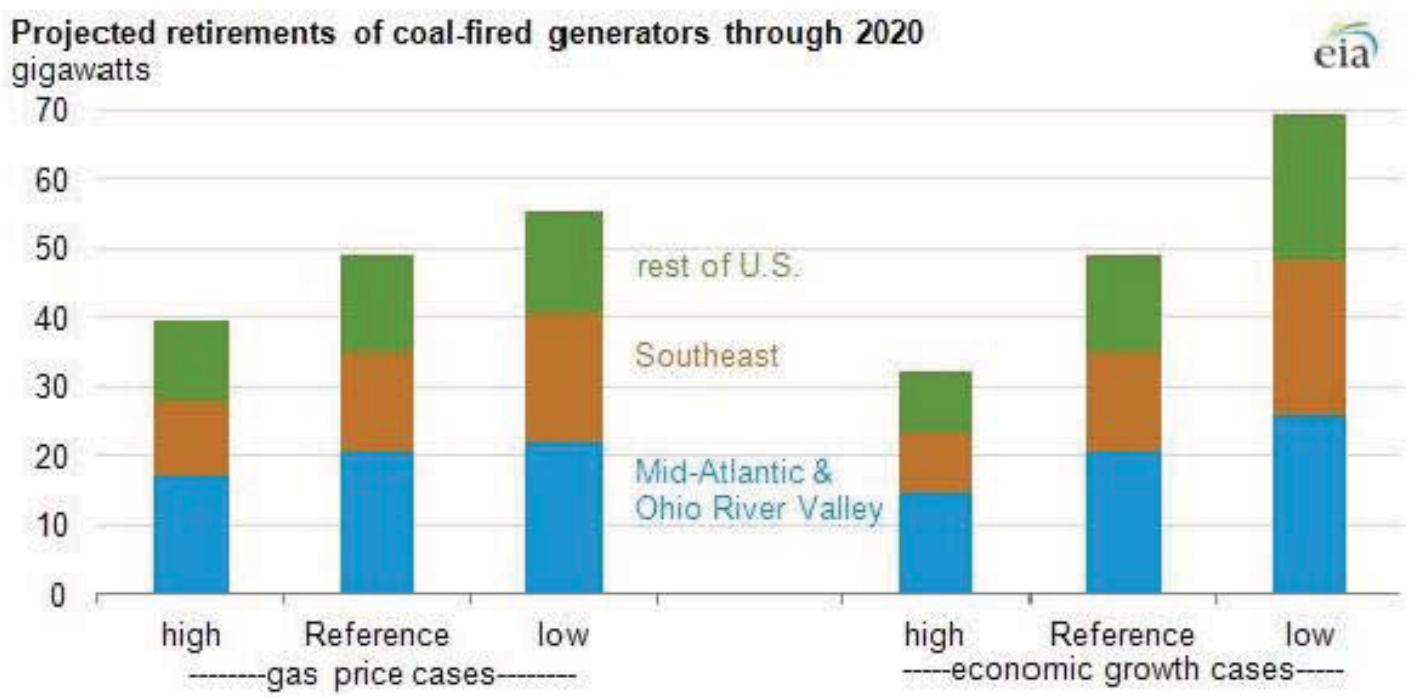

\section{Electricity generation by source} billion kilowatthours 6,000

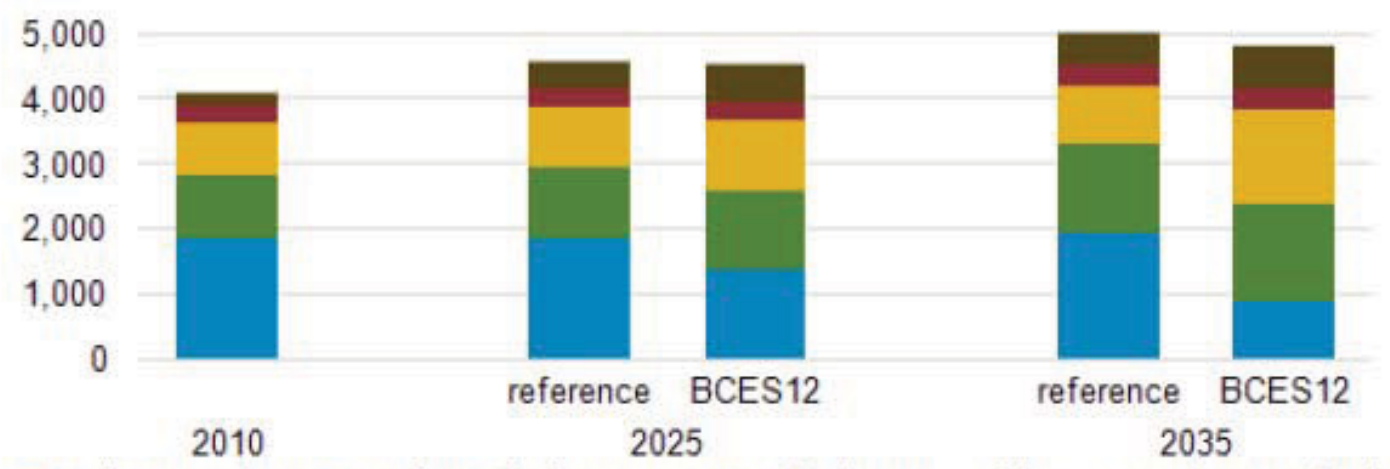

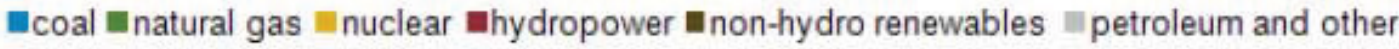

Figure 3-21. ElA projections on retirements of coal-fired piants through 2020 (Source: U.S. Energy information Administration, National Energy Modeling System).

In the reference case EIA projected coal-fired generation of $\sim 1951 \mathrm{BK}$ whe in 2035 consuming $\sim 19.5$ quads $\left(10^{15} \mathrm{Btu}\right){ }^{5}$. The $54 \%$ reduction would amount to reducing consumption by $\sim$ a trillion tons of coal 
or about 2.5 times the annual production of coal in Wyoming in 2011. EIA also estimates a reduction of coal based generation capacity of $26 \%$ or $\sim 90 \mathrm{GW}(\mathrm{e})$. Since Wyoming provides $\sim 40 \%$ of the coal consumed in the U.S. and this is used primarily for electricity generation in 30 states $^{45}$ these retirements and reductions in coal use for electricity would be expected to have a significant impact on Wyoming coal production. If it is assumed that the $54 \%$ reduction in coal based electricity production affects Wyoming coal production by a similar amount the reduction in the contribution of this industry to Wyoming could be as high as that seen for the reduction in natural gas prices; $\sim 2 \mathrm{~B}$ annually. Wyoming has initiated some international export to offset this reduction ${ }^{46}$. However, this is not expected to be able to completely offset the reductions due to retirement of coal based plants.

A robust carbon conversion industry would provide an internal stable market for coal and add value to that coal through conversion to products that have higher value than the coal as a commodity.

\subsubsection{Natural Gas Production in Wyoming}

Figure 3-22 shows the history of production of natural gas in Wyoming through April 2012. Similar to coal, production peaked in 2008 and has a gradual negative trend since. Of more concern, however, is the reduction in price of natural gas due to the glut on the U.S. market from gas shale production. This is shown in Figure 3-23. Prices in 2012 are $\sim 1 / 2$ that of prices in 2008 resulting in a significant reduction in the contribution of the natural gas industry to the state GDP and revenue to the state and local governments.

Figure 3-24 shows the effect of the reduction in natural gas prices on the contribution of the oil and gas extraction component of the mining industry to the Wyoming GDP. Although the total contribution from the mining industry was relatively stable 2009-2011 after the drop in 2009 from the peak in 2008 , the contribution from oil and gas extraction contributed to the majority of the drop in 2009. Review of the natural gas price history in Figure 3-23 leads to the conclusion that this drop was primarily due to reduced revenue from natural gas extraction and that the revenues in 2010 and 2011 were similar if not lower. The actual component values for 2010 and 2011 were not available in the public domain at the time of this writing. 


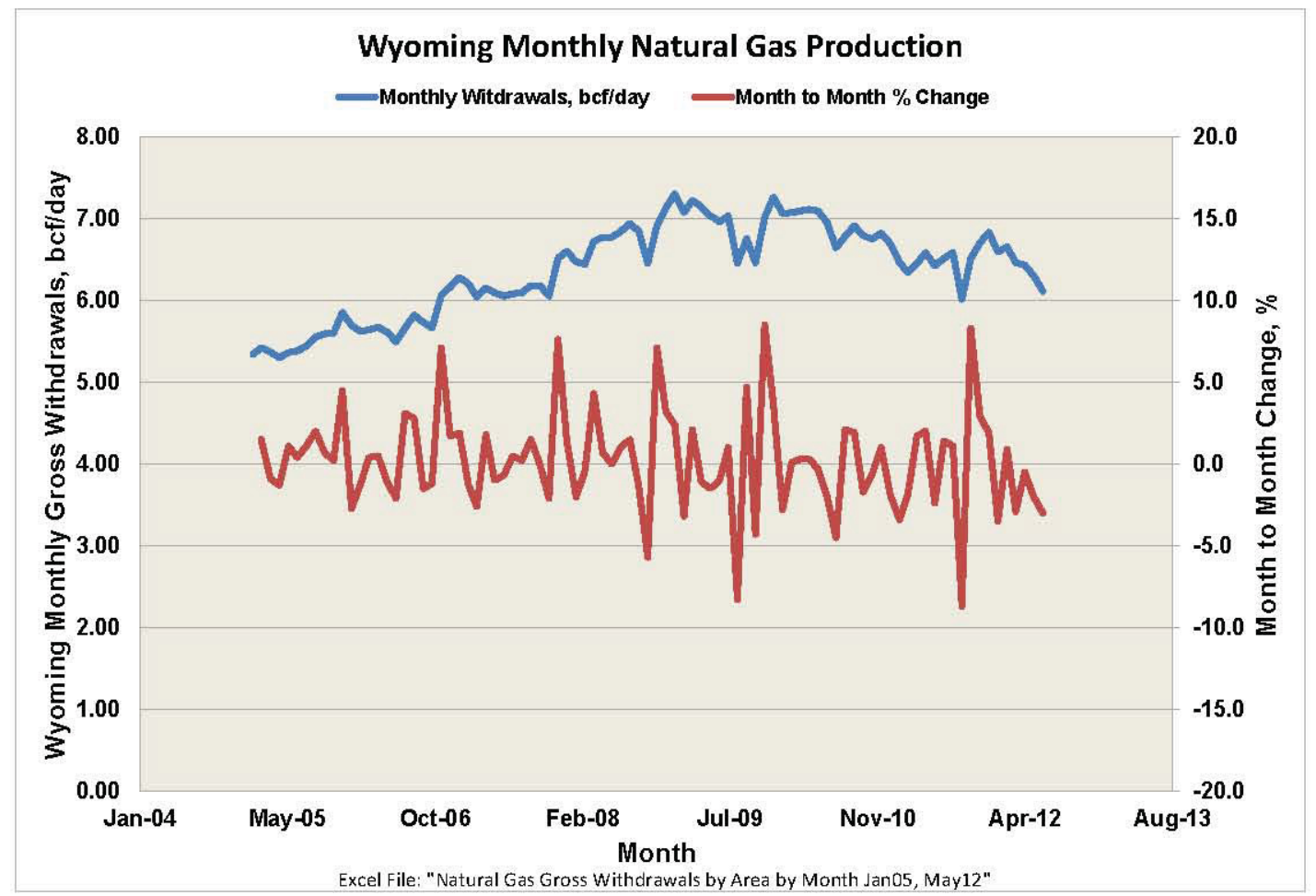

Figure 3-22. Wyoming natural gas production.

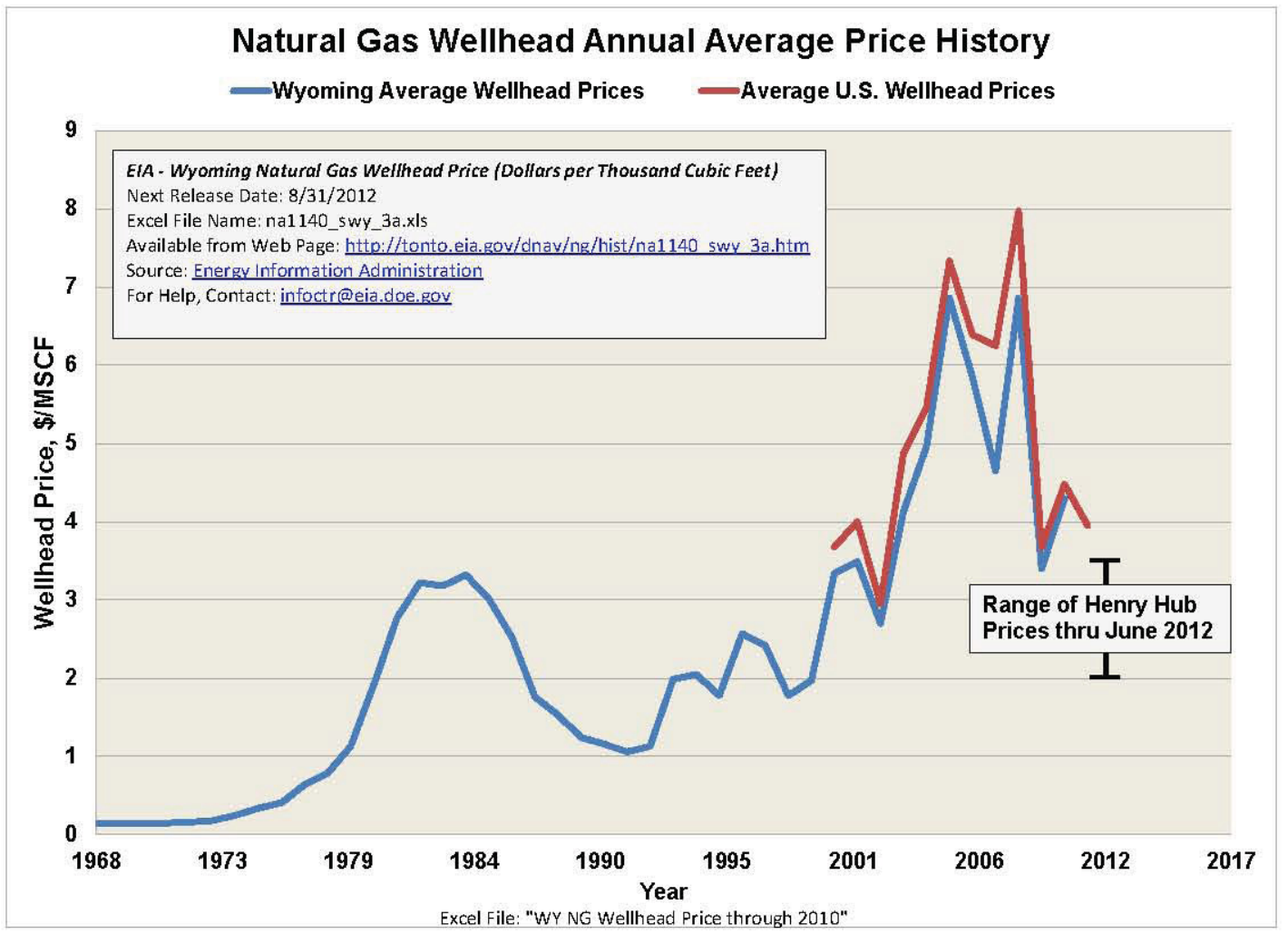

Figure 3-23. History of Wyoming natural gas wellhead prices. 


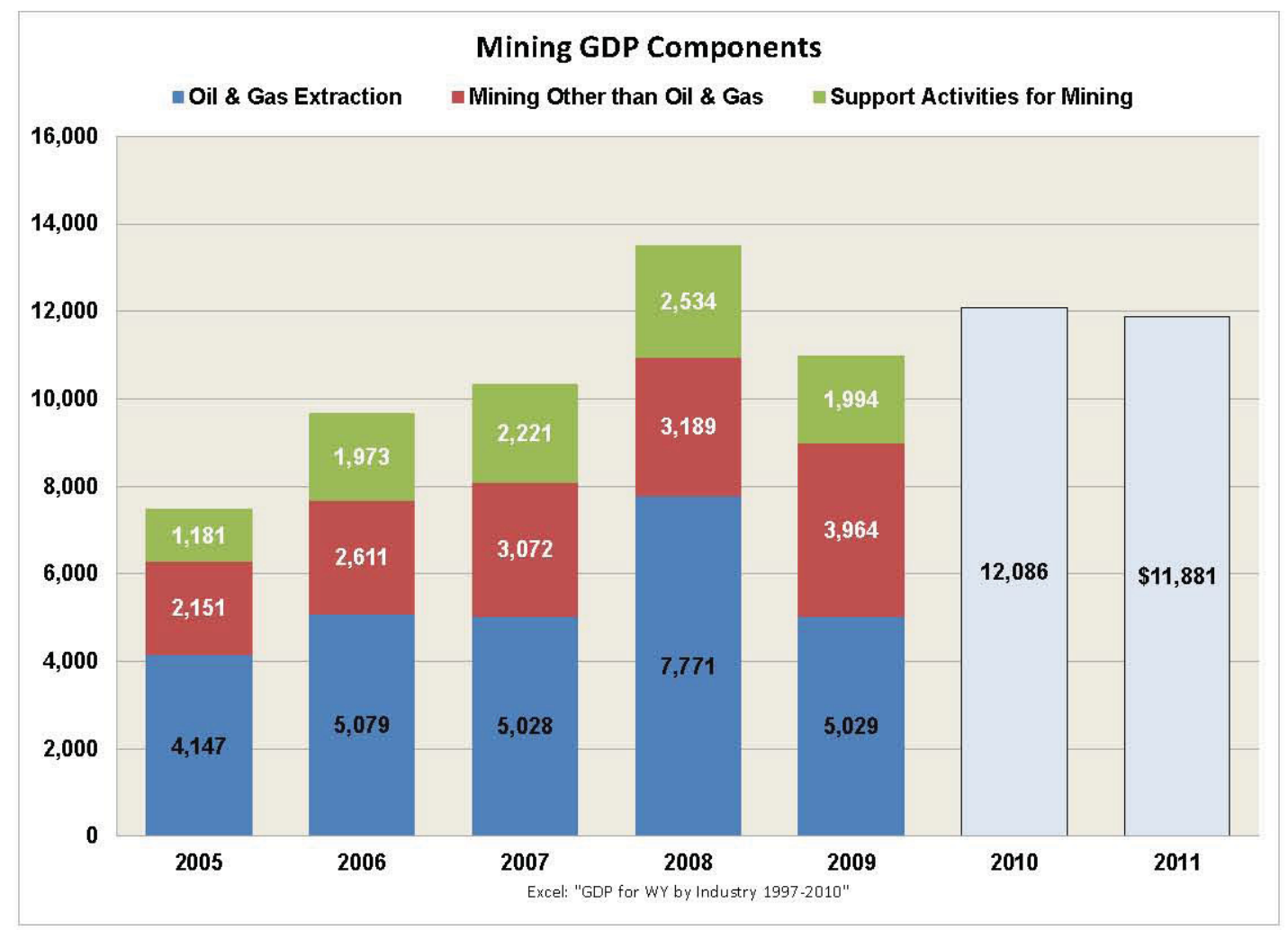

Figure 3-24. History of mining component contributions to the Wyoming GDP though 2011.

\subsubsection{Notional Carbon Conversion Industry}

There is incentive, therefore, to develop the carbon conversion industry to provide stable long term internal markets for Wyoming coal and natural gas but it is also important to increase the value of these indigenous resources through conversion to higher value commodities. To this end the notional expanded carbon conversion industry analyzed herein includes the plants of Table 3-2. Note that four different plants are covered to provide a perspective on the performance characteristics and scope, costs and schedule required for deploying each type of plant.

Table 3-2. Characteristics of the notional Wyoming carbon conversion industry process plants.

\begin{tabular}{|c|c|c|c|c|c|c|}
\hline Type & Capacity bpd & Products & $\begin{array}{l}\text { Natural Gas } \\
\text { Consumption } \\
\text { MMSCFD }\end{array}$ & $\begin{array}{c}\text { Coal } \\
\text { Consumption } \\
\text { short tons per } \\
\text { day }\end{array}$ & $\begin{array}{c}\text { Cost, SMM } \\
\text { (2011S) }\end{array}$ & $\begin{array}{c}\text { Annual } \\
\text { Revenue SMM } \\
\text { (20115) }\end{array}$ \\
\hline GTG & 40,000 & Gasoline \& LPG & 290 & --- & 1,900 & 1,050 \\
\hline GTL & 50,000 & $\begin{array}{l}\text { Diesel, Naphtha } \\
\text { \& LPG }\end{array}$ & 430 & --- & 2,400 & 1,860 \\
\hline CTG & 60,000 & Gasoline \& LPG & 290 & 11,845 & 5,900 & 2,100 \\
\hline CTL & 50,000 & $\begin{array}{l}\text { Diesel, Naphtha } \\
\text { \& LPG }\end{array}$ & 280 & 7,720 & 3,900 & 1,860 \\
\hline Totals & 200,000 & & 1,290 & 19,565 & 14,100 & 6,870 \\
\hline
\end{tabular}

It should be noted that a four plant industry has been developed herein for the purposes of providing a basis for analysis. The mix of processes and feedstock and the number of plants could favor a different 
mix of conversion of coal and natural gas based on economic needs. The actual make-up of the industry and the number of plants would be determined by the owners as it evolves with consideration of market conditions and Wyoming long term objectives.

When deployed these four plants would consume $\sim 424 \mathrm{BSCF}$ of natural gas ( $20 \%$ of 2011 production) and $\sim 6.5 \mathrm{MM}$ short tons of coal ( $1.6 \%$ of 2011 production) per year and generate $\sim \$ 7 \mathrm{~B}$ in sales from the $200,000 \mathrm{bpd}$ of synthetic fuels production. The addition of natural gas consumption is a significant percentage of historical levels while the coal consumption is not. However, the annual sales are a factor 4 greater than the value of the natural gas $(\$ 4 / \mathrm{MSCF})$ and coal $(\$ 10 /$ short ton) combined if sold on the market as commodities. This will provide a long term benefit to the Wyoming economy. The expenditures and jobs created during the construction of the industry will also have benefit to the economy. The full effect of all of the initiatives discussed herein is summarized below.

Once they are commercially available in the late 2020 s four HTGR plants could be either backfit to the process plants or integrated into the original design of the plants. The HTGR plants would provide heat and electricity to the process and electricity to the grid as part of the new generation replacing retiring coal-fired plants. Table 3-3 summarizes the characteristics of these HTGR plants.

Table 3-3. Characteristics of the HTGR plants integrated with the process plants.

\begin{tabular}{|cccccc|} 
Integrated with & $\begin{array}{c}\text { Thermal } \\
\text { Capacity } \\
\text { MW(t) }\end{array}$ & $\begin{array}{c}\text { Number of } \\
\text { Modules }\end{array}$ & $\begin{array}{c}\text { Heat Supply to } \\
\text { Process } \\
\text { MW(t) }\end{array}$ & $\begin{array}{c}\text { Electricity to } \\
\text { Process } \\
\text { MW(e) }\end{array}$ & $\begin{array}{c}\text { Electricity to } \\
\text { the Grid } \\
\text { MW(e) }\end{array}$ \\
\hline GTG & 3,000 & 5 & 387 & 115 & 963 \\
\hline GTL & 3,000 & 5 & 479 & 0 & 1038 \\
\hline CTL & 3,000 & 5 & 928 & 60 & 706 \\
\hline Totals & 3,000 & 5 & 1201 & 91 & 637 \\
\hline
\end{tabular}

\subsubsection{Carbon Conversion Industry Deployment Schedule, Costs, and Benefits}

Figure 3-25 shows a notional schedule for deployment of the Wyoming carbon conversion industry including integration of the HTGR plants providing heat and electricity to the processes and base-load electricity to the Wyoming grid. This is judged to be a non-aggressive schedule that does not require excessive annual expenditures and large labor forces that could strain the Wyoming infrastructure. Figure 3-26 summarizes the projected annual contributions to the Wyoming GDP and accumulative expenditures for this deployment. The total projected cost of $\$ 35.53 \mathrm{~B}$ is spread over 22 years and the highest annual expenditure is in the range of $\$ 3.0 \mathrm{~B}$. These are judged to be reasonable for the benefit to be accrued from this deployment; an addition of $\sim \$ 7 \mathrm{~B}$ in revenue from sales of the products and 3,200 quality jobs. The annual contributions of these expenditures to the Wyoming GDP are also significant; reaching $7 \%$ of the Wyoming GDP in 2011 in peak years. The $\sim 150,000$ man-years required to complete the construction over the 22 year period would also be of benefit to the local and state economies.

f These consumption rates and revenue generation assume a $90 \%$ capacity factor. 


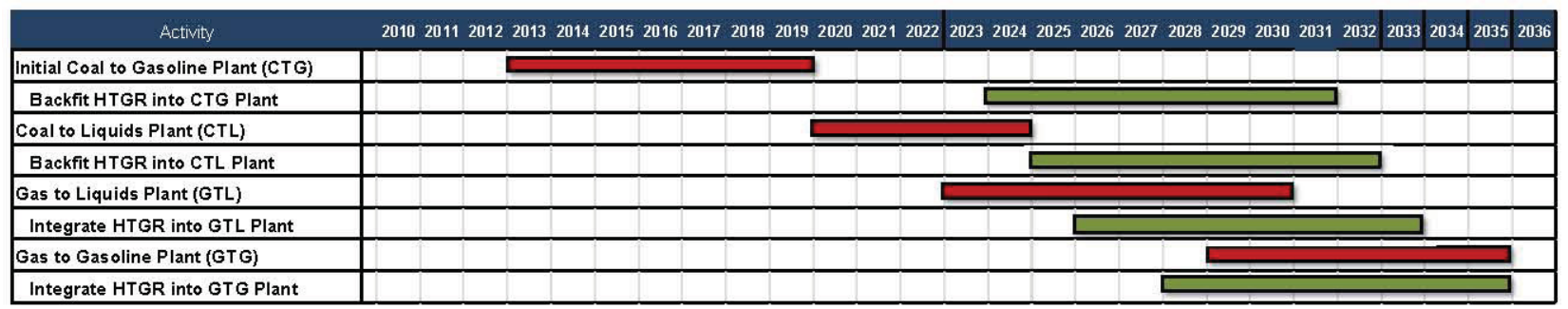

Figure 3-25. Carbon conversion industry deployment by calendar year.

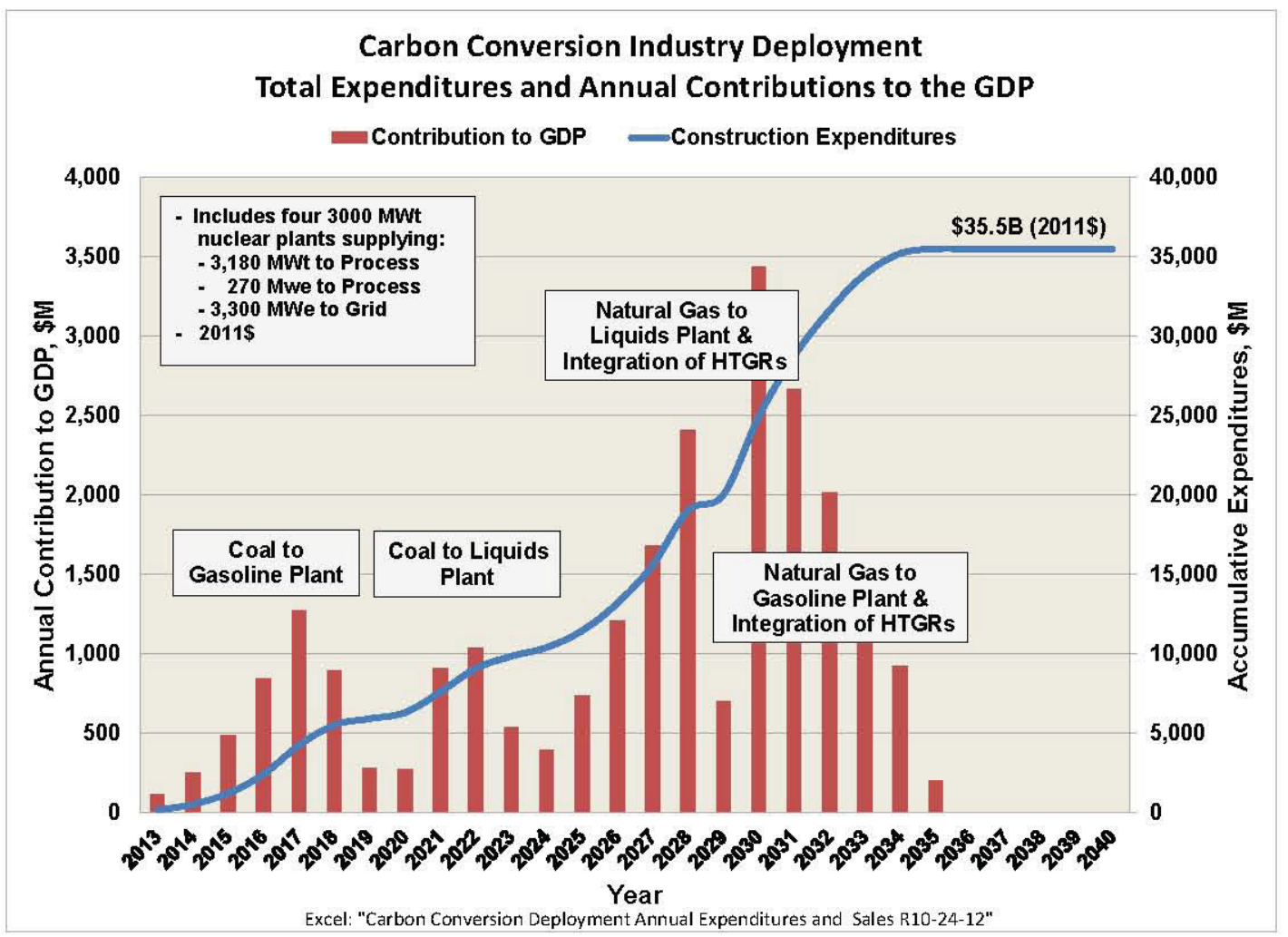

Figure 3-26. Carbon conversion industry deployment expenditures and annual contributions to the GDP.

\subsubsection{A Distributed Configuration for the Carbon Conversion Industry}

Multiple facilities distributed throughout Wyoming fulfilling the several stages of processing may have benefit in taking advantage of area unique feedstock supply, infrastructure, labor force, local interest and distribution access to national and international markets. This concept is portrayed in Figure 3-27.

As discussed previously, many (but not all) coal and natural gas conversion processes have an initial step of converting those materials in synthesis gas, a mixture of hydrogen and carbon monoxide which is then further converted to the desired products. When several plants in this industry are established, it would be feasible for them to develop an integrated syngas exchange network for operational backup, to allow the synthesis of small amounts of specialty products using another plant's possible excess syngas production capacity, and to allow companies to begin specializing in either the conversion of the primary carbon resource or the production and sales of commodity and specialty fuels and chemicals. 
One of the chemical products could be methanol, an important commodity chemical that also can be further converted to many other chemicals and plastics. This variety of uses could lead to a second regional product distribution network specifically for it.

This approach allows a variety of products to be made in less than world-scale amounts because they need not build their own front end to make syngas. It also provides greater flexibility if product markets change. If, for example, in thirty years gasoline is no longer needed in large amounts for the light vehicle fleet, other fuel or chemical products could be made from its former feed of syngas. Depending on the old and new processes, it is plausible that the old synthesis plant need not be scrapped but only converted to make the new product.

Finally this concept allows flexibility in siting the final process plants to optimize their proximity to national and international distribution network whereas the more optimum site for the gasification and reforming processes would be near coal and natural gas sources. These source sites may not be convenient for distributing the products.

Each plant site would also be evaluated for viability of adding HTGR electricity generation at that site and, if viable, the capacity that is optimal for the location and potential markets within and outside Wyoming.

Whether this concept has value in deploying the Wyoming carbon conversion industry would be determined as the strategy for deploying this industry evolves.

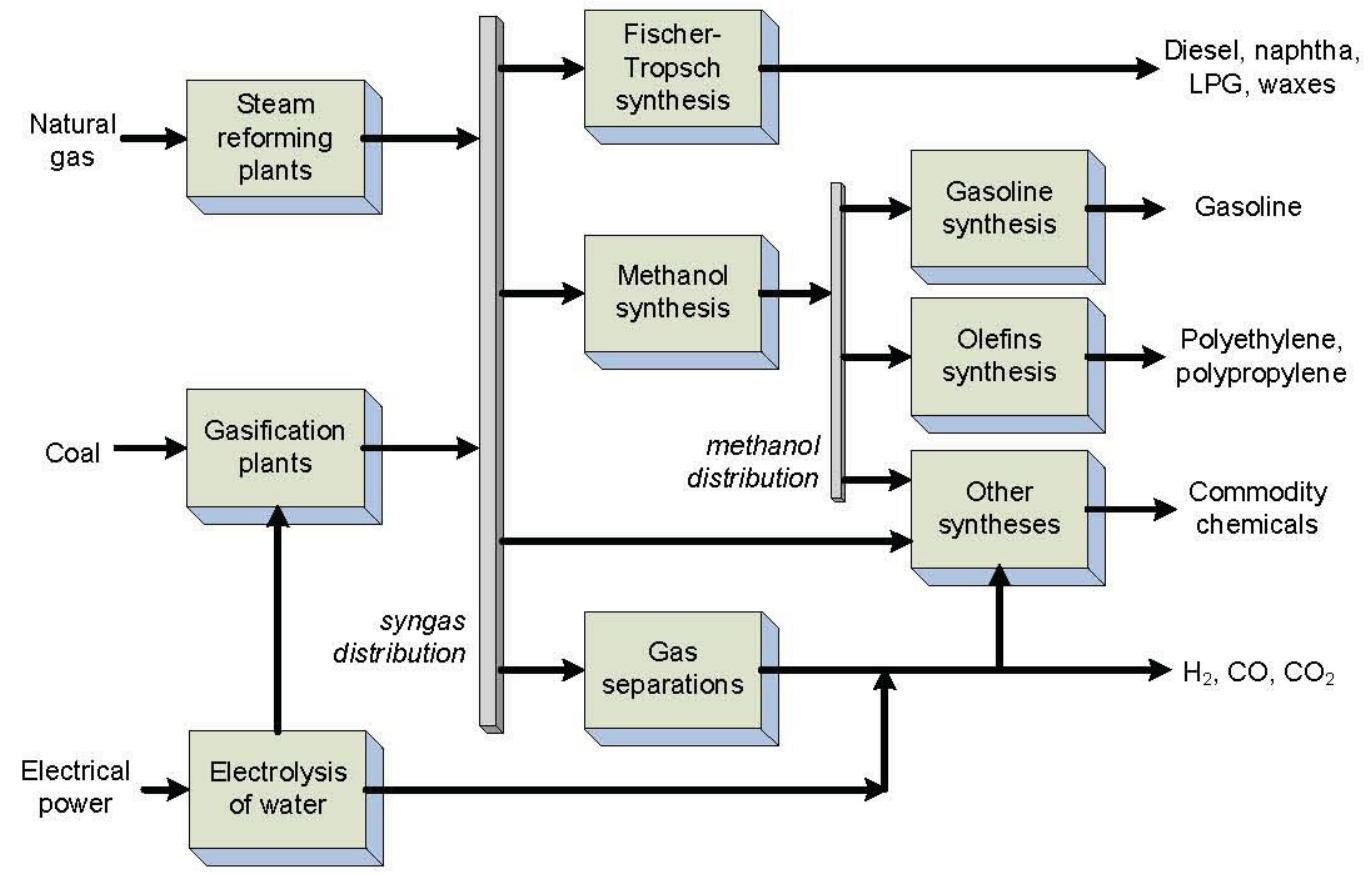

Figure 3-27. A distributed carbon conversion industry concept.

\subsubsection{Plant Siting}

A set of criteria were developed as part of this effort to assist in evaluating and identifying sites that would be acceptable for locating carbon conversion plants with nuclear components supporting the plant processes and supplying electricity to the regional utility. These criteria are summarized in Appendix A of this report. Using input from the principals involved in this effort, these criteria were distilled down and 
prioritized into specific characteristics that are (1) required for any site to be acceptable (referred to as "MUSTS") and (2) optional but desirable for the site (referred to as "WANTS/NEEDS").

These criteria were applied with weighting criteria in site suitability analyses using detailed data on the characteristics and infrastructure of each county in Wyoming. These analyses were performed using resources at the University of Wyoming's Geographic Information Science Center (WyGISC).

Background maps of the State were developed including all of the utility pipelines, transmission systems and infrastructure covered in the selection criteria. This included gathering the most up-to-date information from various state and local agencies within the state of Wyoming. WyGISC then applied the weighting criteria to generate maps of Wyoming that highlight those regions of the state that best fit the criteria and the degrees of conformance. This first cut analysis narrowed the potential site locations in Wyoming to four counties; Laramie, Campbell, Natrona, and Fremont.

A second analysis was performed to identify specific sites within these counties that met the specific criteria. This analysis determined that using the WyGISC data there are no sites that meet the specific criteria; specifically the criteria requiring the site to be a privately held area of 1000 acres that is zoned industrial. Only one site in Fremont County of 500 acres was identified as having met at least two of these three criteria. After review of the results it was concluded that the criteria and data may be too limiting. For example, it did not include any sites owned by coal or natural gas producers.

No more effort is judged to be appropriate as part of this evaluation effort. Just as selecting the specific plant will be the responsibility of the owner, so will selecting the specific site for the initial plant and for subsequent plants. A short term "path forward" action identified in Section 2 engages industry and potential owners of these plants. This engagement should include vetting the site requirements in Appendix A and F.

\subsection{Transformation of Wyoming Electricity Generation Industry}

\subsubsection{Electricity Generation Transformation Objectives}

Over $90 \%$ of electricity in Wyoming is generated using coal. The current and pending EPA regulations on mercury and toxic chemicals require the installation of expensive emissions control equipment that is not economically viable on some Wyoming plants leading to the potential for their earlier retirement than might otherwise be expected. There are also pending EPA regulations on $\mathrm{CO}_{2}$ emissions that currently apply to new plants but the EPA has discussed applying these to existing plants. ${ }^{33,34,35}$ If implemented these regulations could also lead to early retirement of those plants that have become marginally economic or uneconomic due to the regulatory impositions. These retirements in addition to normal retirements due to age and obsolescence require addition of new generation technologies. A notional strategy has been developed for transforming the electric generation industry from one dominated by coal-fired generation to a more diverse mix of generation technologies consistent with the following:

- The current coal-based generation will be fully retired primarily on the basis of age. A retirement age of 60 years from initial operation date is used for the purposes of analysis. Note that no quantifiable projection of the potential for early retirement of plants due to current or emerging emissions regulations has been identified for Wyoming coal-fired plants. Accordingly, this potential has not been included in development of this notional strategy.

- There are some plants on the Wyoming grid of small capacity that have not operated in the last year. These will be retired early in the strategy to fill in gaps between age retired plants.

- The addition of new generation will substitute for retired generation in time to maintain the total grid capacity approximately equal to that in $2011(\sim 9 \mathrm{GW}(\mathrm{e}))$. 
- New technologies shall have controllable or no toxic chemical and greenhouse gas emissions to provide flexibility in adapting to or meeting current and potential government emissions regulations. For example, the addition of fossil fired generation shall include all emissions control technologies including carbon CCS.

- The selection of new technologies shall be based on their proven or projected commercial availability at the time of plant retirements and the needed capacity.

- A steady increase in the capacity of wind generation will be included consistent with Wyoming objectives of having renewable power for export to States with Renewable Portfolio Standards. However, the total wind generation capacity shall be limited to $25 \%$ of the total grid capacity to maintain grid supply to demand balance using currently installed grid control technologies under the variable characteristics of wind generation.

- Addition of coal generation will be included to provide an internal stable market for Wyoming coal.

\subsubsection{Electricity Generation Transformation Strategy}

The strategy for transforming the electricity generation industry is illustrated in Figure 3-28. This strategy is developed in detail in Appendix $\mathrm{F}$ and addresses four principal generation technologies; the addition of new plants using increasing wind generation, natural gas combined cycle units with CCS, coal with CCS and nuclear (HTGR) technologies. With respect to addition of nuclear generation as discussed in previous sections it is assumed that HTGR plants with excess electricity generation capacity would be integrated with the carbon conversion industry. The modular characteristics of this technology and its higher net efficiency are judged to be defining advantages compared with large LWR plants by providing more flexibility in siting particularly in areas where transmission capacity is limited.

The HTGR plant is generally more economical than other forms of non-or-low emission generation technologies. Figure 3-29 compares the costs of generation for several technologies with NGCC plants with and without CCS and with the HTGR as a function of the price of natural gas. As shown the HTGR is competitive with an NGCC plant with CCS for a natural gas price of a little higher than $\$ 6 / \mathrm{MMBtu}$ and above. It is competitive with NGCC without CCS for natural gas prices near \$10/MMBtu and above. Analyses in Appendix $\mathrm{C}$ show that long term prices of natural gas are projected to be in a range that includes these values and above. The HTGR is also competitive with other low or non-GHG emitting sources of power. It is, therefore, a very viable alternative over the longer term for replacing coal based generation in Wyoming.

The transformation strategy is configured to be consistent with the schedule for retirement of existing generation due to age and with the deployment of the carbon conversion industry. The transformation is complete by 2040 .

Figure 3-30 shows the annual change in the sources of generation that results in a full transformation as shown in Table $3-4$.

For the purposes of analysis wind generation was added at a constant rate of $\sim 50 \mathrm{MW}(\mathrm{e})$ at every retirement of a coal-fired plant. The addition of wind was limited to maintain generation below $25 \%$ of the full capacity to reduce the impact of the variable nature of this generation on the supply to demand balance of the grid. Natural gas capacity was added as needed to maintain net capacity reasonably constant and in blocks of $400 \mathrm{MW}(\mathrm{e})$ assuming installation of advanced Natural Gas Combined Cycle Units with CCS. The total addition of natural gas generation was limited to $17 \%$ when the transformation is complete. The downside of maintaining a significant level of natural gas combined cycle (NGCC) generation on the grid is the volatility of natural gas prices and the strong relation between natural gas prices and the price of electricity production of NGCC plants. This is illustrated in Figure 3-29. 


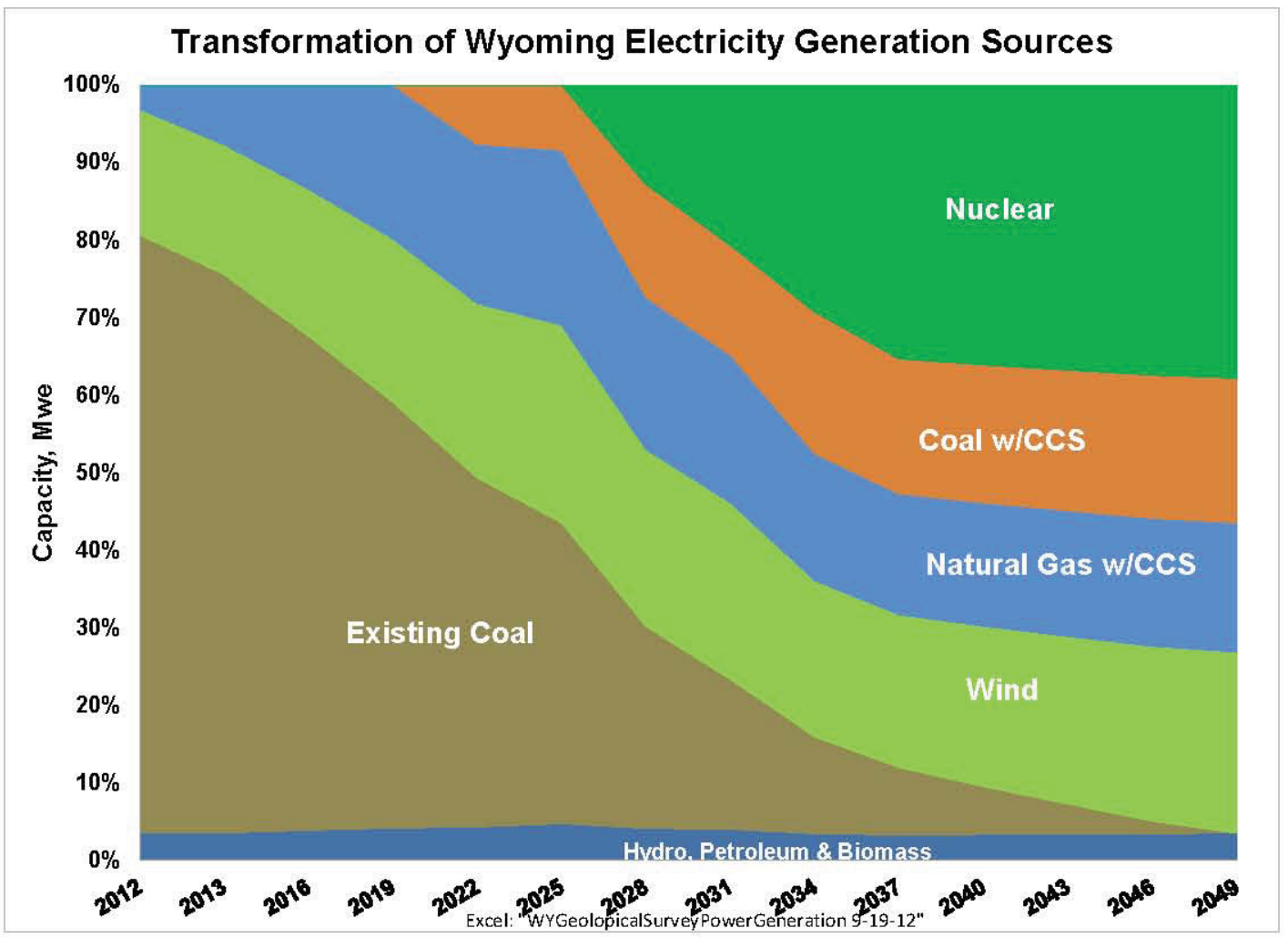

Figure 3-28. Transformation of the Wyoming electricity generation industry.

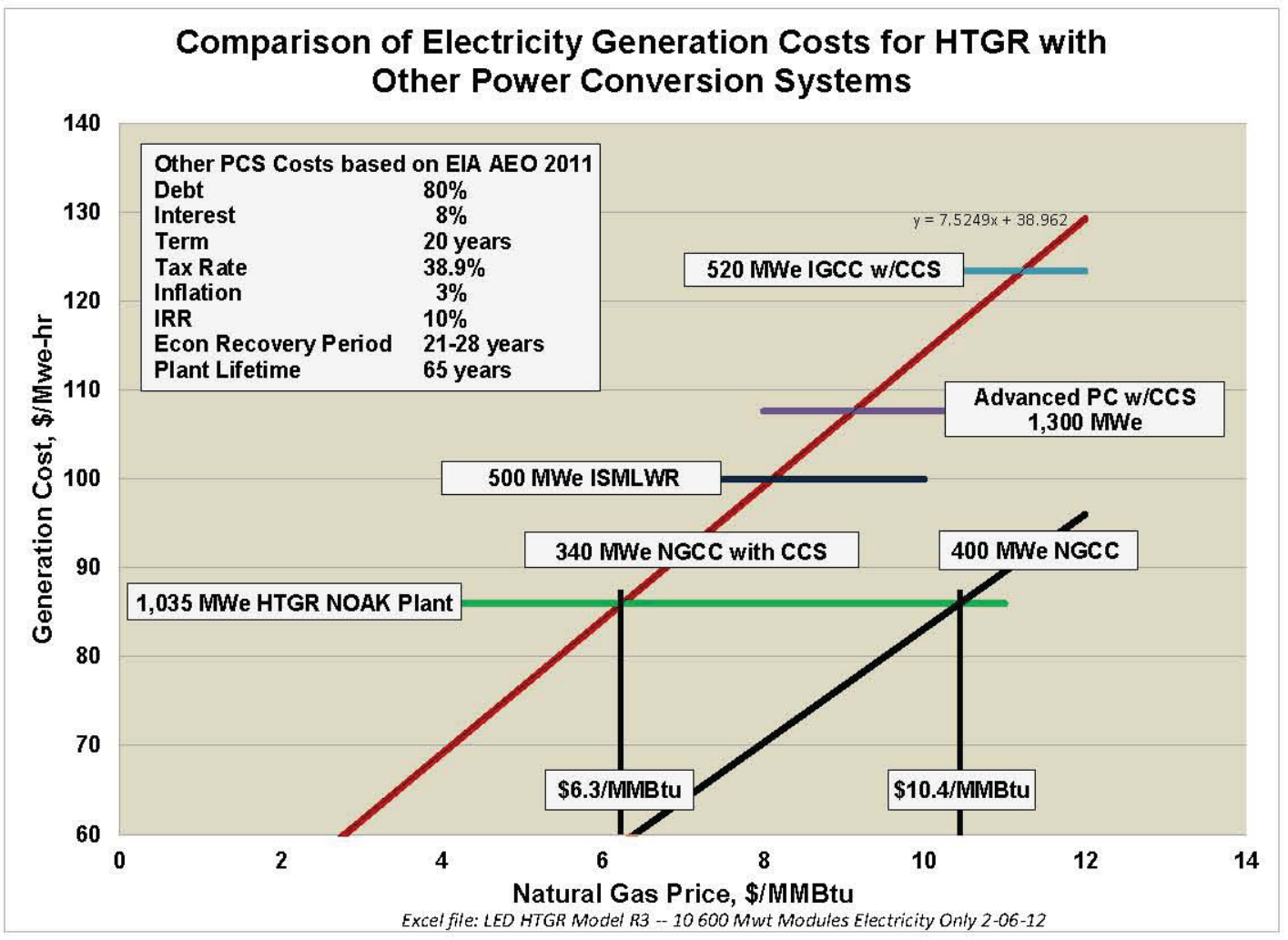

Figure 3-29. Comparison of electricity generation costs for HTGR with other power conversion systems. 


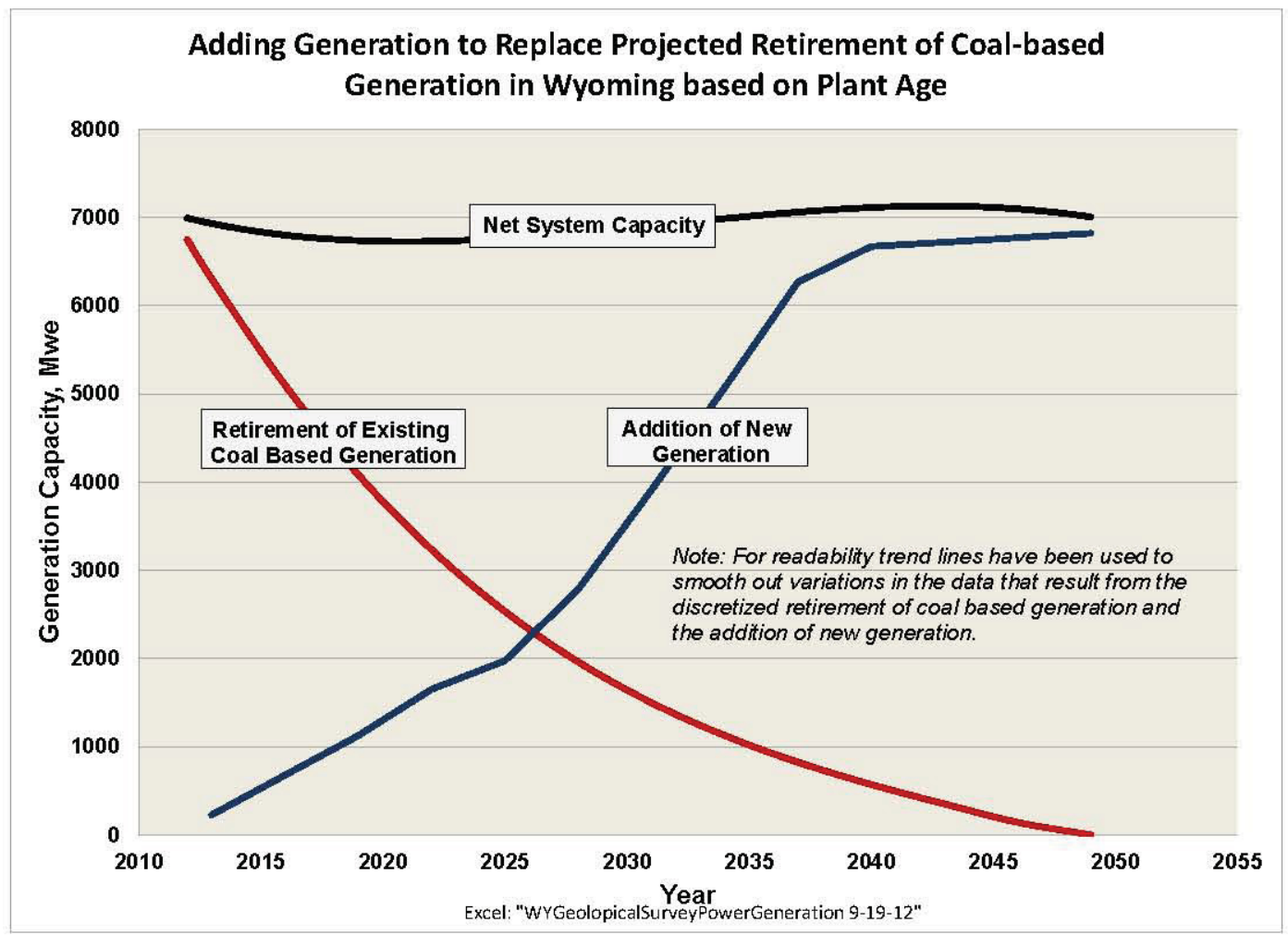

Figure 3-30. Transformation of electricity generation sources.

Table 3-4. Final mix of electricity generation technologies.

\begin{tabular}{|lrc|}
\multicolumn{1}{c}{ Capacity by Fuel } & MW Year 2040 & \\
\hline Wind & 2,065 & $\%$ of Total \\
\hline Natural Gas & 1,474 & $23 \%$ \\
\hline Hydroelectric \& Fuel Oil & 308 & $17 \%$ \\
\hline Coal with CCS & 1,650 & $3 \%$ \\
\hline HTGR & 3,344 & $19 \%$ \\
\hline Total & 8,841 & $38 \%$ \\
\hline
\end{tabular}

\subsubsection{Electricity Generation Transformation Costs}

Figure 3-31 shows the capital expenditure required for replacing the coal based electricity generation in Wyoming with the mix of wind, natural gas and HTGR generation discussed in the preceding section. A total expenditure of $\sim \$ 27 \mathrm{~B}$ would be required over the 35 year period shown. The largest expenditures occur between 2025 and 2038 with the incorporation of the HTGR technology into the process plants, adding coal w/CCS to replace Dave Johnston and Naughton and the largest coal plant in Wyoming (Jim Bridger). It should be noted that annual expenditures for the nuclear plants, the coal w/CCS plants and the natural gas plants are exaggerated by showing the full cost of the plant expensed in a single year. The natural gas w/CCS plants would take $\sim 2$ to 3 years to construct; the coal w/CCS plants $\sim 5$ years to construct and the HTGR plants will take up to eight years to construct. The expenditure profile, therefore, would be more spread out. This presentation was used to emphasize the magnitude and profile of the expenditures. As discussed previously at least $70 \%$ of these expenditures would be expected to derive 
from Wyoming resources. Accordingly, these present a significant boost to the Wyoming economy over this $\sim 30$ year period.

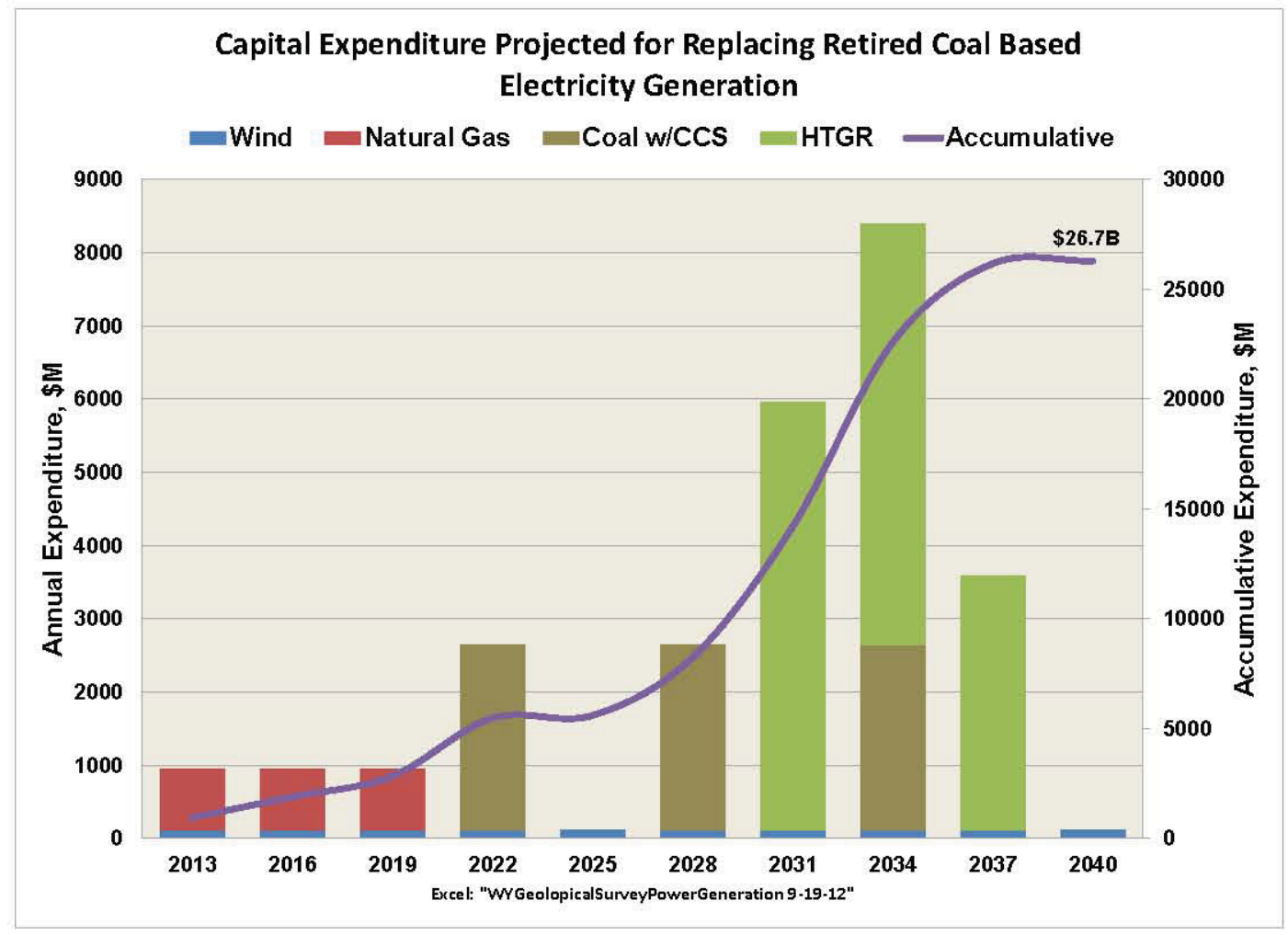

Figure 3-31. Capital expenditure to replace coal-based generation in Wyoming.

Currently Wyoming has one of the lowest electricity rates in the U.S. because the cost of the coal based generation is low. Wyoming has capitalized on this low cost of generation by exporting $60 \%$ of annual generation to other states. As this generation is replaced by other technologies the cost of generation will increase leading to increased costs of electricity for internal consumers and for export. This is illustrated in Figure 3-32. This figure shows the cost of production by all sources (e.g., hydroelectric, petroleum, natural gas, wind, coal w/CCS, HTGR and original coal) as the original coal generation is reduced and the capacity of natural gas, wind, Coal w/CCS and HTGR are increased to replace that generation. The cost of generation for each of these is based on EIA projections for these technologies 2015 and beyond ${ }^{12}$ and from INL analyses of the costs of generation for the HTGR ${ }^{47}$ As shown the projected cost of generation once all coal based generation is retired increases by a little less than a factor of 3 ; bringing the cost of generation in Wyoming close to that in general throughout the U.S. $(\sim \$ 100 / \mathrm{MW}(\mathrm{e})-\mathrm{hr})$. This average value would be expected to increase throughout the U.S. depending on the percentage of current coal-fired generation in the State or on the grid. An earlier INL study ${ }^{48}$ determined that if all coal-fired generation in the U.S. were to be replaced by a mix of renewables and nuclear, the average cost of electricity would increase by $\sim 50 \%$. The large increase in Wyoming would, however, reduce the State's competitiveness on the national market for electricity export. Further analysis is required to determine the full effect of coal-fired generation retirement and develop alternatives to compensate for the increased electricity rates on the Wyoming economy; for example, reducing generation capacity in Wyoming and increasing the production of transportation fuels and chemicals. 


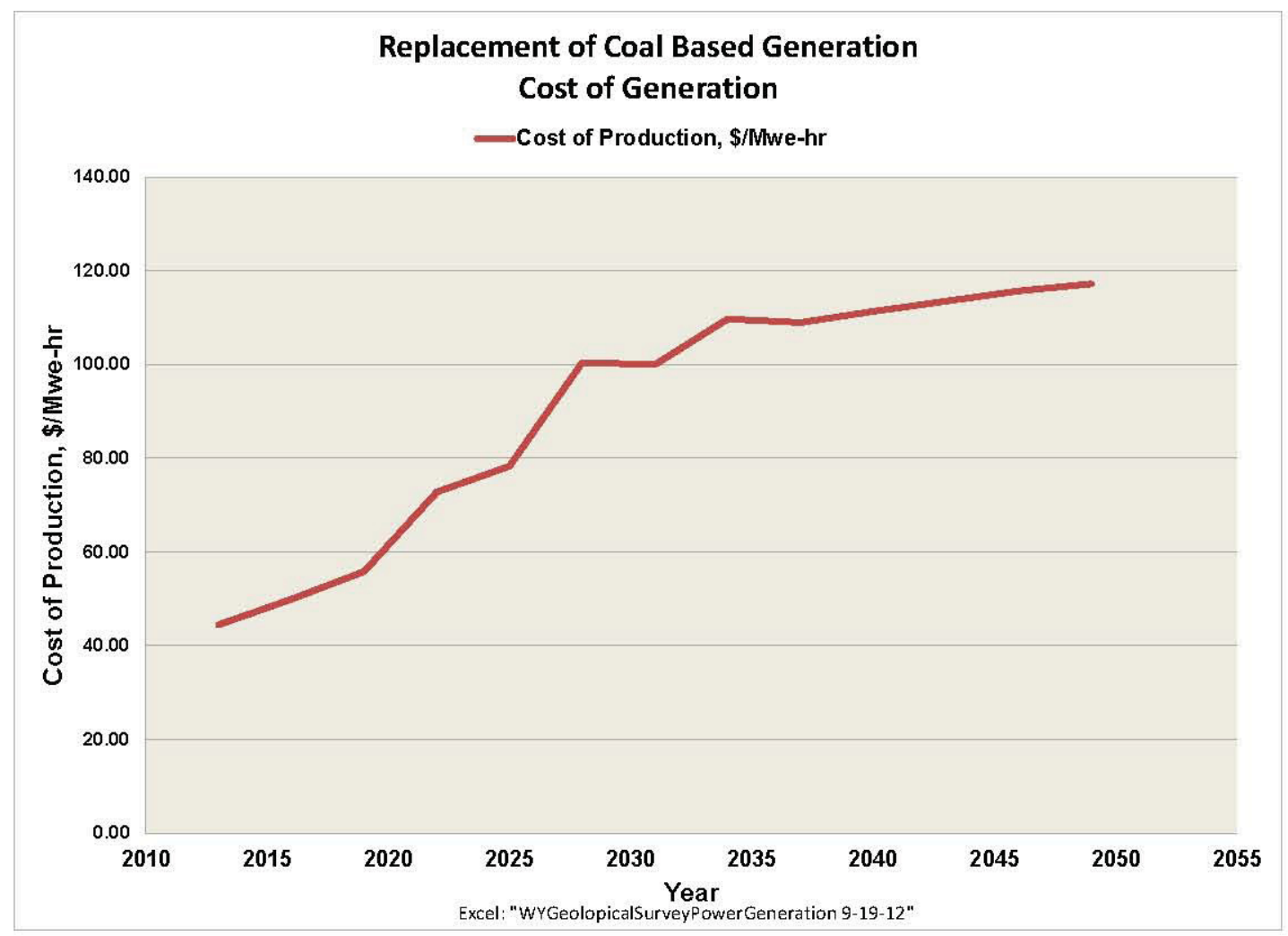

Figure 3-32. Net production and cost of production during replacement of coal-based generation.

\subsection{4 $\quad \mathrm{CO}_{2}$ Emissions Reductions Resulting from Electric Power Industry Transformation}

An important outcome of the transformation of the electricity generation sources is a net reduction in the $\mathrm{CO}_{2}$ emissions associated with electricity generation in Wyoming. The reductions accrue from retirement of existing coal based plants that have the highest emission characteristics of the alternative generation technologies ( 0.97 million metric tons of $\mathrm{CO}_{2}$ per billion kilowatt hour generated [mt/Bkwehr]) and replacing them with technologies that have no emissions (e.g., nuclear). Because there is no definitive analysis of the emissions characteristics of the CCS technologies it has been assumed for analysis purposes that these technologies will result in no emissions. This is clearly uncertain and future evaluations of replacing the original coal generation will have better information to include this factor in the decision on which technologies to use. On this basis the original emissions of 37 million metric tons per year ( $\mathrm{mt} /$ year) attributed to electricity generation in Wyoming are reduced to zero. Over the 27 years of transformation $\sim 318 \mathrm{mt}$ of $\mathrm{CO}_{2}$ emissions are avoided.

\subsection{Composite Effect of Developing a Carbon Conversion Industry and the Electric Power Industry Transformation}

As shown in previous discussions the deployment of a notional carbon conversion industry would have a positive effect on the Wyoming economy by providing a continuing demand for indigenous coal and natural gas resources and increasing the value of these resources by transforming them into high value products. The investment in constructing the facilities that would make up this industry would also add value to the GDP during construction and the construction activity and operation of the facilities will provide jobs. The same is true of the investment required to transform the electricity generation sources in 
Wyoming. During construction of the new generation the investment would add value to the GDP and would create jobs on the plant sites. Figure 3-33 shows the projected contributions from these two initiatives in comparison of what would be projected for the Mining industry if no action is taken. The projections of the GDP contribution of the mining industry without the carbon conversion industry assumes a steady reduction in coal production to a production level in 2040 less than $50 \%$ of 2011 production, a steady production rate of $\sim 6 \mathrm{Bcf} /$ day of natural gas through 2040 and increases in the price of natural gas consistent with the EIA reference case through $2035 .^{18}$

As shown in Figure 3-33, the contributions of the carbon conversion industry developed herein to the GDP are projected to be significant. The maximum contribution projected during deployment is $\sim 8 \%$ of the Wyoming GDP in 2011; the long term contribution is $\sim 6 \%$ of the 2011 GDP. These are also substantive on a real dollar basis and support the State objectives of maintaining the Mining industry and providing a viable sustainable mix of electricity generation over the long term. Also, it should be noted that the economic multiplier effects of business growth (e.g., real estate, retail sales growth) that accompanies such industry development and transformation have not been included.

An important consideration in evaluating the long term effect is that this report does not attempt to quantify the extent to which the carbon conversion industry may continue to grow beyond the notional assumptions evaluated. As an example, if the carbon conversion industry were to continue to grow to utilize the entire current coal production in Wyoming, the effect on the GDP would be several orders of magnitude larger. Long term planning in the State would be well advised to include such considerations in evaluating the overall benefit to Wyoming of developing and growing such an industry.

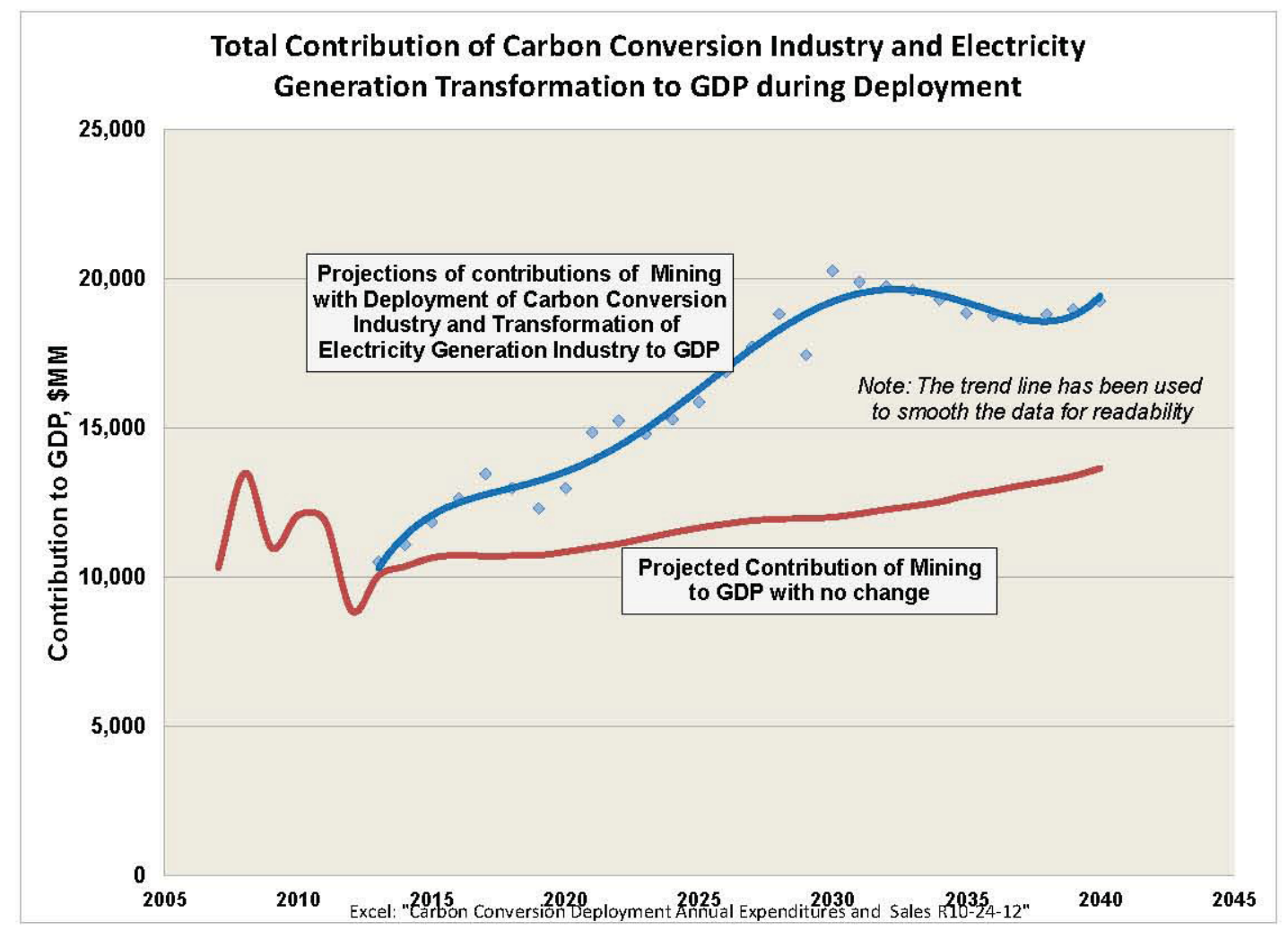

Figure 3-33. Contributions of carbon conversion industry and electricity generation transformation to the Wyoming GDP. 


\section{INFRASTRUCTURE DEVELOPMENT}

There are multiple needs and opportunities for infrastructure expansion and development to support deployment of a carbon conversion industry incorporating nuclear energy technology and transforming the electric power industry in the Commonwealth. Important examples include:

- Industrial equipment manufacturing capabilities ranging from large pressure vessel material forging and fabrication to digital electronics

- Transportation and distribution capabilities for the feedstock and products produced in the carbon conversion industry

- Education and training capabilities to develop and maintain a technically competent workforce

The extent to which these capabilities are, or become, indigenous to Wyoming is directly a function of the character, size and pace at which a carbon conversion industry is developed and the electric power industry is transformed. Further, whether these infrastructure capabilities are indigenous will be dependent on the incentives offered industry to invest in industrial facilities and the education system in Wyoming. Hence, no attempt is made in this report to quantify the effect of such infrastructure expansion and development on the economy of Wyoming. However, to provide some perspective, if the industrial equipment manufacturing capability needed to accomplish the notional scope of a carbon conversion industry and transform the electric power industry were located in Wyoming, there would be a greater than $30 \%$ increase in the contribution to the GDP compared to that shown above (the economic analyses in this report are based on equipment manufacture occurring outside of Wyoming).

Each of the potential areas of development is addressed in brief in the following.

\subsection{Industrial Equipment Manufacturing}

The following summarizes the features of the key equipment and components for the notional carbon conversion industry and transformation of the electric power industry and the nature of support that is required for their design, construction and operation. There is no attempt in the following to estimate the potential market in each of the following areas; that will be dependent on the strategy used for deployment of the industry. As discussed previously equipment and material costs comprise about $50 \%$ of the plant costs. For the deployment of the initial plant of the carbon conversion industry including the HTGR plant this amounts to about $\sim \$ 900$ million per year during construction. Larger scale expansion of carbon conversion facilities and/or HTGR electricity plants throughout Wyoming would result in much larger annual expenditures. These expenditures for new plants combined with maintaining the plants would require a significant support infrastructure.

\subsubsection{Process Plant Vessels}

In general, the largest pieces of equipment in a synthetic fuels plant are the FT reactor and the gasifier. Of these, the FT reactor designs are the largest. Sasol's Oryx GTL plant in Qatar currently includes the largest FT reactors built to date. Each reactor was designed to produce 17,000 bpd of FT liquids. To achieve this capacity, each reactor is 10 meters in diameter by 60 meters tall. Approximate weight of each reactor is 2,100 tons. A picture of one of the Oryx plant FT reactors during fabrication is shown below: 


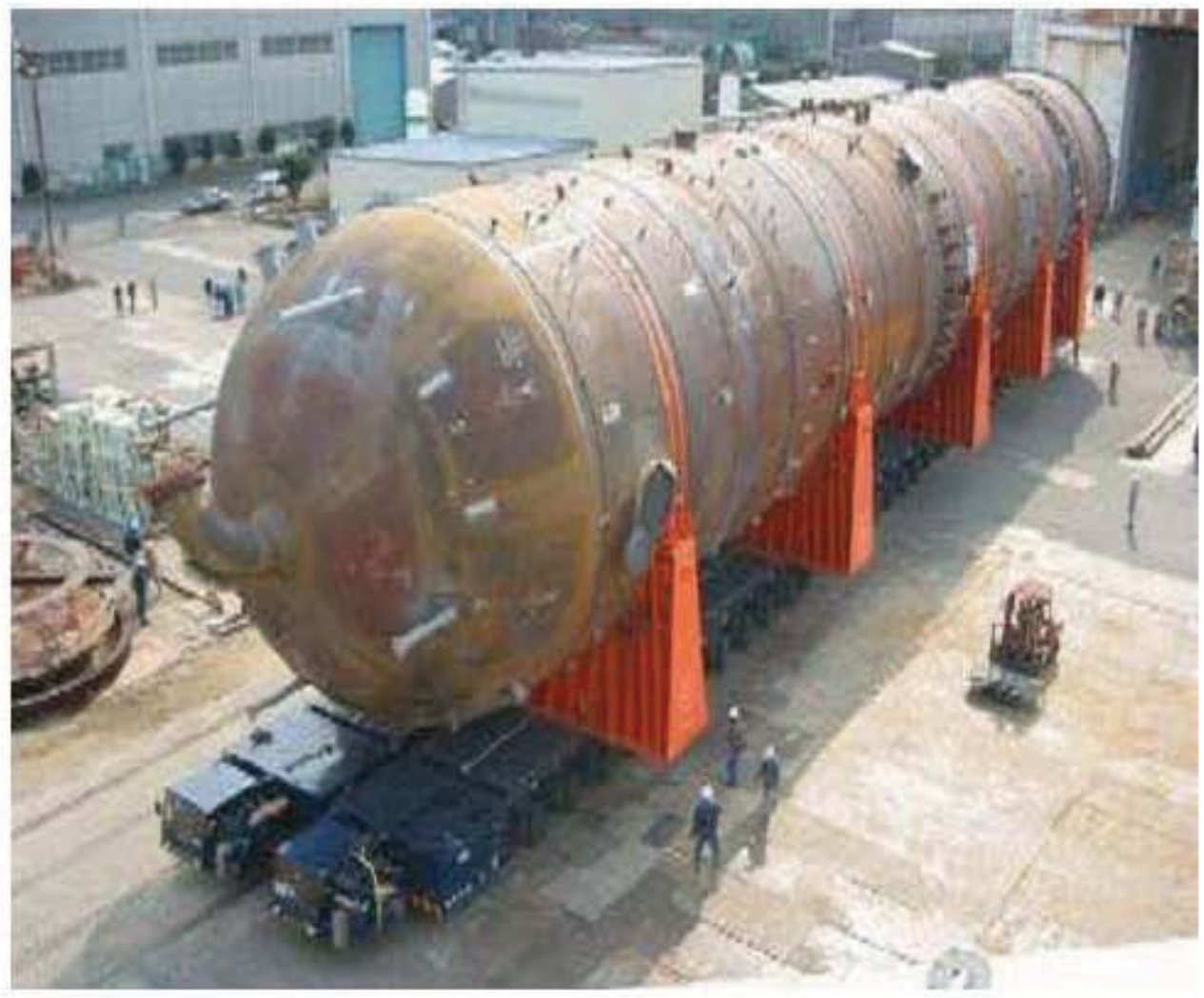

Figure 4-1. Oryx Plant FT reactor.

Gasi fiers can al so be quite large. The GE (Texaco) gasifier installed at Tampa El ectric's Polk Power station can process 2,200 ton/day of coal. This gasifier is approximately 4 meters in diameter. The radiant gas cooler downstream of the gasifier is even larger with a diameter of nearly 5 meters and a height of 30 meters. Weight of the syngas cooler and gasifier combined are around 900 tons. Shell's gasi fier designs are simil arly large. The NUON Power Buggenum pl ant in the Netherlands utilizes a Shell gasifier and can process between 2,000 to 2,500 ton/day of coal. This gasifier has a diameter between 5 to 6 meters and a height of 50 meters. The syngas cooler is also very large with a diameter of 4 meters and a height of 64 meters. A picture of the membrane wall under construction for such a gasifier is shown bel ow (taken from a Shell presentation courtesy of Babcock Borsig Espana, Bilbao, Spain).

With a capacity of nearly 4,000 ton/day of coal throughput, the gasifiers assumed in the INL models are larger than the Polk and Buggenum gasifiers.

In the CTG and CTC processes, the gasoline and olefin synthesis reactors are designed modularly; hence, reasonable sizes for these reactors are maintained by using multiple trains. Methanol synthesis reactors can also be quite large; however, it is possible to keep the di ameter of the methanol synthesis reactor at or bel ow a 6 meter inside diameter and still achi eve a production rate of 5,000 tons/day of methanol. This is true for many commercial methanol reactor designs: Lurgi tubular packed bed reactor, ICI quench reactor, Casale mixed flow reactor, and other common designs. In the coal-to-gasoline (CTG) process models developed herein there are 15 major pumps. In addition to these pumps, numerous other smaller pumps will be required to support the maj or processing units of the plant. Some other large pumps will also be required to support the utility systems. In many critical applications, it will be necessary to install spare pumps to minimize unplanned down time for the plant. Hence, the number of actual pumps in the plant could easily exceed ten times the number of pumps included in the process models developed as part of this study. 


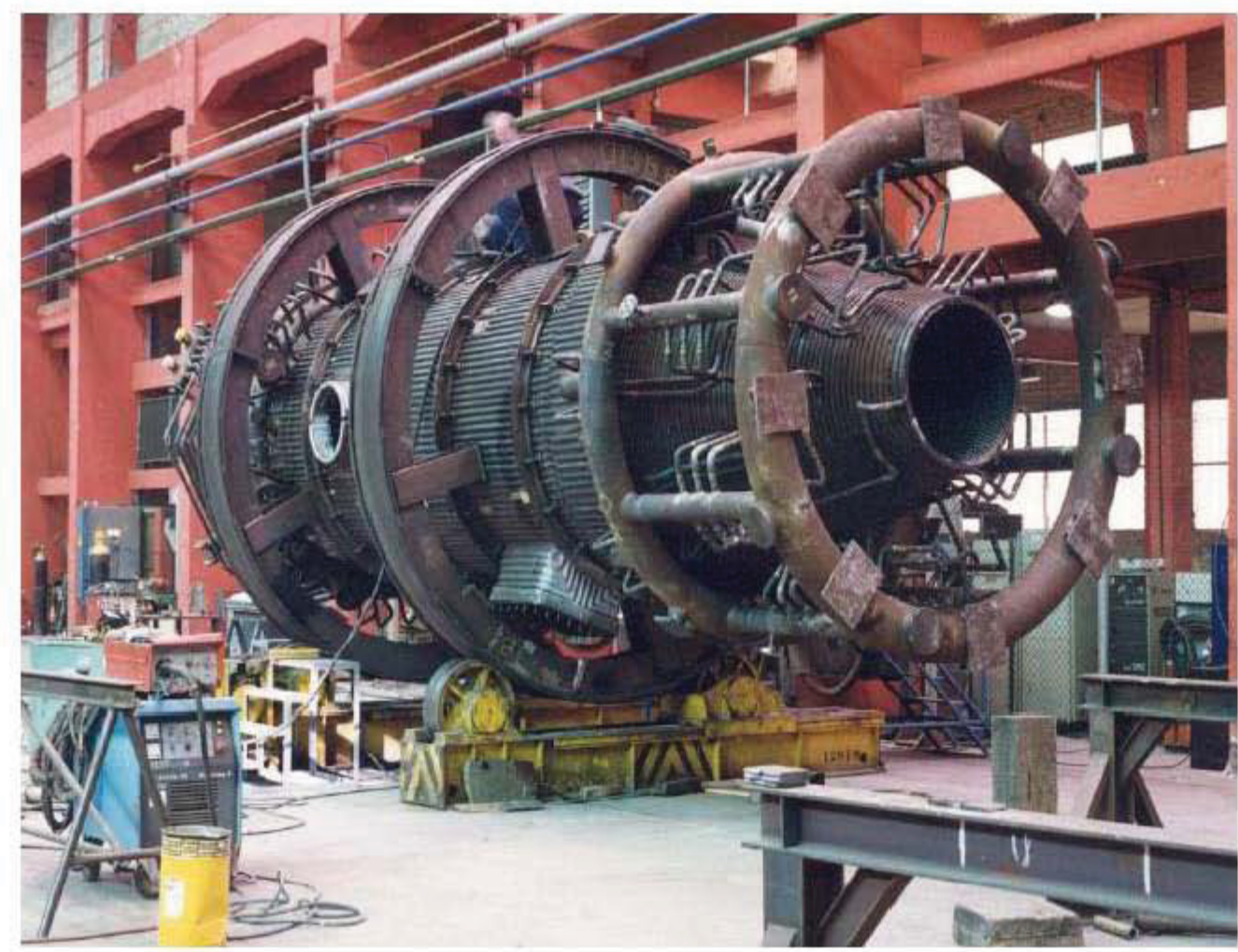

Figure 4.2. Shellgasifier membrane wall.

\subsubsection{Process Plant Pumps, Valves, Piping}

Piping and valves account for a significant fraction of the cost of a synthetic fuels or chemical plant. Typically these costs can range from 18 to $61 \%$ of the FOB equipment cost, which would normally represent about 7 to $15 \%$ of the install ed plant cost. Therefore, the cost associated with piping and valves for such a plant are obviously significant.

\subsubsection{HTGR Major Components}

Seventy-five percent (75\%) of the equipment cost of a HTGR plant is made up of the following components and systems in the order of their relative costs:

Reactor Building

Reactor Vessel

Reactor Initial Core

Reactor Metallic Internals

Reactor Graphite Internals

Reactor Cavity Cooling System

Core Refueling Equipment

Heat Rejection System

Heat Transport System

Power Conversion System. 
The primary system vessels which include the reactor vessel, the crossover vessel and the heat transport system vessel are among the more costly items in the plant. They are also heavy and large and not transportable by rail or road, so unless the plant is located on a major waterway the vessels will be fabricated on or near the plant site. The development of the remote fabrication facility and its operation during construction of the plant is a significant opportunity for a local qualified vessel manufacturer.

Each of the systems is comprised of many valves, blowers (circulators) and pumps that represent a significant fraction of their costs similar to that cited for the process plants.

Additionally, depending on the extent of commitment to nuclear energy, the infrastructure for fabrication of nuclear fuel is an important part of supporting the operation of these plants with expected 80 to 100 year lifetimes. Nuclear energy plant refueling occurs at one year to 18 month intervals.

\subsection{Transport and Distribution Systems}

As the carbon conversion industry is developed, it is important to evaluate the most important markets and the means of transporting the feedstock (coal and natural gas) and transporting and distributing the products, whether by waterways, truck, rail or pipeline. Further, if a distributed configuration for a carbon conversion industry should evolve as described above, a system of pipelines will be required that interconnect the process plants producing synthesis gas and the various process plants that produce synthetic fuels and chemicals.

At the outset, the notional initial natural gas to gasoline plant could utilize existing waterway, rail and truck transport infrastructure. As the carbon conversion industry expands, existing infrastructure is anticipated to be inadequate and planning for production, transport and distribution needs to be accomplished in an integrated manner, with necessary participation by the investing industries and consideration of necessary incentives for investment in an anticipatory manner.

Further, as the electric power generating industry is transformed, the electric transmission system will need modification and enhancement depending on the specific types and location of the new generating plants, and the extent of electric power export that is planned.

\subsection{Education and Training}

A well-educated and trained, technically competent workforce is essential to the successful development of a carbon conversion industry and transformation of the electric power industry to include diverse generating sources. In brief:

- Designing, licensing/permitting and maintaining these industries will require university educated engineering and scientific personnel at both the bachelors and graduate levels

- Construction will require crafts personnel trained and experienced in trades such as welding, pipe fitting, electrical and computer systems

- Plant operations and maintenance will require technician-level training in the respective technologies (e.g., chemical processes; nuclear energy systems; computer systems).

The companies that will invest in, develop and build the process plants and power generation plants could be expected to initially import the management and senior technology personnel. However, typical experience is that the bulk of the industrial workforce for construction, operations and maintenance will need to be developed from within the indigenous population. 


\section{REFERENCES}

1 Idaho National Laboratory, Preliminary Feasibility of Value-added Products from Cogeneration and Hybrid Energy Systems in Wyoming, INL/EXT-12-27249, November 2012.

2 Letter, F. L. Moore (NGNP Industry Alliance) to G.A. Gibbs (Project Director of the NGNP Project), "Forthcoming Meeting on Energy Development Opportunities in Wyoming," December 13, 2011.

3 Letter, Wyoming Governor M. H. Mead to F. L. Moore inviting the Alliance to visit with Wyoming government and industry stakeholders to initiate the collaborative effort, January 13, 2011.

4 Letter, F. L. Moore to M. H. Mead, "Nuclear Concepts - Wyoming and the High Temperature Gas Reactor," January 17, 2011 [Referencing meeting with the Governor and others planned for January 26].

5 Letter, F. L. Moore to Governor M. H. Mead, "NGNP Industry Alliance Meeting," January 30, 2011 [Thanking Governor Mead and Wyoming government and University personnel for their participations in the meetings of January 26, 2011].

6 INL/EXT-12-27626, Overview of Energy Development Opportunities for Wyoming.

7 TEV-672, "HTGR Integration - Coal and Gas to Liquids Production," Rev 3, Idaho National Laboratory, April 27, 2012.

8 TEV-667, "Nuclear-Integrated Methanol-to-Gasoline Production Analysis," Rev. 2, May 15, 2010.

9 TEV-1567, "Nuclear Integrated Methanol-to-Olefins Production Analysis," July 20, 2012.

10 Shell, "The Shell Coal Gasification Process for the U.S. Industry," Gasification Technologies Conference, Washington D.C.,October, 2004; and Shell, "Shell Coal Gasification Process Using Low Rank Coal," Gasification Technologies Conference, San Francisco, CA, October 2005.

11 h-tec Energy Technology Projects, "Technology Fact Sheet," Bergius-Pier Process (1) 1924-1945," April 2006.

12 Sivakumar Vasireddy, Bryan Morreale, Anthony Cugini, Chunshan Song, and James J. Spivey, "Clean liquid fuels from direct coal liquefaction: chemistry, catalysis, technological status and challenges," Energy and Environmental Science, Received 27 May 2010, Accepted 1st September 2010 .

13 American Fuels Coalition, "Chinese Direct Coal Liquefaction Project Profitable (Reuters)," posted on September 8, 2011.

14 Ken K. Robinson, "Reaction Engineering of Direct Coal Liquefaction," Energies 2009, 2, 976-1006; doi:10.3390/en20400976, Received: 14 October 2009, Accepted: 23 October 2009/Published: 29 October 2009. 
15 Gasifipedia, Applications of Gasification - Coal-to-Liquids, Direct Liquefaction Processes, NETL, U.S. Department of Energy.

16 Green Car Congress: "Headwaters Inc and Axens Form Direct Coal Liquefaction Alliance," January $21,2010$.

17 West Virginia Coal Association Chevron Improves Direct Coal Liquefaction| Research \& Development, United States Patent: 4379744, March 26, 2012.

18 DOE, Energy Information Agency, Annual Energy Outlook 2012, April 2012.

19 Varrin, R., et al., NGNP Hydrogen Technology Down-Selection Results of the Independent Review Team (IRT) Evaluation, R-6917-00-01, Rev. 0, July 31, 2009.

20 Section 202 of the CAA, GHGs from stationary sources are currently controlled under the authority of Part C of Title I of the Act.

21 DOE/NETL 2009/1346, "Development of Baseline Date and Analysis of Life Cycle Greenhouse Gas Emissions for Petroleum-Based Fuels."

22 J. J. Dooley (Lead Author), R. T. Dahowski, C. L. Davidson, M. A. Wise, N Gupta, S. H. Kim, E. L. Malone, Carbon Dioxide Capture and Geologic Storage, A Core Element of a Global Energy Technology Strategy to Address Climate Change, A Technology Report from the Second Phase of the Global Energy Technology Strategy Program, April 2006

23 First Commercial-Scale CCS Project Launched In Oil Sands, Thursday, September 6, 2012, The Energy Daily.

24 "In Alabama, going after oil with a coal plant's $\mathrm{CO}_{2}$, " Inside Energy, September 10, 2012.

25 "Carbon injections could revive Midwestern oil fields," Inside Energy, May 21, 2012.

26 Allan Ingelson, Anne Kleffner, and Norma Nielson, "Long-Term Liability for Carbon Capture and Storage in Depleted North American Oil and Gas Reservoirs - A Comparative Analysis," University of Calgary, Energy Law Journal, Vol 31.43, 2010.

27 Semere Solomon, Beate Kristiansen, Aage Stangeland, Tore A. Torp, Olav Kårstad, "A Proposal of Regulatory Framework for Carbon Dioxide Storage in Geological Formations," January, 2007, The Bellona Foundation, Oslo, Norway and Statoil Research Centre, Trondheim, Norway. Prepared for International Risk Governance Council Workshop, March 15-16, 2007, Washington, DC.

28 M.A. de Figueiredo, "The Liability of Carbon Dioxide Storage," MIT, Energy Delta Institute, Energy Business School, February 2007.

29 Alexandra B. Klass, Elizabeth J. Wilson, "Climate Change and Carbon Sequestration: Assessing a Liability Regime for Long-Term Storage of Carbon Dioxide," University of Minnesota, Emory Law Journal, Vol 58, 2008. 
30 Elizabeth J. Wilson (University of Minnesota) and Mark A. de Figueiredo (MIT),The Impact of Liability on the Adoption and Diffusion of Carbon Capture and Sequestration Technologies.

31 Analysis of Liability Regimes for Carbon Capture and Sequestration: A Review For Policymakers, Energy Policy Institute, Center for Advanced Energy Studies, December 2011.

32 Topic Paper \#17, "Carbon Capture and, Sequestration (CCS)," Working Document of the National Petroleum Council Global Oil \& Gas Study, made available July 18, 2007.

33 Expert Workshop on Financing Carbon Capture and Storage, Barriers and Solutions, International Energy Agency, Greenhouse Gas R\&D Programme, Report Number 2007/9, July 2007.

34 "Carbon Capture and Storage," Legal and Regulatory Review, Edition 2, International Energy Agency, May 2011.

35 Quality Guidelines, for Energy System Studies, "Estimating Carbon Dioxide Transport and Storage Costs," DOE/NETL-2010/1447, March 2010.

36 Secure Energy Paducah Gasification Plant, State of Kentucky, Division for Air Quality, "Permit Application Summary Form," Completed by: Philip T. Jarboe, P.E., 4/14/2011.

37 Chisholm Energy, LLC, State of Kentucky, Division for Air Quality, "Permit Application Summary Form," Completed by: Andrew True, 4/20/2011

38 Buffalo Creek Energy, LLC, State of Kentucky, Division for Air Quality, "Permit Application Summary Form," Completed by: Andrew True, P.E., 4/21/2011

39 Jeremy Fugleberg, "While DKRW plans Wyoming coal-to-gasoline plant, other firms switch to natural gas," Star-Tribune, trib.com, Posted: Sunday, March 25, 2012 9:00 am.

40 DKRW Plant -- http://www.uwyo.edu/eori/ files/co2conference11/bob $\% 20$ \%20wyoming $\% 20$ eor $\% 20$ conference $\% 20$ medicine $\% 20$ bow $\% 20$ update $\% 207.13 .2011 \% 20 \mathrm{v} \% 201.0 . \mathrm{p}$ df. The permit application is here: http://deq.state.wy.us/out/downloads/MBFP ISA Permit Application 09-17-07 Final.pdf.

41 EPA 40 CFR Part 60 [EPA-HQ-OAR-2011-0660; FRL- ] RIN 2060-AQ91, Standards of Performance for Greenhouse Gas Emissions for New Stationary Sources: Electric Utility Generating Units, 3/27/12; and

EPA, "National Emission Standards for Hazardous Air Pollutants for Major Sources: Industrial, Commercial, and Institutional Boilers and Process Heaters: Final Rule," 76 FR 15608\& 76 FR 155543/21/11 (so-called Boiler MACT Rule).

42 EPA-452/R-12-001,March 2012, Regulatory Impact Analysis for the Proposed Standards of Performance for Greenhouse Gas Emissions for New Stationary Sources: Electric Utility Generating Units, U.S. Environmental Protection Agency, Office of Air Quality Planning and Standards, Health and Environmental Impacts Division, Research Triangle.

43 Clean Energy Standard Act of 2012 (BCES12). 
44 EIA, Today in Energy, May 4, 2012.

45 The 2011 Concise Guide to Wyoming Coal, Wyoming Mining Association.

46 June 15, 2012 4:33 pm • Associated Press, Cheyenne, Wyo., "Gov. Matt Mead said Friday that he returned from China this week confident that Wyoming should continue exploring how to export coal to meet that nation's growing demand."

"Arch is expanding international coal sales with dedicated seaborne port capacity," Arch Coal.com

"Arch Coal Completes Acquisition of International Coal Group." ST . LOUIS, June 15, 2011 -- Arch Coal, Inc.

"Powder River Basin coal, once limited to domestic consumption, is becoming an international commodity. This shift may prove lucrative for coal companies that expect higher prices in foreign markets. And with declining domestic coal consumption in the U.S., it's a move that Wyoming officials view as necessary to sustain its mining industry and the $\$ 1$ billion it generates in state and local revenue annually.,"WyoFile, May 22, 2012

47 INL/EXT-11-23282, "Next Generation Nuclear Plant Project Evaluation of Siting an HTGR Cogeneration Plant on an Operating Commercial Nuclear Power Plant Site," October 2011.

48 INL/EXT-09-17436, “Transforming the U.S. Energy Infrastructure," July 2010. 


\section{Appendix A}

\section{Site Evaluation Data Requirements}




\section{Appendix A Site Evaluation Data Requirements}

The following summarizes information requested to complete evaluation of options for the long term use of HTGRs in Wyoming including the technical and economic viability and potential sites for locating carbon conversion plants using coal and/or natural gas feedstock. Conversions include production of transportation fuels (e.g., diesel, gasoline), chemical plant feedstock and chemicals (e.g., ethylene). Energy supply to the plants are to minimize production of greenhouse gas emissions, provide long term energy at stable prices with reliability of supply to support high plant capacity factors. Energy supplies may include nuclear, wind, biomass or other, individually or in combination.

1. Location, provide map showing potential sites and surrounding area within 10 miles

2. Available Area of sites, acres

3. Approximate shape and dimensions of the sites (e.g., rectangular X (feet or miles) by Y (feet or miles) Provide plat if available.

4. Topography and condition of sites (e.g., flat, hilly, wet, Greenfield, Brownfield, current or prior application, existing structures, chemical contamination, radiological contamination)

5. Current owners (e.g., private, local government, federal government) and where known the conditions for making the property available for commercial purposes for locating a nuclear energy facility integrated with a carbon conversion facility (e.g., sale, lease)

6. Potential available additional acreage (e.g., property adjacent to sites that could be purchased if additional area is required)

7. Useable significant water availability / proximity (e.g., rivers, lakes, etc. to supply large cooling water needs in a closed loop configuration)

8. Ground or other water availability (e.g., potable water, small cooling and usage demands from wells, local municipal water supply)

9. Ground surface and sub-surface geology; provide survey and bore data if available.

10. Atmospherics (e.g., rain, snow, wind, tornadoes) and atmospheric factors affecting dispersion if available

11. Area seismology

12. Area flood potential

13. Large component transportation facilities and access (e.g., large roads and interstates, railways, navigable waterways with access to principal US waterways (rivers, lakes, ocean)

14. Interfaces with regional grid
a. Full Capacity
b. Available Capacity
c. Proximity
d. Voltage and voltage control
e. Regional utility(s)

f. Opportunity for increase in capacity and/or routing of new or upgraded transmission capacity

15. Nearest population 
a. Name

b. Proximity

c. Nature of population (e.g., rural farms, small town, major city)

16. Industrial facilities, airports, airfields, military bases, railways, major roads, tank farms, etc. within 5 miles of the site; show on location map (item 1)

17. Labor availability

d. Construction

e. Operation

18. Construction material availability (e.g., would a cement plant need to be installed on the site during construction or is concrete and other building materials readily available from local sources)

19. Natural gas availability

20. Pipeline access for product transport

21. Tanker truck and rail facilities access for product transport

22. Shipping access

23. Potential for carbon storage, sequestration and sale as a product

24. Wind generation

f. Existing farms near the potential sites

g. Wind generation potential at the site

h. Transmission line availability to wind site or potential for construction of new lines

25. Solar generation

i. Existing generation near the potential sites

(1) Photovoltaic

(2) Thermal (Concentrated Solar Production)

j. Solar generation potential at the site

k. Transmission line availability to the solar site or potential for construction of new lines

26. Coal availability / proximity

1. Coal resource map (geological survey)

m. Specific Site:

(1) Average production, short tons/day

(2) Peak production, short tons/day

(3) Distance to mine mouth, miles

(4) Transportation means (e.g., railcar, truck, conveyor)

27. Coal Proximate Analysis

n. Moisture, $\%$

o. Fixed Carbon, $\%$ 

p. Volatile Matter, $\%$
q. Ash, \%

28. Coal Ultimate Analysis

r. Ash, \%

s. Carbon, $\%$

t. Hydrogen, $\%$

u. Nitrogen, $\%$

v. Chlorine, \%

w. Sulfur, \%

x. Oxygen, $\%$

29. Sulfanal Analysis

y. Pyritic, \%

z. Sulfate, $\%$

aa. Organic\% 
Appendix B

High Temperature Gas-cooled Reactor Technology and Safety Basis 


\section{Appendix B \\ High Temperature Gas-cooled Reactor Technology and Safety Basis}

\section{B-1. Nuclear Heat Supply System}

The high temperature gas-cooled reactor (HTGR) is helium cooled, with a graphite moderated reactor core and robust ceramic fuel. The HTGR nuclear heat supply system (NHSS) is comprised of three major components: the helium cooled nuclear reactor, a heat transport system, and a cross vessel that routes the helium between the reactor and the heat transport system. The NHSS supplies energy in the form of steam and/or high-temperature fluid that can be used for the generation of high efficiency electricity and to support a wide range of industrial processes.

The NHSS design is modular with module ratings from 200 to $625 \mathrm{MW}(\mathrm{t})$, reactor outlet temperatures from 700 to $850^{\circ} \mathrm{C}$ and heat transport systems that provide steam and/or high temperature fluids. The range of power ratings, temperatures and heat transport system configurations provides flexibility in adapting the modules to the specific application.

As shown Figure B-1, the three major components are enclosed in metallic pressure vessels that make up the primary helium circuit. Under normal operating conditions helium flow is maintained by the main circulator and heat is transferred from the reactor to the heat transport system (shown as the steam generator in Figure B-1) and then to an energy conversion system (e.g., a steam turbine generator) that interfaces with the

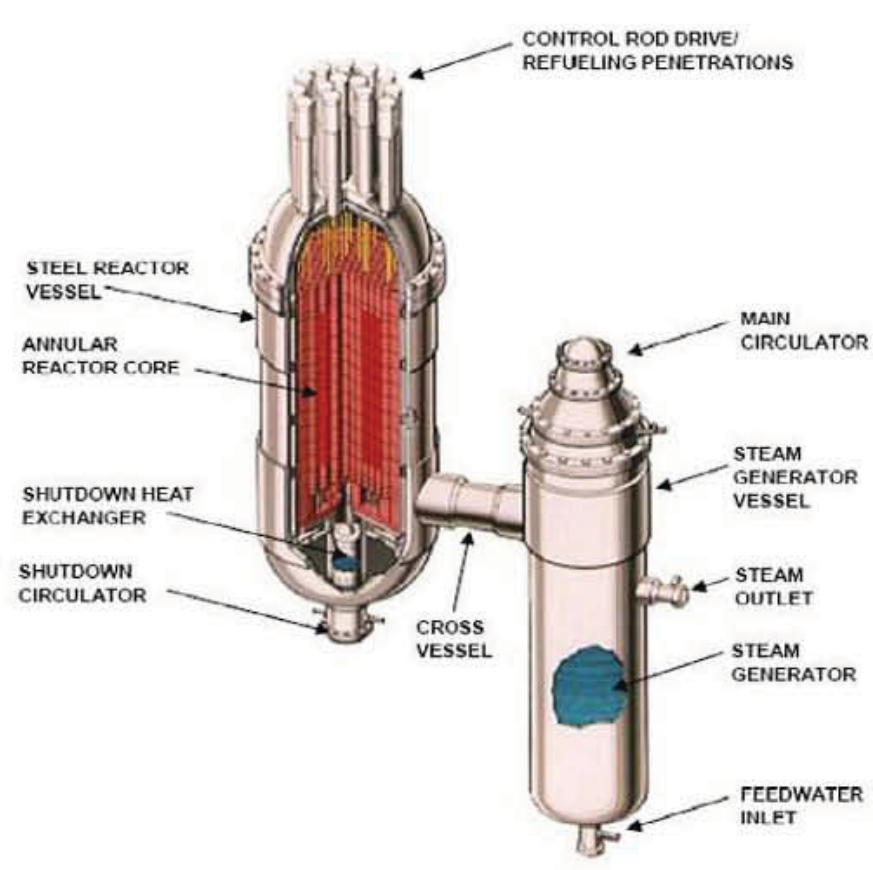

Figure B-1. HTGR Reactor and HTS. industrial process and/or the electrical grid. When the reactor and plant are shut down for maintenance or refueling, reactor temperature is maintained by the shutdown cooling system. In the event the heat transport system or shutdown cooling system are not operational (e.g., on loss of all electrical power), reactor temperature is maintained via a radial conduction path through the reactor pressure vessel to an annular cavity formed between the reactor pressure vessel and the reactor building structure (silo) - the so-called reactor cavity. This cavity can be actively cooled or cooled by natural circulation. In the event neither of these reactor cavity cooling mechanisms is operational, conduction through the reactor building structure to the ground is sufficient to maintain reactor temperatures within acceptable limits.

Several different plant configurations have been developed as part of the Idaho National Laboratory (INL) Next Generation Nuclear Plant (NGNP) Project and in prior work conducted by the Department of Energy (DOE). These are described in References 1 thru $6 .{ }^{1,2,3,4,5,6}$ 


\section{B-2. HTGR Safety Basis}

The principal design objective of the NHSS is to ensure that there is no internal or external event that could lead to substantive rel ease of radioactive material beyond the boundaries of the plant and endanger the safety of the public. This reduces the complexity and extent of emergency planning and response and facilitates use of the HTGR technology in industrial applications.

This objective is met by provision of multiple barriers to the rel ease of radioactive material from the plant that provide retention of those material s, thereby meeting associated regulatory requirements and assuring the protection of public health and safety and the environment under all normal, abnormal, and accident conditions, whether affected by internal (e.g., loss of all electrical power, a leak in a steam generator tube) or external events (e.g., earthquakes, flooding tornadoes). These barriers include:

- A robust carbon-based fuel structure that forms the principal barrier to release and transport radioactive material. As shown in Figure B-2, the fuel is made up of minute ( $\sim 1 \mathrm{~mm}$ diameter) particles comprised of multiple ceramic layers surrounding the uranium based kernels. These ceramic layers are designed to retain the products of nuclear fission and limit release to the fuel el ements and the helium coolant.

- Distribution and containment of the fuel particles in fuel elements (compacts or spheres) of carbon based material.

- Enclosure of the fuel elements in a large graphite core.

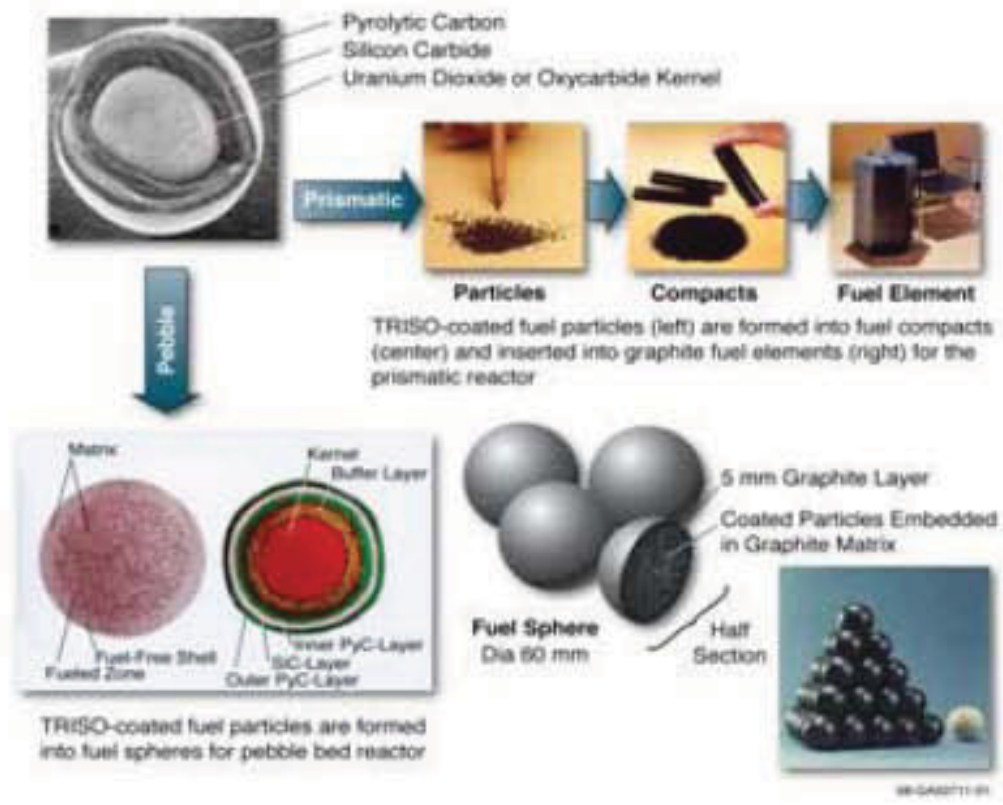

Figure B-2. HTGR TRISO fuel.

- Enclosure of the core structure and the helium coolant system in American Society of Mechanical Engineers (ASME) Nuclear Grade metallic vessels meeting ASME Code requirements for nuclear components.

- Enclosure of the NHSS vessels in a robust underground reactor building.

Additional reactor characteristics that prevent release of radioactive materials include:

- Extreme high temperature capability of the ceramic coated and carbon-based fuel and core structure.

- No metal or water in the fuel and core structure that can, in combination, chemically react to form hydrogen or increase pressure.

- Plant design features limit intrusion of air or water so that the reactor remains shutdown and containment of radioactive materials is maintained.

- Chemically inert helium coolant.

- Inherent nuclear and heat transfer properties of the reactor design that are continuously functional to ensure that the fuel temperatures remain within acceptable limits under all conditions. 
- Inherent properties of the reactor core that regulate nuclear power so no electrical power, coolant flow, or any other active systems or operator actions are required to limit nuclear power levels and fuel temperatures under any condition as shown in Figures B-3 and B-4.

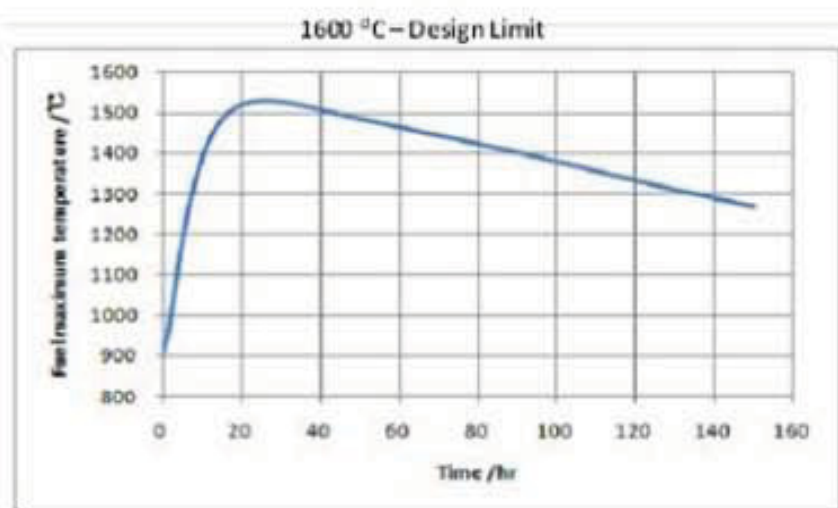

A loss of flow test on an operat ing Chinese test reactoriHTR10) with no control system action - reactor power reduced as a consequence of the $t$ emperat ure increase. Measured temperatures are shown for the fuel as a function of $t$ ime aft er flow is shut off. Core, moderator and reflector, core barrel and react or pressure vessel temperatures are shown at the peak fuel temp. temtemperat ure.

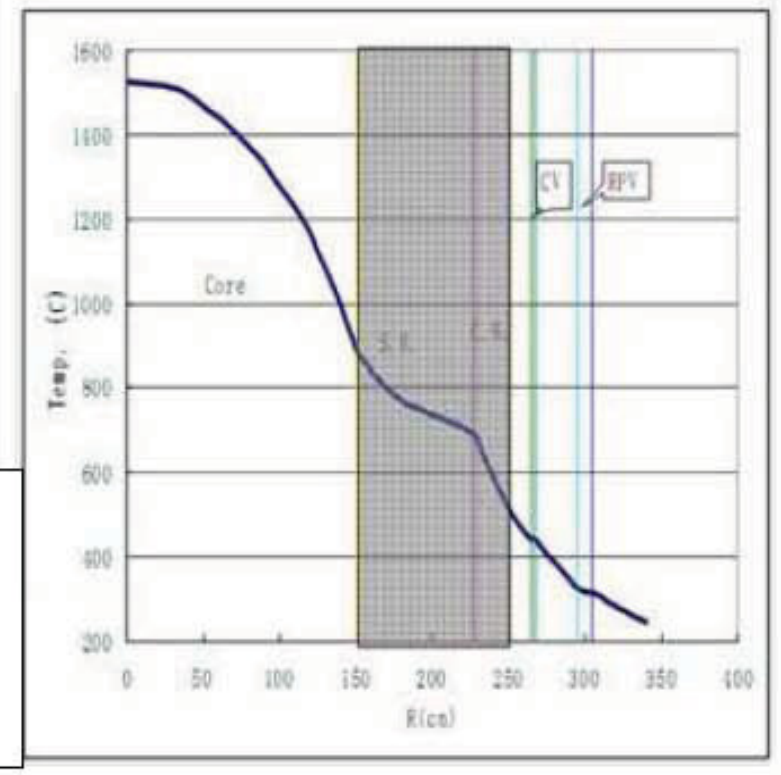

Figure B-3. Demonstration of response to loss of flow accident.

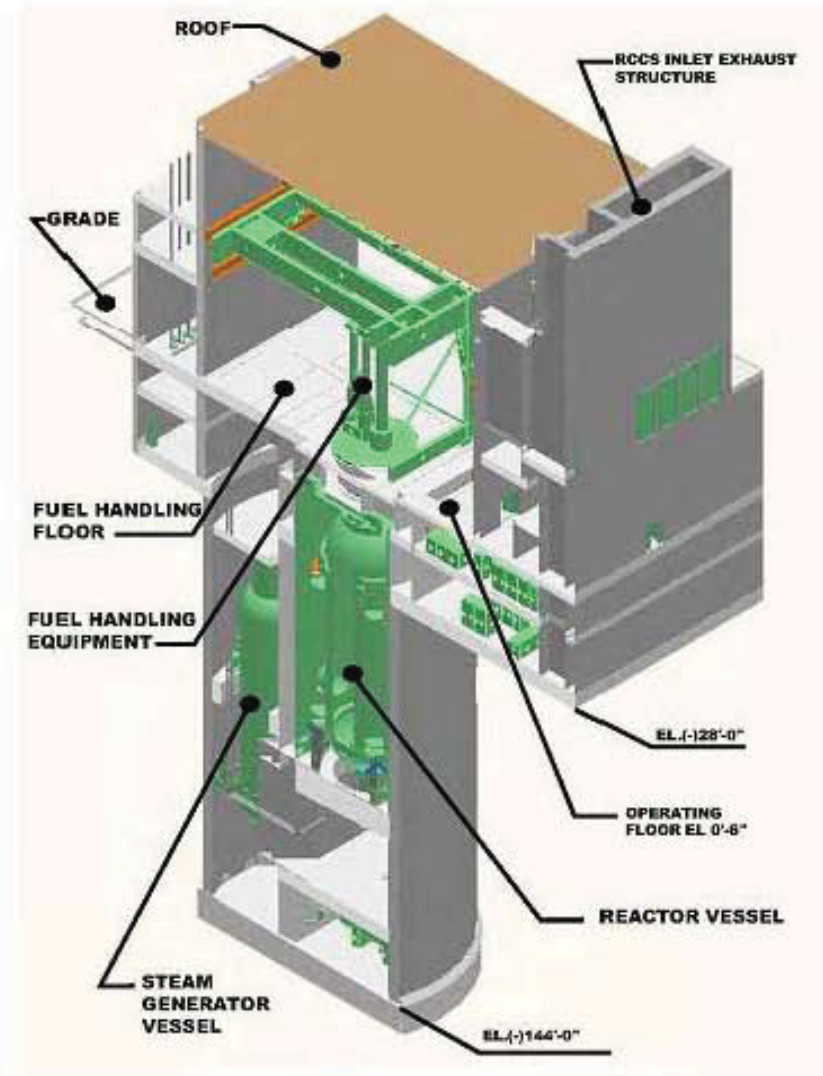

Figure B-4. Typical reactor building. 
- Reactors and heat transport systems are located underground in reinforced concrete silos reducing response to earthquakes and providing a natural heat transfer path from the core, through the reactor pressure vessel, into the silo, and ultimately to the passive reactor cavity cooling system under loss of all forced cooling conditions. If the reactor cavity cooling system is unavailable, heat transfer to the ground is sufficient to maintain fuel temperatures in the acceptable range.

- The graphite core has the ability to absorb large quantities of heat. It takes hours or days to reach peak accident temperatures, independent of whether active cooling systems are working or not.

- The heat transfer path from the core to the reactor cavity cooling system and to the ground is continuously functional, making it available independent of the plant condition.

\section{B-3. Spent and Used Fuel Storage}

- Spent and used fuel is stored in casks or tanks in underground vaults that can be cooled by naturally circulating air as shown in Figure B-5.

- Active systems are not required to maintain acceptable temperatures of stored spent or used (defined as not completely used but removed from the core for maintenance) fuel because of low retained energy and robust carbon based fuel material.

- Carbon based material used for the fuel and fuel elements facilitates long term stable storage

\section{B-4. Status and Path Forward}

The design of the NGNP HTGR Demonstration Plant has not progressed beyond the pre-conceptual design work completed in FY 2007 and the beginning of conceptual design work performed by General Atomics for the DOE in FY 2010. Design

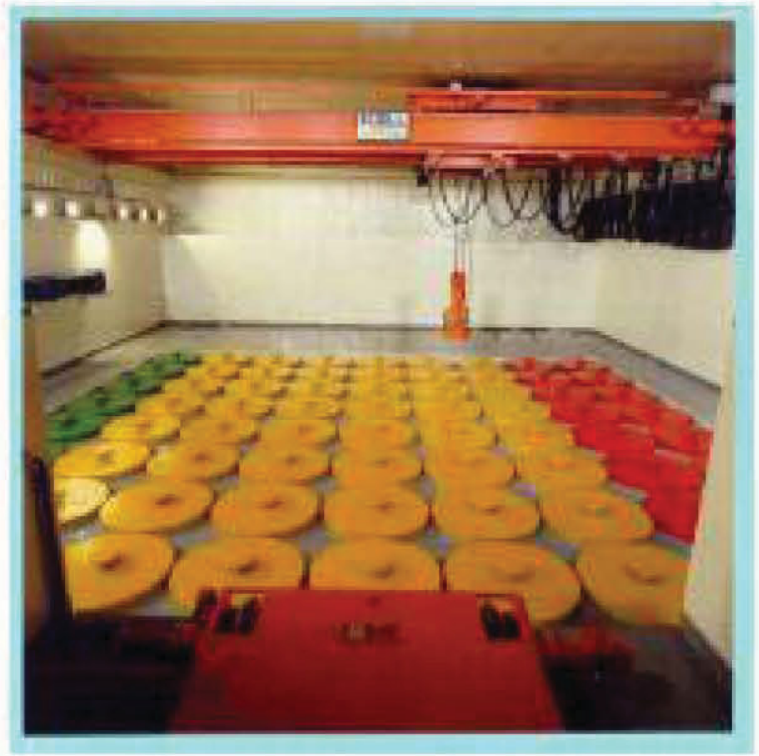

Figure B-5. Spent fuel storage. work was halted by the DOE in early 2008 in anticipation of initiation of the public-private partnership. This partnership has not been formed and is not likely to be formed, if at all, until late 2012 .

The safety basis of the HTGR has been developed and described in detail in several white papers submitted to the Nuclear Regulatory Commission for review. These white papers cover the elements described above and the mechanisms that are being executed to confirm their performance over all possible normal, abnormal, and accident conditions. The following documents provide design descriptions for HTGR plants and the safety basis of the HTGR technology.

\section{B-5. References}

1 INL, Next Generation Nuclear Plant Pre-Conceptual Design Report, INL/EXT-07-12967, Rev. 1, November 2007.

2 General Atomics, Next Generation Nuclear Plant (NGNP) Prismatic HTGR Conceptual Design

Project, Conceptual Design Report - Steam Cycle Modular Helium Reactor (SC-MHR)

Demonstration Plant, NGNP-R00016, Rev. 1, July 15, 2011. 
3 AREVA NP Inc., Pebble Bed Reactor Plant Design Description, 12-914697-000, January 31, 2011.

4 AREVA NP Inc., Pebble Bed Reactor Technology Readiness Study, document 12-9151714-000, January 31, 2011.

5 AREVA NP Inc., Pebble Bed Reactor Scoping Safety Study, 12-9149863-000, January 31, 2011SCMHR Conceptual Design Report.

6 INL, Basis for NGNP Reactor Design Down-Selection, INL/EXT-10-19565, August 2010. 


\section{Appendix C}

\section{NGNP Industry Alliance Limited}




\title{
Appendix C NGNP Industry Alliance Limited
}

\begin{abstract}
ABOUT NGNP
Member companies have joined in this alliance with the primary purpose to promote the development and commercialization of High-Temperature Gas-Cooled Reactor (HTGR) technologies. Our alliance represents the interests and views of our members that intend to mutually support and direct project plans to design, build, operate and use the HTGR technology. We provide a forum and focus to communicate industry needs and requirements and work in concert with the Idaho National Laboratory and others to seek out and promote industrial uses for HTGR technologies within the United States, North America and other continents around the world.

HTGR technology offers a major opportunity to stabilize historically volatile prices for premium fossil fuels and provide a new energy option to provide high temperature process heat for industrial applications. Stabilizing energy costs will encourage a return of process industry facilities to the U.S. from offshore locations where lower and more stably priced fuels and feedstocks have been available. As conventional fossil fuel supplies become more limited in the future due to supply or regulatory restrictions, HTGRs promise to provide new sources of hydrogen and ways to shift chemical and fuels production to new feedstocks with reduced green-house gas (GHG) emissions.

Commercialization of HTGR technology is essential to the National interests in achieving the evolving environmental and energy policy goals. HTGR technology offers benefits including: 1) Reduced GHG through large scale displacement of premium fossil fuels in a wide range of industrial and commercial applications; 2) Reduced reliance on imported oil and gas supplies as industry fuels; 3) Extending life of domestic oil and natural gas supplies as strategic assets for transportation fuels until alternatives become viable technically and economically; 4) Sustainable expansion of American industrial manufacturing capabilities for energy intensive industries; and 5) Job creation within the U.S. supplying materials and equipment to construct and operate HTGR-based industrial infrastructure.
\end{abstract}

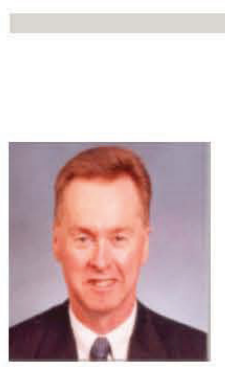

\section{NGNP Industry Alliance Officers}

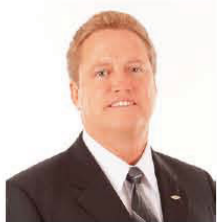

Donald Halter, Executive Director I executivedirector@ngnpalliance.org Don is currently Manager of Business Development for ConocoPhillips. He has over 32 years of global energy industry experience with commercial and operating background in crude oil, natural gas, refined products, heavy oil, biofuels, coal, LPG, heavy oil and management consulting. Mr. Halter holds a B.A. in Economics from the State University of New York, Geneseo and a Master of Business Administration, Finance from the Wharton School, University of Pennsylvania. He has held a Commodity Futures Trading Commission Series 3 license for futures and options trading (inactive status).

Jeff Jarrell, Vice-Chair (Executive Director-Elect) vicechair@ngnpalliance.org Jeff is currently the Technology Center Director for Energy \& Climate Change at The Dow Chemical Company. In his role, he is responsible for our Energy Systems Technology Center and Dow's Global Improvement Organizations - managing energy process safety requirements, technical support of plant/site energy operations, technology development and capital projects implementation in energy-related technologies. Mr. Jarrell has worked for Dow for 30 years, 25 of those years in manufacturing and engineering. He has been a part of Dow's leadership teams for 14 years and has been supervising project and operational teams for the past 23 years. Jeff holds a Bachelor's of Science degree in Chemical Engineering from Texas Tech University.

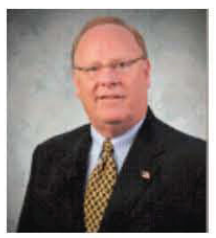

John Mahoney, Secretary-Treasurer I secretary@ngnpalliance.org

John Mahoney has more than 30 years of experience in the commercial energy business in managerial and technical positions. In his current position at the Entergy Nuclear fleet headquarters is in business development and project management working with companies and entities globally in the development of nuclear energy opportunities. Mahoney holds a Bachelor of Science degree in business administration from Northwood University and a Master of Science degree in business from Troy University. He is certified by the Project Management Institute as a project management professional and is President Emeritus of the Central Mississippi PMI Chapter. Mahoney is an officer of the Mississippi Section of the American Nuclear Society and was elected in 2011 to the ANS Executive Committee of the Human Factors, Instrumentation and Controls Division for a 3-year term.

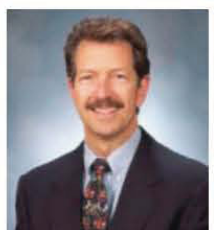

Fred Moore, Executive Director-Emeritus I executivedirector@ngnpalliance.org Fred Moore is the Global Director of Manufacturing \& Technology for the Energy business in Dow. At Dow, he is responsible for the safe and reliable production of power, steam, and other utilities for Dow globally, which represents more than $10 \%$ of Dow's asset base. In his Technology role, he is responsible for development, support and application of Energy technology globally and with Dow's major joint ventures. Fred holds a Bachelor of Science in Environmental Engineering from Purdue University. He was the Alliance executive director from June 2010 to June 2012 and remains a voting member of the Executive Committee in his capacity.
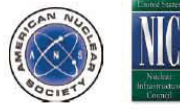

The full NGNP Alliance, Ltd Business Plan is attached to the end of this report. 


\section{Appendix D}

\section{Process Alternatives Functional and Performance Characteristics}




\section{Appendix D \\ Process Alternatives Functional and Performance Characteristics}

\section{D-1. Introduction}

In $2011 \sim 45 \%$ of the electricity consumed in the U.S. was generated from coal fired power plants. Importantly, $\sim 90 \%$ of the electricity consumed in Wyoming in 2011 was generated using coal. The future of this application of coal energy is not certain, however, because of existing and potential federal policy and regulations on mining practices, emissions from the burning of coal, the disposal of coal based waste and transport. Similarly, the low prices for natural gas due to the increased supply from gas shale have resulted in significantly reduced revenue from the extraction, consumption and export of natural gas in Wyoming. Since coal and natural gas are major indigenous resources and major factors in the Wyoming economy it is imperative that alternative applications for coal and natural gas be identified and deployed to stabilize and increase their contributions to Wyoming's economy.

Markets exist for synthetic transportation fuels (e.g., diesel, gasoline) and commodity chemicals (e.g., ethylene, propylene) that can be produced using technically and economically viable carbon conversion processes using coal and natural gas as feedstock. These processes provide (1) additional uses and markets for the indigenous coal and natural gas resources of Wyoming and (2) the opportunity to increase the value of these resources by converting them to higher value products; a benefit to the Wyoming economy.

Processes for the conversion of coal to synthetic transportation fuels were developed by the Germans to support their campaigns during World Wars I and II. South Africa has used these processes for decades. Conversion of coal to chemicals has been extant in the U.S. for decades (e.g., Eastman Chemical) and is being exploited in large scale in China. However, these traditional processes have been characterized by large scale emissions of greenhouse gases (e.g., $\mathrm{CO}_{2}$ ) that have made them environmentally challenging and would be subject to the same regulations that are causing the early retirement of coal fired power plants. Fortunately, modern carbon conversion processes provide means to minimize and control these emissions to reduce their environmental impact through carbon capture for enhanced oil recovery or sequestration. Incorporation of non-emitting nuclear energy supplies such as the High Temperature Gas-cooled Reactor (HTGR) and the non-emitting High Temperature Steam Electrolysis (HTSE) supply of hydrogen results in further reductions making these processes even more viable from an environmental perspective.

Natural gas is also a viable feedstock for conversion to transportation fuels (e.g., major oil companies are developing natural gas to gasoline plants in Louisiana and elsewhere ${ }^{1}$ ) and is the primary feedstock for chemical production. The natural gas resources in Wyoming are also considered for conversion either as the primary feedstock or in combination with coal.

The following sections describe the alternative carbon conversion processes covered in this study and characterizes their functional and performance characteristics. 


\section{D-2. Carbon Conversion Alternatives}

\section{D-2.1 Syngas generation}

The carbon (coal and natural gas) conversion processes evaluated include those producing some combination of diesel, naphtha, LPG, gasoline and commodity chemicals (e.g., ethylene and propylene). In all cases the first step in these processes is the conversion of the feedstock to synthetic gas composed of a specific ratio of $\mathrm{CO}$ and $\mathrm{H}_{2}$; see Figure D-1. With coal as the feedstock the Syngas is produced in a gasifier. There are several types of gasifiers commercially available; for the purposes of this evaluation a dry-fed gasifier similar to those supplied by Uhde and She $11^{4}$ was used. ${ }^{\mathrm{g}}$

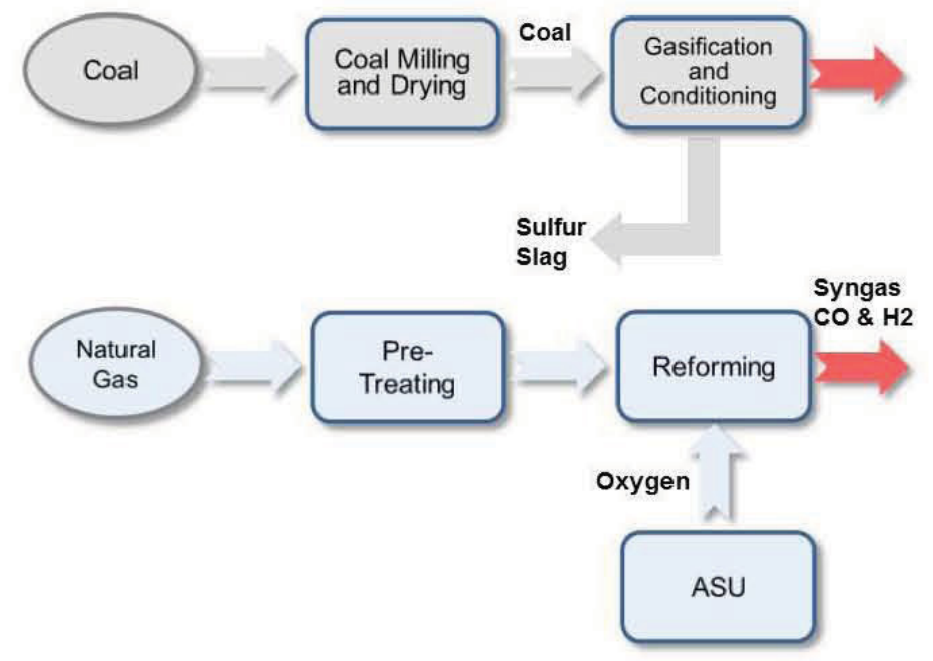

Figure D-1, Syngas generation.

In the coal gasification process the coal is burned generating $\mathrm{CO}$ and hydrogen among other tramp constituents in the coal and slag. There is insufficient hydrogen in the coal to achieve the required ratio of $\mathrm{H}_{2}$ to $\mathrm{CO}$ in the syngas; another supply of hydrogen is required. In most commercial gasifiers this is done by injecting steam and using the water shift reaction to produce the hydrogen; $\mathrm{CO}+\mathrm{H}_{2} \mathrm{O} \gg \mathrm{CO}_{2}+\mathrm{H}_{2}$. This is a major source of $\mathrm{CO}_{2}$ in this process.

For natural gas feedstock the syngas is produced through a reforming process splitting the carbon and hydrogen in the gas and adding oxygen to produce the $\mathrm{CO}$ and $\mathrm{H}_{2}$ components of the syngas. In this case there is sufficient hydrogen in the natural gas to obtain the required ratio of $\mathrm{H}_{2}$ to $\mathrm{CO}$. This is an endothermic process and the heat is supplied by burning some of the natural gas. This is a major source of $\mathrm{CO}_{2}$ in this process.

The quantities of $\mathrm{CO}_{2}$ produced in the coal gasification process are significantly higher than that for the natural gas reformer. In both cases, however, the majority of the $\mathrm{CO}_{2}$ generated in these processes can be captured, compressed and transported for sequestration or enhanced oil recovery (EOR). This is costly, there is uncertainty in the viability of sequestration as a method for disposing of this $\mathrm{CO}_{2}$ and there is insufficient capacity in EOR to make that a viable long term repository. Pending government regulation of $\mathrm{CO}_{2}$ emissions also makes release an untenable option. Accordingly, there is advantage to reducing the amount of $\mathrm{CO}_{2}$ generated in the syngas processes. Figure D-2 shows the four approaches evaluated.

$\mathrm{g}$ There is an alternative process for direct production of synthetic transportation fuels using coal liquefaction reactor developed originally by the Germans and being promoted by KBR. This is also being considered but its evaluation is in an early stage. 


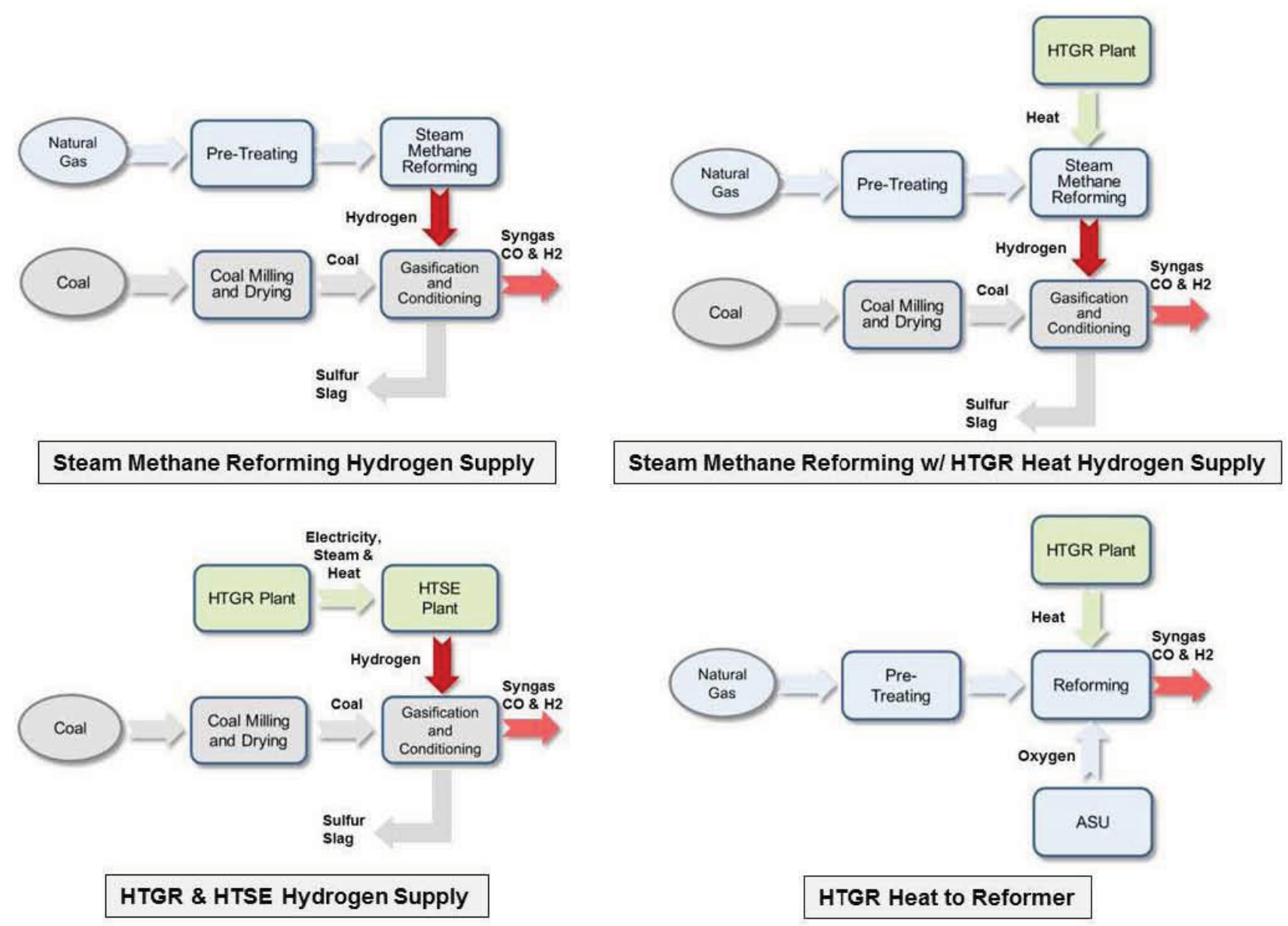

Figure D-2. Alternative syngas supply feedstocks and configurations.

Referring to Figure D-2, three different configurations are shown for providing an external supply of hydrogen to the coal gasifier as a substitute for the water shift reaction to produce the required $\mathrm{H}_{2}$ to $\mathrm{CO}$ ratio.

- Steam methane reforming; steam methane reforming is a common process used in the U.S. to produce hydrogen from natural gas and water. These components are used throughout the petrochemical industry with good success.

- Steam Methane Reforming with HTGR heat; conventional steam methane reforming burns some of the natural gas to supply the heat required for the endothermic reaction. This and the reaction itself produces about 9 tons of $\mathrm{CO}_{2}$ for every ton of hydrogen produced. Adding high temperature heat from the HTGR reduces this by 7.5 tons per ton ( $83 \%$ reduction) and also generates about $15 \%$ more hydrogen for the same feed rate of natural gas.

- HTGR and HTSE; the HTGR supplies heat and electricity to the high temperature steam electrolysis (HTSE) process to produce hydrogen with no $\mathrm{CO}_{2}$ emissions. This is the most effective process for reducing $\mathrm{CO}_{2}$ emissions in the gasification process.

- Natural Gas Reforming, the addition of HTGR heat to the reformer in the natural gas to syngas process reduces the generation of $\mathrm{CO}_{2}$ by $23 \%$ and reduces the amount of natural gas required for the process.

All of these methods for providing an external supply of hydrogen and heat have been evaluated for the process alternatives considered herein. 


\section{D-2.1.1 Syngas Conversion}

The Syngas can be used to synthesize many different products. In the evaluations reported herein the following processes were analyzed:

- Coal and Natural Gas to Liquids producing diesel fuel, naphtha and LPG using the conventional Fischer-Tropsch (FT) process.

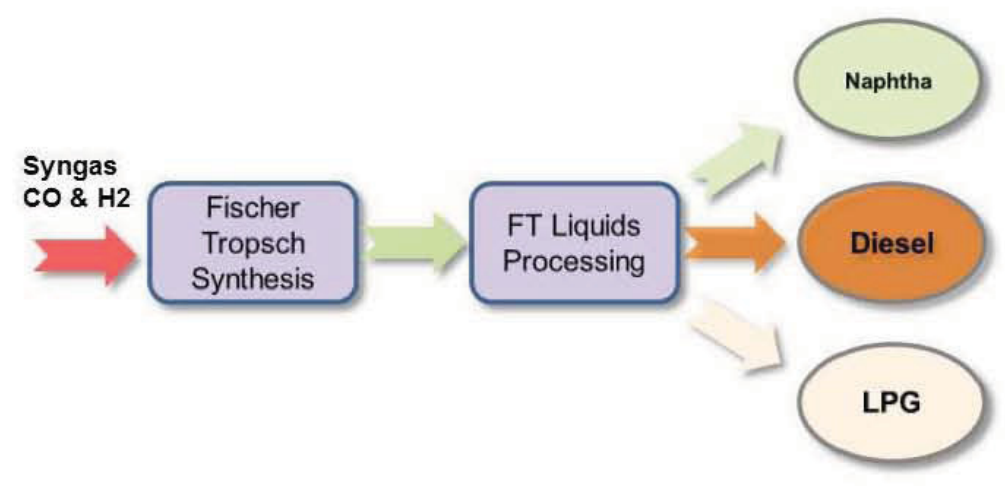

Figure D-3. Conventional FT production of diesel, naphtha and LPG.

- A CTL alternative of converting the naphtha to higher value products including gasoline and olefins was also evaluated.

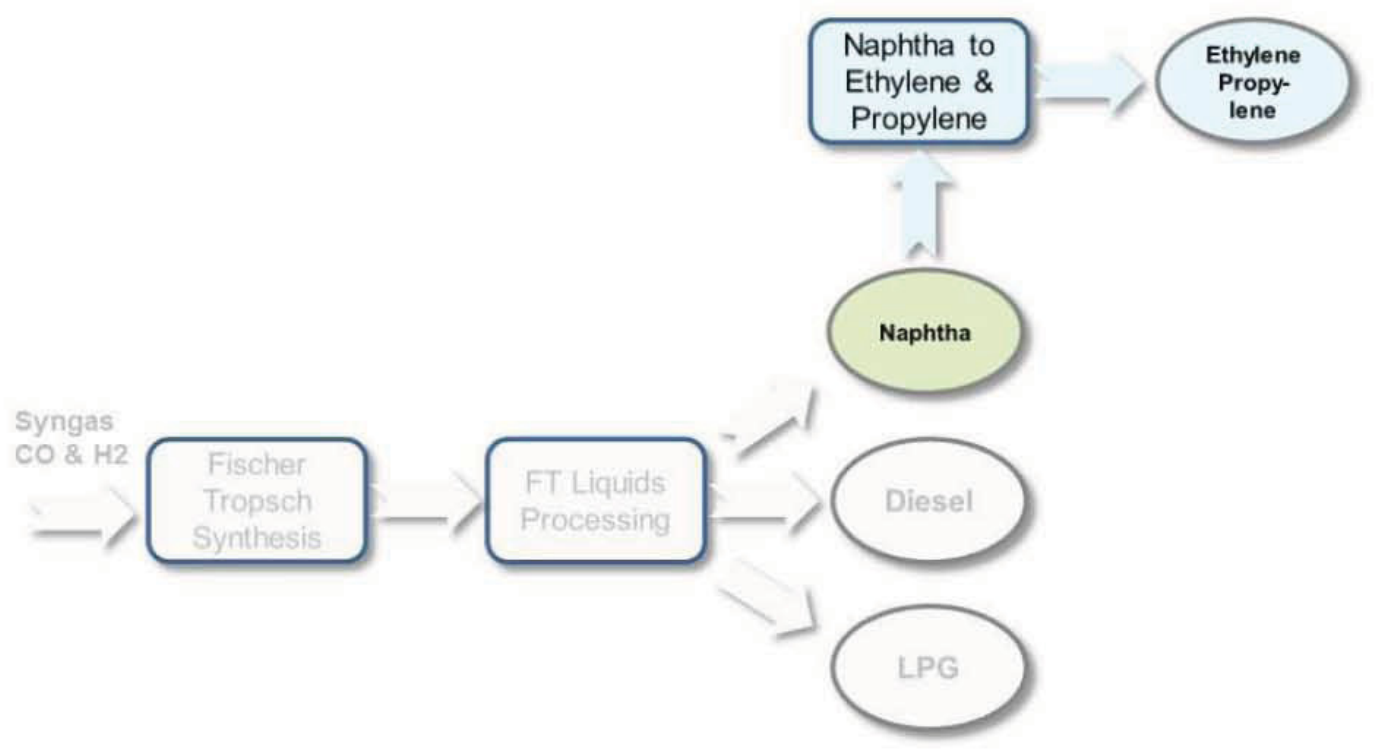

Figure D-4. Alternative further processing of F-T naphtha to produce chemicals.

- Coal and Natural Gas to Gasoline using the MTG process 


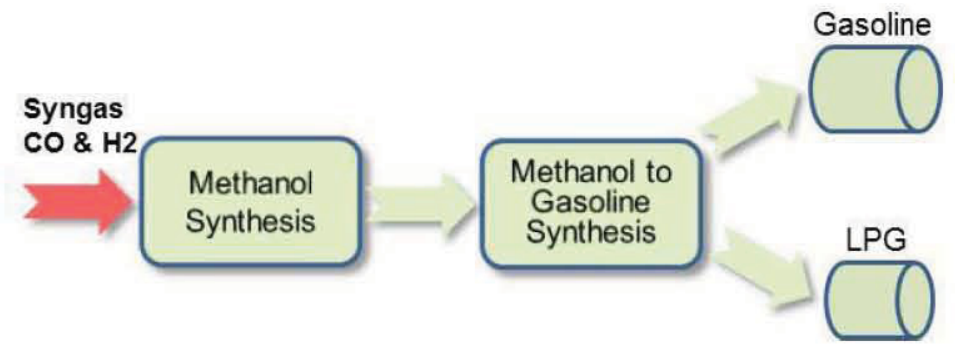

Figure D-5. Methanol to gasoline and LPG.

- Coal to chemicals (e.g., olefins such as ethylene, propylene) using the coal to methanol to olefins (CTO) process

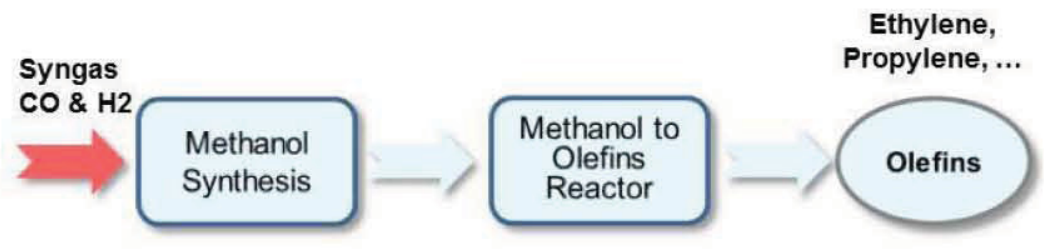

Figure D-6. Methanol to olefins.

A total of 16 process configurations were evaluated. For the purposes of discussion and to distinguish the processes, the processes that use current technologies are designated as "Conventional". The configurations that apply HTGR and HTSE technologies are described as "incorporating HTGR and, where applicable, HTSE technologies". The processes evaluated are listed in Table D.1.

Table D.1. Carbon conversion alternatives evaluated.

\begin{tabular}{|c|c|}
\hline Acronym & Process \\
\hline CTL & $\begin{array}{l}\text { Conventional CTL using the FT process producing diesel, naphtha and liquefied } \\
\text { petroleum gas }\end{array}$ \\
\hline CTL w/SMR & Conventional CTL with SMR supplying hydrogen to the coal gasifier \\
\hline CTL w/SMR \& HTGR & $\begin{array}{l}\text { CTL w/SMR with HTGR supplying heat and electricity to the steam methane } \\
\text { reformers }\end{array}$ \\
\hline CTL w/HTGR \& HTSE & CTL with HTGR and HTSE supplying hydrogen to the coal gasifier \\
\hline GTL & $\begin{array}{l}\text { Conventional natural GTL using the FT process producing diesel, naphtha and } \\
\text { liquefied petroleum gas }\end{array}$ \\
\hline GTL w/HTGR & Natural GTL with HTGR supplying heat to the primary reformer \\
\hline GTG & $\begin{array}{l}\text { Conventional natural GTG using the MTG process producing gasoline and liquefied } \\
\text { petroleum gas }\end{array}$ \\
\hline GTG w/HTGR & Natural GTG with HTGR supplying heat to the primary reformer \\
\hline CTG & Conventional CTG using MTG producing gasoline and liquefied petroleum gas \\
\hline CTG w/SMR & Conventional CTG with SMR supplying hydrogen to the coal gasifier \\
\hline CTG w/SMR \& HTGR & $\begin{array}{l}\text { CTG w/SMR with HTGR supplying heat and electricity to the steam methane } \\
\text { reformers }\end{array}$ \\
\hline CTG w/HTGR \& HTSE & CTG with HT GR and HTSE supplying hydrogen to the coal gasifier \\
\hline CTO & Conventional $\mathrm{CTO}$, olefins such as ethylene and propylene \\
\hline CTO w/HTGR \& HTSE & CTO with HTGR and HTSE supplying hydrogen to the coal gasifier \\
\hline
\end{tabular}


Modifications of the traditional processes developed as part of this evaluation are in the gasification and reforming stages. These include the use, for example, of steam methane reforming (SMR) or high temperature gas-cooled reactor (HTGR) and high temperature steam electrolysis (HTSE) for hydrogen production as a substitute for the traditional water-shift reaction in the CTL process. The advantage of these substitutions is a significant reduction in the quantities of $\mathrm{CO}_{2}$ produced and emitted in the gasification and reforming stages. As also shown the HTGR technology is incorporated into the processes in these stages supplying heat and electricity as well as hydrogen.

Figure D-7 illustrates the advantages in emissions reductions that result from the use of SMR and HTGR/HTSE for hydrogen generation in the alternative processes. For example in the CTL process, the use of SMR reduces the total $\mathrm{CO}_{2}$ generated by $\sim 60 \%$ whereas full use of the HTGR/HTSE technology offers reductions $>90 \%$.

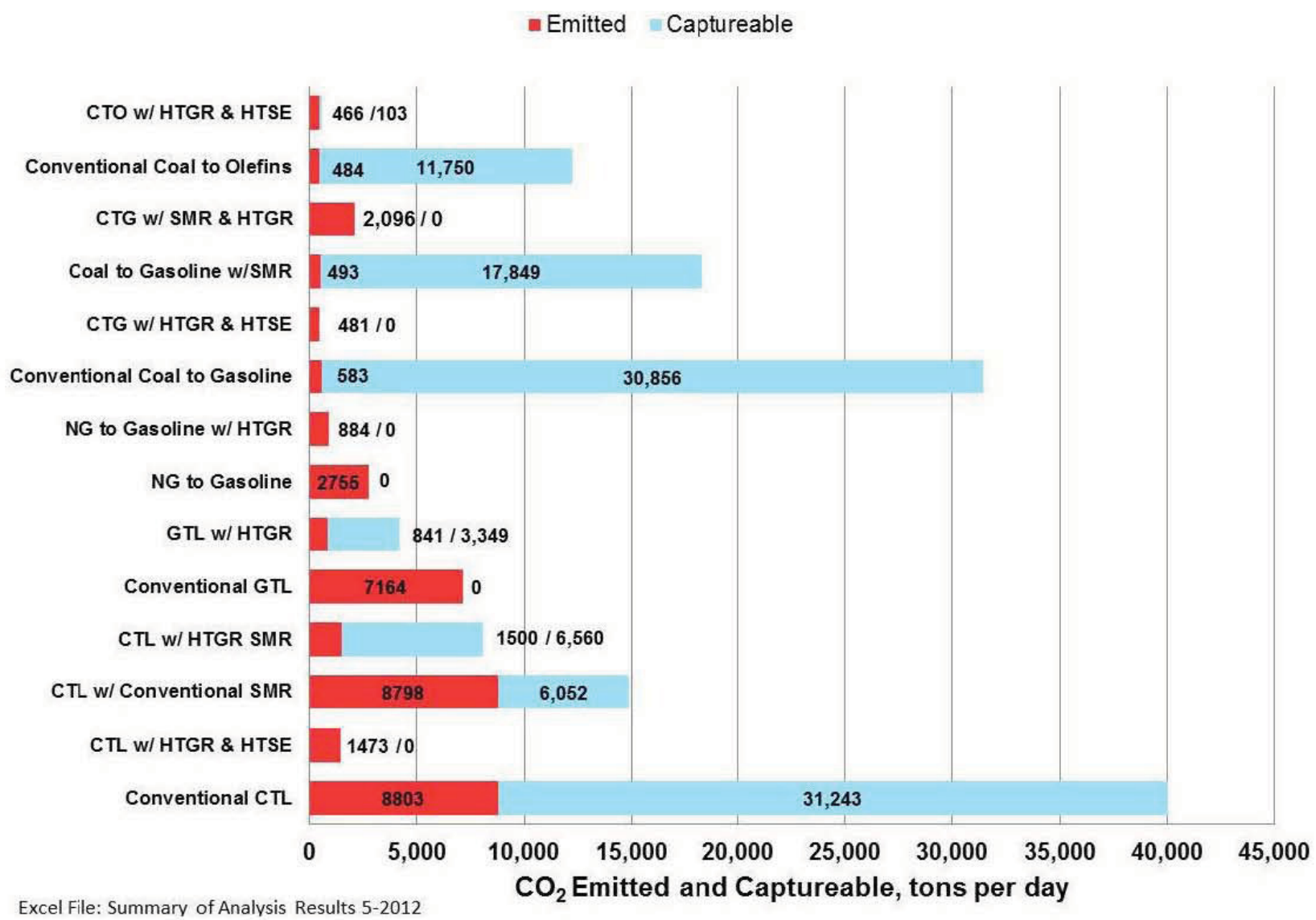

Figure D-7. Comparison of $\mathrm{CO}_{2}$ generation and the potential for capture in coal to liquids process alternatives.

\section{D-2.2 Aspen Models}

Detailed development of each of the processes evaluated in this study is documented in INL technical evaluation reports referenced herein. In all cases detailed models of the processes in the conventional configurations and with HTGR and HTSE incorporated were developed in Aspen+C to establish their performance characteristics. The following discusses the characteristics and bases of the process models used in this evaluation. 


\section{D-2.2.1 Coal to Liquids}

Figures D-8 and D- 9 are schematics of the models of the Conventional and HTGR/HTSE incorporated CTL plant using the traditional FT process. Figures D-10 and D-11 show schematics of these models for the CTL processes in which SMR is used to provide hydrogen, including that configuration with the HTGR providing heat to the SMR process. Each of the blocks in these figures represent very detailed Aspen+C models that INL has developed over several years to support these analyses. These are typical of the models used in the evaluations herein ${ }^{2}$.

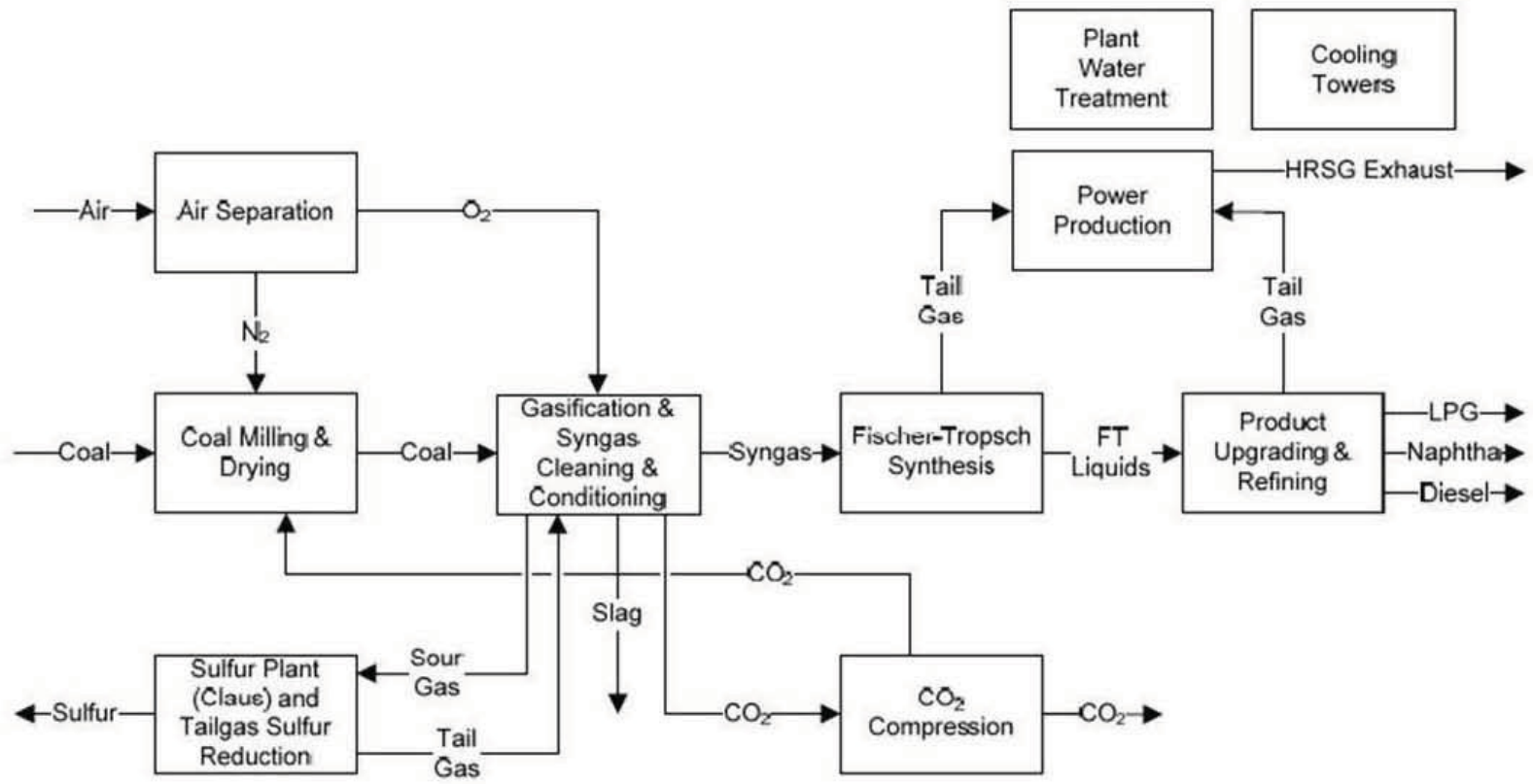

Figure D-8. Conventional coal to liquids using the traditional Fischer-Tropsch process.

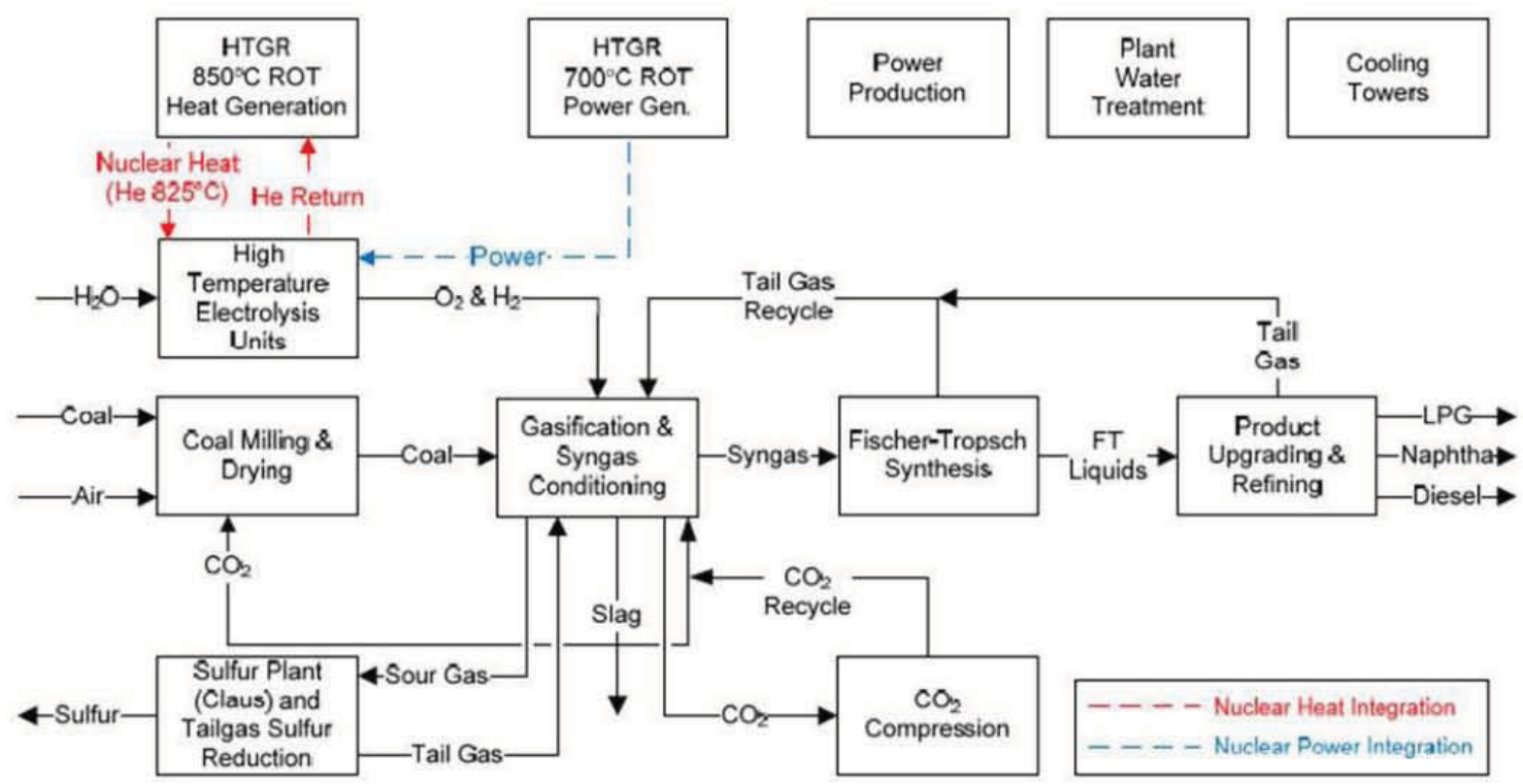

Figure D-9. Coal to liquids process incorporating HTGR and HTSE technologies. 


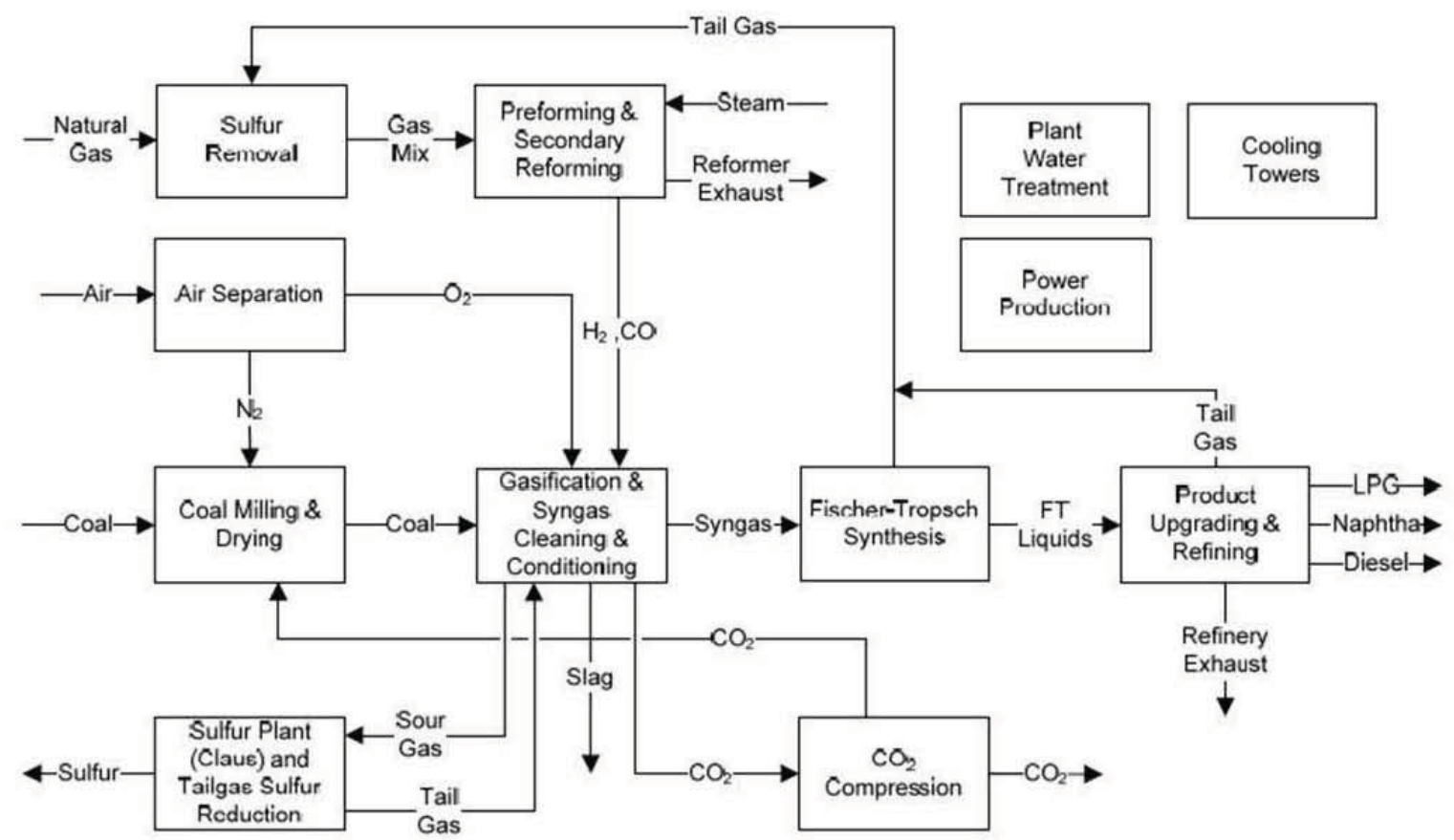

Figure D-10. CTL FT process using conventiona/ steam methane reforming for hydrogen supply.

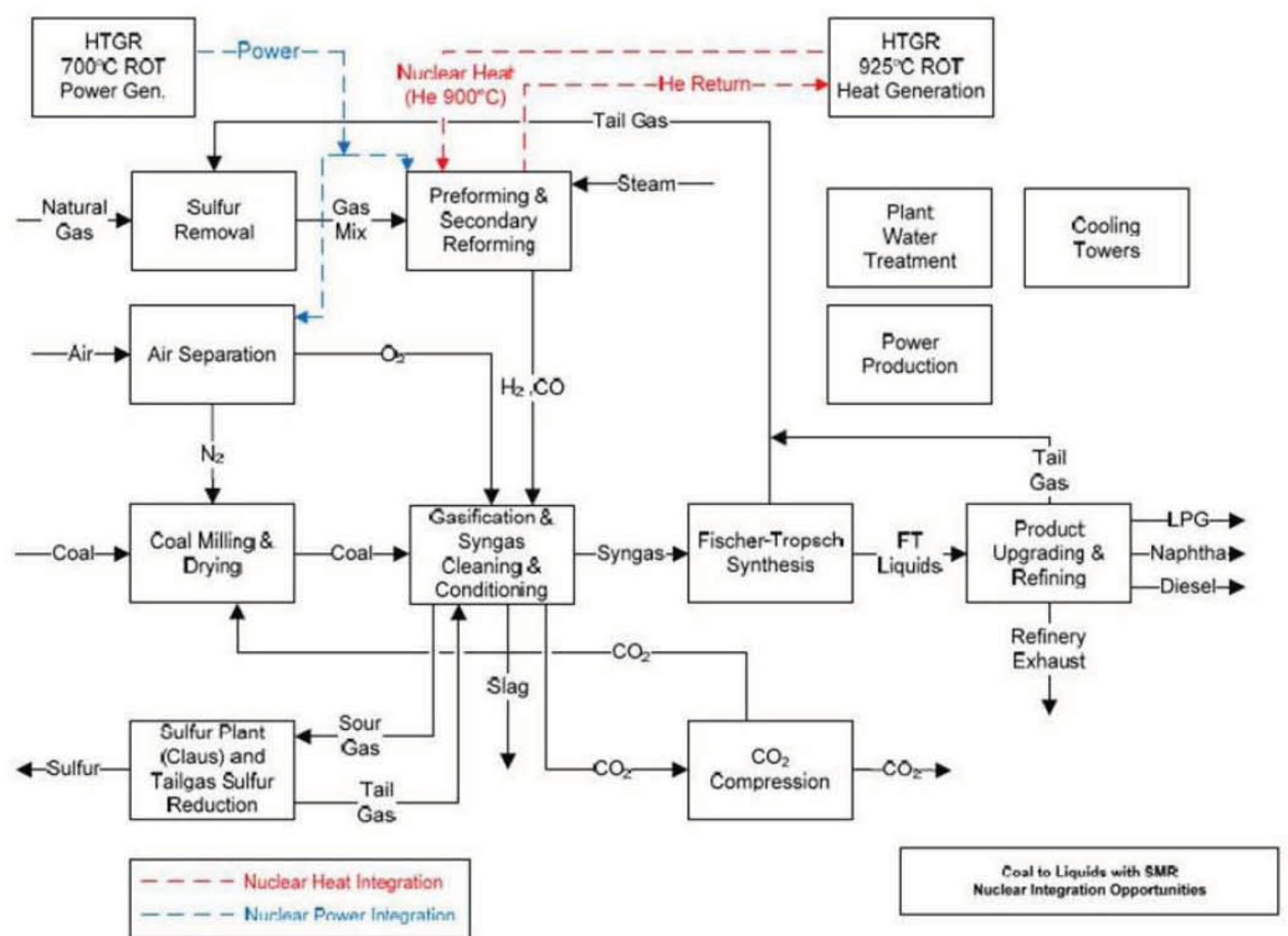

Figure D-11. CTL FT process using HTGR incorporated steam methane reforming for hydrogen supply. 
Each of the coal-based models relies on gasification to convert coal into synthesis gas. Gasification is a mature technology which has been used to produce gas for lighting and heat since the early $19^{\text {th }}$ century. Although the discovery of natural gas in the late $19^{\text {th }}$ century displaced coal gasification for these applications, coal gasification technology has continued to evolve. Entrained flow gasification represents the state-of-the-art today, with several commercial vendors offering such designs. GE and ConocoPhillips currently market slurry-fed entrained-flow gasifiers, while Shell, ${ }^{3}$ Uhde, and Siemens offer dry-fed entrained-flow gasifiers. The Aspen $+(C)$ gasification models selected for use in this study are representative of the dry-fed designs offered by Shell and Uhde.

The Conventional CTL process, Figure D-8, uses the water shift reaction to produce the additional hydrogen needed in the coal gasification process to develop the hydrogen to CO ratio required for the FT reaction. The water shift reaction is one of the largest sources of the large quantity of $\mathrm{CO}_{2}$ generated in this process, see Figure D-7. The integration of the HTGR and HTSE technologies, Figure D-9, provides an external source of hydrogen eliminating the need for the water shift reaction and the $\mathrm{CO}_{2}$ associated with that reaction. The HTGR also supplies electricity required for operation of the process permitting recycle of tail gases that are used in the Conventional process for electricity generation. This eliminates the other large source of $\mathrm{CO}_{2}$ generation in the Conventional process. As shown in Figure D-7, the integration of the HTGR and HTSE technologies in the CTL process reduces $\mathrm{CO}_{2}$ generation by over $95 \%$.

Figure D-10 and Figure D-11 show alternative configurations using steam methane reforming (SMR) for supplying hydrogen to the CTL process as a substitute for the water shift reaction. Steam methane reforming is the most widely used technology in the world today for production of hydrogen. Hence, it is a critical technology supporting an array of processes from ammonia production to petroleum refining. Many variations of the technology have been commercialized, such as auto-thermal reforming. In these studies, hydrogen production is modeled using conventional steam methane reforming. In conventional steam methane reforming using natural gas as the feedstock some of the natural gas is burned to produce the temperatures required in the endothermic reforming process, Figure D-10. When the HTGR technology is applied to the process, Figure D-11, the heat for reforming is provided by hot gas from the HTGR as well as electricity for operation of the ASU and SMR plants. As shown in Figure D-7, use of conventional steam methane reforming in place of the water shift reaction reduces $\mathrm{CO}_{2}$ generation in the conventional CTL process by more than $60 \%$ and the use of HTGR results in a further reduction of more than $90 \%$.

For syngas purification in all processes, only mature, commercial technologies were selected. In the steam methane reforming scenarios, sulfur was removed prior to reforming using a standard zinc oxide sorbent. In the gasification scenarios, sulfur was removed using Rectisol solvent in an absorber/stripper configuration, and captured sulfur was further processed using a Claus and SCOT process. In the gasification processes, Rectisol was also used to capture $\mathrm{CO}_{2}$ from the process gas. In some of the steam methane reforming scenarios, $\mathrm{CO}_{2}$ was captured using a Fluor propylene carbonate solvent. Hydrogen separation in all scenarios was accomplished using pressure swing adsorption (PSA). All of these technologies have broad commercial application and are considered mature.

In the CTL processes and in the Gas to Liquids (GTL) process shown later, purified syngas is converted to diesel, naphtha, and LPG using the Fischer-Tropsch (FT) process. The Fischer-Tropsch process was commercialized by Germany prior to WWII, and was used to produce fuels for use in both war machinery and automobiles. The FT process was later implemented by Sasol in South Africa in 1952. Today this technology is used to produce most of that country's diesel fuel. In the early years of FT commercialization, iron-based catalysts were primarily used. More recently, cobalt-based catalysts have also been developed and used commercially for FT synthesis. In the technical evaluations considered in this study, a cobalt-based catalyst was modeled. 


\section{D-2.2.2 Coal to Gasoline (CTG) and Coal to Chemic als (CTC)}

In the coal-to-gasoline (CTG) and coal-to-chemicals (CTC) scenarios considered in this study, methanol is produced as an intermediate product.5 Figure D-12 and Figure D-13 are schematics of the CTG Conventional process, and the HTGR/HTSE incorporated configuration supplying hydrogen, using the methanol to gasoline process. Figure D-14 and Figure D-15 are schematics of the CTG process using SMR for the hydrogen supply and HTGR supplying heat and electricity to the SMR process.

Figures Figure D-16 and Figure D-17 are similar schematics for the CTC process.

These processes use gasification processes similar to those described for the CTL processes but the synthesis gas is used to produce methanol suited for processing into gasoline and chemicals.

Figure D-13 and Figure D-17 show the processes incorporating the HTGR and HTSE technologies to supply hydrogen and electricity similar to that discussed for the CTL processes. As discussed in the preceding section this external source of hydrogen and electricity provides more than $90 \%$ reduction in $\mathrm{CO}_{2}$ generation in these processes.

In Figure D-15 the HTGR is supplying heat and electricity to the SMR plant to substitute for the burning of natural gas, similar to that for the CTL w/SMR configuration discussed previously. In this case the $\mathrm{CO}_{2}$ generation is also reduced by $\sim 90 \%$.

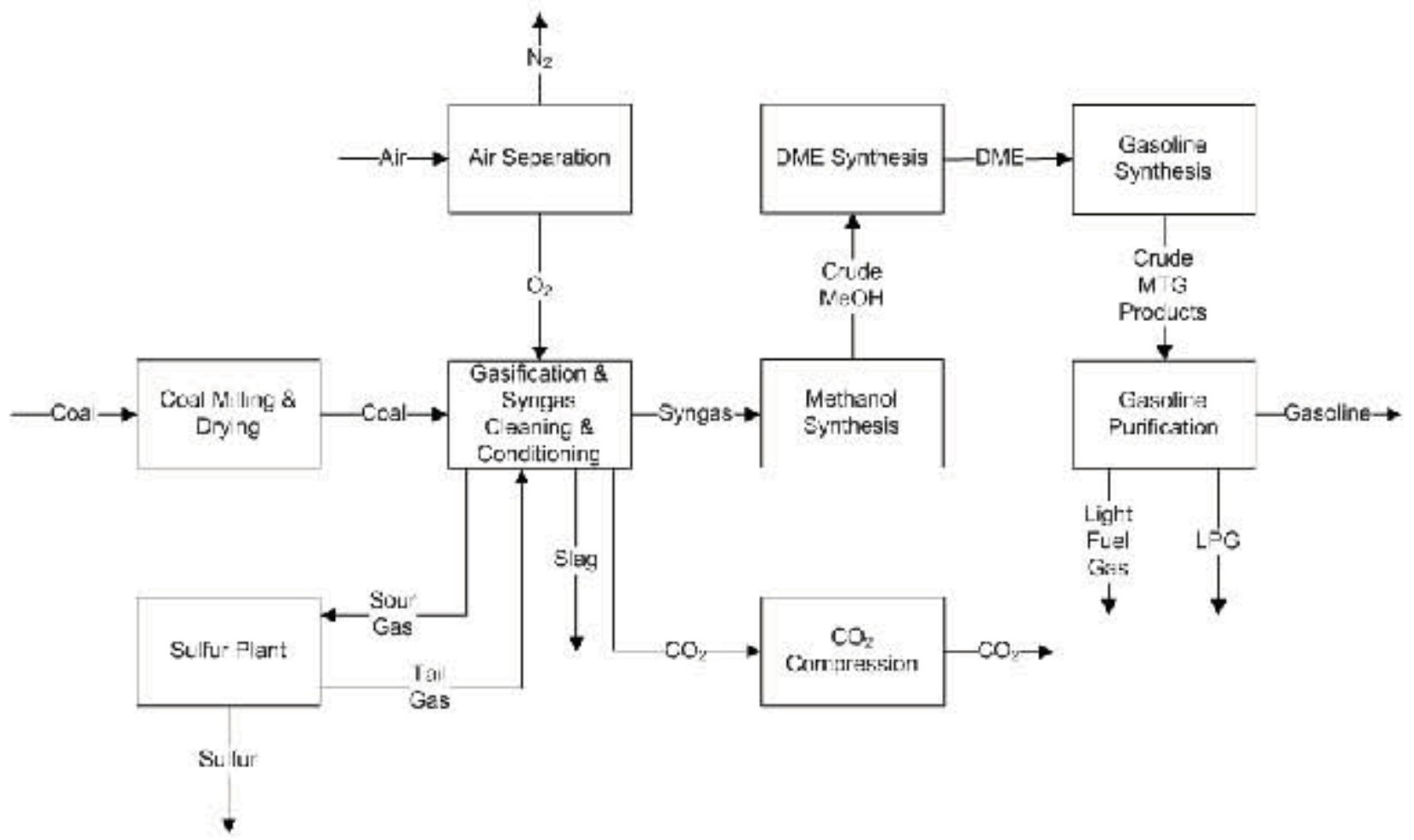

Figure D-12. Conventional coal to gasoline using the methanol to gasoline process 


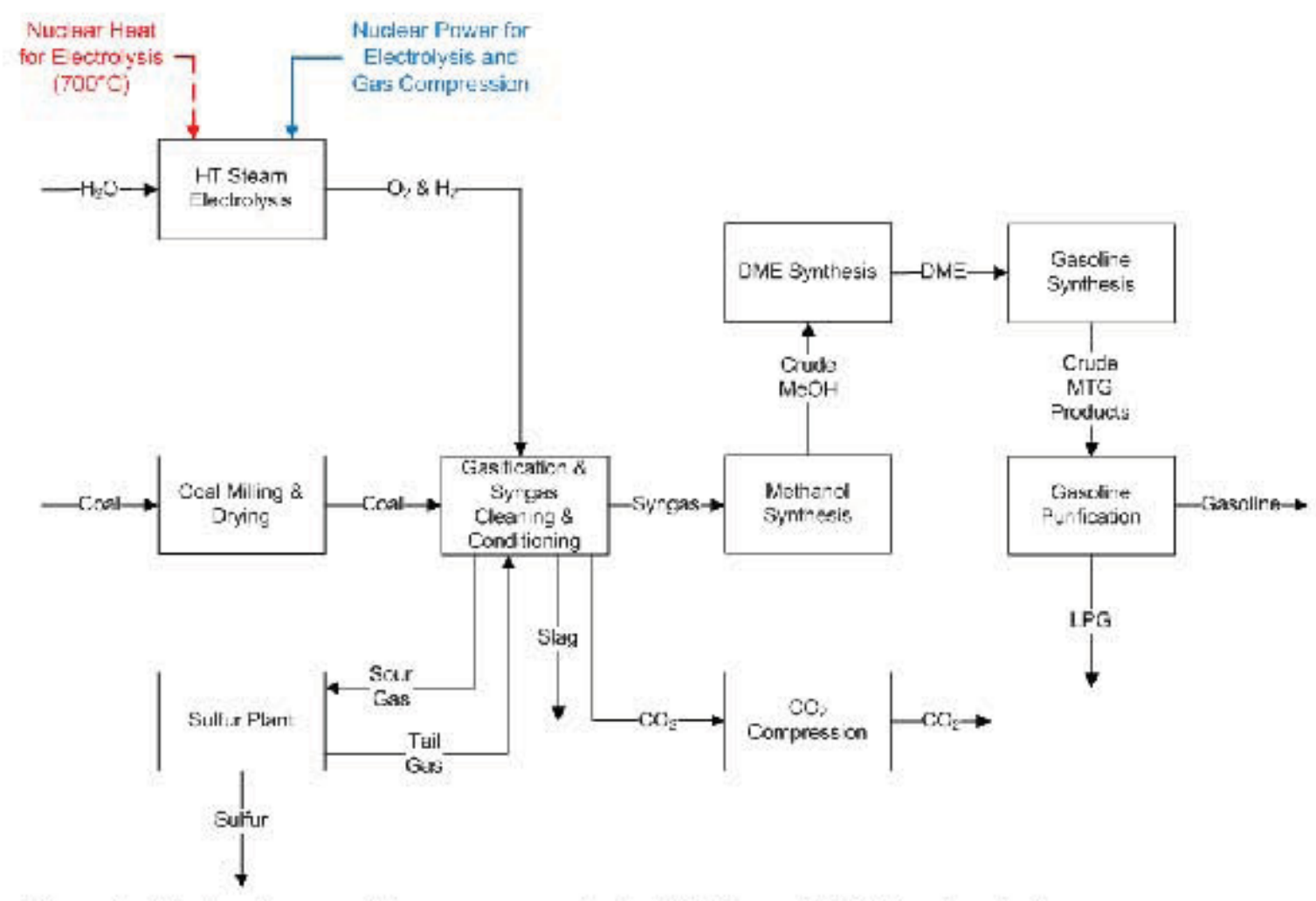

Figure D-13. Coal to gasoline process applying HTGR and HTSE technobgies.

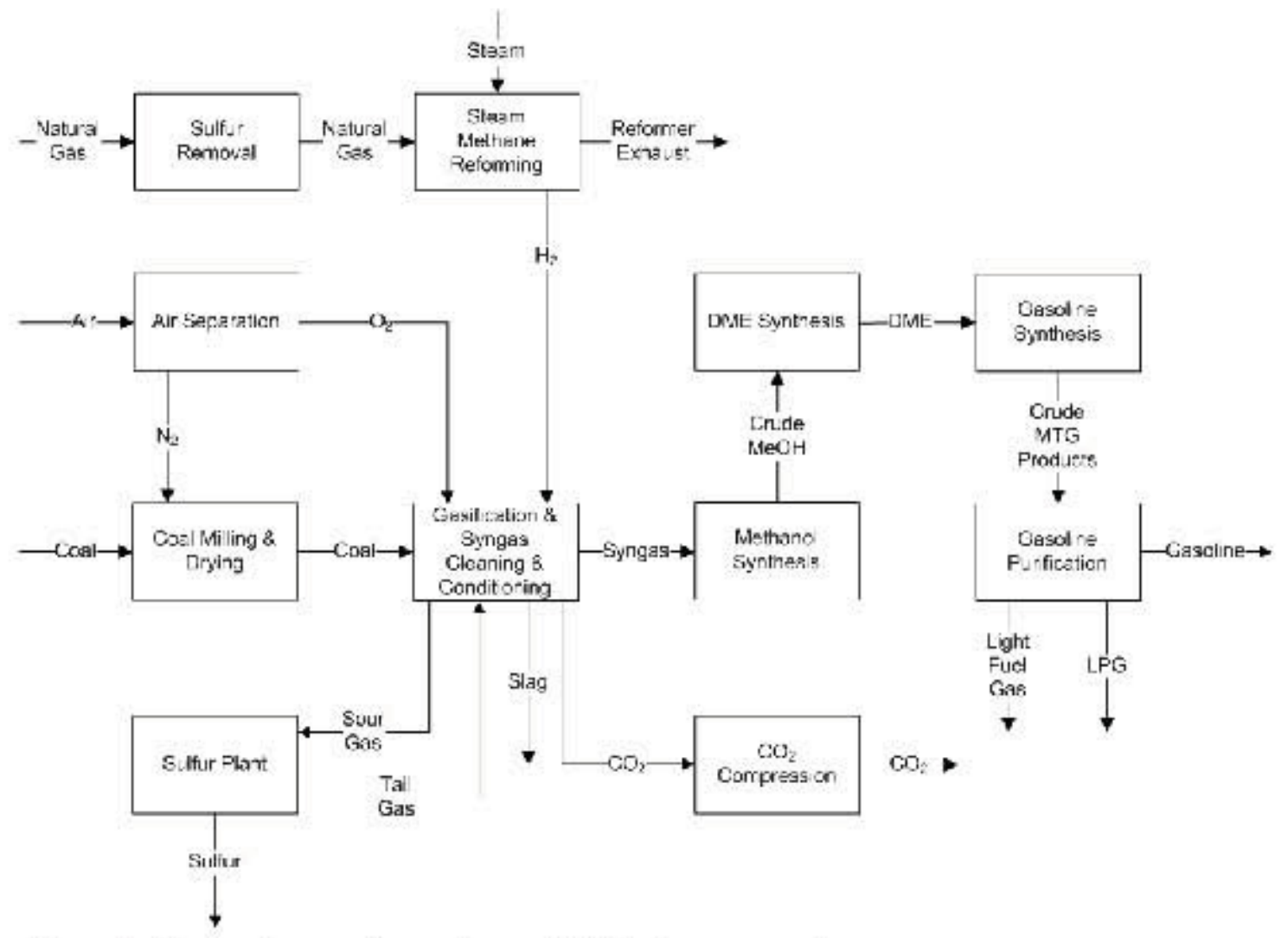

Figure 0-14. Coaito gasoline using an SMR hydrogen supply. 


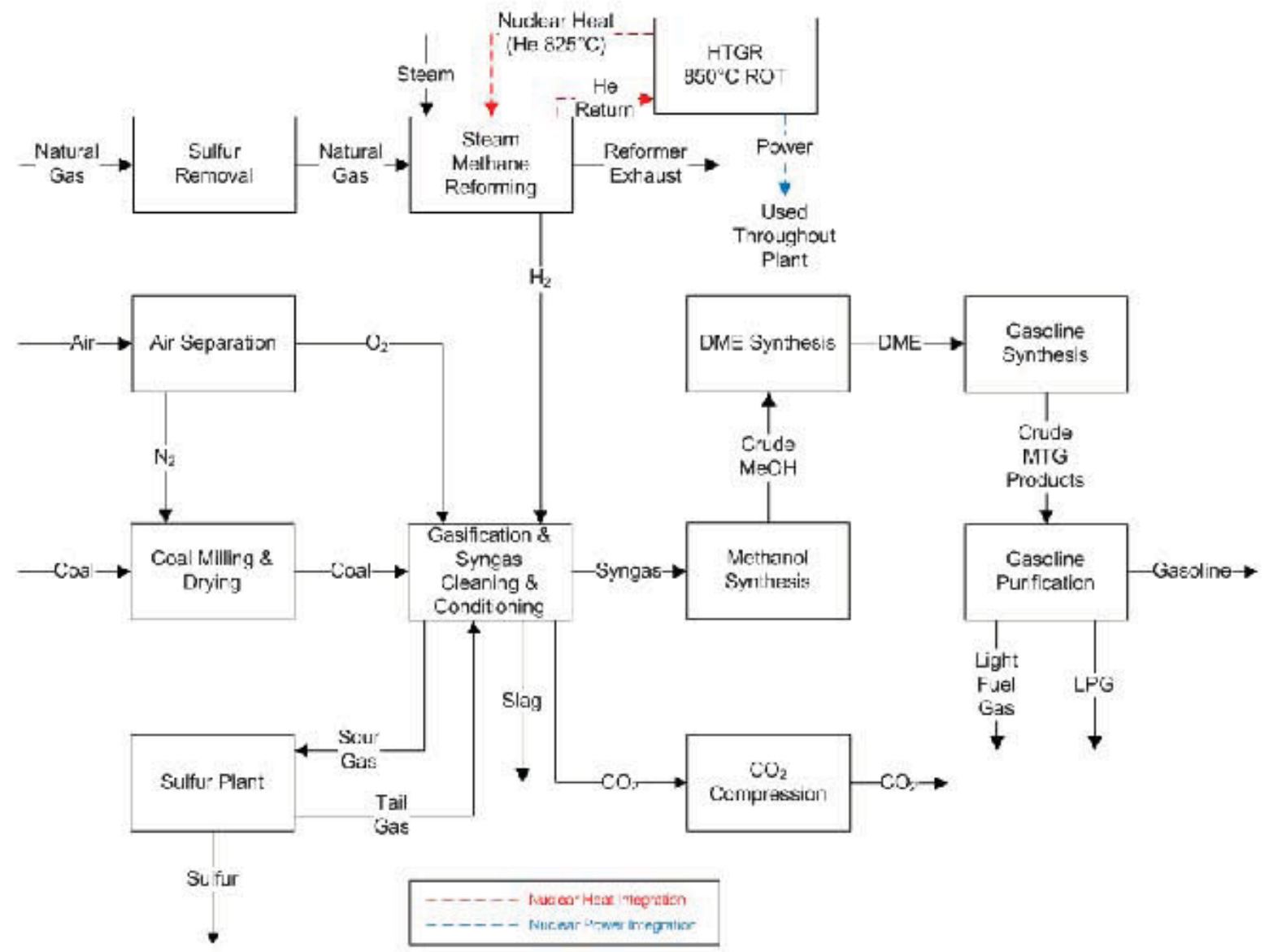

Figure D-15. Coal to gasoline using an SMR with HTGR hydrogen supply.

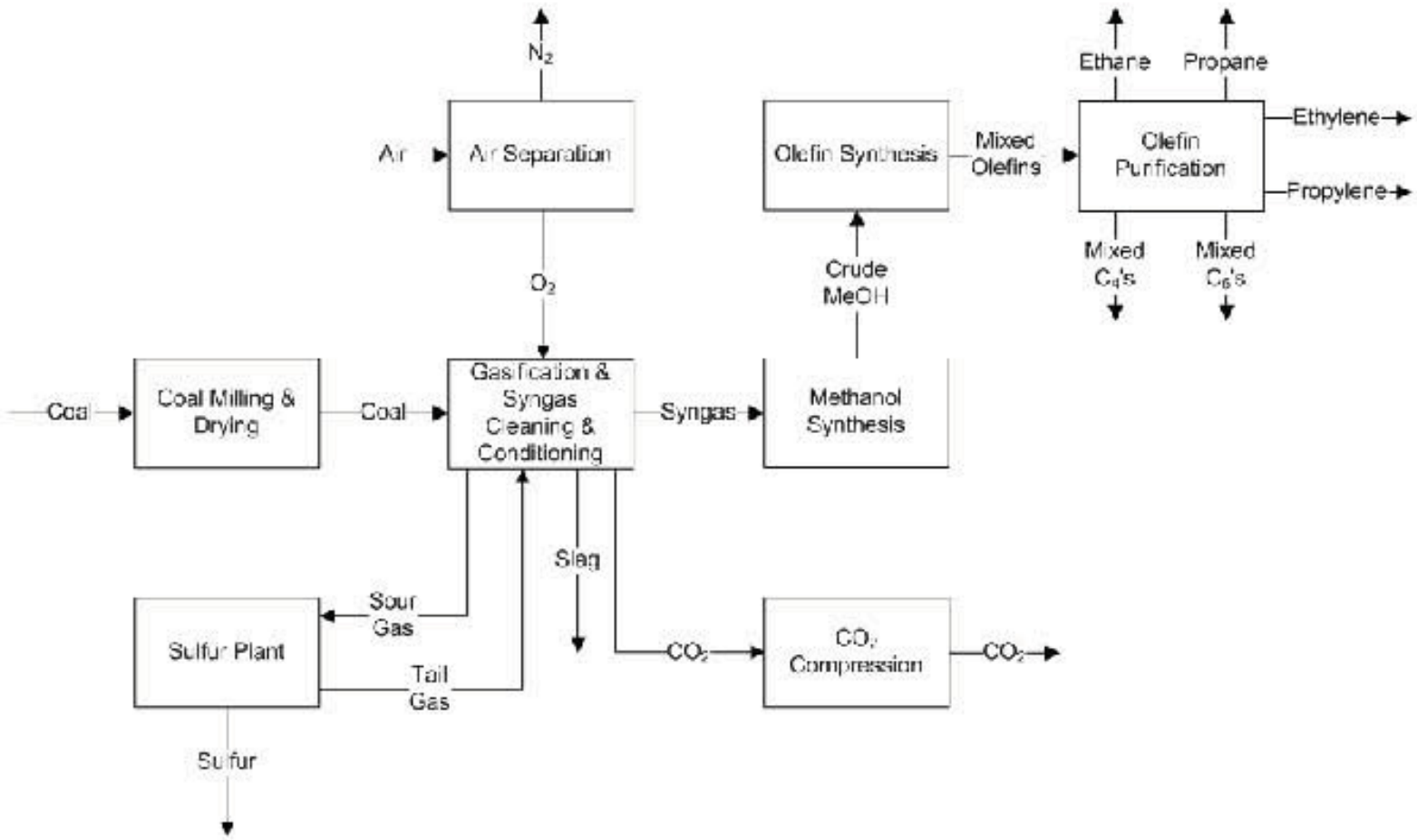

Figure D-16. Conventional coal to chemicals. 


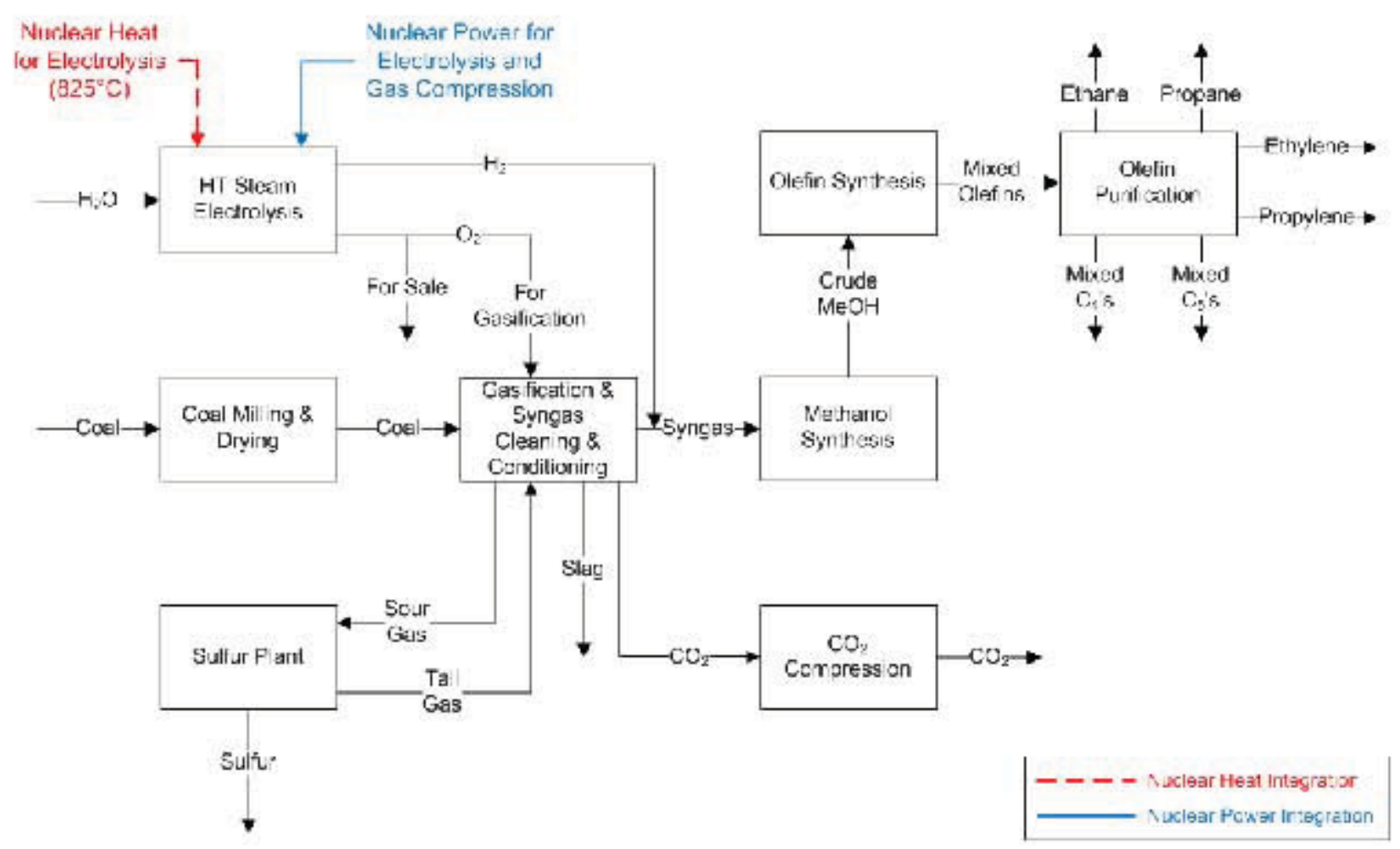

Figure D-17. Coal to chemicals process incorporating HTGR and HTSE technologies.

Synthetic methanol production is well devel oped, with the first plant beginning production in 1923 at BASF's plant in Leuna, Germany. Refinements to that process were developed by ICI in the 1960s, thus allowing synthesis to be performed at much lower pressures. The ICI process and its derivatives are still widely used to day, although significant improvements in energy utilization have been realized. In the coal-to-gasoline scenario, methanol is further converted to dimethyl ether and then to gasoline using a zeolite catalyst. For the evaluations in this study, ExxonMobil's methanol-to-gasoline (MTG) process was selected. This technology was first demonstrated on a commercial scale as a partnership between ExxonMobil and the New Zealand government ${ }^{6}$. The plant began operation in 1985 and ran for approximately 10 years; production rate of the plant was 14,500 barrels per day of gasoline.

There is considerable current activity in development of coal to gasoline plants:

- In June of 2009, Jincheng Anthracite Mining Group (JAMG) in Shanxi Frovince, China started up Phase 1 of a second generation MTG plant ${ }^{7}$. Phase 1 of the plant development has a relatively low capacity of $2,500 \mathrm{bbl} /$ day. This plant was producing on-spec gasoline 60 hours after initial startup of the plant. That is fairly impressive for this type of facility. Phase 2 will exp and the plant to approximately $25,000 \mathrm{bbl} /$ day.

- This same technology has been selected for a synthetic fuels plant under construction by DKRW near Medicine Bow, Wyoming ${ }^{8}$. Engineering for Phase $1(11,000 \mathrm{bpd})$ of this $\mathrm{pl}$ ant is complete, and construction is scheduled to ramp up during 2012.

- TransGas is (or was) planning a coal-to-gasoline plant for Mingo county, $W^{9}$.

- Synthesis Energy Systems (SES) has an agreement with ExxonMobil to build up to 15 MTG plants. Their agreement was put in place in 2008. They have since teamed with CONSOL Energy, and a plant was announced for Benwood, WV. 
- There are also three Conventional MTG plants that have initiated construction in Kentucky including the Secure Energy Paducah Gasification Plant on the Ohio Triple Rail Megasite near Paducah $(\sim 12,000 \mathrm{bpd})^{10}$, Chisholm Energy in Pike County $(18,000 \mathrm{bpd})^{11}$ and Buffalo Creek Energy in Pikeville $(18,000 \mathrm{bpd})^{12}$.

In reference to Figure D-16 and Figure D-17 that show the models for the chemical production scenarios in this study, methanol is converted to ethylene and propylene using a zeolite catalyst with a slightly smaller pore size than that used for gasoline production. The specific process selected in this evaluation is UOP's methanol-to-olefins (MTO) process. This process was successfully demonstrated in Norway in 1995. In 2005, UOP and Total Petrochemicals began collaboration on a process to further increase ethylene and propylene yields from the process. A demonstration unit was built and began operation in 2008 at Total's petrochemical complex in Feluy, Belgium. The first commercial plant based on this technology has been announced in China, and is targeted to start up in $2013^{13}$.

It should be noted that coal to chemicals processing has been extant in the U.S. for many decades; principally, by the Eastman Chemical company in Georgia.

\section{D-2.2.3 Natural Gas to Liquids and to Gasoline $e^{2,14}$}

When natural gas is chosen as the feedstock, steam methane reforming is used to convert natural gas into synthesis gas which can then be processed using Fischer-Tropsch to produce diesel, naphtha and LPG or into gasoline and LPG using the methanol to gasoline process. Figure D-14 and D-15 are schematics of the Aspen $+(\mathrm{C}$ models for the Conventional and nuclear incorporated Gas to Liquids processes. Figure D-18 and Figure D-19 are schematics of the Aspen+C models for the conventional and nuclear incorporated Natural Gas to Gasoline processes.

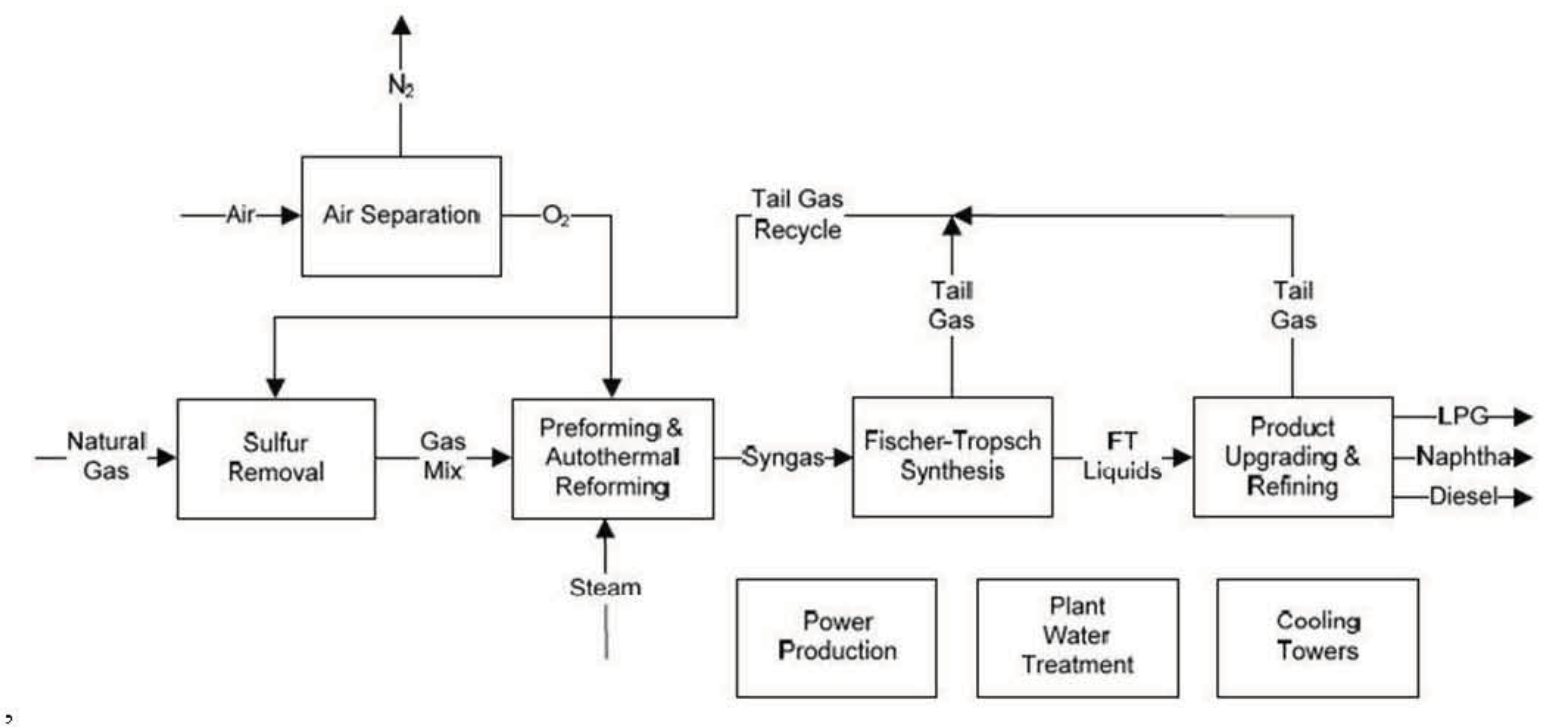

Figure D-18. Conventiona/ natural gas to liquids process. 


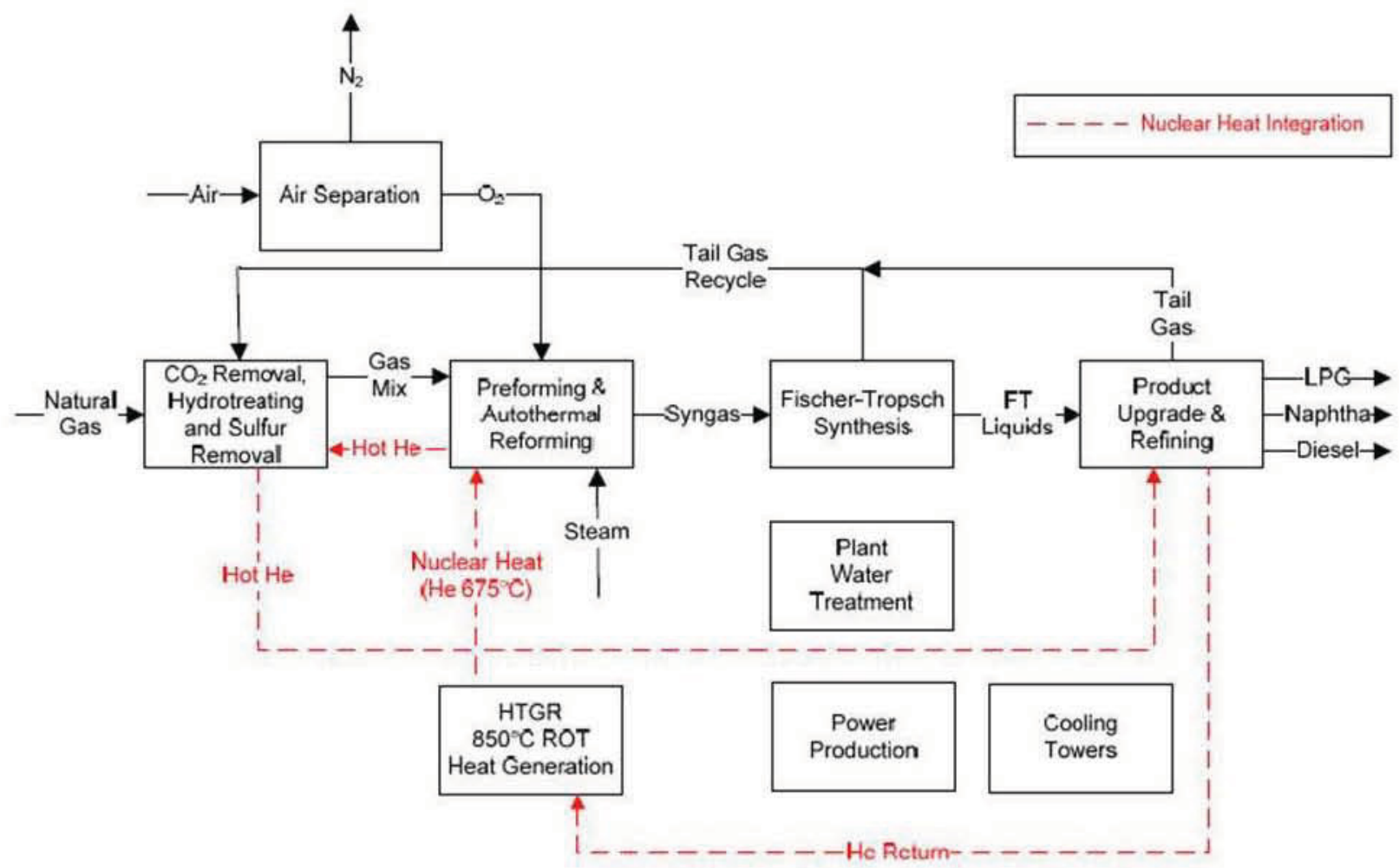

Figure D-19. Natural gas to liquids process incorporating HTGR heat.

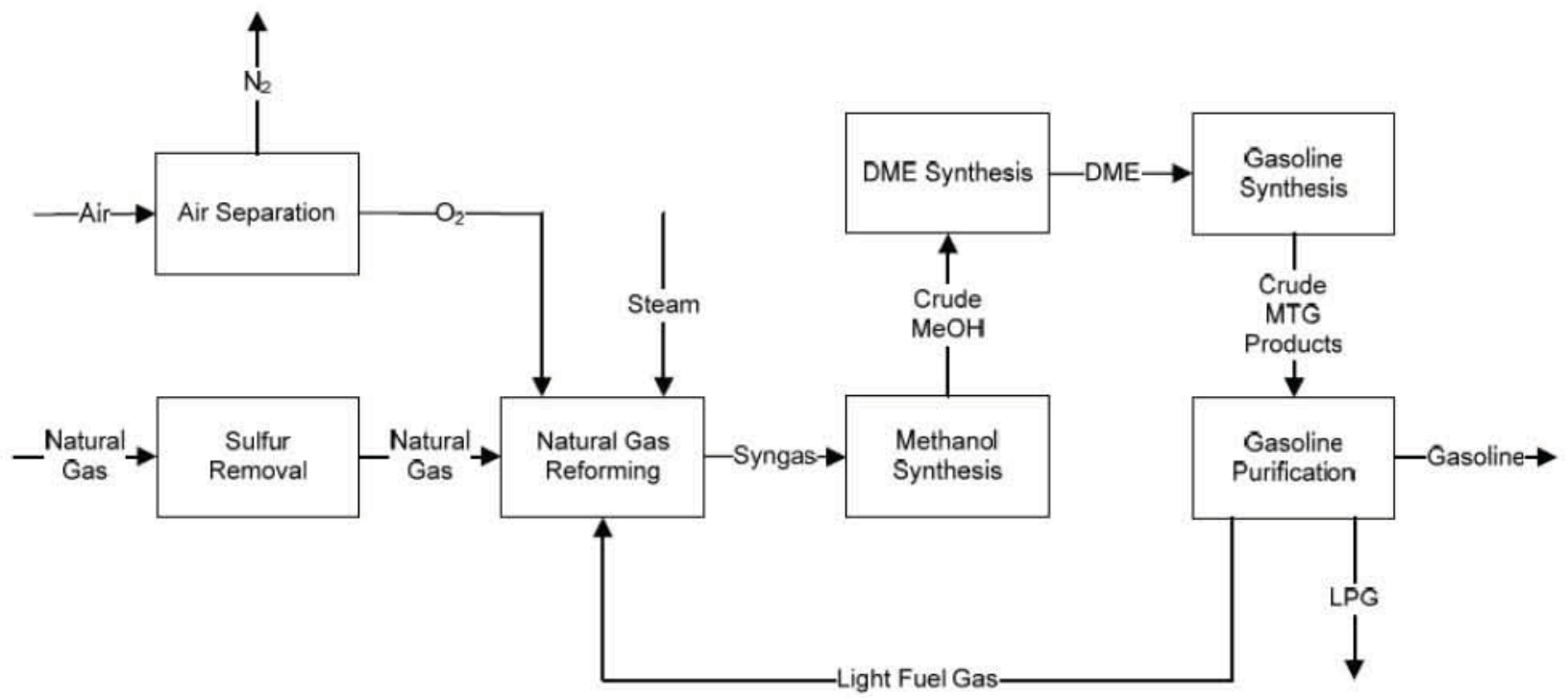

Figure D-20. Natural to gasoline using the MTG process. 


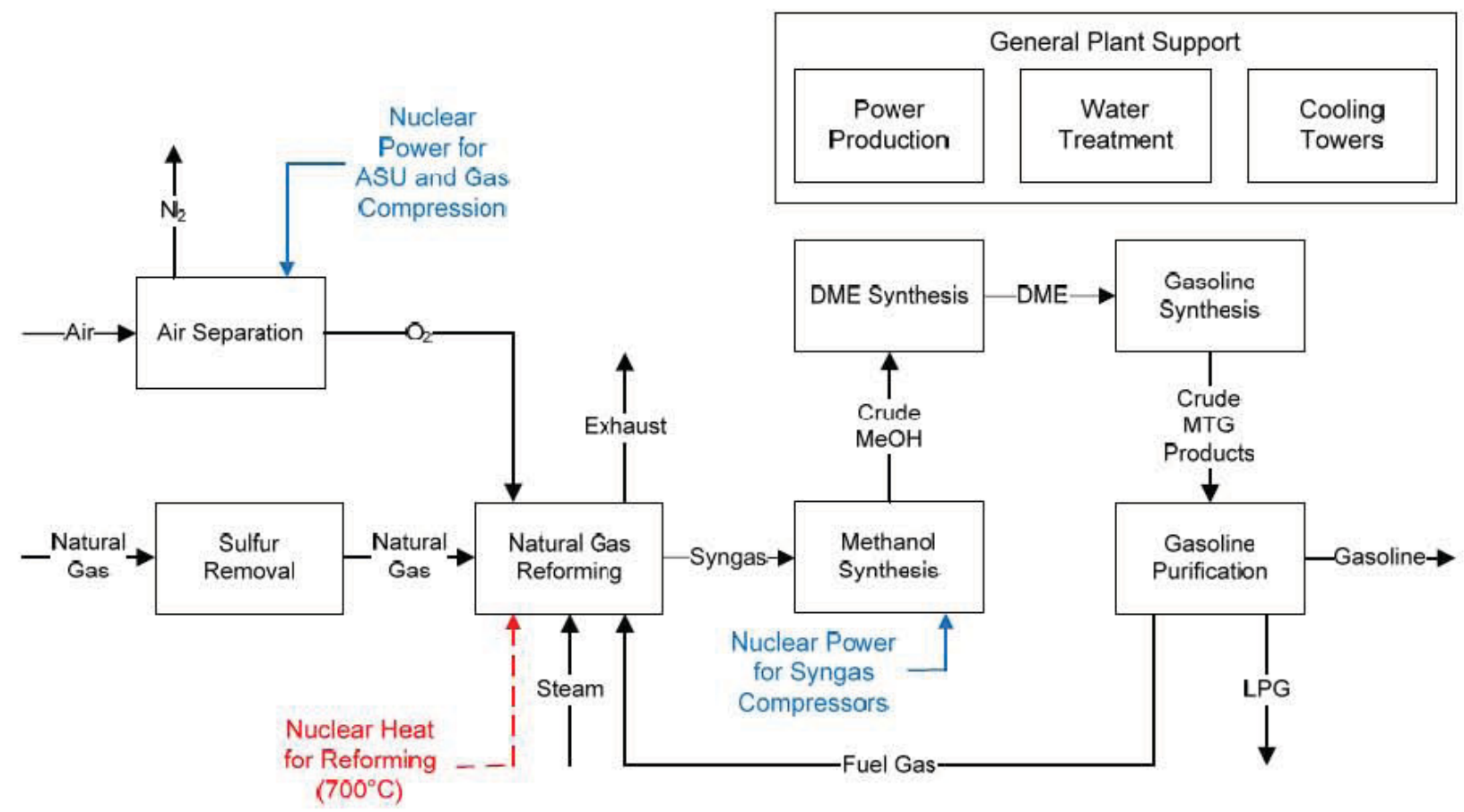

Figure D-21. Natural gas to gasoline using HTGR.

When the syngas is used to make Fischer-Tropsch liquids, autothermal reforming alone was modeled. When the syngas is used to make methanol for the natural gas to gasoline process two-step reforming was selected. In two-step reforming, an autothermal reforming stage is placed downstream of a conventional steam methane reforming stage. Selecting the appropriate reforming scenario allows great flexibility to produce a synthesis gas with the optimal $\mathrm{H}_{2} / \mathrm{CO}$ ratio for the downstream process.

As shown in Figure D-15, the HTGR provides heat in the form of high temperature helium or other chemically inert gas to offset the burning of natural gas in the Conventional process in the endothermic parts of the process. This reduces the $\mathrm{CO}_{2}$ generation by more than $40 \%$. Similarly, in Figure D-17 HTGR heat is substituted for the burning of natural gas in the reformer and for electricity to operate the process. This reduces the $\mathrm{CO}_{2}$ generation by $\sim 70 \%$.

\section{D-2.3 Performance Characteristics of the Alternatives}

The following discusses and makes brief comparisons of the performance characteristics of the carbon conversion alternatives. A 50,000 bpd plant was modeled for the processes converting coal or natural gas to transportation fuels. A 3,000 tpd plant was modeled for the coal to chemicals process. The following figures show the inputs and outputs of each of the processes; (e.g., for the CTL process the coal feed rate, water requirements, the quantities of diesel, naphtha, $\mathrm{LPG}$ and $\mathrm{CO}_{2}$ produced) and consolidated figures compare these factors for the conventional and nuclear incorporated processes.

In addition to calculating the total amount of $\mathrm{CO}_{2}$ produced in each process, assessments were also made of the capability to capture some of that $\mathrm{CO}_{2}$ for sequestration or Enhanced Oil Recovery (EOR); the balance not captured is cited as that emitted. In the cases where sequestration is judged feasible, the equipment costs and energy requirements for capture and preparation for sequestration are estimated and included in the evaluation. $n$ example of this effect can be seen in the summary for conventional CTL. This process generates excess electricity that can be sold to regional utilities on the grid. The amounts of that electricity are shown for the process with and without sequestration; the lower value reflecting the 
electricity required to capture and pressurize the $\mathrm{CO}_{2}$ for transport to the storage or EOR site. The operating costs include the costs of transporting and injecting the $\mathrm{CO}_{2}$ at the sequestration site.

\section{D-2.3.1 Conventional Coal to Liquids}

- The nuclear incorporated case requires $65 \%$ less coal feed than the conventional case for the same production rate with a commensurate reduction of $96 \%$ in $\mathrm{CO}_{2}$ emissions.

- The use of high temperature steam electrolysis for hydrogen production in the nuclear incorporated case requires the supply of over $2.4 \mathrm{GW}(\mathrm{e})$ and $\sim 700 \mathrm{MW}(\mathrm{t})$ of heat. This requires the installation of 10 HTGR plants to support the 50,000 bpd production rate.

- The nuclear incorporated configuration requires $25 \%$ less water than the conventional case
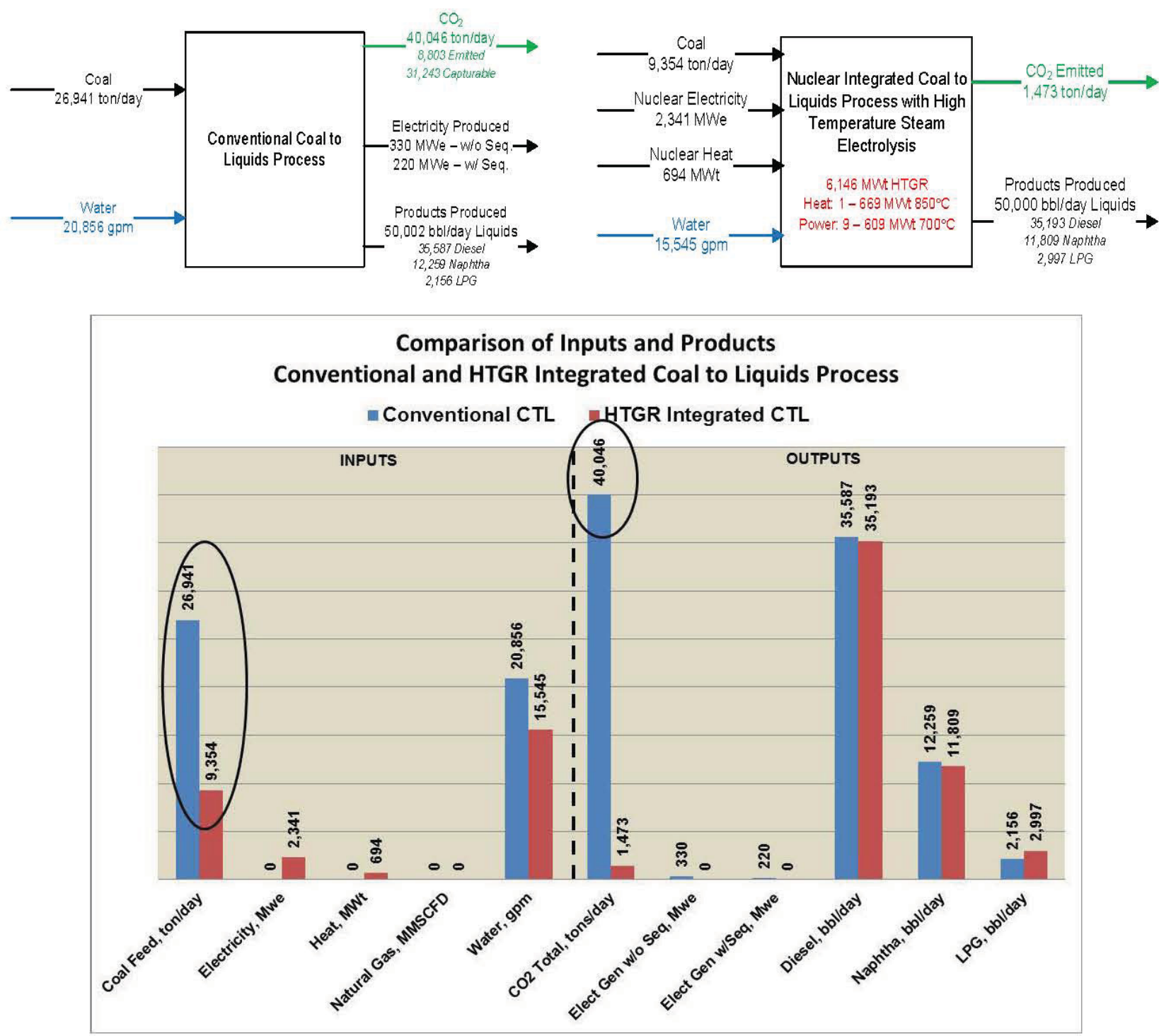

Figure D-22. Coal to liquids process with and without HTGR and HTSE. 


\section{D-2.3.2 CTL with Steam Methane Reforming}

- The carbon in the natural gas supplying hydrogen in the steam methane reformer reduces the coal feed rate by $\sim 70 \%$ when compared with conventional CTL

- The rates of $\mathrm{CO}_{2}$ generation in the CTL w/SMR process are $\sim 65 \%$ lower than the conventional CTL process, but with incorporation of HTGR heat are higher than the CTL process with incorporation of HTGR and HTSE. This is primarily due to the addition of $\mathrm{CO}_{2}$ production in the SMR. In the conventional CTL process all of the excess $\mathrm{CO}_{2}$ in the gasification process can be recycled to extinction in the gasifier. The addition of the $\mathrm{CO}_{2}$ from the SMR exceeds the amount that can be recycled. Therefore, some of the captured $\mathrm{CO}_{2}$ in the CTL with SMR scenario must be sequestered, used for EOR, or emitted.

- The inputs and outputs for the conventional and the HTGR incorporated configurations are very similar; the HTGR incorporated configuration having $45 \%$ less $\mathrm{CO}_{2}$ generation
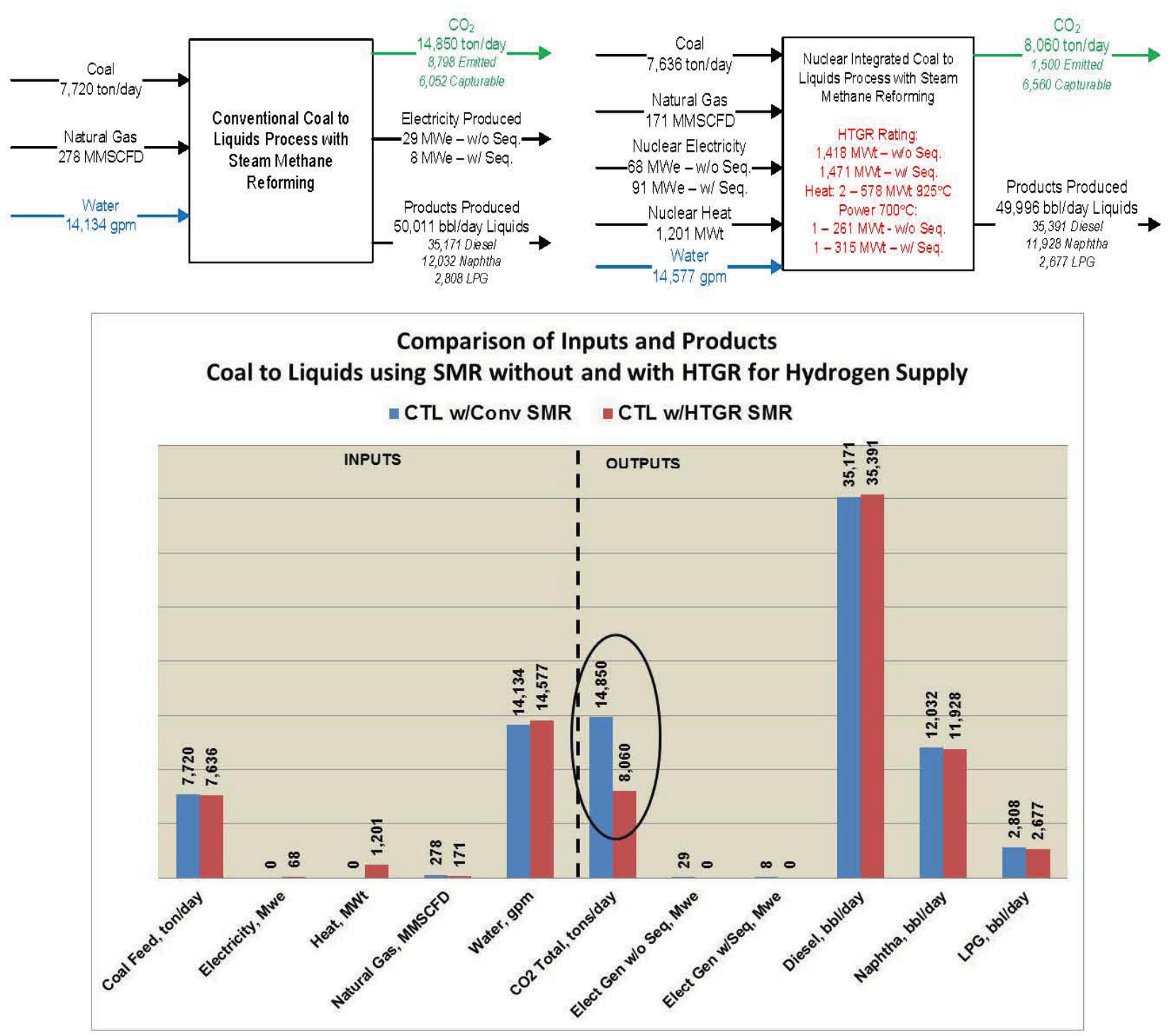

Figure D-23. CTL with SMR with and without HTGR. 


\section{D-2.3.3 Coal to Gasoline using the MTG Process}

- Gasoline is the primary product ( $85 \%$ gasoline $15 \%$ LPG); (e.g., when compared with CTL where the production is divided $71 \% / 24 \% / 5 \%$ Diesel/Naphtha/LPG.

- The integration of HTGR and HTSE into the process reduces the coal feed rate by $\sim 50 \%$ and $\mathrm{CO}_{2}$ generation by $>98 \%$.

- The methanol process could be converted to chemical production (see Section on Coal to Chemicals, below), if the economics and the market justified this shift later in the life of the plant.
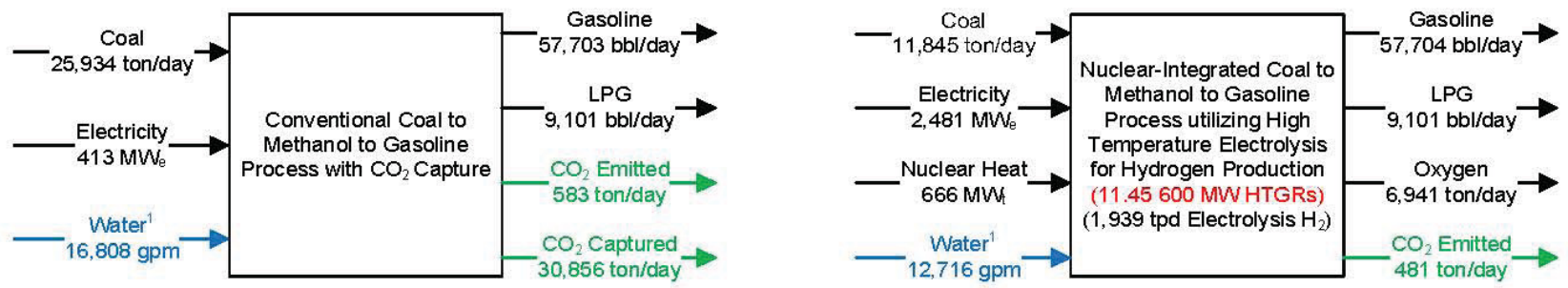

$\mathrm{T}$

Comparison of Inputs and Products

Conventional Coal to Gasoline (CTG) Process and CTG with HTGR

a Conventional CTG $\triangle$ CTG w/HTGR

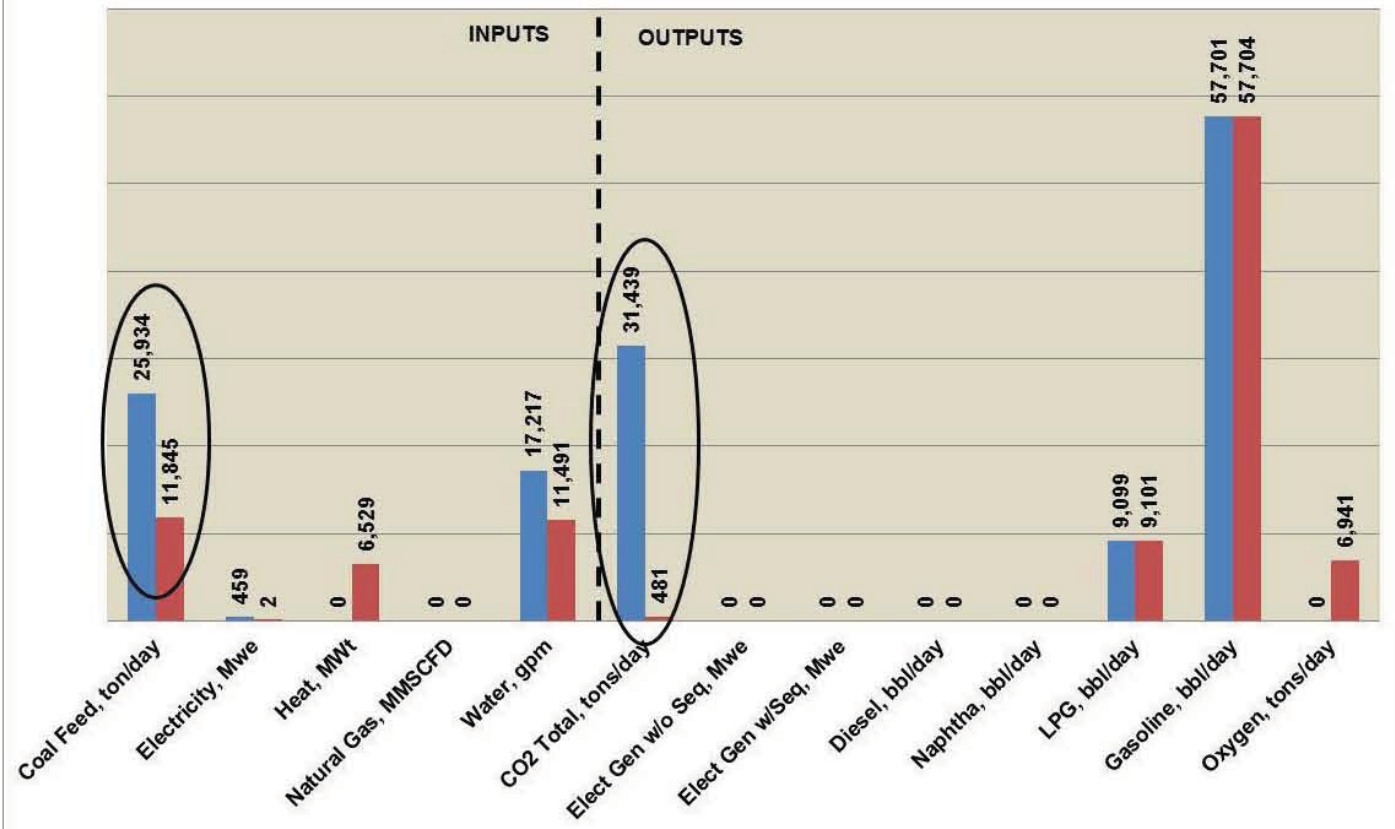

Figure D-24. Coal to gasoline process with and without HTGR and HTSE. 

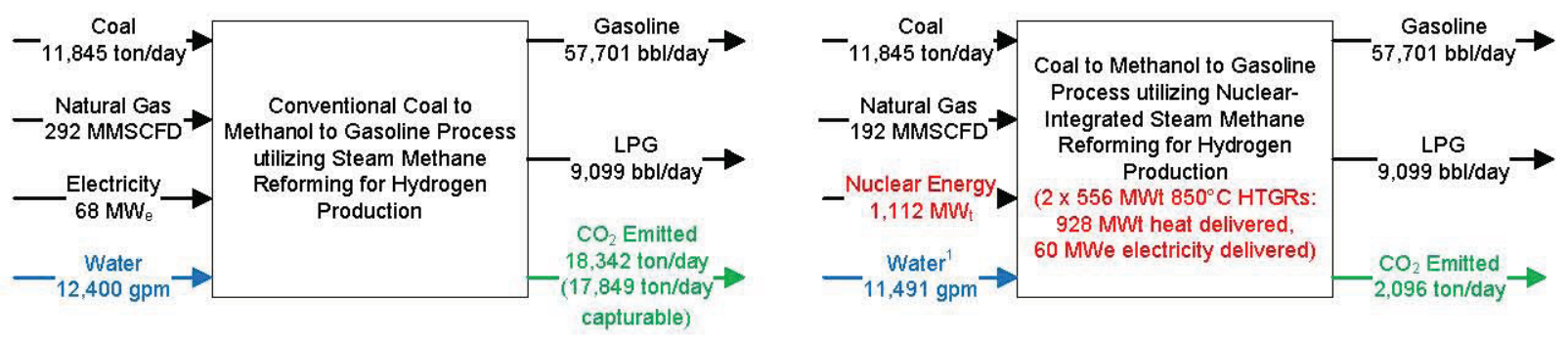

${ }^{1}$ Does not include heat rejection requirement for the nuclear or HTSE plants.

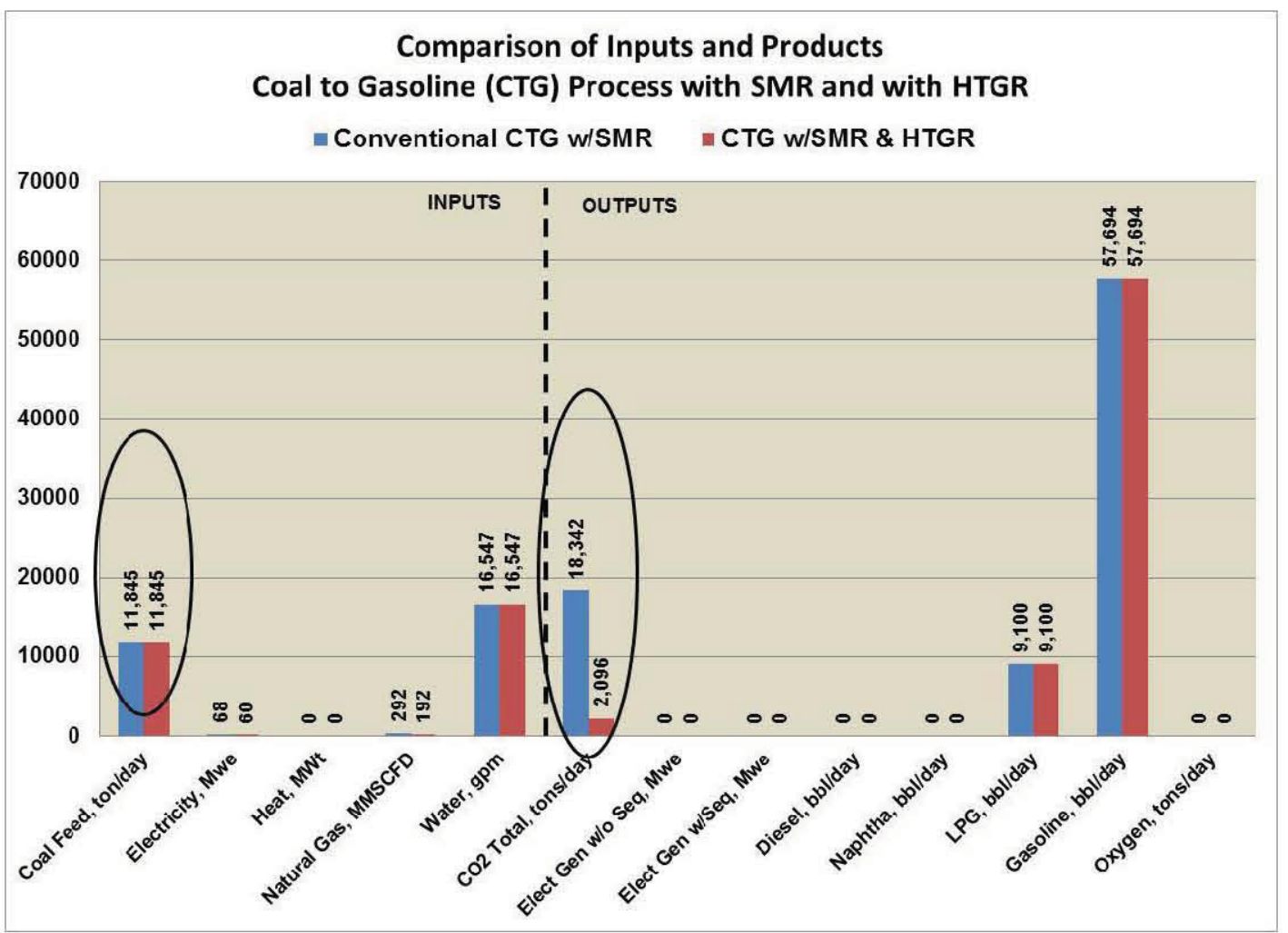

Figure D-25. Coal to gasoline with SMR hydrogen supply and with HTGR heat. 


\section{D-2.3.4 Natural Gas to Liquids}
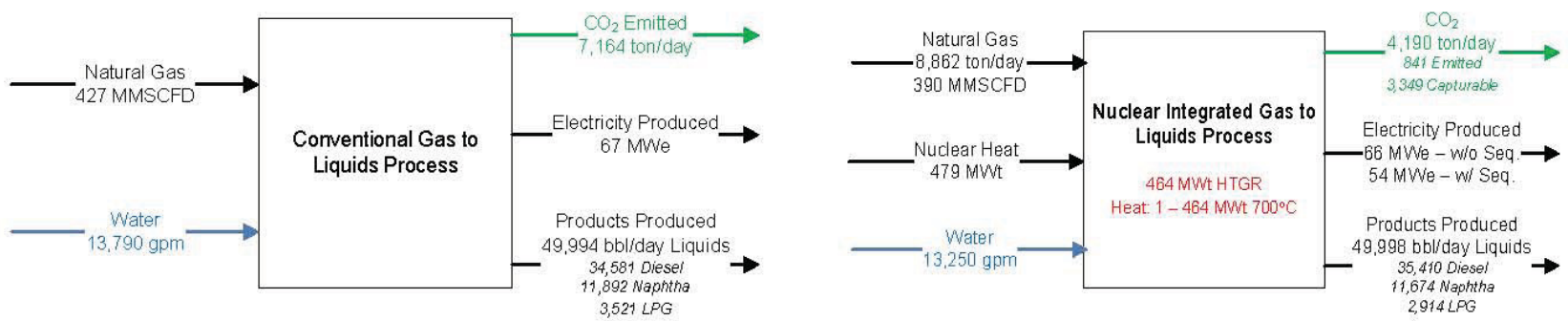

There is little difference in the performance characteristics of this process without and with incorporation of HTGR heat except for a $\sim 50 \%$ reduction in $\mathrm{CO}_{2}$ generation.

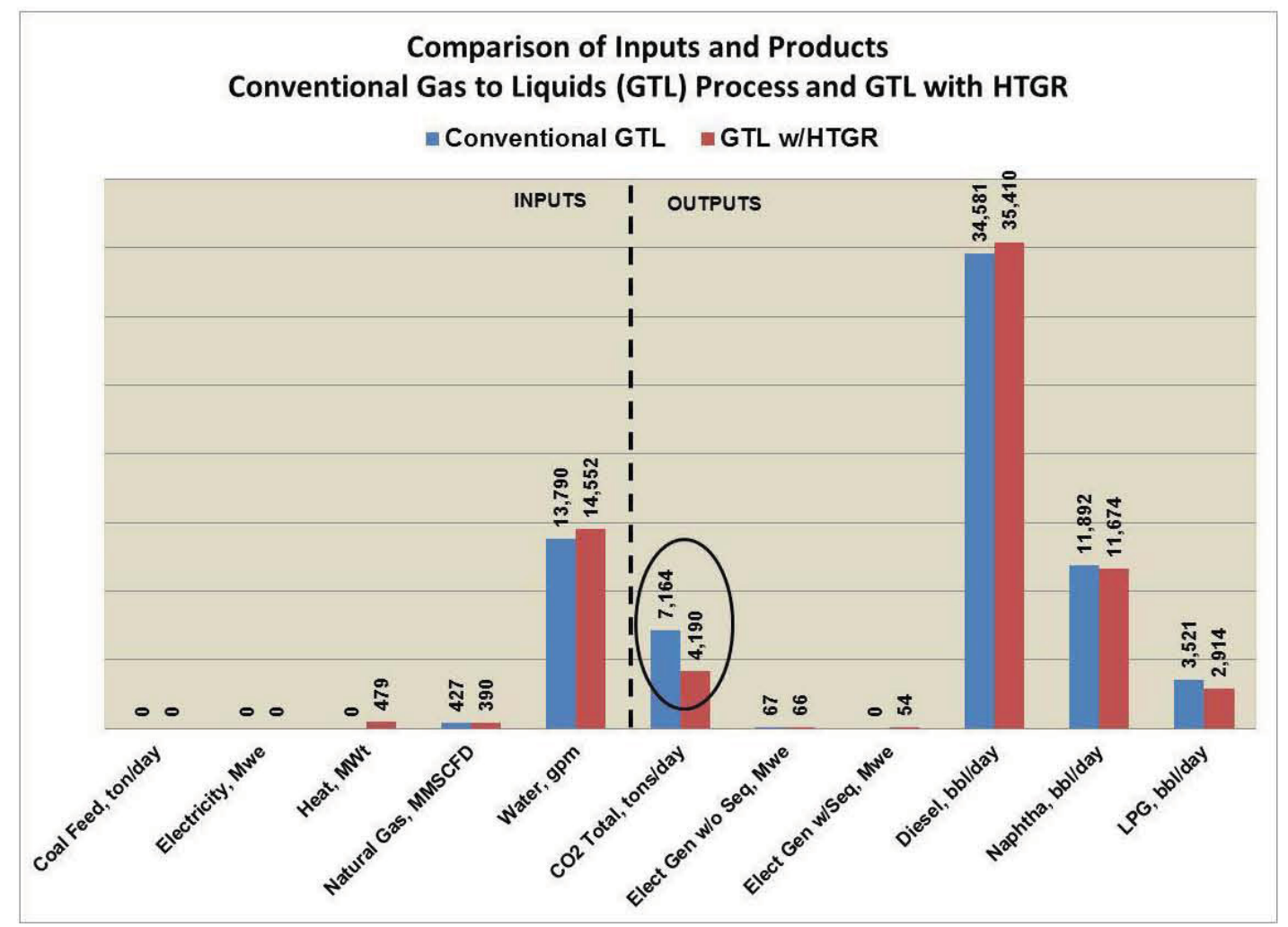

Figure D-26. Natural gas to liquids with and without HTGR.

\section{D-2.3.5 Natural Gas to Gasoline}

- There are at least two natural gas to gasoline plants currently in the planning and construction stages in the U.S. due to the current low prices of natural gas.

- This plant has low $\mathrm{CO}_{2}$ generation in the Conventional configuration but the incorporation of the HTGR heat reduces that generation by $\sim 70 \%$.

- A coal gasification unit could replace the natural gas reformers and the reformers could be converted to steam methane reforming hydrogen production with HTGR heat to convert the plant to a coal to gasoline plant if the economics make that attractive. 


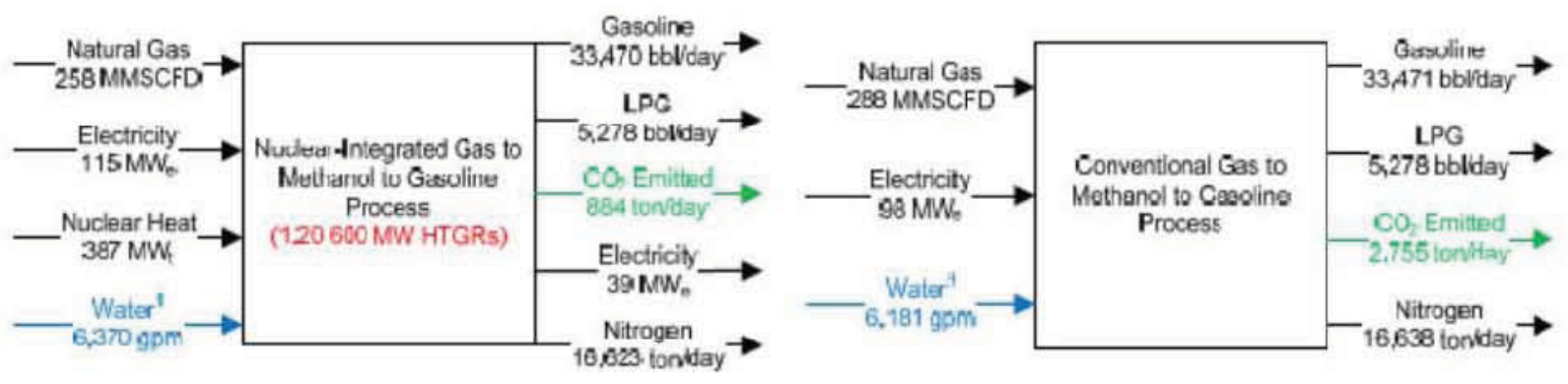

\section{Comparison of Inputs and Products}

Conventional Natural Gas to Gasoline (GTG) Process and GTG with HTGR

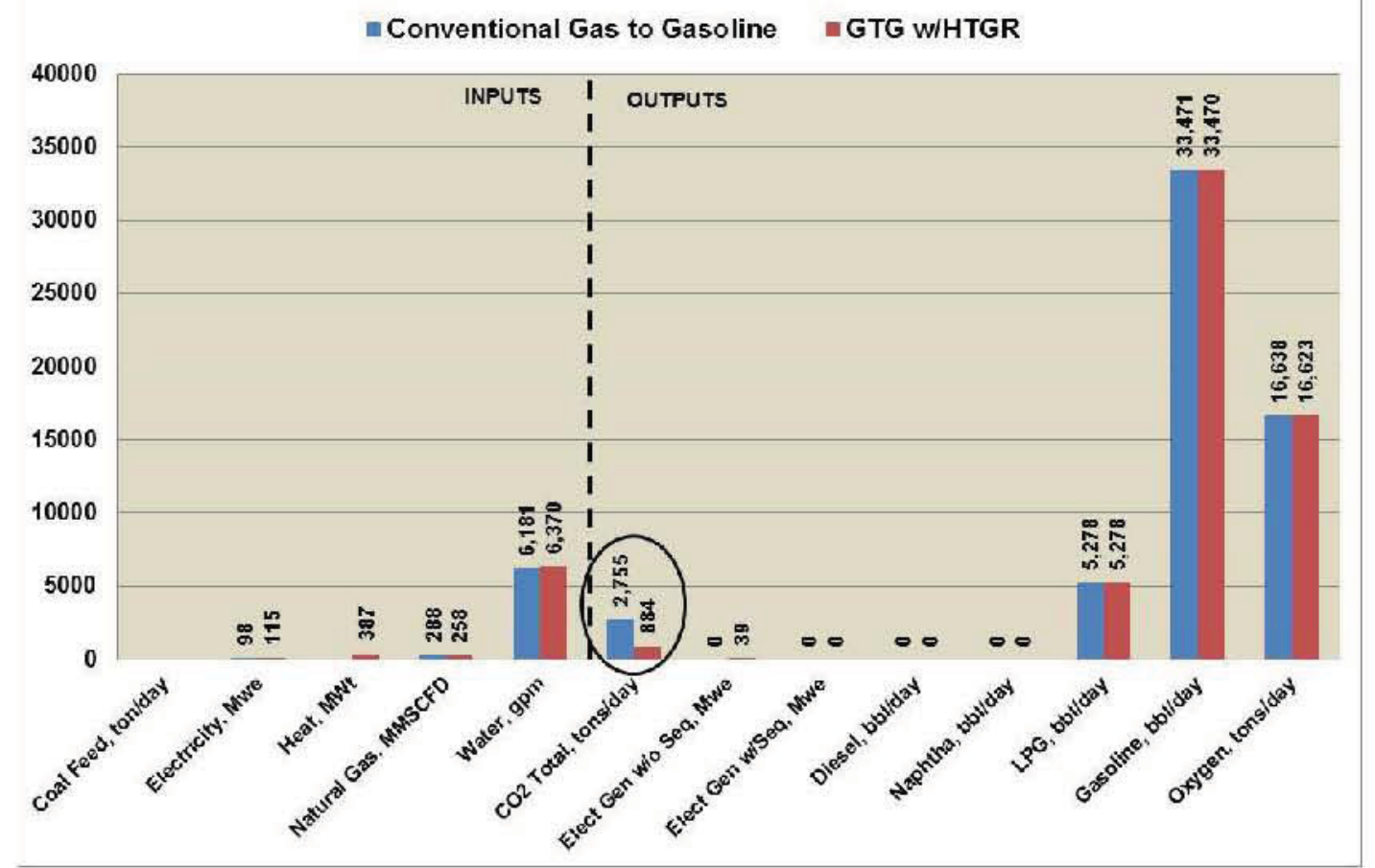

Figure D-27. Natural gas to gasoline without and with incorporation of HTGR heat and electricity.

\section{D-2.3.6 Coal to Chemicals}

- This process produces a large array of chemicals with good market potential.

- Integration of the HTGR technology in the process reduces the coal feed rate by $\sim 55 \%$ and the $\mathrm{CO}_{2}$ generation by $\sim 95 \%$.

- This process could evolve from an initial coal to gasoline plant using the methanol to gasoline process, see discussion on coal to gasoline (CTG) process above. 

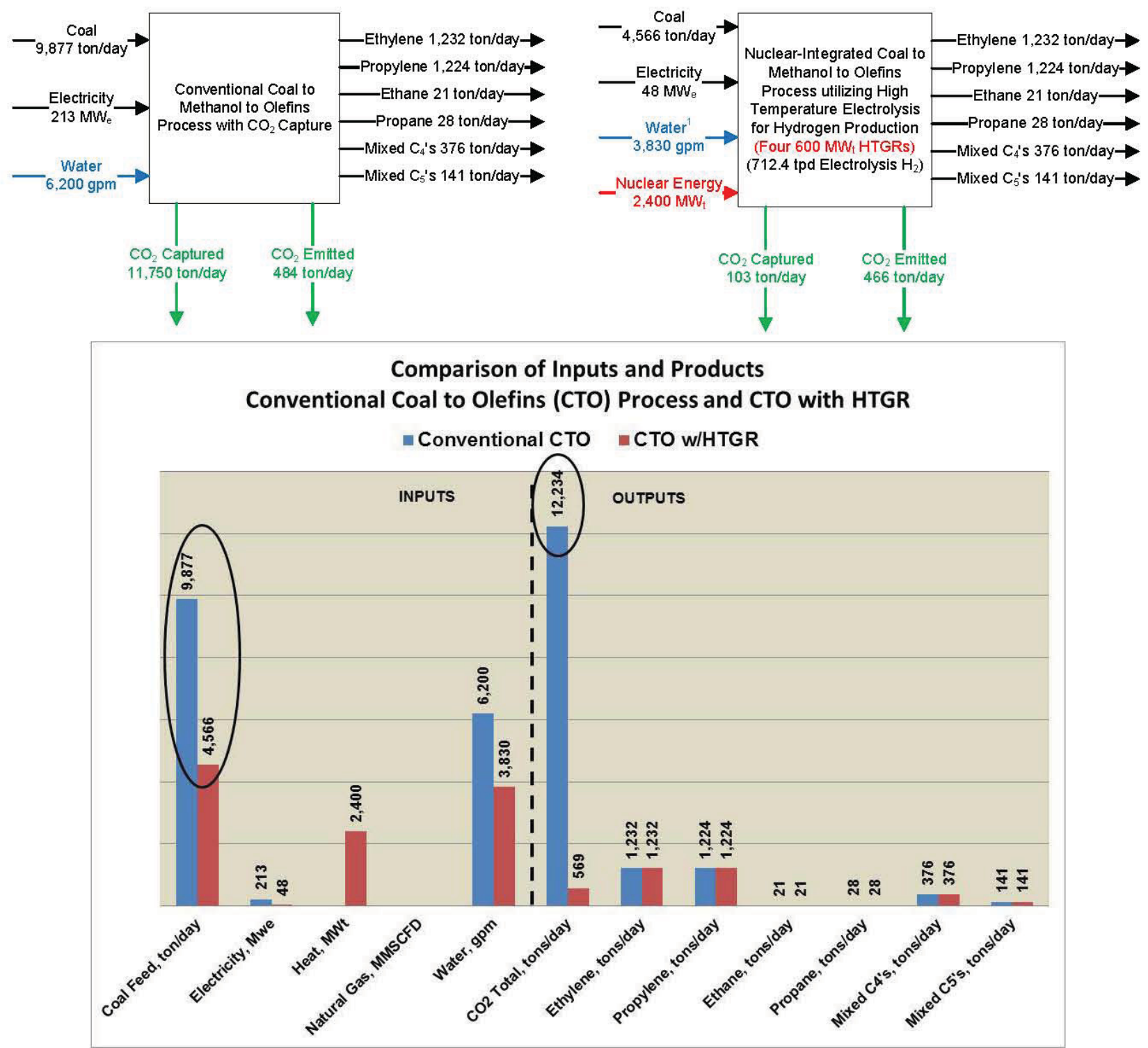

Figure D-28. Coal to olefins with and without HTGR.

\section{D-2.3.7 CTL Process with Naphtha Converted to Gasoline and Olefins}

- This is a complicated process generating a large number of products. It is a process that could evolve from an initial CTL plant if the relative prices of naphtha, gasoline and the olefins warranted adding the equipment. 

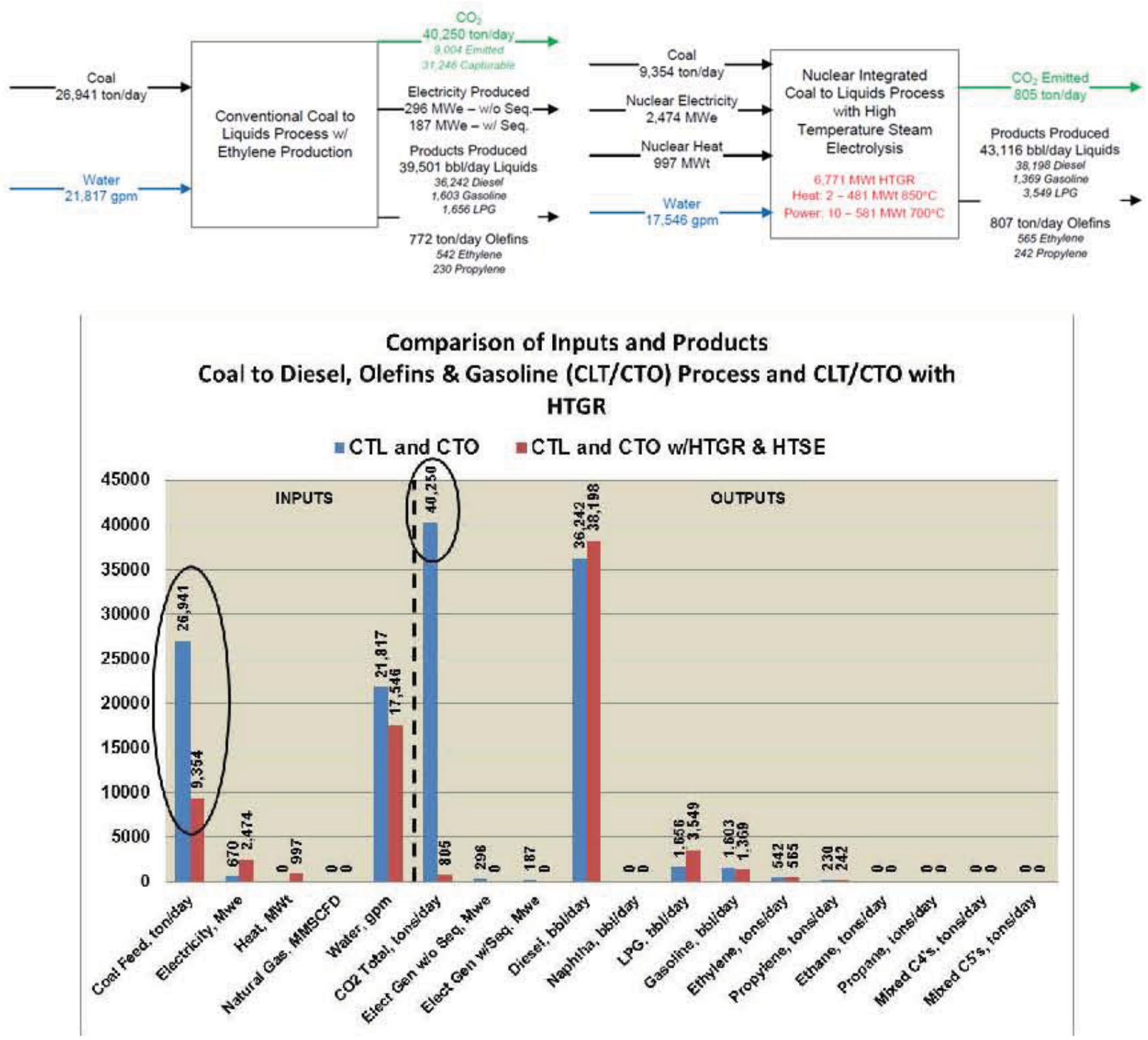

Figure D-29. Expansion of the CTL process to producing chemicals from naphtha.

\section{D-3. Conclusions on the Performance Characteristics of the Alternatives}

The following conclusions are drawn from review of the data in these figures and the summary comparisons of the performance characteristics of the conventional and HTGR incorporated configurations.

1. The conventional processes utilize currently available equipment and facilities that could be deployed in a reasonable period of time - initial start of the Project to deploy a plant to initial start of plant operation in the 3 to 5 year time frame.

2. The conventional processes generate significant quantities of $\mathrm{CO}_{2}$. In most cases analyses have shown the feasibility of capturing a large percentage of that generated for sequestration or enhanced oil recovery. There is significant uncertainty, however, in the costs of capture and sequestration particularly at the scale required for large scale deployment of these technologies. The economic 
analyses conducted herein have assumed a cost of $\sim \$ 16 /$ ton of $\mathrm{CO}_{2}$ for transport and injection based on a recent Global Energy Technology Strategy Program (GTSP) ${ }^{15}$. However, this cost is very location specific and much higher costs may arise. There is also uncertainty in the costs to cover the potential for leakage of the $\mathrm{CO}_{2}$ over the long term. The State of Wyoming, for example, has passed legislation identifying the owner of the sequestration facility as having that liability for 10 years past the date on which the last quantity of $\mathrm{CO}_{2}$ is injected into the storage facility. After that the State transfers the liability to the Federal Government.

3. There is a market for the $\mathrm{CO}_{2}$ for enhanced oil recovery throughout the U.S. The availability of EOR sites, however, is limited. As stated in the GTSP report that evaluated the broad applicability and long term viability of $\mathrm{EOR}$ as a repository for excess $\mathrm{CO}_{2}$ generation:
Although gigatons of low-cost $\mathrm{CO}_{2}$ storage opportunities may be associated with value-added reservoirs in North America alone 112 gigatons in depleted oil fields with EOR potential], the long-term challenge presented by the need to stabilize atmospheric concentrations of $\mathrm{CO}_{2}$ indicates that, because the storage capacity available in oil-and gas-bearing reservoirs is dwarfed by capacity in reservoirs that do not bear saleable products, over the long term, $\mathrm{CO}_{2}$ storage in value- added reservoirs may not represent as significant a portion of total $\mathrm{CO}_{2}$ stored as is widely believed. Our research suggests that all classes of $\mathrm{CO}_{2}$ storage reservoirs are valuable and will be needed once CCS technologies begin their expected large-scale commercial deployment. ...
... there is likely some potential for very low and even negative cost (and therefore perhaps already profitable) CCS opportunities, but these opportunities represent only a small portion of the emissions mitigation potential to be exploited. Many are likely already being utilized by the marketplace, albeit often without application of MMV [Measurement, Monitoring and Verification] systems, which would be required to demonstrate the long-term retention of the injected $\mathrm{CO}_{2}$ if the primary purpose of these projects was climate protection...

Alternatively, a study by the Enhanced Oil Recovery Institute of the University of Wyoming for the Society of Petroleum Engineers ${ }^{16}$ concluded that EOR opportunities exist in Wyoming for $\mathrm{CO}_{2}$ flooding from 8 to $300 \mathrm{MMSCFD}$ with a total after EOR capacity of $\sim 21$ trillion cubic feet. This would persist for several decades and could be a potential for sequestration of the $\mathrm{CO}_{2}$ emissions from the carbon conversion industry. Additions would be required to the existing network of $\mathrm{CO}_{2}$ pipelines in Wyoming to transport the $\mathrm{CO}_{2}$ from the carbon conversion plants to the EOR sites. A large number of the larger sites are in the Powder River and Big Horn Basins which would also be supplying coal to the plants. Accordingly, the additions of the new pipelines may not be prohibitive.

4. Wyoming State Geological Survey has commissioned a study of potential $\mathrm{CO}_{2}$ sequestration sites in Wyoming. The reports on several sites are scheduled to be issued beginning in late August 2012. It is anticipated that significant storage capacity will be identified in Wyoming.

5. The costs of the capture, transport and injection need to be fully understood and included in the process costs. Figure D- 30 for the GTSP study predicts costs that range from ( $\$ 18 /$ ton) to $\$ 100 /$ ton depending on the specifics of the source of $\mathrm{CO}_{2}$ and the sequestration site. The negative value reflects the effect of gaining revenue from a nearby EOR site and very low costs for capture and compression and transport (e.g., from a naturally occurring $\mathrm{CO}_{2}$ reservoir). 

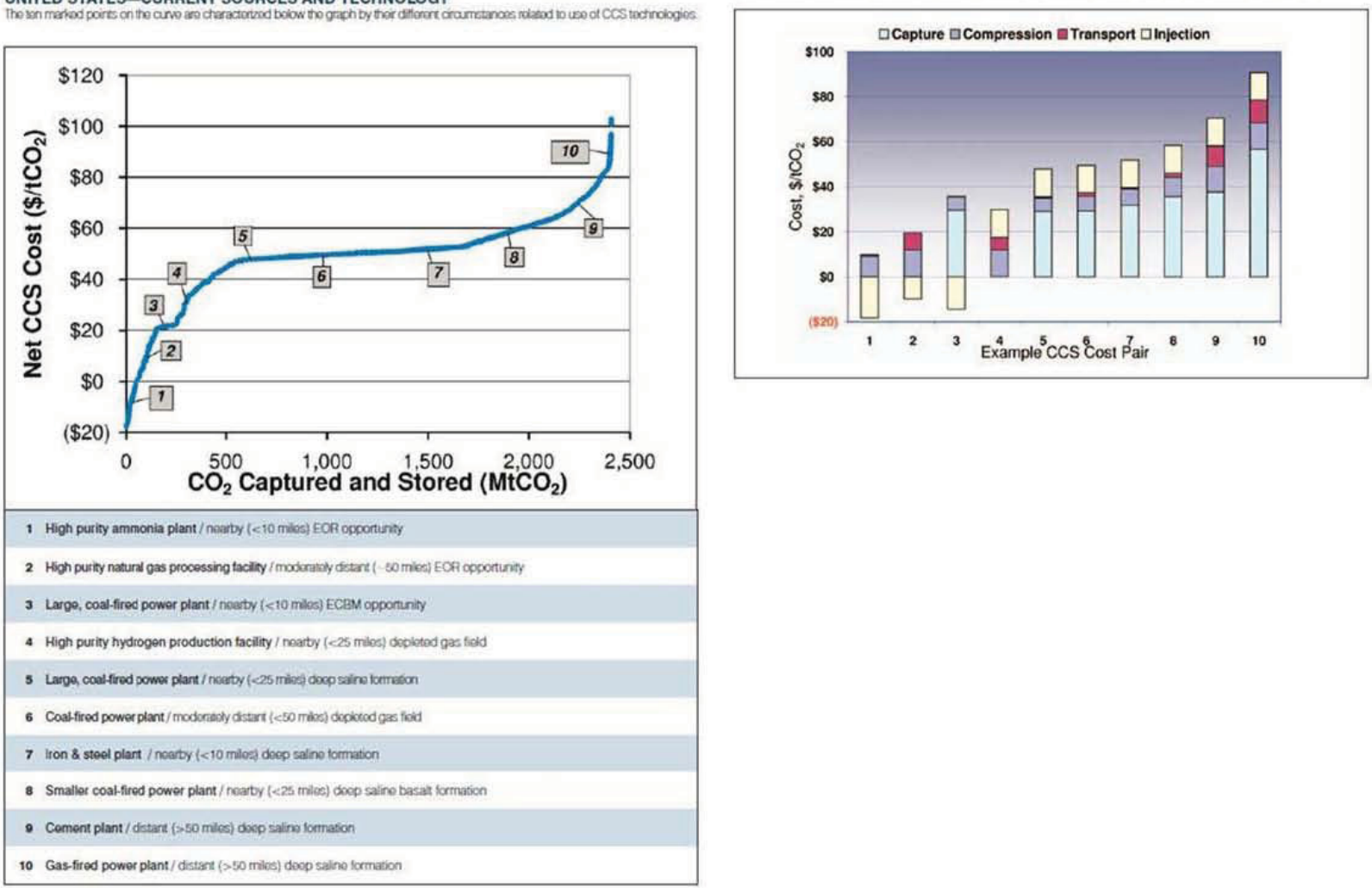

Figure D-30. Net cost of employing CCS within the U.S.

6. Incorporation of the HTGR and HTSE technologies has the advantage of making significant reductions in the $\mathrm{CO}_{2}$ generation of the carbon conversion processes reducing the long term concern with disposition of the $\mathrm{CO}_{2}$. The HTGR energy also has a very stable price. The price of uranium has less than a $10 \%$ impact on the cost of energy production. This shelters the carbon conversion plant operating costs from the high variability of natural prices that have been experienced in the U.S. over the last few decades as shown in Figure D-31.

7. Incorporation of the HTGR and/or HTSE technology into these processes requires completion of the development of these technologies and of the interfacing equipment (e.g., the HTGR interface with the Steam Methane Reforming process for hydrogen production). This integration would take place in the longer term 15 to 20 years out. The strategy for deployment considers that the process selected for deployment in the shorter term (e.g., 2013 - 2028) can be re-configured over the longer term (2028 and beyond) to react to changes in the market or feedstock and to be compatible with incorporation of the HTGR and the HTSE technologies as they are proved technically and economically viable. 


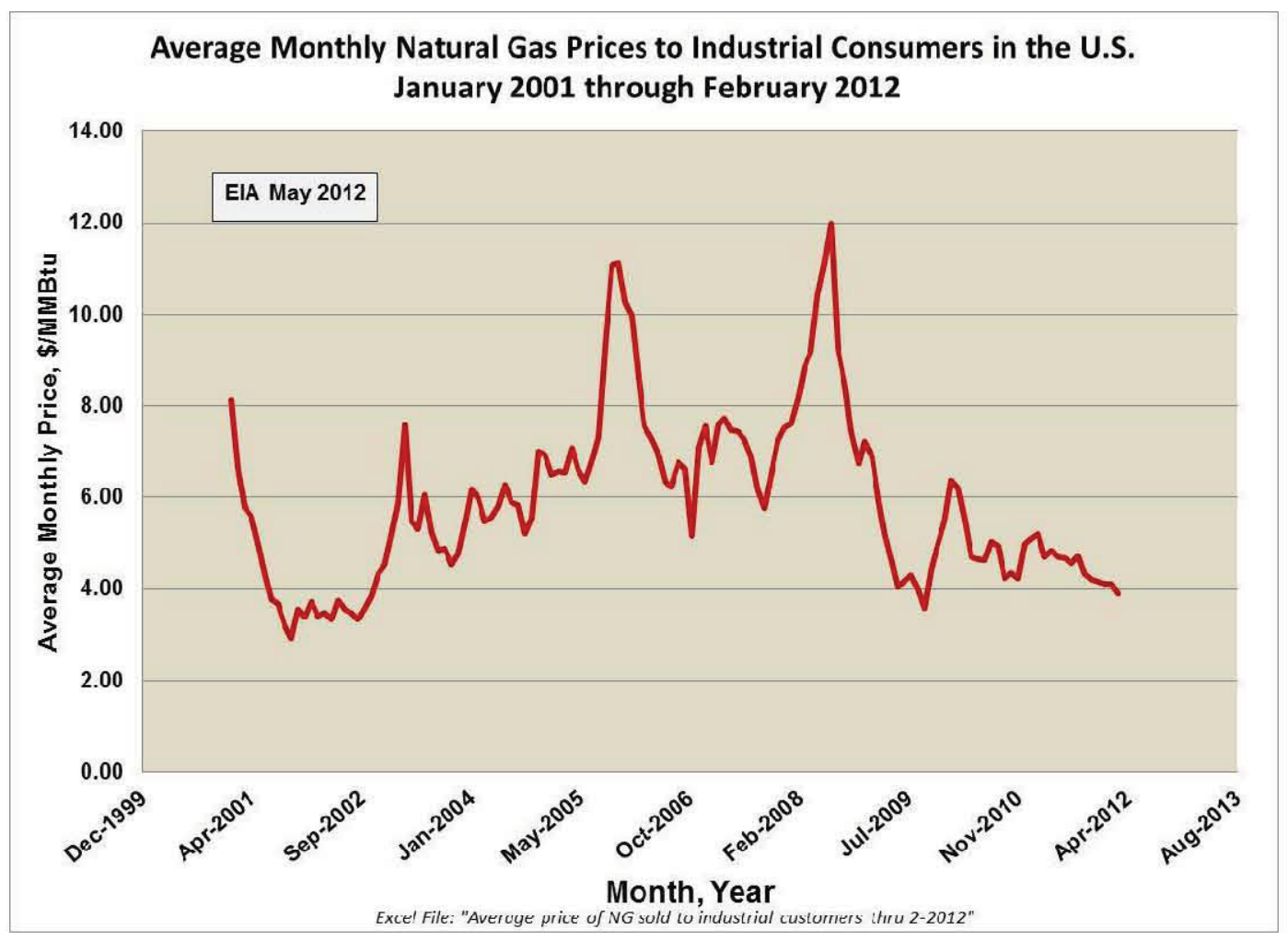

Figure D-31. History of natural gas prices to industrial consumers, January 2001 through February 2012.

\section{D-4. References}

1 http://online.wsj.com/article/SB10001424052702304072004577323770856080102.html and http://www.sasol.com/sasol_internet/downloads/SASOL_GTL_Brochure_1332426778928.pdf and "North America's Syngas Boom," Nitrogen \& Syngas, July-Aüg 2012.

2 TEV-672, HTGR Integration - Coal and Gas to Liquids Production, Rev 3, Idaho National Laboratory, April 27, 2012.

3 Shell, "The Shell Coal Gasification Process for the U.S. Industry," Gasification Technologies Conference, Washington D.C.,October, 2004. , and Shell, "Shell Coal Gasification Process Using Low Rank Coal," Gasification Technologies Conference,San Francisco, CA, October 2005.

4 TEV-667, "Nuclear-Integrated, Methanol-to Gasoline, Production Analysis," Rev 2, Idaho National Laboratory, 05/15/2010.

5 TEV-1567, "Nuclear Integrated Methanol to Olefins Production Analysis," Idaho National Laboratory, July 2012 (DRAFT).

6 New Zealand Institute of Chemistry, "The Production of Methanol and Gasoline," 1996, http://nzic.org.nz/ChemProcesses/energy/7D.pdf, 2008, April 26, 2010.

7 Chinese MTG Plant, www.worldfuels.com/wfExtract/exports/Content/33fead92---fc $2 \mathrm{~d}---447 \mathrm{~d}-$ --bc2e---3e95a8ff6e12.html.

8 DKRW Plant, http://www.uwyo.edu/eori/ files/co2conference11/bob\%20$\% 20$ wyoming $\% 20$ eor $\% 20$ conference $\% 20$ medicine $\% 20$ bow $\% 20$ update $\% 207.13 .2011 \% 20 \mathrm{v} \% 201.0$.pdf, 
the permit application is here: http://deq.state.wy.us/out/downloads/MBFP_ISA_Permit_Application_0917-07 Final.pdf.

9 TransGas Plant, http://www.uhde.eu/press/press-releases/singleview/archive/2011/may/09/article/transgas-coal-to-gasoline-complex-begins-construction.html.

10 Secure Energy Paducah Gasification Plant, Commonwealth of Kentucky, Division for Air Quality, "Permit Application Summary Form," Completed by: Philip T. Jarboe, P.E., 4/14/2011.

11 Chisholm Energy, LLC, Commonwealth of Kentucky, Division for Air Quality, "Permit Application Summary Form," Completed by: Andrew True, 4/20/2011.

12 Buffalo Creek Energy, LLC, Commonwealth of Kentucky, Division for Air Quality, "Permit Application Summary Form," Completed by: Andrew True, P.E., 4/21/2011.

13 China Coal to Chemicals Plant: http://chinaplas.info/archives/1960.html http://www.platts.com/RSSFeedDetailedNews/RSSFeed/Petrochemicals/7937988 http://honeywell.com/News/Pages/Honeywell-UOP\%E2\%80\%99s-Advanced-Methanol-To-OlefinsTechnology-Selected-In-China-To-Produce-Chemical-Products. aspx

14 TEV-667, "Nuclear Integrated Methanol to Gasoline Production Analysis," INL 2010, Rev 2.

15 J. J. Dooley (Lead Author), R. T. Dahowski, C. L. Davidson, M. A. Wise, N. Gupta, S. H. Kim, E. L. Malone, "Carbon Dioxide Capture and Geologic Storage, A Core Element of a Global Energy Technology Strategy to Address Climate Change," A Technology Report from the Second Phase of the Global Energy Technology Strategy Program.

16 R. Wo, SPE, L. D. Whitman, SPE, J. R. Steidtmann, Enhanced Oil Recovery Institute, University of Wyoming, Society of Petroleum Engineers, SPE 122921, April 2009. 


\section{Appendix E}

\section{Economic Analyses}




\section{Appendix E Economic Analyses}

\section{E-1. Description of the Economic Model}

\section{E-1.1 Methods}

The INL NGNP Project has developed a detailed discounted cashflow economics model for the purposes of analyzing the economic viability of applying the HTGR technology as a high temperature energy supply in industrial applications including the generation of electricity. ${ }^{1}$ The technical evaluation reports listed in Appendix D summarize the results of applying this model to compare the economics of the HTGR incorporated processes with the conventional processes considered herein. In this regard, the metrics used for these comparisons are the costs of the products of each process that are calculated to achieve a required return on investment. The economic model includes correlations on the overnight direct and indirect costs, including owners cost and contingency, for industrial, HTGR, power conversion and HTSE plants versus the size and operating characteristics of these plants (e.g., as a function of the process and the production rate for a CTL plant, the operating temperature and electricity and steam generation rate for an HTGR plant with, for example, a sub-critical Rankine cycle power conversion system and the hydrogen production rate for an HTSE plant). Typical construction periods and spending profiles are applied for calculation of interest during construction and the debt ratio is applied to allocate the cashflow during construction between debt and equity. Phased construction and start of operation for modular expansion of plants can be accommodated in developing the annual cashflows; for example, when parts of the plant are operating and generating revenue while other parts are still under construction. The model will account for the effects on capacity factor of the plant due to planned and unplanned shutdowns (e.g., turnarounds in a petro-chemical plant, refueling of a nuclear plant).

There are several options for the calculations performed in the model. An internal rate of return for the project ${ }^{\mathrm{h}}$ can be calculated for a given set of product prices or an iteration can be performed on the products pricing to achieve a given internal rate of return. In the case where an HTGR plant is incorporated with the process, the calculation of return can be made for the industrial and HTGR plants separately or as an integrated entity. This permits evaluating conditions where there are separate owners of the plants and different financial parameters are used for each plant.

\section{E-1.2 Financial Parameters}

The financial parameters used by the model include the following. The values shown are those used for the evaluations described herein.

The analyses discussed herein were all performed for the set of financial parameters listed above to support comparison of the economics of each process. These parameters were recommended by the NGNP Industry Alliance, Ltd for evaluation of nth-of-a-kind HTGR applications. It should be noted that the economic analyses reported in the INL technical reports listed in Appendix D were performed for different financial parameters than those listed so the results in those reports are slightly different than those reported herein.

h In this context "project" refers to the full scope of the plant design, procurement and construction, financing, operation and, where applicable, decommissioning and disassembly. 
Table E-1. Summary of financial parameters.

\begin{tabular}{|ll|}
\hline \multicolumn{1}{|c|}{ Item } \\
\hline Debt to Equity Ratio & $80 \%$ \\
\hline Interest During Construction & $8 \%$ \\
\hline Financing Interest & $8 \%$ \\
\hline Financing Term & 20 years \\
\hline Required Internal Rate of Return & $10 \%$ \\
\hline Effective Tax Rate & $38.9 \%$ \\
\hline Depreciation Rate & MACRS, 15 years \\
\hline
\end{tabular}

\section{E-1.3 Costs for $\mathrm{CO}_{2}$ and its Disposition}

The model also has provision to account for any operating costs associated with the production of $\mathrm{CO}_{2}$ from the processes. These costs could arise from taxes on emissions of $\mathrm{CO}_{2}$ to the environment or for capture of $\mathrm{CO}_{2}$ for sequestration or EOR. In the latter case if capture of $\mathrm{CO}_{2}$ is included in the plant, costs for the equipment necessary for capture are included in the overnight costs of the plant and the costs for the electricity required to operate that equipment is included in the operating costs of the plant. The costs for transport and injection of the $\mathrm{CO}_{2}$ are also included in the operating costs. If it is assumed that there is a cost associated with emissions of $\mathrm{CO}_{2}$ these costs are also included in the operating costs.

There is considerable uncertainty in what the costs of emissions and sequestration may be. Accordingly, analyses were performed with and without these costs. In the case where analyses were performed including costs for $\mathrm{CO}_{2}$, as shown in the preceding section, the $\mathrm{CO}_{2}$ was sub-divided into a fraction that could be captured and transported for sequestration or EOR and the balance that could not be captured and would be emitted to the environment. The costs for transport and sequestration were obtained from a GTSP study ${ }^{6}$. The costs for emission were varied over a wide range (e.g., $\$ 0 /$ ton to $\$ 200 /$ ton) to determine its impact on the required product pricing. Sensitivity analyses were also performed to determine the effect of applying carbon capture and sequestration (CCS) and not applying CCS with variations in the cost of the additional emission. The results of these sensitivity analyses are discussed below.

\section{E-1.4 Sensitivity Analyses}

Finally the model has provisions for performing analyses to establish the sensitivity of results to variations in inputs, such as the costs of $\mathrm{CO}_{2} \mathrm{CCS}$ and emissions, capital cost, debt ratio, internal rate of return, etc. The results of these analyses are presented in tornado charts. Examples of these charts are shown below for the carbon conversion alternatives. It is also possible to perform Monte Carlo analyses for the same variations in input values to develop a probability distribution for the product pricing that represents the composite effect of these variations. A typical chart is shown below for the CTL process with SMR.

\section{E-2. Results of Economic Analyses}

\section{E-2.1.1 Short and Long Term Deployment Time Frames}

As cited previously the potential for deployment of carbon conversion technologies has been evaluated over short term and long term time frames. This subdivision accounts for the time that will be required to complete development and commercialization of the HTGR and HTSE technologies. The 
short term covers the period 2013 through 2028; the longer term 2028 and beyond. The carbon conversion technologies considered for deployment in the short term are designated as "Conventional" and, in general, are non-developmental with current and historical operating experience. The incorporation of the HTGR and HTSE technologies would be over the longer term subject to demonstration of their technical and economic viability.

\section{E-2.1.2 Carbon to Transportation Fuel Conversions}

Figure E-1 shows the results of evaluating the economics of the Conventional carbon conversion processes for the production of diesel fuel. Since the majority of diesel fuel is produced by refining crude oil and the price of refined diesel oil is a strong function of the price of crude oil, the economic viability of the carbon conversion processes is estimated by comparing the production cost of diesel produced using these processes against that refined from crude oil as a function of the price of crude oil. The correlation of the price of refined diesel with the price of crude oil shown in Figure E-1 was developed using historical data supplied by the DOE Energy Information Agency. ${ }^{2}$ Also shown on this figure is the range of EIA projections on the price of crude oil through $2035 .{ }^{14}$ Figure E-2 shows these projections and their wide range of uncertainty.

Figure E-1 shows the projected production costs and the equivalent cost per barrel of crude oil for refined diesel for the conventional coal and natural gas to diesel processes and for those processes integrated with HTGR and HTSE technologies. The HTGR and HTSE technologies are shown for several different configurations:

- The HTGR supplying heat and electricity to the SMR process producing hydrogen to be used in coal gasification to achieve the required $\mathrm{H}_{2}$ to $\mathrm{CO}$ ratio in the synthesis gas (CTL with SMR \& HTGR).

- The HTGR supplying heat to the primary natural gas reformer as a substitute for burning the natural gas in that stage of reforming (GTL w/HTGR)

- The HTGR supplying electricity to HTSE supplying hydrogen to the gasification process instead of the SMR (CTL w/HTGR \& HTSE)

- HTSE supplying hydrogen to the coal gasification process and obtaining electricity for a source other than an HTGR (CTL w/HTSE @ \$40/Mw(e)-hr)

As shown all of the processes except the CTL w/HTGR \& HTSE have production costs that are grouped in the lower half of the projections of crude oil prices; $\$ 60$ to $\$ 96 / \mathrm{bbl}$. However, the production costs for the CTL w/HTGR \& HTSE is still within the upper range of the EIA projections 


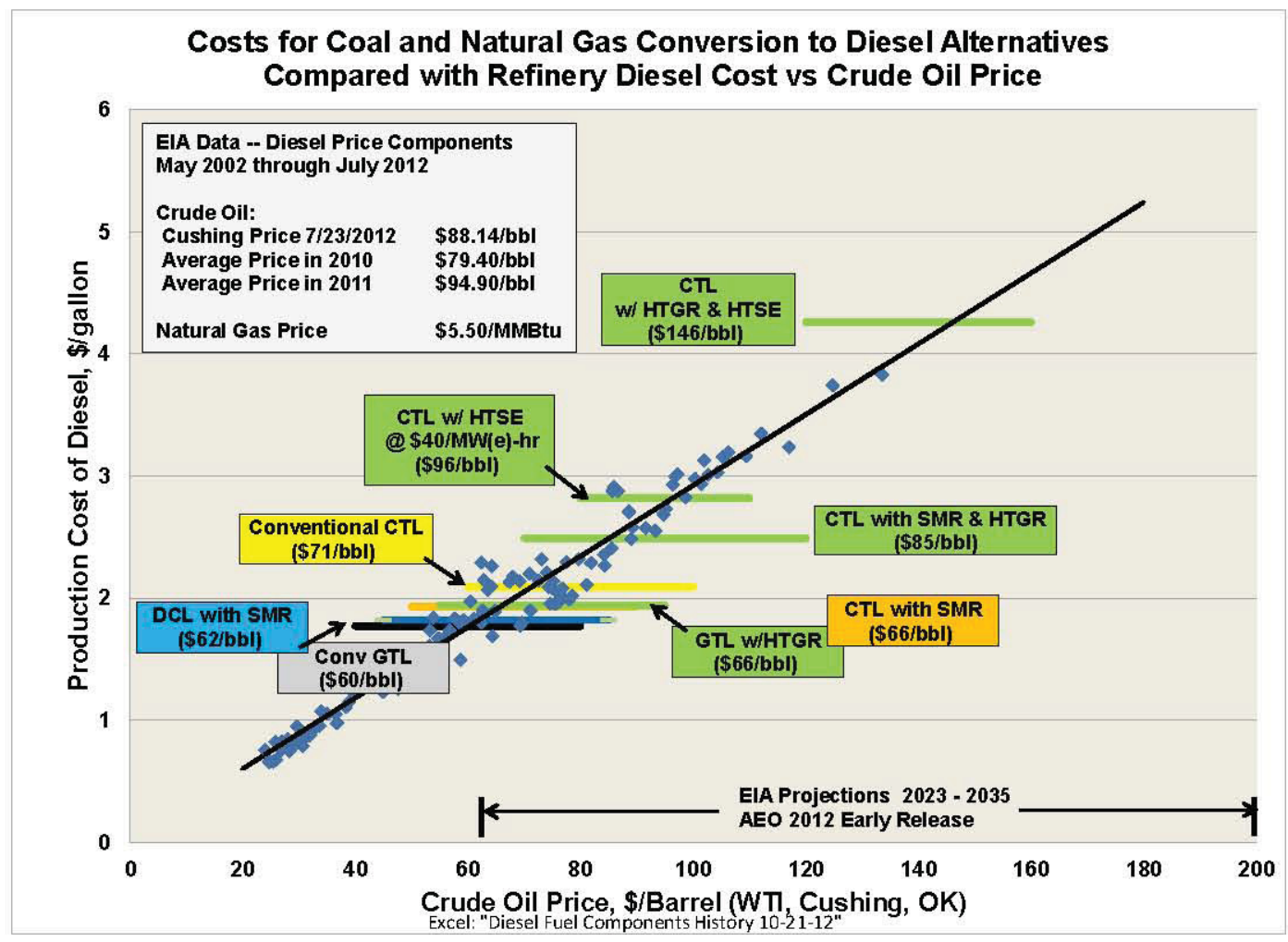

Figure E-1. Comparison of the production costs of conventional carbon conversion processes with the production cost of diesel refined from crude oil vs. the price of crude oil.

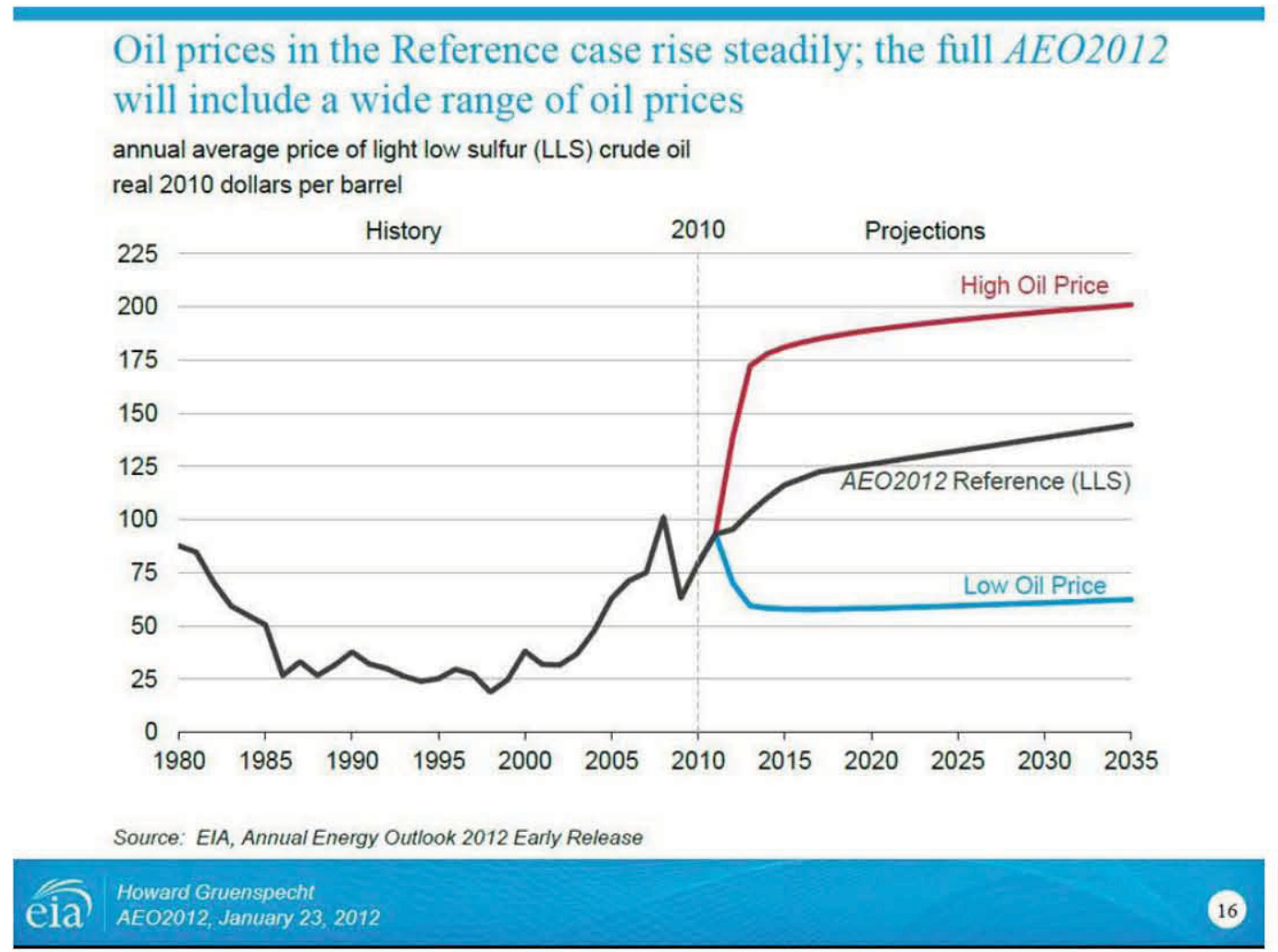

Figure E-2. EIA projections of the potential range of crude oil prices from the present through 2035. 
Figure E-3 is a similar figure showing the results of evaluating the coal and natural gas to gasoline MTG processes with the correlation of gasoline price with crude oil price. As cited for the correlation of diesel production cost versus crude oil price, this correlation was also developed from EIA data. The same variations in the use of the HTGR and HTSE technologies are shown in this figure. All but the CTG w/HTGR \& HTSE processes have equivalent costs of crude oil grouped in the lower half of the EIA long term price projections; $\$ 56$ to $\$ 96 / \mathrm{bbl}$ ). Again the CTG w/HTGR \& HTSE production costs are in the range of refined diesel production costs for EIA projections of crude oil prices.

As shown in these figures the production costs estimated for the conventional carbon conversion processes are competitive with the production cost of diesel and gasoline refined from crude oil for the lower half of the EIA projections for the price of crude oil from the present through 2035 (\$60 to $\$ 145 / \mathrm{bbl})$.

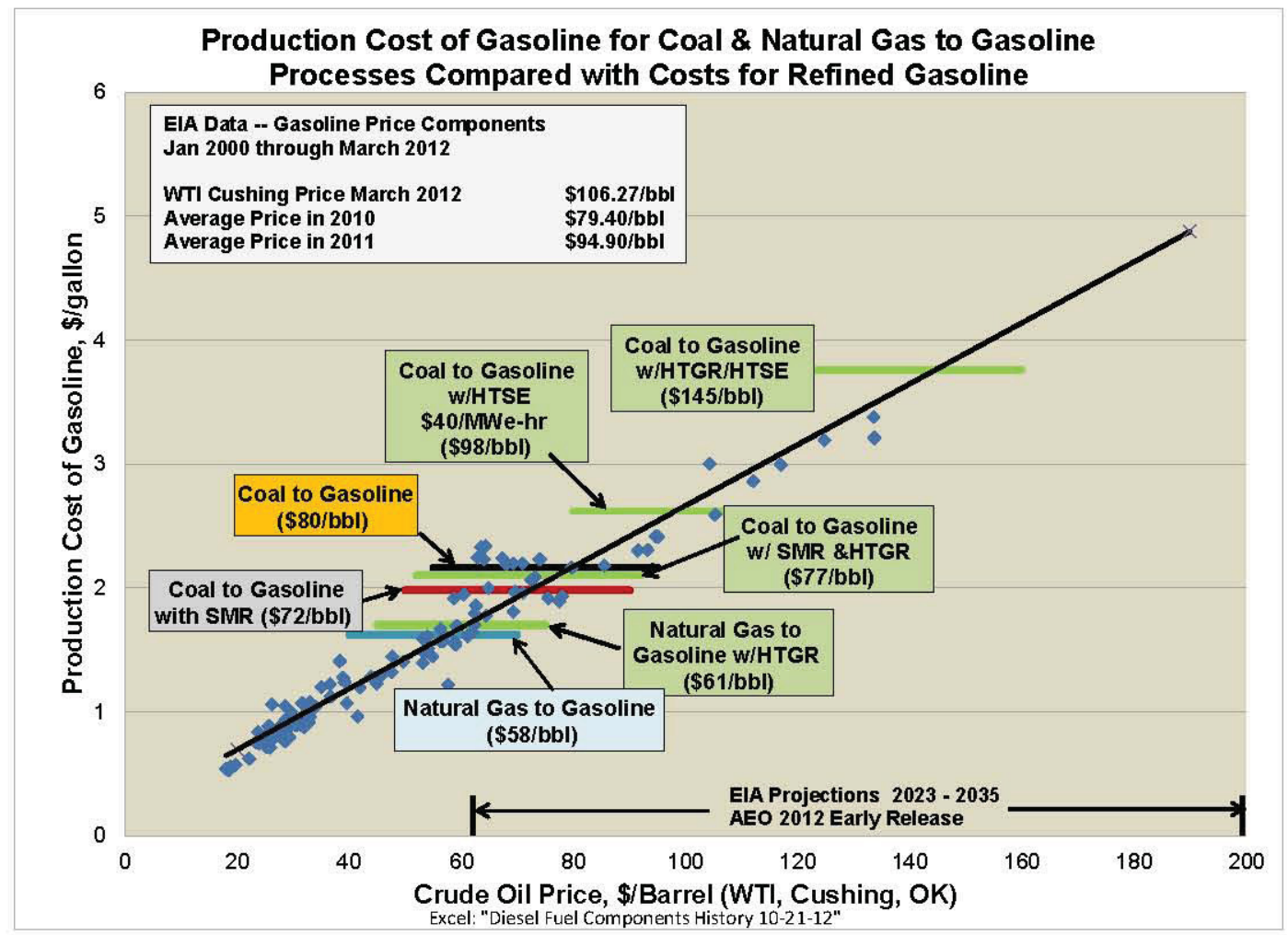

Figure E-3. Production costs of conventional and nuclear incorporated coal and natural gas to gasoline processes compared with the production cost of gasoline refined from crude oil vs. the price of crude oil.

Figure E-4 consolidates the results of the economic evaluations of all of the carbon conversion processes comparing the production costs of the conventional with the HTGR/HTSE incorporated cases and the costs of $\mathrm{CO}_{2}$ emissions that would be required to raise the conventional process costs equal to the nuclear incorporated process; a range of $\$ 17 /$ ton to $\$ 170 /$ ton. As shown, all of the candidate processes except for those incorporating the HTGR and HTSE technologies have production costs lower than the production costs of diesel and gasoline at $\$ 100$ /crude oil price.

The $\mathrm{CO}_{2}$ cost required to bring the production costs for the conventional processes in line with those for the nuclear incorporated case as shown in Figure E-5 vary considerably for several reasons. In those cases where the conventional process generates large quantities of $\mathrm{CO}_{2}$ (e.g., CTL) the effect of $\mathrm{CO}_{2}$ costs on production costs are higher than for those processes where the generation of $\mathrm{CO}_{2}$ is lower (e.g., 
CTL w/SMR, GTL and MTG). Secondly, for those cases using HTSE the cost of hydrogen produced by HTSE is a strong function of the cost of electricity as shown in Figure E-4 and Figure E-5. The economic evaluations performed for the case where the HTGR supplies electricity to the HTSE process, (red bars in Figure E-4) used a conservative model of the HTGR with an equivalent electricity cost of $\sim \$ 80 / \mathrm{MW}(\mathrm{e})$-hr and an equivalent hydrogen production cost $\sim \$ 3 / \mathrm{kg}$. For an electricity cost in the $\$ 40 \mathrm{MW}(\mathrm{e})$ - $\mathrm{hr}$ range which is typical of the cost to industrial users in Wyoming the equivalent hydrogen production cost would be $\sim \$ 1.6 / \mathrm{kg}$. For comparison the production cost of hydrogen using SMR with a natural gas price of $\$ 6.50 / \mathrm{MSCF}$ is $\sim \$ 1.9 / \mathrm{kg}$. As shown in Figure E-4 (orange bars) for the case where the cost of electricity is in this range the production costs using HTSE only are more competitive with the other processes. This issue is discussed further in the conclusions below.

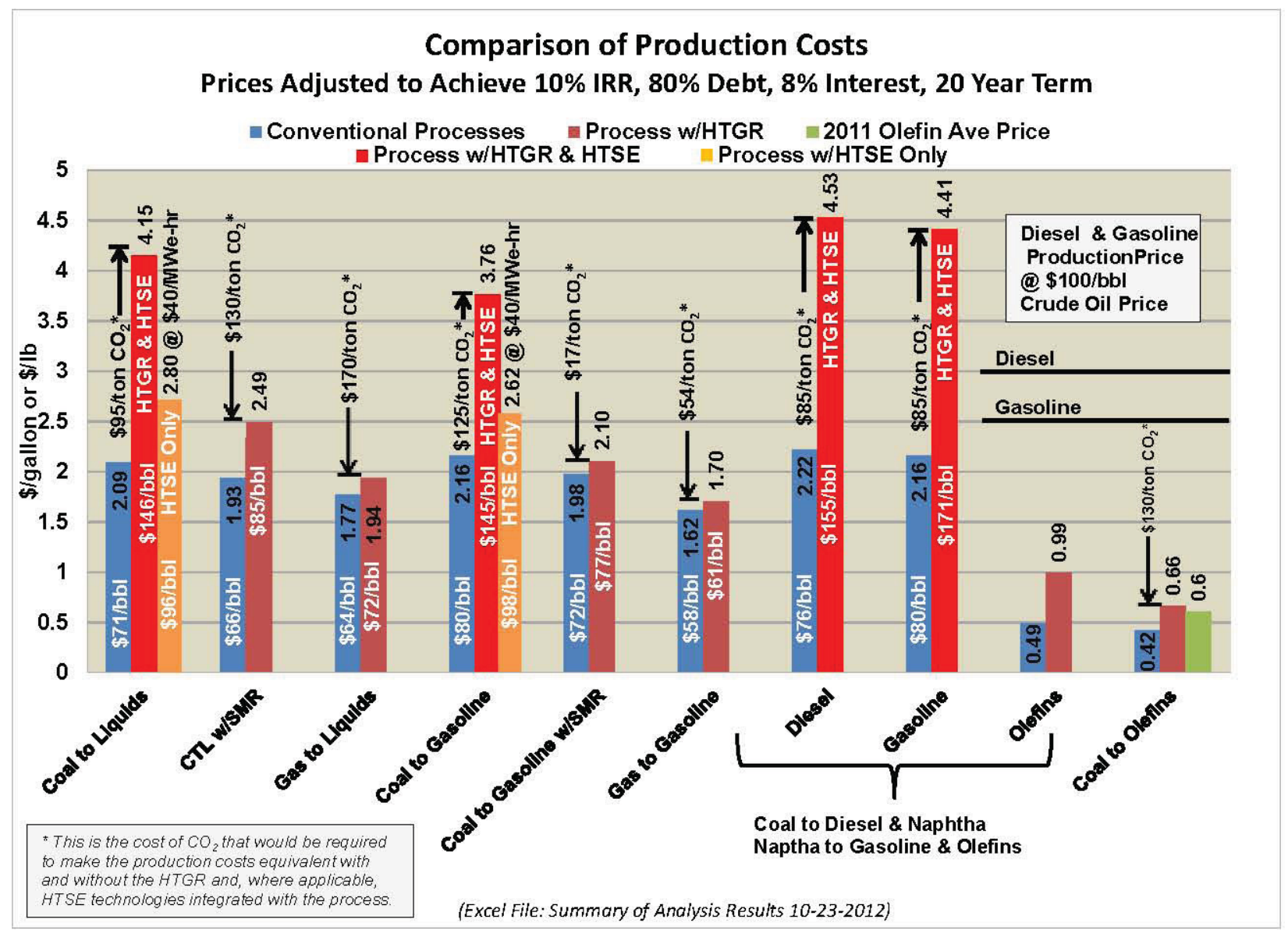

Figure E-4. Comparison of production costs for alternative carbon conversion processes. 


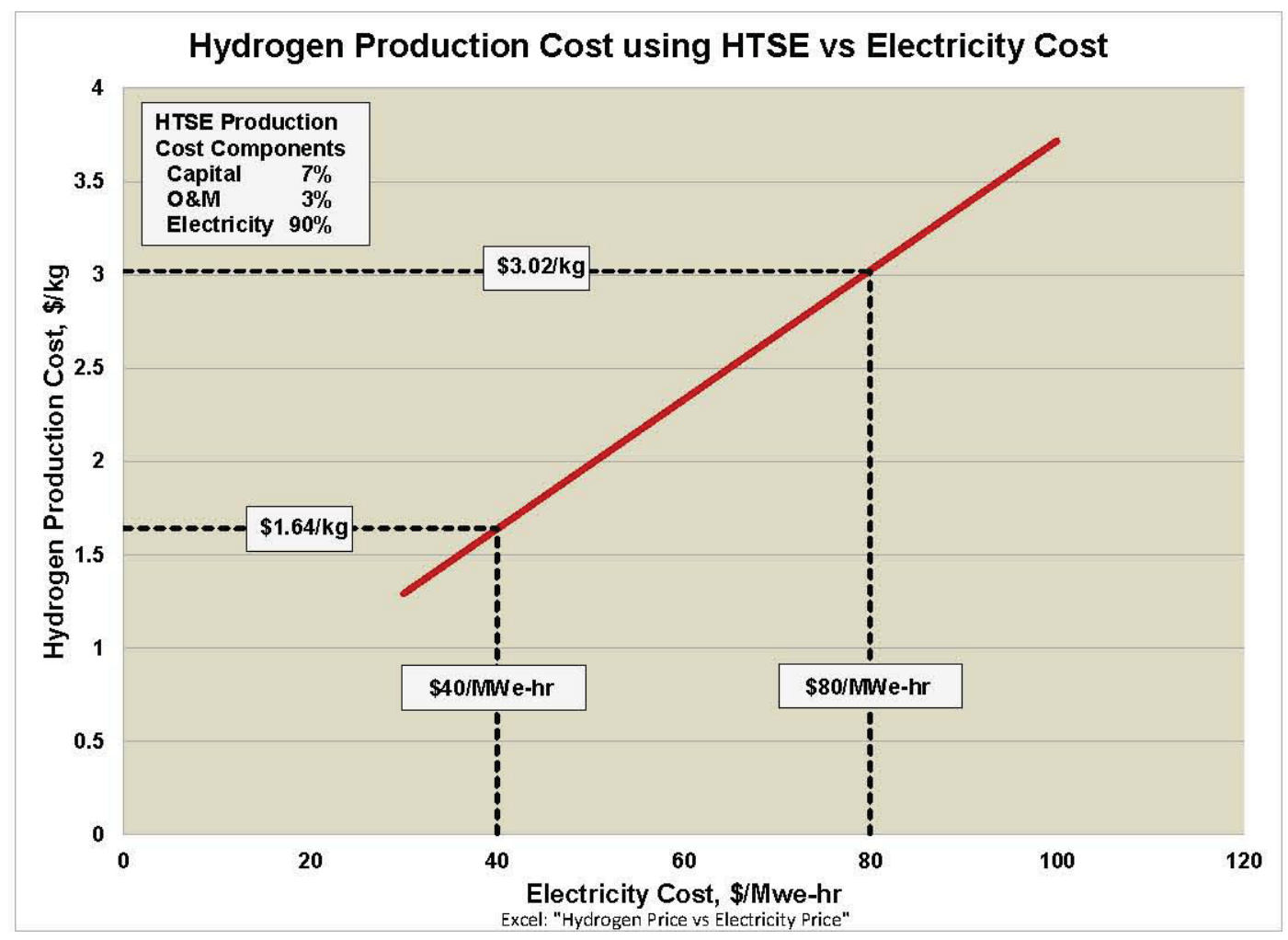

Figure E-5. HTSE hydrogen production cost versus cost of electricity.

\section{E-2.2 Carbon to Chemicals Conversion}

The comparison of the costs for chemical production using the Conventional and nuclear incorporated processes is also shown on Figure E-4 along with the current price of Olefins represented by the price of Ethylene. For the purposes of the discussion Ethylene is used as representative of the full range of chemicals produced in these processes. As shown, the current price of Ethylene lies about half way between the costs estimated for the Conventional and nuclear incorporated cases.

\section{E-2.3 Projections on Natural Gas Long Term Prices}

Since most chemical production in the U.S. uses natural gas as the feedstock, the price of Ethylene shown in Figure E-4 reflects the current low price for natural gas. There are, however, several factors that may result in an increase in natural gas prices over the next two decades. Figure E-6 summarizes the effect of these factors. The curve extending from 2010 to 2035 and bracketed by the dotted lines reflects estimates by the EIA in the initial release of the 2012 Annual Energy Outlook (AEO) on the potential increase in natural gas prices over this time frame and the uncertainty in those prices at that time (2011\$). The range of potential prices in 2035 projected by EIA ( $\$ 5.35$ to $\$ 9.26$ ) is based on their assessment of the uncertainty in the quantities of gas shale reserves and the large variation in the economics of extracting gas from the shale in the several locations currently being produced.

There are other factors, however, that can affect this uncertainty range and were not considered in the EIA assessment. The low price of natural gas in the U.S. coupled with the high price of natural gas outside the U.S. (see Figure E-7) presents an arbitrage opportunity through export. At the time of this writing at least seven of the nine major LNG terminals in the U.S. have submitted requests to become exporters and two of these had received approval. ${ }^{3}$ The amount of natural gas that will be exported and the effect of this export on natural gas prices in the U.S. is uncertain. Review of the literature shows 


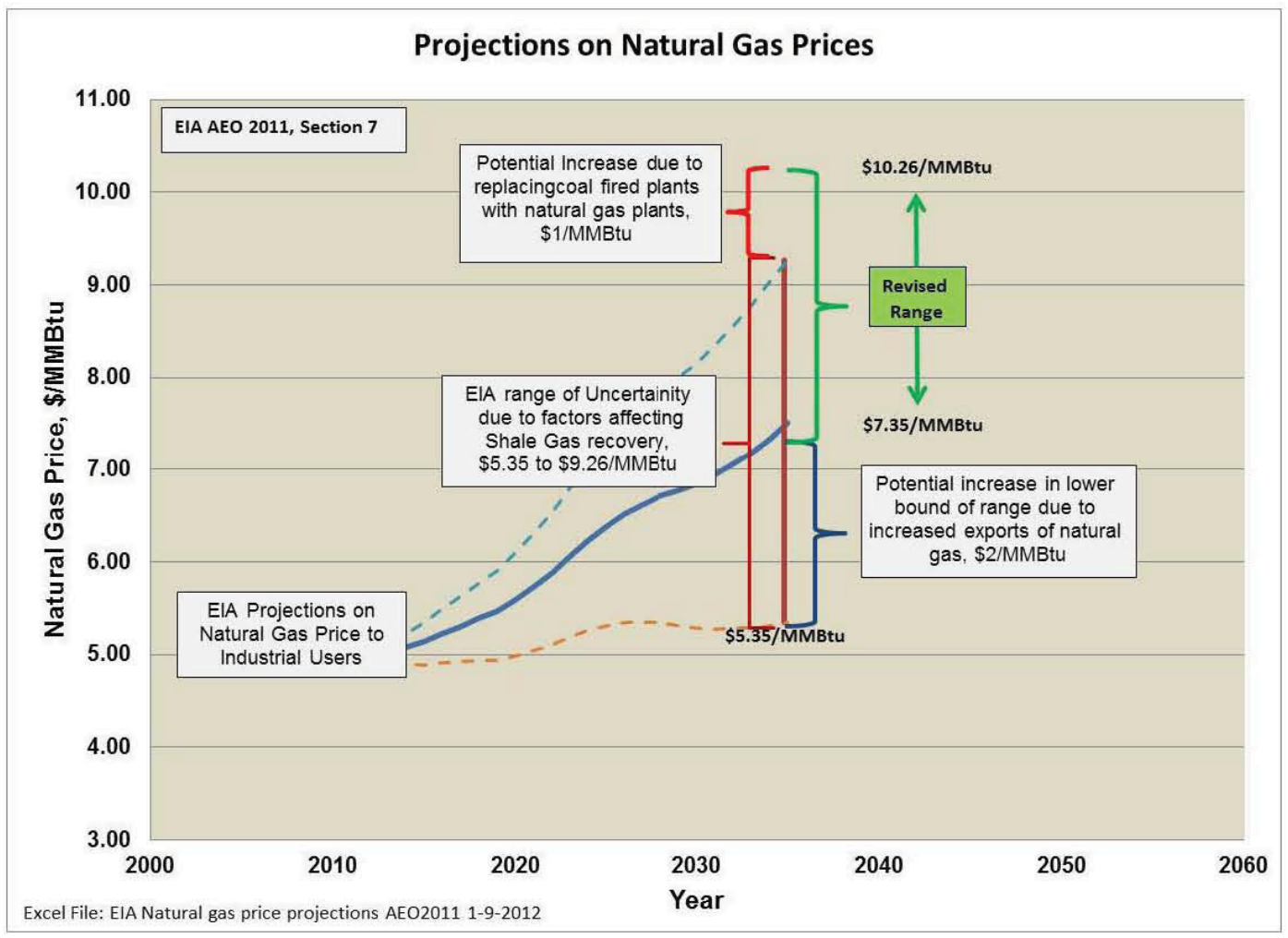

Figure E-6. Projections on long term price of natural gas.

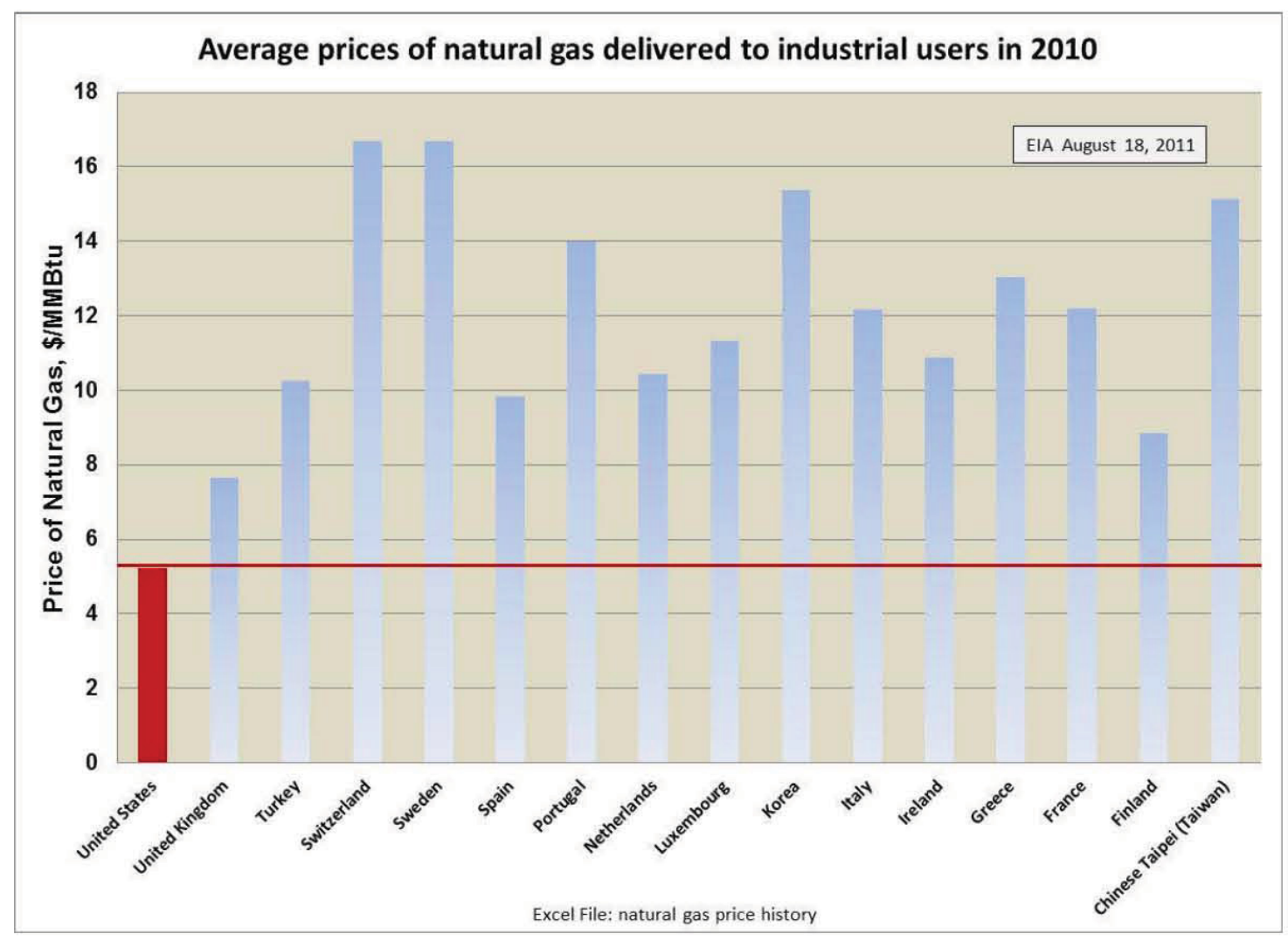

Figure E-7. Comparison of U.S. with international natural gas prices in 2010 . 
a wide range of conclusions on this subject. On average an effect of $\$ 2 / \mathrm{MMBtu}$ is judged possible. As shown in Figure E-6 this factor has been applied to the lower end of the range of uncertainty because prices in the U.S. must remain low to make export economically viable (with an addition of $\$ 2$ to \$3/MMBtu for compression and shipping).

The other factor potentially affecting natural gas prices over the long term as shown in Figure E-6 is the potential for expanded use of natural gas for the generation of electricity. This is projected to occur because of the low price of natural gas and the increase in EPA regulation on emissions that has resulted in the actual and projected early retirement of coal fired power plants. Again there is uncertainty in this effect but a review of the literature ${ }^{4}$ shows a conservative estimate of a $\$ 1 / \mathrm{MMBtu}$ effect.

This latter effect is assumed to affect the upper range of the natural gas pricing for the following reason. As low natural gas prices make this technology viable as a substitute for the generation lost due to premature retirement of coal fired plants the percentage of the electricity generation infrastructure in the U.S. based on natural gas will obviously become higher. As natural gas prices increase due to the several factors discussed herein there will come a price at which natural gas generation is not the most economic compared with alternatives (e.g., the HTGR or other nuclear based technologies). This price will be lower if there are governmental actions that result in costs for $\mathrm{CO}_{2} \mathrm{CCS}$ or emissions. It will not, however, be economic at that time to replace the natural gas infrastructure over a short term because of the significant investment required. This will result in the continued use of the natural gas technologies for electricity, even in the face of rising natural gas prices, for some period until retirement of that infrastructure becomes economic.

Based on this analysis the range of the potential price of natural gas in 2035 is projected to be $\$ 7.35$ to $\$ 10.26$ (2011\$). This would have the effect of at least doubling the cost of chemicals produced by natural gas raising the price of Ethylene to the range of $\$ 1.20 / \mathrm{lb}$. On this basis both the Conventional and the nuclear incorporated case would be competitive. The application of the nuclear technologies would depend on the economics and governmental regulations on carbon. $\mathrm{A} \mathrm{CO}_{2} \operatorname{cost}$ of $\sim \$ 130 /$ ton or a prohibition on the release of $\mathrm{CO}_{2}$ would be required to bring the costs of the Conventional up to the projected costs of the nuclear incorporated process.

\section{E-2.4 Capital Costs}

Figure E-8 summarizes and compares the estimated total capital investment required for the candidate process plants (2011\$). These estimates were developed from determining the costs for the plant equipment with the design and performance characteristics developed in the Aspen+ analyses with additional factors for design, installation and contingency. Costs were also estimated for plant engineering, permitting, site preparation, project and construction management, labor, startup and testing and plant commissioning. Operating costs were also developed from the bottoms up using industry experience on staffing, outage costs and materials and services as determined in the Aspen + analyses.

The capital and operating costs for the HTGR and HTSE plants are based on the module sizes, number of modules, operating conditions and power conversion system design using correlations developed as part of the INL NGNP Project. ${ }^{5}$

As shown the natural gas plants have lower capital requirements than the coal plants due to lower costs for the steam reformers used in the gas plants vice the large gasifiers of the coal plants. The addition of the HTGR/HTSE add significant capital costs to the plant. This is reflected in the figures in the preceding that show those processes having higher production costs that, in the case of those processes utilizing HTSE, would be non-competitive in today's markets. In all cases the capital expenditures are large providing incentive for the modularized phased approach that is proposed for deploying these plants to reduce the annual expenditure rate to a manageable level. 


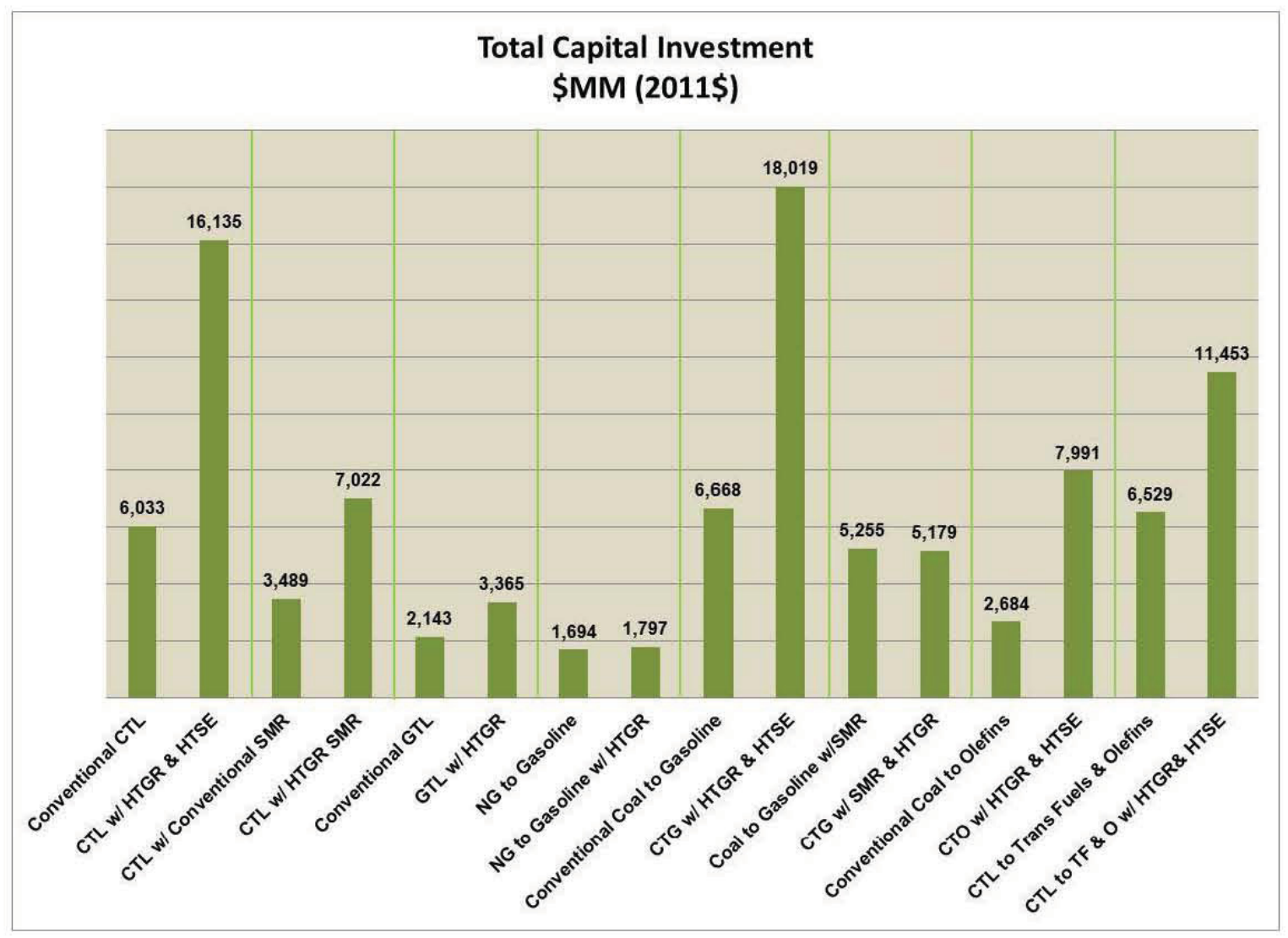

Figure E-8. Total capital investment for candidate process plants.

\section{E-2.5 Electricity Generation}

The high operating temperatures of the HTGR support electricity generation at high net efficiencies. Depending on the Power Conversion System net efficiencies in the range of $40 \%$ to $50 \%$ are achievable. These are higher than net efficiencies achievable with traditional light water (LWR) technologies that operate at lower temperatures and typically have net efficiencies of $\sim 33 \%$. The improved net efficiencies result in lower per unit costs for electricity generated by the HTGR than for LWRs including Integrated Small Modular Light Water Reactors (ISMLWR, $<300 \mathrm{MW}(\mathrm{e})$ ) that are being proposed in lieu of the larger traditional LWRs (up to $1650 \mathrm{MW}(\mathrm{e})$ ). As is true of other nuclear technologies the HTGR generates electricity with essentially no greenhouse gas emissions. This makes it an attractive alternative in the event of governmental action to regulate these emissions.

Figure E-9 compares the costs of generation for the HTGR with other generating technologies that have no or low emission characteristics. In addition to the ISMLWR projected costs for an Integrated Gasification Combined Cycle (IGCC) plant fueled by coal and an Advanced Natural Gas Combined Cycle (NGCC) plant, both with carbon capture and sequestration (CCS), are shown. Also shown is the range of projected natural gas prices in 2035 developed in the prior discussion. As shown in Figure E-9 the HTGR cost of generation is lower than projected for the ISMLWR and the IGCC with CCS and for the Advanced NGCC with CCS plant at natural gas prices above \$5.5/MMBtu. 


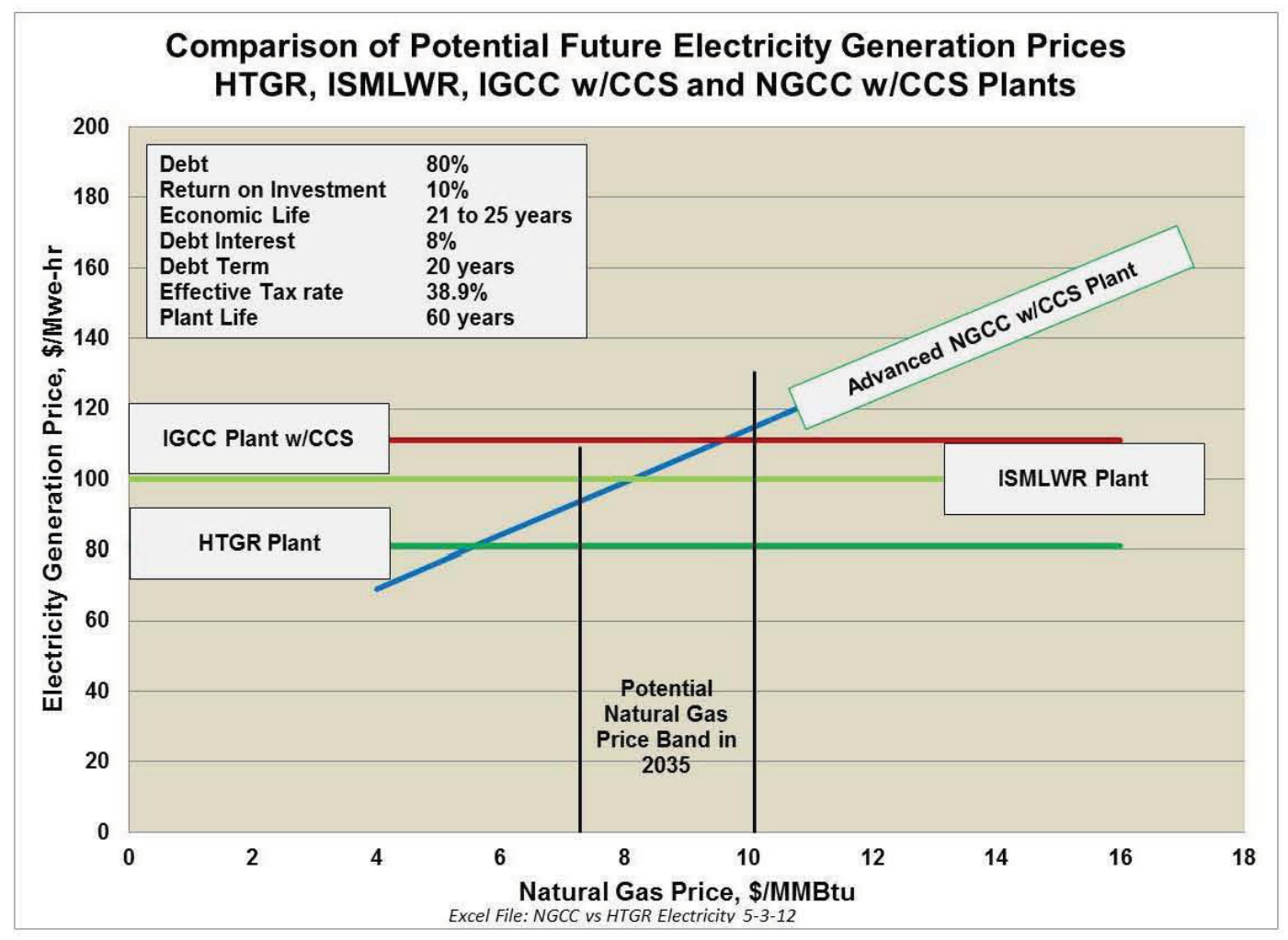

Figure E-9. Comparison of costs of electricity generation for several technologies.

\section{E-2.6 Sensitivity Analyses}

Figures E-10 and E-11 summarize in the form of Tornado charts the sensitivity of the calculated production cost of Diesel for the CTL process with and without the use of SMR for the production of hydrogen and with and without incorporation of the HTGR and HTSE technologies. The sensitivity of the calculated production costs is calculated for the variations listed in Tables E-2 and E-3.

The Tornado charts are organized to show the variations in the order of their impact from highest to lowest. It should be noted that the results show the effect of individual variations in each parameter while the others are held at the baseline value. Accordingly, these results are not additive. 

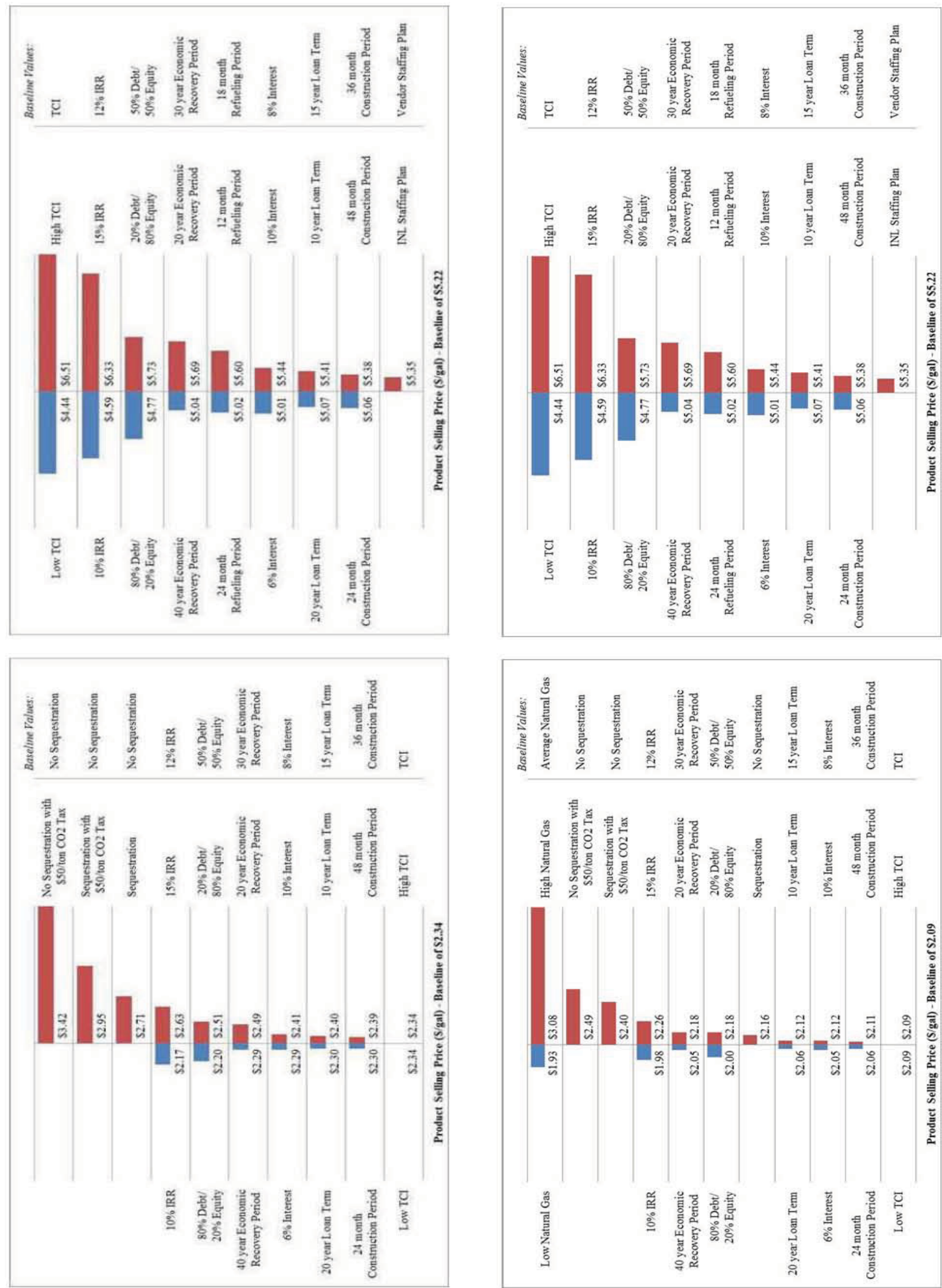

Figure E-10. Effect of variations in key parameters on diesel pricing for conventional CTL without and with HTGR and HTSE (top chart).

Figure E-11. Effect of variations in key parameters on diesel pricing for CTL with SMR without and with HTGR (bottom chart). 
Table E-2. Variations for conventional CTL processes without HTGR and HTSE technologies.

\begin{tabular}{|c|c|c|c|}
\hline Item & Lower Value & Baseline Value & Upper Value \\
\hline \multirow{3}{*}{$\mathrm{CO} 2$ Sequestration and Taxation } & None & No Sequestration & $\begin{array}{l}\text { No Sequestration } \\
\text { with } \$ 50 / \text { ton Tax }\end{array}$ \\
\hline & None & No Sequestration & $\begin{array}{l}\text { Sequestration with } \\
\$ 50 / \text { ton Tax }\end{array}$ \\
\hline & None & No Sequestration & Sequestration \\
\hline Natural Gas Price & $\$ 4.50 / \mathrm{MSCF}$ & $\$ 5.50 / \mathrm{MSCF}$ & $\$ 12.00 / \mathrm{MSCF}$ \\
\hline Internal Rate of Return & $10 \%$ & $12 \%$ & $15 \%$ \\
\hline Debt to Equity Ratio & $80 \%$ & $50 \%$ & $20 \%$ \\
\hline Economic Recovery Period & 40 years & 30 years & 20 years \\
\hline Financing Interest & $6 \%$ & $8 \%$ & $10 \%$ \\
\hline Financing Term & 10 years & 15 years & 20 years \\
\hline Construction Period & 24 months & 36 months & 48 months \\
\hline Total Capital Investment & $100 \%$ & $100 \%$ & $100 \%$ \\
\hline
\end{tabular}

Table E-3. Variations for CTL processes with HTGR and HTSE technologies.

\begin{tabular}{|llll|}
\hline Item & Lower Value & Baseline Value & Upper Value \\
\hline Internal Rate of Return & $10 \%$ & $12 \%$ & $15 \%$ \\
\hline Debt to Equity Ratio & $80 \%$ & $50 \%$ & $20 \%$ \\
\hline Economic Recovery Period & 40 years & 30 years & 20 years \\
\hline Financing Interest & $6 \%$ & $8 \%$ & $10 \%$ \\
\hline Financing Term & 10 years & 15 years & 20 years \\
\hline Construction Period & 24 months & 36 months & 48 months \\
\hline Total Capital Investment & $85 \%$ & $100 \%$ & $125 \%$ \\
\hline Refueling Period & 24 months & 18 months & 12 months \\
\hline Staffing Plan & None & Vendor & $\mathbb{I N L}$ \\
\hline
\end{tabular}

Figure E-12 shows the results of applying the ranges of parameter variations listed above for the Conventional CTL with SMR case in a Monte Carlo analysis of the cost of diesel. This shows the combined effects of these variations in the form of a probability distribution on the cost. As shown the $2 \sigma$ range for the cost spans from a low of $\$ 1.78 / \mathrm{gal}$ to a high of $\$ 2.86 / \mathrm{gal}$. This wide range reflects the large uncertainty in the input values.

i Note that these baseline values are different from the parameters listed in Table E-1 that were used to perform the economic analyses as discussed in the preceding sections. As cited in discussion of Table E-1 those values were recommended for use in these analyses by the NGNP Industry Alliance Limited. The Baseline values and variations used in the sensitivity studies summarized in Tables E-2 and E-3 were selected to bound the expected range of the parameters evaluated.

j The INL Economic Model has two variations in the staffing plan for the HTGR plant; one that was generated from HTGR Supplier data developed by the INL NGNP Project and an INL plan that was developed from review of existing LWR plant staffing and adapting that data to the specific characteristics of the HTGR modular design. The INL staffing plan projects a much higher number than the Vendor plan -382 personnel for the first module and 71 for each additional module versus 165 personnel for the first module and 25 for each additional module. 


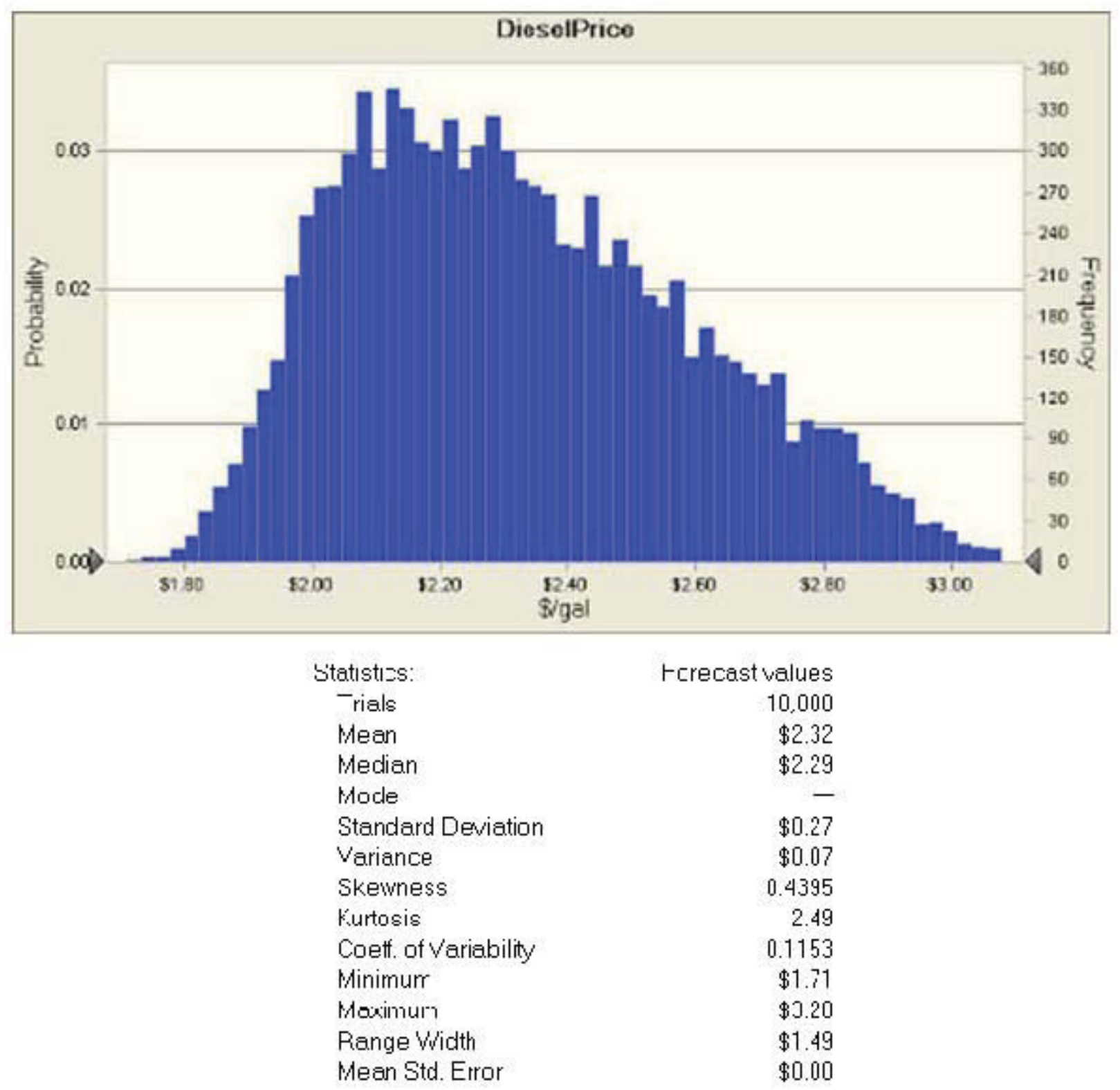

Figure E-12. Resuls of Monte Cario analysis of parameter variations on the probabinty of diesel productions costs using the CTL with SMR process. 


\section{E-3. CONCLUSIONS ON ECONOMICS}

8. The conventional processes are competitive with the market prices of transportation fuels refined from crude oil and primary chemicals produced from natural gas or coal at the time of this writing. This conclusion supports the strategy of beginning the steps required to deploy a process as soon as practical.

9. The economics of incorporating HTGR technology to supply heat in the CTL w/SMR and the GTL processes are the more favorable of the nuclear incorporation alternatives. These processes can benefit from the zero $\mathrm{CO}_{2}$ emissions and the stable energy cost characteristics of the HTGR technology.

10. The economics of using the HTGR technology for electricity generation are very favorable even at the time of this writing where the costs of natural gas are low. In February 2012, the price of natural gas delivered to industrial customers in the U.S. averaged a little less than \$4/MMBtu but ranged from a low of $\$ 2.80 / \mathrm{MMBtu}$ to a high $>\$ 11 / \mathrm{MMBtu}$ in the continental U.S. As was shown in Figure E-9 generation of electricity using the HTGR is very competitive with other forms of non- or low $\mathrm{CO}_{2}$ emitting baseload technologies including NGCC in the upper level of this range. As shown in Figure E-9 it will be competitive with the alternative no or low- $\mathrm{CO}_{2}$ emitting technologies for natural gas prices projected in 2035 .

11. The economics of incorporating the HTGR and HTSE technologies in the CTL, CTO and MTG processes as discussed above do not appear favorable. As cited previously the unfavorable economics stem from the high cost of hydrogen produced using the HTSE process. There are two primary factors in the HTSE costs; the costs of the plant that accounts for $\sim 11 \%$ of the operating costs and the costs of the electricity to operate the unit that accounts for the balance. As demonstrated above if electricity can be obtained at costs in the $\$ 40 / \mathrm{MW}(\mathrm{e})$-hr range, such as is the case in Wyoming, then it is possible to produced hydrogen for $\sim \$ 1.6 / \mathrm{kg}$

12. As cited earlier the principal process used to produce hydrogen in the U.S. is steam methane reforming (SMR) using natural gas as the feed stock. The principal factor in the cost of hydrogen produced using SMR is the cost of natural gas. If the government imposes taxes or regulation on the emissions of $\mathrm{CO}_{2}$, that would also increase the cost of the hydrogen. The SMR process generates $\sim 9$ tons of $\mathrm{CO}_{2}$ for every ton of hydrogen produced. Figures E-13 and E-14 show the effect of varying natural gas and $\mathrm{CO}_{2}$ costs on the cost of hydrogen produced using SMR. Figure E-13 is for the case where the $\mathrm{CO}_{2}$ is captured and sequestered. Figure E-14 is without any capture and sequestration. The $\$ 2 / \mathrm{kg}$ cost line is highlighted on both figures.

As shown for the sequestration case, the $\$ 2 / \mathrm{kg}$ line is crossed at natural gas costs in the range of $\$ 6 / \mathrm{MMBtu}$ to $\$ 8 / \mathrm{MMBtu}$ for $\mathrm{CO}_{2}$ emission costs in the range of $\$ 0 /$ ton to $\$ 100 /$ ton. Note that in this case $70 \%$ of the $\mathrm{CO}_{2}$ is assumed to be transported and sequestered at a cost of $\$ 15.65 /$ ton. As cited previously there is considerable uncertainty in this cost and it could be much higher which would shift the crossing of the $\$ 2 / \mathrm{kg}$ line to a much lower range of natural gas costs.

As shown for the no sequestration case, the $\$ 2 / \mathrm{kg}$ line is crossed at natural gas costs in the range $\$ 5$ to $\$ 8.50 / \mathrm{MMBtu}$ for $\mathrm{CO}_{2}$ costs between $\$ 0 /$ ton and $\$ 50 /$ ton. At the higher price of $\mathrm{CO}_{2}$ emissions the line would be crossed in the range of $\$ 2 / \mathrm{MMBtu}$.

At the projected lower limit of the projected long term price of $\$ 7.35 / \mathrm{MMBtu}$ (Figure E-6) the HTSE process could be competitive with SMR assuming current estimates of construction and operating costs prevail as the process is developed further. 


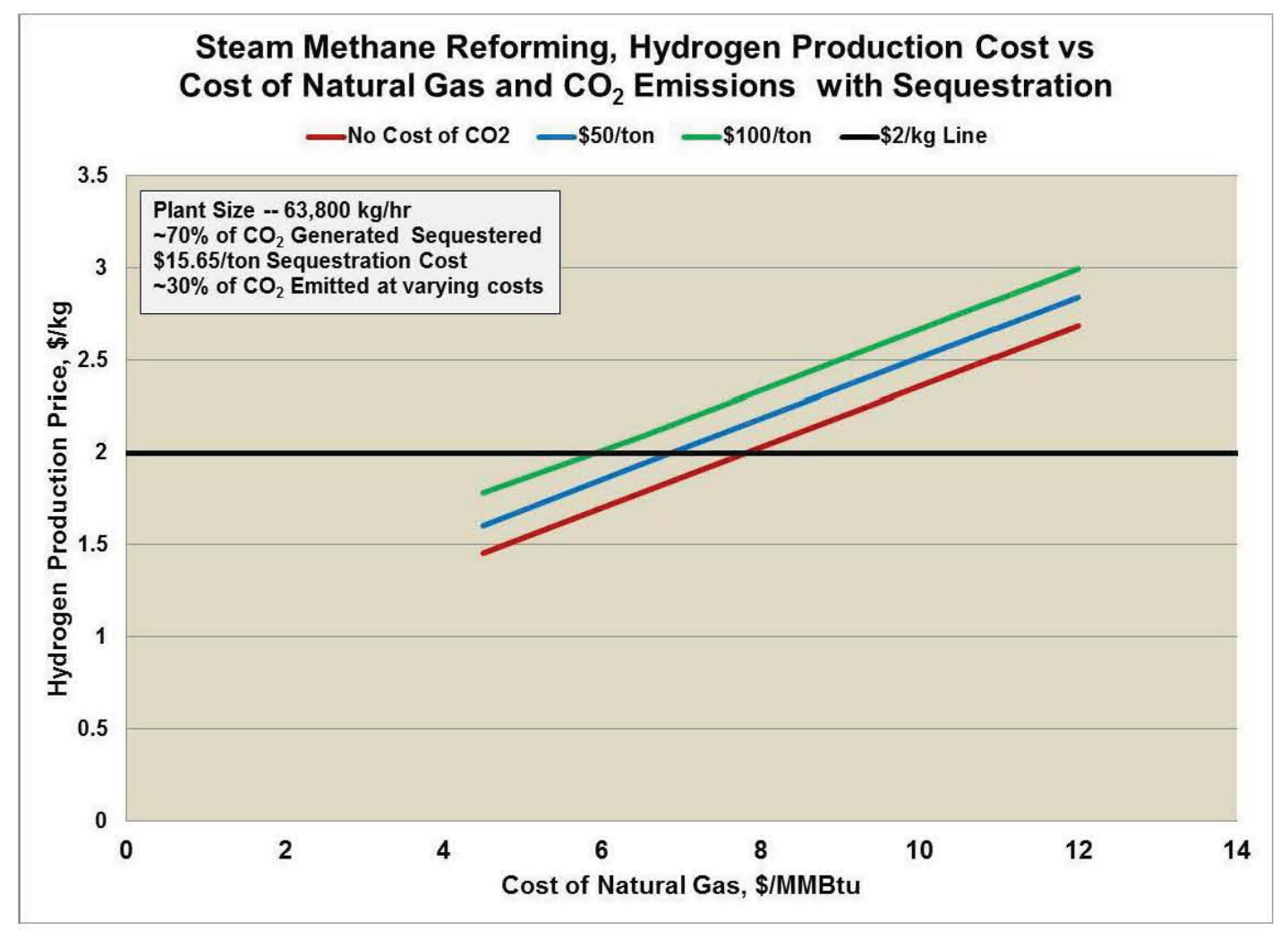

Figure E-13. SMR hydrogen production costs vs cost of natural gas and $\mathrm{CO}_{2}$ with sequestration.

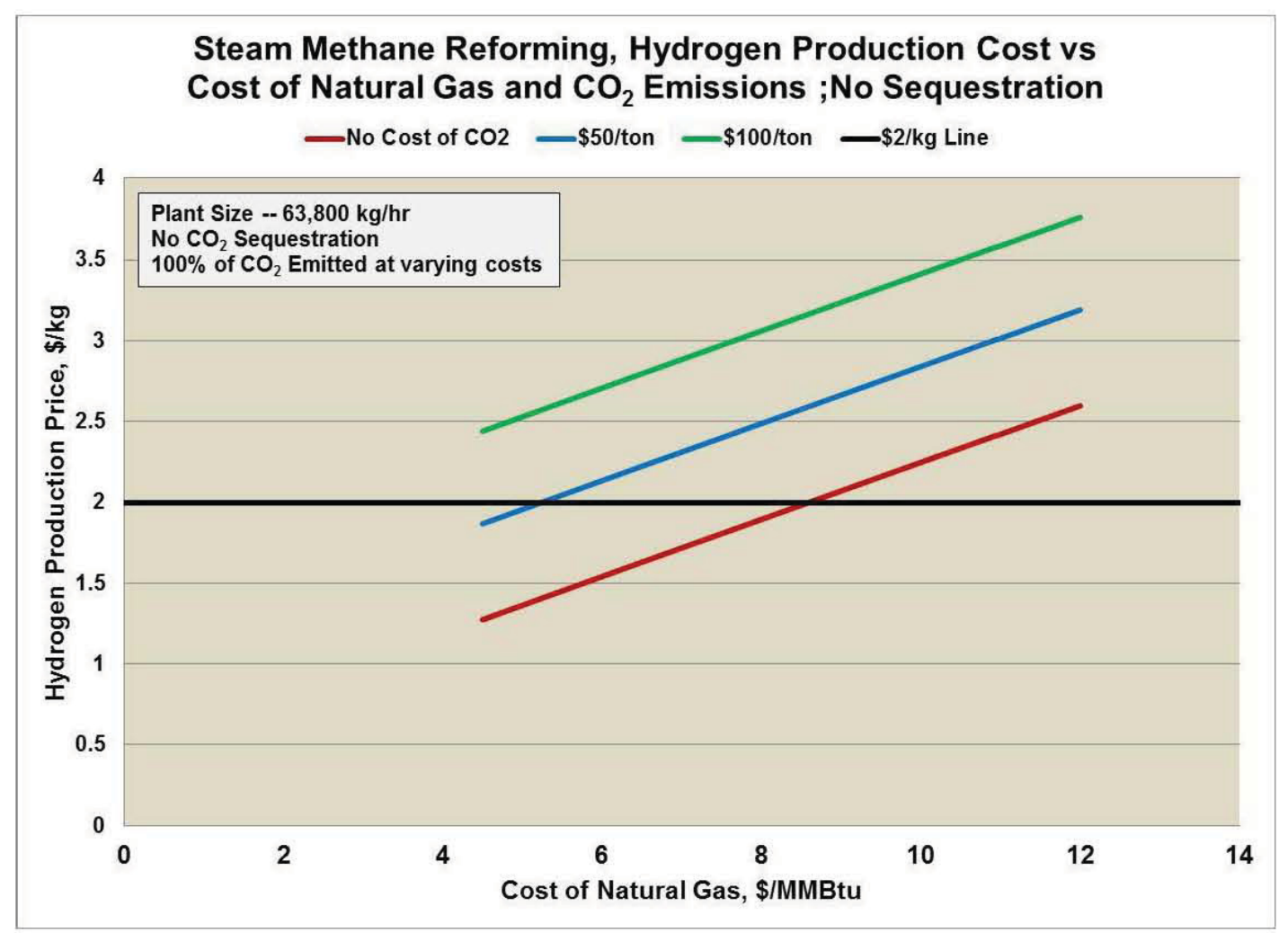

Figure E-14. SMR hydrogen production cost versus cost of natural gas and $\mathrm{CO}_{2}$ without sequestration. 
13. The development of the HTGR is proceeding with the initial startup of the first demonstration module currently planned for the 2025 time frame. As the development progresses better estimates of the costs of construction and operation will be developed. As the cost estimates become more refined they will add to the confidence in updates to the economic analysis of these processes using these estimates.

The Wyoming interests should support the development of both of the HTGR and HTSE technologies and monitor the progress of their development to ensure that they are available in the long term for meeting the energy needs of the State with environmentally beneficial technologies at stable long term costs. This becomes more important as government regulation on emissions expand reducing the viability of applying coal in its traditional role of electricity generation. The HTGR technology projects to be very competitive in that role and depending on the nature of the emissions regulations can also be competitive in the conversion of coal and natural gas to transportation fuels and/or chemicals.

\section{E-4. REFERENCES}

1 Gandrik, A. M. HTGR Application Economic Model User's Manual, INL/EXT-11-24143, Idaho National Laboratory, January 2012.

2 EIA, Annual Energy Outlook 2012 (Early Release April 2012 and June 25, 2012 Release).

3 Platts, Inside Energy, "LNG exports could drive up low gas prices, EIA says," January 23, 2012 and Navigant Consulting, Inc., :Market Analysis for Sabine Pass LNG Export Project," FERC Docket No. CP04-47, CP05-396, PF10-24 and EIA, "Effect of Increased Natural Gas Exports on Domestic Energy Market," Independent Statistics and Analysis, January 2012.

4 George Lobsenz, "Wall Street Study: Big Gas Price Rebound By 2013 From Fuel Switching," Friday, March 16, 2012, Energy Daily Vol 40 • No 53 and, AEP To Shutter 4,600 MW Of Coal-Fired Capacity In PJM, SPP, The Energy Daily, March 23, 2012.

5 TEV-1196, "Assessment of High Temperature Gas-Cooled Reactor (HTGR) Capital and Operating Costs," Idaho National Laboratory, 04/29/2011. 


\section{Appendix F}

\section{Deployment Strategy}




\section{Appendix F \\ Deployment Strategy}

The deployment strategy has the ultimate goal of developing a carbon conversion industry in Wyoming that provides a stable and significant long term contribution to the State's GDP and tax revenue using indigenous coal and natural gas resources. Objectives of this development are to provide alternative markets (1) for the State's coal resources, as its traditional supply to coal fired electricity generation is reduced through retirement of these plants due to age and potentially expanding emissions regulations, and (2) for the State's natural gas that has significantly reduced revenue generation because of the current low prices attendant to the glut of gas on the market from numerous gas shale plays nationally. The Mining industryk that is made up of the coal extraction, oil and gas extraction and support activities contributes $\sim 30 \%$ to the State's GDP and more than \$2B in State and Local revenues. Accordingly, maintaining the viability of this industry is important to the State's economy.

An additional objective is to incorporate nuclear power into the energy supply portfolio of Wyoming including integration with conventional carbon conversion processes where technically and economically beneficial and for electricity generation in place of retired coal based generation. The nuclear technology judged to have the most benefit in these applications is the high temperature gas-cooled reactor because its high temperatures are compatible with the needs of the carbon conversion processes and generates electricity at high net efficiencies with no generation of greenhouse gases.

The development strategy incorporates two phases. The first involves the deployment of a modestlysized plant to prove the technical and economic viability of carbon conversion as a use of coal and natural gas to sustain and improve the State's economy. The deployment of this plant will also begin to establish the Project development, plant design, financing, permitting, construction, commissioning, operation and product distribution processes and infrastructure necessary for deployment of the full scale carbon conversion industry in Wyoming.

The second phase expands the carbon conversion processes State-wide to achieve the economic objectives. This second phase also includes incorporation of nuclear technology.

The following sections summarize the design and preliminary siting criteria for the initial carbon conversion plant, the strategy for developing the carbon conversion industry, a strategy for transforming the electricity generation industry from domination by coal-fired plants to a more diverse mix of technologies and an assessment of the economic impact of these initiatives on the Wyoming economy over the short and long term.

In the development of the Wyoming State GDP, the Mining industry contribution to the GDP includes the Gross Value

Added from Oil \& Gas Extraction, Mining other than Oil \& Gas Extraction and Support Activities for Mining 


\section{F-1. INITIAL PLANT DEPLOYMENT \\ F-1.1 Initial Plant Process Selection \& Design}

Any of the processes identified in the prior appendices as technically and viable al ternatives using either coal and/or natural gas as the feedstock and producing synthetic transportation fuels or chemicals could be applied for the initi al plant. The coal to gasoline process using natural gas steam reforming (known as steam methane reforming (SMR)) for the hydrogen supply has been used as a surrogate first step in development of the carbon conversion industry in Wyoming. There are several reasons for selecting the coal to gasoline process for this purpose:

- As shown in Figure F-1 coal production in Wyoming peaked in 2008. Although there was a slight rebound in production in 2010 and 2011 the projections for 2012 and beyond are for continued reductions in production. Wyoming supplies $\sim 40 \%$ of the coal in the U.S. and the maj ority of this coal is used for electricity generation. Current and proposed EPA regulations on emissions have led to early retirement of coal-fired plants throughout the U.S. and are strong impediments to repl acement of these plants or other $\mathrm{pl}$ ants retiring due to age from being replaced by newer coal-fired plants. The current trend in the U.S. is al so to install natural gas fired electricity generation because of the current low prices of natural gas. The reduction in coal-fired generation in the U.S. is the principal reason for the reduction in Wyoming coal production and this condition is expected to persist over the longer term. Although increases in international export of Wyoming coal can slow the rate of reduction in production new markets are necessary to have a major impact. The use of coal as a major feedstock in the carbon conversion industry will provide such an al ternative market. An initial coal to gasoline plant will begin the development of this industry, provide a new coal market and increase the value of the coal to the Wyoming economy by converting it to higher value products.

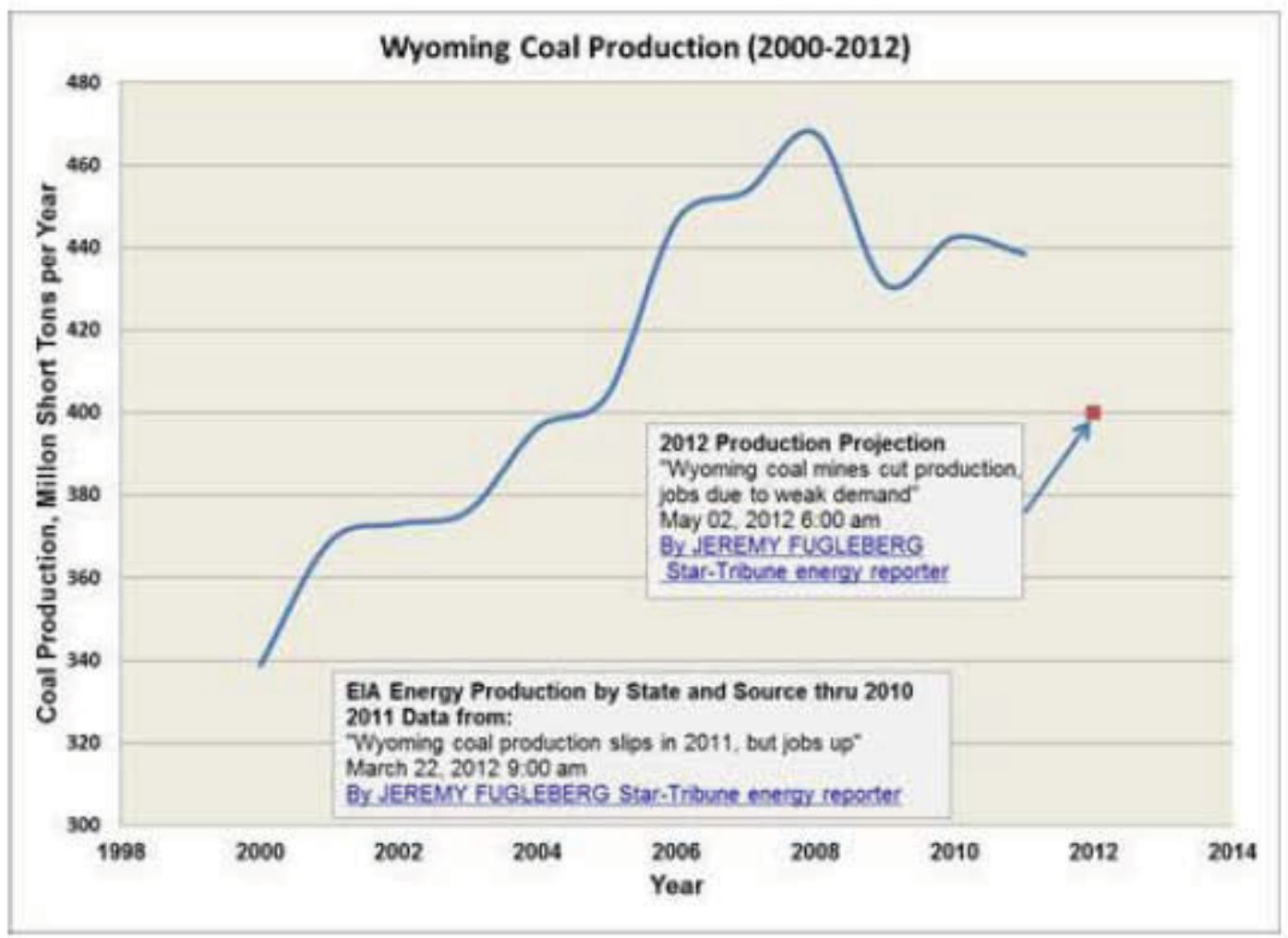

Figure F-1. Wyoming coalproduction (2000-2011). 
Similar to coal production natural gas production in Wyoming al so peaked in the 2009-2010 time frame. Production in 2011 and that projected for 2012 is reduced from that peak This reduction is due primarily to costs of production in Wyoming that are not economic with the low prices of natural gas that have resulted from the significant production of natural gas shale nationally. More significant than reduction in production is the reduction in the price that can be obtained for the gas. For every $\$ M S C F$ reduction in price the revenue from natural gas production drops by $\sim \$ 2 \mathrm{~B}$ annually. Using SMR for the hydrogen supply provides a mechanism for increasing the value of natural gas through production of higher value products and provides another market for Wyoming natural gas that would help offset the reductions in demand from other markets.

- The coal to gasoline process and SMR are well developed. Figure F-2 shows the principal components that make up these processes. All of these are commercially available and have extensive operating experience. Accordingly, this process could be deployed as soon as a Project is initiated.

This process facilitates later incorporation of the HTGR technology. As shown in Figure F-3 HTGR heat at a temperature $>800^{\circ} \mathrm{C}$ can be used as a substitiute for natural gas firing in the SMR. The HTGR plant also supplies electricity to the process. This reduces the amount of natural gas required to be combusted in the reformer reducing $\mathrm{CO}_{2}$ generation by $>90 \%$ and natural gas feed rate by $35 \%$ compared with the conventional process. This modification of the cycle also facilitates capture and transfer of the $\mathrm{CO}_{2}$ for $\mathrm{EOR}$ or sequestration.

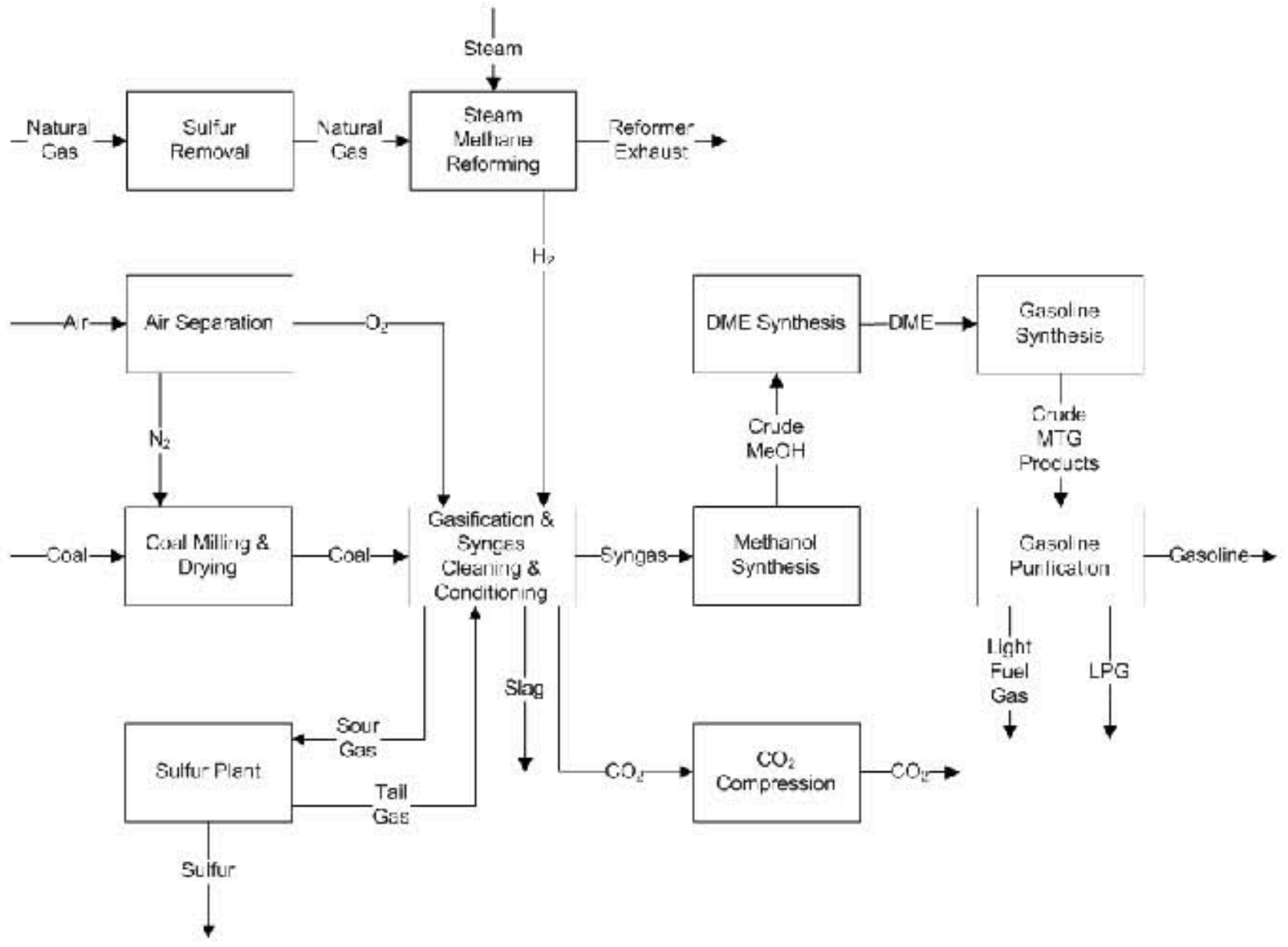

Figure F-2. Coal to gasoline process using a steam methane reforming hydrogen supply. 


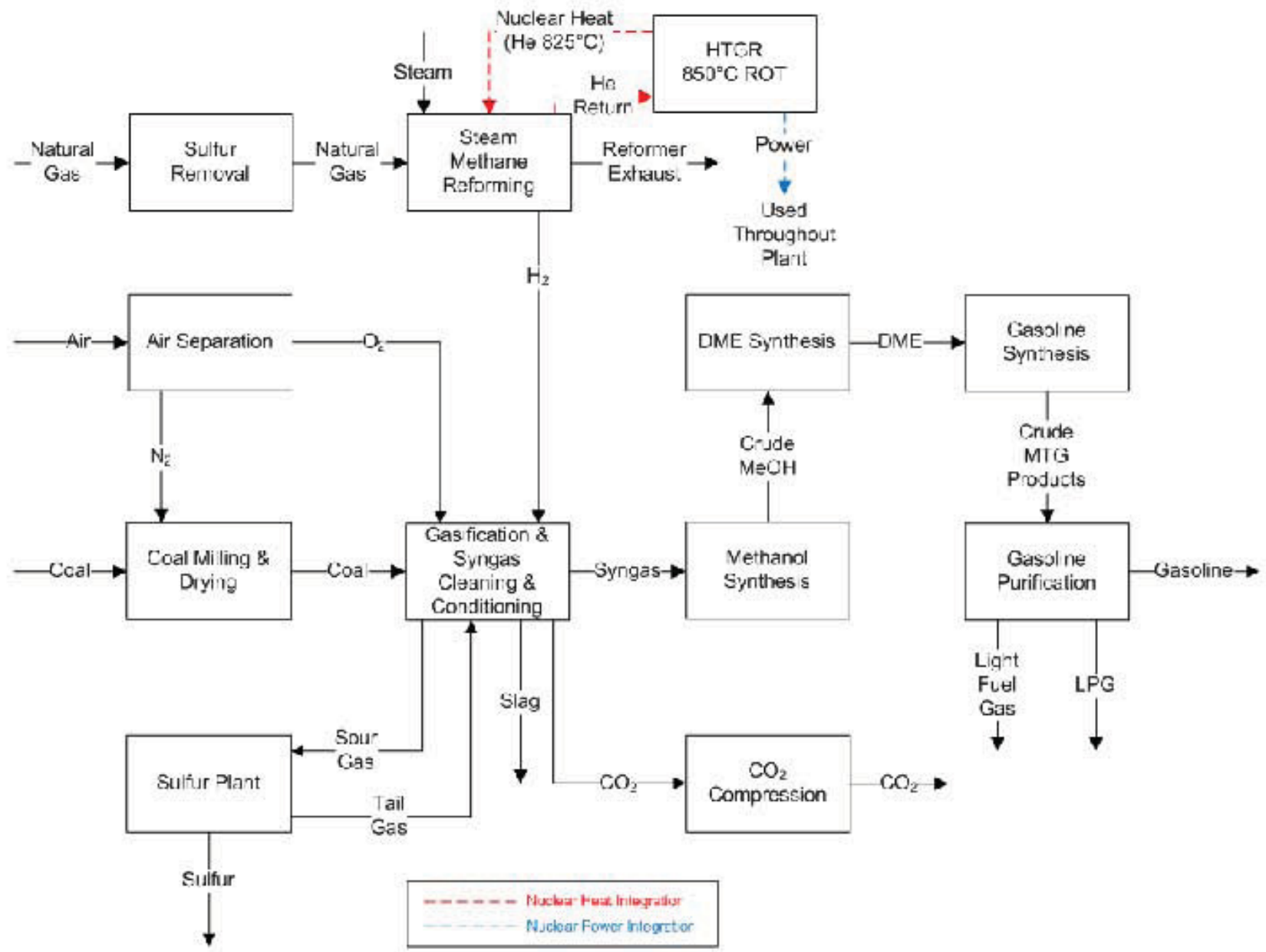

Figure F-3. Integration of HTGR technology with the coal to gasoline process.

- This process produces gasoline at a cost that is competitive with costs of refining gasoline from crude oil at crude oil costs equal to or greater than $\$ 72 / \mathrm{bbl}$ ( $\$ 5.50 \mathrm{MSCF}$ natural gas price). With integration of the HTGR technology the equivalent crude oil cost increases to $\$ 77 / \mathrm{bb} 1$. These production costs are similar to those for other carbon conversion processes (conventional/with HTGR te chnology incorporated) deemed practical for Wyoming (e.g., natural gas to gas oline ( $\$ 58$ to $\$ 61 / \mathrm{bbl}$ ), coal to liquids ( $\$ 66$ to $\$ 85 / \mathrm{bbl}$ ) and natural gas to liquids ( $\$ 64$ to $\$ 72 / \mathrm{bbl}$ ).

- Gasoline and liquefied petroleum gas produced in this process have mature markets and distribution systems nationally. EIA projections on liquids fuels consumption in the U.S. through $2013^{1}$ show an annual decrease of $0.4 \%$ in the consumption of gasoline but an annual increase in diesel consumption of $0.9 \%$. In 2011 the U.S. consumed 8.76 million barrels per day (MMbpd) of gasoline and 3.27 MMbpd of diesel. EIA projects these at $8.16 \mathrm{MMbpd}$ gas oline and $4.10 \mathrm{MMbpd}$ of diesel in 2035. These levels of consumption over the next 20 years represent viable markets for Wyoming production of either or both gasoline and diesel.

In the short term, distribution of the products from the initial carbon conversion plant is likely to be by rail car. As the carbon conversion industry is developed and production increases construction of pipelines connecting the Wyoming plants with national distribution pipelines may be justified. The access to the se pipelines will be a factor in siting these plants. 
- It is assumed that the initial plant would be deployed in phases starting with a conventional plant without integration of the HTGR technology. In the first phase a module with a capacity of $\sim 17,000$ bpd would be deployed. This plant could be expanded over time to achieve a capacity of $\sim 67,000$ bpd comprising 4 of the initial plant modules. These modules would be independent of each other so could be constructed, operated and maintained independently. Figure F-4 shows the performance characteristics of a notional full scale plant of $\sim 67,000$ bpd capacity. As shown, production comprises $\sim 57,700$ bpd of Gasoline and $\sim 9,100$ bpd of Liquid Petroleum Gas (LPG). This plant will require $\sim 12,000$ tons per day and $\sim 290$ million cuft (MSCFD) of natural gas feed. The production and feed requirements for each module are just $1 / 4$ of these values.
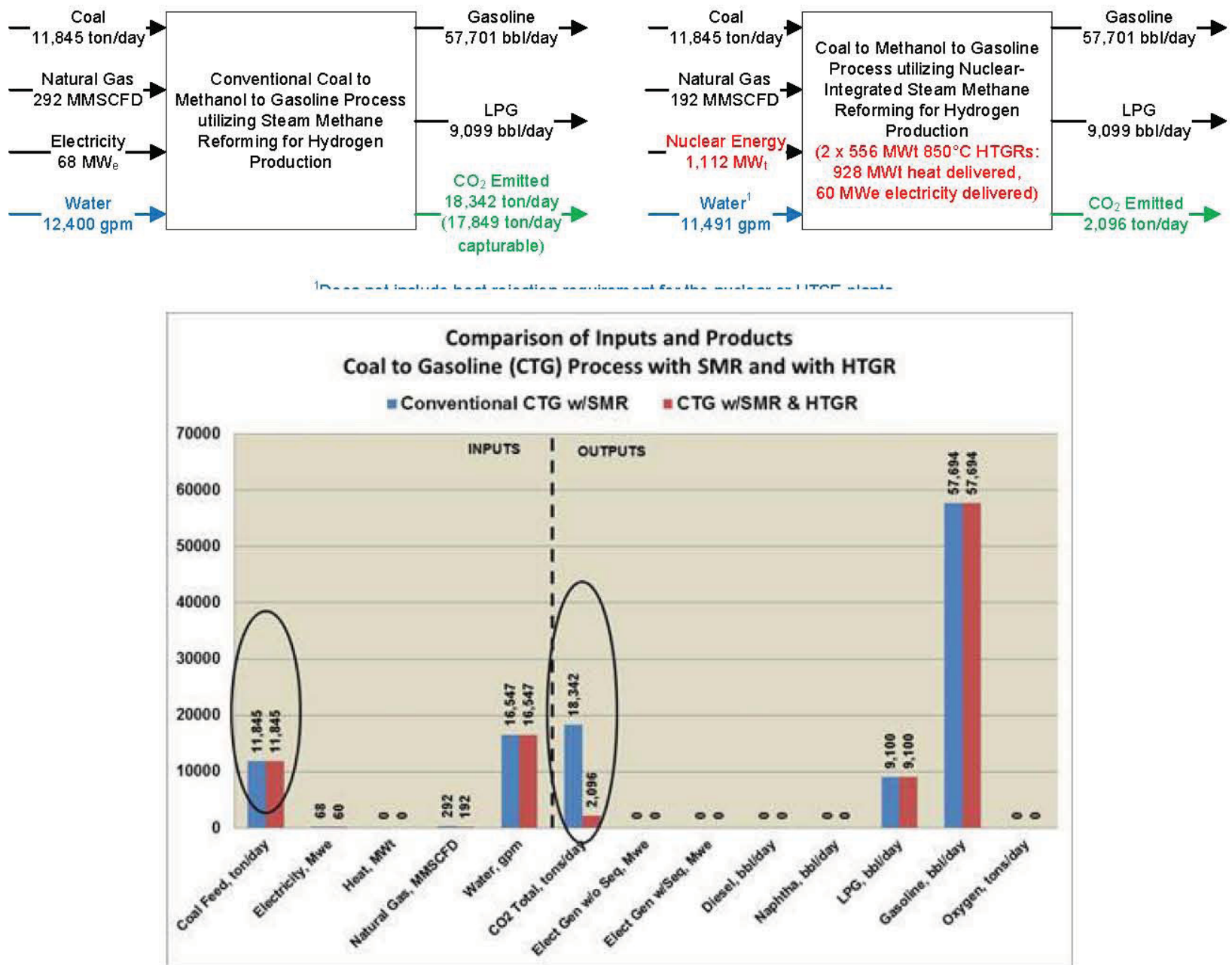

Figure F-4. Coal to gasoline plant performance characteristics.

Figure F-5 is a notional depiction of the plan view of this plant when fully developed including the integration of the HTGR technology. The site when fully deployed is $\sim 1$ mile wide by $1-1 / 2$ mile deep comprising a total area of $\sim 950$ acres. It is emphasized that this is a notional layout derived from multiple similar facilities and does not represent any specific facility. The actual plant component selections and layout would be part of the plant design process. 


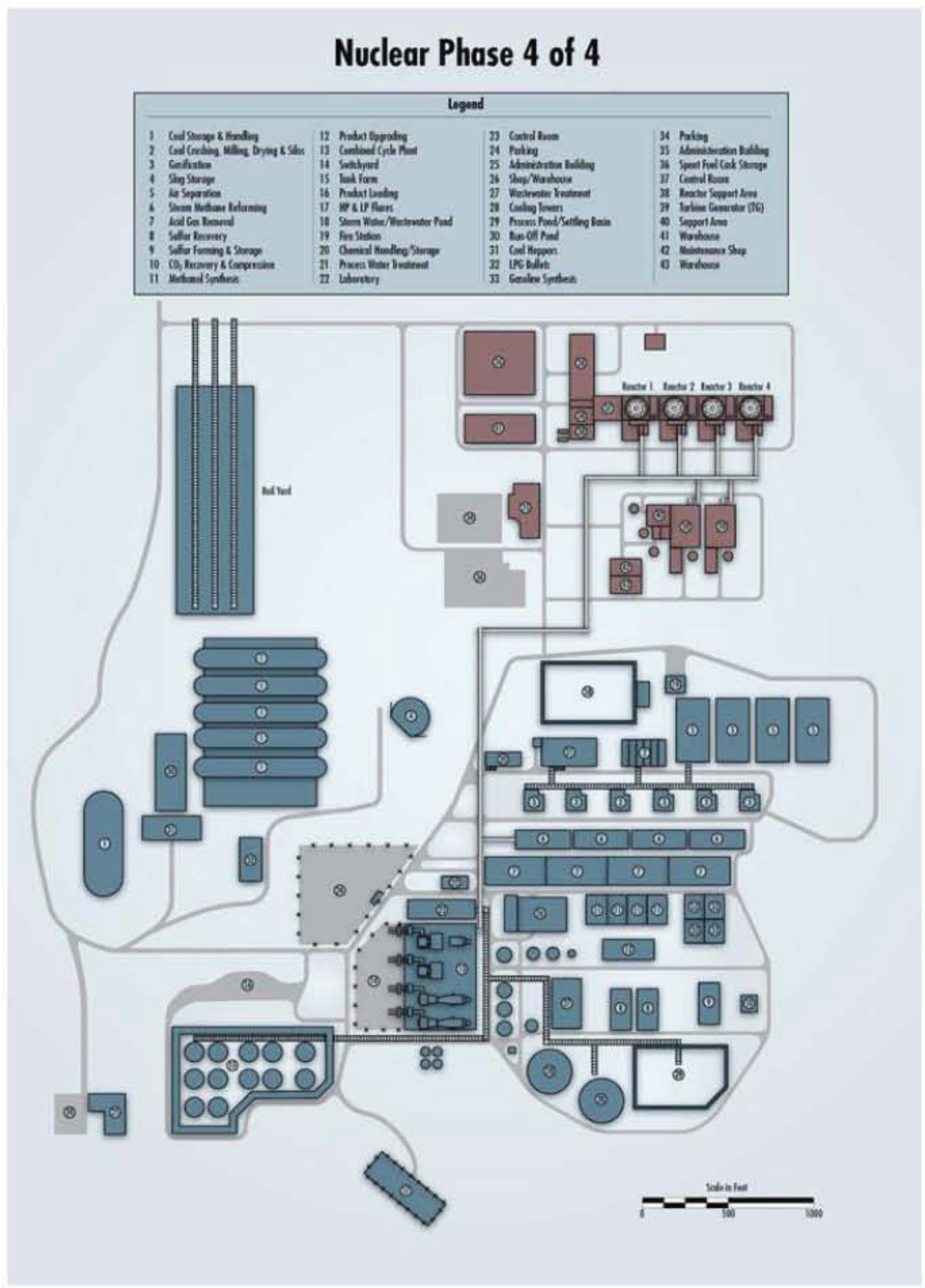

Figure F-5. Notional plan view of fully deployed coal to gasoline plant.

Each module of the conventional plant will produce $\sim 4,600$ tpd of $\mathrm{CO}_{2}$ There is considerable uncertainty in the nature of regulations that the government may impose on $\mathrm{CO}_{2}$ emissions in the future and the costs of addressing those regulations (e.g., capture for sequestration or EOR). There is incentive over the longer term to incorporate high temperature gas-cooled reactor technology into the process to reduce $\mathrm{CO}_{2}$ generation. Figure $\mathrm{F}-4$ shows the performance characteristics of the plant with HTGR supplying heat to the SMR process. Total $\mathrm{CO}_{2}$ generation is reduced by $>90 \%$. The use of HTGR to supply heat also reduces the quantity of natural gas required by $\sim 35 \%$.

The HTGR shown in Figure F-5 comprises 5-600 MW(t) modules supplying $930 \mathrm{MW}(\mathrm{t})$ of heat and $60 \mathrm{MW}(\mathrm{e})$ of electricity to the process and $\sim 700 \mathrm{MW}(\mathrm{e})$ to the regional grid. This plant would also be deployed in a phased approach by module. The excess plant capacity is sufficient to meet $100 \%$ availability requirements of the coal to gasoline plant during plant refueling and other outages. It also will 
supply significant non-greenhouse gas emitting electricity to the regional grid, replacing retiring coal fired generation.

\section{F-1.2 Site Selection}

A set of criteria were developed as part of this effort to assist in evaluating and identifying sites that would be acceptable for locating carbon conversion plants with nuclear components supporting the plant processes and supplying electricity to the regional utility. These criteria are summarized in Appendix A of this report. Using input from the principals involved in this effort, these criteria were distilled down and prioritized into specific characteristics that are (1) required for any site to be acceptable (referred to as "MUSTS") and (2) optional but desirable for the site (referred to as "WANTS/NEEDS"). Table F-1 summarizes these specific characteristics with weighting criteria for those in the optional but desirable category.

These criteria were applied in site suitability analyses using detailed data on the characteristics and infrastructure of each county in Wyoming. These analyses were performed using resources at the University of Wyoming's Geographic Information Science Center (WyGISC). Background maps of the State were developed including all of the utility pipelines, transmission systems and infrastructure covered in the selection criteria. This included gathering the most up-to-date information from various state and local agencies within the state of Wyoming. WyGISC then applied the weighting criteria to generate maps of Wyoming that highlights those regions of the state that best fit the criteria and the degrees of conformance.

The results of the analyses are presented in color coded maps of Wyoming; the colors indicating the level at which the colored area is consistent with the criteria. Figure F-6 is representative of these maps. Different maps were provided to show major towns, location of mines and power plants, major roads, railways, airports, pipelines, water resources, conservation easements, air quality attainment areas, earthquake epicenters and faults, populations, etc. This first cut analysis narrowed the potential site locations in Wyoming to four counties; Laramie, Campbell, Natrona and Fremont.

A second analysis was performed to identify specific sites within these counties that met the specific criteria. This analysis determined that using the WyGISC data there are no sites that meet the specific criteria; specifically the criteria requiring the site to be a privately held area of 1000 acres that is zoned industrial. Only one site in Fremont County of 500 acres was identified as having met at least two of the three criteria. After review of the results it was concluded that the criteria and data may be too limiting. For example, it did not include any sites owned by coal or natural gas producers.

No more effort is judged to be appropriate as part of this evaluation effort. Just as selecting the specific plant will be the responsibility of the owner, so will selecting the specific site for the initial plant and for subsequent plants. It is sufficient at this time, therefore, to have identified characteristics of the site that need to be included in assessing the suitability of a specific area for locating these plants. Table 4.1 and the more detailed listing in Appendix A provide those characteristics. A short term "path forward" action identified in the main body of the report engages industry and potential owners of these plants to discuss these initiatives. This should include vetting the site requirements of Table F-1 and Appendix A. 
Table F-1, Site Selection Criteria Form.

\begin{tabular}{|c|c|c|c|c|c|c|c|c|c|c|c|c|c|}
\hline \multicolumn{2}{|l|}{\begin{tabular}{|l} 
LEGEND \\
\end{tabular}} & \multicolumn{2}{|c|}{$\# 1$} & \multicolumn{2}{|c|}{ \#2 } & \multicolumn{2}{|c|}{$\# 3$} & \multicolumn{2}{|c|}{ \#4 } & \multicolumn{2}{|c|}{$\# 5$} & \multicolumn{2}{|c|}{$\# 6$} \\
\hline \multicolumn{14}{|l|}{ WT $=$ Weight of Want/Need (1-10) } \\
\hline \multicolumn{14}{|l|}{$R=$ Rating on Scale of $0-10$} \\
\hline \multicolumn{14}{|l|}{$P=$ Product of WT $\times R$} \\
\hline \multicolumn{2}{|l|}{ MUSTS: (YES/NO) } & \multicolumn{2}{|c|}{$\mathrm{Y} / \mathrm{N}$} & \multicolumn{2}{|c|}{$\mathrm{Y} / \mathrm{N}$} & \multicolumn{2}{|c|}{$\mathrm{Y} / \mathrm{N}$} & \multicolumn{2}{|c|}{$\mathrm{Y} / \mathrm{N}$} & \multicolumn{2}{|c|}{$\mathrm{Y} / \mathrm{N}$} & \multicolumn{2}{|c|}{$\mathrm{Y} / \mathrm{N}$} \\
\hline \multicolumn{14}{|l|}{1000 Contiguous Acres } \\
\hline \multicolumn{14}{|l|}{ Zoned for Industrial; not near housing } \\
\hline \multicolumn{14}{|l|}{ Permits allow heavy industrial } \\
\hline \multicolumn{14}{|l|}{ Water (21000 gpm); Sewer $(5,250 \mathrm{gpm})$} \\
\hline Proxmity to substation (230kV) & & & & & & & & & & & & & \\
\hline No undergroud or overhead obstruction & & & & & & & & & & & & & \\
\hline No legal agreement not to build & & & & & & & & & & & & & \\
\hline Out of flood plain (50yr.) & & & & & & & & & & & & & \\
\hline Access to major Highway \& Rail & & & & & & & & & & & & & \\
\hline Access to Natural gas pipeline & & & & & & & & & & & & & \\
\hline Access to petroleum pipeline & & & & & & & & & & & & & \\
\hline Access to coal fields or delivery & & & & & & & & & & & & & \\
\hline Clear Title to land or long term lease availabl & & & & & & & & & & & & & \\
\hline All Mineral rights & & & & & & & & & & & & & \\
\hline Wind power with 20 to higher $\%$ capacity fact & & & & & & & & & & & & & \\
\hline Pass/Fail Musts (P/F) & & & & & & & & & & & & & \\
\hline WANTS/NEEDS: & WT & $\mathbf{R}$ & $\mathbf{P}$ & $\mathbf{R}$ & $\mathbf{P}$ & $\mathbf{R}$ & $\mathbf{P}$ & $\mathbf{R}$ & $\mathbf{P}$ & $\mathbf{R}$ & $\mathbf{P}$ & $\mathbf{R}$ & $\mathbf{P}$ \\
\hline Within 20 miles of product pipeline, eg CO2 & 6 & & 0 & & 0 & & 0 & & 0 & & 0 & & 0 \\
\hline State maintained road w/i $10 \mathrm{mi}$. & 7 & & 0 & & 0 & & 0 & & 0 & & 0 & & 0 \\
\hline Substation or Tranmission line w/i 10 miles & 9 & & 0 & & 0 & & 0 & & 0 & & 0 & & 0 \\
\hline Sufficient housing/hotels & 6 & & 0 & & 0 & & 0 & & 0 & & 0 & & 0 \\
\hline Proximity to Medical/ENT/fire & 9 & & 0 & & 0 & & 0 & & 0 & & 0 & & 0 \\
\hline NG Pipeline within 10 miles & 7 & & 0 & & 0 & & 0 & & 0 & & 0 & & 0 \\
\hline Seismic Richter TBD \& below & 8 & & 0 & & 0 & & 0 & & 0 & & 0 & & 0 \\
\hline Treated/untreated $\mathrm{H}_{2} \mathrm{O}$ with in 20 miles & 7 & & 0 & & 0 & & 0 & & 0 & & 0 & & 0 \\
\hline Sanitary Discharge within 20 miles & 7 & & 0 & & 0 & & 0 & & 0 & & 0 & & 0 \\
\hline Proxmity to Commercial Air & 5 & & 0 & & 0 & & 0 & & 0 & & 0 & & 0 \\
\hline Non-attainment Status & 8 & & 0 & & 0 & & 0 & & 0 & & 0 & & 0 \\
\hline Proximity to Class 1 airshed & 8 & & 0 & & 0 & & 0 & & 0 & & 0 & & 0 \\
\hline Surface water/runoff & 9 & & 0 & & 0 & & 0 & & 0 & & 0 & & 0 \\
\hline Fire water/hydrants & 3 & & 0 & & 0 & & 0 & & 0 & & 0 & & 0 \\
\hline Industrial Gas supply & 4 & & 0 & & 0 & & 0 & & 0 & & 0 & & 0 \\
\hline Atmospherics & 2 & & 0 & & 0 & & 0 & & 0 & & 0 & & 0 \\
\hline Local support (NIMBY) & 8 & & 0 & & 0 & & 0 & & 0 & & 0 & & 0 \\
\hline Labor Availability & 8 & & 0 & & 0 & & 0 & & 0 & & 0 & & 0 \\
\hline EOR and/or Sequestration reservoir available & 5 & & 0 & & 0 & & 0 & & 0 & & 0 & & 0 \\
\hline PROJECT TOTAL (SUM OF P'S) & & & & & & & & & & & 0 & & \\
\hline PROJECT RANK & & & & & & & & & & & & & \\
\hline
\end{tabular}




\section{Suitability with County Labels}

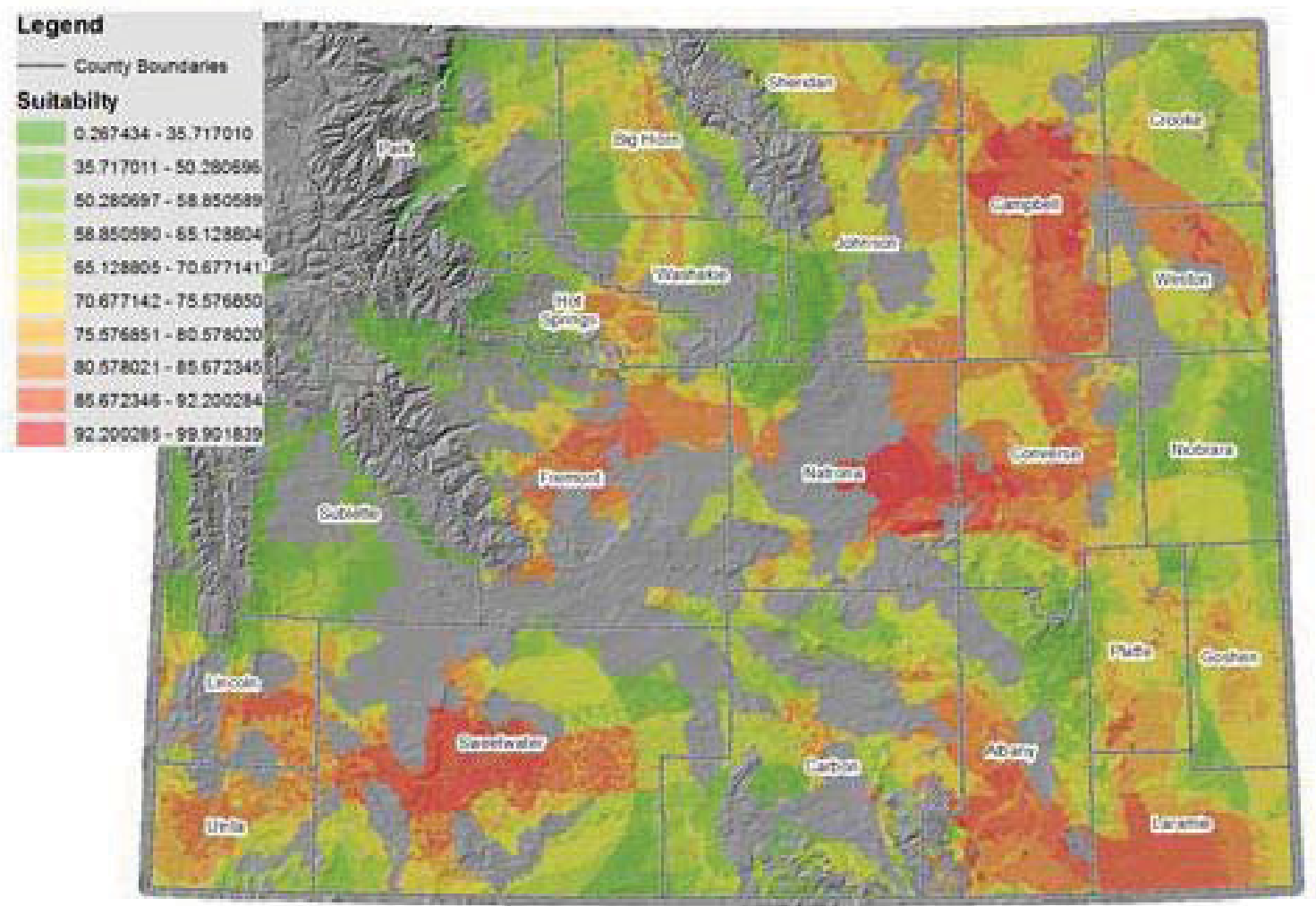

Figure F-6. Statew die ste sukability analysis.

\section{F-1.3 Initial Plant Deployment}

\section{F-1.3.1 Process Plant}

Based on past experience with projec ts developing proces plants sirnilar to the initial coal to gasoline (CTG) plant a Project period of 4 years from notice to proceed to ope ration of the first module is projec ted. Figure F-7 is a notional schedule for de ployment of the complete CTG plant. As shown in Figure F-7 the initial module is deployed over a four year period. This period includes one year for design, pe rmitting and site preparation and three years for plant construction and commissioning including 6 months for startup testing and commisioning. A one year "shakedown period" is assumed for this initial module. During this period the conce pt would be proved, design and operating problems would be ironed out and the deve lopment strategy for full scale deployment of carbon conversion plants in Wyoming would be fleshed out. A decision on whether to expand the initial plant in-kind, modify it or incorporate it into the full industry sche me would be made during this time frame.

For the purposes of analyses it is assumed that this plant would be expanded to incorporate 4 modules with a total capacity of $\sim 67,000 \mathrm{bpd}$. It is also assumed that this ex pansion wo uld result in commissioning the three modules at one year intervals with the second module on-line one year after the completion of the one year initial operating period and the last module fully ope rational two years later. The de ployment of the additional three modules is shown in Figure F-7. The total time for deployment of the full scale plant is 7 years. 


\begin{tabular}{|c|c|c|c|c|c|c|c|c|c|c|c|c|c|c|c|c|c|c|c|c|c|c|c|}
\hline Activity & 10 & 11 & 12 & 13 & 14 & 15 & 16 & 17 & 18 & 19 & 20 & 21 & 22 & 23 & 24 & 25 & 26 & 27 & 28 & 29 & 30 & 31 & 32 \\
\hline \multicolumn{24}{|l|}{$\begin{array}{l}\text { Development \& Deployment of } \\
67,000 \text { BPD CTG Plant w/SMR }\end{array}$} \\
\hline \multicolumn{24}{|l|}{ First Phase CTG Plant Deployment } \\
\hline \multicolumn{24}{|l|}{ Design, Permitting, Site Preparation } \\
\hline \multicolumn{24}{|l|}{ Procurement } \\
\hline \multicolumn{24}{|l|}{ Construction } \\
\hline \multicolumn{24}{|l|}{ Startup and test } \\
\hline \multicolumn{24}{|l|}{ Initiate commercial operation } \\
\hline \multicolumn{24}{|l|}{ First Module "Shakedown" Operation } \\
\hline \multicolumn{24}{|l|}{ Second Module Deployment } \\
\hline \multicolumn{24}{|l|}{ Third Module Deployment } \\
\hline \multicolumn{24}{|l|}{ Fourth Module Deployment } \\
\hline \multicolumn{24}{|l|}{ Process Plant Fully Operational } \\
\hline \multicolumn{24}{|l|}{ HTGR Plant Deployment } \\
\hline \multicolumn{24}{|l|}{ Licensing } \\
\hline \multicolumn{24}{|l|}{ Design } \\
\hline \multicolumn{24}{|l|}{ Procurement } \\
\hline \multicolumn{24}{|l|}{ 1st Module Const \& Commissioning } \\
\hline \multicolumn{24}{|l|}{ 2nd Module Const \& Commissioning } \\
\hline \multicolumn{24}{|l|}{ 3rd Module Const \& Commissioning } \\
\hline \multicolumn{24}{|l|}{ 4th Module Const \& Commissioning } \\
\hline HTGR Plant Fully Operational & & & & & & & & & & & & & & & & & & & & & & & \\
\hline
\end{tabular}

Figure F-7. Initial coal to gasoline plant deployment.

Figure F-8 is an estimate of the annual funding profile for this deployment schedule based on the INL estimates of the cost of this plant in 2011\$. The start date of the project is 2013 for the purposes of preparing the schedule. The capital investment is based on a total capital investment (TCI) developed in the INL economic model ( $2011 \$$ ), no inflation, a debt to equity ratio of $80 \%$ and an interest rate during construction of $8 \%$. Figure F-8 shows the breakdown of annual funding by the amount financed, the required equity and the interest during construction. As shown the peak annual funding required is above $\$ 1,800 \mathrm{MM}$ in the $5^{\text {th }}$ year. This reflects the fact that some construction is going on with several modules. The overlap in construction is required to complete the full project in the 7 year period. This large expenditure in one year may require a larger work force than can be accommodated at the selected site. Detailed discussion with an EPC is required to make that determination. If that is the case the schedule for deployment of the $2^{\text {nd }}$ through $4^{\text {th }}$ module will need to be extended.

The effort to deploy the first module will include items that will not be included in the effort required to construct subsequent modules, such as final design work to adapt the first and subsequent modules to the site, site preparation and long term procurement for the first and ultimately for subsequent modules. Based on prior work the cost to deploy the first module will account for about $40 \%$ of the total estimated project cost, the cost to complete the construction and commissioning of the four module plant). Some of this upfront work carries over into the cost of the second module (e.g., long term procurement) and its cost is about $25 \%$ of the total with the third and fourth module costs covering $18 \%$ and $17 \%$ of the total cost, respectively. 


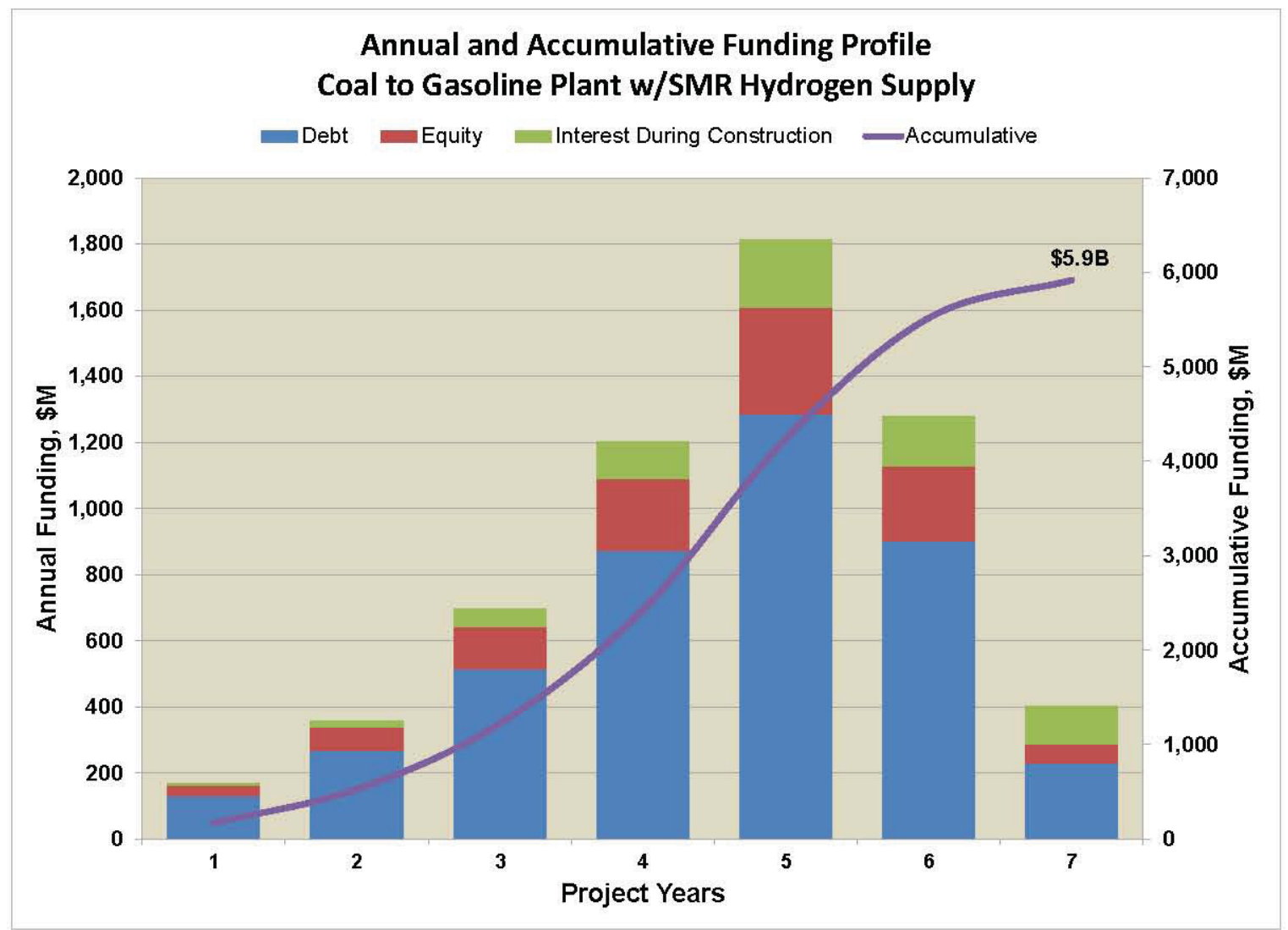

Figure F-8. Initial plant annual and accumulative funding requirements.

The times to construct and commission the modules also vary with the first module taking an estimated 4 years; final design, permitting, early site preparation and long term procurement taking the first two years. This effort and long term procurement expenses in those two years account for about $10 \%$ of the total cost of the Project. As noted the first module would undergo a one year "shake-down" period of operation of the first module before initiating completion of the construction and operation of the second module. The construction period of the second module is estimated at 42 months and 36 months for the third and fourth modules. Six month intervals following initial operation of the second module are used for the initial operation of the third and fourth modules. The total time from start of the Project to full deployment is 7 years.

Figure F-9 shows the number of jobs required during the construction of the process plant. On average $\sim 3,600$ personnel will be required per year with a peak of $\sim 8,000$ in the $5^{\text {th }}$ year. The breakdown in estimated expenditures for the plant projects that $56 \%$ of the total cost will be in labor, $30 \%$ in equipment procurement and $14 \%$ in material procurement. It is expected that the majority of labor and material will be supplied from within Wyoming. Coordination with Wyoming interests in the industrial sector would ensure that as much of the equipment procurement as possible would be from Wyoming sources. At a projected cost of $\sim \$ 5.9 \mathrm{~B}(2011 \$)$ this would represent a significant boost to the Wyoming economy. When fully deployed the process plant will employ $\sim 400$ with significant increases in personnel during turnarounds. 


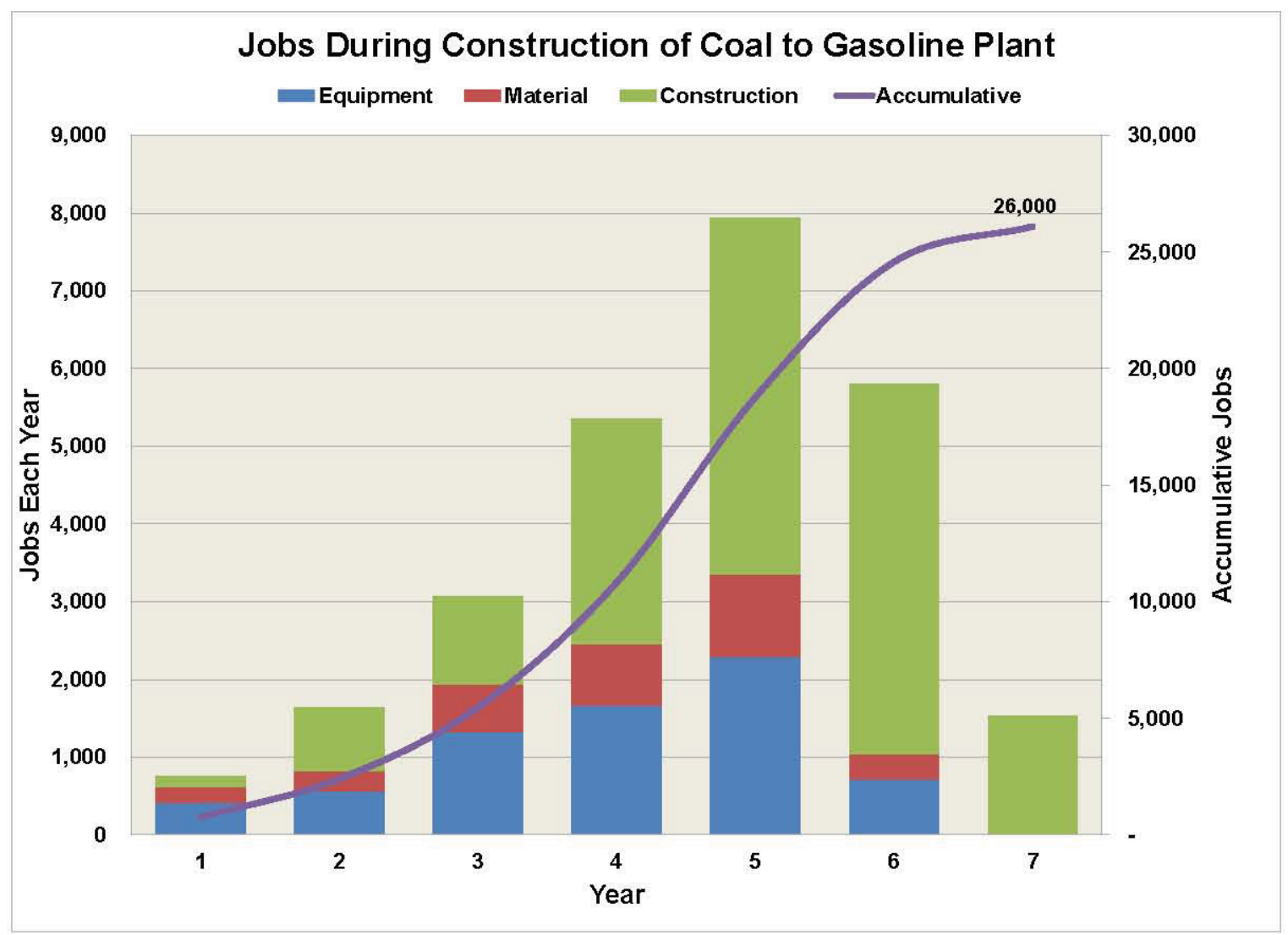

Figure F-9. Jobs during construction of the initial process plant.

Figure F-10 shows cumulative cash flow for this plant through 2028. The product revenues are based on the prices required to achieve $10 \%$ IRR (after tax) over the economic period of the plant; assumed to be 27 years (the time to retire the debt). As shown the Project achieves full return of investment in about 14 years as the full plant capacity comes on-line. The maximum negative cash flow is $\sim \$ 1,500 \mathrm{M}$ during construction of the second, third and fourth modules. The fairly flat section during the initial operation of the full plant reflects the payback of debt. Once debt is paid off the rate of cash accumulation increases significantly. If it is necessary to extend the schedule because annual work scope is too large the costs will increase due to inflation and the time to recover the full investment will be longer. 


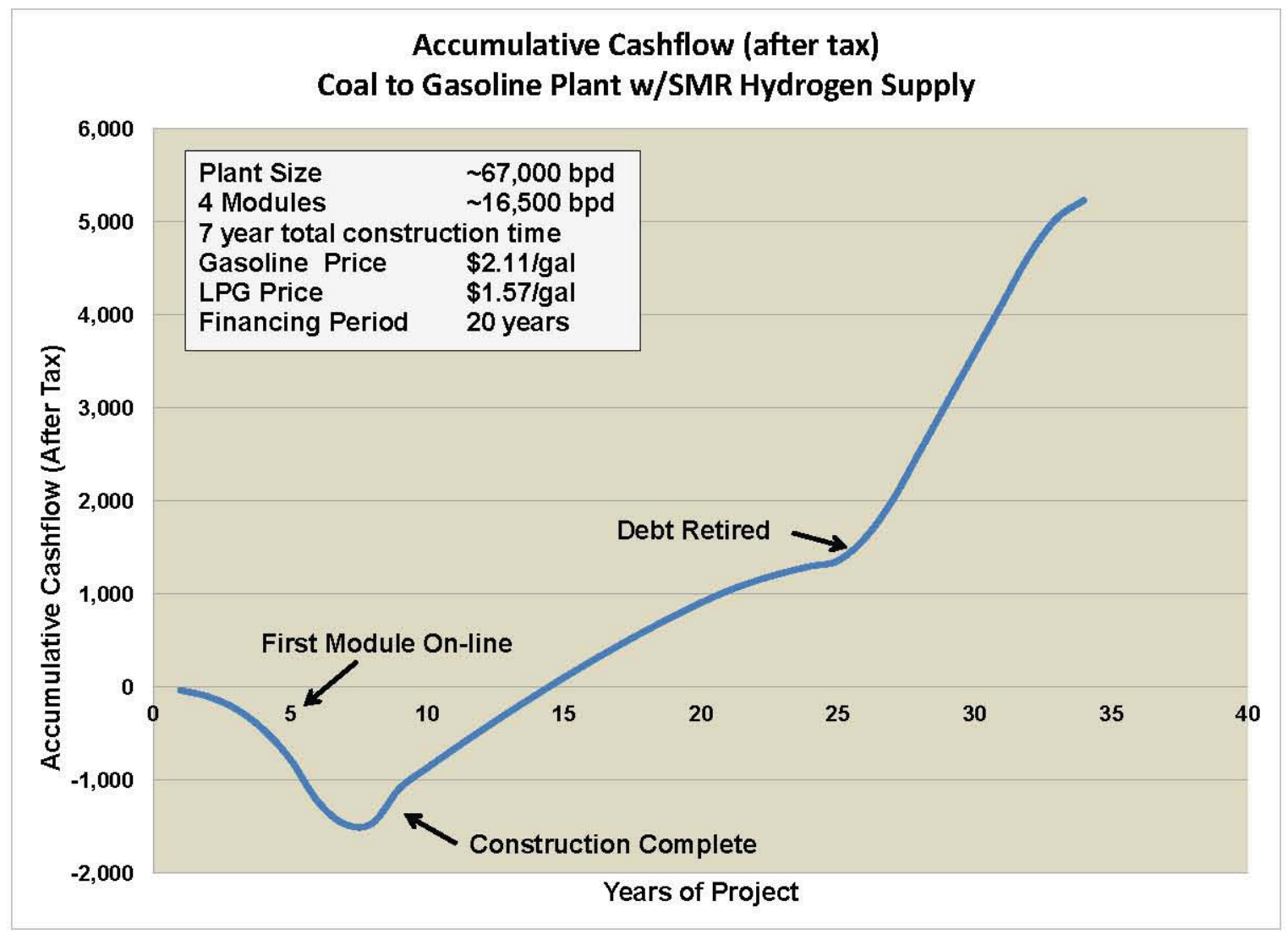

Figure F-10. Project accumulative cash flow.

\section{F-1.3.2 Incorporation of an HTGR Plant}

Figure F-11 shows the current projected schedule for development of the HTGR and HTSE technologies. It is anticipated that the first demonstration HTGR module and the first plant will be in an application supplying steam and electricity to an industrial facility. As shown the full deployment of that plant is not anticipated until 2029. However, at the end of the three year initial operating period of the first module over 2024 through 2026 the performance of the technology will have been demonstrated and the open licensing issues resolved. It is expected that this will engender sufficient confidence to consider broader application of the technology. Accordingly, as shown in Figure F-7 it is assumed that in $2024 \mathrm{ta}$ decision would be made to incorporate the HTGR technology into the process plant design. This plant would provide heat and electricity to the process plant and electricity to the regional utility. It will take 8 years to complete with the first module supplying heat and electricity to the process plant in 2031 .

The HTSE technology is not needed for the initial process plant design developed herein, but could be later if government regulations and economics warranted its application. It would provide hydrogen to the coal gasification process with no $\mathrm{CO}_{2}$ emissions. This technology may be developed and commercialized earlier than the HTGR. If it can be shown that the HTSE is an economic alternative for hydrogen production, its incorporation in the process could proceed at that time using electricity from the electrical grid. It will be necessary to monitor the progress and results of its development to make a decision on its implementation. 


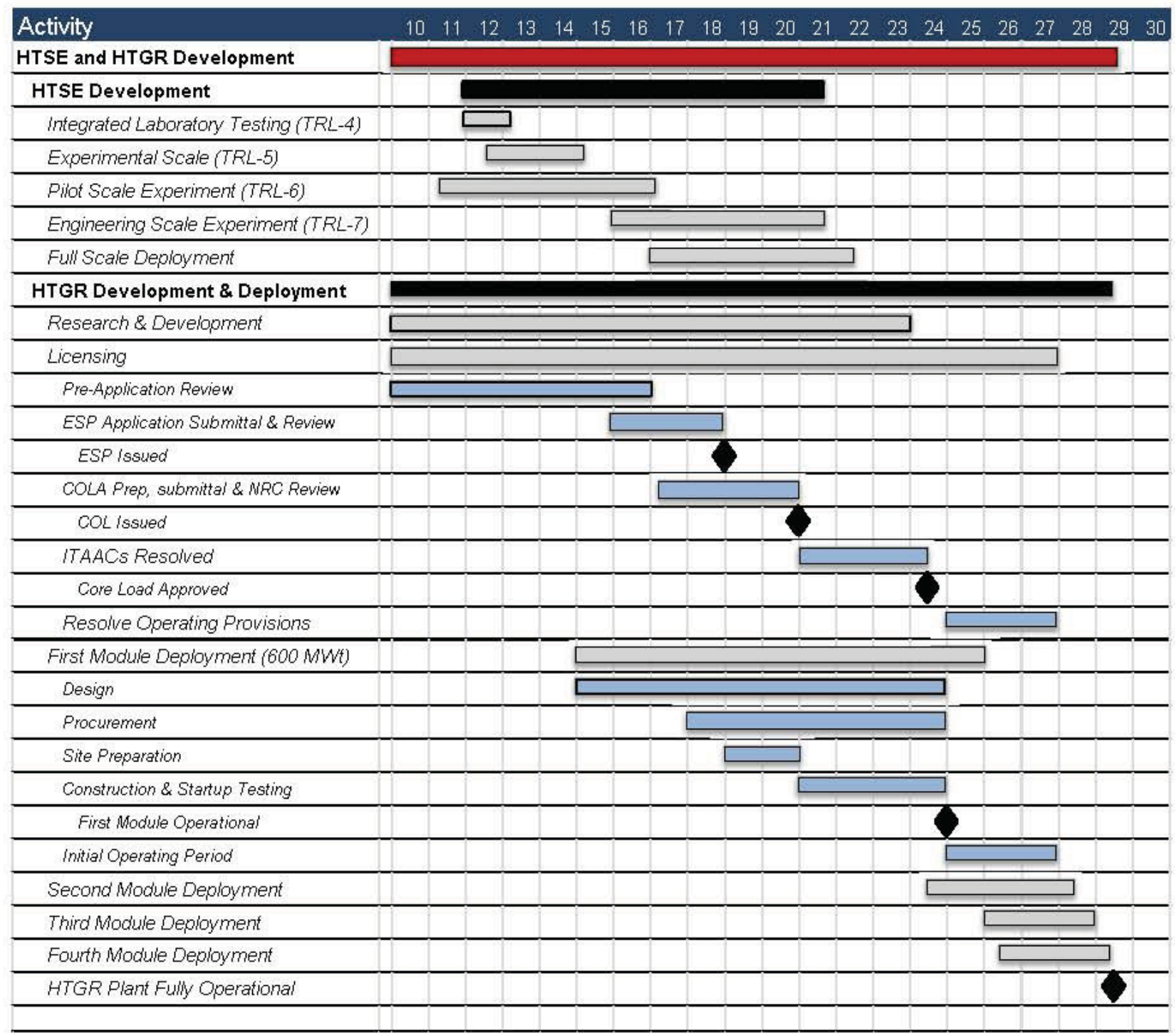

\section{Figure F-11. HTGR \& HTSE technology development projected schedule.}

The HTGR plant design assumed for incorporation in the natural gas to liquids plant is comprised of 5-600 MW(t) modules supplying heat and electricity to the process and electricity to the grid. As shown in Figure F-7 it is projected to start construction in 2024 with first module operation beginning in 2030. This is a little over 10 years after the full deployment of the process plant. This is an appropriate period of operation for instituting major maintenance on the plant such as modify ing the SMR to interface with the HTGR heat supply. The HTGR plant will also be interfaced with the grid transmission lines at that time. The projected cost of the HTGR plant is $\sim \$ 5$ billion (2011\$) spread over 8 years of construction. The Inflated cost is estimated at $\$ 6.4$ billion including interest on debt. Figure F-12 and Figure F-13 show the projected annual funding required to complete the plant design, licensing, equipment and material procurement, construction and commissioning of the plant (2011\$) and the annual and accumulative jobs developed during the deployment of this plant. During construction the site will employ 3,400 personnel on average each year and 7,300 peak in the fifth year of the project. The finished plant will employ 400 personnel. When fully deployed the Process and HTGR plant will employ at least 800 full time personnel. 


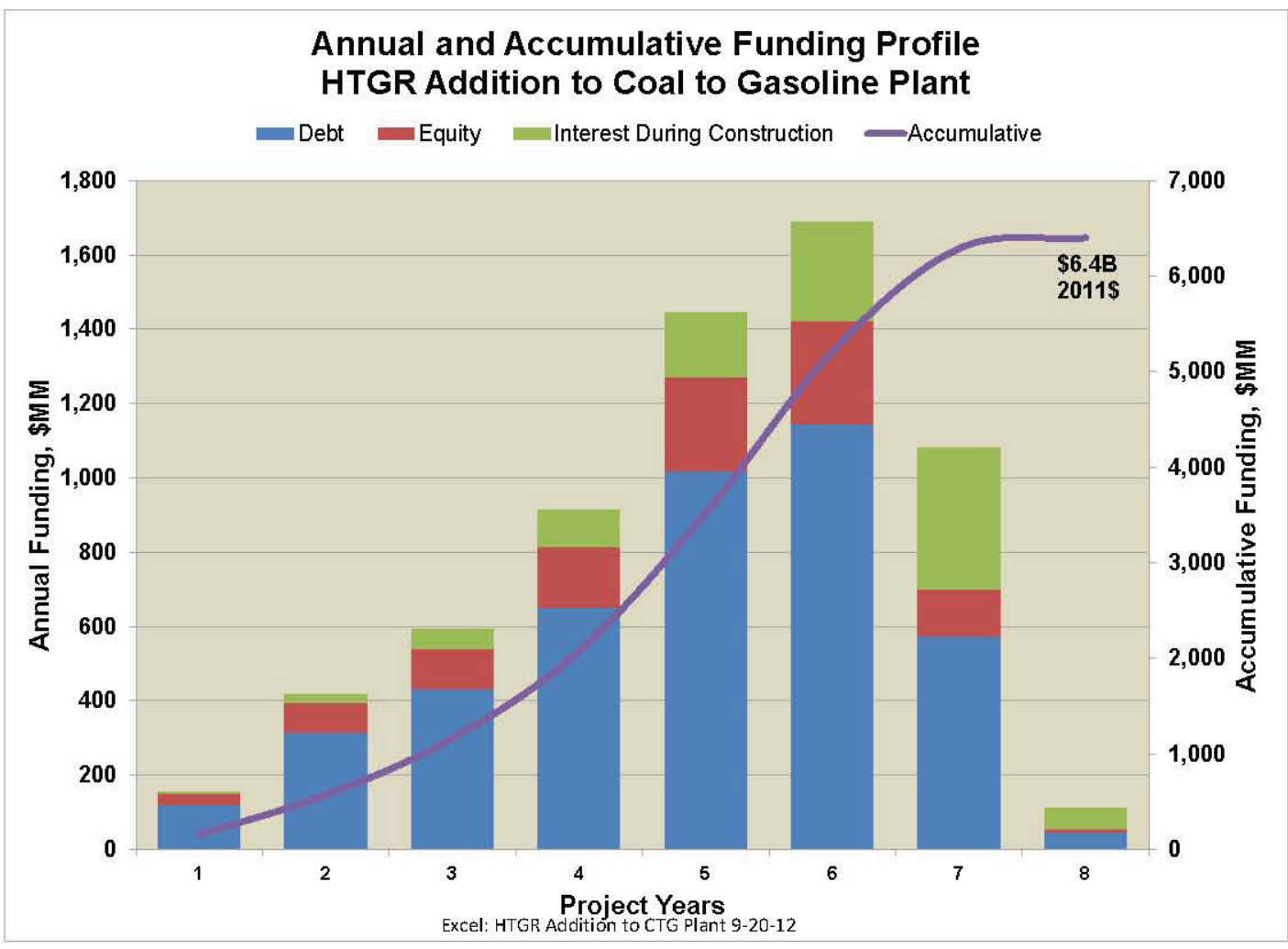

Figure F-12. Annual and accumulative funding required for deployment of the HTGR plant.

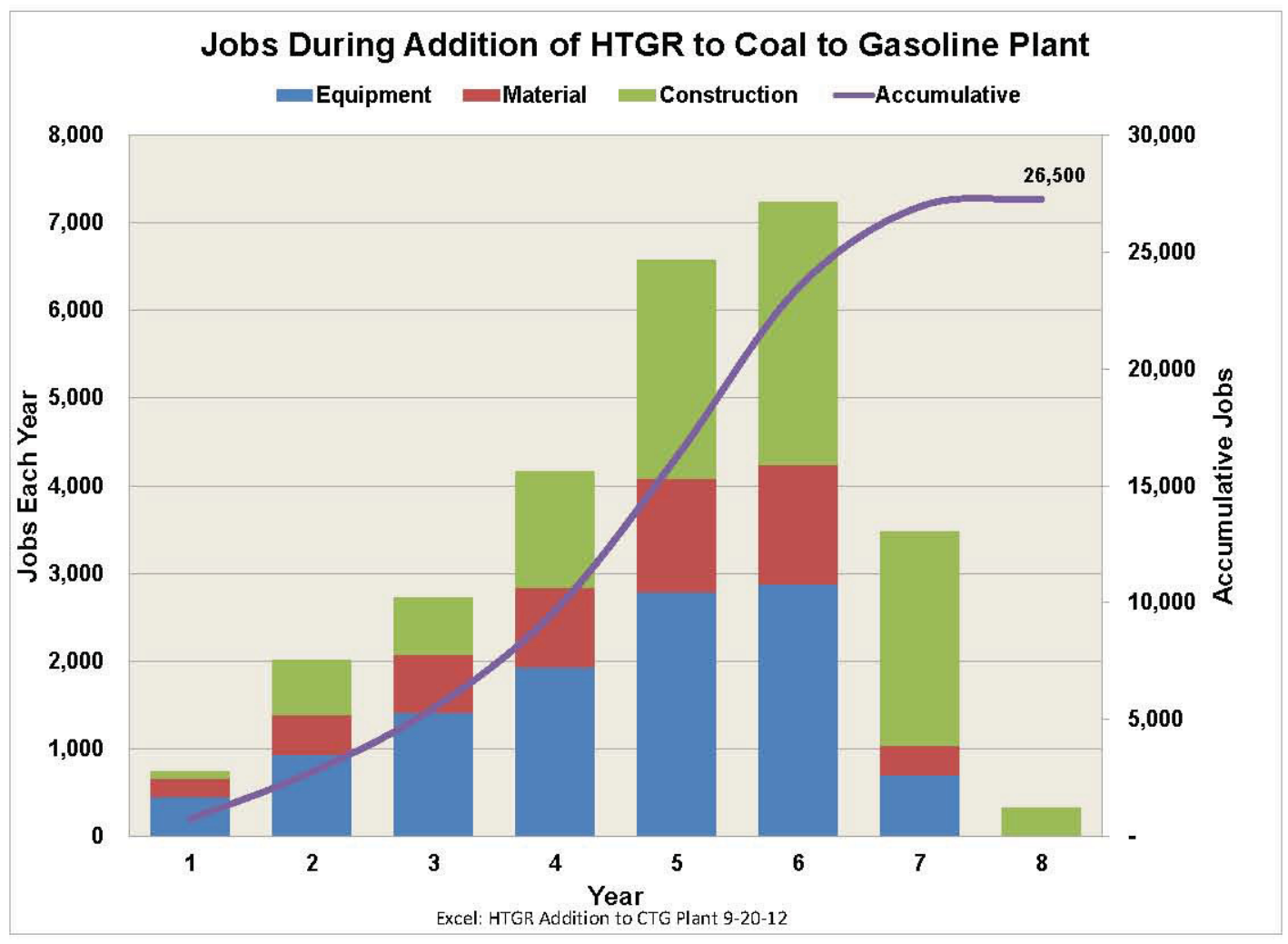

Figure F-13. Jobs during deployment of the HTGR plant. 
The construction, permanent employment and added value of coal and natural gas attendant to the deployment of the initial plant would provide significant benefit to the Wyoming economy. The following section discusses deployment of these plants to develop the carbon conversion industry, the deployment of HTGR technology for electricity generation and projections of the long term benefits of these developments.

\section{F-2. Development of a Carbon Conversion Industry in Wyoming}

\section{F-2.1 Objectives}

The development of a carbon conversion industry in Wyoming through expansion of HTGR integrated process plants and electricity generation is intended to meet the goals described in Section 2 of this report.

As developed in the prior sections of this report the deployment of a carbon conversion industry that uses the indigenous coal and natural gas resources in Wyoming as feedstock to produce higher value products such as synthetic transportation fuels, chemical feedstocks and chemical building blocks is judged an effective approach to meet these goals. Further, integrating HTGR technology in the deployment of this industry and for generation of electricity in place of coal-fired generation in the State addresses the principal concerns with the current uses of coal and natural gas by providing a nongreenhouse emitting source of energy at a long term economic and stable cost. The following presents the scope of the issues to be addressed through this initiative and presents a "strawman" deployment of the carbon conversion industry that addresses these issues.

\section{F-2.1.1 Coal and Natural Gas Production \& Revenue}

Deployment of multiple coal conversion plants throughout Wyoming would be beneficial to the Wyoming economy by establishing a coal conversion industry that will provide an alternative demand for Wyoming coal, increase the value of that coal to the Wyoming economy by producing higher value products and provide quality jobs throughout the State. Figure F-14 shows the decline in Wyoming coal production over the last few years that has prompted the pursuit of an alternative market for coal.

Figure F-15 shows the history of gross withdrawals of natural gas in Wyoming January 2005 through May $2012^{2}$. The trend of gross withdrawals shows a decline of about $10 \%$ in 2010 compared with the peak in 2008. What is of more significance, however, is the decline in the price of the natural gas over this time frame. Figure F-16 shows the history of the annual average of the natural gas wellhead price in Wyoming through 2010 compared with the average wellhead price in the U.S. As shown the Wyoming prices follow the U.S. trend but are slightly below them. The peak price in Wyoming in 2008 and 2010 was $\$ 6.86 / \mathrm{MSCF}$. It was $\$ 3.4 / \mathrm{MSCF}$ in 2009 . It rebounded to an average of $\$ 4.3$ in 2010 and dropped to the range of $\$ 4 / \mathrm{MSCF}$ in 2011 based on the U.S. average. The range of Henry Hub prices is also shown in Figure F-16; $\$ 2$ to $\$ 3.4 / \mathrm{MSCF}$. The NYMEX futures for natural gas show natural gas prices remaining in the $\$ 2.50$ to $\$ 4 / \mathrm{MMbtu}$ range for the next several years; Figure F-17. Projections are that this trend will persist for at least a decade, see Figure F-25.

Figure F-18 summarizes the history of the GDP in Wyoming from 2005 through 2011along with the contribution to that GDP from Mining. As shown the State GDP and the Mining contribution drop then level off after reaching a peak in 2008. This reflects the general recession affecting the U.S. economy starting in 2008 . Over this period, however, the Mining industry has consistently contributed $30 \%$ to $35 \%$ to the State's GDP. 


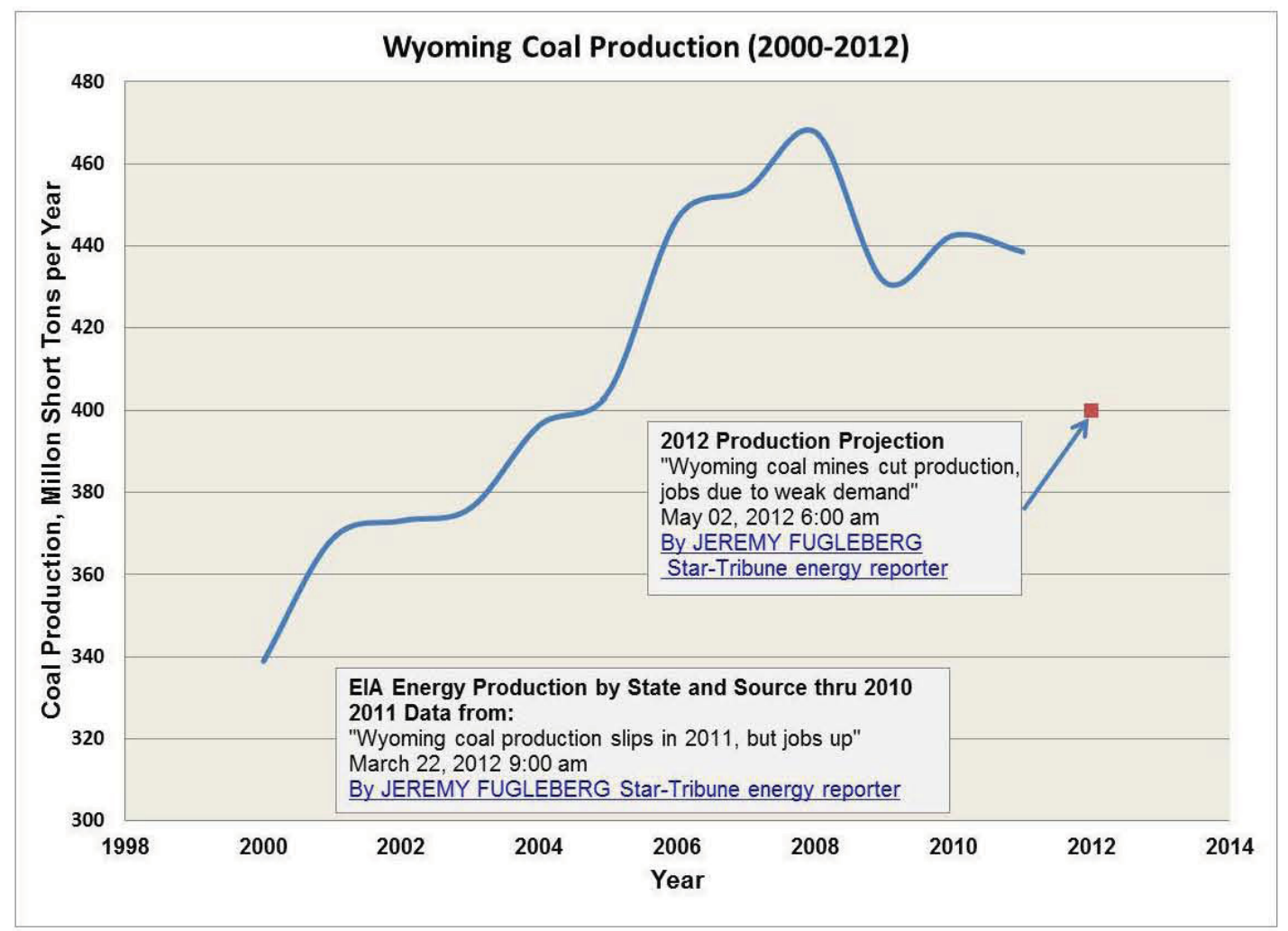

Figure F-14. History of Wyoming coal production, 2000-2012.

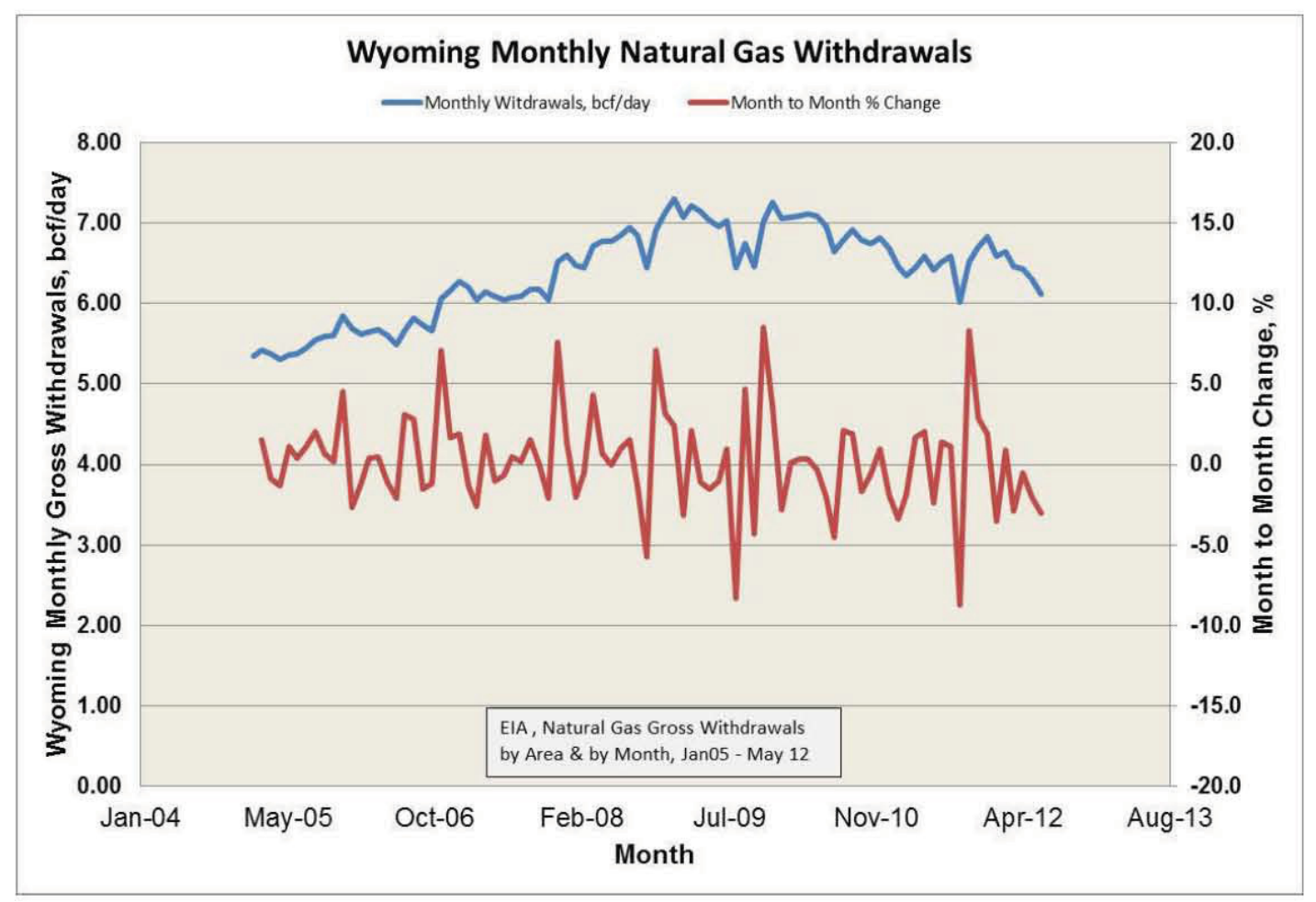

Figure F-15. Wyoming monthly natural gas withdrawal. 


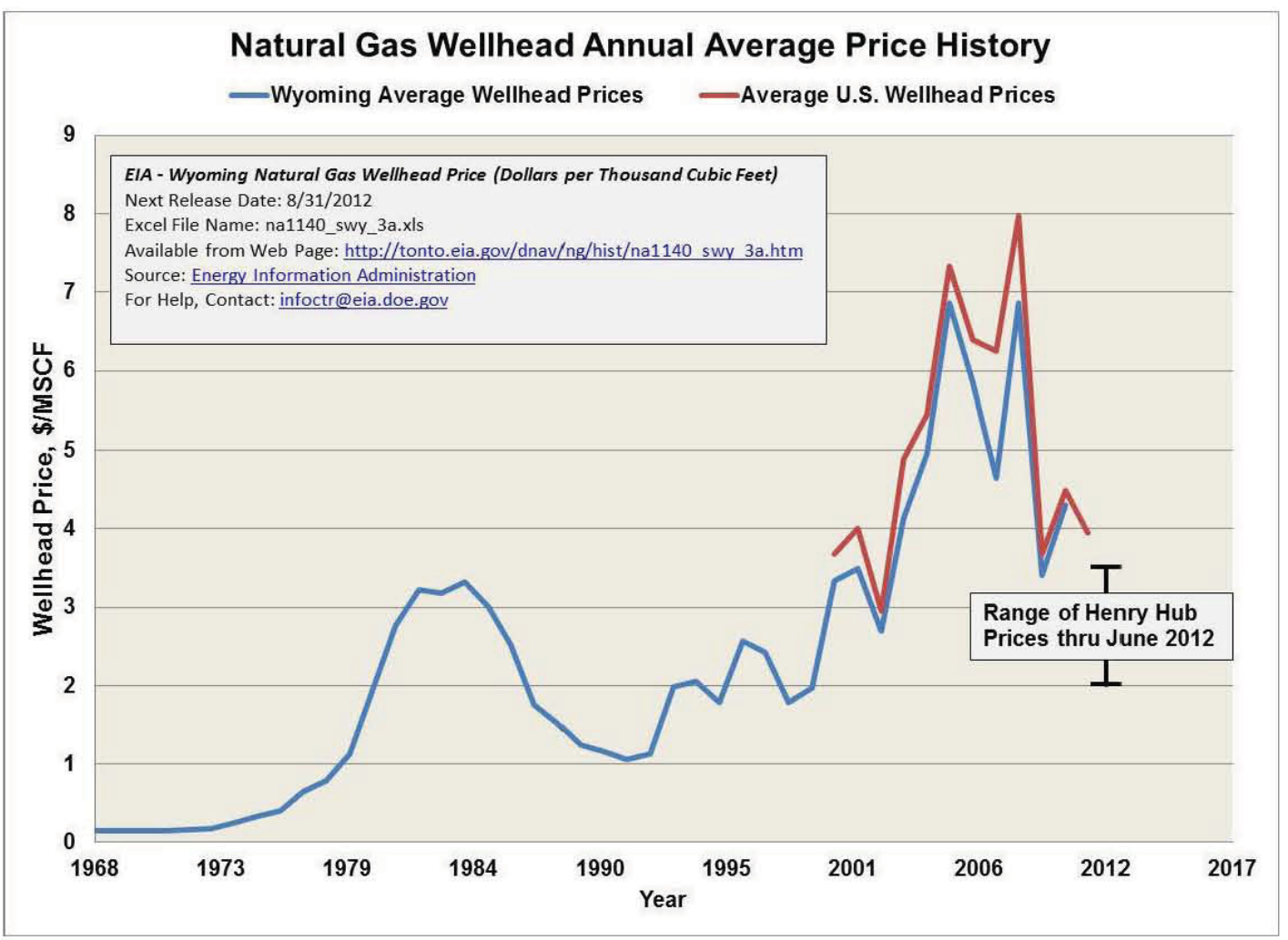

Figure F-16. Wyoming natural gas wellhead annual price, 1968-2010.

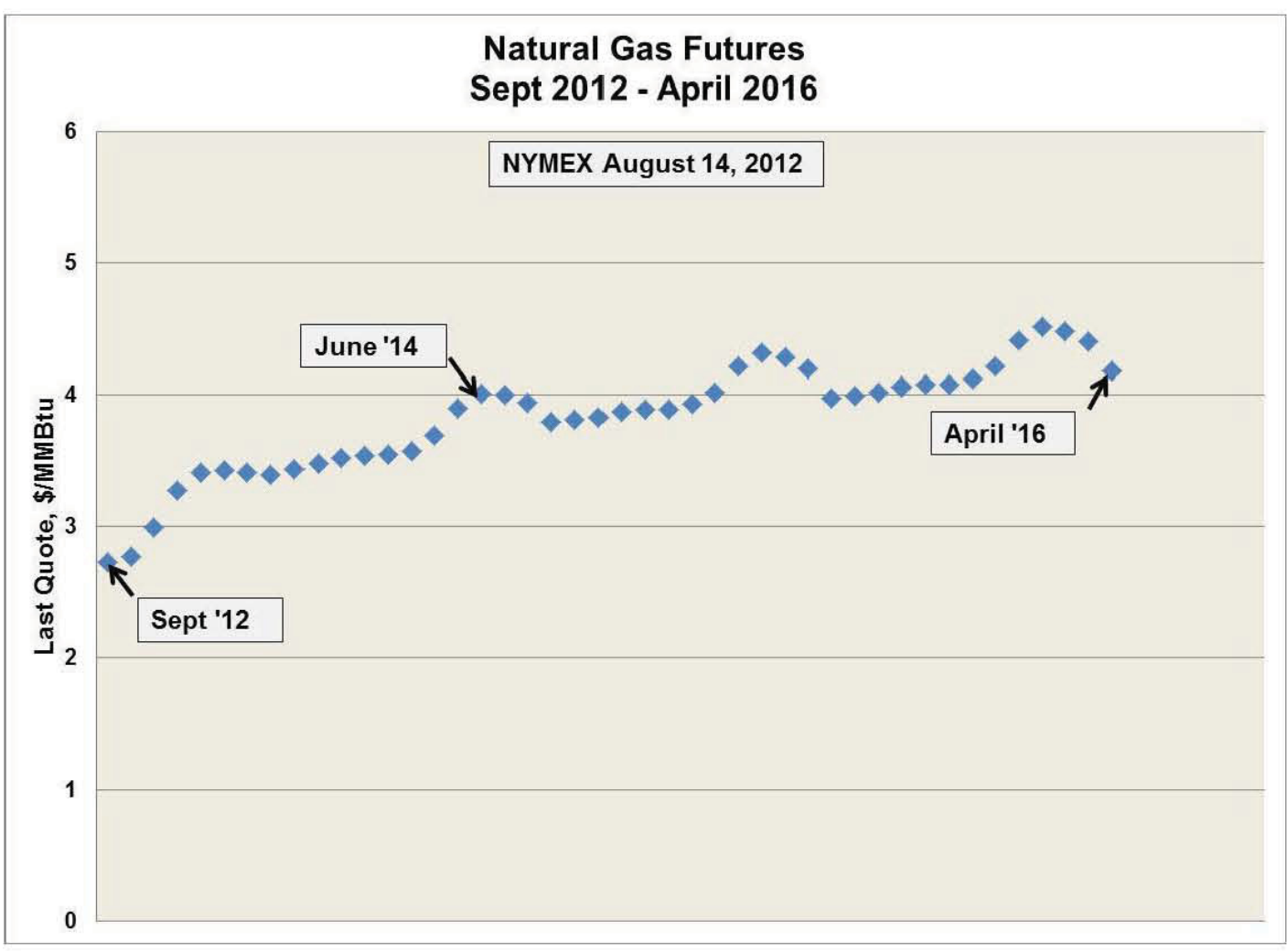

Figure F-17. Natural gas futures, August 14, 2012. 


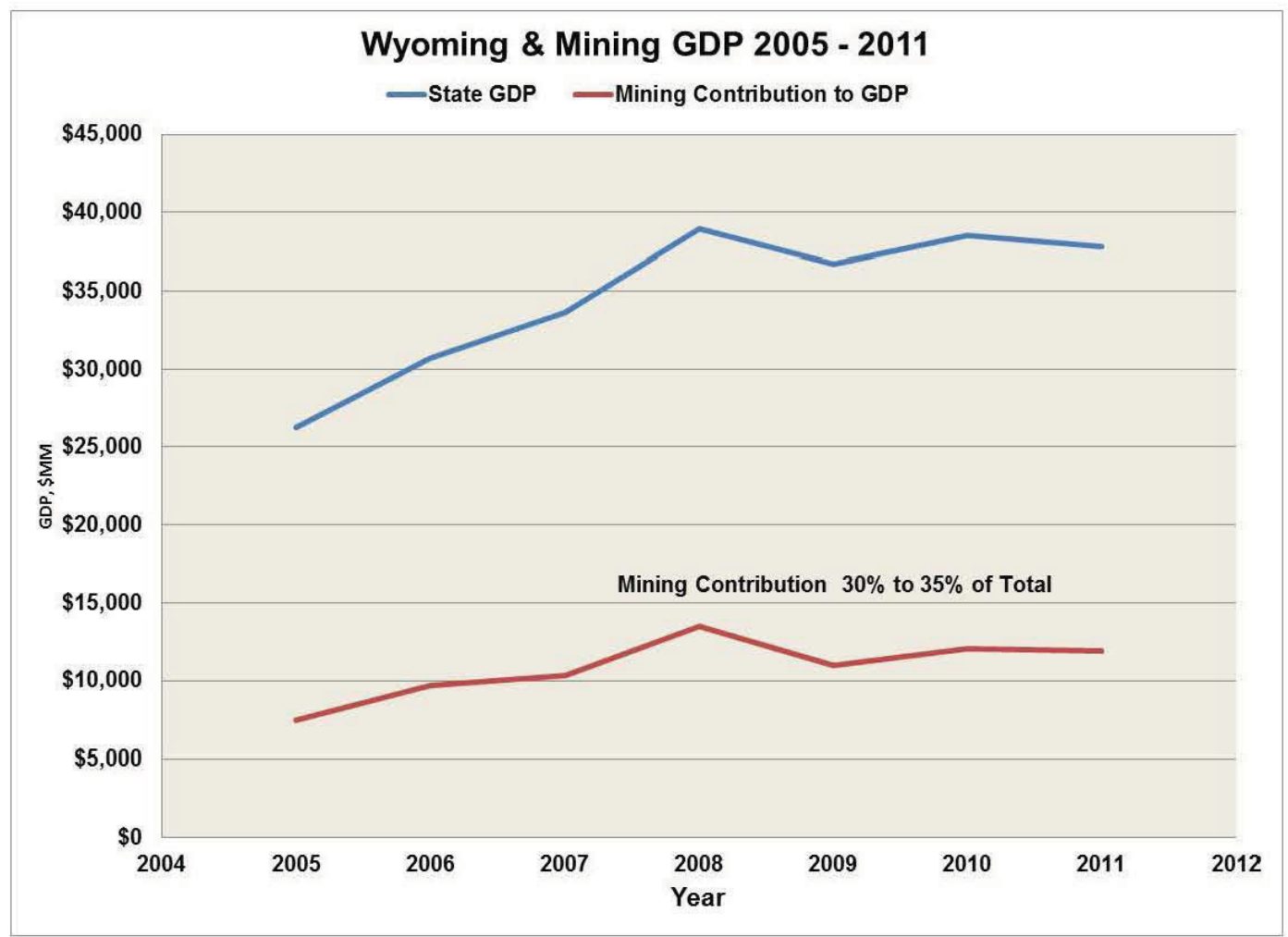

Figure F-18. Wyoming State and mining contribution to GDP 2005-2011.

The impact of the reductions in the production of coal and the reductions in the price of natural gas on the contribution of coal and oil \& natural gas extraction to the Wyoming economy is illustrated in Figure F-19. This figure summarizes the Gross Domestic Product (GDP) ${ }^{1}$ of the Mining industry in Wyoming 2005 through 2011. In this context the Mining industry is characterized in three segments; Oil \& Gas Extraction, Mining other than Oil \& Gas Extraction and Support of Mining Activities. The figure shows the contributions of each of these segments of the Mining industry through $2009^{3}$. The segment data for 2010 and 2011 was not available; just the total for that industry.

\section{F-2.1.2 Influence of Reductions in Natural Gas Prices on Wyoming Economy}

The trends in the contributions of each of the Mining industry segments in Figure F-19 and F-20 show that the oil and gas extraction contribution dropped by $\sim \$ 2.8 \mathrm{~B}$ between 2008 and 2009 ; accounting for the majority of a similar drop in the Mining industry contribution to State GDP. As shown in Figure F-15 the production of natural gas declined slightly over this period. Oil production also fell slightly as well. However, the reas on for the lower GDP was a drop in average natural gas wellhead price from $\sim \$ 7 / \mathrm{MSCF}$ to $\$ 3.4 / \mathrm{MSCF}$ and oil price from $\sim \$ 85 / \mathrm{bbl}$ to $\$ 52 / \mathrm{bbl}^{4}$. Since 2009 the oil prices have rebounded to $\sim \$ 85 / \mathrm{bbl}$ so far in 2012. Although the Oil \& Gas Extraction contributions in 2010 and 2011 are not known it is reasonable to assume that since the oil revenues have rebounded to pre-2009 levels, the oil contribution would be back to 2008 levels so the 2010 and 2011 contributions would follow the average natural gas wellhead prices in these years. As noted previously natural gas prices in 2010 and 2011 were in the same range as 2009 and 2012 have been lower and are not expected to increase

1 Reference 10 defines GDP and the reporting thereof as follows: "Originally referred to as Gross State Product (GSP), Gross Domestic Product (GDP) by state is an inclusive measure of economic activity within a state. It is the total market value of goods and services produced by the labor and property within a state during a specified period of time. Also, equivalent to sales less intermediate inputs ..." 


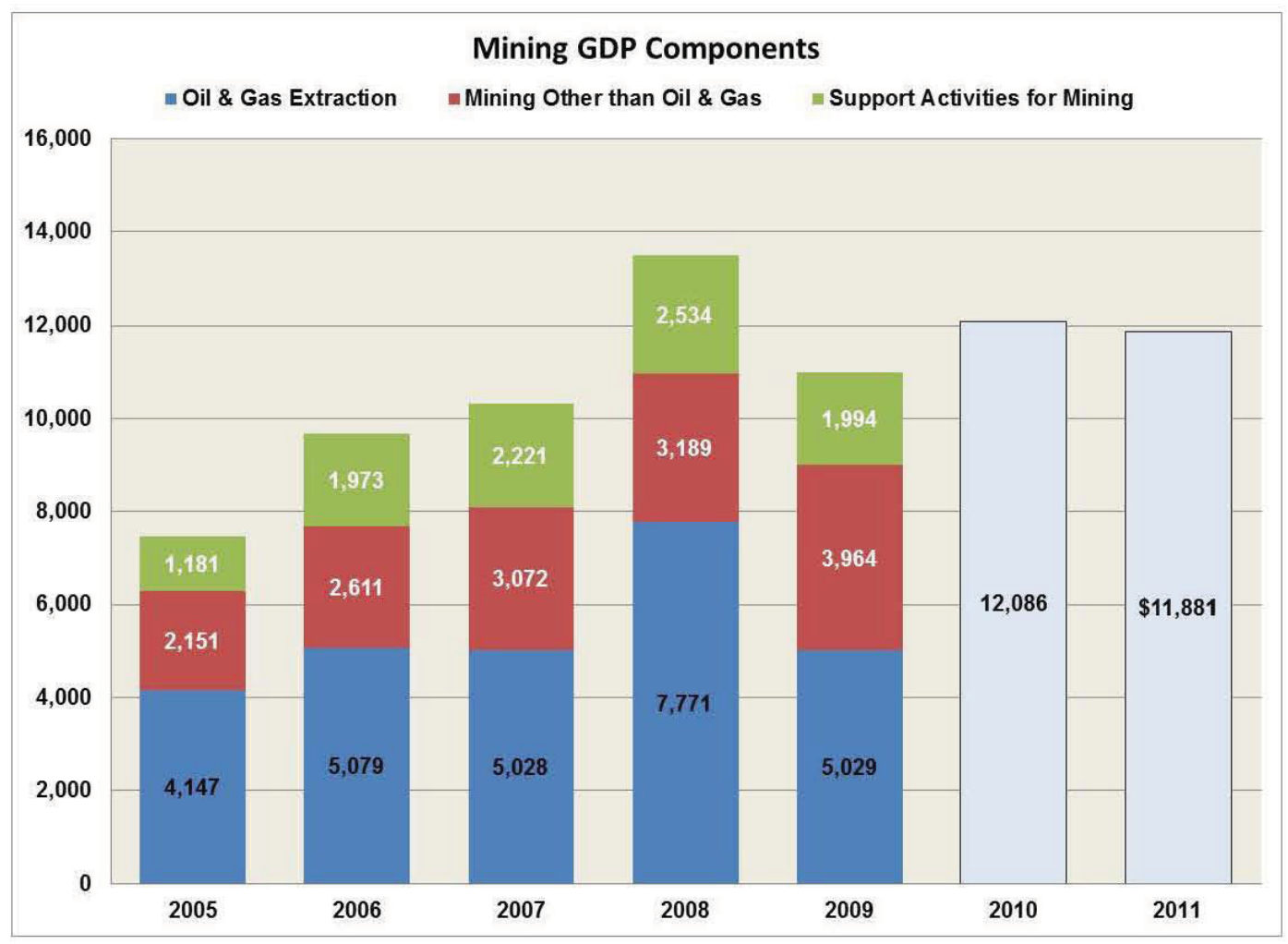

Figure F-19. Influence of reductions in coal production on Wyoming economy.

significantly over the next decade. Accordingly, a $\sim$ \$2B reduction in GDP contribution from oil and gas extraction was likely in 2010 and 2011 from 2008 levels and is expected to persist for at least another decade.

This reduction in GDP contribution results in comparable reductions in revenue of several hundred million to State, Local and Tribal governments from severance taxes, property taxes, franchise and other taxes. ${ }^{5}$ Accordingly, there are several incentives to develop another industry that provides an additional market for natural gas as well as increases the value of the natural gas to the Wyoming economy. The development of the carbon conversion industry in Wyoming and specifically the initial coal to diesel plant using an SMR hydrogen supply developed herein would address these incentives.

As shown in Figure F-14 the effects of current EPA regulations on emissions (e.g., mercury, etc.) have had impact on Wyoming coal production due to retirement of coal based electricity generation in the U.S. There are several other factors such as the low natural gas prices causing utilities to switch from coal to natural gas fired plants and pending EPA regulations on $\mathrm{CO}_{2}$ emissions ${ }^{6}$ that are expected to result in no new construction of coal based electricity generation. ${ }^{7}$ The EPA has also indicated in this reference that it is developing new NSPS with the States that will include greenhouse gas emissions. This latter action could cause early retirement of coal based generation. These factors provide other incentives for developing an industry for use of Wyoming coal and for increasing its value to the Wyoming economy.

Figure F-20 shows the projections by EIA for retirement of coal-fired electricity generation through 2020. This chart shows a range of retirements depending on assumptions on economic growth and the trends in natural gas prices. Assuming that natural gas stays near $\$ 4 / \mathrm{MMBtu}$ over the long term and the economy continues to slowly improve the total retirements would projected to be in the 50 to $55 \mathrm{GW}(\mathrm{e})$ range (e.g., Gas Price Case - low \& Economic Growth Case - Reference). This is $\sim 16 \% \%$ of the total coal electricity capacity in the U.S.in $2011 .^{5}$ 


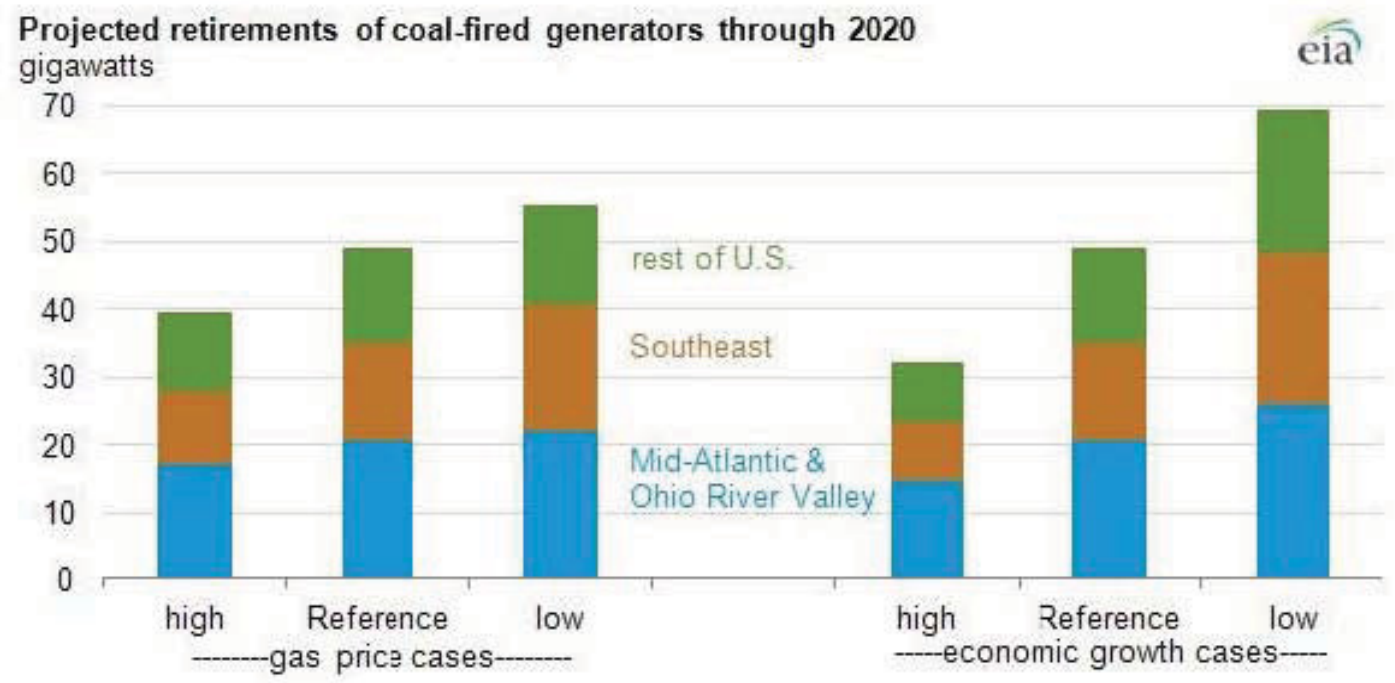

\section{Electricity generation by source billion kilowatthours 6,000}

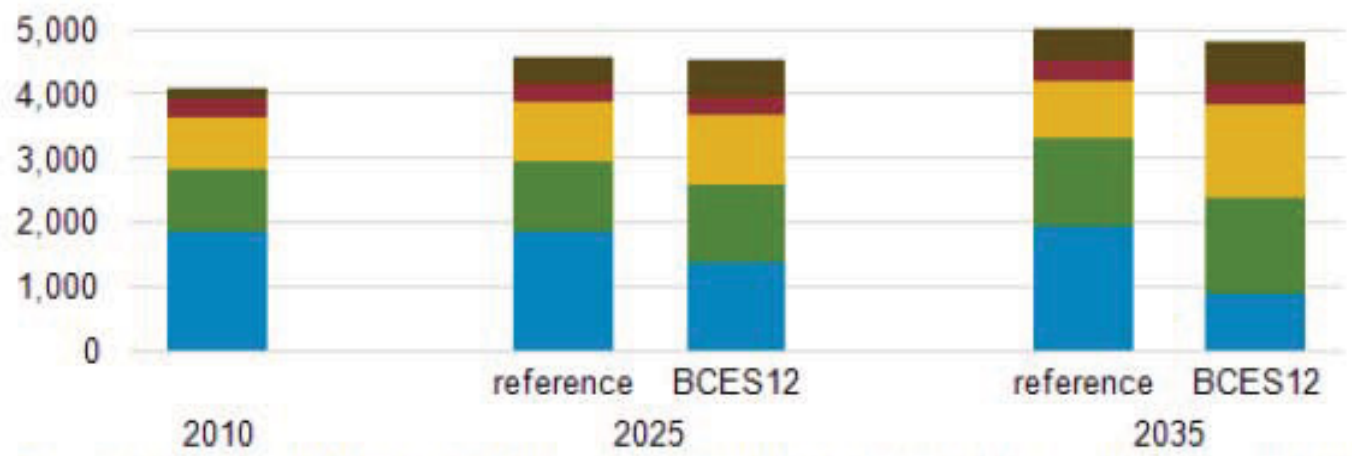

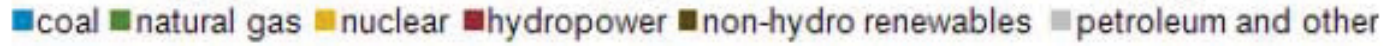

Figure F-20. ElA projections on retirements of coal-fired plants through 2020 (Source: U.S. Energy information Administration, National Energy Modeling System).

It is understood that this does not reflect any increased regulation of $\mathrm{CO}_{2}$ emissions on existing plants. Legislation proposed by Senator Jeff Bingaman ${ }^{8}$ provides some insight into the potential effect of such regulation. The EIA analysis of this legislation projects the following':

"The policy also results in a significant shift in the long-term electricity generation mix, with coalfired generation in 2035 falling $54 \%$ below the Reference case level. The significant increase in coal retirements under the $B C E S 12$ policy is primarily offset by increased natural gas-fired generation through 2020, while increased nuclear and non-hydropower renewable generation plays a larger role between 2020 and 2035. In addition, total electric power generation falls slightly under the $B C E S 12$ policy.

In the reference case ELA projected coal generation of $\sim 1951$ BK whe in 2035 consuming $\sim 19.5$ quads $\left(10^{15} \mathrm{Btu}\right)$ of coal in the reference case. ${ }^{1}$ The $54 \%$ reduction would amount to reducing consumption by $\sim$ a trillion tons of coal or about 2.5 times the annual production of coal in Wyoming in 2011. EIA also estimates a reduction of coal based generation capacity of $26 \%$ or $\sim 90 \mathrm{GW}(\mathrm{e})$. Since Wyoming provides $\sim 40 \%$ of the coal consumed in the U.S. and this is used primarily for electricity generation in 30 states ${ }^{10}$ these retirements and reductions in coal use for electricity would be expected to have a significant impact 
on Wyoming coal production. If it is assumed that the $54 \%$ reduction in coal based electricity production affects Wyoming coal production by a similar amount the reduction in the contribution of this industry to Wyoming could be as high as that seen for the reduction in natural gas prices; $\sim \$ 2 \mathrm{~B}$ annually. Wyoming has initiated some international export to offset this reduction ${ }^{11}$. However, this is not expected to be able to completely offset the reductions due to retirement of coal based plants.

\section{F-2.2 Deployment of the Carbon Conversion Industry}

The objective of deployment of the carbon conversion industry is to develop a stable and long term revenue stream from use of indigenous natural gas and coal in Wyoming to offset the factors discussed in the preceding that have been and are projected to reduce the revenue from sales of these resources. This carbon conversion industry will provide a market for these resources as well as increase their value to the Wyoming economy by converting them to higher value transportation fuels, chemical feedstock and chemical building blocks.

A phased approach is developed herein as an illustration of how this carbon conversion industry could be deployed. It begins with the initial deployment of the $67,000 \mathrm{bpd}$ coal to gasoline plant described in preceding sections of this report. As shown in the schedule of Figure F-7 its deployment could begin in 2013 with the first stage of the plant operational at the beginning of 2018 . This initial module would generate $\sim \$ 500 \mathrm{M}(2011 \$)$ in revenue assuming sales at the average prices of gasoline and LPG in 2011. This segment of the plant would consume $\sim 24 \mathrm{Bcf}$ of natural gas per annum. If this module were integrated into a venture supplying coal and natural gas directly to the process, the gross added value (GAV) to the GDP of the State would be $\sim \$ 350 \mathrm{M}$; taking account of the intermediate added value from the commodities used in producing the liquid products from the natural gas. ${ }^{\mathrm{m}}$ If the coal and natural gas supply were separated from the gas production facility the GAV would be $\sim \$ 200 \mathrm{M}$; reduced by the cost of the coal at $\$ 10$ /ton and natural gas at $\$ 5.50 / \mathrm{MSCF}$. The total GAV for the sale of the liquids and the natural gas, $\$ 350 \mathrm{M}$ per annum, would then account for about $\sim 9 \%$ of the reduction in contribution of the mining industry to the GDP due to the reduction in coal production and prices of natural gas.

The schedule for deployment of this initial plant shows an expansion to a four module plant with a 67,000 bpd capacity that would reach full capacity in 2022 . At that time the full plant would be generating GAV of \$1.9B (2011\$) annually.

For the purposes of illustration a second coal plant with an SMR hydrogen supply has been selected to be part of the notional carbon conversion industry for Wyoming, but would produce diesel instead of gasoline. This plant would generate synthesis gas by adding hydrogen to the output of the coal gasifier the same as is done to produce gasoline but instead of using the methanol process to produce gasoline the synthesis gas will be used with the Fischer-Tropsch process to produce diesel, naphtha and LPG. The detailed description of this process (CTL w/SMR) and its performance characteristics and economics are included in Appendices D and E of this report. This plant will convert $\sim 7,700$ tpd of coal and $\sim 280$ million cuft per day of natural gas to produce $\sim 35,000$ bpd of diesel, $\sim 12,000$ bpd of naphtha and 3,000 bpd of LPG and generate $\sim \$ 1.9 \mathrm{~B}$ GAV annually (2011\$). The deployment of this plant will help to offset

$\mathrm{m}$ Per the definition of GDP used in Wyoming, the Gross Added Value to the State's GDP is calculated as the total sales less the value of the intermediates; the value of intermediates produced in Wyoming are assumed to already be accounted in the GDP contribution of the process. For this analysis it has been assumed that intermediates used in the production of the liquids from natural gas are produced in Wyoming and are, therefore, already accounted in the Wyoming GDP. For the purposes of this discussion it has been assumed that this is the case since the majority of the higher cost commodities that are used in the process, (e.g., water makeup and treatment, insurance, taxes, royalties on natural gas usage, labor \& maintenance, overhead) would be from Wyoming. It is not certain that other commodities such as the catalysts used in the processes would be produced in Wyoming, however, the costs for these are not significant and have been included as intermediates for simplicity. 
some of the loss of revenue from coal production and low natural gas prices and support some gains in the Wyoming economy.

To address the reduction in natural gas prices, natural gas coal to gasoline and diesel plants are included as part of the notional carbon conversion industry. The natural gas to diesel plant production would complement the coal to diesel plant and would generate GAV of $\sim \$ 1.9 \mathrm{~B}$ annually. The natural gas to gasoline plant would be smaller than the coal to gasoline plant and would generate $\sim \$ 1.1 \mathrm{~B}$ in annual revenue. The construction of these plants will also contribute to the State's GDP with estimated costs of \$2.4B (2011\$) for the natural gas to diesel plant and \$2.4B (2011\$) for the Natural Gas to Gasoline Plant.

Table F-2 summarizes the performance characteristics of these four plants.

Table F-2, Characteristics of the Notional Wyoming Carbon Conversion Industry Process Plants

\begin{tabular}{|c|c|c|c|c|c|c|}
\hline Type & $\begin{array}{c}\text { Capacity } \\
\text { bpd }\end{array}$ & Products & $\begin{array}{l}\text { Natural Gas } \\
\text { Consumption } \\
\text { MMSCFD }\end{array}$ & $\begin{array}{l}\text { Coal } \\
\text { Consumption } \\
\text { short tons } \\
\text { per day }\end{array}$ & $\begin{array}{l}\text { Cost, \$M } \\
(2011 \$)\end{array}$ & $\begin{array}{c}\text { Annual } \\
\text { Revenue SM } \\
\text { (2011\$) }\end{array}$ \\
\hline $\begin{array}{l}\text { Natural Gas to } \\
\text { Gasoline (GTG) }\end{array}$ & 40,000 & $\begin{array}{l}\text { Gasoline \& } \\
\text { LPG }\end{array}$ & 290 & - & 2,200 & 1,050 \\
\hline $\begin{array}{l}\text { Natural Gas to } \\
\text { Liquids (GTL) }\end{array}$ & 50,000 & $\begin{array}{l}\text { Diesel, Naphtha } \\
\text { \& LPG }\end{array}$ & 430 & - & 2,400 & 1,860 \\
\hline $\begin{array}{l}\text { Coal to Gasoline } \\
\text { (CTG) }\end{array}$ & 60,000 & $\begin{array}{l}\text { Gasoline \& } \\
\text { LPG }\end{array}$ & 290 & 11,845 & 5,900 & 2,100 \\
\hline $\begin{array}{l}\text { Coal to Liquids } \\
\text { (CTL) }\end{array}$ & 50,000 & $\begin{array}{l}\text { Diesel, Naphtha } \\
\& \text { LPG }\end{array}$ & 280 & 7,720 & 3,900 & 1,860 \\
\hline Totals & 200,000 & & 1,290 & 19,565 & 14,100 & 6,870 \\
\hline
\end{tabular}

Figure F-21 shows the notional schedule for the extended deployment of the carbon conversion industry.

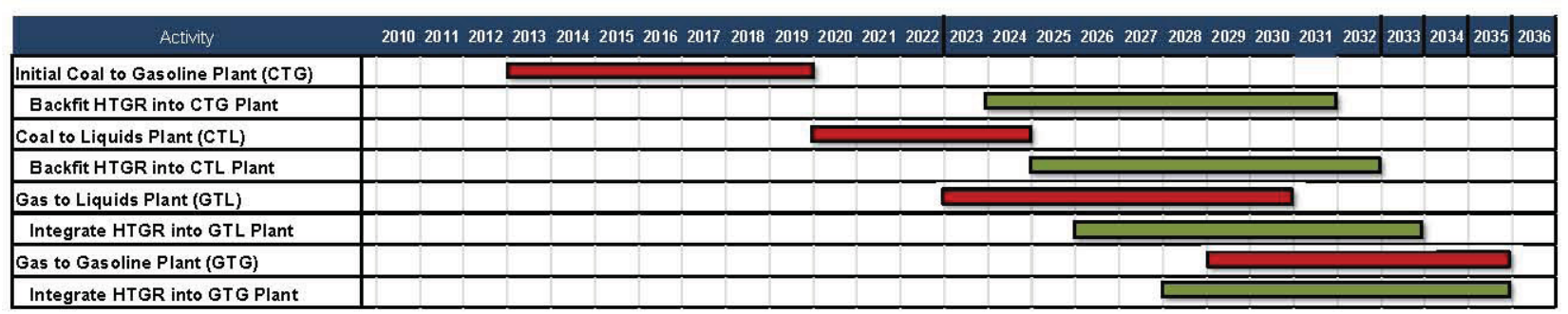

Figure F-21. Carbon conversion industry development.

Figure F-22 summarizes the annual expenditures, accumulative expenditures and the annual contribution of the carbon conversion industry to the State's GDP. All of the values shown on this figure are in $2011 \$$. There is a significant amount of expenditure related to the overlapping deployment of the GTL, CTL and Gas to Gasoline plants in the 2020 through 2035 time frame. The actual schedule for developing the industry would likely be configured to smooth out the costs over the full two decades of development. The development of sales using natural gas and coal provides a revenue stream and contributions to the GDP to the Wyoming economy that more than compensates for the low national natural gas prices and reduced coal production due to environmental regulation projected over the next two decades. 


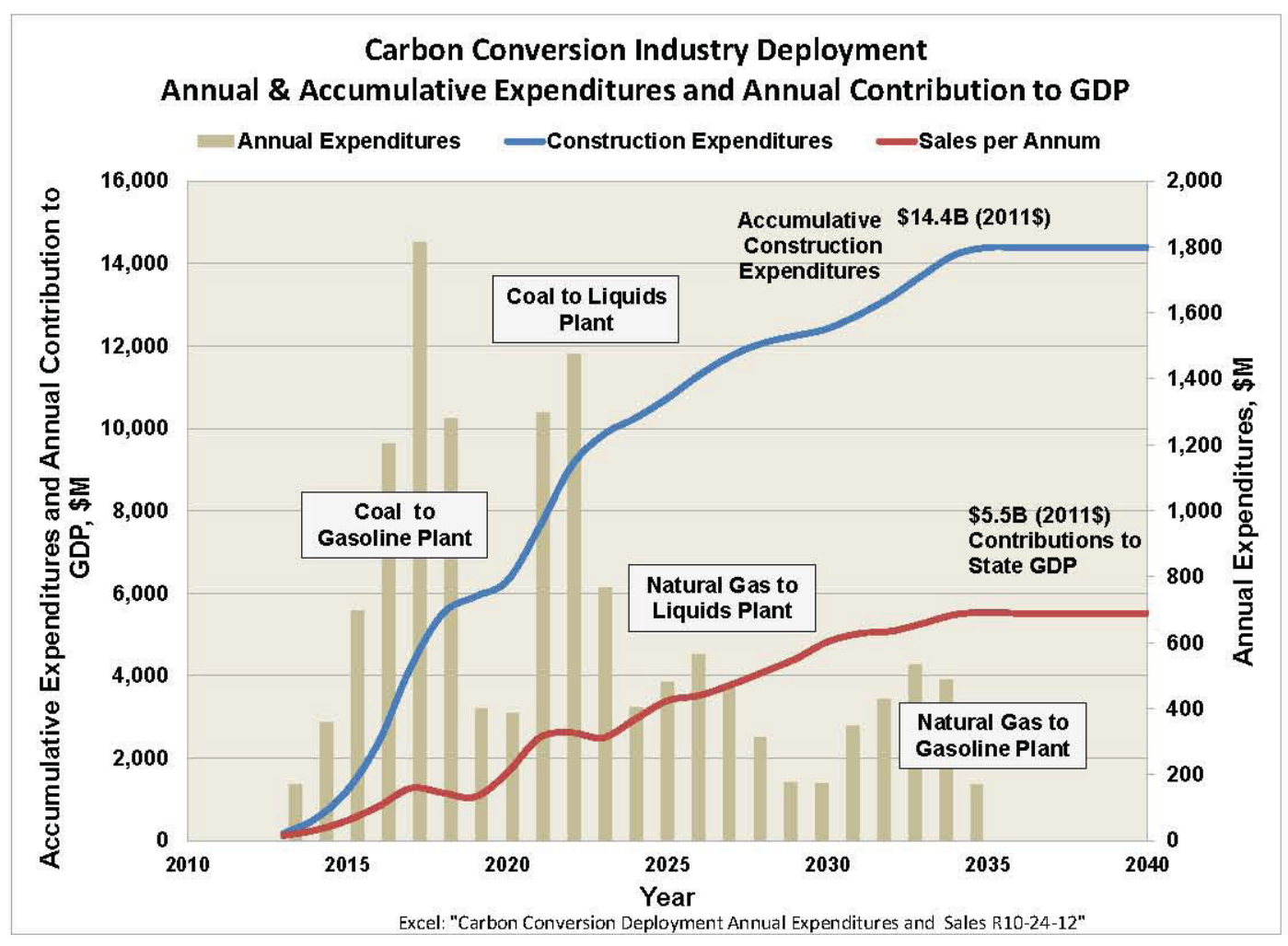

Figure F-22. Expenditures and contributions to the state's GDP from deployment of the carbon conversion industry.

As noted earlier, beginning in 2025, HTGR technology could be integrated into the processes and also can be substituted for the retirement of coal generation in Wyoming. A section below discusses this integration as well as the general topic of replacing coal based electricity generation over the next few decades.

\section{F-2.3 Effect of Carbon Conversion Deployment on Wyoming GDP}

Figure F-19 shows the decline in GDP due to reduced coal production and reduced natural gas and crude oil prices since 2008 . Although crude oil prices have rebounded, natural gas prices have continued to fall and are projected to be $<\$ 3 / \mathrm{MSCF}$ on average in 2012. As shown in Figure F-15 natural gas production has also been declining since 2008. Coal production is also projected to continue to fall as more coal based plants in Wyoming and the U.S. are retired either due to age or increasing EPA regulations on $\mathrm{CO}_{2}$ emissions. All of these factors will have a negative effect on the Wyoming GDP and State and Local government revenue from severance and other taxes. The deployment of the carbon conversion industry is a means to offset these negative influences on the Wyoming GDP by providing an alternative use for the coal and natural gas and an increase in their value to the State through sale of the industry products. Figure F-23 compares an assessment of the contribution of the Mining Industry to the Wyoming GDP if no action is taken over the next two decades with the GDP if the carbon conversion industry is deployed as developed herein. 


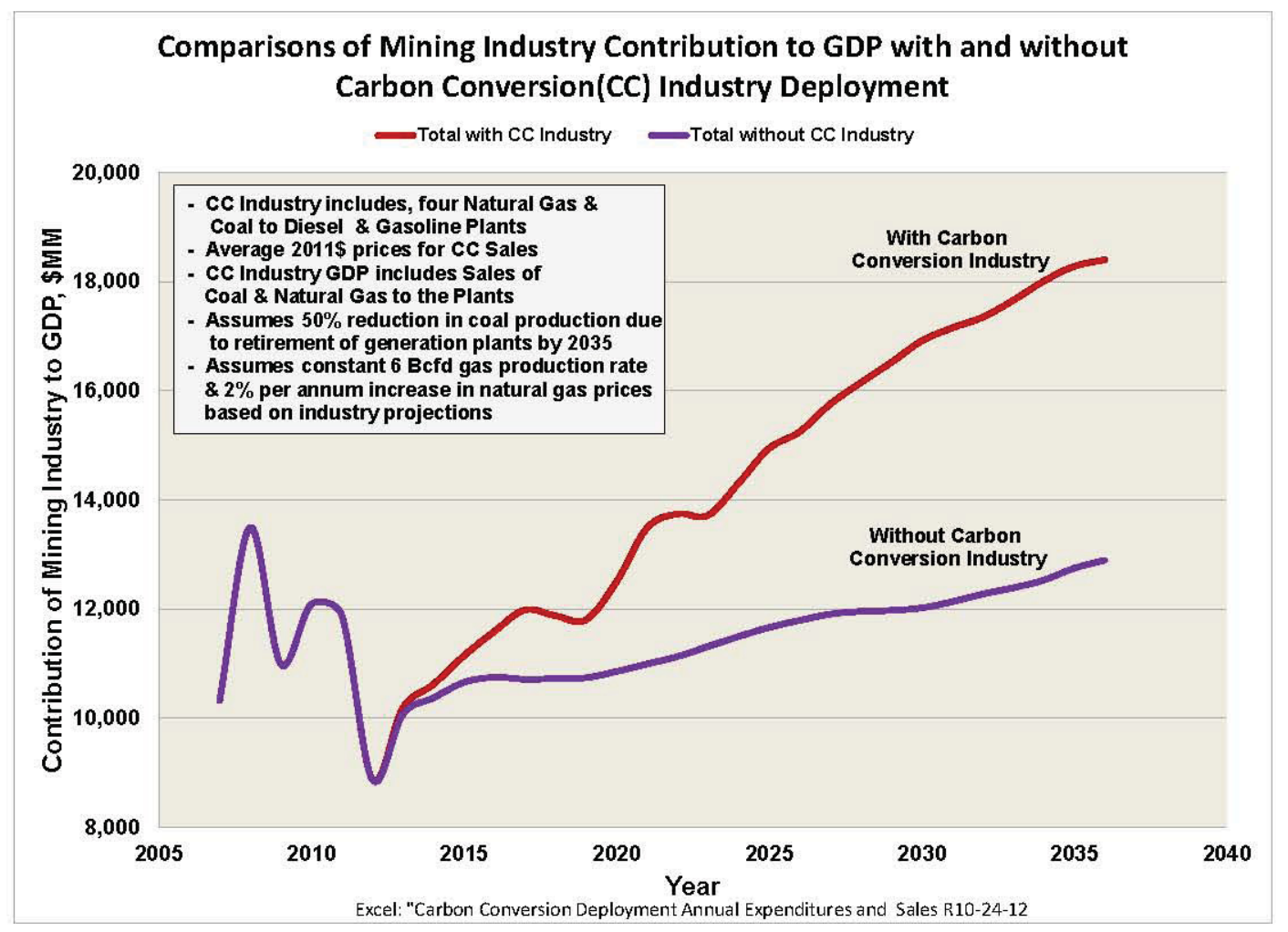

Figure F-23. Effect of carbon conversion deployment on the Wyoming GDP.

The results in Figure F-23 were generated for the following projected conditions:

- Coal production will continue to fall as more plants are retired in Wyoming and the U.S. For the purposes of analyses the large scale retirements projected by the EIA as a result of the Bingaman proposal discussed previously is projected to occur by 2035 as shown in Figure F-24. Note that this does not take into account any other actions that might be taken to offset these reductions (e.g., increasing international exports). This curve also does not show the coal that would be used by the carbon conversion industry. That effect is included in Figure F-23.

- Natural gas prices remain low through the next decade and then rise as shown in Figure F-25. The short term projections are based on a combination of EIA short term evaluations and NYMEX futures market. The long term projections are from the EIA Annual Energy Outlook ${ }^{1}$ evaluations. There is considerable uncertainty in the long term prices of natural gas. The EIA projections may be high; Appendix E provides an analysis that uses EIA projections for natural gas in 2035 that range from $\$ 5$ to $\$ 7.50 / \mathrm{MSCF}$. If the price projections are high the calculation of the effect of future natural gas receipts on the Wyoming GDP are high.

- Wyoming natural gas production rate will level out at a constant 6 million cubic feet per day through 2035.

- The Mining Industry Gross Value contribution to the Wyoming GDP is determined annually assuming that the ratio of the natural gas and coal receipts to the oil receipts and the value of support activities to the mining industry are similar to that over the 2007-2010 time frame (e.g., $70 \%$ ). This is the baseline noted as "Without Carbon Conversion Industry" on Figure F-23.

- The "With Carbon Conversion Industry" curve was generated by adding the Gross Added Value of the annual construction costs, receipts from sale of the production of the carbon conversion industry products and the costs of the natural gas and coal used by the industry to the baseline curve. 
Figure F-24. Potential reductions in Wyoming coal production through 2035 due to coal-based electricity generation retirements.

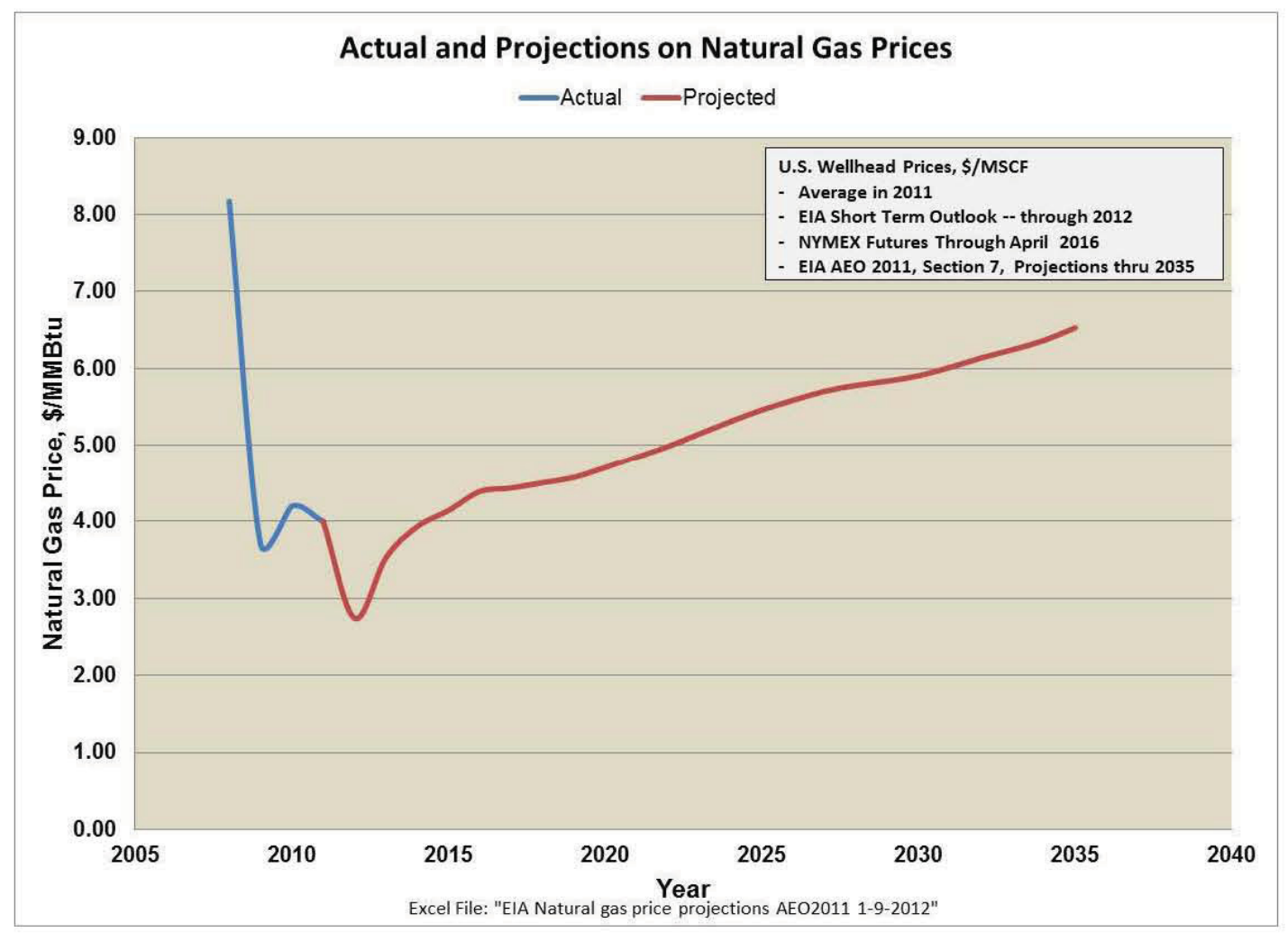

Figure F-25. Actual and potential natural gas prices thru 2035.

This analysis was completed to provide insight into the potential effect of deploying the carbon conversion industry on the Wyoming GDP. It was based on many speculative assumptions and the results are highly uncertain. However, these results provide a perspective on what factors are involved in this evaluation, the magnitude of the costs and revenues and provides a mechanism for evaluating the viability of specific projects in deployment of the industry using more up-to-date information.

\section{F-2.4 HTGR Integration}

As cited earlier the HTGR technology is expected to be available to begin its application to commercial projects in the 2025 time frame. Based on the notional schedule of Figure F-21 the HTGR could be incorporated in the original design and deployment of the Coal to Liquids, Natural Gas to Diesel and Natural Gas to Gasoline plants. It could be incorporated as a backfit to the initial Coal to Gasoline plant. Table F-3 summarizes the performance characteristics of the HTGR plants that would be incorporated into these processes. As shown a total of $12 \mathrm{GW}(\mathrm{t})$ would be incorporated over the 2025 to 2035 time frame including $\sim 3,200 \mathrm{MW}(\mathrm{t})$ and $266 \mathrm{MW}(\mathrm{e})$ to the process plants. 
Table F-3. Characteristics of the HTGR plants integrated with the process plants.

\begin{tabular}{|lrrrrrr|} 
Integrated with & $\begin{array}{c}\text { Thermal } \\
\text { Capacity } \\
\text { MW(t) }\end{array}$ & $\begin{array}{c}\text { Number of } \\
\text { Modules }\end{array}$ & $\begin{array}{c}\text { Heat Supply } \\
\text { to Process } \\
\text { MW(t) }\end{array}$ & $\begin{array}{c}\text { Electricity to } \\
\text { Process } \\
\text { MW(e) }\end{array}$ & $\begin{array}{c}\text { Electricity to } \\
\text { the Grid } \\
\text { MW(e) }\end{array}$ \\
\hline Natural Gas to Gasoline (GTG) & 3,000 & 5 & 387 & 115 & 963 \\
\hline Natural Gas to Liquids (GTL) & 3,000 & 5 & 479 & 0 & 1038 \\
\hline Coal to Gasoline (CTG) & 3,000 & 5 & 1112 & 60 & 706 \\
\hline Coal to Liquids (CTL) & 3,000 & 5 & 1201 & 91 & 637 \\
\hline \multicolumn{2}{r}{ Totals } & 12,000 & 20 & 3,179 & 266 & 3,344 \\
\hline
\end{tabular}

Table F-3 also shows the addition of $\sim 3,300 \mathrm{MW}(\mathrm{e})$ to the state's electrical grid. This generation would replace retired coal-fired generation in Wyoming due to age or increasing regulation of emissions. The quantity and timing of these additions correspond with a notional estimate of the rate at which this coal-fired generation has been projected to be retired.

\section{F-3. Replacement of the Existing Coal-fired Electricity Generation}

\section{F-3.1 Retirement of Old and Addition of New Generation}

For discussion purposes, a possible scenario for retirement of coal-based generation in Wyoming and replacing it with wind, natural gas, Coal w/CCS and HTGR generation is illustrated in Figure F-26 and Figure F-27. This scenario is consistent with the following:

- The current coal-based generation will be fully retired primarily on the basis of age. A retirement age of 60 years from initial operation date is used for the purposes of analysis. Note that no quantifiable projection of the potential for early retirement of plants due to current or emerging emissions regulations has been identified for Wyoming coal-fired plants. Accordingly, this potential has not been included in development of this notional strategy.

- There are some plants on the Wyoming grid of small capacity that have not operated in the last year. These will be retired early in the strategy to fill in gaps between age retired plants.

- The addition of new generation will substitute for retired generation to maintain the total grid capacity approximately equal to that in $2012(\sim 9 \mathrm{GW}(\mathrm{e}))$. 


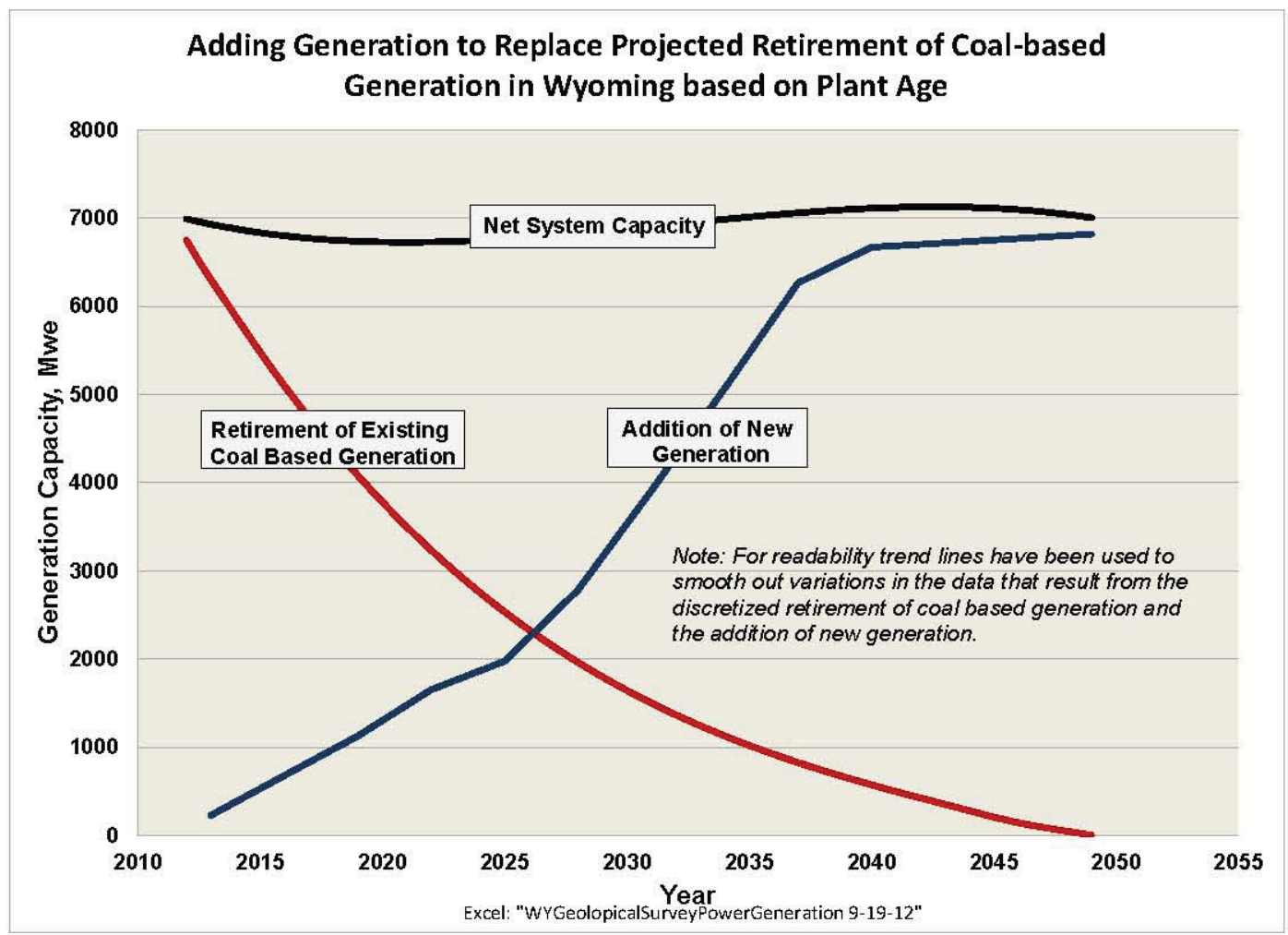

Figure F-26. Adding generation to replace retirement of coal-based generation.

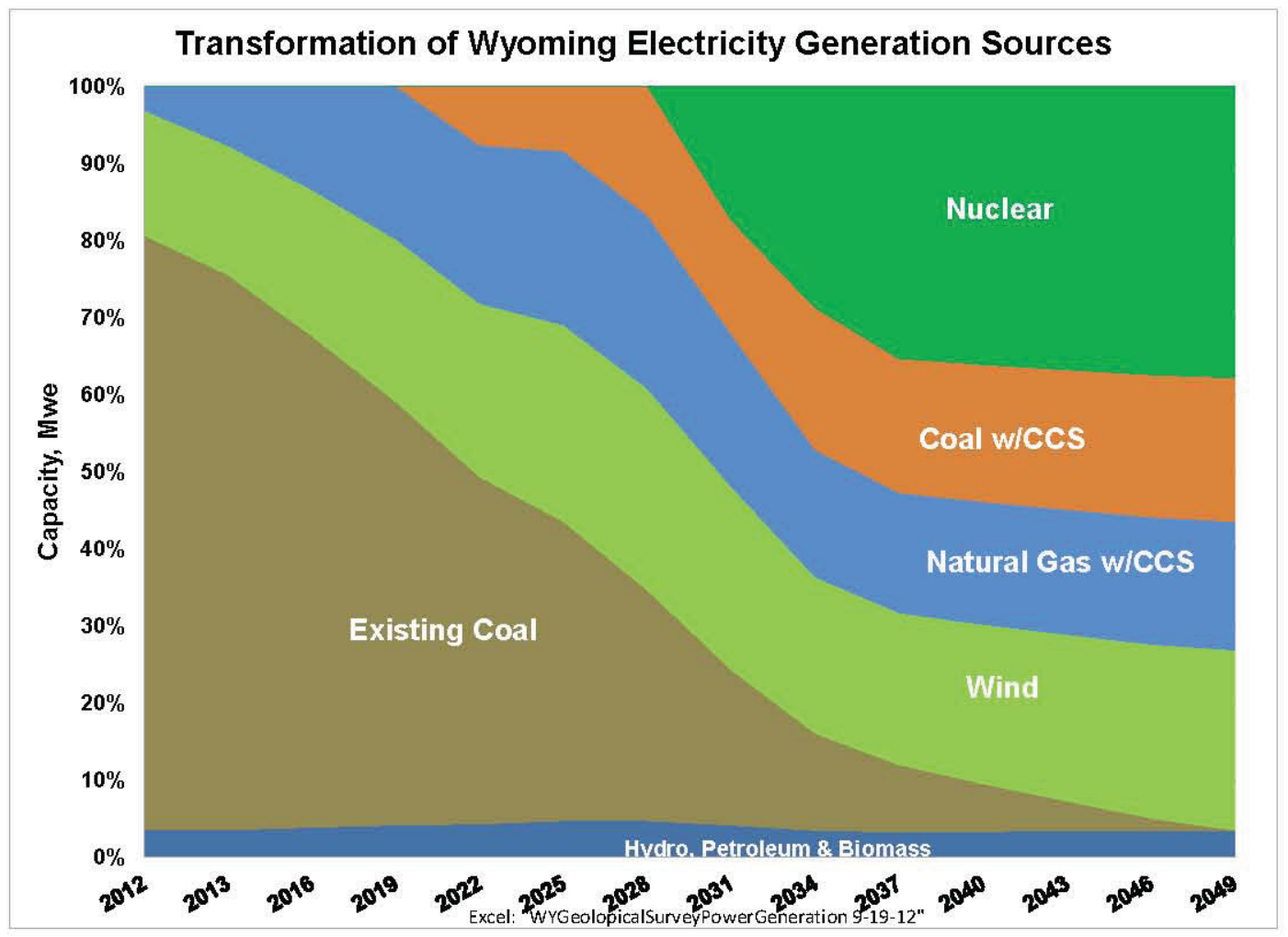

Figure F-27. Generation type added to replace retired coal-based generation. 
- New technologies shall have controllable or no toxic chemical and greenhouse gas emissions to provide flexibility in adapting to or meeting current and potential government emissions regulations. For example, the addition of fossil fired generation shall include all emissions control technologies including carbon capture and storage (CCS).

- The selection of new technologies shall be based on their proven or projected commercial availability at the time of plant retirements and the needed capacity.

- A steady increase in the capacity of wind generation will be included consistent with Wyoming objectives of having renewable power for export to States with Renewable Portfolio Standards. However, the total wind generation capacity shall be limited to $25 \%$ of the total grid capacity to maintain grid stability under the fluctuating characteristics of wind generation.

- Addition of coal generation will be included to provide an internal stable market for Wyoming coal.

Table F-4 and Table F-5 show the mix of electricity generation technologies at the beginning (end of 2012) and the end of the transformation (2040).

Table F-4. Total electricity generation by type in 2012.

\begin{tabular}{|c|c|c|}
\hline \multicolumn{3}{|c|}{ By Year 2040} \\
\hline Capacity by Fuel & $M W(e)$ & $\%$ of Total \\
\hline Wind & 1,415 & $16 \%$ \\
\hline Natural Gas & 274 & $3 \%$ \\
\hline Hydroelectric \& Fuel Oil & 308 & $3.1 \%$ \\
\hline Coal & 6,748 & $77 \%$ \\
\hline Total & 8,744 & $100 \%$ \\
\hline
\end{tabular}

Table F-5. Total electricity generation by type after retirement of coal based generation.

\begin{tabular}{|lrc|}
\multicolumn{1}{c}{$\begin{array}{c}\text { Capacity by Fuel } \\
\text { Wind }\end{array}$} & MW(e) & 2040 of Total \\
\hline Natural Gas & 2,065 & $23 \%$ \\
\hline Hydroelectric \& Fuel Oil & 1,474 & $17 \%$ \\
\hline Coal with CCS & 308 & $3 \%$ \\
\hline HTGR & 1,650 & $19 \%$ \\
\hline & 3,344 & $38 \%$ \\
\hline
\end{tabular}

It should be noted that this scenario and these values of generation are presented for illustrative purposes and to frame the timing and expenditure issues that need to be considered when addressing the retirement of the Wyoming coal generation. The actual scenario will be dictated by government regulation, age and economic viability of the plants and the potential replacement technology, the actual deployment of the carbon conversion industry and the needs for State consumption and export.

\section{F-3.2 Investment Required to Replace Coal-Based Generation and Impact on Cost of Electricity Generation}

Figure F-28 shows the capital expenditure required to replace coal-based electricity generation in Wyoming with a mix of wind, natural gas, coal w/CCS, and HTGR generation discussed in the preceding 
section. A total expenditure of $\sim \$ 27 \mathrm{~B}$ would be required over the $\sim 35$ year period shown. The largest expenditures occur between 2025 and 2038 with the incorporation of the HTGR technology into the process plants, adding coal w/CCS to replace Dave Johnston and Naughton and the largest coal plant in Wyoming (Jim Bridger). It should be noted that annual expenditures for the nuclear plants, the coal w/CCS plants and the natural gas plants are exaggerated by showing the full cost of the plant expensed in a single year. The natural gas w/CCS plants would take 2 to 3 years to construct; the coal w/CCS plants $\sim 5$ years to construct and the HTGR plants will take up to eight years to construct. The expenditure profile, therefore, would be more spread out than shown on this figure. This presentation was used to emphasize the magnitude and profile of the expenditures. As discussed previously at least $70 \%$ of these expenditures would be expected to derive from Wyoming resources. Accordingly, these represent a significant boost to the Wyoming economy over this 35 year period.

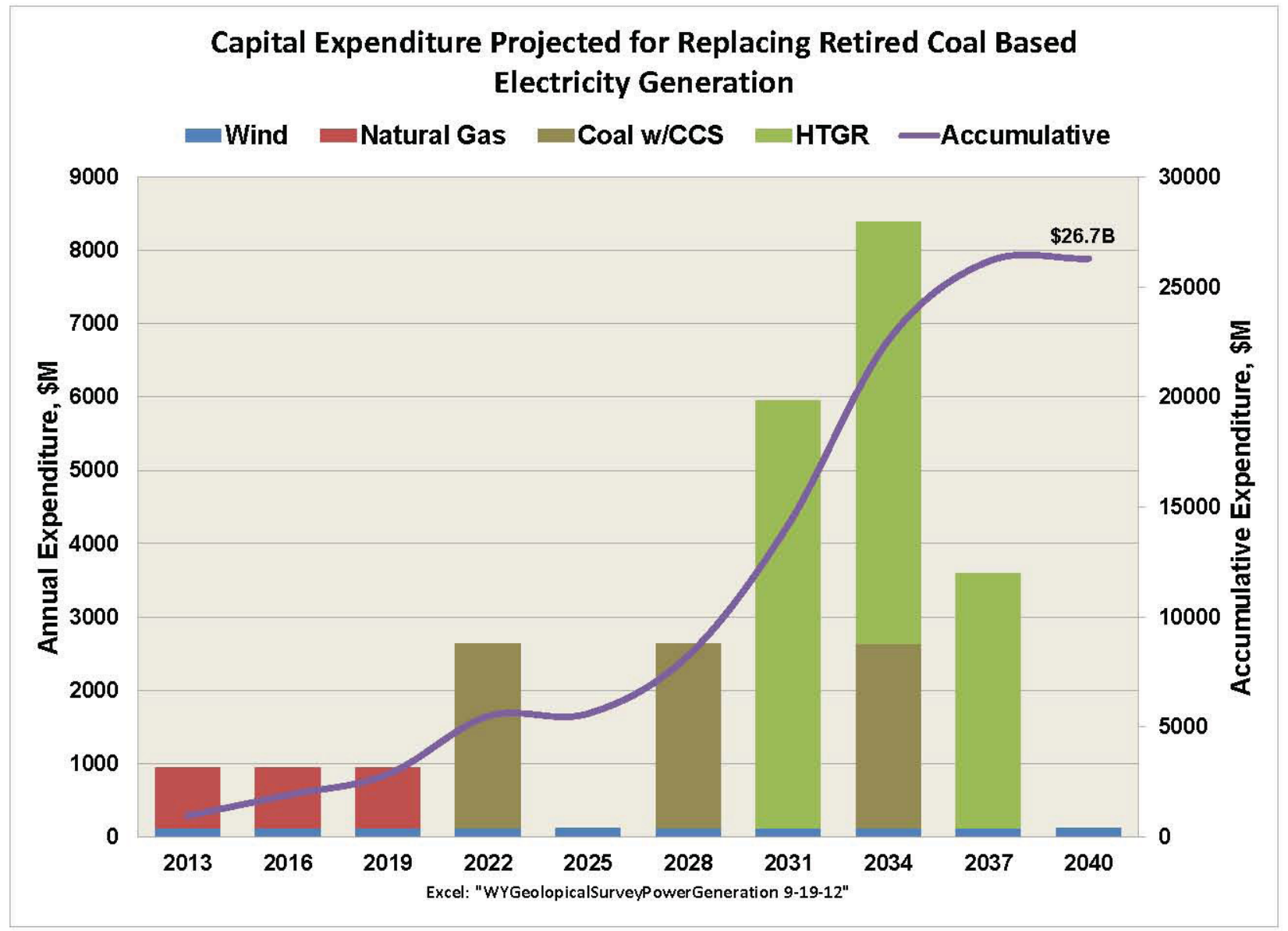

Figure F-28. Capital expenditure to replace coal-based generation in Wyoming

Currently Wyoming has one of the lowest electricity rates in the U.S. because the cost of the coalfired generation is low. This has permitted Wyoming to develop a large electricity export position; about $60 \%$ of the electricity generated in the State is exported to other States. ${ }^{12}$ As this generation is replaced by other technologies the cost of production will increase leading to increased costs of electricity for the consumers. This is illustrated in Figure F-29 for the transformation scenario. This figure shows the change in the production costs as the original coal-fired generation is reduced and the capacity of natural gas, wind and HTGR are increased to replace that generation. The cost of generation for each of these is based on EIA projections for these technologies 2015 and beyond ${ }^{13}$ and from INL analyses of the costs of generation for the HTGR ${ }^{14}$ As shown the projected cost of generation once all coal based generation is retired increases by a little less than a factor of 3 . Increases are likely to be felt throughout the U.S. for the 
same reasons depending on the percentage of current coal based generation in the State or on the grid. An earlier INL study ${ }^{15}$ determined that if all coal based generation in the U.S. were to be replaced by a mix of renewables and nuclear, the average cost of electricity would increase by $\sim 50 \%$. The $100 \%$ increase in Wyoming would, therefore, reduce the State's competitiveness on the National market for electricity export. Further analysis is required to determine the full effect of coal based generation and develop alternatives to compensate for the increased electricity rates on the Wyoming economy; for example, reducing capacity in Wyoming and increasing the production of transportation fuels and chemicals.

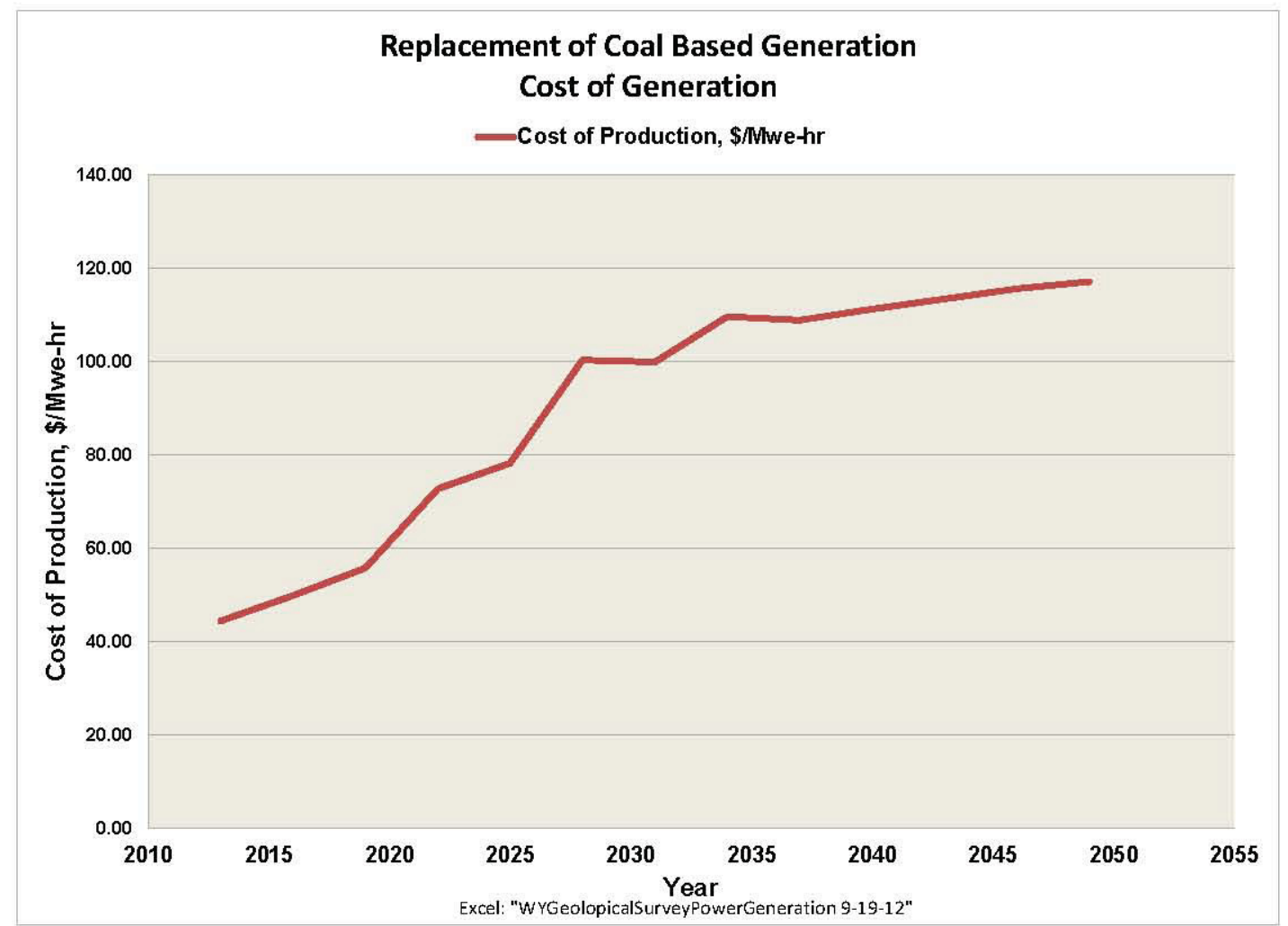

Figure F-29. Net production and cost of production during replacement of coal-based generation.

\section{F-4. REFERENCES}

1 EIA 2012 Annual Economic Outlook, April 2012.

2 EIA natural gas gross withdrawals by area and month, Jan 05-May12.

3 Gross Domestic Product for Wyoming by Industry (NAICS): 1997 to 2010 \& 2011; U.S. Bureau of Economic Analysis.

4 Wyoming Crude Oil First Purchase Price (\$/barrel), Release Date: 8/1/2012, Next Release Date: 9/4/2012, Excel File Name: f004056 3m.xls, Available from Web Page:

http://tonto.eia.gov/dnav/pet/hist/LeafHandler.ashx?n=PET\&s=F004056_3\&f=M, Source: Energy Information Administration, For Help, Contact: infoctr@eia.doe.gov, (202) 586-8800.

5 USA Today, "Falling Gas Prices hit state's Pocketbooks," May 10, 2012 [Comment by Governor Mead].

6 EPA 40 CFR Part 60 [EPA-HQ-OAR-2011-0660; FRL- ] RIN 2060-AQ91 Standards of Performance for Greenhouse Gas Emissions for New Stationary Sources: Electric Utility Generating Units, 3/27/12 
EPA, National Emission Standards for Hazardous Air Pollutants for Major Sources: Industrial, Commercial, and Institutional Boilers and Process Heaters: Final Rule, 76 FR 15608\& 76 FR 155543/21/11 (so-called Boiler MACT Rule).

7 EPA-452/R-12-001,March 2012, Regulatory Impact Analysis for the Proposed Standards of Performance for Greenhouse Gas Emissions for New Stationary Sources: Electric Utility Generating Units, U.S. Environmental Protection Agency, Office of Air Quality Planning and Standards, Health and Environmental Impacts Division, Research Triangle.

8 Clean Energy Standard Act of 2012 (BCES12).

9 EIA, Today in Energy, May 4, 2012.

10 The 2011 Concise Guide to Wyoming Coal, Wyoming Mining Association.

11 June 15, 2012 4:33 pm • Associated Press, CHEYENNE, Wyo. — "Gov. Matt Mead said Friday that he returned from China this week confident that Wyoming should continue exploring how to export coal to meet that nation's growing demand."

"Arch is expanding international coal sales with dedicated seaborne port capacity," Arch Coal.com.

"Arch Coal Completes Acquisition of International Coal Group." ST . LOUIS, June 15, 2011 -- Arch Coal, Inc.

"Powder River Basin coal, once limited to domestic consumption, is becoming an international commodity. This shift may prove lucrative for coal companies that expect higher prices in foreign markets. And with declining domestic coal consumption in the U.S., it's a move that Wyoming officials view as necessary to sustain its mining industry and the $\$ 1$ billion it generates in state and local revenue annually," WyoFile, May 22, 2012.

12 EIA, Electricity, State Electricity Profile 2010, Table 10, January 2012 release date.

13 EIA, Updated Capital Cost Estimates for Electricity Generation Plants, November 2010, Office of Energy Analysis, U.S. DOE.

14 INL/EXT-11-23282, "Next Generation Nuclear Plant Project Evaluation of Siting an HTGR Cogeneration Plant on an Operating Commercial Nuclear Power Plant Site," October 2011.

15 INL/EXT-09-17436, "Transforming the U.S. Energy Infrastructure," July 2010. 


\section{Appendix G}

\section{Technical Development Requirements}




\section{Appendix G Technical Development Requirements}

\section{G-1. STEAM METHANE REFORMER MODIFICATION}

Prior to initiating the incorporation of the high temperature gas-cooled reactor (HTGR) technology it will be necessary to revise the small modular reactor (SMR) reformer designs to use the HTGR heat in a convective heat exchange mechanism in place of the burning of natural gas and a radiant heat exchange mechanism.

In a conventional steam methane reformer, heat is transferred from the combustion gas to the reforming tubes via radiation. In the HTGR integrated steam methane reformer scenarios considered in this study, convective heat transfer will be required. Due to this difference, a redesign of the reformer will be required in order to ensure adequate heat transfer in the HTGR integrated scenario. Fortunately, significant work has already been done by industry to develop and commercialize convective steam reformers. Although the objectives in prior development of this technology have not focused on nuclear heat integration, the concepts and designs appear to be easily adaptable to using hot gas from an HTGR as the heat source. The Haldor Topsoe convective reformer (HTCR) was developed in the 1980's and has been in large-scale industrial operation since 1997. This technology was designed to use flue gas as the heat source, and integrates a combustor into the design. A schematic of the reformer design is shown in Figure G-1. The HTCR reactor consists of a vertical, refractory lined vessel, containing the tube bundle with several bayonet tubes. Each tube assembly is surrounded by a flue gas guiding tube, and the heat flux is adjusted by a proprietary flue gas control device. Below the vertical section is a horizontal combustion chamber containing the burner. Note that in this design, the flue gas temperature $\left(1,270^{\circ} \mathrm{C}\right)$ is significantly hotter than the gas that can be delivered by an $\operatorname{HTGR}\left(850^{\circ} \mathrm{C}\right)$. Also, the flue gas exit temperature in this design $\left(600^{\circ} \mathrm{C}\right)$ is slightly warmer than the helium exit temperature assumed in the HTGR scenario $\left(563^{\circ} \mathrm{C}\right)$.

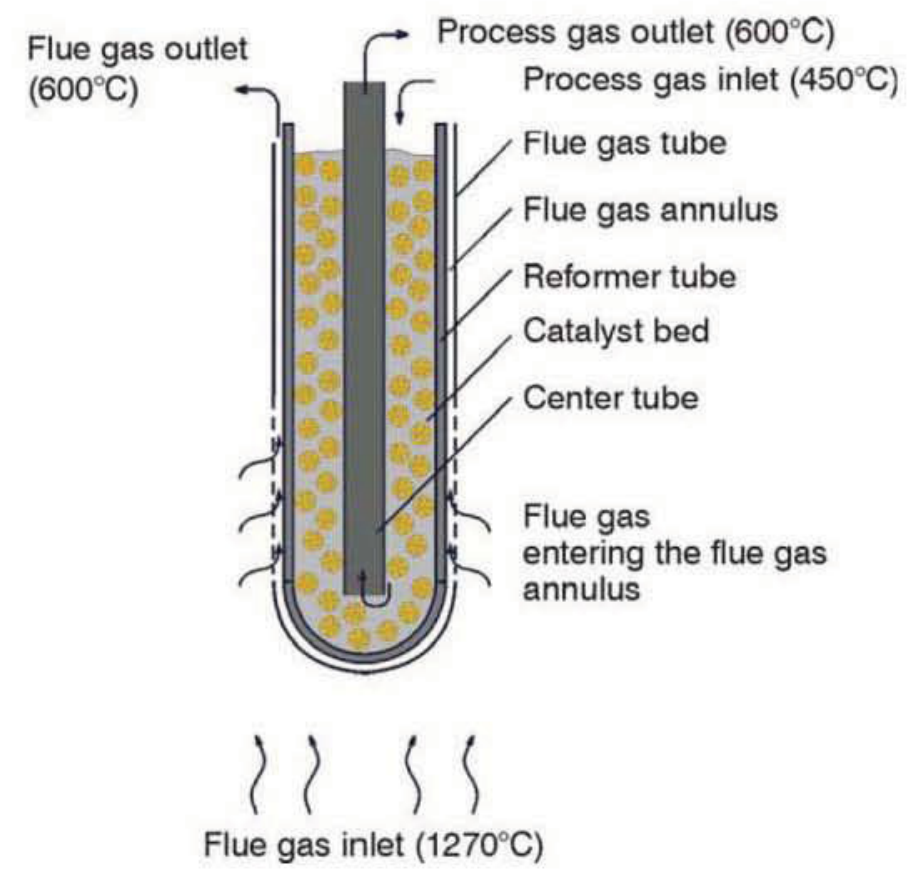

Figure G-1. HTCR design. 
Haldor Topsoe has also developed a convective reformer that relies on process gas as the heat source. In this design, the hot gas enters the reformer at $1,040-1,050^{\circ} \mathrm{C}$. This design, known as the Haldor Topsoe exchange reformer (HTER), was first used on a commercial scale in 2003 at Sasol's Secunda, South Africa synfuels complex. A picture of the HTER internals being lifted after arrival at this site is shown in Figure G-2. One key difference between the HTER and the HTCR designs is that the HTER is designed for operation at higher pressures, which would be desirable when using an HTGR for the heat source.

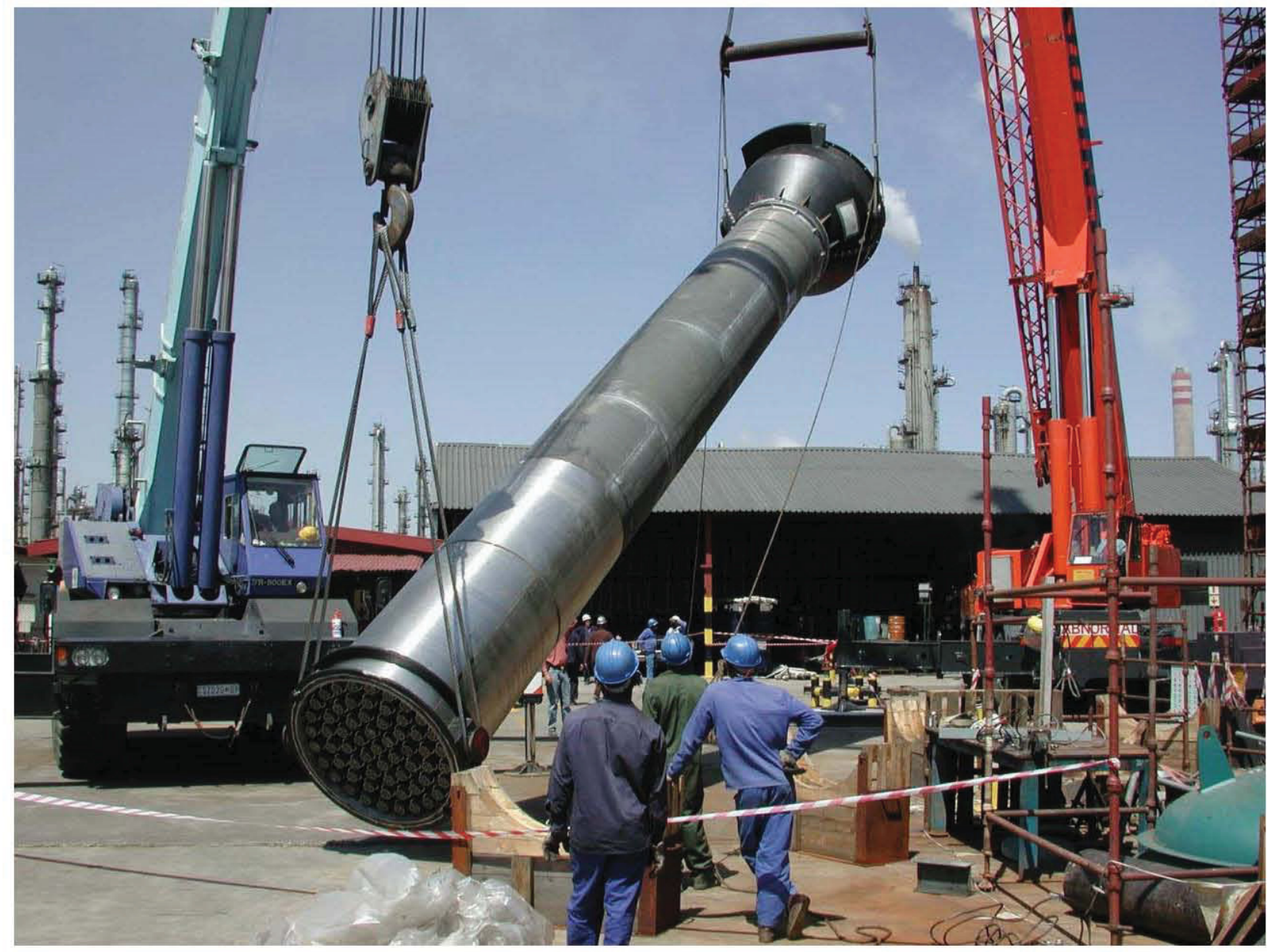

Figure G-2. HTER internals being installed at Sasol facility.

Based on the commercial success of convective steam reforming in recent years, it is believed that this technology could be adapted to use an HTGR for the heat source. Due to the lower temperature of the HTGR heat compared to previously proven heat sources, it is anticipated that a somewhat larger design would be required. Development is needed to quantify this issue, identify any other potential issues, and ensure a trouble-free design. 


\section{Attachment}

\section{NGNP Industry Alliance Limited Business Plan}




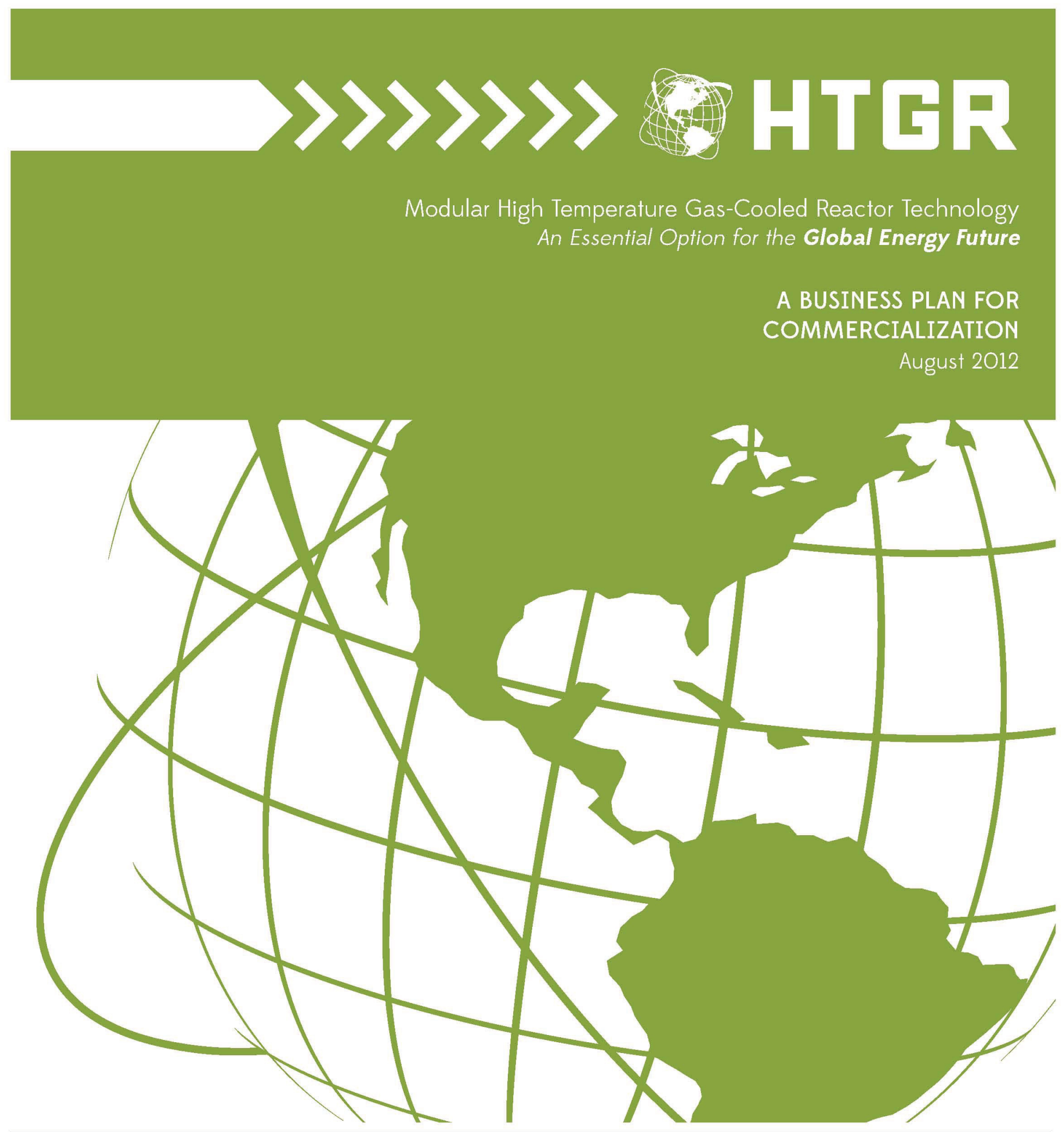

\section{AREVA ConocǒPhillips Dow Entergy.}

The NGNP Industry Alliance

Promoting the development and commercialization of High Temperature Gas-cooled Reactor (HTGR) technology

\section{GRAF Techln \\ MERSEN \\ PTAC \\ G SGL GROUP} $\mid \begin{array}{r}\text { TECHNOLOGY } \\ \text { INSIGHTS }\end{array}$ 


\section{AN INTRODUCTION TO THE HIGH TEMPERATURE GAS-COOLED REACTOR}

A nuclear, near-zero carbon source of process heat and power for industry

The industrial sector was responsible for more than $20 \%$ of energy usage in North America and Europe in 2009 and above $25 \%$ in OECD Asia. Refining, chemical processing and iron \& steel industries rely on fossil fuel for high temperature process heat and account for over $40 \%$ of this industrial sector total.

Today, there are no other choices for lower carbon footprint pathways to provide high temperature process heat. The HTGR provides the only option on the technology horizon that addresses this industry's carbon footprint, energy security and price volatility.
The HTGR is at least $30 \%$ more efficient in the production of electric power than light water Small Modular Reactors (SMRs) and can uniquely address industrial process heat requirements. The potential market for HTGRs is at least twice that of any other proposed modular reactor - as many as 700 reactor modules in North America alone.

\section{High Temperature Gas Reactor (HTGR) - The Game Changer}

1. The design of the HTGR is intrinsically safe. Post-Fukushima, the importance of this capability is clear.

- Intrinsic safety allows co-location with new or existing industrial facilities

- There are no failure scenarios that result in any significant release of radioactive materials based upon:

o Fission products are contained within ceramic-coated fuel particles

- The reactor shuts itself down well below temperatures that can damage the ceramic fuel particles

- No heat transfer fluid (water, gas, etc.) is required for post accident cooling

o Spent fuel is air cooled without motive force required

o No motive power, electric or otherwise, or operator intervention is needed to safely shut down the reactor

2. The HTGR is the only technology on the near-term horizon capable of displacing the use of fossil fuel for electricity and high temperature process heat while emitting zero carbon.

- Supplies process heat requirements for petrochemical refining, chemical processes and extraction and upgrading of bitumen from oil sand and shale, and provides higher efficiency electrical power (more than $30 \%$ higher) and lower-cost power generation compared to SMRs

- Displaces/supplements premium fossil fuels, lowers $\mathrm{CO}_{2}$ emissions and provides stable process heat pricing as fossil fuels are fungible global commodities and pricing is tied to oil intrinsic energy parity in many parts of the world

- Allows premium fossil fuels to be used for higher-value products, such as chemical feedstocks that add multiples of GDP vs. simply burning as fuel

3. It is economically competitive with natural gas in most places of the world today without any price for carbon.

- Competes globally today for process heat and power at about \$6 per MMBTU equivalent natural gas price

- Even in North America (NA), the Alliance concludes this will be competitive in the commercialization time frame of $2025^{+}$

- The Alliance estimates that the first 25 -year build out with only a $25 \%$ market penetration in NA only will likely create more than $\$ 1$ trillion in GDP

- Creates high-paying jobs in infrastructure (large industrial forgings \& other ancillary equipment), construction and operation

- Helps assure energy security by providing long-term stable energy costs \& enabling conversion of carbon (coal, pet coke, solid waste) to synthetic fuels and chemicals via nuclear-assisted conversion processes with a minimal carbon footprint

4. The business model will likely not require loan guarantees based on large industrial end-user long-term purchase agreements and multi-investor ownership.

- The business model envisions third-party fence line commercial agreements with the process heat and power off-takers, enabling the long-term agreement to serve as collateral and eliminate the need for loan guarantees 


\section{The North American Potential Market alone is represented by:}

\section{Co-generation}

Petrochemical, Refinery, Fertilizer/Ammonia plants and others

\section{Premilinary Economics - Cogeneration}

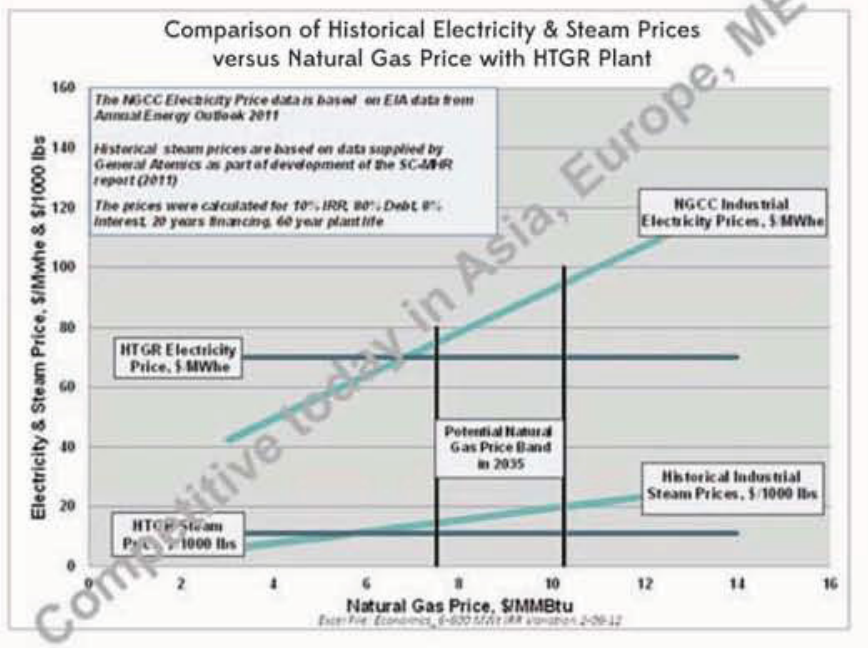

75 GWt (-125-600 MW' modules)

Oil Sands / Oil Shale

Steam, electricity, hydrogen \& water treatment

$18 \mathrm{GW}+(-30-600 \mathrm{MW}+$ modules)

Hydrogen Merchant Market

$36 \mathrm{GWH}(-60-600 \mathrm{MW}$ - modules)

Synthetic Fuels \& Feedstock

Steam, electricity, high temperature flids, hydrogen

$249 \mathrm{GW}+(-415$ - $600 \mathrm{MW}$ - modules $)$

IPP Supply of Electricity

110 GWt ( 180 - 600 MWt modules)

\section{Figh Temperature Gas-Cooled Reactors (HTCRs)}

\section{A nuclear, near-zero carbon source of process heat and power for industry}

- The business model envisions many of the installations being joint venture (JV) structures with typical financing ( $80 / 20$ debt to equity) enabling many to participate in financing. A $\$ 4$ billion 4 reactor Nth of a kind installation with $4 \mathrm{JV}$ partners would only require cash infusion by the partners of $\$ 200$ million each

5. The key challenge centers not on the HTGR or its economics, rather it is the financial lift associated with maturing this game-changing fechnology. The fwo-decade-plus fimeframe for an inifial economic refurn on invesfment is difficult for private industry to make alone considering the business risks - parficularly those introduced by the government regulatory process.

\section{Summary}

Post-Fukushima, the HTGR brings a new level of intrinsic safely that enables its co-location with other industries and communities. It dramatically reduces $\mathrm{CO}_{2}$ emissions from petrochemical production, petroleum refining and extraction of bitumen from oil sands and shale. It is economical today in Europe, Asia and the Middle East where natural gas price is tied to oil parity. The Alliance concludes that even U.S. gas prices are likely to emerge in a range that will make this technology competitive for process heat and power in the $2020+$ timeframe as utilities, transportation and natural gas compete to arbitrage the current U.S. price advantage. Further, if one envisions oil in the $\$ 130+$ per-barrel range in the 2020 + timeframe, it provides an economic approach to production of synthetic fuels from indigenous carbon sources with virtually no carbon footprint. It is the game-changing technology that can address the overarching global energy policy goals of energy and feedstock security, economic growth/GDP (jobs) and carbon footprint (climate). Based on the current trajectory, if funding were sufficient in the coming years, this technology could be deployed initially in the mid-2025 timeframe. 


\section{A BUSINESS PLAN FOR COMMERCIALIZATION}

This business plan includes the following summation:

- HTGR Technology - brief introduction to HTGR technology and its most important attributes

- Market and Economics - characterization of the potential market and the associated economics

- Investment Perspectives - why HTGR technology is a well-founded investment for industry, equity and national policy makers

- Commercialization Strategy - steps to commercialization and deployment

- Enterprise Structure - description of the major activities and organization to implement the commercialization strategy. Example investment scenarios are developed around this structure and described in more detail in the referenced Appendices

- Enterprise Risk - summary characterization of the most important risks associated with completion of the commercialization strategy

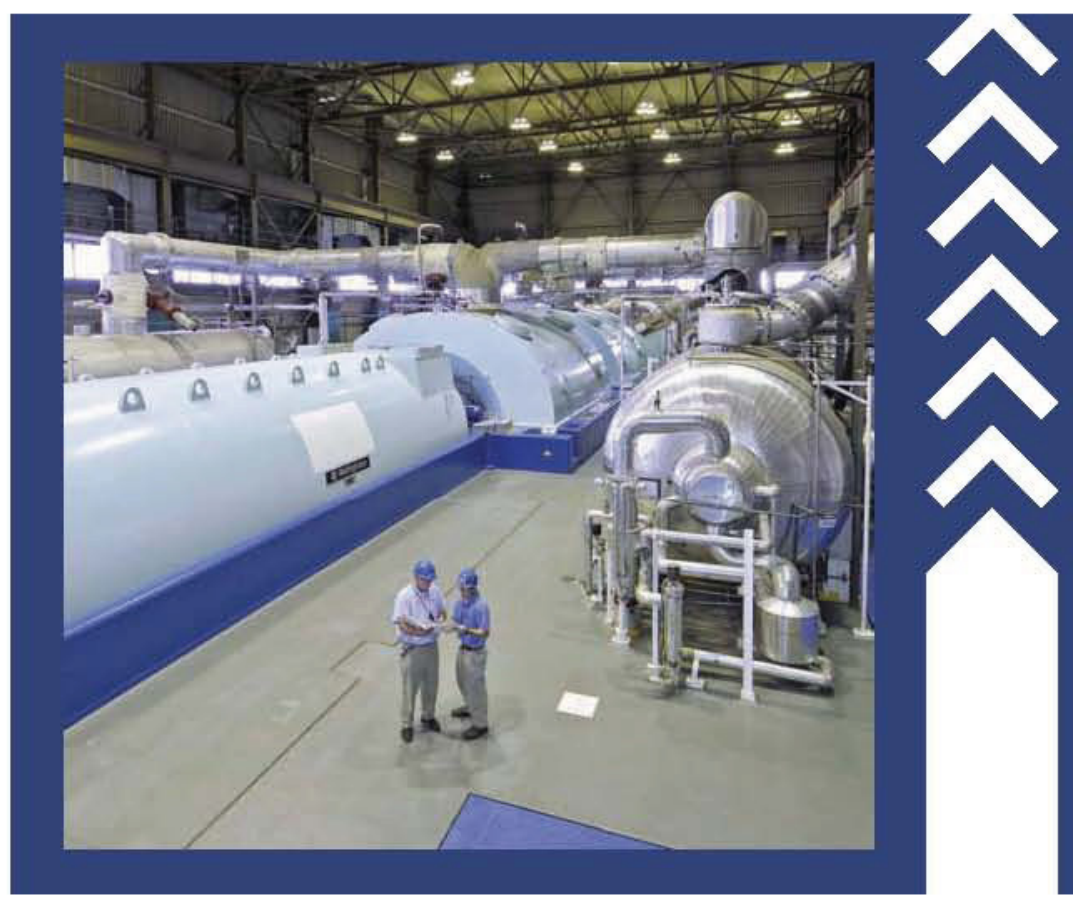

Selected topics are amplified in the Appendices, including:

- Appendix A: The Target Markets, Competition and Preliminary Economics

- Appendix B: Development Venture - completing the development for commercialization

- Appendix C: Deployment Project - constructing and operating the initial HTGR plant

\section{HTGR TECHNOLOGY}

Today, the process heat requirements for the energy-intensive industries around the globe are provided almost entirely by fossil fuels. In addition, power for these industries is provided by solid, liquid and gaseous fossil fuels. Consequently, these industries are hostage to evolving environmental concerns, unpredictable government policies, uncertainty of supply and price volatility. Modular HTGR nuclear technology provides an important option that addresses these issues head-on. It provides process heat at the temperatures needed by industry and power with competitive economics, compelling safety, and minimal environmental concerns.

For those markets that rely on premium fossil fuels, commercializing the HTGR makes available the only game-changing technology on the horizon that can address the overarching and global energy policy goals of energy and feedstock security, economic growh/GDP (jobs) and carbon footprint. In addition, trends in fossil fuel prices suggest that modular HTGR technology integrated with modified versions of conventional carbon conversion technologies provide an economic approach to production of synthetic transportation fuels, chemical feedstocks and chemicals with a minimal carbon footprint.

\section{Fulfills the Energy Needs of Energy-Intensive Industry}

A prismatic core modular HTGR with a conventional steam cycle has been selected as the reference concept for commercialization. The concept, developed by AREVA US, provides the best match to near-term energy needs with competitive economics and acceptable risks for investment readiness, while also laying the foundation for more advanced modular HTGR concepts. It is envisioned that the reference concept module will be incorporated in multi-module plants that can provide over-the-fence supplies of energy analogous in capacity and reliability to conventional combined cycle facilities used by industry. For example, a large industrial complex might typically have 4 to 6 modules for reliable process heat and power supply.

The nuclear supply system module is based on a $625 \mathrm{MW}$ thermal (MW/t) annular reactor core in a large steel reactor vessel. It is a two-loop system with the reactor connected to two parallel steam generators and helium circulators.

Ceramic-coated particle nuclear fuel is a key part of the modular HTGR concept. Each fuel particle consists of a fuel kernel surrounded by multiple ceramic-coating layers which provide the primary fission product retention barrier under all conditions. The total fuel supply includes roughly 30 billion such particles per core. As shown below, the particles 

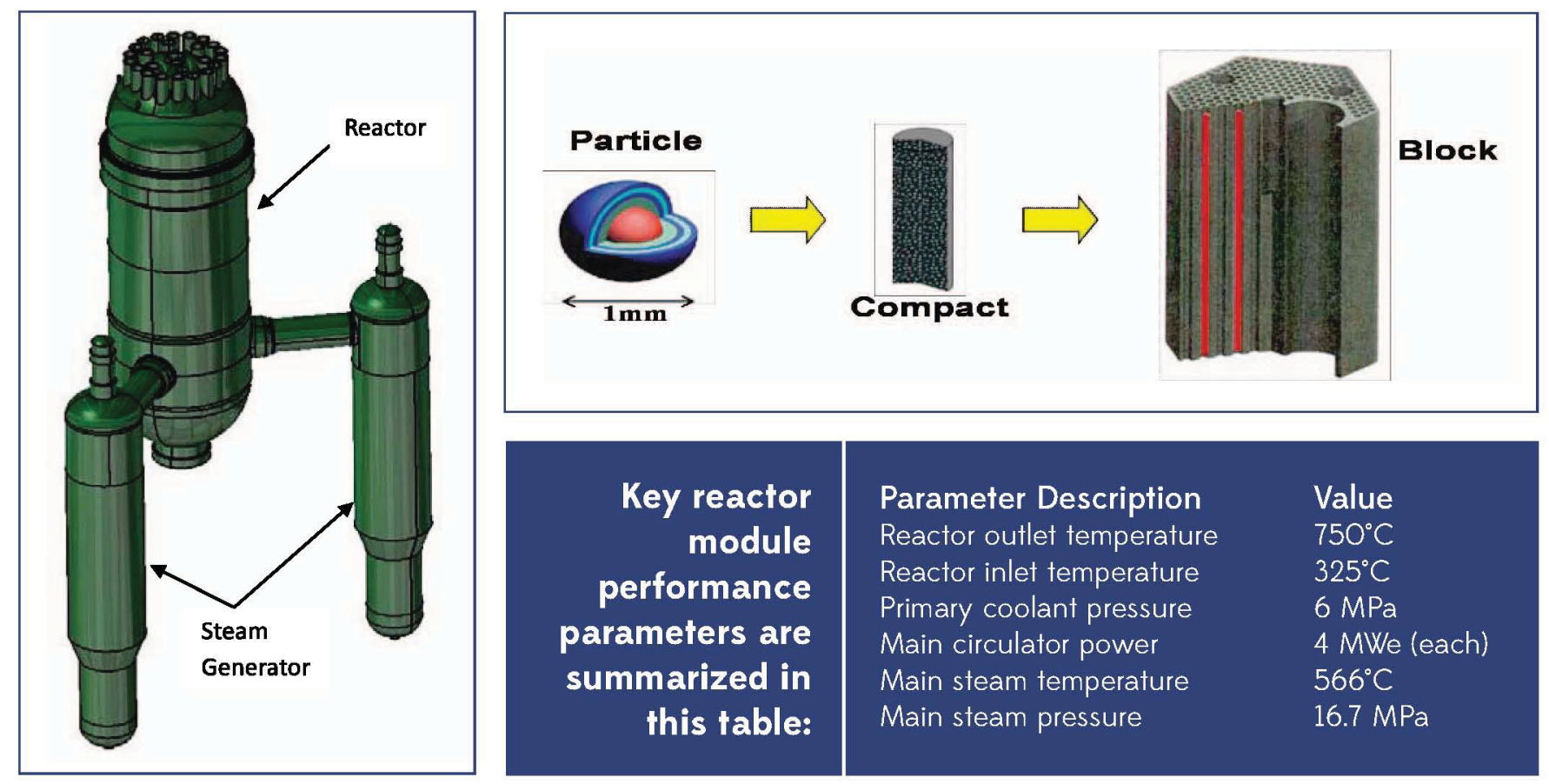

\section{Parameter Description \\ Reactor inlet temperature \\ Primary coolant pressure \\ Main circulator power \\ Main steam temperature \\ Main steam pressure}

Value

Reactor outlet temperature $\quad 750^{\circ} \mathrm{C}$

$325^{\circ} \mathrm{C}$

$6 \mathrm{MPa}$

$4 \mathrm{MWe}$ (each)

$566^{\circ} \mathrm{C}$

16.7 $\mathrm{MPa}$

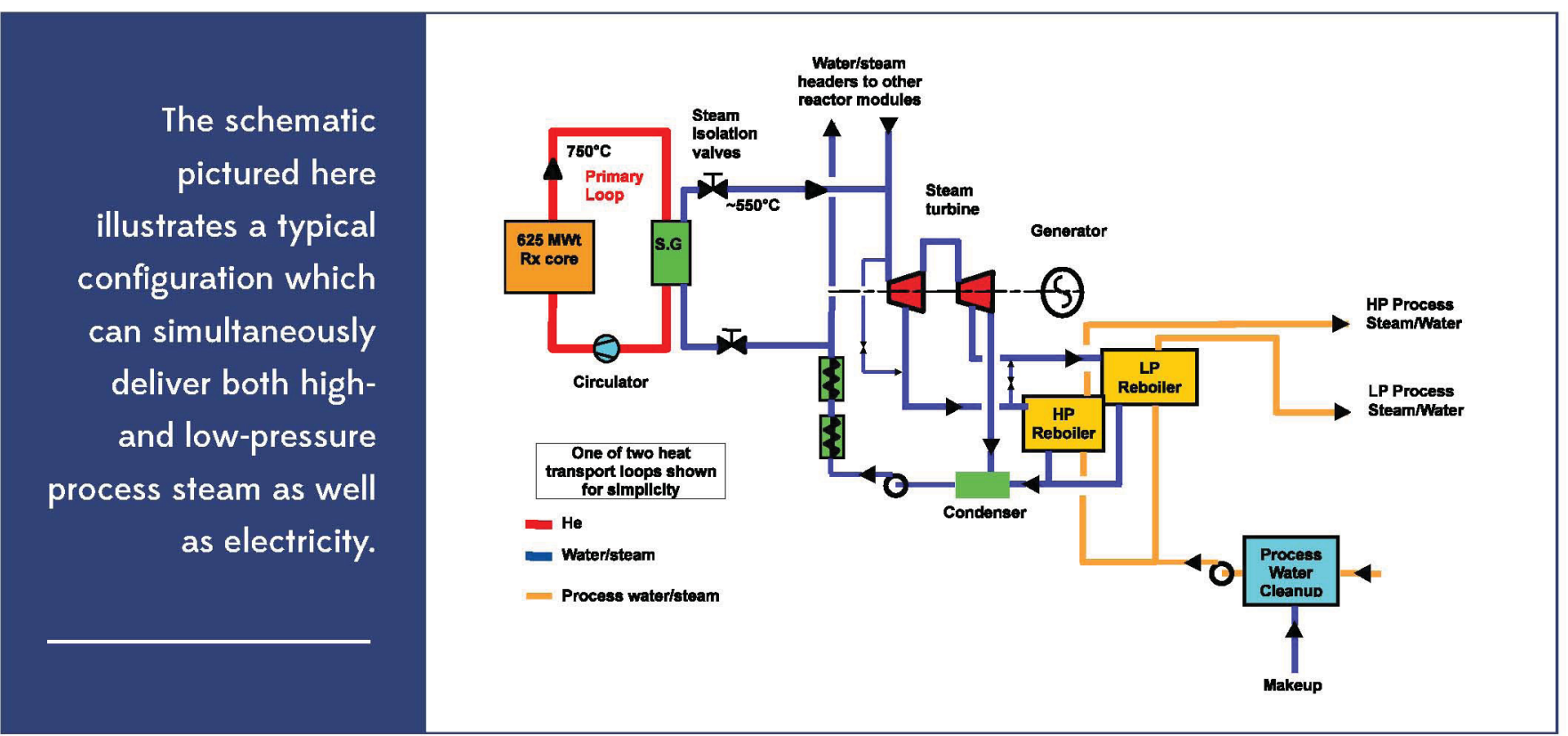

are distributed in graphitic cylindrical compacts, and the compacts are placed in holes drilled in the graphite fuel blocks. The fuel blocks are loaded into the fueled annulus of the core. The rest of the core is made up of non-fueled graphite reflector blocks, that due to its heat treatment (up to 3,000 degrees $\mathrm{C}$ ), also behaves as a ceramic. Hence the basic core structure is entirely ceramic.

Circulating helium carries the heat produced in the reactor to the steam generators to produce high temperature superheated steam. The remaining steam distribution system can be configured in a variety of different ways depending on the specific needs of each energy user.

The initial fleet will adapt multiple standard reactor modules with application-specific process steam and/or power generation modules for a range of plant sizes for the target applications discussed above. 


\section{Compelling Safety}

The superior safety characteristics of modular HTGR technology provide a nuclear energy system design that intrinsically protects the public and the environment. The safety case supports acceptable business risk for collocation at the energy end-user's facility.

The compelling safety case directly addresses extraordinary events such as interruption by natural causes (e.g., flood or earthquake), human error or equipment failure that affect the plant normal operations. Power and heat generation is managed through intrinsically self-limiting reactor shutdown without operator action and without the need for fluid management systems (e.g., water or gas) or electric power.

No explosive gases can be produced by the fuel materials or core infrastructure - the materials were selected and designed to preclude this. Used nuclear fuel from a HTGR requires no cooling water or active systems for storage or heat transfer over time, relying instead on natural convective flow of air.

The safety case has been demonstrated in the German AVR HTGR and recently in the 10 and 30 MW designs in Japan and China respectively. In those tests, the reactor was allowed to heat up to the point where it simply shut itself down.

\section{Intrinsic Nuclear Safety}

No need to evacuate or shelter the public and no threat to food or water supplies under any conditions.

Multiple assured barriers to the release of radioactive material are provided.

Reactor power levels are limited and the nuclear reactor shuts down if reactor temperatures exceed intended operating conditions.

No actions by plant personnel or backup systems are required to either ensure shutdown of the reactor or ensure cooling.

No power and no water or other cooling flid is required.

Reactor materials including the reactor fuel are chemically compatible and in combination will not react or burn to produce heat or explosive gases.

Achievable levels of air or water intrusion do not result in substantive degradation of the capability to contain radioactive materials.

Spent or used fuel is stored in casks or tanks in underground dry vaults that can be cooled by natural circulation of air and shielded by steel plugs and concrete structure.

Proximate public and industries need not shelter or evacuate for any internal or external event challenging reactor safety. This translates into a close-in siting capability needed for process steam/heat loads, plus anticipated improved public and investor acceptance.

\section{Extensive Development History}

The basis for the HTGR technology was first developed over 50 years ago in the UK, the U.S. and Germany. Seven experimental and demonstration reactors have been built world-wide, including U.S. commercial scale demonstrations of specific HTGR concepts for electric power generation at the Fort St. Vrain plant located in Colorado 1 that operated from 1976 through 1989 and the Peach Bottom Atomic Power Station, Unit 1, a 200 MWt, HTGR located in Delta, Pennsylvania, that was operated ${ }^{2}$ from June of 1967 to its final shutdown on October 31, 1974.

Current HTGR system-related development efforts exist in China, Korea, Japan and Russia, and there has been recent revived interest from the process heat industry in Europe.

Through 2011, $\$ 445$ million dollars ${ }^{3}$ has gone into confirmatory research and development for HTGR technology by the U.S. Department of Energy under the Next Generation Nuclear Plant (NGNP) program. Activities currently underway to complete qualification and codification for fuel, graphite and high temperature materials will complete in five to six years if sustainable funding is provided. These activities are being conducted at the Idaho National Laboratory (INL) and elsewhere in the national laboratory complex.

In complementary activities over the past decade, industry has invested more than a billion dollars ${ }^{4}$ in advancing design concept and pre-licensing work with the vision for completing a commercial-scale demonstration project. 


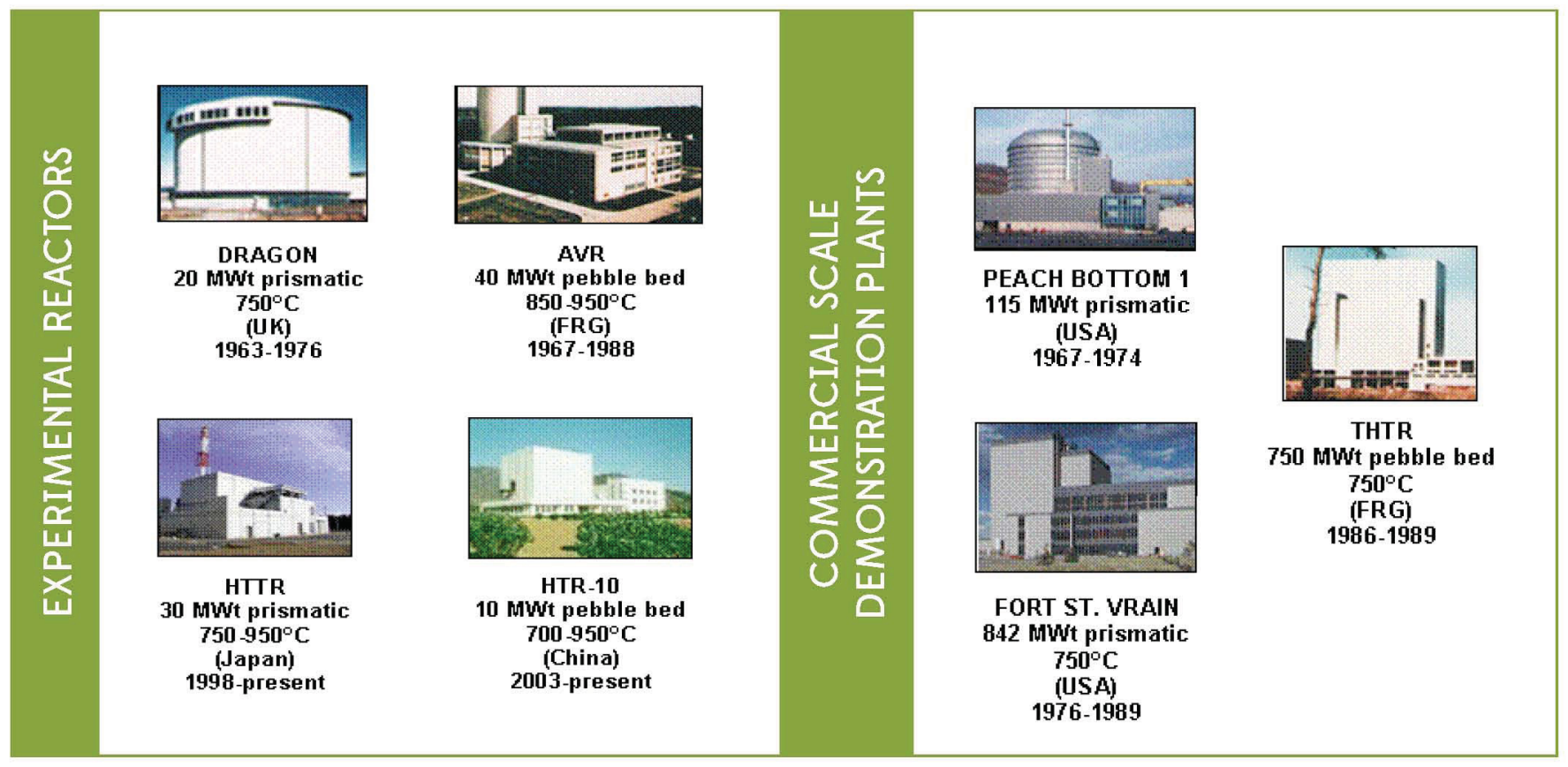

\section{MARKET AND ECONOMICS}

As described in more detail in Appendix A, substantive evaluations comparing the technology and economics of the HTGR with conventional technologies have been completed for about 20 different industrial processes including co-generation supply of steam and electricity to industrial plants, electricity generation as a merchant or regulated power generator, non-conventional oil extraction and upgrading, production of hydrogen, conversion of coal and natural gas to transportation fuels and chemical feedstock, production of ammonia and ammonia derivatives, seawater desalination, and coke and steel production. These evaluations addressed applications where the high temperature capabilities of the HTGR extend the use of nuclear energy beyond the traditional role of conventional light water reactors to supply electricity only. Based on these evaluations, and making conservative estimates regarding the extent of anticipated market penetration, the potential market in North America alone is represented by the summary in the adjacent figure.

For purposes of this business plan, the initial target market is limited to three broad market sectors: 1) delivery of high temperature process steam; 2) co-generation of process heat and electric power; and 3) power generation. This initial target market is selected based on the functional and performance capabilities of the reference concept described earlier, and assessment of preliminary economics for the associated applications. Each sector is summarized in the following with the estimated production capacity that could be installed, the cumulative contribution to the economy for the period 2025 through 2050, and a preliminary characterization of economics.
The North American Potential Market alone (assuming conservative market penetration):

\section{Co-generation}

Petrochemical, Refinery, Fertilizer/Ammonia plants and others

75 GW† ( 125 - 600 MW† modules)

Oil Sands / Oil Shale

Steam, electricity, hydrogen \& water treatment

$18 \mathrm{GW}+$ ( $\sim 30-600 \mathrm{MW} \uparrow$ modules $)$

\section{Hydrogen Merchant Market}

$36 \mathrm{GW}+$ ( 60 - $600 \mathrm{MW}$ t modules)

\section{Synthetic Fuels \& Feedstock}

Steam, electricity, high temperature flids, hydrogen 249 GWt $(\sim 415-600$ MWt modules)

IPP Supply of Electricity

$110 \mathrm{GW} \uparrow$ ( 180 - $600 \mathrm{MW} \uparrow$ modules)

\section{Price of Carbon}

For every $\$ 10$ per ton of $\mathrm{CO}_{2}$, the cost-effectiveness of the HTGR improves by $\$ 0.50 / \mathrm{MMBTU}$ equivalent natural gas price. $\mathrm{A} \$ 50$ price per ton of $\mathrm{CO}_{2}$ improves the competiveness of the HTGR from $\$ 6 / M M B T U$ to \$3.5O/MMBTU. 
1. Petrochemical, Chemical, Petroleum and Other Processing Facilities - These production facilities have large energy demands typically addressed via natural gas-fired on-site power generation and high temperature steam supply for combinations of process heating, mechanical drivers and direct steam injection. In support of assessing representative potential applications, a recent site-specific report, "Evaluation of Siting an HTGR Co-generation Plant on an Operating Commercial Nuclear Plant Site" 5 has been prepared by the INL with the support of Entergy Louisiana, LLC, Entergy Nuclear, Inc., and The Dow Chemical Company. This report addresses the technical feasibility and economic viability of locating an HTGR co-generation plant at the Waterford Steam Electric Station site in St. Charles Parish, Louisiana, and providing the energy needs of two nearby large petrochemical process facilities.

- Installed rating of plants for potential market ${ }^{6}-75 \mathrm{GW} / \mathrm{t}$ or -125 modules

- Cumulative contribution to the economy - $\$ 330 \mathrm{~B}$

- Competes with natural gas at an energy equivalent price of $-\$ 6 / \mathrm{MMBtu}$

2. Oil Sands Recovery Operations in Alberta, Canada - These operations have modest electrical demands for on-site generation but require large process steam loads in the form of distributed injection of steam for bitumen recovery. In support of assessing this potential application, a recent report "Integration of HGTR Technology with Oil Sands Processes" has been jointly prepared by the INL and the Petroleum Technology Alliance Canada that represents the leading petroleum companies who operate on an international scale and are heavily involved in the oil sands industry in Canada. This report addresses the technical feasibility and economic viability of using a central HTGR cogeneration plant to provide the energy needs of multiple bitumen recovery sites over a period of several decades, and upgrading the extracted bitumen to premium synthetic crude.

- Installed rating of plants for potential market ${ }^{8}-18 \mathrm{GW}$ t or $\sim 30$ modules

- Cumulative contribution to the economy - \$95B

- Competes with natural gas at an energy equivalent price of $-\$ 10 / \mathrm{MMBtu}^{9}$

3. Power Generation - Adding power generation units has unique siting constraints such as geographic close-in locations to load centers, transmission capacity and/or cooling water. In addition, the modular HTGR is an ideal technology fit for replacing small to medium coal-fired plants scheduled to be retired in the timeframe of interest due to tightening environmental requirements.

- Installed rating of plants for potential market ${ }^{10}-110 \mathrm{GW} /$ or 180 modules

- Cumulative contribution to the economy $-\$ 480 B$

- Competes with natural gas at an energy equivalent price of $-\$ 6 / \mathrm{MMBtu}$

In addition to the three sectors identified above, direct heating growth applications are emerging for industrial manufacturing processes such as ethane cracking, steam methane reforming and water-to-hydrogen thermal processes for hydrogen production. These growth areas can extend the market potential for the above target applications. New market applications such as carbon conversion for production of synthetic transportation fuels and chemical feedstock are other areas that are expected to emerge prior to mid-century. In addition, a higher temperature capability can be applied to advanced energy conversion cycles for more efficient and cost-effective power generation. Serving these growth areas requires further high temperature materials qualification, development of high temperature heat exchange capability and commercialization of highly efficient hydrogen production technology. The groundwork for these growth areas has been established in previous development work by industry and the Idaho National Laboratory.

While the North American market, noted above, is very large, the global market is enormous. Appendix A provides a comprehensive evaluation of these markets, the projected prices for natural gas and oil that constitute the competition, and preliminary economics for each sector.

\section{INVESTMENT PERSPECTIVES}

For those markets that rely on premium fossil fuels, commercializing the modular HTGR provides the option to use the only game-changing technology on the horizon that can address the overarching global energy policy goals of energy and feedstock security, economic growth/GDP (jobs) and carbon footprint (climate). Further, trends in fossil fuel prices suggest that modular HTGR technology integrated with modified versions of conventional carbon conversion technologies provides an economic approach to production of synthetic transportation fuels and chemical feedstocks with a minimal carbon footprint.

Modular HTGR plants can produce competitively priced electric power and high temperature process heat/steam that assures energy security and stabilization of energy prices for about $60 \%$ of global energy needs. Of these energy 


\section{\ame Changer for Industry}

It's the only game-changing technology on the horizon that can address the overarching global energy policy goals of energy and feedstock security, economic growth/GDP (jobs) and carbon footprint (climate).

needs, over half of the associated applications have been evaluated at the conceptual level and show promising economics.

Using HTGR nuclear-produced process heat dramatically reduces $\mathrm{CO}_{2}$ emissions from petrochemical production and petroleum refining facilities. It is economically competitive today in many parts of the world where gas prices are tied to oil, such as Europe, Japan and the Middle East. Further, we conclude that even U.S. natural gas prices are likely to emerge in a range that will make this technology competitive for process heat and power in the $2 \mathrm{O}^{2} \mathrm{O}^{+}$timeframe as utilities, transportation and LNG exports compete to arbitrage the current U.S. price advantage. (See Appendix A)

Further, if we are able to envision oil in the $\$ 130^{+}$per-barrel range over the next decade and beyond, the modular HTGR technology option integrated with carbon conversion processes provides an economic approach to production of synthetic transportation fuels - and/or in a carbon emissions-constrained environment, an alternative source of chemical feedstock.

The HTGR can create an expanding marketplace beyond electricity generation and enable industrial growth that is today solely relying upon a natural gas supply. HTGR-produced energy can be a hedge that can insulate industry from energy price volatility. Unlike natural gas energy production, HTGR use is largely immune to fuel price swings where $70 \%$ of the cost is driven by the capital investment with fuel being $<20 \%$. This is entirely opposite of natural gas used for industrial process application where $-70 \%$ of the cost of energy is directly tied to the cost of fuel and the enormous volatility this brings with it.

\section{Why would an energy end-user be interested in this technology?}

Current industrial plants are using one primary source of energy, natural gas, to develop the process heat. Modular HTGR technology provides an important option based on: 1) high temperature output, 2) competitive, stable long-term energy prices and 3) intrinsic safety.

1. High Temperature Output - HTGR technology is capable of delivering process heat at the heat and pressure ranges required by manufacturing and processing plants. Reliable and sustainable supply can be offered through multiple nuclear heat supply units (multiple HTGR modules) with close to $100 \%$ availability. The output produced is several hundred degrees above what is possible with conventional light water reactor technology and is produced without $\mathrm{CO}_{2}$ emissions.

2. Competitive and Stable Long-term Energy Prices - This technology offers flexible scalable deployment, high reliability and attractive economics. It is flexible, in part, due to its relative size that is comparable to the thermal output of a conventional gas turbine, making it a like-for-like functional replacement of thermal and power needs where redundancy is also a requirement. Because HTGR nuclear fuel cost is projected to be consistent with today's commercial nuclear fuel (accounting for $<20 \%$ of total production $\cos ^{1{ }^{11}}$ ) and is purchased for multi-year capabilities, it is largely

\section{Energy Supply}

- The HTGR is competitive today in many parts of the world

- Creates a new market for nuclear energy within industrial heat applications and a brand-new energy option using indigenous carbon to produce synthetic fuels and feedstocks

- Supports requirements of industry that are not serviceable from lower temperature light water reactors

- Provides for higherefficiency power production

- Provides stable energy price uncoupled from volatile pricing for natural gas - a fungible global commodity tied to oil parity 
immune to volatility in pricing and market swings; largely in opposition to natural gas for industrial production where $-70 \%$ of the operational costs are tied to fuel.

3. Intrinsic Safety - Intrinsic safety is the entry card to co-locating near or next to any large integrated manufacturing complex. The HTGR provides a nuclear energy system design that is intrinsically safe at a size and scale that will meet the needs for commercialization and provides intrinsic safety design to protect personnel, the public and the environment. The fuel design is at the heart of the safety case and supports collocation of modular nuclear units with existing or new industrial facilities. Due to the robust fuel design, it is a candidate for close-in siting capability needed to expand the existing industrial capacities.

One only needs to survey the world today to see that, in many places, natural gas price is indexed to oil price and, even in North America, higher natural gas prices seem only logical by the mid-2O2Os based upon several important considerations: 1) Projects are underway to export U.S. liquid natural gas (LNG) by reconfiguring import terminals to export capabilities - increased demand and export will eventually result in higher U.S. prices due to international arbitrage; 2) Additional natural gas-fired base load power generation and growth in industrial use will likely create an inelastic demand and associated volatile pricing; and 3) A move to natural gas as a transportation fuel is yet another likely inelastic demand that can lead to increased price volatility over the next decade.

\section{Why would a national policy maker be interested in this technology?}

1. Growth in the Economy and Jobs - The Alliance's market analysis indicates that within the first 25 years of application in the U.S. and the Alberta oil sands industry, nearly a trillion dollars in gross domestic product could be generated. Further, the modular HTGR is particularly well suited for small to medium and developing countries, with its scalable modular deployment and superior safety characteristics that do not rely on intervention of any systems or people to safely avoid major events during operation. Altogether, this translates into profitable growth in new market sectors for the nuclear energy system and equipment suppliers, owner/operators and energy end-user industries with many thousands of highly skilled, high-paying jobs. This growth is good for industry and good for the U.S., North America and other countries that choose to participate and engage this technology. China is already underway with the deployment of their version of a modular HTGR design that may compete globally.

\section{HTGR Deployment}

- Grows the economy by introducing

opportunities to rebuild manufacturing

infrastructure in stakeholder countries

- Creates high-value technical and

manufacturing jobs and new major

export markets

- Enables companies to compete globally

in a volatile and oil-indexed energy market

- Penetration of HTGR technology to

the likely markets would conservatively

create over $\$ 1$ trillion in GDP by 2050

in North America alone
2. Energy Price Stability - The HTGR energy pricing is expected to be stable over an operational plant life of more than 60 years by virtue of the fact that $<20 \%$ of the energy cost is tied directly to the fuel raw material. By supplanting natural gas and other fossil fuels for producing heat, the modular HTGR provides insulation from energy price variability.

3. Alternative Uses for Indigenous Carbon Resources \& Improving Energy Security - HTGR technology provides an attractive path to take advantage of indigenous carbon (coal, pet coke, municipal solid waste, etc.) by gasifying the carbon with co-production of hydrogen, all using the modular HTGR technology, and ending up with chemical feedstock or transportation fuels. As an example, if you matched up about thirty one 50,000-barrelsper-day carbon conversion plants with the annual coal production output of Kentucky, you could convert that coal to transportation fuels equivalent to about one-fourth of the U.S. import demand today with minimal $\mathrm{CO}_{2}$ emissions. This improves both energy security and independence. 
4. Minimizes Carbon Emissions - Environmental factors range from incremental advantages associated with fuel utilization, waste management, land use and cooling water requirements. Unique within nuclear, the modular HTGR is the only carbon-reducing game-changing technology on the foreseeable horizon for supplanting fossil fuels in the production of high temperature process heat. The end-user community that is driving the Alliance envisions a path that would eliminate as much as $80 \%$ of its carbon footprint with this technology. Substantially lower carbon footprints cannot be achieved without bold technology advances.

5. Minimizes Water Usage - The high thermal efficiency of modular HTGR technology can make use of dry cooling as an economic alternative in those areas where water is limited.

\section{COMMERCIALIZATION STRATEGY}

The commercialization strategy is comprised of the following elements, most of which are overlapping, to achieve a commercially viable energy supply technology:

Complete the Technology Development - The development activities for the nuclear fuel, graphite structural materials, high temperature metals and composite materials, and contemporary analytical methods. The extant development activities are currently being led by the Idaho National Laboratory and have, as a foundation, the past design and qualification work that has been advanced by others on similar nuclear technologies.

Complete the Design Development - The development activities for the reference prismatic reactor concept and a Rankine cycle steam plant capable of co-generating process heat (as steam) and electricity.

Establish the Licensing and Regulatory Requirements - A licensing plan that continues the pre-application iterative process of collaboratively working with the US Nuclear Regulatory Commission (USNRC) to establish the regulatory performance and design requirements for modular HTGRs. The licensing plan will then continue into the preparation of a license application for a selected site based on the design being developed for the reference concept.

Develop the Supply Infrastructure - Establish a supply chain for nuclear fuel, graphite and other major equipment that can be matured to support construction and operation of the demonstration and follow-on plants.

Construct and Deploy the Demonstration Module and the First-of-a-Kind Plant - The demonstration will consist of the initial single reactor module to confirm technology and licensing implementation. This is then expanded to a FOAK plant comprised of multiple modules supplying energy with a compelling business case.

\section{ENTERPRISE STRUCTURE}

The NGNP Industry Alliance is leading the industry effort to commercialize modular HTGR technology and anticipates a structure for the enterprise to commercialize HTGR technology as summarized below. This structure includes enterprise activities that comprise the equity investment opportunities that are expected to realize important long-term and continuing returns as the HTGR technology is widely adopted across the globe. Each of the activities envelops some or all of the components of the commercialization strategy described above.
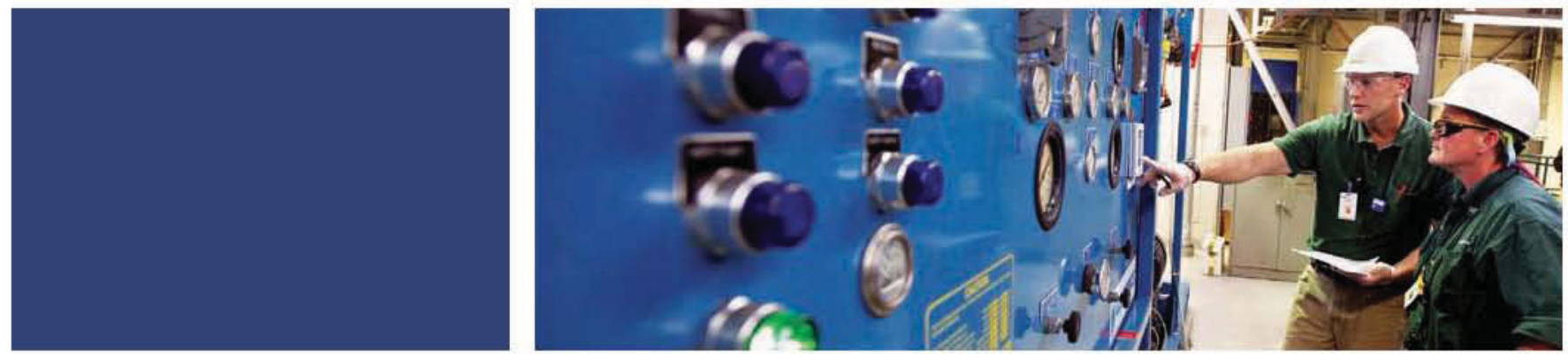


\section{Overall Structure}

1. Development Venture - A joint venture led by the Nuclear System Supplier (NSS) with the Prospective Owner entity (Owner). Equity investors are anticipated to include nuclear system suppliers, vendors of major equipment and materials, governments, industrial energy end-users and other equity investors. The NSS will lead completion of technology development, and perform design development through preliminary design. The Owner will lead completion of pre-application activities with the USNRC and lead preparation of license applications supporting the Deployment Project (e.g., an Early Site Permit application (ESP), a Construction Permit application or a combined Construction and Operating License application (COLA) ${ }^{12}$.

2. Deployment Project - A joint venture led by the Owner for procurement, construction and operation of the FOAK plant. Equity investors are anticipated to include energy producers (e.g., utilities; power-generating companies; independent power/energy producers), municipalities, architect-engineers/constructors (AE/C) and industrial energy end-users. The Owner and/or the designated Operator will lead final site and plant licensing submittals and hold the operating license; the NSS and the AE/C will complete the final design; and the AE/C will manage construction.

3. Infrastructure Framework - Activities to establish a supply chain for nuclear fuel, graphite and major equipment that can be matured to support construction and operation of the demonstration and follow-on HTGR plants. The structure of this activity will depend on the extent to which the NSS elects to be the supplier versus purchasing from others. It is anticipated that nuclear fuel production capability will be developed as part of the development venture. Initial indications are that the graphite and major equipment vendors will make the necessary investments.

4. Technology Expansion Program - Activities to pursue advanced and alternative technologies to broaden the initial market for HTGR technology. This could include technology advances such as higher temperature materials, gasto-gas heat exchangers, and a high-efficiency hydrogen production capability. Advanced HTGR plant designs will support higher temperature process heat needs and the production of hydrogen, essential to the carbon-conversion technologies. There are several carbon-conversion technologies that could be economically integrated with HTGRs. This is envisioned as a separate investment and is not integral to the initial development venture.

5. Program Direction - Activities led by the NGNP Industry Alliance to ensure appropriate direction and overall integration for commercialization of HTGR technology. The Alliance will lead an activity to mature the understanding of market opportunities and associated economics. The Alliance anticipates that membership will expand to include at least each of the entities represented in the above activities.
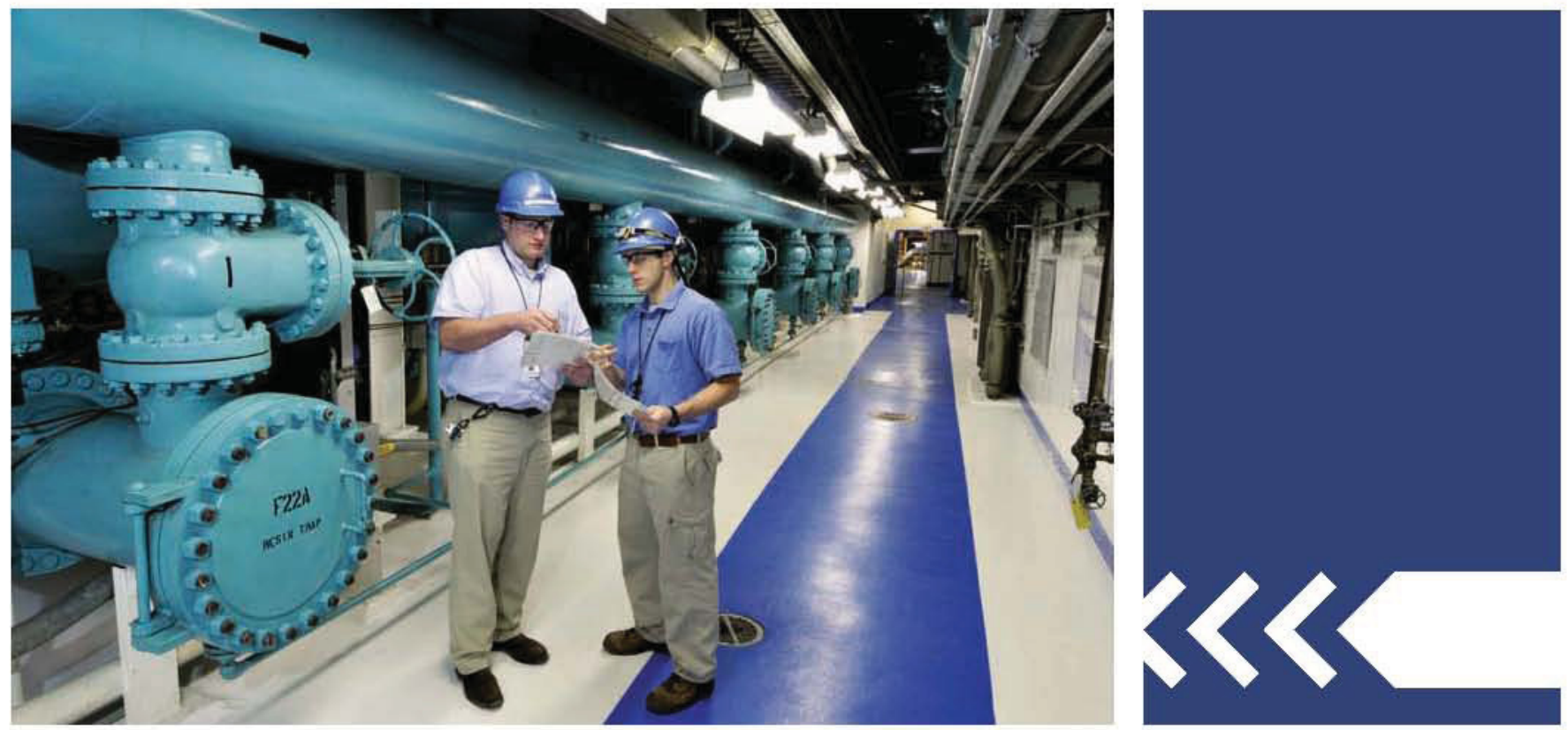


\section{Estimated Costs}

The estimated costs to complete each of the Enterprise activities are summarized as follows:

\begin{tabular}{|c|c|}
\hline Development Venture & \$ millions (2011) \\
\hline Development & 316 \\
\hline Conceptual/ Preliminary Design & 280 \\
\hline Final Design & 200 \\
\hline Licensing through preparation of application ${ }^{13}$ & 165 \\
\hline Equipment and infrastructure development & 648 \\
\hline $\begin{array}{l}\text { Inspections, Testing and Modifications } \\
\text { (Demonstration initial operations) }\end{array}$ & 75 \\
\hline Deployment Project & $\$$ millions (2011) \\
\hline Complete site-specific design & 200 \\
\hline Construction permit/license application/review & 32 \\
\hline Equipment procurement & 432 \\
\hline Construction & 625 \\
\hline Startup \& testing ${ }^{14}$ & 55 \\
\hline Initial operations ( 3 years) & 348 \\
\hline Revenue (initial 3 years) & -265 \\
\hline Infrastructure Framework & $\$$ millions (2011) \\
\hline Nuclear fuel production facility & 440 \\
\hline Graphite production facility & 150 \\
\hline $\begin{array}{l}\text { Technology Expansion Examples } \\
\text { (Future - Second-Generation Product) }\end{array}$ & $\$$ millions (2011) \\
\hline Intermediate $\mathrm{HX}$ & 100 \\
\hline Hydrogen production & 200 \\
\hline Higher temperature materials & 100 \\
\hline Program Direction & \$ millions (2011) \\
\hline Program Support & 90 \\
\hline
\end{tabular}




\section{Schedule}

A notional schedule for the Enterprise follows. This includes completing the Development Venture and the Deployment Project, as summarized earlier, that culminates in completing the first-of-a-kind HTGR technology plant.

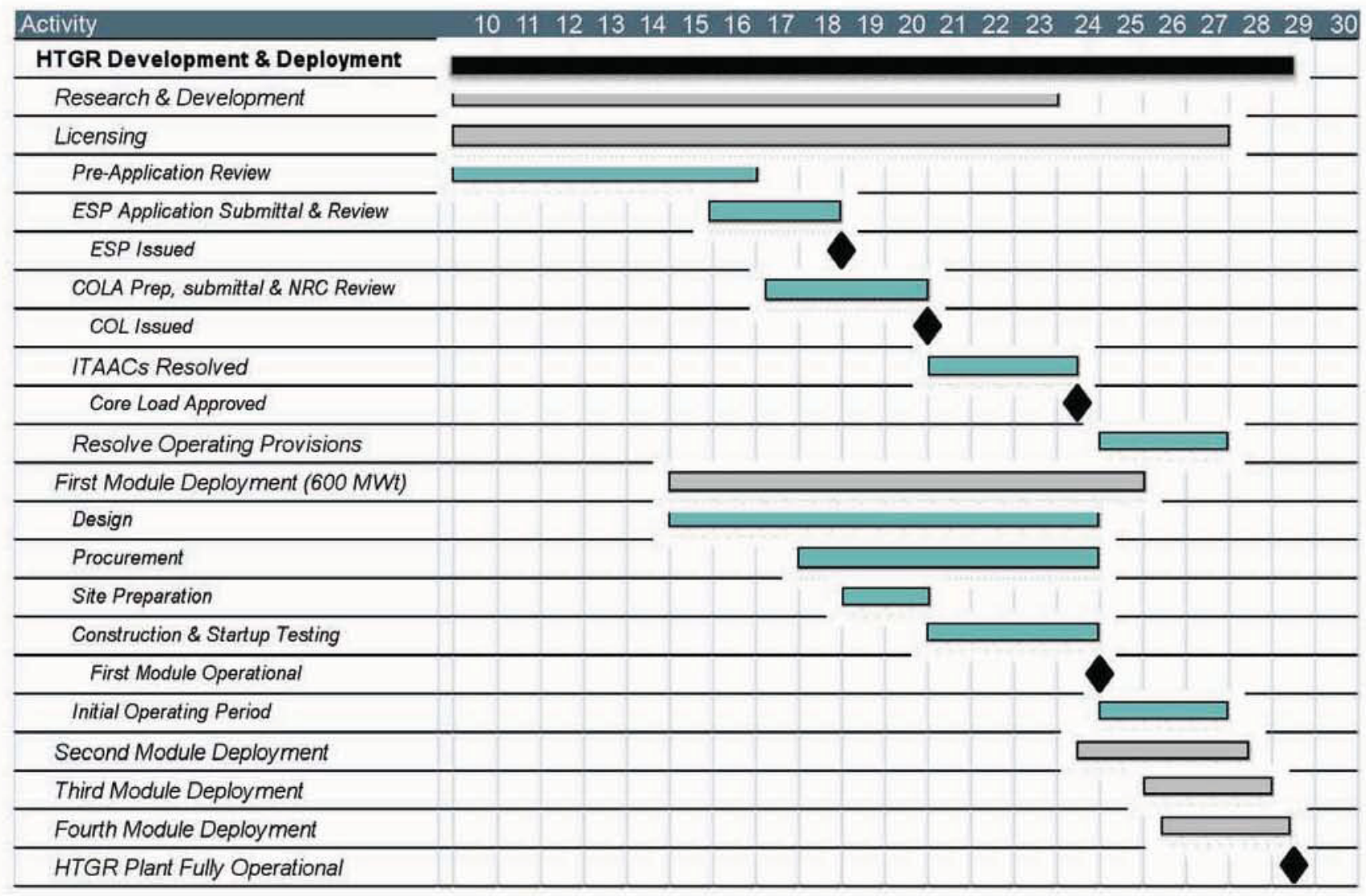

\section{Investment Opportunities}

For possible investment purposes, two areas of the Enterprise structure are developed more fully in Appendices B and C.

Development Venture - Appendix B provides a summary of possible approaches to executing the Development Venture. The Development Venture includes providing the technical foundation and regulatory framework for commercialization of modular HTGR technology and supporting the licensing and construction of the initial fleet of modular HTGRs for commercial application. A large equity investment is required for which a return will be realized following completion of several modular HTGR plants. The return is in the form of intellectual property ownership that can be realized after a build-out of less than $5 \%$ of the conservatively estimated market penetration.

Deployment Project - Appendix C provides a summary of a possible approach to executing the Deployment Project. The Deployment Project constructs and operates the demonstration module and the FOAK plant based on modular HTGR technology. Return on investment begins to be realized about eight years from initial investment and includes both revenues from operation and ownership of intellectual property associated with the techniques and experience gained in the construction and startup of the FOAK plant.

Specifics regarding breakdown of scope, the investment framework, the interaction and interdependencies of these activities, investment risk and the character of intellectual property and other return on investment are the subjects for detailed discussions with interested equity investors.

\section{ENTERPRISE RISK PERSPECTIVE}

The potential consequences for three areas of overall risk are of particular importance to the success of the Enterprise are identified below. Executing the risk mitigation activities and accommodating the residual risk are essential for success. 
1. Technology Development - These are the important technologies necessary to support initial deployment. This includes the ongoing development and design support activities such as codification in consensus technical standards and providing technical support for development of a regulatory framework via pre-application licensing activities.

Risk mitigation:

INL/EXT-11-23907, NGNP Project - 2011 Status and Path Forward, December 2011, and detailed development plan references therein. These constitute a comprehensive plan for the remaining technical development activities including codification.

Residual risk (low):

Unanticipated technical issues or untimely processing and acceptance of code cases by consensus standards committees and NRC

2. Nuclear Facility Licensing - This includes ongoing pre-licensing application interactions with the NRC directed toward developing the regulatory technical requirements and review processes applicable to HTGR technology. The development of this licensing framework for the HTGR may require important changes to existing regulatory requirements that have evolved primarily for light water reactor technology. The framework is needed for eventual certification of the HTGR reactor design as well as site licensing requirements for collocation of the reactor with industrial processes. Progress on and the credibility of this developing framework is essential to beginning detailed design work with an acceptable business risk.

Risk mitigation:

- Next Generation Nuclear Plant Licensing Strategy - a report to Congress, August 2008. This report, prepared jointly by NRC and DOE, summarizes the preferred licensing development approach and necessary NRC resources.

- PLN-3202, NGNP Licensing Plan, June 26, 2009. A detailed implementation plan prepared by INL for DOE that is in effect until January 1, 2013.

- Entergy Licensing Plan for HTGRs - in preparation (a June 2012 draft is anticipated). This plan, effective January 1, 2013, will describe the licensing implementation approach through completion of pre-application activities, preparation of the construction permit and operating license applications and executing the license for the initial HTGR plant.

- Aggressive pre-application activities with NRC to adapt/augment current regulatory requirements for applicability to HTGR technology since 2009 are continuing.

- A licensing plan will be formulated under the development venture. This plan will enable preparation of design and licensing documents and determine the licensing application requirements ${ }^{16}$. It will provide the approach that can best share the investment risk during technology development as well as for investors in the deployment projects.

Residual risk (high):

- NRC finalization of the requirements framework will not be fully complete until an operating license is issued.

- There is exposure to public hearings during the licensing and permitting process.

3. Successful Execution of Interdependent Enterprise Activities - Success in three of the Enterprise activities is highly interdependent (i.e., Development Venture; Deployment Project; Infrastructure Framework). As a consequence, investment, execution and coordination among these activities and the involved companies and investors are paramount.

Risk mitigation

- Preparation of this Business Plan for Commercialization

- Development of prospectus for Enterprise activities that provide a conceptual approach to an investment model and characterization of alternatives for return on investment

- Contractual vehicles and business arrangements are anticipated between the companies that lead each of the Enterprise activities and describe coordination between the investment ventures

Residual risk (currently high)

- Assured funding path is not established and, therefore, investment, execution and coordination planning is not planned 


\section{THE ALLIANCE AND ITS CURRENT MEMBERS}

Member companies have joined in this alliance with the primary purpose to promote the development and commercialization of HTGR technologies through support of, and participation in, the DOE's Next Generation Nuclear Plant (NGNP) Project. Our alliance represents the interests and views of our members that intend to mutually support and direct project plans to design, build, operate and use the HTGR technology. We provide a forum and focus to communicate industry needs and requirements and work in concert with the Idaho National Laboratory and others to seek out and promote industrial uses for HTGR technologies within the United States, North America and other continents around the world.

\section{Description}

4 AREVA

\section{ConocoPhillips}
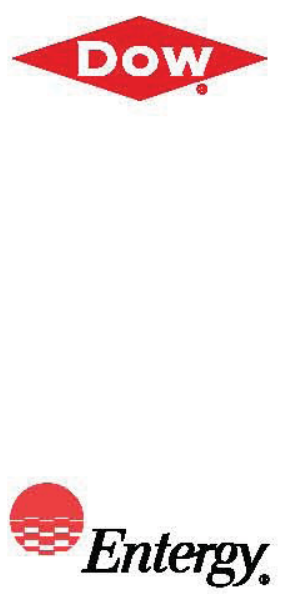

GraF International
AREVA supplies solutions for carbon-free power generation. Its expertise and know-how in this field are setting the standard, and its responsible development is anchored in a process of continuous improvement. As the global nuclear industry leader, AREVA's unique integrated offer to utilities covers every stage of the fuel cycle, nuclear reactor design and construction, and related services. AREVA has designed, built and operated high temperature gas-cooled reactors and is active in further development of the prismatic graphite block HTGR.

ConocoPhillips traces its beginnings to 1875. They are one of the world's largest independent Exploration and Production companies, based on proved reserves and production of liquids and natural gas. As of May 1, 2012, the company had operations in almost 30 countries and more than 16,000 employees. Production averaged 1.62 million Barrel of Oil Equivalent (BOE) per day in 2011, and proved reserves were 8.4 billion BOE as of Dec. 31, 2011.

Dow, founded in 1897 combines the power of science and technology with the "Human Element" to passionately innovate what is essential to human progress. The Company connects chemistry and innovation with the principles of sustainability to help address many of the world's most challenging problems such as the need for clean water, renewable energy generation and conservation, and increasing agricultural productivity. Dow's diversified industry-leading portfolio of specialty chemical, advanced materials, agro-sciences and plastics businesses delivers a broad range of technology-based products and solutions.

Entergy Corporation is an integrated energy company engaged primarily in electric power production and retail distribution operations. Entergy owns and operates power plants with approximately 30,000 megawatts of electric-generating capacity, and it is the second-largest nuclear generator in the United States. Entergy delivers electricity to 2.8 million utility customers in Arkansas, Louisiana, Mississippi and Texas. Entergy has annual revenues of more than $\$ 11$ billion and approximately 15,000 employees. In 1999, as a part of the company's unregulated growth strategy, Entergy began to grow the nuclear fleet by acquiring the first of six additional operating nuclear plants that provide electric power via long-term power agreements. Entergy has been one of the fastest growing and successful nuclear companies in the nation and was recently ranked 7th in the world for nuclear electricity generation. Additionally, in 2003 a long-term management services contract was signed with Nebraska Public Power District for Entergy to support the management of the Cooper Nuclear Station in Nebraska. The Cooper contract was extended in 2010 to provide management support through 2028 . Through its TLG Services Company, Entergy also provides decommissioning services for the industry. Other management, technical and engineering services for the nuclear industry are provided by Entergy Nuclear Incorporated.

Graftech International is a global company with more than 125 years in the graphite materials industry, offering innovative solutions for the most challenging applications. Its customers are located in more than 70 countries and represent a wide range of industries and end markets, including steel manufacturing, advanced energy and latest-generation electronics. Graftech operates 19 principal manufacturing facilities on four continents and employs nearly 3,300 people. 


\section{MERSEN}

PTAC

SGL GROUP

THE CARBON COMPANY

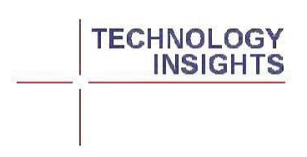

TOYO TANSO

inspiration for Innovation

(w) Westinghouse

* US unuclasafe
Mersen is a global expert in materials and equipment for extreme environments and for the safety and reliability of electrical equipment. They are focused on serving expanding markets: energy, electronics, chemicals and pharmaceuticals, transportation and process industries. Major product offerings are in: graphite anticorrosion equipment for the chemicals and pharmaceuticals industries; fuses for power semiconductors brushes and brushholders for electrical machinery; and high-temperature applications of isostatic graphite. Mersen has sales and/or manufacturing base in more than 40 countries.

The Petroleum Technology Alliance Canada (PTAC) is an association that facilitates collaborative research and technology development to improve the performance of the Canadian hydrocarbon energy industry. Members include the conventional oil and gas business - oil and gas producers, processors and transporters, high technology service and supply companies, research providers and others in specialty and expert fields directly supporting the energy industry. The purpose of PTAC is to provide a mechanism that facilitates collaboration on DEVELOPMENT to the benefit of those involved.

We are "SGL Group - The Carbon Company," one of the worldwide leading manufacturers of carbon-based products. W/e have an in-depth materials, production, applications and engineering expertise, a comprehensive graphite and carbon fiber-based product portfolio, and an integrated value chain from carbon fibers to composites. We operate close to our customers through a global sales network and state-of-the-art production sites in Europe, North America and Asia.

Technology Insights is a consulting firm that specializes in assessing and supporting the development and deployment of emerging technologies related to energy generation, distribution, utilization and management.

Toyo Tanso Co., LTD. produces and sells isotropic graphite, other specialized carbon products and carbon products for general industries. It also manufactures for sale composite materials made from carbon and ceramic, metal or organic materials. In addition, it produces for sale carbon electrode for fluorine electrolysis and business of surface treatment on various materials with fluorine gas.

Westinghouse Electric Company LLC is the world's pioneering nuclear energy company and is a leading supplier of nuclear plant products and technologies to utilities throughout the world. Westinghouse supplied the world's first pressurized water reactor in 1957 in Shippingport, PA, USA. Today, Westinghouse technology is the basis for approximately one-half of the world's operating nuclear plants, including 60 percent of those in the United States. Worldwide, the nearly 14,000 employees of Westinghouse Electric Company continue to pioneer value-added engineering and services creating success for our customers in their increasingly demanding markets. The four core product lines of Westinghouse - Nuclear Automation, Nuclear Fuel, Nuclear Services and Nuclear Power Plants - support this mission. Through these core businesses, Westinghouse aims to serve the needs of utility, government and industrial customers in nuclear power-related industries. Through alliances with customers, Westinghouse plays a key role in the design and implementation of integrated solutions.

Ultra Safe Nuclear Corporation (USNC) is participating in the development and commercialization of new "Ultra Safe" technology to enhance the robustness of nuclear reactors and nuclear fuels, including the Fully Ceramic Micro-encapsulated (FCM) TRISO-based fuel for LWRs. The Company provides design and analysis services for fuel, core and reactor systems on gas- and water-cooled reactors and has representation and technical contributors in the United States, Europe and Asia. 
BIBLIOGRAPHY

1. Owned and operated by Public Service Company of Colorado and granted an operating license by the Atomic Energy Commission (AEC) on December 21, 1973 (initial criticality on January 31,1974 )

2. Owned and operated by the Philadelphia Electric Company (later shortened first to PECO Energy and later to just PECO) USNRC docketed by USNRC (License No.: DPR-12 Docket No.: 50-171)

3. INL/EXT-11-23907, NGNP Project. 2011 Stafus and Path Forward, December, 2011

4. Historical investment by the industry - see Next Generation Nuclear Plant Implementation Strategy (11/30/2009 section 3.3 .1 attachment to letter to DOE Secretary Chu dated 11/30/2009 from the NGNP Industry Alliance in response to FOA DE-FOA-O000149 issued 9/18/2009)

5. Report No. INL/EXT-11-23282 (October 2011)

6. Assumes replacement of $50 \%$ of the existing co-generation facilities with ratings in excess of $900 \mathrm{MWW}$ ( 125 operating facilities) as they are retired due to increased natural gas prices and/or carbon emission costs/regulation over the period 2025-2050

7. Report No. INL/EXT-11-23239 (October 2011)

8. Assumes installation of six central energy facilities to provide the energy needs for $25 \%$ of the growth in the oil sands in-situ production that is projected over the period 2025-2050

9. $\$ 10 / M M B t u$ equivalent natural gas price (higher than previously noted $\$ 6 / M M B+u$ ) is based on a capital construction cost multiplier for the Alberta oil sands region of $-1.7 \times$

10. Assumes installation of $-45 \mathrm{GWe}$ capacity over the period $2025-2050$. This is about $10 \%$ of the nuclear electricity generation that would be required as replacement and/or alternatives to coal and natural gas based generation plants to meet emissions regulations such as those recently issued by EPA

11. Fuel cost includes: conversion $-2 \%$; fabrication $-50 \%$; waste fund $-8 \%$; enrichment $-16 \%$; uranium $-23 \%$. Ref: AREVA

12. The licensing plan prepared in the Development Venture will determine licensing requirements under USNRC Regulations 10 CFR Part 50 (Domestic Licensing of Praduction and Utilization Facilities) or 1OCFR Part 52 (Licenses, Certifications, and Approvals for Nuclear Power Plants)

13. The licensing plan prepared in the product development venture will determine licensing requirements under USNRC Regulations 10 CFR Part 50 (Domestic Licensing of Production and Utilization Facilities) or 10CFR Part 52 (Licenses, Certifications, and Approvals for Nuclear Power Plants)

14. Design certification is planned following first plant demonstration

15. Some funds may come through government DEVELOPMENT programs

16. USNRC Regulations 10 CFR Part 50 (Domestic Licensing of Production and Utilization Facilities) or 10CFR Part 52 (Licenses, Certifications, and Approvals for Nuclear Power Plants) 


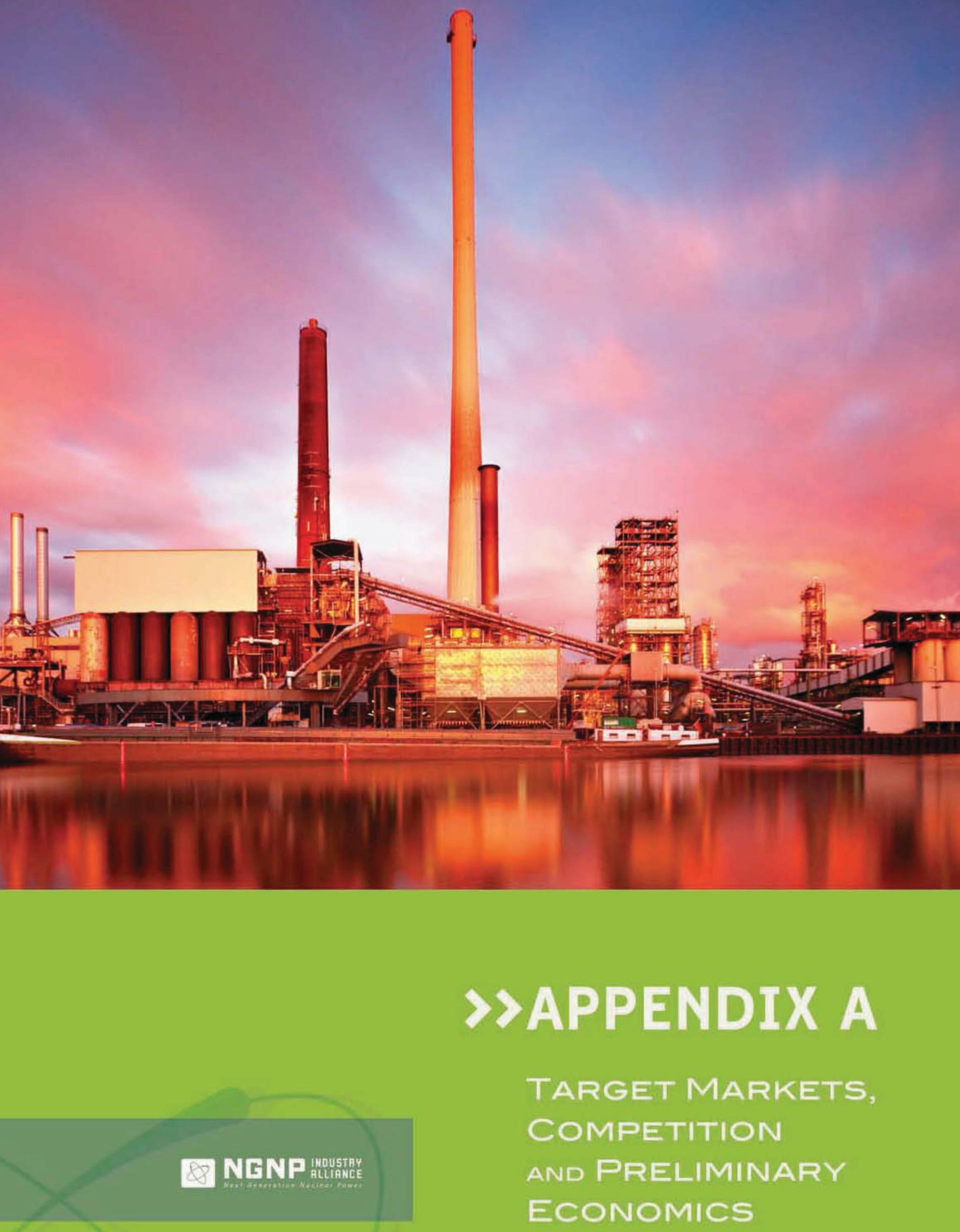




\section{APPENDIX A}

Target Markets, Competition and Preliminary Economics

\section{PREFACE}

Scoping economic analyses for potential applications in the targeted energy markets shows that industrial plants integrated with modular HTGR technology can be competitive currently (much of the world) or are expected to be competitive (North America) at the time of initial deployment ( 2025$)$.

This appendix examines the target markets for HTGRs. The discussion on natural gas price forecasting is specific to North America.

- Assesses 1) the competition based on natural gas as a source of heat and feedstock, and 2) competition of refined petroleum products with production of synthetic transportation fuels and feedstock

- Summarizes preliminary economics for HTGR technology plants compared to the competition.

Globalty, the potential market is considerably larger and current energy economics suggest that HTGR fechnology could be expected to be even more competitive as shown in the graphic to the right. Much of the rest of the world, unitike North America, has gas pricing fied to off on a BIU parity basis, and this targely sets pricing.

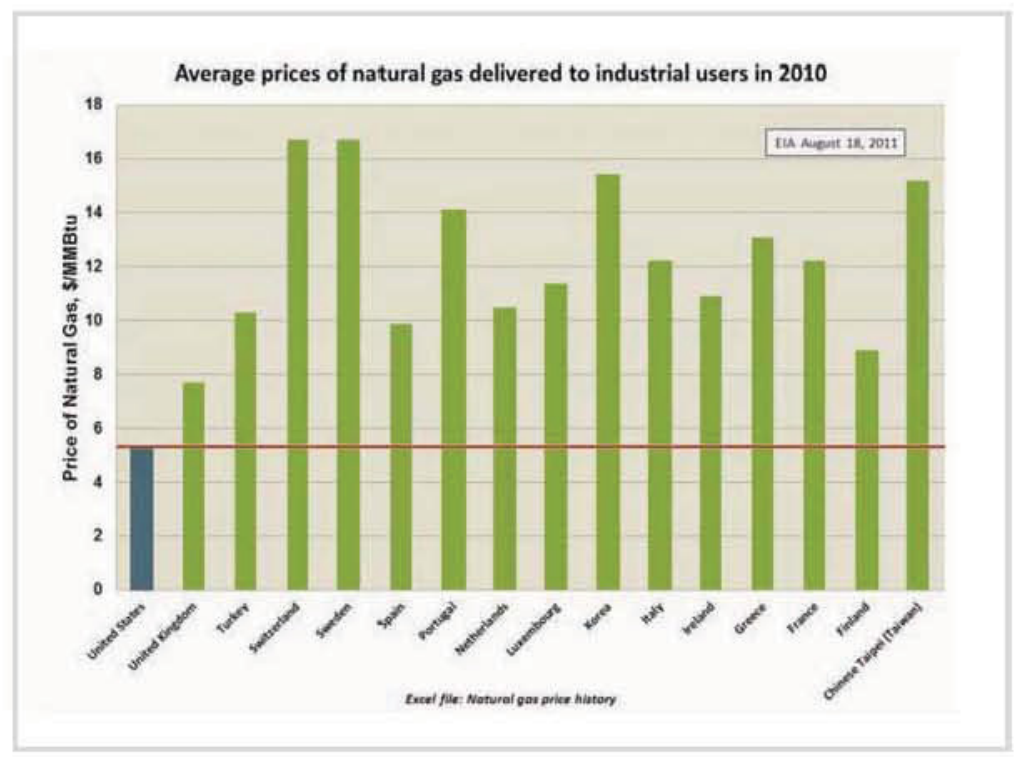

\section{THE TARGET MARKETS}

Substantive evaluations comparing the technology and economics of the HTGR technology with conventional technologies have been completed for about 20 different industrial processes including co-generation supply of steam and electricity to industrial processes, electricity generation as a merchant or regulated utility, non-conventional oil extraction and upgrading, production of hydrogen, conversion of coal and natural gas to transportation fuels and chemical feedstock, production of ammonia and ammonia derivatives, seawater desalination, and coke and steel production. ${ }^{2.6}$

These evaluations addressed applications where the high temperature capabilities of the HTGR extend the use of nuclear energy beyond the traditional role of conventional light water reactors to supply electricity, only.

Of these, the application of the HTGR technology in co-generation, oils sands operations, electricity generation, hydrogen production and carbon conversion (e.g., coal to liquids) are judged to be most viable in the initial phase of the HTGR commercialization. However, it is noted that hydrogen production and carbon conversion require the complementary commercialization of high temperature steam electrolysis to fully utilize the potential of HTGR technology.

A preliminary market study was conducted to assess the size of the potential market in terms of the number of HTGR modules (nominal $600 \mathrm{MW} / \mathrm{t}$ rating) that could be deployed in these areas over an assumed initial deployment period of 2025-2050 (see figure at right). The market penetrations projected for the first four application areas are based on the size of the current market and projections for its growth. The latter synthetic transportation fuels and chemical feedstock market would be essentially a new market with uncertain size. This market is estimated based on a goal of substantially reducing the amount of imported crude oil in the next three decades. Aside from possible policy drivers, it is estimated future crude oil prices in the range of $\$ 65$ to $\$ 200 / \mathrm{bbl}$ could provide a compelling business case for synthetic transportation fuels production using HTGR energy integrated with carbon conversion processes. The total 


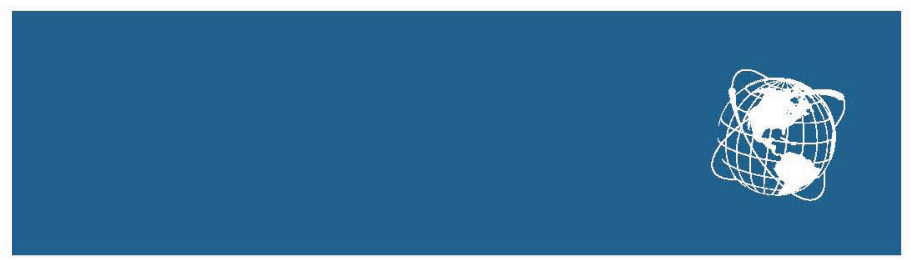

number of projected HTGR modules deployed over this period is projected somewhere between 400 and 800 ; even at the low end, this is a substantial potential market that readily justifies development and commercialization of HTGR technology.

Beyond the overall market characterization, detailed assessments have been performed for applying the HTGR technology to specific proxy industrial applications 1) for supplying steam and electricity to collocated petrochemical facilities ${ }^{d}$, 2) steam, electricity and high temperature gas to support bitumen recovery and upgrading in the Alberta, Canada, oil sandse, and 3) electricity generationf. Evaluations were performed for HTGRs integrated with multiple carbon conversion processes. Each of these evaluations compared the economics of applying the HTGR technology in these potential applications with conventional energy technologies; principally the firing of natural gas. Whereas the HTGR has very high front-end capital requirements and very low operating costs, the natural gas technologies, (e.g., gas-fired steam generators, natural gas combined cycle units) have relatively low capital costs but high operating costs; the operating costs are dominated by the cost of natural gas. The price of natural gas is, therefore, a major factor in assessing the competition. The potential for government policies that effectively establish a price on $\mathrm{CO}_{2}$ emissions is also another distinguishing factor; HTGR technology has no $\mathrm{CO}_{2}$ emissions during operation.

\section{ASSESSING THE COMPETITION}

\section{Historical and EIA Projected Natural Gas Price}

The figure at the right shows the historical prices of U.S. natural gas at the well head and delivered over the last two decades. The current low prices reflect the large potential reserves and low costs for extraction of gas from shale gas. (Note the differences in price delivered to end users versus well head price; the latter is the price quoted at Henry Hub).

The prospects for continued extraction of natural gas from shale gas in the U.S. has led the EIA to predict modest increases in natural gas prices through 2035 to a value of $\sim \$ 7 / \mathrm{MMBtu}(2009 \$)^{\mathrm{h}}$. It is of interest that current futures market for natural gas has bids in the $\$ 7.5 / \mathrm{MMBtu}$ range for December 2024 deliveries; a rate of increase in projected prices greater than predicted by the EIA'.
High Temperature Gas-cooled Reactors - Application Beyond Electricity
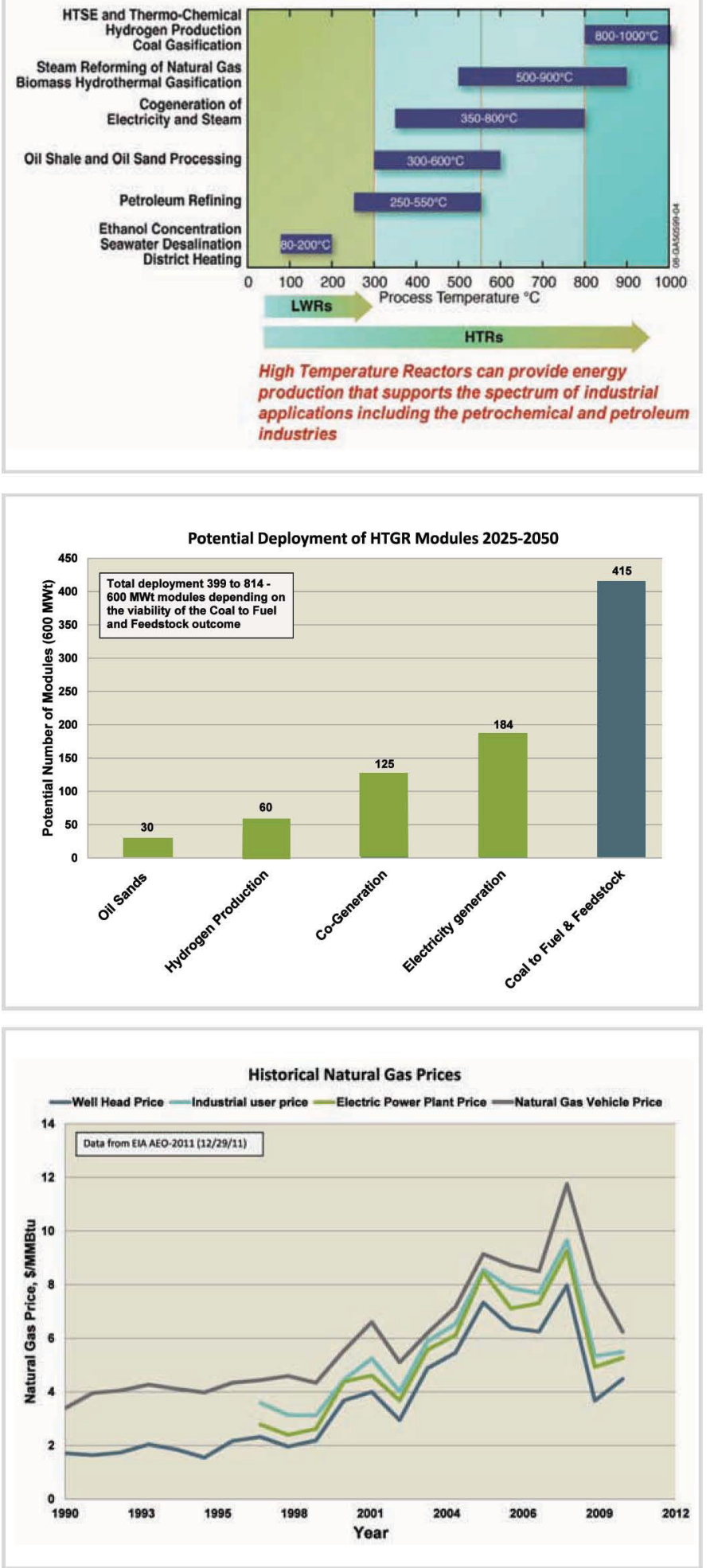


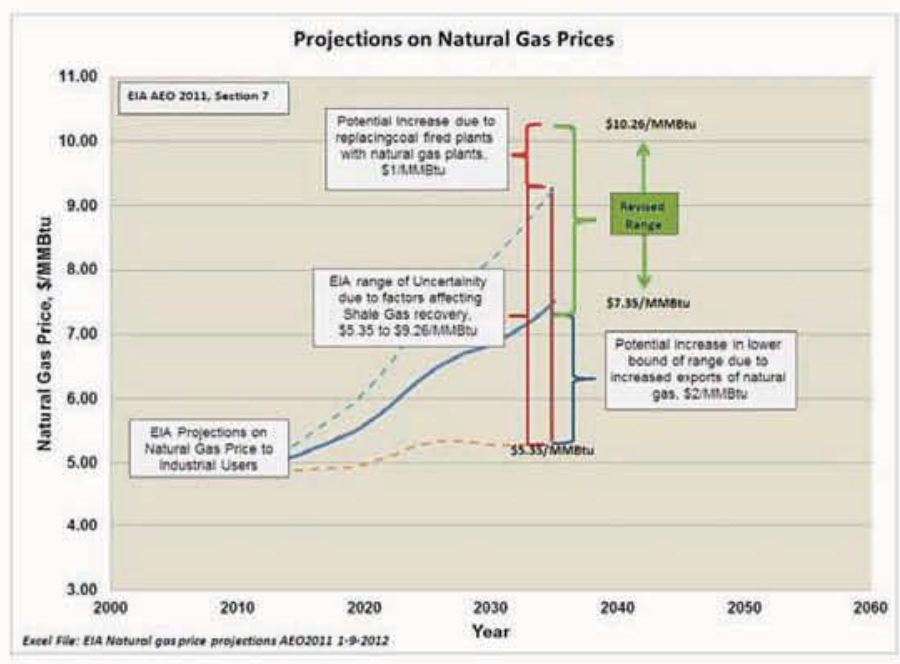

As shown in the figure to the left, the EIA has evaluated several positive and negative factors potentially affecting the size of the shale gas reserves and the long-term costs for extracting the gas that led to establishing upper and lower bounds on the price projections in 2035 with a range from $\$ 5.35 / \mathrm{MMBtu}$ to $\$ 9.26 / \mathrm{MMBtu}^{\mathrm{h}}$.

\section{Effect of Environmental Regulations on Natural Gas-Fired Electricity Generation}

There are other factors that could raise natural gas prices even if shale gas continues as a viable and economic source. These include the impact of recent EPA regulations on the emissions of mercury and other constituents (referred to as CATR + MACT regulations) on the retirement of coal-fired plants. The supposition is that the capacity of these plants will be replaced with natural gas plants. The EPA has estimated that these regulations would increase the retirements by 2016 when the regulations are fully in effect from 7GW under no regulation conditions to $9 \mathrm{GW}$ under the regulations. An industry study, however, predicts an increase of $48 \mathrm{GW}$ in retirements when the inventory of coal plants over 40 years old with poor heat rates and no current scrubber installations is considered. This study concludes that replacing these plants with natural gas plants in 2016 would increase electricity production from natural gas plants by $26 \%$, increase natural gas demand for electricity generation by $-25 \%$ and increase natural gas prices by $\sim 17 \%$. The $25 \%$ increase in natural gas usage for electricity generation increases the total consumption in the U.S. by $\sim 8 \%$. The increase in natural gas price of $17 \%$ is approximately equivalent to an increase of $\$ 1 / \mathrm{MMBtu}$ in that timeframe.

\section{International Market Arbitrage}

Another significant factor is the likelihood of increased exports of natural gas from the U.S. to other countries that have significantly higher prices. As shown in the following figure, these differentials are currently over factors of three. It has been projected that recent requests for permits to convert existing LNG import facilities for export, if implemented, could result in exports amounting to $20 \%$ of current production ( $\sim 4$ trillion cubic feet annually). This is twice the increase in demand projected for the early retirement of coal plants cited previously. Using that correlation between the increase in price with the increase in demand (or the decrease in supply for this case), such exports would be expected to increase the price of natural gas by about $35 \%$ or $-\$ 2 / \mathrm{MMBtu}$.

Even with the expected increase in production from the abundant shale gas, the U.S. and OECD countries in general are expected to continue to be importers of natural gast. This would also have a net effect on the prices in the U.S. No

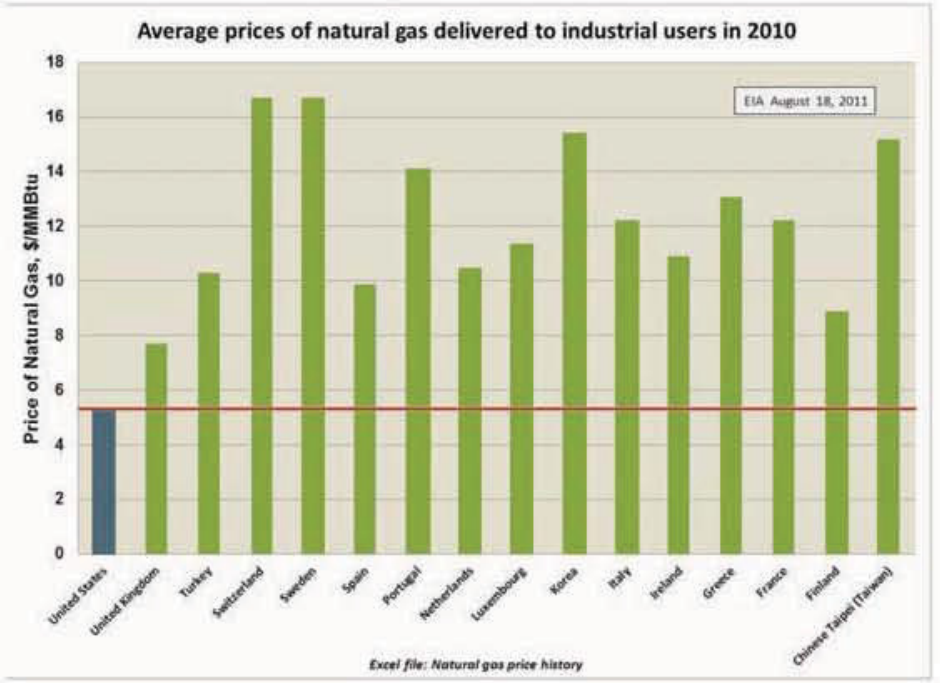
attempt has been made to address that factor in this assessment.

In summary, the EIA uncertainty band on natural gas prices in 2035 ranges from $\$ 5.35$ to $\$ 9.26 /$ MMBtu, based on potential positive and negative effects on shale gas extractions. The effect of early retirements on coal-fired plants due to EPA regulations on emissions could shift that band up to a high of $\$ 10.26 / \mathrm{MMBtu}$. Finally, increased exports of natural gas due to favorable price differentials between the US and other countries could shift the band up by another $\$ 2 / \mathrm{MMBtu}$. It is assumed that this would only affect the lower bound (from $\$ 5.35$ to $\$ 7.35 / \mathrm{MMBtu}$ ); an increase to a price in excess of $\$ 12 / \mathrm{MMBtu}$ would reduce the favorable differential that would spur increased 
exports. This leads to the revised potential range of natural gas prices of $\$ 7.35$ to $\$ 10.26 / \mathrm{MMBtu}$, delivered, as shown in the previous figure.

It should be noted that this analysis has not considered any effects of governmental actions to regulate or tax carbon dioxide emissions, i.e., establish an effective cost for carbon dioxide. Regulation would affect the ability to use natural gas technology in specific regions of the country, (e.g., similar to the attainment and non-attainment regions under the current Clean Air Act). Taxes would affect the effective price of the gas. There is too much uncertainty at the time of this writing to include these considerations on future viability of natural gas.

\section{Alternative Approaches to Assessing the Competition - Comparing Natural Gas to Oil Prices}

An alternative way of looking at projected natural gas prices is to compare the price of oil and the price of natural gas on an equivalent energy basis, i.e., projecting the price of natural gas based on the projected price of oil using a developed rationale for the ratio. Historically, this ratio has been roughly 10:1. EIA projections of oil and gas prices through 2035 are shown in the following.

These projections include a reference (best estimate) case and high and low projections around the reference case for variations in economic growth and for high and low projections in the price of oil. The projections for oil and gas prices and oil-to-gas price ratio for the variations in economic growth considered by EIA are shown, as well as similar data for the variations in oil prices.

The reference case predicts that the oil-to-natural gas price ratio that has traditionally been near 10 , but has risen recently as high as 40, will settle a little above 15 . The variations in the projected ratio due to changes in economic growth are not large.

The variations in projected oil prices from the reference case through 2035 are large; over $+\$ 50 / \mathrm{BBL}$. The projections of natural gas prices for that case do not vary significantly from the reference case. Accordingly, there are wide swings in potential oil-to-gas price ratios through 2035; leveling out between 6 and 27 depending on the scenario.

The highest price projected for natural gas is $\$ 7.5 / \mathrm{MMBtu}$ (Henry Hub), which would result in an oil-to-natural gas price ratio of $\sim 17$ in 2035 for the reference oil price $\$ 125 / \mathrm{BBL}$. In our prior analyses, we have shown that pressures on natural gas pricing due to increased usage for electricity production, increased exports and factors affecting the availability, and extraction of shale gas could increase the price in 2035 to the $\$ 10 / \mathrm{MMBtu}$ range. This would reduce the ratio to 12.5 for the reference oil price, closer to the traditional ratio of 10 .

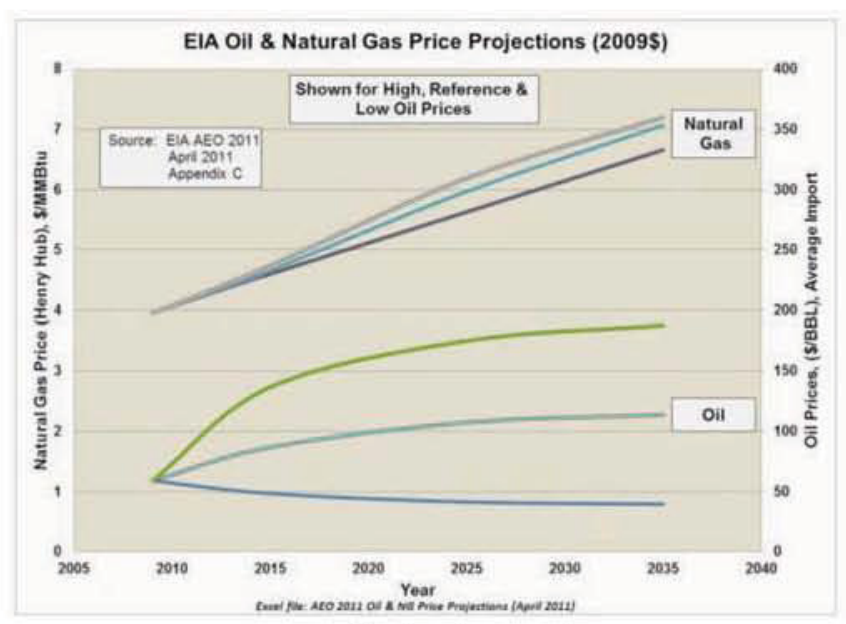

EIA Projections of Oil and Natural Gas Prices projections for variations in oil prices

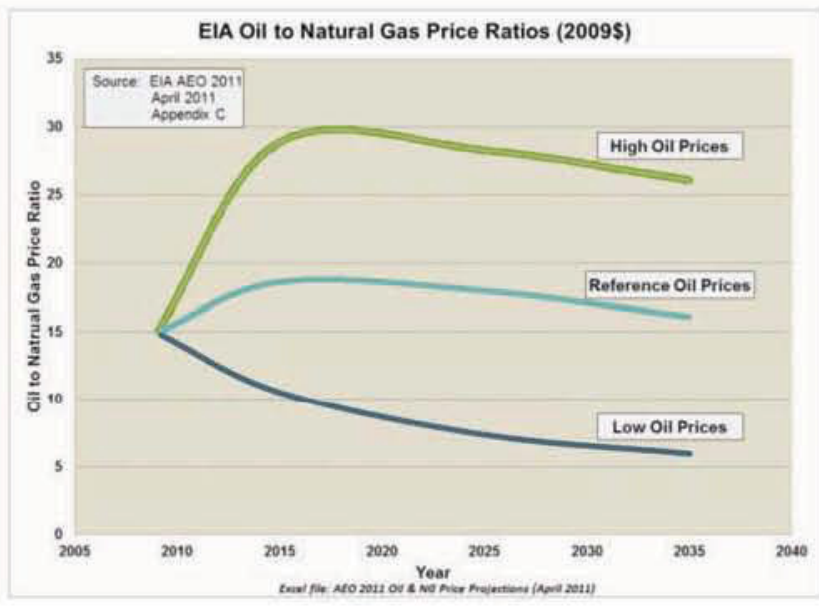

Oil to Natural Gas Price Ratios using for variations in oil prices

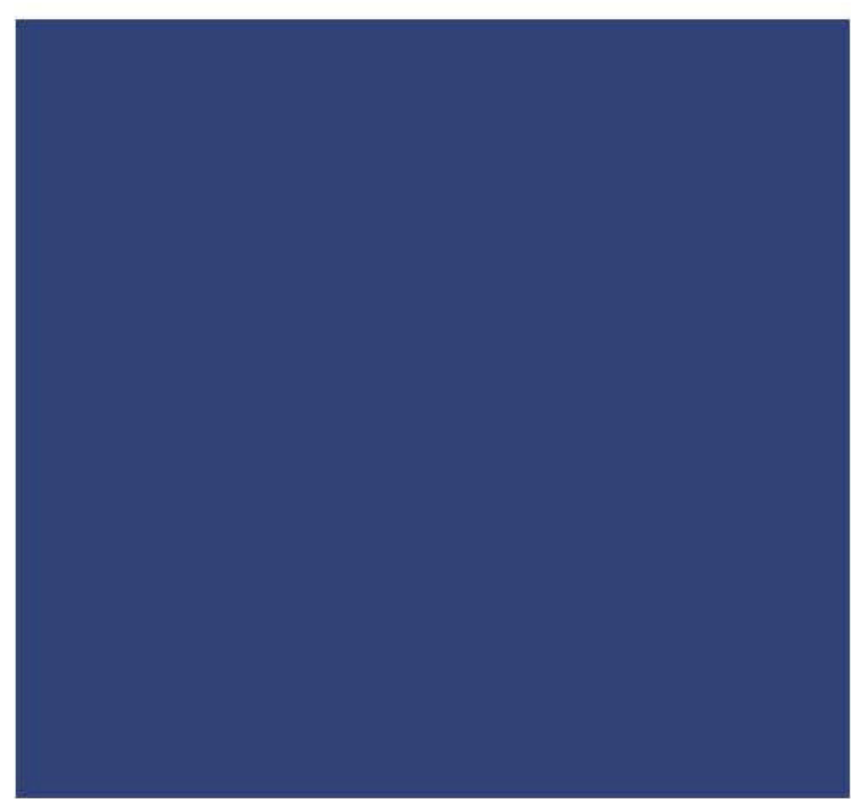


Other factors that could increase natural gas prices over the longer term include:

- Increased production by the chemical processing industries in the U.S. using higher quantities of natural gas feedstock. The high oil-to-gas price ratio improves the competitiveness of U.S. production compared with foreign companies whose price of feedstock is tied to the oil price, either because the feedstock is an oil derivative or the natural gas price is indexed to the oil price.

- Reduced shale gas production because of low natural gas prices. Shifts away from drilling for natural gas to drilling for oil have already been observed due to reduced profit margins for the latter.

- Increasing costs for transport of the natural gas from areas where it is plentiful to end users, (e.g., from Texas into the Midwest. New pipelines will be required increasing the cost of transport.

Consequently, as before, a projected upper-bound price for natural gas into the $\$ 10 / \mathrm{MMBtu}$ range in the 2035 timeframe appears reasonable.

\section{PRELIMINARY ECONOMICS FOR HTGRS COMPARED TO THE COMPETITION}

The following figures summarize the results of preliminary economic analyses for the evaluations of proxy industrial applications previously described in the market assessment. These results are based on best available information regarding the estimated all-in costs including overnight cost, financing costs, operating costs, maintenance costs and decommissioning costs. Discounted cash flow analyses have been utilized on a consistent basis using an HTGR plant with a reactor outlet temperature of $750^{\circ} \mathrm{C}$ and a Rankine cycle energy conversion plant. The results are compared to the projected range of delivered natural gas costs in 2035 as discussed above.

\section{Co-generation of Steam and Electricity for Industrial Processes}

The HTGR is competitive with natural gas technologies applied in co-generation of steam and electricity generation for delivered natural gas prices in the range of $\$ 6$ to $7 / \mathrm{MMBtu}$. Delivered natural gas prices in the U.S. to industrial users averaged $-\$ 5.5 / \mathrm{MMBtu}$ in 2010 . The projected range of delivered natural gas prices in -2035 suggests that the HTGR will be readily competitive.

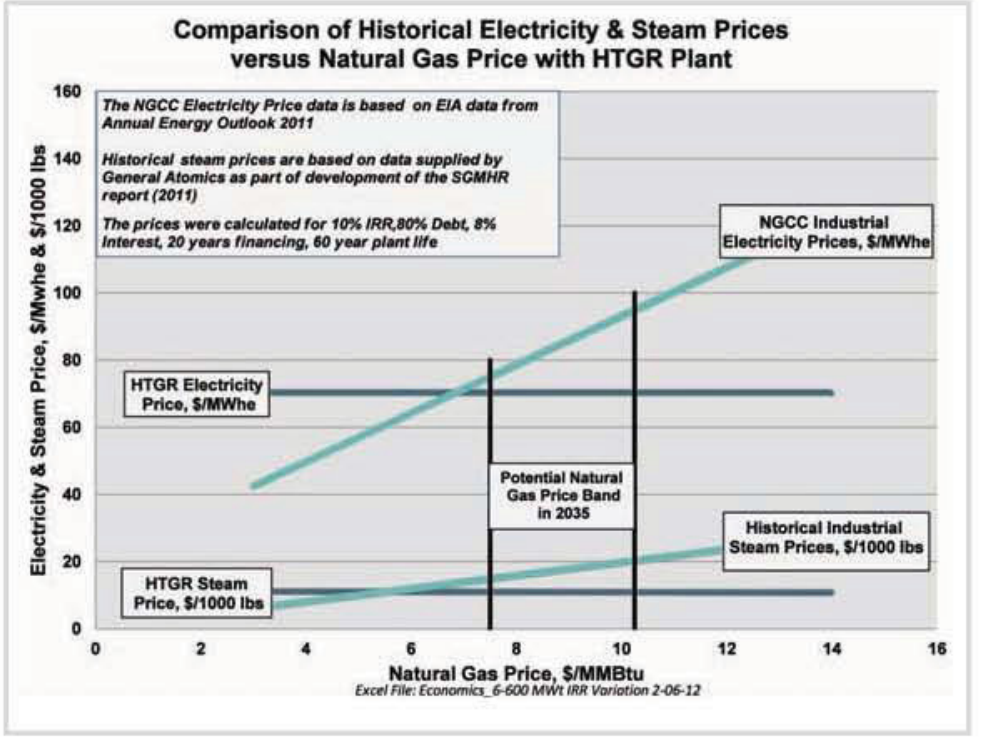

Note: A \$1O/MT tax on $\mathrm{CO}_{2}$ emissions is equivalent to an increase of $\$ 0.50 / \mathrm{MMBtu}$ Natural gas price. 


\section{Oil Sands Operations}

The results for the oil sands show that the current prices for energy in the oil sands, (i.e., $-\$ 6 / \mathrm{MMBtu}$ for natural gas energy supply with no $\mathrm{CO}_{2}$ charge), are significantly lower than that projected for the HTGR central energy supply facility; about $\$ 12.5 / \mathrm{MMBtu}$. However, for the projected natural gas price band in $\sim 2035$ (mid-way in the projected deployment of the HTGR technology cited previously) of $\$ 7.50 / \mathrm{MMBtu}$ to $\$ 10.25 / \mathrm{MMBtu}$, the HTGR facility becomes more competitive. Additionally, the HTGR becomes even more competitive if regulation or a tax on $\mathrm{CO}_{2}$ emissions is imposed and/or there are reductions in the availability of the natural gas supply. A $\$ 120 /$ ton tax on $\mathrm{CO}_{2}$ would be required to make the HTGR competitive at current delivered natural gas prices ( $\$ 5 / \mathrm{MMBtu})$. However, as shown, a $\$ 40 /$ ton tax would be sufficient to make the HTGR technology competitive for a natural gas price of $\sim \$ 8 / \mathrm{MMBtu}$. Accordingly, the HTGR technology becomes much more economically attractive depending on the actual price and the effects of carbon tax or regulation in the oil sands market.

\section{Electricity Generation}

The economic results for base load electric power generation show a cost of $\sim \$ 82 / \mathrm{MW}$-hr. Comparing this with an advanced natural gas-combined cycle plant with carbon capture and storage/sequestration suggests that the HTGR could be competitive for delivered natural gas prices greater than about $\$ 5.6 / \mathrm{MMB}$.
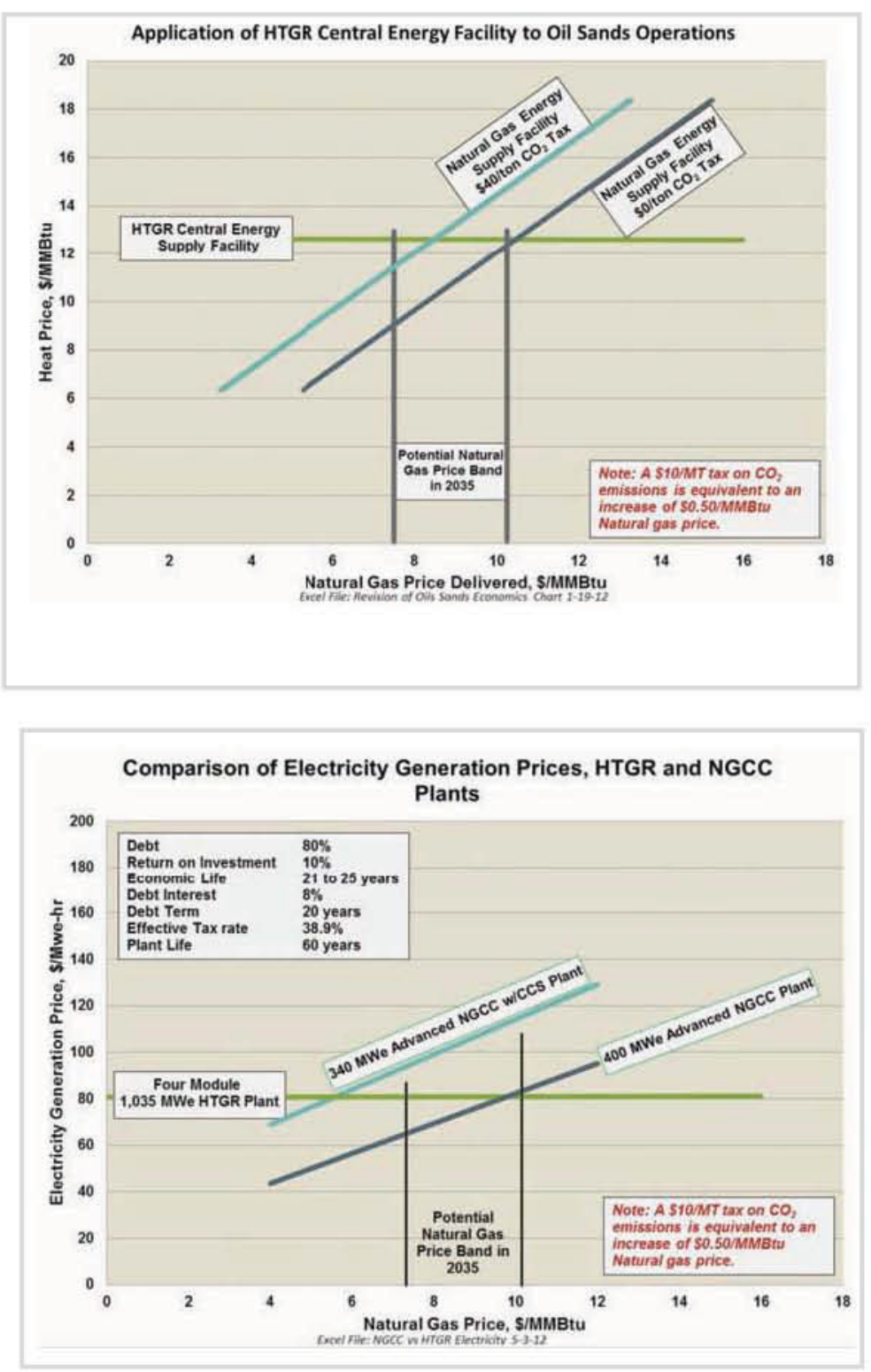
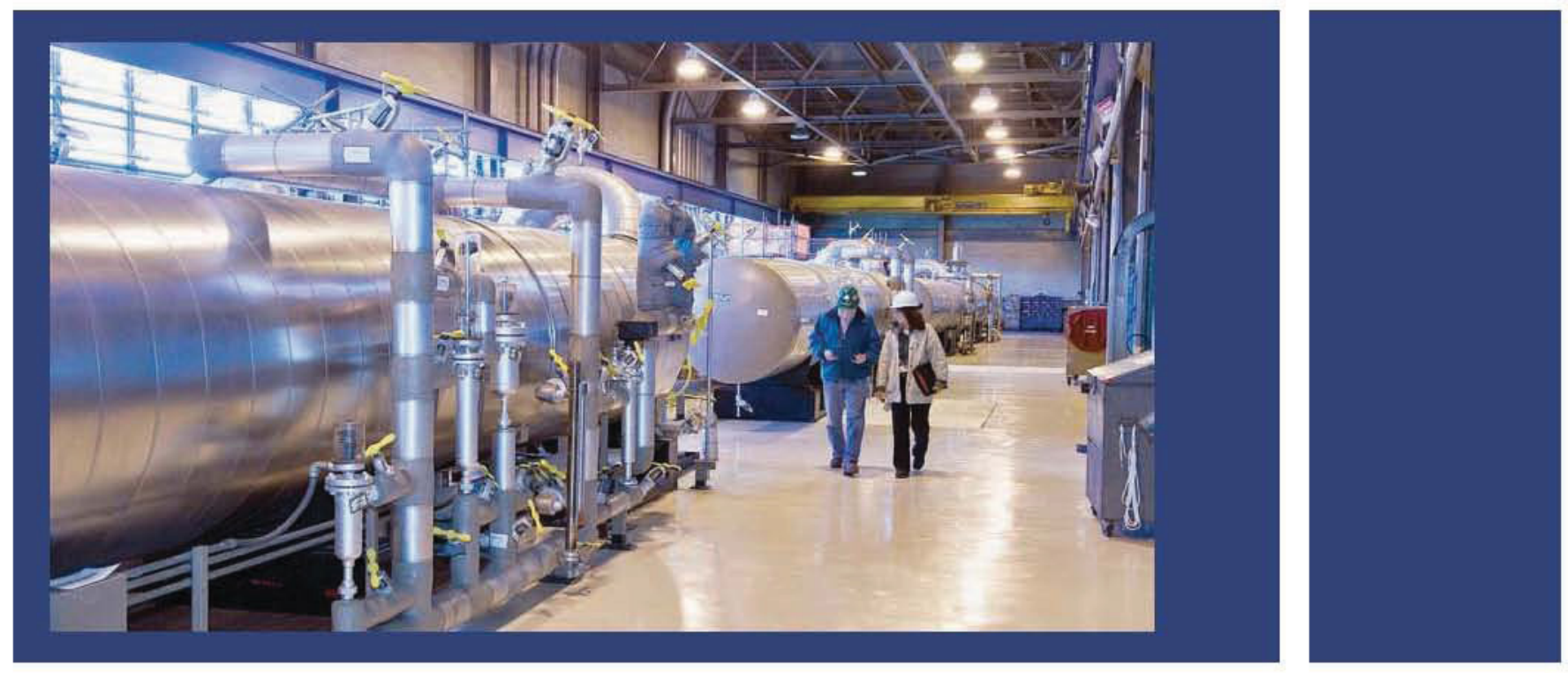


\section{Hydrogen Production}

Two variations in applying the HTGR technology to hydrogen production have been evaluated. The first is to substitute high temperature energy from the HTGR for the burning of natural gas in conventional natural gas steam methane reforming processes. As shown, the HTGR is competitive with steam methane reforming for a natural gas price of $-\$ 6.5 /$ MMBtu. This approach only eliminates about $15 \%$ of the $\mathrm{CO}_{2}$ emissions from the conventional steam methane reforming process; accordingly, the price of hydrogen produced by either of these methods would be affected by any cost imposed on these emissions.

A non- $\mathrm{CO}_{2}$ emission alternative to steam methane reforming is to use high temperature steam electrolysis (HTSE) to generate hydrogen and oxygen using the HTGR to supply high temperature heat and electricity. As shown, this approach would be competitive with conventional steam methane reforming for a natural gas price of $\sim \$ 12 / \mathrm{MMBtu}^{\circ}$ or a $\mathrm{CO}_{2} \operatorname{cost}$ of $-\$ 70 /$ ton. The HTSE process is in an early stage of commercialization; the hydrogen prices for this process shown are judged to be conservative.
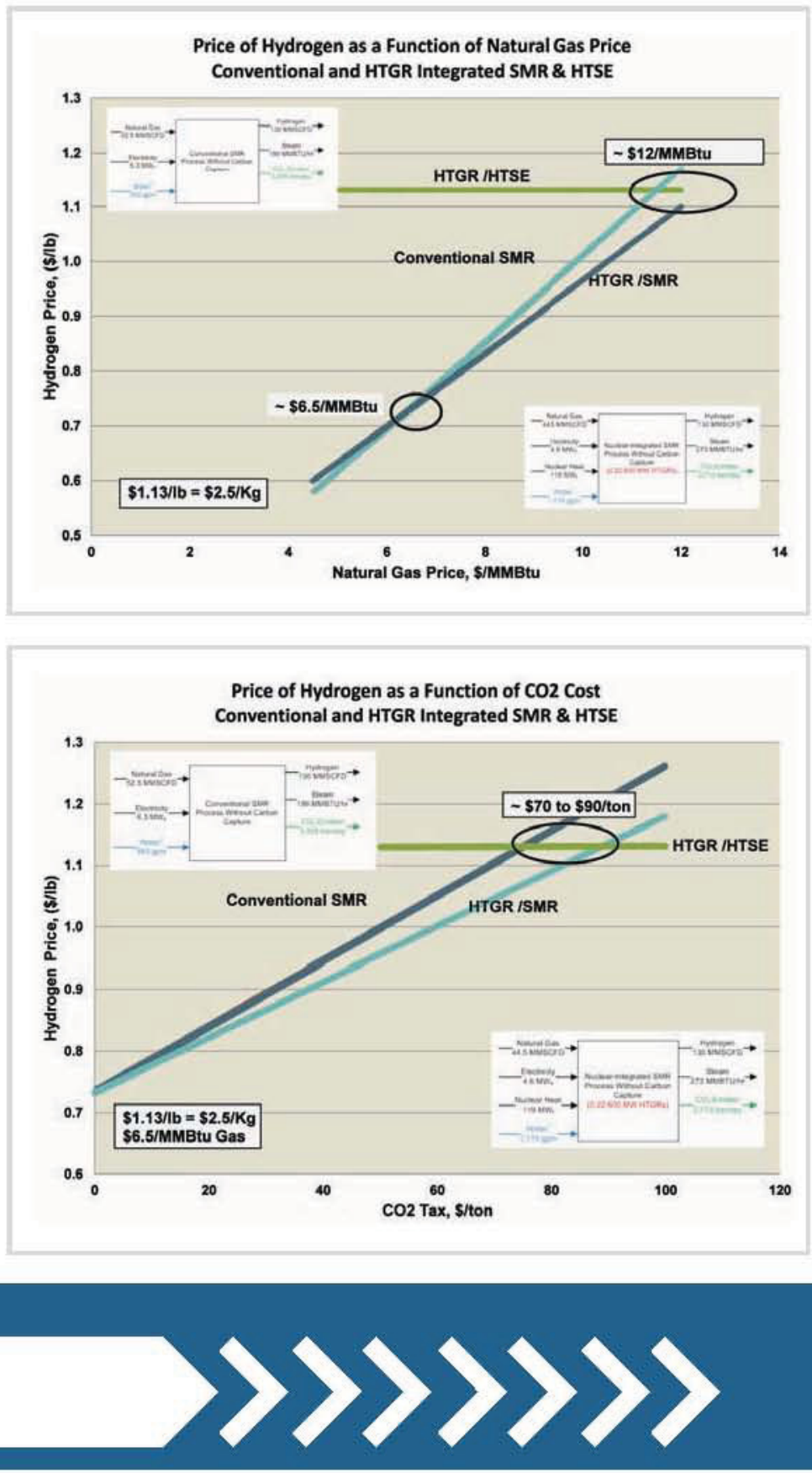


\section{Carbon Conversion to Synthetic Transportation Fuels and Chemical Feedstock}

The following figures show that coal-to-liquids and natural-gas-to-liquids synthetic production of diesel fuel integrating HTGR and HTSE technology with conventional processes could be competitive with traditional petroleum refining at current crude oil prices $(-\$ 80 / \mathrm{bbl}$ at the time of this writing) and in the range predicted by EIA in the 2023 to 2035 timeframe; (e.g., $-\$ 60-\$ 200 /$ bbl $).^{17}$

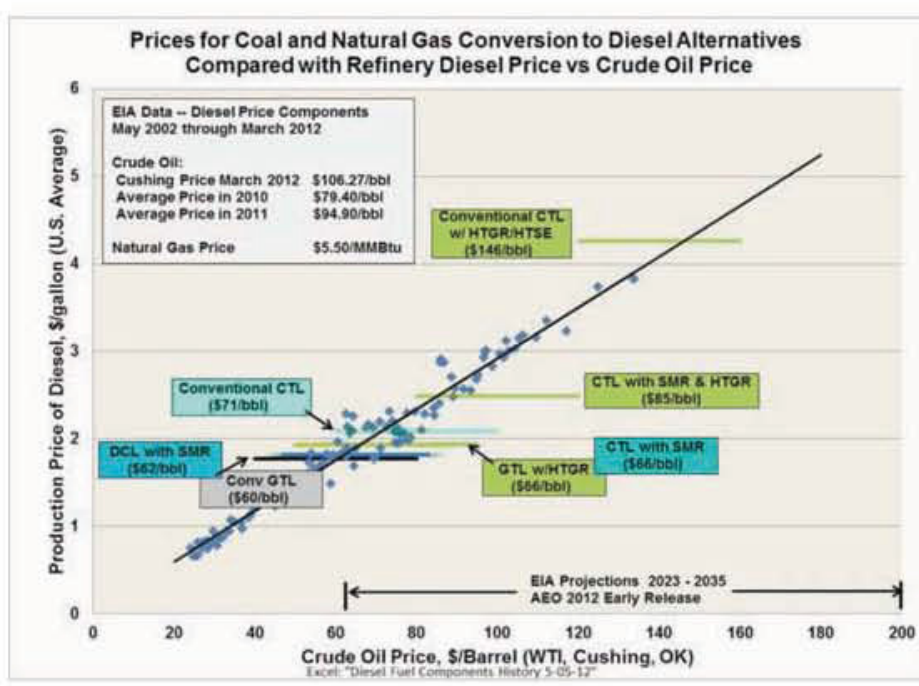

Oil prices in the Reference case rise steadily: the full $A E O 2012$ will include a wide range of oil prices

annual average price of light low suifur (LLS) crude oil real 2010 dollars per barrel

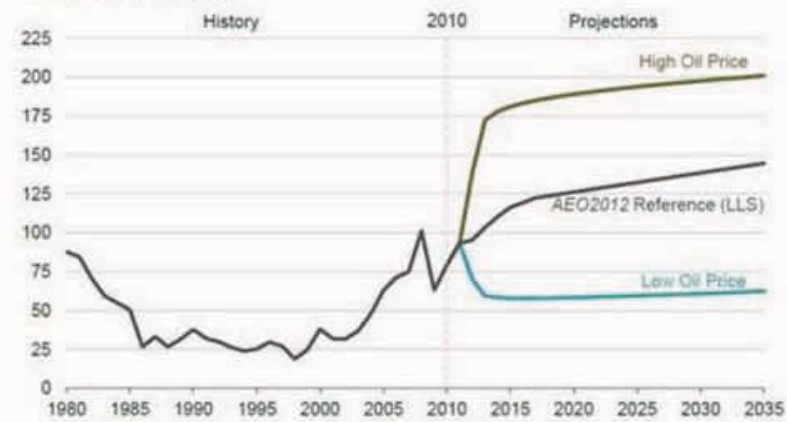

Socice EM Avival Energy Oubbot 2012 Early Alebate

\section{BIBLIOGRAPHY}

17. CTL - Coal to Liquids producing diesel, naphtha and LPG

SMR - Steam Methane Reforming hydrogen production that can be integrated with HTGR technology

GTL - Natural gas to liquids producing diesel, naphtha and LPG

DCL - Direct coal liquefaction using SMR that can be integrated with HTGR technology

\section{REFERENCES}

a. INL, Integration of High Temperature Gas-Cooled Reactors into Industrial Process Applications, INL/EXT-09-16942, Rev. 2, May 2010

b. INL, Integration of High Temperature Gas-Cooled Reactors into Selected Industrial Process Applications, INL/EXT-23008, Rev. O, August 2011

c. INL, NGNP Project Evaluation of Siting a HTGR Cogeneration Plant on an Operating Commercial Nuclear Power Plant, INL/EXT-11-23282, Rev. 1, October 2011

d. INL and Petroleum Technology Alliance Canada, NGNP Integration of High Temperature Gas-cooled Reactor Technology with Oil Sands Processes, INL/EXT-11-23239, Octaber 2011

e. Idaho National Laboratory, High Temperature Gas-Cooled Reactor Projected Markets and Preliminary Economics, INL/EXT-10-19037, Rev. 1, August 201l.

f. TEV-988. INL, 2011, "Sensitivity of HTGR Heat and Power Production to Reactor Qutlet Temperature, Economic Analysis" Idaho National Laboratory, TEV-988, Rev. 1, June 30,2011

g. TEV-672, "HTGR-Integrated Coal and Gas to Liquids Production Analysis", Idaho National Laboratory, September 2011

h. DOE/EIA Annual Energy Outlook 2011 (April 2Oll)

i. NYMEX:NG 1-18-12

j. NERA Economic Consulting, Proposed CATR + MACT, prepared for the American Coalition for Clean Coal Electricity, May 2011 (DRAFT)

$k$ energyBIZ, 1-17-12 


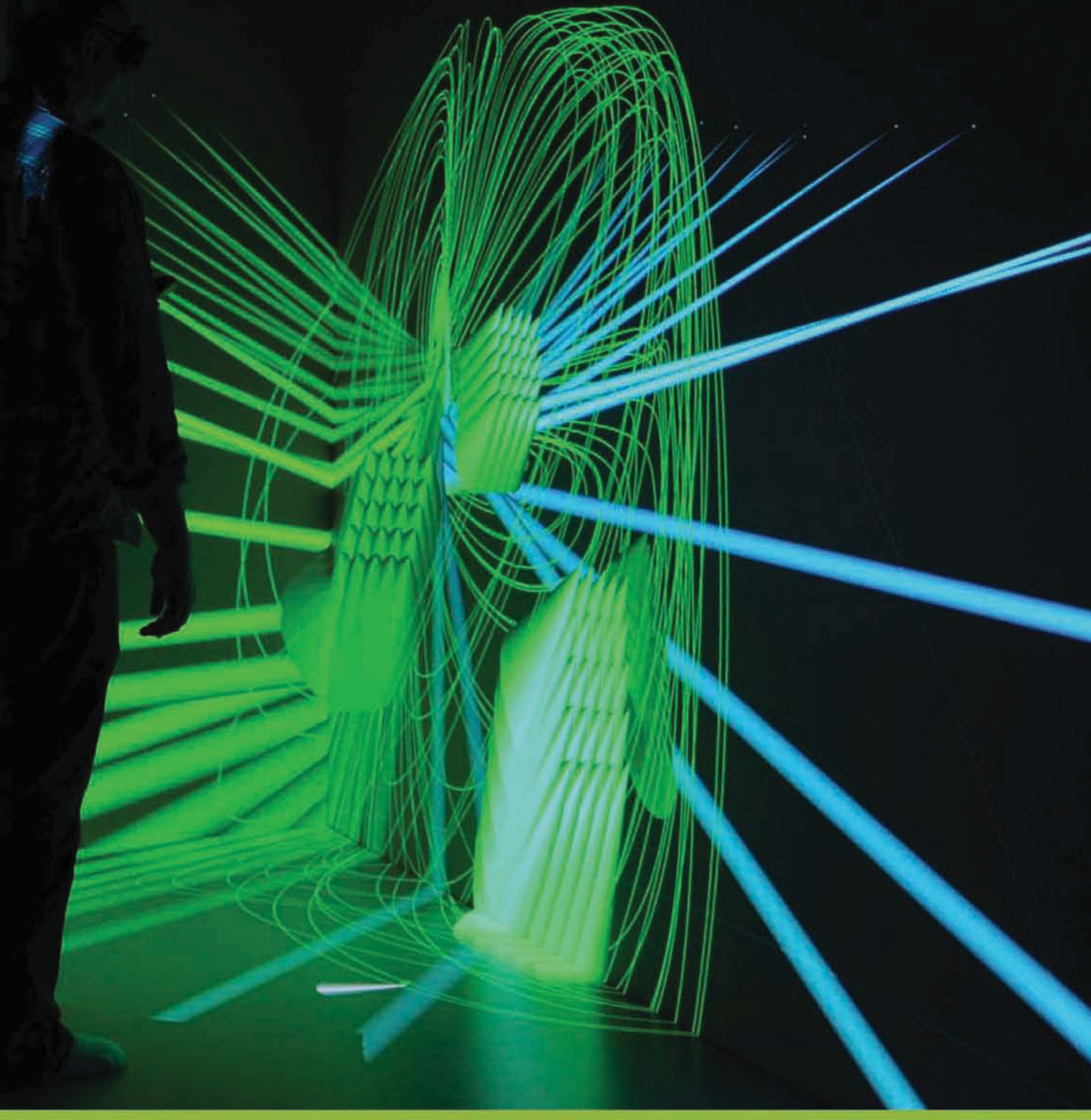

\section{\APPENDIX B}

NENP hausiny

DEVELOPMENT VENTURE 


\section{APPENDIX B}

Development Venture

This Appendix provides a summary of a possible approach to executing the Development Venture. Specifics regarding breakdown of scope, the investment framework, the interaction and interdependency with the Deployment Project, investment risk and the character of intellectual property are the subjects for detailed discussions with interested equity investors.

\section{PURPOSES}

The purposes of the Development Venture include providing the technical foundation and regulatory framework for commercialization of modular high temperature gas-cooled reactor (HTGR) technology and supporting licensing and construction of the initial fleet of modular HTGRs for commercial applications. These initial applications are anticipated to be co-generated electricity and process heat as steam, or solely the generation of electricity.

The Development Venture is led by the Nuclear System Supplier (NSS) in collaboration with the prospective Owner entity (the Owner - possibly an Owner Consortium). The NSS will lead completion of technology development, perform design development through final design, support preparation of the license application by the Owner and/or Operator, and ensure that the necessary infrastructure development (e.g., vendors to supply nuclear fuel; structural materials for the reactor core; major equipment) occurs as necessary to support construction of multiple modular HTGRs. This Appendix summarizes the constraints, the business model, the investment opportunities and the anticipated means of achieving a continuing return on investment as the initial fleet of HTGR modules is deployed in a merchant marketplace. The costs estimated to be incurred are one-time costs that support licensing and construction of the initial fleet of plants using HTGR technology.

\section{STATUS OF HTGR TECHNOLOGY COMMERCIALIZATION}

Over the past several years, technology development, pre-conceptual design, design trade-off studies and pre-application licensing activities have been funded in major part by the U.S. Department of Energy (DOE) and managed by the Idaho National Laboratory through the NGNP Project. The NGNP Project builds upon the considerable work performed by industry on HTGR technology in the past. Recently, because of budget restrictions and revised priorities, DOE has reduced support for the NGNP Project.

Essential to commercialization of HTGR technology is completion of government funded R\&D (particularly ongoing irradiation tests) supporting qualification of production fuel and core materials necessary to achieve design completion and licensing of HTGR technology. Additionally, particular attention must be applied to continuing the pre-application activities with the US Nuclear Regulatory Commission (NRC) that have to date primarily focused on the most important policy and high-level technical issues necessary to develop a regulatory framework to support licensing of HTGR technology. Pre-application activities have been led to date by the Idaho National Laboratory NGNP Project. Transition to Entergy Nuclear as the industry license applicant is anticipated for the fourth quarter of 2012. Completing technology development and pursuing a regulatory framework both require continuing progress on a reference design.

The Development Venture is directed toward completing the development activities, continuing licensing pre-application activities with NRC, completing design of the overall plant through preliminary design and safety systems through final design, and supporting preparation of a construction permit application or combined construction and operating license application. The Development Venture activities will transition to a Deployment Project that will complete detailed design and construct and operate the initial plant using the HTGR technology, including the commercial demonstration module that will be used to complete first-of-a-kind testing in support of licensing.

\section{ANTICIPATED EQUITY INVESTORS}

The Development Venture requires a large equity investment for which a return on investment will not be realized for on the order of 25 years. Further, it is expected that a combined equity position of 50 to $60 \%$ of the estimated cost of the Deployment Venture will be required to attract necessary debt financing. 


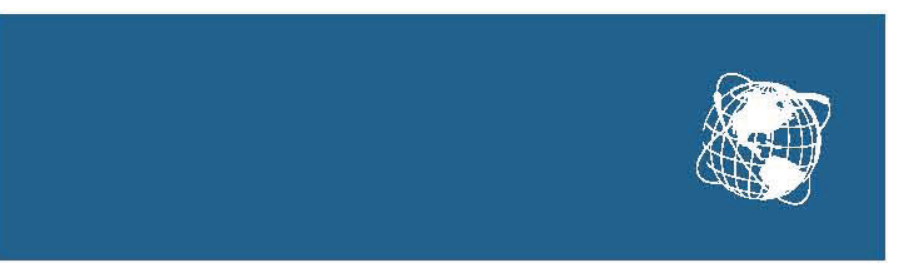

As a consequence, the anticipated major equity investors will have a long-term view of the importance of commercialization and deployment of HTGR technology in the global marketplace with the goals of achieving reduced volatility of energy and feedstock prices, increased energy security, and important reductions in emissions for large industrial applications, as well as for electric power generation. Anticipated equity investors include:

- Nuclear system suppliers

- Vendors of major equipment and materials

- End-users

- Governments

- Private visionary/Angel

\section{SCOPE, ESTIMATED COST AND SCHEDULE FOR THE HTGR DEVELOPMENT VENTURE}

The scope of the Development Venture includes the following:

- Complete technology development - The R\&D activities including: a) qualification of the nuclear fuel; b) qualification and codification of reactor structural materials; c) qualification and codification of high temperature metals and composite materials; and d) development and validation of contemporary analytical methods. ${ }^{18}$

- Complete design - Design for a prismatic reactor concept and a Rankine cycle steam plant for co-generation is required to prepare an application for a construction permit or a combined construction and operating license, and to support long lead development and procurement of materials, equipment and components for constructing a modular HTGR plant.

- Establish the licensing and regulatory requirements - A licensing plan and an iterative process of collaboratively working with the NRC is required to establish a regulatory framework including the safety performance and design requirements for modular HTGRs.

- Develop the supply infrastructure - Establish a supply chain for nuclear fuel, graphite and other core structural materials, and other major equipment to support construction and operation of the initial modular HTGR plant.

- Develop and perform first-of-a-kind inspections and testing - It is anticipated that one-time testing, inspection and modification requirements may be imposed on the demonstration module. This may require FOAK instrumentation and design features.

The overall cost of the Development Venture is summarized as follows. These are one-time costs. This overall estimate is considered to be conservatively high and is based on detailed estimates for these activities developed over the period 2006-2011 by design teams led by AREVA, Westinghouse/PBMR, and General Atomics, and by the Idaho National Laboratory.

\begin{tabular}{|l|r|}
\hline R\&D & $\$ 316 M^{19}$ \\
Conceptual and Preliminary Design & $\$ 280 \mathrm{MM}$ \\
Final Design & $\$ 200 \mathrm{MM}$ \\
Licensing thru COLA Preparation & $\$ 165 \mathrm{MM}$ \\
Equipment and Infrastructure Development & $\$ 648 \mathrm{MM}$ \\
Inspections, Testing and Modifications (FOAK initial operations) & $\$ 75 \mathrm{MM}$ \\
\hline Total & $\$ 1684 \mathrm{MM}$ \\
\hline
\end{tabular}

A notional schedule follows, including the Development Venture and the Deployment Project (see Appendix C), that culminates in completing the first-of-a-kind HTGR technology plant. 


\begin{tabular}{l}
\hline Activity \\
\hline HTGR Development \& Deployment \\
\hline Research \& Development \\
\hline Licensing \\
\hline Pre-Application Review \\
\hline ESP Application Submittal \& Review \\
\hline ESP /ssued \\
\hline COLA Prep, submittal \& NRC Review \\
\hline COL Issued \\
\hline ITAACs Resolved \\
\hline Core Load Approved \\
\hline Resolve Operating Provisions \\
\hline First Module Deployment (600 MWt) \\
\hline Design \\
\hline Procurement \\
\hline Site Preparation \\
\hline Construction \& Startup Testing \\
\hline First Module Operational \\
\hline Initial Operating Period \\
\hline Second Module Deployment \\
\hline Third Module Deployment \\
\hline Fourth Module Deployment \\
\hline HTGR Plant Fully Operational \\
\hline
\end{tabular}

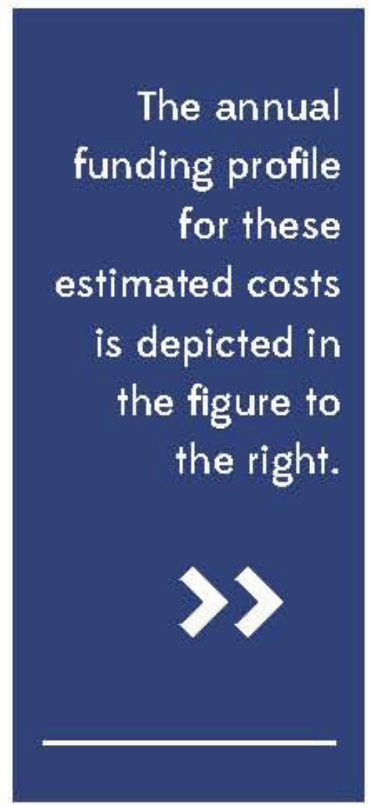

HTGR Commercialization -- Owners Required Funding for First Module Annual and Accumulative Funding Required

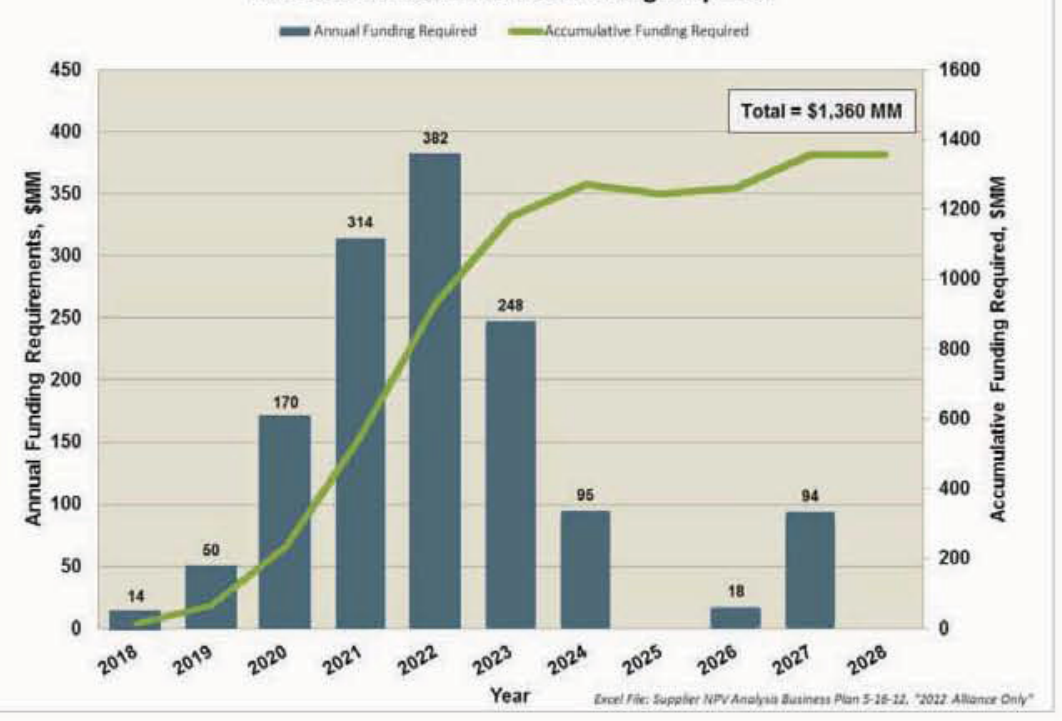

\section{INVESTING IN THE HTGR DEVELOPMENT VENTURE}

The Development Venture is a necessary part of commercializing HTGR technology. The scope of activities for this venture must be completed to provide the energy industry the option to choose HTGR technology for production of high temperature process heat and electricity for industrial applications. The potential market for HTGR technology and evaluation of preliminary economics are summarized in the body of the business plan and described in more detail in Appendix A.

As described in the following, economic evaluations of the overall commercialization and deployment enterprise indicate that penetration of less than $5 \%$ of the conservatively targeted market will create considerable investor value. 


\section{DEVELOPMENT VENTURE BUSINESS MODEL}

The Development Venture is led by the NSS with the collaboration of the Owner. It is anticipated that several equity investors will make the long-term investments as necessary over the timeframe for the venture, with return on investment gained from ownership of the intellectual property for modular HTGR technology and its commercialization. Return on investment is anticipated from modular HTGR plant sales, ongoing nuclear fuel sales and provision of services for the operation, refueling and maintenance of the plants. For purposes of the analyses summarized in the following, the NSS and its venture partners are not assumed to be equity holders with the Owner or in an Owner Consortium in the Deployment Project.

Fundamental to the Development Venture concept is that return on investment will be delayed for an extended period to support plant sales at overnight prices that allow the Owner to realize energy prices to the energy end-user that are competitive with alternative energy sources and comparable to the nth-of-a-kind energy prices that will apply to plants sold beyond the initial offerings. Collocated end-user industrial process facility owners are anticipated to execute multiple-year purchase energy agreements that provide a firm foundation for equity investment in the Development Venture as well as the deployment projects within which the plants are constructed and operated (see Appendix C for description of the initial Deployment Project).

\section{INVESTMENT OPPORTUNITIES}

The Development Venture includes one-time costs of $\$ 1684 \mathrm{MM}$. For the reference case wherein DOE funds completion of $R \& D(\$ 316 M M)$, return on investment is expected to approach an internal rate of return of $-12 \%$ from sales which will be realized after the initial six modular HTGR plants (24 modules) are completed and operating (by about 2037). Additionally, starting with the first plant in about 2028 , the profit on fuel sales and plant services is estimated to run about $\$ 4 M M$ annually for each plant. The investment covers two stages as follows:

First Stage (\$18MM over - fwo years) - a continuation of selected activities that have been ongoing or activities that need to be initiated in the short term including obtaining stakeholder support and financing to initiate the design activity.

1. Assumes continued funding by DOE in FY2O13 and FY 2014 for the R\&D activities on a schedule consistent with that for the Development Venture.

2. Continue pre-application activities with the NRC to develop a regulatory framework for the licensing of HTGR technology.

3. Complete conceptual and initiate preliminary design activities. Detailed design schedules will be developed supporting the R\&D and licensing progress.

4. Select a site for the first HTGR plant, including the demonstration module. Initiate site assessment and evaluation.

Second Stage ( $\$ 1666 \mathrm{MM}$ over $\sim 13$ years) - development, design, licensing and equipment specification activities supporting the initial modular HTGR plant design, licensing and construction. Major activities will include the following:

1. Completing scheduled R\&D activities and acceptance of results into the regulatory framework via Topical Reports, codification in consensus standards or other accepted methods.

2. Completing the reference plant design to support completion of an application for a construction permit or a combined construction and operation license

3. Preparing an application for a construction permit or combined construction and operating license for selected site for the reference design

4. Developing equipment specifications and the supply chain for major procurements including nuclear fuel, graphite and other core structural materials, major equipment and materials. 


\section{EVALUATION OF ALTERNATIVE INVESTMENT SCENARIOS}

Several investment scenarios have been evaluated that consider variations on the extent of government funding contributing to the completion of the Development Venture. These analyses examine the relative viability of investment scenarios recognizing the extended time until a return on the investment may be realized by the Development Venture equity investors.

Assumptions:

- An upper bound energy price of $\$ 10$ per MMBtu to provide competitive pricing with alternative sources of energy. This energy price establishes the overnight price that can be charged for a modular HTGR plant, and acceptable ranges of O\&M and other costs. This assumes no price for carbon. Price for carbon will allow the $\$ 10$ per MMBtu upper bound to increase.

- Within the $\$ 10$ per MMBtu energy price, about $\$ 2$ per MMBtu for nuclear fuel and $\$ 0.30$ per MMBtu for operations, refueling and maintenance services are established as representative based on anticipated TRISO nuclear fuel costs and historical service costs

- An overnight price of $\$ 2,200$ per $\mathrm{KW}$ th $(\$ 5,200 \mathrm{KW}$ ) for the plant rating for a reference four module HTGR plant, each module rated at $600 \mathrm{MW} / \mathrm{th}$

- Construction of the first module commences in 2020 with initial operations at the beginning of 2025 . The second module is operational within three years with six months to each of the third and fourth modules

- Construction of two plants with four modules in each plant begins every year following completion of the initial operation of the demonstration plant

Four cases were considered as follows:

- U.S. Government (DOE) funds and completes required R\&D

- All external/private funding (No US Government cost share)

- $80 \%$ U.S. Government cost share of all Development Venture costs

- $50 \%$ U.S. Government cost share of all Development Venture costs

The result is shown graphically in the following figures. The first case, above, is chosen as the reference for discussion elsewhere within this Appendix based on a judgmental balance between return on investment and expected U.S.
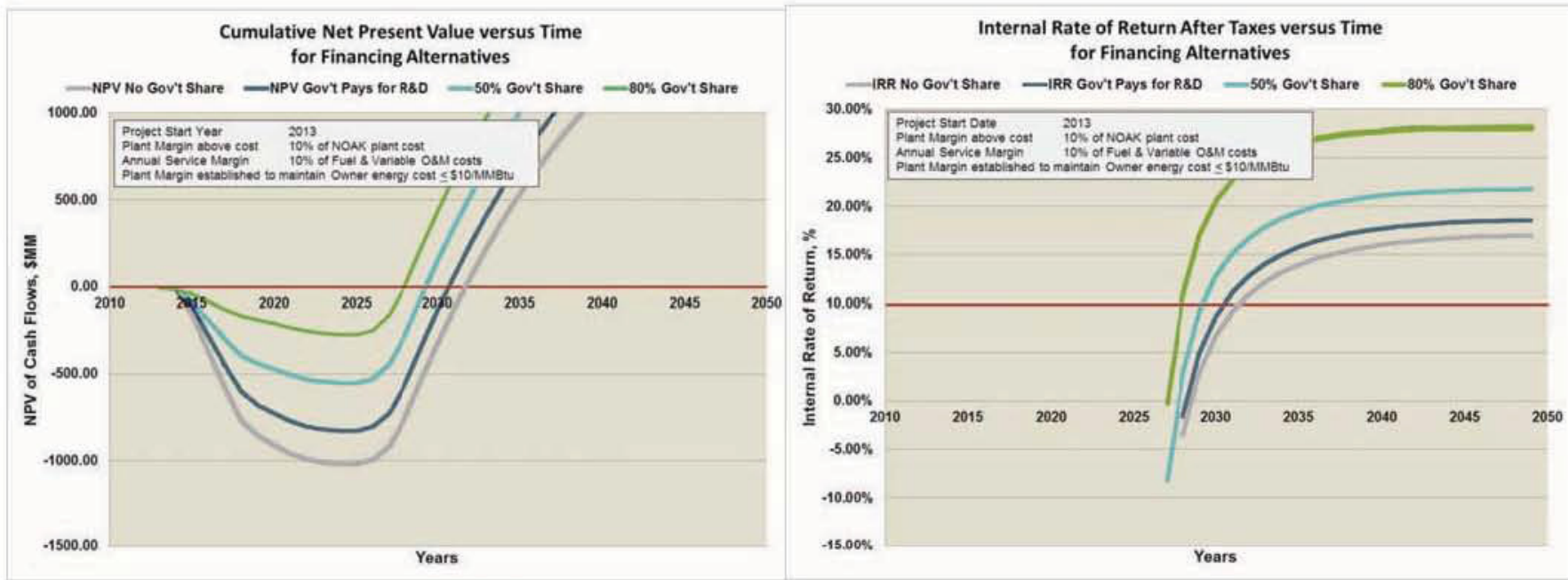


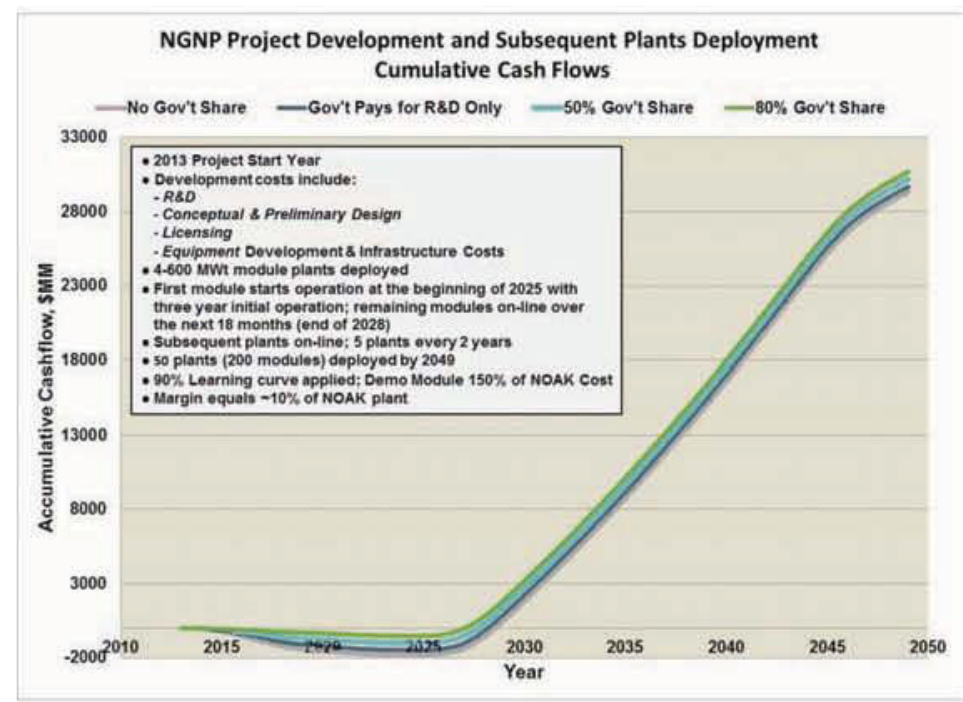

The preceding is based on deployment of fifty 4-600 MW/th module plants with the procurement and construction of the demonstration module starting in 2018. All 50 plants are on line by 2049 .

Government funding and support.

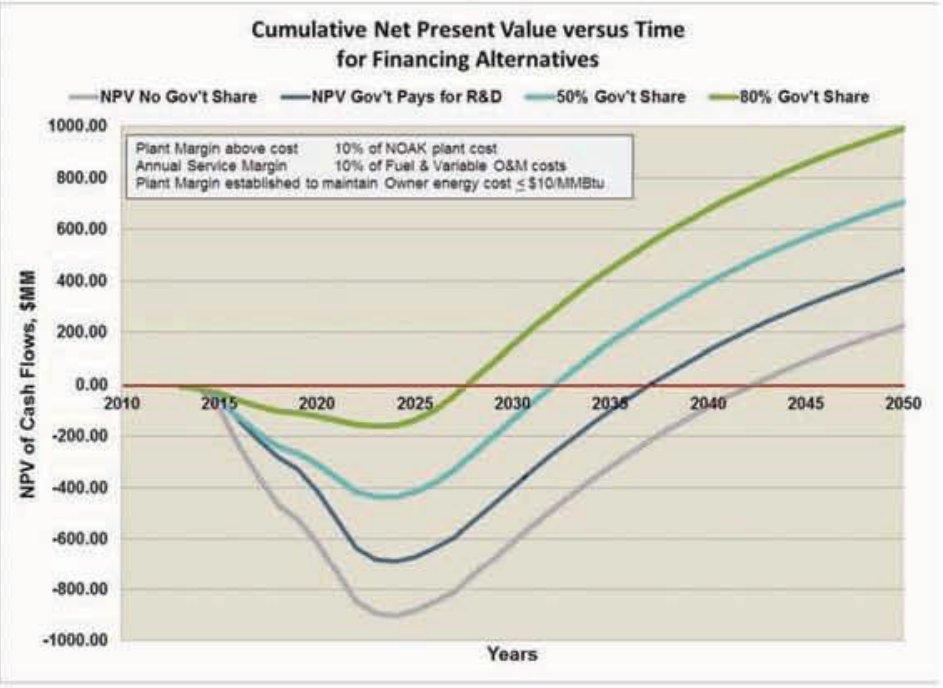

The cumulative net present value figure at left changes the assumed build rate, resulting in 12 fourmodule plants in 2050 instead of 50 as in the prior module. The impact is to delay a positive net present value of the investments from 2031 to 2046 , in the case of no government investment. In the event of $50 \%$ government cost share, achieving positive net present value is delayed from 2029 to 2032 .

\section{INVESTMENT RISK AND RISK MITIGATION}

The primary Development Venture investment risks and possible risk mitigation activities are summarized in the following. The specific characterization of risk and its mitigation will depend on the specific equity investment arrangement.

The Alliance is convinced that HTGR technology is unique in its ability to fill a very large energy niche in the U.S. and worldwide, and that the benefits that will accrue from its deployment warrant investment even in light of the substantial residual risks. The Alliance believes that the level of risk will diminish to normal acceptable project levels with time and appropriate investment.

\section{Inadequate Equity Investment and Debt Financing}

\section{Risk mitigation:}

- Aggressive activities to attract necessary equity investment to ensure the success of the Development Venture. The two-stage investment approach supports investors gaining confidence in venture by direct participation in planning activities during First Stage.

- Project management will proceed with development activities only when applicable equity investment and debt financing have been confirmed, including all criteria for exiting the agreements for performance inadequacies or unfulfilled conditions. This is anticipated to require the venture to be phased with value creating activities providing the criteria for proceeding. 
Residual risk (high):

- Development Venture requires large equity investment for which a return will not be realized for over two decades. It is anticipated that the position will need to be about $50-60 \%$ to attract the necessary debt financing.

- In consideration of the costs involved, there are multiple opportunities for differences in expectations being encountered in equity investment and debt financing. Of particular concern are unilateral actions by equity investors and debt holders that may be resolved over time, but are disruptive to the orderly progression of the project.

- Unanticipated Development Venture cost increases.

2. Untimely Technology Development Activities

Risk mitigation:

- Create technology development plan with starting point of INL/EXT-11-23907, NGNP Project - 2011 Status and Path Forward, dated December 2011. The technology development plan should be based on the design and construction needs and schedule for the Deployment Project.

- Develop a formal partnership with the Department of Energy (DOE) for continuation and completion of R\&D activities in the areas of fuel qualification, materials codification and analytical methods verification.

- Continue ongoing interaction with Congress, DOE, and the Office of Management and Budget to ensure adequate funding for completion of technology development activities.

- Develop a contingency plan in the event federal funding is not adequate to support the technology development plan. (Cost estimates for the Development Venture include the estimated cost of completing the R\&D activities irrespective of federal funding.)

Residual risk (Currently high due to uncertainty in federal funding; technical risk due to unforeseen technology hurdles is low):

\section{Untimely Design and Design Support Activities}

Risk mitigation:

Aggressive project management, planning, schedule adherence and open item management.

Residual risk (low):

Future business opportunities incentivize timely support for resolution of design issues.

\section{Untimely Licensing Activities}

This includes ongoing pre-licensing application interactions with the NRC directed toward developing the regulatory technical requirements and review processes applicable to HTGR technology. The development of this licensing framework for the HTGR may require important changes to existing regulatory requirements that have evolved primarily for light water reactor technology. The framework is needed for eventual certification of the HTGR reactor design as well as site licensing requirements for collocation of the reactor with industrial processes. Progress on and the credibility of this developing framework are essential to beginning detailed design work with an acceptable business risk.

The figure below illustrates the effect of a two-year licensing delay on the time to achieve a positive net present value assuming the baseline is to start one new four-module plant every two years. The net effect is the positive NPV is reached at 2029 with a build rate of two plants starting per year, 2032 for one plant every two years, and 2035 with a two-year licensing delay of the demonstrator and a build rate of one plant every two years. Therefore, licensing is one of the key risks to assure mitigation and government support. Each of these results assuming an overall government cost share of $50 \%$.

\section{Risk mitigation:}

- Next Generation Nuclear Plant Licensing Strategy - a report to Congress, August 2008. This report, prepared jointly by NRC and DOE, summarizes the preferred licensing development approach and necessary NRC resources. 

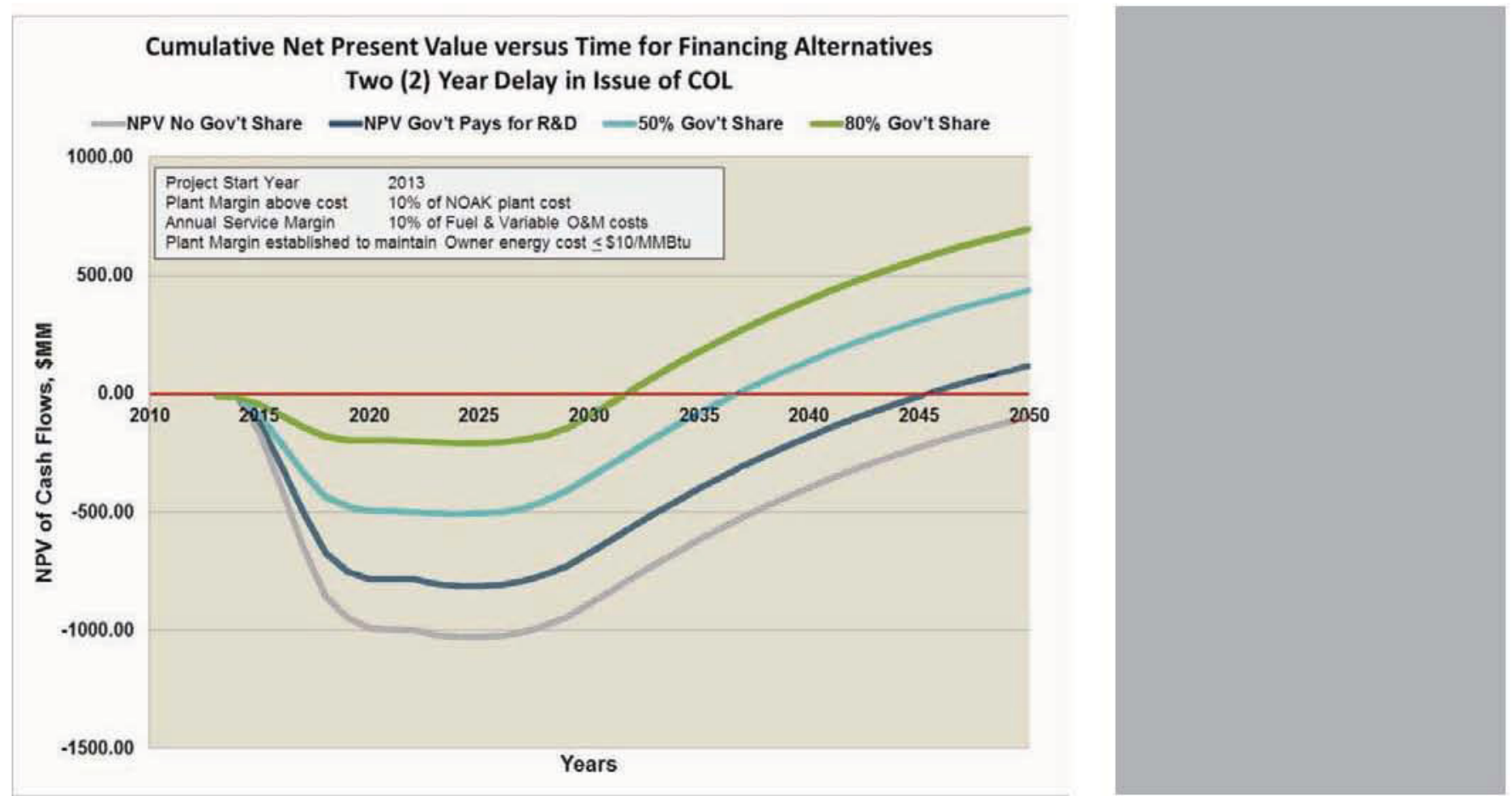

- PLN-3202, NGNP Licensing Plan, June 26, 2009. A detailed implementation plan prepared by INL for DOE that is in effect until January 1, 2013.

- Entergy Licensing Plan for HTGRs - in preparation (a fall 2012 draft is anticipated). This plan, effective January 1, 2013, will describe the licensing implementation approach through completion of pre-application activities, preparation of the construction permit and operating license applications and executing the license for the initial HTGR plant. This licensing plan will be completed under the Development Venture. This plan will enable preparation of design and licensing documents and determine the licensing application requirements. This should include planned topicals $5^{20}$ and other design documents intended to be submitted to NRC prior to submittal of the construction permit application or COL application. This plan will provide input to the technology development plan for necessary R\&D activities.

- Aggressive pre-application activities with NRC to adapt/augment current regulatory requirements for applicability to HTGR technology since 2009 are continuing.

- NSS in collaboration with the license applicant will prepare a detailed plan for development of the detailed design report that is used in lieu of a Design Certification for input to preparation of the construction permit application of the COL application.

- The reference design is at the conceptual design stage that limits the ability to identify specific design and licensing needs of a more mature design. Selected design studies will be performed as part of the pre-application licensing activities.

Residual risk (high):

- NRC finalization of the requirements framework will not be fully complete until an operating license is issued.

- There is exposure to public hearings during the licensing and permitting process. 
5. Untimely Development of Supply Infrastructure

Risk mitigation:

- Early interaction with potential suppliers of nuclear fuel, major equipment and other materials not readily available in commercial market, particularly if required to be purchased or dedicated for use in safety-related applications.

- Obtain commitment from suppliers regarding investments to develop supply chain. This may include development of supply chain strategies, partnerships and plans.

Residual risk (low):

The NSS and its suppliers are incentivized by future business opportunities to timely development.

6. Unanticipated Technical Issues with Startup and Initial Operations

\section{Risk mitigation:}

- Ensuring that necessary technical resources for resolution are timely available.

- Minimize unanticipated issues via detailed project reviews, FMEA analysis, detailed training, etc.

Residual risk (high for demonstration module; low for subsequent modules):

\section{VALUE CREATION ACTIVITIES FOR THE DEVELOPMENT VENTURE}

During development of the detailed plan and schedule for execution of the Development Venture in the First Stage, value creating activities will be identified that provide an objective means of measuring progress and assessing reduction in investment risk (the largest risks are described in the body of the business plan). The detailed plan and schedule will provide overall milestones, major deliverables, the investment schedule and logic ties between the elements of the Development Venture as well as with the Deployment Project. It is presumed that pre-established progress milestones will be required to be completed before additional investment is made. A complementary plan will be developed during the First Stage that describes the form and substance of intellectual property that is created during the Development Venture and how that intellectual property is apportioned among the initial and subsequent equity investors.
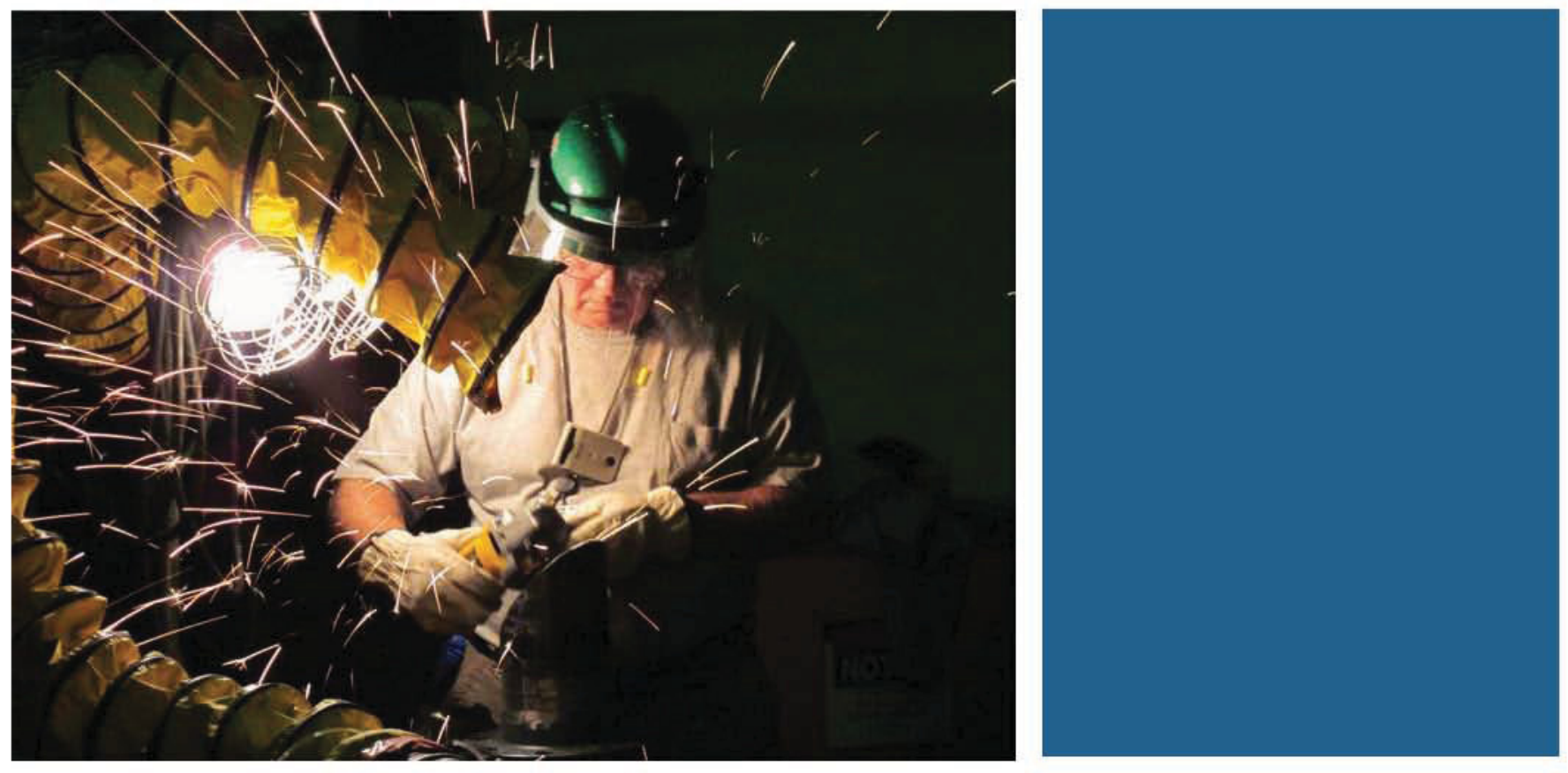
BIBLIOGRAPHY

18. Current status and path forward are summarized in INL/EXT-11-23907, NGNP Projecf-2011 Status and Path Forward, dated December 2011; see also Investment Risk and Risk Mitigation section

19. Assumes that government funds the R\&D activities in fiscal years 2013 and 2014 at about $\$ 87 M M$ total; the R\&D estimated cost is the balance for 2015 through the planned completion in 2026. Federal funding for R\&D through 2013 and 2014 is about $\$ 404 \mathrm{MM}$

20. Topical denotes a subject specific submittal for approval to the NRC that provides a basis for review (e.g., fuel licensing basis) 


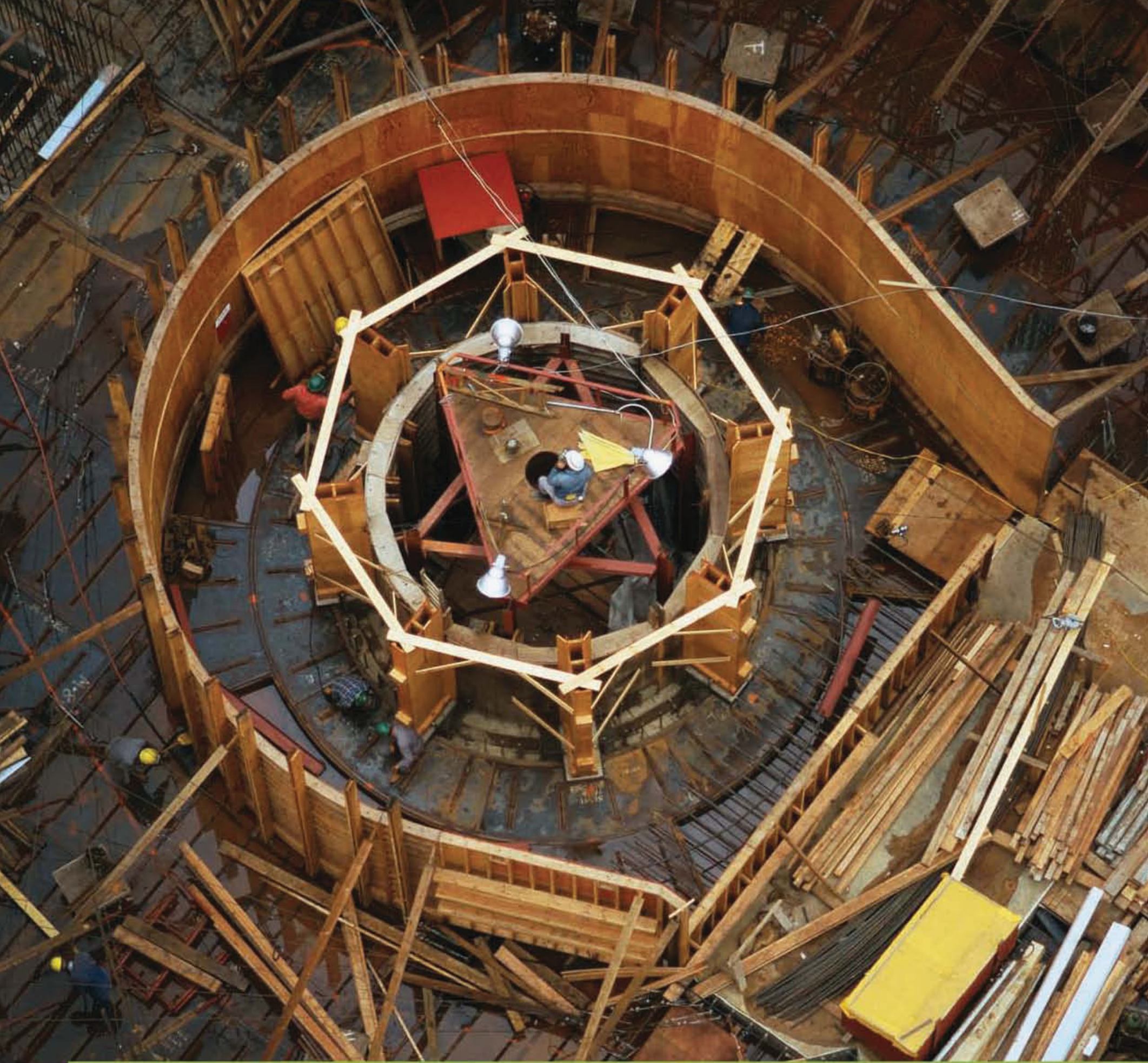

\APPENDIX C 


\section{APPENDIX C}

Deployment Project

This Appendix provides a summary of a possible approach to executing the Deployment Project. General information of interest to equity and debt investors is provided for a proxy scope. Specifics regarding breakdown of scope, the investment framework, the interaction and interdependency with the Development Venture, investment risk and the character of the intellectual property are the subjects for detailed discussion with interested equity investors.

\section{PURPOSE}

The purpose of the Deployment Project is to construct and operate the first-of-a-kind (FOAK) commercial plant based on high temperature gas-cooled reactor (HTGR) technology. This FOAK plant will build on the experience gained in previous HTGR technology demonstrations and establish the economic viability of this technology to co-generate high temperature process heat and electricity for use in industrial applications.

The Deployment Project is led by the Owner entity in collaboration with the Nuclear System Supplier (NSS) and the Architect-Engineer/Constructor $(\mathrm{AE} / \mathrm{C})$. The Owner will complete site-specific design, obtain a construction permit and operating license (or alternatively a combined construction and operating license), construct, start up and initially operate the first-of-a-kind (FOAK) plant comprised of a demonstration HTGR module, additional modules and the associated energy conversion and transport systems necessary for a viable business case. This Appendix summarizes the constraints, the possible business model, the investment opportunities and the anticipated means of achieving a continuing return on investment.

\section{ANTICIPATED EQUITY INVESTORS}

The Deployment Project requires a large equity investment for which a return will be realized upon completion and operation of the HTGR multi-module plant. The return is anticipated to be in the form of a share of operating revenues and ownership of intellectual property on construction and licensing of the FOAK plant that will continue to provide returns for further build-out of the HTGR plant fleet. It is expected that a combined equity position of at least $20 \%(80 / 20$ Debt to Equity) of the estimated cost of the Deployment Project plus a commitment for execution of a purchase energy agreement by the end-user(s) will be required to attract necessary debt financing. Anticipated equity investors include:

- Energy producers (utilities; power-generating companies; independent power/energy producers)

- Municipalities

- Architect/Engineers

- End-users

- Venture capital

\section{DEPLOYMENT PROJECT SCOPE AND ESTIMATED COST}

The scope of the Deployment Project includes the following:

- Complete site-specific design - The design for the standard HTGR prismatic reactor and a reference Rankine cycle steam plant will be completed under the Development Venture (see Appendix B). The Deployment Project will complete the site-specific design to support procurement and construction activities for a reference-four HTGR module plant. Site-specific design will include any application-specific adaptation of the Rankine cycle steam plant 


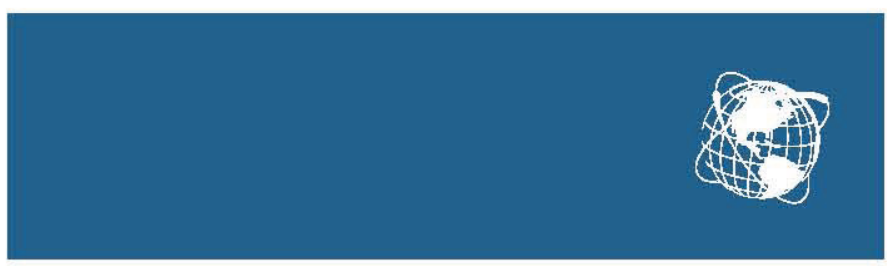

and site-specific support systems and configuration (e.g., condenser cooling system; waste management systems; energy transport systems from the HTGR plant to the industrial end-user; interconnections with the commercial electric grid; utility connections).

- Obtain site NRC license and regulatory permits - An NRC construction permit or combined construction and operating license $(\mathrm{COL})$ will be required to begin substantial on-site construction activities as specified in NRC regulation. This will include major site-specific evaluations of hazards and development of the emergency plan for collocated facilities. A subsequent operating license or $\mathrm{COL}$ will be required to load fuel, start up and operate the reactor facility.

- Construct First-of-a-Kind (FOAK) Plant - This includes constructing the demonstration module and associated energy conversion/transport plant followed by completing the remainder of the four-module plant.

- Perform initial operations - The reference concept for initial operations of the demonstration HTGR module includes supplying energy to the industrial application, providing electricity to industrial user and/or the grid, an initial refueling and first-of-a-kind testing and inspection. It is anticipated that these demonstration activities will require about three years. Construction and initial operations of the other HTGR modules will be as mutually established by the Owner and NRC. This reference concept ends at the completion of the warranty period for the multiple module plant.

The overall cost of the Deployment Project is summarized as follows. These are site-specific costs. All one-time costs are included in the Development Venture. This overall estimate is considered to be conservatively high and is based on detailed estimates developed over the period 2006-2011 by design teams led by AREVA, Westinghouse/PBMR, and General Atomics, and by the Idaho National Laboratory.

The overall cost estimate and initial revenues for the demonstration module portion of the Deployment Project are summarized as follows:

\begin{tabular}{|l|r|}
\hline Complete site-specific design & $\$ 100 \mathrm{MM}$ \\
Construction permit/license application/review & $\$ 65 \mathrm{MM}$ \\
Equipment procurement & $\$ 432 \mathrm{MM}$ \\
Construction & $\$ 625 \mathrm{MM}$ \\
Startup \& testing & $\$ 55 \mathrm{MM}$ \\
Initial operations (3 years) & $\$ 348 \mathrm{MM}$ \\
Revenue (initial 3 years) & $-\$ 265 \mathrm{MM}$ \\
\hline Total & $\$ 1,360 \mathrm{MM}$ \\
\hline
\end{tabular}

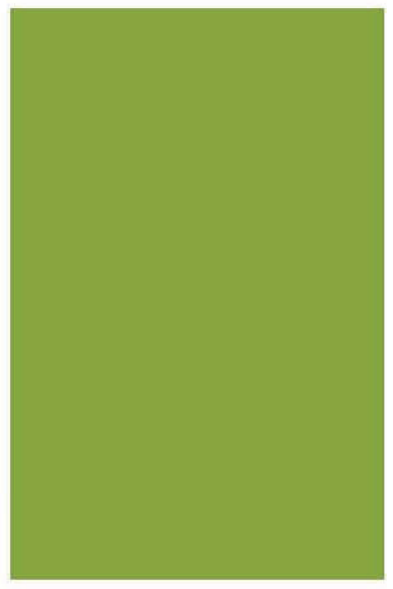


The total estimated cost for the reference four-module plant including the demonstration module is $\$ 4,250 \mathrm{MM}$ and is the all-in overnight capital cost in 2012 dollars. The $\$ 2,890 \mathrm{MM}$ estimated cost beyond the initial module and associated energy conversion/transport systems includes procurement, construction and startup costs. For cost-estimating purposes, it is assumed that the second module achieves initial operations within three years, with six months additional to each of the third and fourth modules.

The annual funding profile for these estimated costs is depicted in the following figures for the demonstration module and associated energy conversion/transport systems, alone, and separately for the entire FOAK multi-module plant (i.e., the cost for the demonstration module is included in the total cost for the FOAK plant).
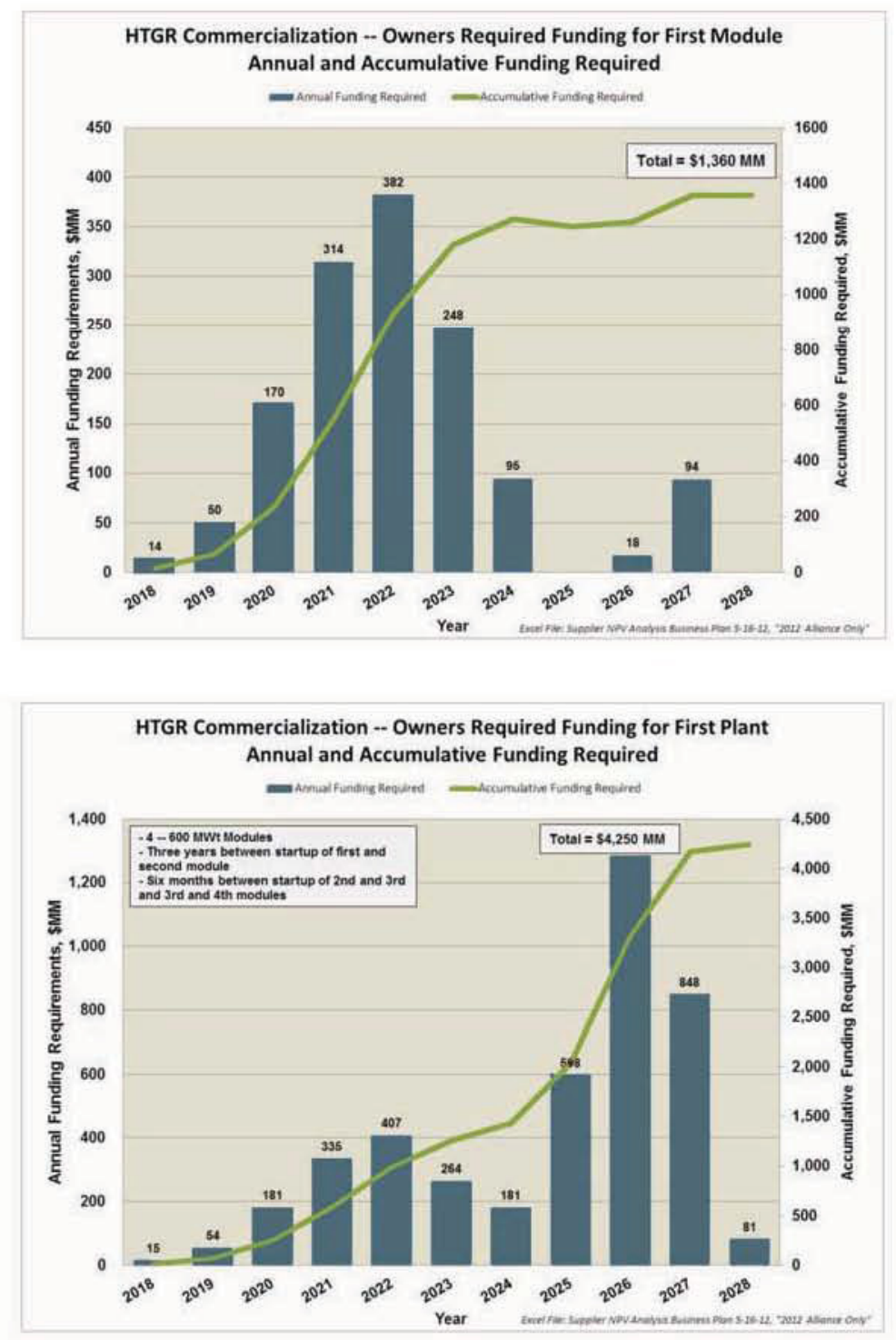


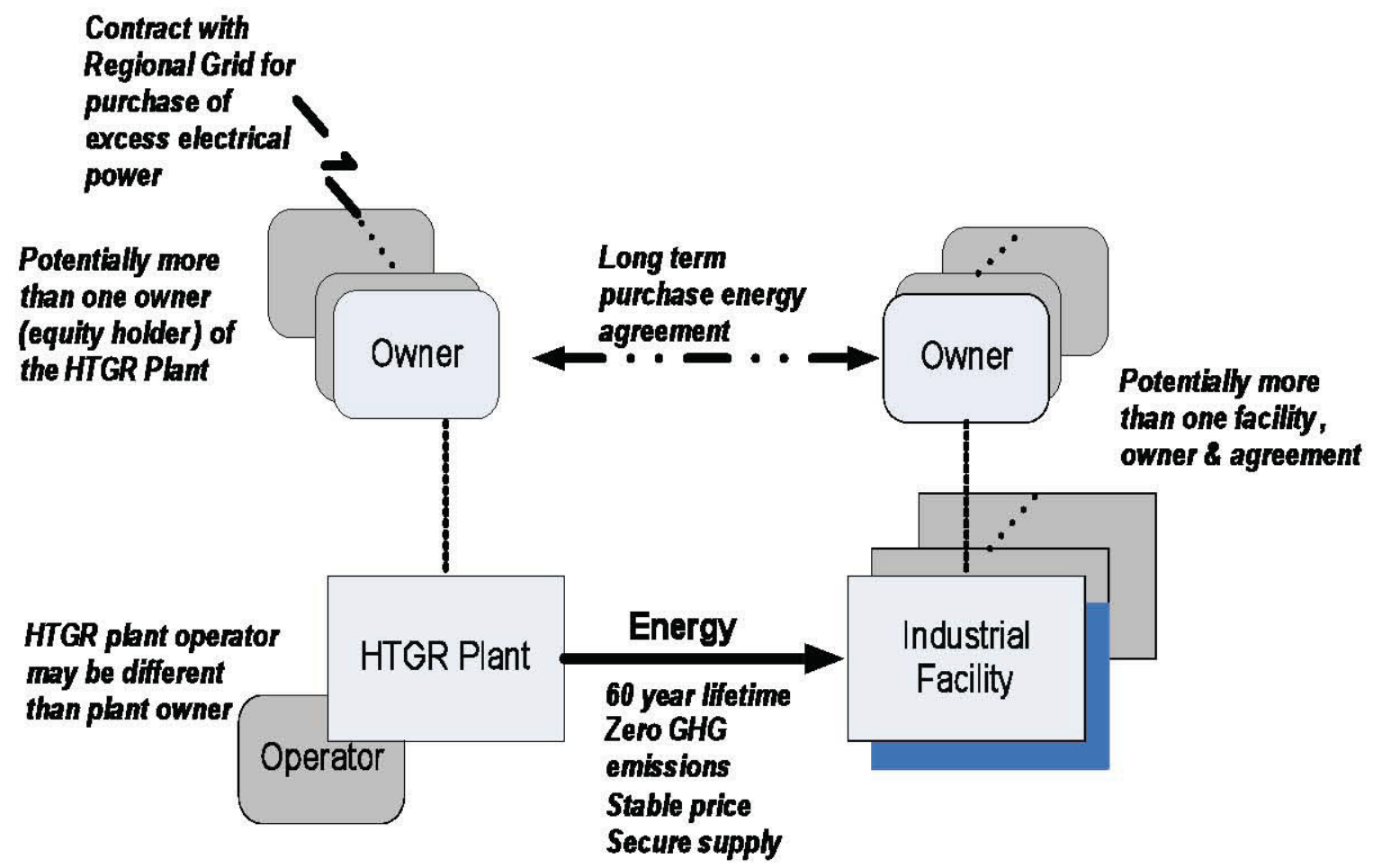

\section{DEVELOPMENT PROJECT BUSINESS MODEL}

Initial deployment via the FOAK plant will be undertaken through a venture that involves one or more entities taking an equity position as the Owner (or consortium of owners) for completing the site-specific design, licensing and constructing the FOAK plant that includes the demonstration module, additional modules, and the energy conversion and transport plant necessary to achieve a credible business case. The anticipated business model is as shown in the figure. The FOAK plant will provide the reference for subsequent deployment of multiple plants for the purpose of providing high temperature process heat and electricity for industrial use. Since the application of HTGR technology is targeted across multiple business sectors, the partnering and contractual arrangements to finance and deploy the follow-on plants could be expected to vary from the model shown. The follow-on plants are intended to use a standardized reactor module design with energy conversion/transport plant design variations as needed for the particular industrial applications.

The return on investment for the FOAK multi-module plant will be in the form of:

- Revenues from plant operations (direct energy sale and capacity support for peak availability)

- Royalties from intellectual property regarding technology deployment and construction techniques for next plant 


\section{INVESTMENT RISK AND RISK MITIGATION}

The primary Deployment Project investment risks and possible risk mitigation activities are summarized in the following. The specific characterization of risk and its mitigation will depend on the specific equity investment arrangement.

\section{Inadequate Equity Investment and Debt Financing}

Risk mitigation:

Project management will proceed with project activities only when applicable equity investment and debt financing have been confirmed, including all criteria for exiting the agreements for performance inadequacies or unfulfilled conditions. This is anticipated to require the project to be phased with value-creating activities providing the criteria for proceeding.

\section{Residual risk (high):}

In consideration of the costs involved, there are multiple opportunities for differences in expectations being encountered in equity investment and debt financing. Of particular concern are unilateral actions by equity investors and debt holders that may be resolved over time, but are disruptive to the orderly progression of the project.

\section{Untimely Design and Design Support Activities}

Risk mitigation:

Aggressive project management, planning, schedule adherence and open item management.

Residual risk (low):

The NSS is incentivized by future business opportunities to timely support resolution of design issues.

\section{Untimely Licensing Activities}

Risk mitigation:

Aggressive project management, planning, schedule adherence and open item management.

Residual risk (high):

Licensing activities typically require action by the NRC. Those activities requiring action in the public stakeholder environment have the potential to be delayed to ensure adequate stakeholder involvement.

\section{Untimely Procurement Activities}

Risk mitigation:

Aggressive project management, planning, schedule adherence and open item management. Selected presence of project management personnel at vendor sites for schedule-critical equipment will be utilized.

Residual risk (low):

The NSS and AE/C are incentivized by future business opportunities to timely support resolution of equipment specification, technical and schedule issues.

\section{Construction Performance and Quality Issues}

Risk mitigation:

Aggressive project management, planning, schedule adherence and open item management. Will utilize modular construction techniques, where practical, with intent to resolve technical and fabrication issues in the vendor's shop rather than at the construction site.

Residual risk (high):

Unproven use of modular construction techniques for the HTGR modular reactor.

\section{Unanticipated Technical Issues with Startup and Initial Operations}

Risk mitigation:

Ensuring that necessary technical resources for resolution are timely available. Minimize unanticipated issues via detailed project reviews, FMEA analysis, detailed training, etc.

Residual risk (high for demonstration module; low for subsequent modules): 


\section{STAKEHOLDER PARTNERING TO MANAGE RISKS}

The Deployment Project will require the stakeholder partners (e.g., Owner, Operator, equity investors, NSS and AE/C) to support the major project phases: 1) project initiation; 2) planning and procurement; 3) construction and performance testing; 4) start-up; 5) transfer to operations; 6) initial operations, testing and inspections necessary to fulfill commercial acceptance testing and licensing conditions; and 7) project close-out. The project will undergo detailed analysis for engineering constructability, licensing requirements and environmental impact as part of the initiation and planning phases. Supplemental expertise for project success may be required and include other skills that are not specifically identified above. These include, but are not limited to, such disciplines as project managers, expert engineering services, environmental and technical consultants, technical integrators and technologist.

The license applicant (Owner or Operator) will lead site and plant licensing and permitting with regulators and will coordinate with the other stakeholders for technical responses and information required to support licensing/permitting activities during the deployment project and into plant operations.

The NSS, Owner and Operator will work collaboratively on operational and technical support training programs and other safety and socialization requirements prior to final acceptance of the plant and in accordance with regulatory requirements for operations.

\section{VALUE CREATION ACTIVITIES FOR THE DEPLOYMENT PROJECT}

During development of the detailed plan and schedule for execution of the Deployment Project, value-creating activities will be identified that provide an objective means of measuring progress and assessing reduction in investment risk. The detailed plan and schedule will provide overall milestones, major deliverables, the investment schedule and logic ties between the elements of the Deployment Project as well as with the Development Venture. It is presumed that pre-established progress milestones will be required to be completed before additional investments are made. A complementary plan will be developed that describes the form and substance of intellectual property that is created and how that intellectual property is apportioned among the initial and subsequent equity investors.
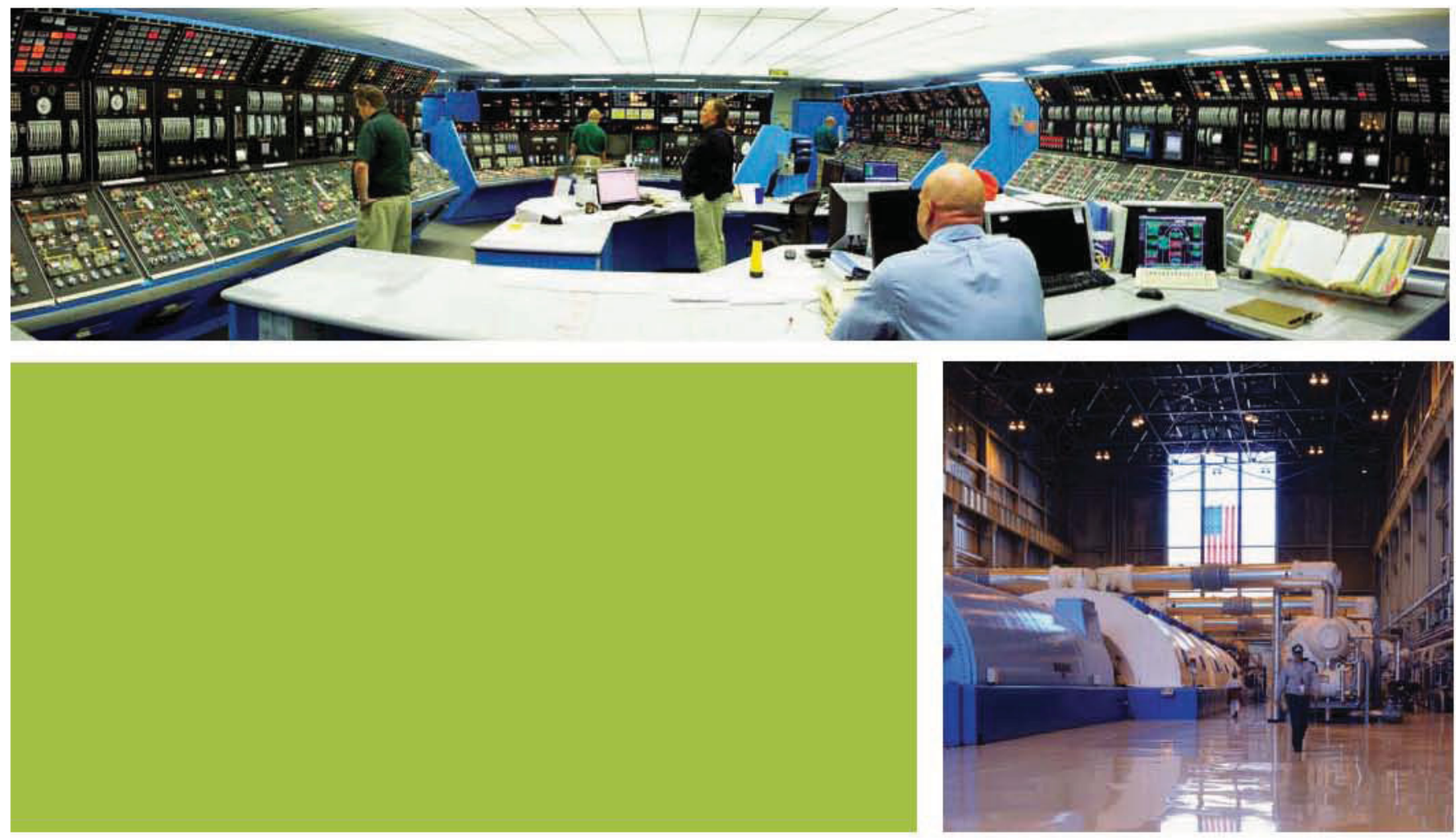
Member companies have joined in this alliance with the primary purpose to promote the development and commercialization of High-Temperature Gas-Cooled Reactor (HTGR) technologies. Our alliance represents the interests and views of our members that intend to mutually support and direct project plans to design, build, operate and use the HTGR technology. We provide a forum and focus to communicate industry needs and requirements and work in concert with the Idaho National Laboratory and others to seek out and promote industrial uses for HTGR technologies within the United States, North America and other continents around the world.

HTGR technology offers a major opportunity to stabilize historically volatile prices for premium fossil fuels and provide a new energy option to provide high temperature process heat for industrial applications. Stabilizing energy costs will encourage a return of process industry facilities to the U.S. from offshore locations where lower and more stably priced fuels and feedstocks have been available. As conventional fossil fuel supplies become more limited in the future due to supply or regulatory restrictions, HTGRs promise to provide new sources of hydrogen and ways to shift chemical and fuels production to new feedstocks with reduced green-house gas (GHG) emissions.

Commercialization of HTGR technology is essential to the National interests in achieving the evolving environmental and energy policy goals. HTGR technology offers benefits including: 1) Reduced GHG through large scale displacement of premium fossil fuels in a wide range of industrial and commercial applications; 2) Reduced reliance on imported oil and gas supplies as industry fuels; 3) Extending life of domestic oil and natural gas supplies as strategic assets for transportation fuels until alternatives become viable technically and economically; 4) Sustainable expansion of American industrial manufacturing capabilities for energy intensive industries; and 5) Job creation within the U.S. supplying materials and equipment to construct and operate HTGR-based industrial infrastructure.

\section{NGNP Industry Alliance Officers}

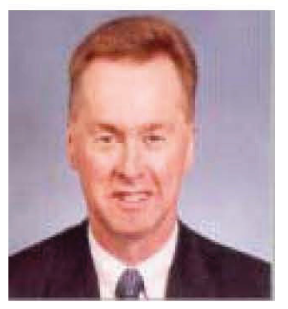

\section{Donald Halter, Executive Director I executivedirector@ngnpalliance.org}

Don is currently Manager of Business Development for ConocoPhillips. He has over 32 years of global energy industry experience with commercial and operating background in crude oil, natural gas, refined products, heavy oil, biofuels, coal, LPG, heavy oil and management consulting. Mr. Halter holds a B.A. in Economics from the State University of New York, Geneseo and a Master of Business Administration, Finance from the Wharton School, University of Pennsylvania. He has held a Commodity Futures Trading Commission Series 3 license for futures and options trading (inactive status).

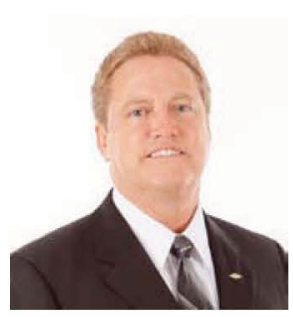

Jeff Jarrell, Vice-Chair (Executive Director-Elect) vicechair@ngnpalliance.org Jeff is currently the Technology Center Director for Energy \& Climate Change at The Dow Chemical Company. In his role, he is responsible for our Energy Systems Technology Center and Dow's Global Improvement Organizations - managing energy process safety requirements, technical support of plant/site energy operations, technology development and capital projects implementation in energy-related technologies. Mr. Jarrell has worked for Dow for 30 years, 25 of those years in manufacturing and engineering. He has been a part of Dow's leadership teams for 14 years and has been supervising project and operational teams for the past 23 years. Jeff holds a Bachelor's of Science degree in Chemical Engineering from Texas Tech University.

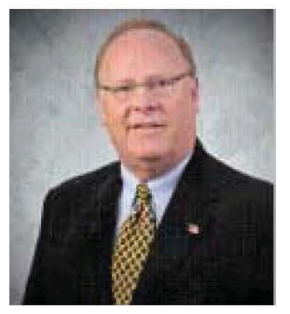

\section{John Mahoney, Secretary-Treasurer I secretary@ngnpalliance.org}

John Mahoney has more than 30 years of experience in the commercial energy business in managerial and technical positions. In his current position at the Entergy Nuclear fleet headquarters is in business development and project management working with companies and entities globally in the development of nuclear energy opportunities. Mahoney holds a Bachelor of Science degree in business administration from Northwood University and a Master of Science degree in business from Troy University. He is certified by the Project Management Institute as a project management professional and is President Emeritus of the Central Mississippi PMI Chapter. Mahoney is an officer of the Mississippi Section of the American Nuclear Society and was elected in 2011 to the ANS Executive Committee of the Human Factors, Instrumentation and Controls Division for a 3-year term.

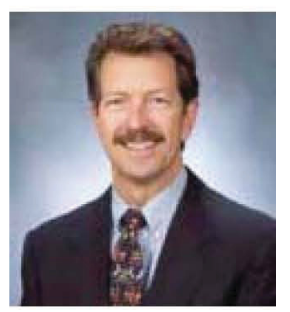

Fred Moore, Executive Director-Emeritus I executivedirector@ngnpalliance.org Fred Moore is the Global Director of Manufacturing \& Technology for the Energy business in Dow. At Dow, he is responsible for the safe and reliable production of power, steam, and other utilities for Dow globally, which represents more than 10\% of Dow's asset base. In his Technology role, he is responsible for development, support and application of Energy technology globally and with Dow's major joint ventures. Fred holds a Bachelor of Science in Environmental Engineering from Purdue University. He was the Alliance executive director from June 2010 to June 2012 and remains a voting member of the Executive Committee in his capacity. 


\section{NGNP}

NGNP Industry Alliance Limited P.O. Box 837, Ridgeland, MS 39158-0837 | ngnpalliance.org | find us on facebook 